Linköping Studies in Arts and Science No. 783

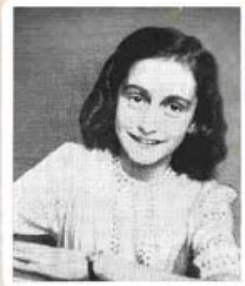

ctunetranks dagbok
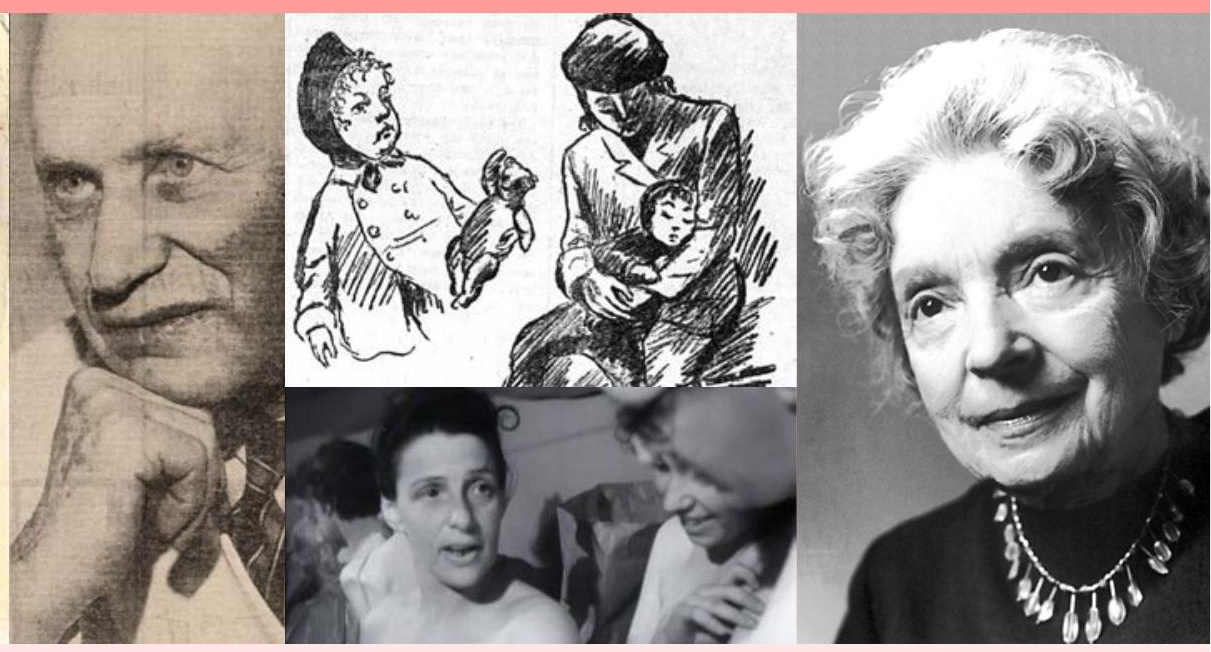

"Chorus of the Saved"

CONSTRUCTING THE HOLOCAUST SURVIVOR IN SWEDISH PUBLIC DISCOURSE, 1943-1966

Kristin Wagrell

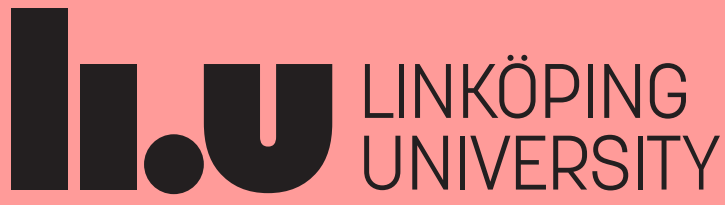


Linköping Studies in Arts and Science

No. 783

\title{
"Chorus of the Saved"
}

\section{Constructing the Holocaust Survivor in Swedish Public Discourse, 1943-1966}

\author{
Kristin Wagrell
}

Linköping University

Institutionen för kultur och samhälle, Tema Q

Filosofiska Fakulteten

Linköpings universitet, SE-581 83 Linköping, Sweden

Linköping, 2020 
(C) [Kristin Wagrell, 2020]

Omslagsbilder från vänster: Anne Franks Dagbok, (Hökerbergsförlag, 1953). Källa: Bokstugan, Bergby antikvariat. Ovan: Urklipp ur nyhetsartikel "Svenskar vittnar i nazistprocessen," i Aftonbladet, 21 Februari, 1964, 6. Källa: Kungliga bibliotekets digitala nyhetsarkiv. Urklipp av teckning publicerad i Göteborgs Handels- och Sjöfartstidning, 8 Oktober, 1943. Källa: Kungliga bibliotekets digitala nyhetsarkiv Under: Bild från filmen Vittnesbördet. Källa: Filmarkivet.se. Porträttbild av Nelly Sachs. Källa: Svenska Akademien.

Printed in Sweden by Linköping University Press, Linköping Sweden

ISSN 0282-9800

ISBN 978-91-7929-894-4 
"Chorus of the Saved"

Constructing the Holocaust Survivor in Swedish Public Discourse, 1943-1966

\author{
By \\ Kristin Wagrell \\ January 2020 \\ ISBN 978-91-7929-894-4 \\ The title of the series \\ No. 783 \\ ISSN 0282-9800
}

\begin{abstract}
In this dissertation I examine how the Holocaust survivor has been constructed in Swedish public discourse during the 1940s, 1950s and 1960s. This is done using a Foucauldianinspired genealogical method through which an eclectic collection of sources-newsreels, films, radio programs, television programs and newspaper articles-is analyzed. The theoretical underpinnings of this analysis are based on Ian Hacking's concept of discourse where the classification of survivor 'types' has a direct bearing on the expressions possible for those who are classified, i.e. individuals with Holocaust experience. The overarching research question of the dissertation therefore asks: how did a Holocaust survivor 'type' develop in Sweden during the 1940s, 50s and 60s? The main thrust of the argument presented in the dissertation is that the concepts of 'silence' and 'excess' have always disciplined the ways in which Holocaust survivors have been conceived of as both victims and witnesses in Swedish public discourse. The communication of Jewish suffering by survivor-witnesses has both been framed as a dangerous, destructive force which could instigate unnecessary conflict while it, at the same time, has been positioned as a remedy to collective forgetfulness as well as a solution to rising levels of xenophobia and antisemitism. How survivors have been constructed historically also demonstrates the flawed logic of a historical progressivism within which Holocaust memory is seen to steadily go from silence to interest/increased knowledge. What the research presented in this dissertation shows is that this process is not determined by historical progression but by the underlying problematization of Holocaust survivors' utility.
\end{abstract}

Keywords: The Holocaust, Survivors, Gender, Witnessing, Victimization, Silence, Excess.

The Department for Culture and Society

Linköpings universitet

SE-581 83 Linköping, Sweden 


\section{Acknowledgements}

In her autobiography, the amazingly clever and funny comedian, actress and writer, Amy Poehler, communicates the ultimate wisdom about writing a book: "it is the doing that is the thing" (this author's italics). The thing is not worrying about the book being written, or thinking about the book or how it will be received (will my readers wipe a lone tear off their cheek in absolute awe of my genius? Or will they point me to the nearest sand-box alt. psych ward? We all know there is no inbetween). It is the doing itself-fingers on the keyboard tapping away at the rhythm of your clearest thoughts- that is the thing. This will not come as a surprise to many of my colleagues, but I have tried many strategies to make myself practice this ultimate of wisdoms. I have used timers to make sure I work efficiently (aka making sure I don't stop mid-writing to maybe snack on some pretzels or sour candies in order to manage the performance anxiety that is evoked every time I stare at a half-empty page imbued with nothing but promise). I have also become that annoying person who preaches the importance of yoga and meditation although perpetually falling into the type of thinking that most smug, over-achieving meditators fall into: "is this working? I am not sure this is working...I hope this works because I really need to finish that chapter".

Whatever I have done to keep on the straight and narrow doing path, I have always depended on the brilliant people around me for love, support and sage advice. First and foremost, I would like to thank my eminent head supervisor, Malin Thor Tureby. For the past five years I have had the fortune to experience and interact with your extensive intellect as well as with your warmth and kindness. Other than always making time for me, reading my texts on short notice and still providing me with the most insightful comments, you have introduced me to the intricate world of professional scholarship. For someone like me, who sometimes equates her sense of self-worth with her academic achievement, it has been a saving grace to have a supervisor like you; someone who both critiques and encourages, cares deeply about the well-being and happiness of those around her, and whose intellectual output inspired me to continue even when pressures ran high. In addition to Malin, I would like to thank my assistant supervisors, Bodil Axelsson and Johanna Dahlin, for their patience, support and advice about everything from writing-styles to how to deal with final seminar anxiety (thanks again Johanna for gifting me that "pearl the unicorn" arts and crafts project, it was really good for my atrocities-infused brain). Other senior staff at Tema Q who have been integral to my research process are Bengt-Erik Eriksson and Martin Fredriksson. Thank you, Bengt-Erik for always being generous with your praise and for recognizing and encouraging my love of writing. Thank you, Martin for pointing out that the chapter I was going to present in 2017 seemed like a whole dissertation; turned out you were right. Thanks also to Eva Hemmungs-Wirtén and Martin Kylhammar for guiding me through my research process (as Eva knows, guiding sometimes also means good conversations over a bottle of champagne). And last but certainly not least, a huge thank you to Jenny Sjöholm; someone who spreads laughter and light 
around her wherever she goes. You have been a great confidant and friend to me throughout this grueling process.

Although the senior faculty at Tema Q have led by example and shown me how to be a researcher, there would be no dissertation if not for my wonderful Ph.D. colleagues. To Tin-tin, Matilda, Gustav, Sofia, Svante, Isabelle, Olga, Johan, Tomas, Madeleine, Johan and Daniela: thank you. To my good friend and professional nemesis Mattis: thank you for everything; for boosting my ego by giving me the nick-name Ackordhöjare - a derogatory term used to describe the worker whose diligence and efficiency sets the bar for the rest-for making me laugh (at you, as well as with you) and for inspiring me with your deep thoughts about Marxism, Latour and the Lord of the Rings. I am also in awe of your beer knowledge and beer-drinking skills. Where would the world be without the long and storied tradition of Ph.D. students complaining about everything and everyone over beer? (it would probably be fine, but I definitely wouldn't be). Another huge thank you to the brilliant Tori. Tori, you have made my endeavors at Tema Q more fun and meaningful. Thank you for reading and language-reviewing everything that I write, for always being willing to discuss the Holocaust with me (surprisingly, not everyone's favorite topic) and for being such a good and loyal friend. A humongous thank you also goes to Monica Bödker-Pedersen, Ulrika Sund and Sofie Gustafsson for helping me with literally everything. I would have been lost without you.

Now to the most important people in my life: my sisters. Sofia, Johanna and Charlotta. Where to begin...At the dawn of time sisters constituted the most supportive structure...just kidding. In all seriousness, nothing would be worth anything if I couldn't share it with you. You are my world and everything that is beautiful in it. To my mother: thank you for making me the best person I can be (also for teaching me how to drive). Thank you for always encouraging my passions and for making me believe that my creativity and my interest in philosophy and history mattered. You are truly my idol. To my father: thank you for letting me dream big and for showing your pride in my accomplishments. You have always been an inspiration to me; showing by example what can be accomplished through passion, hard work and determination. I have also been graced with an extra set of parents in my in-laws. To Mark and Julie: thank you for making me feel welcome in your family, for introducing me to knitting, American breakfast foods and football (not soccer, football). Also, thank you to my sister-in-law Jeri and her husband Chris for your positivity and encouragement.

And finally, to my love and greatest supporter, Chris Thompson. Thank you for your patience and kindness, your meticulous reviewing of my footnotes, and for being a safe haven in the storm. This dissertation is for you. 


\section{Table of Contents}

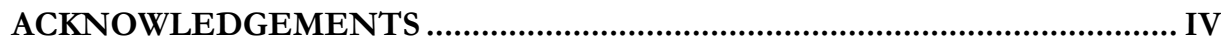

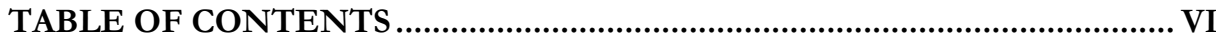

CHAPTER 1 - INTRODUCING THE HOLOCAUST SURVIVOR ....................1

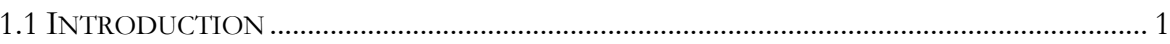

1.2 The Discursive CONSTRUCTION OF THE SuRVIVOR: AIMS AND RESEARCH

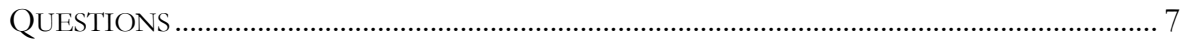

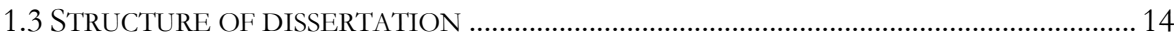

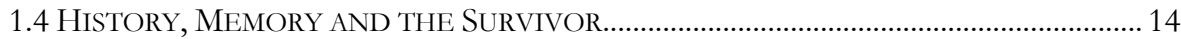

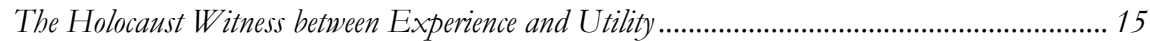

The 'How', 'Why' and 'From What' of Holocaust Survival....................................................... 22

The Perils of Periodization: 'The thesis of silence' and the Holocaust survivor ............................ 28

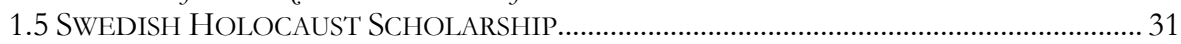

1.6 'Public Discourse', Genealogy And the Question of ARCHIVES .................. 38

Public Discourse as Media Discourse...................................................................................... 38

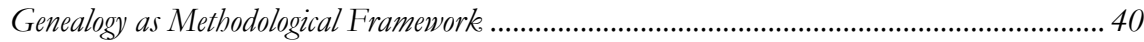

Source-selection and Authority ............................................................................................. 46

Delimiting the Timespan: The Importance of Origins and Endings.......................................... 49

Problematizing Digital and Physical Archives ........................................................................ 53

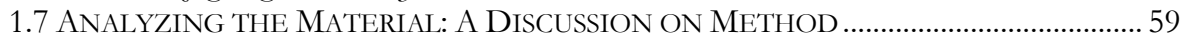

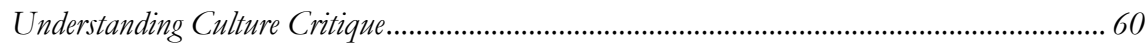

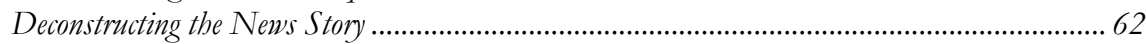

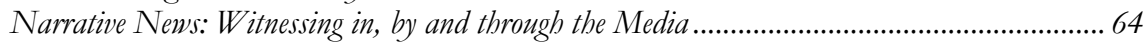

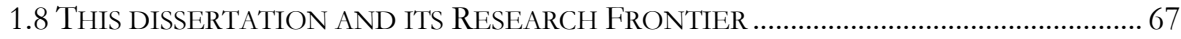

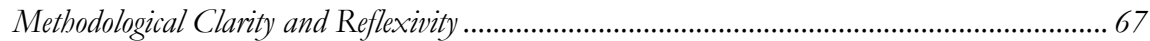

Connecting the Dots: Gender in History or History of Gender? ............................................... 71

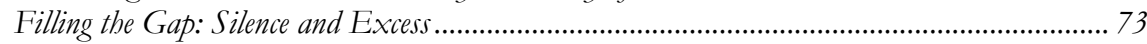

CHAPTER 2 - PROLOGUE: LOCATING THE PROBLEM-COMPLEX ..........77

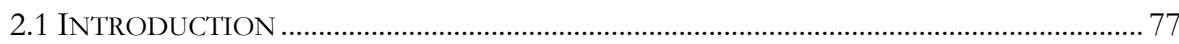

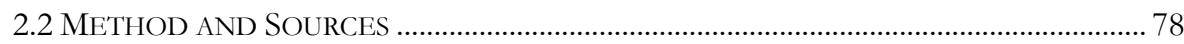

2.3 THE THREAT OF NEO-NAZISM, LIVING HISTORY AND THE ROLE OF THE

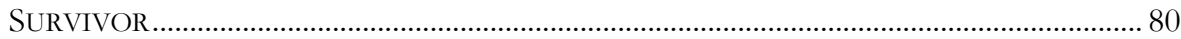

2.4 LIVING History's CREATION OF A “MEMORY ARCHIVE” FOR THE FUTURE ........ 89

2. 5 CONCLUSIONS: PRESENTING THE PROBLEM-COMPLEX …………............................... 104

CHAPTER 3 - VICTIMIZATION, WITNESSING AND SURVIVAL: AN

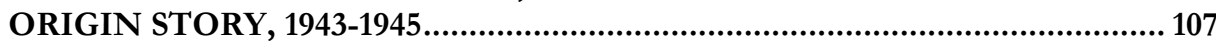

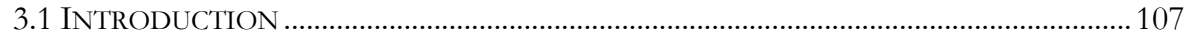

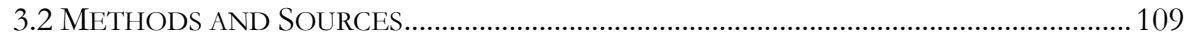

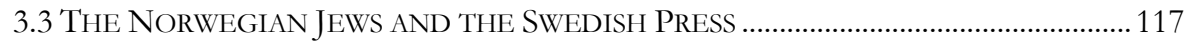

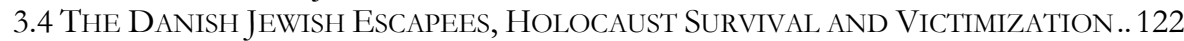
"We'd rather give up all our possessions than get deported to Poland"...................................... 123 


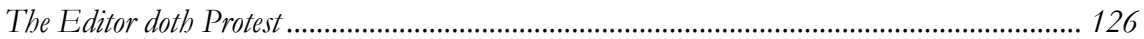

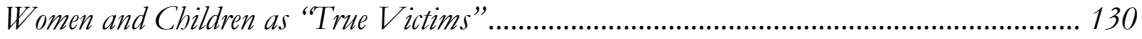

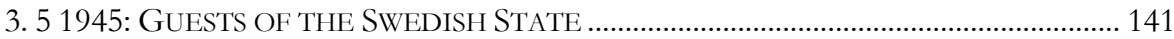

Swedish Rescue Missions during the Second World War Revisited....................................... 142

Camp Survivors: Scandinavian Resilience and Jewish Suffering in the Stockholm-based Press. 146

Visual Encounters: The Case of Vittnesbördet .................................................................... 156

Witnessing the Witness: Radio news and Reports from a "White Ship"................................ 163

3. 6 ACCusation AND RECOVERY: THE BELSEN TRIAL, THE WitnesSES AND THE

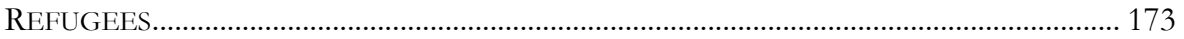

The Survivor-Witnesses: Sensation and Accusation ............................................................. 174

The Survivor-Refugees: On the mend through the Grace of a Benevolent Country...................... 183

3. 7 CONCLUSIONS: THE DESCENT OF THE "TRUE VICTIM" AND THE "MORAL

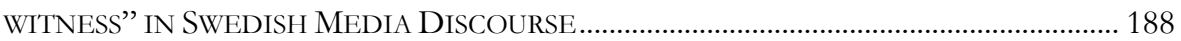

\section{CHAPTER 4 - ANNE FRANK: THE EXEMPLARY WITNESS AND THE}

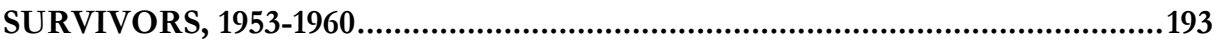

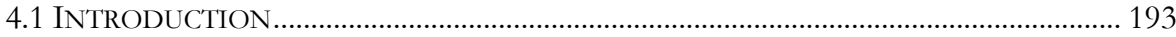

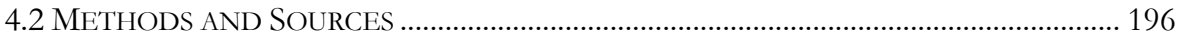

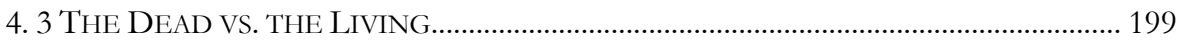

4.4 The DiARY OF A YOUng GIRL: A SubJECT OF GENDER AND AGE........................ 203

The Book's Swedish Becoming .......................................................................................... 204

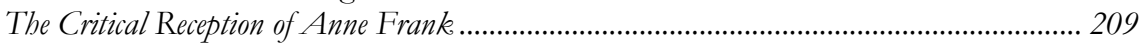

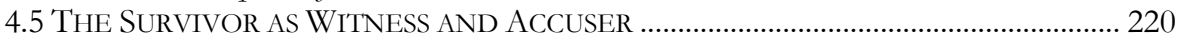

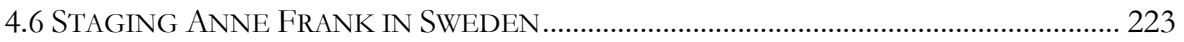

Riksteatern and the Many Successes of The Diary of Anne Frank ....................................... 226

The Diary of Anne Frank: Gruel-free Jewish Theatre ......................................................... 228

4.7 GRUEL AND GLAMOUR: ERNST SCHNABEL AND ANNE FRANK ON SCREEN ....... 241

The Importance of Documentation ........................................................................................ 242

4.8 CONCLUSIONS: ANNE FRANK AND THE SURVIVORS .................................................... 250

CHAPTER 5 - THE ERA OF HOLOCAUST TRIALS ...................................255

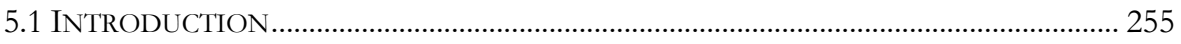

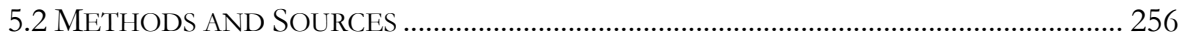

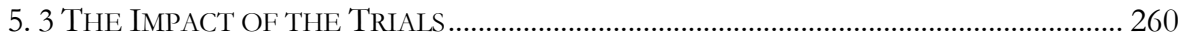

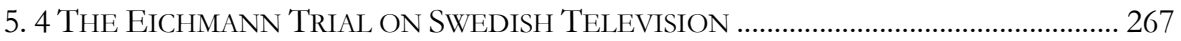

5.5 FOREIGN CORRESPONDENCE AND REPRESENTATIONS OF THE EICHMANN TRIAL

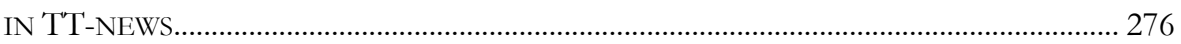

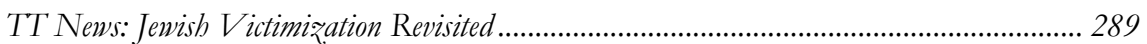

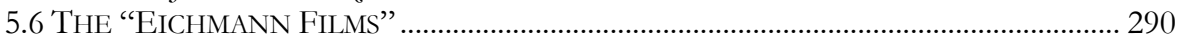

Leiser's Documentary Film About the Victims ................................................................. 292

Kapo and the Credibility of a Victim's Trajectory ................................................................... 297

5.7 The First Frankfurt Auschwitz Trial and PETER Weiss's Die ERMitTLung

Swedes in the Auschwitz Trial: Reluctant yet Heroic Witnesses ............................................. 301

Die Ermittlung and the Utility of Holocaust Representation ................................................... 306

5.8 CONCLUSIONS: THE EICHMANN TRIAL AS TRANSFORMATIVE: IDEALIZING THE

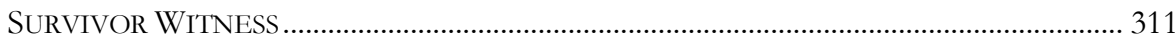


CHAPTER 6 - THE POET AFTER AUSCHWITZ: THE GENIUS OF THE

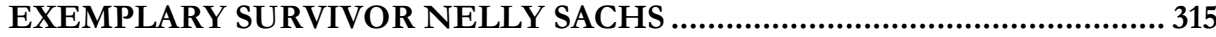

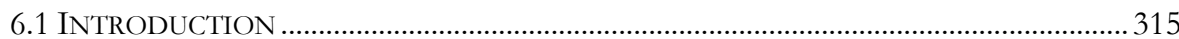

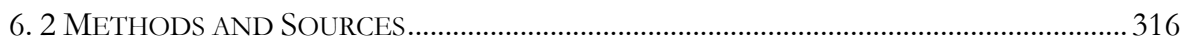

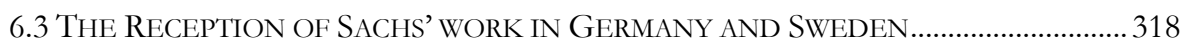

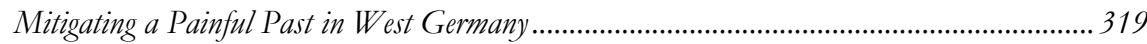

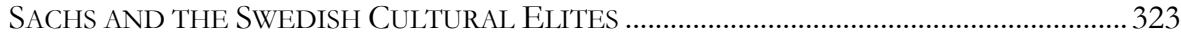

6. 4 The Beauty of Pain: Olof Lagercrantz Constructs Nelly SaCHS.......... 328

6.5 “THE QUEEN OF THE NOBEL BANQUETTE”: SACHS IN THE MEDiA............................343

6.6 CONCLUSIONS: NELLY SACHS AS THE EXEMPLARY JEWISH SURVIVOR .....................352

CHAPTER 7 - CONCLUSION: THE EARLY SURVIVOR OBJECT, GENDER AND THE MECHANISMS OF SILENCE AND EXCESS .............................355

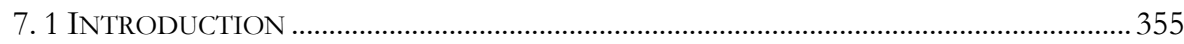

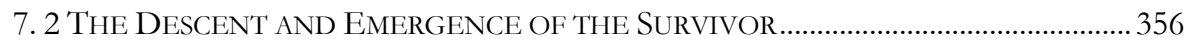

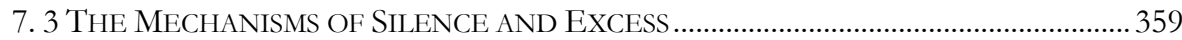

7. 4 THE GENDERED SurVivor: ObJECTS OF CARE AND THE TransCENDENTAL

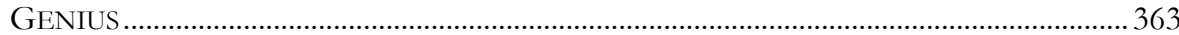

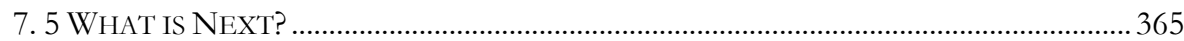

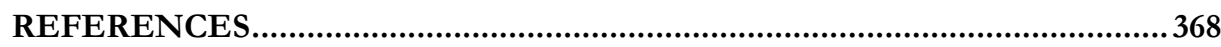

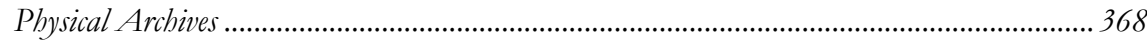

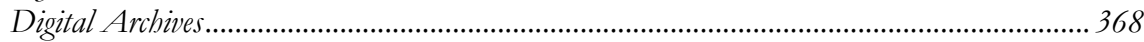

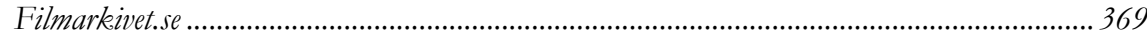

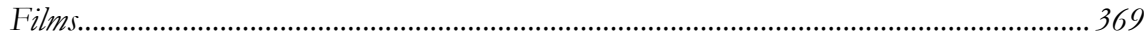

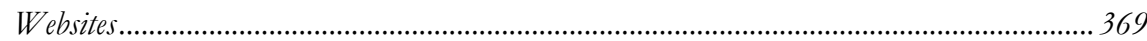

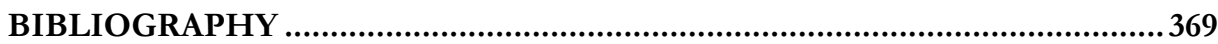

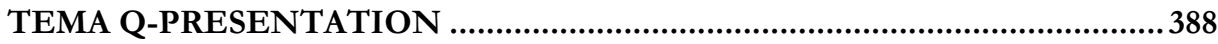

AVHANDLINGAR VID TEMA KULTUR OCH SAMHÄLLE: ........................389

viii 


\section{Chorus of the Saved}

We who are saved, out of whose hollow bones

death has already fashioned his flutes, on whose sinews death has already drawn his bow our bodies still complain with their crippled music.

We who are saved

still see the nooses looped for our necks hanging in the blue air our dripping blood still fills the hourglass.

We, who are saved, are still gnawed by worms of fear.

Our star is buried in dust.

We who are saved beg you:

Show us your sun, but slowly.

Lead us step by step from star to star.

Let us learn to live again, but softly.

Otherwise, the song of a bird, the bucket filling at the well, might break open the weak seals of our pain and foam us away -

We beg you:

don't show us - yet - a dog that bites we might, we might crumble to dust -

crumble to dust before your eyes.

What holds our web together? our breath is gone out of midnight our souls fled to Him long before our bodies were saved in the Ark of the moment. We who are saved hold your hand 


\author{
we recognise your eyes - \\ but only the farewell holds us together \\ the farewell in the dust \\ keeps us together with you. ${ }^{1}$
}

1 Nelly Sachs, "Chorus of the Saved", (Original title, "Chor der Geretteten") in translation by Catterel and Catherine Sommer (2013) published on the blog, Poems of Nelly Sachs in English: Beauty for Ashes https:// nellysachsenglish.wordpress.com/2013/04/28/chorus-of-the-saved/, (accessed on January 10 2020). "Chor der geretteten" was published as part of the book of poetry, Fahrt ins Staublose: Die Gedichte der Nelly Sachs in 1961 (Suhrkamp Verlag: Frankfurt), 5. 


\section{Chapter 1 - Introducing the Holocaust Survivor}

\subsection{Introduction}

In the poem "Chorus of the Saved", written by the Nobel Prize Laureate and poet Nelly Sachs, every stanza begins with the words, "We who are saved". This 'we' refers to the classification that has been more commonly known under the rubric, 'Holocaust survivor'. Notions about the survivor as a figure in a post-Holocaust world are also expressed in the poem; those who were saved remained fearful, those who were saved still carry illnesses and physical pains from their experiences, those who were saved live in limbo between the living and the dying and have a special connection with those who died. First published as part of Nelly Sachs's, Fahrt ins Staublose in 1961, the poem is situated in a context in which the Jewish camp survivor-witness was gaining more visibility through Western mediations of war crimes trials. The 111 witnesses who testified against Adolf Eichmann in Jerusalem and the hundreds of witnesses who took the stand in Germany in the Frankfurt Auschwitz trials, the Treblinka trial, the Sobibor trial etc. were all included in the "Chorus of the Saved". The 'we', however, also encompassed Sachs herself who fled Nazi-Germany with her elderly mother in 1940 and was, therefore, not a camp survivor. What "Chorus of the Saved" demonstrates is that the modern figure that is the Holocaust survivor has been imbued with a plethora of meanings; meanings that rely on preconceived notions of who the Holocaust survivor is.

The 'we' expounded in Sachs's poem has more often been a 'they'-created and manifested by the majority who did not live through the Holocaust. In his book On Listening to Holocaust Survivors, Henry Greenspan expounds that all rhetoric about Holocaust survivors circulates around the opposite poles of life and death, making them either "guilty, ghostly, and estranged" or "heroic witnesses, tellers of tales, redeemers of the human spirit and of hope". ${ }^{2}$ Greenspan also suggests that although the twentieth and the twenty-first centuries have seen an exponential increase in talk about survivors, this has not necessarily led to more talk with them. ${ }^{3}$ By this he does not mean that survivors have remained silent or that the world has not shown interest in their stories. Rather, what Greenspan is after relates to the

2 Henry Greenspan, On listening to Holocaust Survivors: Beyond Testimony, 2nd ed. (Ann Arbor, MI, Paragon press, 2010), 41-42.

3 Greenspan, On Listening to Holocaust Survivors, 42. 
quality of talk, the depth of interest—not in the survivor story's ability to prevent genocide, hatred or intolerance-but a genuine interest in how survivors narrate their pasts, how they are affected by these narrations emotionally and what the narrations come to express. What this lack in quality of talk demonstrates is that survivor-hood is not merely defined by one's experiences but also relates to a number of discourses pertaining to the value and utility of witnessing, the nature and power of victimization and ideas about the propriety of Holocaust representation.

The debate that has circulated around the Swedish camp survivor and memory activist, Hédi Fried, is a good example of this. For the past four decades she has been visible to the public in museum exhibitions, newspaper articles, television programs, documentary films and books on account of her work to promote human rights and human dignity by telling her own story of survival. ${ }^{4}$ To many, Fried signifies courage and strength in the face of seemingly insurmountable pain and suffering. However, she has also been accused of being a "decoy" for the leftan expression used by a prominent conservative pundit in an editorial published just before the 2018 election. ${ }^{5}$ The statement created a controversy within which the contours of a greater complex of ideas about the 'proper' role of Holocaust survivors appeared. The position given to survivors in political debates was, by some, seen as too substantial for what they could (or should) contribute in terms of opinions, perspectives and ideas. One critic, for instance, thought that although Fried's feelings about the rise of right-wing extremism and populist parties should be "respected", these feelings were not to be "used" for political reasons in debates that should rationally weigh the evidence for or against a possible neo-Nazi or

4 Fried was a member of the first committee assigned to establish a more permanent form for Göran Persson's educational campaign Living History in 1998. In 2019 she contributed to the exhibition Speaking Memories, at the National History Museum in Stockholm and a year prior to this, in 2018 she was also included in Mikael Jansson's photographic exhibition, Witnesses, at Kulturhuset in Stockholm. Fried has written a great number of books about her life and her Holocaust experiences, some of which have been translated into English. See for example, Hédi Fried, Fragments of a life: the road to Auschwitz, trans. Michael Meyer, (Bath: Chivers, 1990). -The Road to Auschwitz: fragments of a life, trans. Michael Meyer, (Lincoln, Neb. University of Alaska Press, 1996). -Questions I am asked about the Holocaust, trans. Alice E. Olsson, (London: Scribe, 2019).

5 The editorial article was published on September 26 in Göteborgsposten by its, then, political editor

Alice Teodorescu who, in her piece, criticized the way Fried had been portrayed in a series of articles in the liberal newspaper Dagens Nyheter a few years prior to the publication of her own article. See "Nej 1930-talet är inte här igen” September 26, Göteborgsposten, 2018. 
right-wing extremist threat. ${ }^{6}$ On the other side of the debate, anger was expressed over how Holocaust survivor activists were stripped of any agency, referencing the life-long struggle some of these individuals had endured in order to warn society against the rise of 'brown' ideas and the politics that inevitably follow in their wake.

In addition to the poles of life and death, Fried has started circulating around ideology and truth. For some she is used (and abused) in order to score political and ideological points, for others she is the one authentic connection still left between the ultimate catastrophe caused by Nazism and the new political movements that it has spawned. The manner in which survivors are spoken of, or as I will term it here- how they are discursively constructed—constitutes a form of boundary-making that all individuals who were victimized during the Holocaust have to relate to, one way or another. In essence, talk about survivors affects the manner in which the Holocaust is given current relevance and also influences discourses on more general phenomena such as survival, victimization, loss and redemption. Society's talk and survivors' impressions of what they can and cannot say are therefore intrinsically linked to one another. Although recent studies on early Holocaust memory in Sweden indicate that there never was a complete silence around the Holocaust in the early decades after the war, many survivors maintain that they were encouraged to forget and move on and that few were willing to listen to their stories in the decades following the war. ${ }^{8}$ Hence, not all talk about survivors has been conducive to the individual's own expression of what they have been through. At times the boundaries for how these individuals can act and speak have been strict, seeming almost unyielding while these boundaries at other points have allowed for various forms of self-expression.

Many scholars have attempted to understand the role played by Holocaust survivors and their communicating of Holocaust memory. Does trauma distort memory? And, if so, how does this distortion affect survivors' ability to transmit factually correct accounts of the past to future generations? ${ }^{9}$ Or, is that their task?

6 Dan Korn, “Osmakligt när Förintelsen blir slagträ i debatten,” September 29, Expressen, 2018. 7 See for example Johan Hilton, “Exempellöst rått av Alice Teodorescu," September 27, DN, 2018. 8 Johannes Heumann \& Pontus Rudberg (eds) Early Holocaust Memory in Sweden (Palgrave Macmillan, Forthcoming).

9 See for example James E. Young, "Between History and Memory: the Uncanny Voices of Historian and Survivor," History and Memory, vol. 9, no. 1-2, (Fall, 1997): 47-58. Dominick LaCapra, Representing the Holocaust: History, Theory, Trauma (Ithaca and New York: Cornell University Press, 
Should we care for these individuals themselves or for those who are supposed to learn from their experience? Are these two aims mutually exclusive or can they be combined? How victims should act (and have acted), how they should narrate their experiences, be treated and be remembered have also been the subject of continuous debate, not just in relation to the Holocaust but, more recently, in relation to sexual abuse-the 'me too'-movement opening up fields of contestation regarding victimhood, extra-juridical justice and the value and use of testimony.

Perceived both as victims and as bearers of other victims' memories, some of those who survived the Holocaust have come to enter (or have been entered into) a community whose survivor-hood is continuously being contested and redefined. Notions concerning 'too much' memory, false victimhood and exaggerated expressions of pain and suffering that have followed in the aftermath of the 'me too'-movement have also been intrinsic to the continuous scrutiny of Holocaust survivors. As the American historian Carolyn J. Dean contends in her work Aversion and Erasure, "the fact remains that victims in whose experience much is at stake must now overcome a particularly heavy dose of skepticism unless their claims are made in specific ways". ${ }^{10}$ Hence, the more traction the argument about Fried is a mere "decoy" for ideological interests gains, the more she will have to fight to maintain not just the legitimacy of her activist cause, but also the authenticity and importance of her wounds. Dean also argues that in discussing the veracity and utility of survivors" stories rather than "address[ing] the rhetorical construction of victims and how it generates affective responses to survivors" 11 , expert discourse on Holocaust memory contributes to the "erasure" of victims" experiences. Erasure is a term explained by Dean as "“our' usually inadvertent refusal to acknowledge fully victims' past or present suffering" which, according to Dean, constitute phenomena which "are rarely discussed, and certainly not in terms of the discomfort victims arouse."12 How survivors as victims are "rhetorically

1994). Marianne Hirsch, The Generation of Post-Memory: Writing and Visual Culture after the Holocaust, (New York and Chichester: Columbia University Press, 2012). For a practical as well as a theoretical perspective on survivors as communicators of memory in archival projects see Dori Laub, "Bearing witness or the vicissitudes of listening", in Laub D. and Felman S. (eds) Testimony: Crisis of Witnessing in Literature, Psychoanalysis and History, (New York: Taylor and Francis, 1992). Noah Shenker, Reframing Holocaust Testimony, (Bloomington, IN: Indiana University Press, 2015) and Geoffrey H. Hartman, The Longest Shadow: In the Aftermath of the Holocaust, (Bloomington and Indianapolis, IN: Indiana University Press, 1996), 133-150.

10 Dean, Aversion and Erasure, 143.

11 Dean, Aversion and Erasure, 144.

12 Dean, Aversion and Erasure, 144. 
fashioned" thus relates to the communication of Holocaust experience-the 'good' witness having to speak, write and act according to certain aesthetic and moral codes. In understanding these codes, one can also grasp the ways in which survivors have been conditioned and enabled to contribute, both to a cultural memory of the Holocaust but also to the political and cultural conversation at large. These disciplinary discourses surrounding survivors and their ability to convey true stories of pain and suffering are also intimately connected to notions of utility which, in turn, inform attitudes towards survivors, not least in large-scale archival projects. Talk about survivors is often permeated by perspectives on what they can provide the rest of the population with, be it histories, moral lessons, courage or empathy.

Sweden stands out as one of the few countries that many survivors passed through on their way to new lives after the catastrophe. Adhering to a policy of neutrality during the Second World War, Sweden was, to a certain extent, willing and able to assist individuals escaping Nazi perpetration as well as to receive and care for those who survived the camps. Due to the expansive rescue missions led by the Swedish Red Cross and the United Nations Rescue and Relief Association (UNRRA) in the spring and summer of 1945, many camp survivors found themselves in Sweden after liberation. From studies of registers over these camp survivors, it can be gleaned that a majority of them were women and out of the some thirty thousand survivors, a third were of Jewish descent. ${ }^{13}$ Some found a spouse in Sweden and settled down, while others only stayed to recover from the worst suites of their physical injuries before migrating to other countries around the world. ${ }^{14}$ Sweden admitted different groups of individuals who came to be targeted for annihilation during the war, including the Jewish children who arrived through the so called "child quota" and the young men and women who arrived as

13 It is difficult to say anything conclusive, however about this break-down of rescuees as the scholar who has presented the most detailed categorization, Svante Hansson, does not consistently refer to his primary sources. This is, however, most likely not due to his conclusions being unfounded. Rather, the archives used for Hansson's study were not organized and catalogued at the time when he conducted his research. See Svante Hansson, Flykt och överlevnad: flyktingverksambet $i$ mosaiska församlingen i Stockholm, 1933-1950, (Stockholm, Hillelförlaget, 2004), 281-282.

14 As the trajectories of the survivor community in Sweden have not been studied to a great extent in Swedish historiography, no exact numbers have been established with regards to settlement, migration, deaths etc. One of the only historical explorations of the establishments of survivors in Sweden is Miriam Sterner Carlberg's Gemenskap och Överlevnad: om den judiska gruppen i Borås och dess Historia, (Doctoral diss.: Gothenburg University Press, 1994). 
part of the Chaluz quota in the 1930s. ${ }^{15}$ A significant number of individuals who were persecuted in Sweden's neighboring countries-primarily Norway and Denmark —also found a safe-haven in Sweden before, during and after the war. As such, Sweden has a rich survivor history through both escape and rescue as well as through survivors who subsequently became Swedish citizens.

Despite there being little research conducted on the role of the Holocaust survivor in Swedish cultural, political and social life throughout the post-war period, it is often claimed that 'they' (thus assuming a homogenous group) were a 'silent generation'. ${ }^{16}$ At the same time, when Holocaust memory moved up on the Swedish political agenda at the end of the 1990s, through prime minister Göran Persson's Living History campaign, so called "överlevande"- a term that was primarily used to describe Jewish camp survivors-were slowly but surely marginalized from the official history constructed about Sweden and the Holocaust. In a collection of memories, conducted by the Living History project that was planning for a new government institution under the name, The Living History Forum, Jewish camp survivors were largely excluded. Instead, a "Swedish perspective" - characterized by moral questions regarding bystanderism and the government's policy of neutrality during the war-was to frame the new collection. It thus seemed that no one considered survivors-Jewish survivors in particularas a viable link between Sweden and the Holocaust. Rather, they were considered living, and indeed, vital examples of what Antisemitism, bystanderism and intolerance could do to Swedish society. Their history, it was argued, had already been documented elsewhere, in testimonial archives all over the world. Including them into the new collection of memories from the Holocaust would therefore be excessive and bordering on exploitative.

What these arguments of both silence and excess show is that attitudes toward the utility of the survivor in Sweden have been ambivalent at best. Also, these arguments have created their own silences and excesses. In the most recent

15 For a historical account of the "child quota" see Ingrid Lomfors, Förlorad barndom, atervunnet liv, (Doctoral diss.: Gothenburg University Press, 1996). For the Chaluz quota see Malin Thor Tureby, Hechaluz - en rörelse i tid och rum. Tysk-judiska ungdomars exil i Sverige 1933-1943, (Doctoral diss.: Växjö University, 2005).

16 See for example, Ingrid Lomfors, "Inledning", in ed. Britta Johansson, Judiska minnen. Berättelser från Förintelsen, (Stockholm: Nordiska Museet, 2000): 8. Anders Ohlsson, "Men ändå måste jag berätta," Studier i skandinavisk, förintelselitteratur, (Falun: Nya Doxa, 2002), 7-42. Ulf Zander, "Efterskrift" in Ben Shephard, Befrielsen av Bergen-Belsen, (Lund: Historiska Media, 2005): 233. 
historiography on Swedish Holocaust memory it has been asserted that Holocaust memory was almost non-existent in Sweden until the 1990s. ${ }^{17}$ Yet, what about all those decades in between? Was there no talk about the Holocaust or those who had lived through it in the 1940s, 1950s and 1960s? As the Swedish historian Johan Östling has famously argued, throughout the post-war period the idea that Swedish neutrality had been righteous (and strictly neutral) reigned supreme in public discourse with few counter-narratives that could really challenge its hegemony. ${ }^{18}$ This argument is also what has brought most Swedish historians to the conclusion that the Holocaust was not present in a significant way before the 'moral turn' of the 1990s when Sweden's role in the Holocaust began to be questioned. It has, therefore, almost became a part of a Swedish national identity or national selfperception that "we", the Swedes, were bystanders to the Holocaust; an event that created "them", the survivors. However, if one only focuses on the question of Swedish neutrality and bystanderism (and its opposite—heroism), it is easy to miss the narratives that run parallel to these particular questions.

The task of restoring the Holocaust survivor to the Swedish historical record is an important endeavor. However, it is also a huge and complicated task that will require a joint effort, with participants coming from different disciplines and different fields. It is thus not a task that I intend to take on in full, in this dissertation. Nevertheless, the research that will be presented in the coming chapters will hopefully serve as a first step in this process by focusing on the construction of the survivor in Swedish public discourse during the 1940s, 1950s and 1960s.

\subsection{The Discursive Construction of the Survivor: Aims and Research Questions}

The aim of this dissertation is threefold: 1) to understand how the survivor as a discursive construct came to be in Swedish public discourse, 2) to understand the mechanisms behind the concepts of silence and excess, and 3) to understand the

17 See for example, Antero Holmila \& Karin Kvist Geverts, "On forgetting and rediscovering the Holocaust in Scandinavia," Scandinavian Journal of History, vol. 36, no. 5 (2011): 520-535. Johan Östling, "The Rise and Fall of Small-State Realism" in eds Henrik Stenius, Mirja Österberg, \& Johan Östling, Nordic Narratives of the Second World War: National Historiographies Revisited, (Lund: Nordic Academic Press, 2011): 127-147. Karlsson, “'Tell Ye Your Children...' The Twisted Road to Swedish Holocaust Recognition," Scandinavian-Canandian Studies, vol. 23, (2016): 78-94.

18 Östling, "The Rise and Fall of Small-State Realism," 127-147. 
relationship between gendered conceptions of the Holocaust survivor and the notions of victimization and witnessing. These aims, however, are intrinsically linked to one another with the first aim encompassing the latter two. Their interrelation also has a very specific history that will be presented in the coming section.

My aims were not preconceived or based on gaps in the previous research. Rather, they were the result of a long and sometimes arduous research process of understanding the role of the survivor in Sweden. As alluded to above, the purpose of this dissertation is to demonstrate how the survivor - as a discursive constructhas been present, productive and disciplined in Swedish public discourse since the earliest decades after the war. This purpose, however, was the result of a long research process in which the aims continued to change and evolve. Even though it is not always explicated, most research-processes (at least within the humanities) are abductive, meaning that the researcher moves back and forth between primary sources and theory as well as between primary sources and previous research. My own research process began with an aim to understand the political decisions made in relation to the creation of a Swedish government agency for Holocaust remembrance and human rights_the Living History Forum. In focusing on the formation of public policy around Holocaust memory, I came across the Australian political scientist Carol Bacchi's What's the Problem Represented to be? (WPR) approach to policy analysis. ${ }^{19}$ In her work on WPR, Bacchi claims that it is through the study of policy problematizations that we can understand how assumptions about the world underpin policy decisions. ${ }^{20}$ This understanding of policy is based on the ontological premise that policy-processes are endogenous, meaning that political problems are both created and solved within the process itself. Even though social problems are very much real and effect people every day, it is not the truth of these problems that lead to political solutions, according to Bacchi. Thus, to understand the mechanisms of policy, one needs to study the construction of political problems; how, where and why these are formed, and subsequently, in what ways they create political solutions.

In the case of the Living History Forum, its establishment and early development was heavily based on perceptions of Holocaust memory as an educational issue. Concerns that the Holocaust was not remembered 'properly' were therefore

19 See for example, Carol Lee Bacchi, Analyzing Policy: What's the Problem Represented to be?" (Frenchs Forrest: Pearson, 2009).-Women, Politics and Policy: The construction of policy problems, (London: Sage, 1999).

20 Bacchi, Analyzing Policy: What's the Problem Represented to be?' 235. 
presented as a young person's problem—a history-less society was put on the shoulders of fourteen- and fifteen-year olds. The policy response to this constructed problem was to create a government agency which focused on educational activities such as exhibitions directed at high school students and teacher training programs. As previously noted, the debate on Holocaust memory and the inception of a mnemonic institution for Holocaust remembrance in Sweden also focused on what 'we' could learn and how important it is that 'we' learn. This focus on an 'us' made me consider who 'they' were, or rather, who 'they' were made to be. Why did few seem to care for survivors as individuals as much as they cared for their ability to prevent catastrophe? And why were they included as experts in some contexts while excluded in others? These questions, however, could not be answered in the immediate context of The Living History Forum but required a more extensive spatial and temporal perspective on how the Holocaust survivor had been understood over time, meaning that I had to shift the aim away from understanding a particular policy-process in the late 1990s and early 2000s, to understanding the construction of the Holocaust survivor, with a beginning in the 1940s.

However, my primary aim still continued to inform my analyses. Delving deeper into the theories that informed Bacchi's WPR approach-primarily Foucauldian genealogy — the present, which for me was the late 1990s and early 2000s, remained relevant to my research questions. Understanding how the survivor had been constructed gained its relevance from the ways that survivors had been problematized in relation to Living History and The Living History Forum, and how they continue to be problematized today. Thus, what I had found in my previous studies - that many Swedish historians, educational experts and museum experts retreated from perspectives that centered on Jewish victimization, witnessing and survival—continued to inform my research process. The perspective that Jewish survivors were "un-Swedish" and overexposed had already been broached by the late Swedish-American historian Paul Levine who, in an article published in 2005, argued that Swedish historians displayed a "troubling disinterest" in the Holocaust as it was deemed uninteresting to Swedes and thus only relevant to "Jews and Germans, and perhaps even only Jewish historians". ${ }^{21}$ Levine's assertions seemed to fit with what I observed in the extensive documentation covering the creation of The Living History Forum. The question that

21 Levine, "Whither Holocaust Studies in Sweden? Some Thoughts on Levande Historia and Other Matters Swedish," Holocaust Studies: A Journal of Culture and History, vol. 11, no. 1, (2005): 85. 
remained, however, was how this disinterest and the notion of the Holocaust's 'unSwedish-ness' had developed over time; not only within Swedish historiography, but through other forms of expert discourse.

The "troubling disinterest" that Levine identified regarding the role of Sweden in the memory of the Holocaust, I had also observed in my research. It was particularly visible in the planning process for the "Memory Archive" for the future Forum. This project-initiated by the first planning committee for the Forumaimed to collect "testimonies, documents and material from the Second World War". ${ }^{22}$ The title of the first memorandum that circulated regarding this "Memory Archive" was "Collection of material with a connection to the Holocaust" (This author's italics). The vague language used in this early communication on the project indicated that a consensus had not yet been reached regarding what the Holocaust was or how it related to Swedish memory of the war years. Because of this vagueness that inevitably opened up fields of contestation regarding the relationship between Sweden and the Holocaust, I chose to scrutinize the problematizations that informed the creation of a "Memory Archive" based on personal reflections and accounts from the time of the Holocaust.

The most important insight gathered from Bacchi's WPR approach was that the notion of who survivors are is inherently connected to how they have come to be. By referring to 'who they are' I do not mean to imply that there is some form of essential survivor. Rather, in this dissertation I have chosen to examine the survivor in relation to the idea that there are multiple survivor 'selves' whose creation are contingent upon the discursive and non-discursive forces that surround Holocaust memory and more specifically those discursive events that concern victimization and witnessing. In creating a "Memory archive", the Levande Historia project actualized questions regarding the "silent generation" of camp survivors as well as the hypertrophy of Jewish memory — something that led to further questions about where these ideas stemmed from. The difference between the survivor and 'survivors' is a crucial one in this context, the former denoting the conceptualization of a survivor type whereas the latter signifies physical beings with Holocaust experience. This distinction can be further elucidated using the Canadian philosopher Ian Hacking's idea that people "come into being by a

22 Riksarkivet (RA), Kommittén Forum för Levande Historia med Projekt Levande Historia, vol. 13, Promemoria, "Insamling av material med anknytning till Förintelsen”, June 14, 1999, 1. 
dialectic between classification and who is classified". ${ }^{23}$ This "dialectical realism" distinguishes between the physical subject and the discursive object—one being the person with real-world experience, the other denoting the discourses surrounding that experience. The easiest way of capturing this relationship is locating the terminology used to create the classification, meaning that the survivor in Sweden came into being when the term "överlevande" was first used to describe "the classified". However, this dissertation's ambitions extend beyond mere nominalism. Rather than tracing the language categories used to denote Holocaust survival, the research examines how the Holocaust survivor has emerged in Swedish public discourse in relation to the problematization of utility as well as disciplinary discourses surrounding the concepts of silence and excess.

Initially, all decades leading up to the creation of Living History's "Memory Archive" were supposed to be studied. However, since very little research had been conducted on Swedish Holocaust memory in the twentieth century, I found myself drowning in relevant material, making the task of exploring the becoming of the survivor impossible for the whole period. For practical reasons, then, I had to limit my study to the first three decades following the war; a decision that left a sizeable gap between 1966 and 1997. As I will expand on in section 1.7, the genealogical method that I adopted in order to understand how the survivor had come to be in Swedish public discourse, rested on an understanding of how history is simultaneously a continuous and discontinuous process. The object of the survivor may change due to economic, political and cultural discursive and non-discursive events, but these may still be underpinned by the same problematization and, as I argue in my research, by the same disciplinary mechanisms. What I detected in my studies of all periods (the late 1990s and early 2000s included) was that the concepts of silence and excess were used as arguments for or against the inclusions of survivors into different contexts. Thus, my aim of understanding the construction of the survivor also came to include a metahistorical ambition of demonstrating how silence and excess served to discipline the survivor object.

Similarly, the gendered perspective on Holocaust survival was not included in my initial aim to understand the survivor object and how it had been formed. Instead, I stumbled across it in my archival searches. It was not just that women were more prevalent in the material, their representation as specifically female

23 Ian Hacking, "Between Michel Foucault and Erving Goffman: Between discourse in the abstract and face-to-face interaction" Economy and Society, vol. 33, no. 3 (2004): 280. This idea will be explored further in section 1.7 . 
objects and subjects continued to appear in my sources. Now, I would undoubtedly not have detected these gendered constructions if I had been wholly unaware of feminist theories on gender and representation. Rather than adopt feminist theories to study the object, however, I chose to primarily understand the construction of the female object in relation to previous research on gender and representation within the field of Holocaust studies. This was a conscious choice made in order to include the study of gender into a history of Holocaust representation, rather than conduct a feminist study of the survivor which would run the risk of becoming an appendage rather than a constituent part of research on the Holocaust.

Even though the focus of this dissertation is on the classification rather than the classified the latter cannot be completely severed from the object due to its dynamic relationship with the former. In other words, the physical boundaries of survivor-hood have been affected by the physical presence and expressions of individuals with Holocaust experience. For example, as few gay and lesbian victims wanted to, or were afforded the opportunity to speak of their experiences, there was little hope of finding any "faces" of a gay/lesbian Holocaust in Swedish public discourse. Kai Hammerstain argues that, "whereas the suffering of the Jews is commemorated in works like those by Anne Frank, Primo Levi, and Elie Wiesel, we know of no comparable gay narratives". ${ }^{24}$ This, according to Hammerstein, is because only a small number of the surviving gay victims (a total number of survivors is not known) have communicated their Holocaust experiences, a majority of which wanted to remain anonymous. ${ }^{25} \mathrm{~A}$ similar argument could also be made for the Roma Holocaust (often referred to as Porrajmos), whose narration in a Swedish context has been limited by both the absence of Roma who survived the Holocaust as well as the structural discrimination that the Roma continues to endure; something that has served to limit different forms of self-expression. ${ }^{26}$ As the German historian Wulf Kansteiner explains,

Small groups whose members have directly experienced such traumatic events (veterans' or survivors' groups) only have a chance to shape the national memory if they command the means to express their visions, and if

24 Kai Hammerstein, "Inventing History: Toward a Gay Holocaust Literature," The German Quarterly, vol. 70, no. 1, (1997): 19.

25 Hammerstein, "Inventing History", 19.

26 Little research has been conducted on Roma Holocaust survivors in Sweden. In 2008, historian Laura Palosuo, undertook an inventory of research on the Roma in Sweden including a section on Holocaust experience, see En inventering av forskningen om romer i Sverige, (Uppsala, Center for Multiethnic Research). 
their vision meets with compatible social or political objectives and inclinations among other important social groups, for instance, political elites or parties. $^{27}$

There are, of course, exceptions to this rule - the most obvious being the attention that the late Roma activists Katarina and Rosa Taikon brought to the issue of the Roma Holocaust as early as the mid-1960s. ${ }^{28}$ This dissertation could deal with the silences that such structural obstacles have produced as well as with the narratives that involve non-Jewish groups and individuals with Holocaust experience. However, since one of the starting points for my inquiry was a problematization that related specifically to Jewish Holocaust survivors, the analyses center on the ways in which the discursive object of the Jewish Holocaust survivor changes over time. To be sure, the historiographical and commemorative creation of a specifically Jewish Holocaust was by no means inevitable. Yet, this aspect of constructing the survivor is but the first step in my analysis which always strives toward a greater understanding of how the survivor becomes and transforms. That the Holocaust survivor became Jewish will of course also be explored but the focus remains on the ways in which this position has been disciplined. In the coming chapters I thus attempt to answer the following questions:

1) How was the Holocaust survivor constructed in Swedish public discourse in the 1940s, 1950s and 1960s?

2) How was the survivor object disciplined by contemporary commentators and culture critics in these decades?

3) How did conceptions of gender inform the construction of the Holocaust survivor?

4) How did the survivor object transform during the 1940s, 1950s and 1960s in Swedish public discourse?

27 Wulf Kansteiner, "Finding Meaning in Memory: A Methodological Critique of Contemporary Memory Studies," History and Theory, vol. 41, (2002): 187.

28 See for example a review of Katarina Taikon's book Zigenare är vi. Bo E. Åkermark, "Rollen som Zigenare," October 11, 1967, Göteborgs Handels- och Sjöfartstidning, 7. 


\subsection{Structure of dissertation}

In Chapter one I attempt to position the survivor in current scholarly debates on Holocaust survival, victimization and witnessing. This is followed by an overview of Swedish scholarship pertaining to the Holocaust and how this loosely held field of studies has presented some challenges to my research process. After this, I proceed with an explication of the theoretical framework of the dissertation as well as the dissertation's methodological approach with accompanying principles of source selection. In Chapter two the problem complex is presented through an analysis of the creation of Living History's "Memory Archive" in the late 1990s. Chapter three is dedicated to the descent of the Holocaust survivor in Swedish public discourse, including an exploration of how the survivor formed in relation to notions of Holocaust survival, victimization and witnessing. The analysis focuses on how the Danish Jews were represented in Swedish newspaper discourse beginning in October 1943 as well as how camp survivors were represented in newspapers, news reels and radio programs in the spring and summer of 1945. In Chapter four I investigate victimization in relation to witnessing- two concepts which have deeply impacted perceptions on the role of Holocaust survivors in the Western world. More specifically, the chapter includes analyses of the cultural critique of the many iterations of Anne Frank's writings; the book, the play and the film. Chapter five deals with the 'trial era' of the 1960s, focusing especially on the Eichmann trial and the first Frankfurt Auschwitz trial. The chapter also includes an analysis of the culture critique surrounding the so called "Eichmann films" as well as a discussion concerning communicators of Holocaust experience outside of the witness realm: the journalist and film-maker Erwin Leiser and the filmmaker, play write and writer Peter Weiss being the foremost examples. In chapter six I study the construction of the poet and Nobel Laureate, Nelly Sachs, in Swedish public discourse. As the first 'emblematic' survivor, Sachs is studied in relation to her 'discoverers' with a particular focus on the newspaper editor, writer and cultural critic Olof Lagercrantz. Chapter seven concludes the dissertation and offers some suggestions for further research on Holocaust memory in Sweden.

\subsection{History, Memory and the Survivor}

The past four decades have seen a sharp increase in studies of Holocaust memory, with the theoretical development of memory as an operational concept being one 
of its crucial consequences. ${ }^{29}$ Furthermore, the field usually referred to as 'memory studies', also grew out of an increasing scholarly interest in how the Holocaust was historicized, memorialized and commemorated. ${ }^{30}$ One of the central quandaries for memory studies is thus how to understand the relationship between history and memory. ${ }^{31}$ For several decades, professional history's claims to truth as well as memory's political and ideological character have been discussed and debated by academics and non-academics alike. The survivor has often been positioned in the middle of these discussions: as historical informant, as historical agent, as psychiatric/psychological object, as memory activist and as economic claimant. In this section I attempt to disentangle some of these scholarly debates, beginning with an exploration of the role of the Holocaust witness followed by a discussion on how survival has been understood in relation to Holocaust experience. Throughout this dissertation I will refer to Holocaust memory but since I have found that the concept itself provides little analytical clarity in the study of the Holocaust survivor, I have chosen to merely engage with memory as a scholarly field, rather than with theories developed therein.

\section{The Holocaust Witness between Experience and Utility}

As highlighted by the historikerstreit in Germany in the 1980s, the Holocaust has been the example through which post-structural ideas about the constructed-ness of professional historical narratives can be problematized as threatening to the truth claims of survivors and other Holocaust witnesses. In the 1970s and early 1980s the American philosopher Hayden White famously posited that many politically abhorrent interpretations of the Holocaust still reached "the standards of evidence developed in the historical profession". ${ }^{32}$ Through his arguments

29 See discussion in Astrid Erll, "Cultural Memory Studies: An Introduction” in eds Ansgar Nünning \& Astrid Erll, Cultural Memory Studies, Berlin, (Berlin: De Gruyter Inc, 2008), 1-13.

30 See for example, Dominick LaCapra, History in Transit: Experience, identity, Critical Theory, (Ithaca NY: Cornell University Press, 2004).

31 See for example, Kerwin Lee Klein "On the emergence of memory in historical discourse," Representations, vol. 69, (2000): 127-150. Aleida Assmann, "History, Memory and the Genre of Testimony", Poetics Today, vol. 27, no. 2 (2006): 261-273. Saul Friedländer Memory, History, and the Extermination of the Jews of Europe, (Bloomington, IN: Indiana University Press, 1993). Wulf Kansteiner, "Finding Meaning in Memory: A Methodological Critique of Contemporary Memory Studies", History and Theory, 41, (2002): 179-197.

32 Wulf Kansteiner, "Success, Truth and Modernism in Holocaust Historiography: Reading Saul Friedländer Thirty-Five Years after the Publication of 'Metahistory"', History and Theory, vol. 48, no. 2, (2009): 30 . 
White was attempting to show that professional history's legitimacy rests as much on narrative "emplotments" as it does on epistemology or logic. ${ }^{33}$ In a special issue on Holocaust witnessing in the academic journal Parallax some twenty years later, White expanded on this notion by referring to the example of Primo Levi's Se questo é un nomo, claiming that the book derived its testimonial power from the artistic expression of "what it felt like to have had to endure" the Holocaust rather than the perceived accuracy of the account itself. ${ }^{34}$

Preferences with regards to how those feelings should be communicated, however, have changed over time. Some critics have also, as a reaction to White's contentions, contributed to a disciplining of survivor literature by arguing for a minimalist style of all writing pertaining to the Holocaust. In her analysis of American and French literary critique in the 2000s, Dean explains that,

some critics believe that all styles that are styles - that are self-reflexive, experimental, ornate, or exuberant — distract from the facticity and authenticity of the Holocaust victim's experience and are particularly egregious when used to represent extreme experiences of suffering and death. ${ }^{35}$

Individuals with Holocaust experience who testify to their pasts are thus embraced as true witnesses on account of their narrative style's ability to convey feeling. Yet, at the same time, this effective communication of feeling also makes them objects of suspicion; as less accurate and reliable in their witnessing. Where the survivor witness is placed on this sliding scale depends on the epistemology of the institutional context in which he or she is witnessing. The importance of the underlying epistemology of the institutional context in which a testimony is given is effectively exemplified in the construction of two different American testimonial archives.

In his book Re-Framing Holocaust Memory, Noah Shenker presents three mnemonic institutions, all based in the United States, which created extensive and influential collections of Holocaust testimonies in the 1970s, 80s and 90s: The Yale Fortunoff archives, the Shoah Foundation's Visual History Archives and the

33 See Hayden White, Metahistory: the Historical Imagination in Nineteenth Century Europe, (Baltimore, Johns Hopkins University Press, 1973). - The Content of the Form: Narrative Discourse and Historical Representation, (Baltimore: Johns Hopkins University Press, 1987).

34 Hayden White, "Figural Realism in Witness Literature”, Parallax, vol. 10, no. 1, (2004): 113-124. See also Kansteiner's (2009) discussion on White's contention that "figurative" language constitutes the crucial components in testimonial literature's potency as witnessing, 32 .

35 Dean, Aversion and Erasure, 104. 
United States Holocaust Memorial Museum. ${ }^{36}$ Shenker provides analyses for how the epistemologies underpinning the archival processes of each of these institutions have differed from one another with regards to their perspectives on what survivors can contribute. The main mission of the Yale Fortunoff archive was, for example, described by the literary scholar and co-founder Geoffrey Hartman as "a supportive, emotional community" whose main purpose was to help survivors make sense of their experiences. ${ }^{37}$ For this collection process, the "mutual labor" that existed between interviewer and interviewee in finding ways to narrate Holocaust experience was just as important as the story that emanated from this labor. This also meant that individual memory as historical record was secondary to, or rather, heavily contextualized by, the inner workings of remembering a traumatic event.

One of the most well cited examples used to describe the challenge of survivor testimony as historical record comes from the camp survivor and psychiatrist Dori Laub who, in gathering testimonies for what was to become the Yale Fortunoff Archives interviewed a woman who had witnessed the sondercommando uprising in Auschwitz. Months later, Laub showed the video-taped interview at an interdisciplinary conference on the Holocaust. To his astonishment the testimony was brushed off as severely flawed and unusable by the historians at the conference because the woman had claimed that four of Auschwitz' chimneys went "up in flames" although the historical record showed that only one chimney had been destroyed. ${ }^{38}$ So, "to [the historians' minds], such a 'flawed' testimony was as worthless to their inquiry into events as it was dangerous to historical truth". ${ }^{39}$ However, as Laub proceeded to argue at the conference,

the woman was testifying, not to the number of chimneys blown up, but to something else, more radical, more crucial: the reality of an unimaginable occurrence. The event itself was almost inconceivable. The woman testified to an event that broke the all-compelling frame of Auschwitz, where Jewish armed revolt just did not happen, and had no place. She testified to the breakage of a framework. That was historical truth. ${ }^{40}$

36 Noah Shenker, Re-framing Holocaust Testimony, (Bloomington, Indiana University Press, 2015).

37 Shenker, Re-framing Holocaust Testimony, 28.

38 Laub, "Bearing witness or the vicissitudes of listening," 59.

39 Laub, "Bearing witness or the vicissitudes of listening," 54.

40 Laub, "Bearing witness or the vicissitudes of listening," 60. 
This testimony, then, could be understood as evidence of something other than the details of the uprising itself - it said something about the experience of resistance against impossible odds rather than about the actual ramifications of the uprising. Experience is also a concept which shifts meaning depending on the underlying epistemology of the institutional context in which the testimony is given. In contrast to the Yale Fortunoff archives, Stephen Spielberg's Visual History Archive (VHA) collection of 50000 testimonies from Holocaust survivors, a project which commenced in 1994, "was motivated by the goal of 'collecting as many varied survivor experiences as possible while there [was] still time". ${ }^{41}$ Although primarily searching for Jewish survivors in the first leg of collection, "the varied survivor experiences" also referred to other groups affected by Nazi policy. When searching the digitalized archive today, one can, therefore, look for categories such as "Roma and Sinti survivors" and "homosexual survivors". ${ }^{42}$ Although the archive contributed a wealth of knowledge by including individuals with Holocaust experience who were rarely heard, this ambition was still based on a pragmatic view of what the survivor as witness provided the archive with in terms of historical truth. Rather than viewing the survivor as part in a relational process of working through trauma, the interview subjects were described as "informants", who were all contributing to a greater understanding of the Holocaust as historical event. As Shenker explains,

while the VHA aimed to provide future generations with voices and faces of the Holocaust, it often positioned witnesses as exemplars and illustrations of an established historical narrative. Rather than interrogating or underscoring the multivocal qualities of Holocaust histories, this tendency re-inforced, or fleshed out if you will, an already established rather than an open account of the events. ${ }^{43}$

The epistemology underpinning the archive was thus one of difference, only in so far as it maintained pre-established notions of victimization, be it that victimization experienced by a Roma child survivor or a Jewish female survivor. This epistemological definition of the survivor witness as informant, promoted a history of diversity along the lines of identity politics, thus "[asserting] the authenticity and authority of each survivor, according to his or her place in the discourses of

41 Shenker, Reframing Holocaust Testimony, 114.

42 Shenker, Reframing Holocaust Testimony, 134.

43 Shenker, Reframing Holocaust Testimony, 117-118. 
Holocaust suffering and testimony" while at the same time demonstrating inclusivity and breadth. ${ }^{44}$

Using Holocaust survivors as truth-tellers and informants are, of course, nothing that is unique to the VHA. Already before the war ended, efforts were made to collect evidence of the Jewish catastrophe. The Oneg Shabbat archives, created in secret in the Warsaw ghetto in the early 1940s, was later accompanied by a massive effort from several, primarily Jewish, organizations committed to document the Holocaust by interviewing survivors all over the Displaced Persons (DP) camp system. ${ }^{45}$ Most often, the urge and incentive to document came from the survivors themselves. As the American historian Laura Jockusch explains,

These Jewish documentation efforts emerged as a grassroots movement created by a diverse group of survivors, dissimilar in their education, nationalities, and class status, as well as in their wartime experiences. By and large untrained in the historical profession, these activists were lawyers, accountants, teachers, writers, journalists, engineers, artists, medical doctors, manual laborers and homemakers who felt obliged to document the past. ${ }^{46}$

Some of these early collectors also came to be key witnesses in the great Holocaust trials as well as curators of witness accounts through their continued work at commemorative institutions. Two such examples were Rachel Auerbach, a former member of Oneg Shabbat as well as a founder of Yad Vashem, and Miriam Novitch, one of the crucial members of the Ghetto fighters' Museum in Israel. ${ }^{47}$ Both having survived the camps, Auerbach and Novitch played key roles in contributing documentation in the form of witness accounts and physical

44 Shenker, Re-framing Holocaust Testimony, 122.

45 See for example, Laura Jockusch, Collect and Record! Jewish Holocaust Documentation in Early Post-war Europe, (Oxford: Oxford University Press, 2015). - "Historiography in Transit: Survivor Historians and the Writing of Holocaust History in the late 1940s," Leo Baeck Institute Year Book, vol. 58, (2013): 75-94. Boaz Cohen, "The Children's Voice: Postwar Collection of Testimonies from Child Survivors of the Holocaust," Holocaust and Genocide Studies, vol. 21, no. 1, (Spring, 2007): 73-95."Survivor Care-givers and Child Survivors: Rebuilding Lives," Holocaust and Genocide Studies, vol. 32, no. 1, (2018): 49-65.

46 Jockusch, "Historiography in transit", 75-76.

47 The full name of the Museum is “The Ghetto Fighters' House: Itzhak Katzenelson Holocaust and Jewish Resistance Heritage Museum” and was set up at the Kibbutz Lochamei Hageta'ot in 1949. The Ghetto Fighter's Museum is considered to be the first Holocaust museum in the world. See Sharon Geva (2015) “"To Collect the Tears of the Jewish People': the story of Miriam Novitch", Holocaust Studies, 21(1), 73-92. 
documents to the Eichmann trial. ${ }^{48}$ In the case of Auerbach, she both testified herself and provided most of the 111 witnesses for the trial. ${ }^{49}$

Although Sweden lacked Jewish survivor organizations committed to documenting the Holocaust in the direct aftermath of the war, two interview projects-both with the goal of collecting evidence for future trials and historical research — were launched in 1945 and 1946. The first project, spearheaded by Einar and Gunhild Tegen, came to collect nearly two hundred accounts from both men and women who had lived through the camps and were, at the time of collection, residing in so called 'internment camps' in Sweden. ${ }^{50}$ Even though the work conducted by the married couple was intended for academic publication and further research, no funding was ever secured and the testimonies were deposited at Uppsala University's library. ${ }^{51}$ The second project was funded by the Swedish government and was led by the Polish academic Zygmunt Lakocinski together with Lund-based historian Sture Bolin. Although focusing on Polish nationals and containing relatively few Jewish testimonies, the project collected some five hundred testimonies which, above all, contain detailed stories of camp existence. ${ }^{52}$ The purpose of the Lakocinski material was, first and foremost, to provide evidence for the coming war crimes trials, an ambition which was accomplished in 1946, when a representative from the War Crimes Investigation unit was able to gather a substantial amount of important evidence from the collection for a trial regarding the Ravensbrück concentration camp. ${ }^{53}$

The use of testimonies in trials and other legal processes aimed at justice have also been surrounded by discourses regarding the 'proper' amount of attention given each 'victim group'. In the 1990s, several controversies regarding the perceived undue attention paid to certain victim groups cropped up in discussions

48 See Zoë Waxman, Writing the Holocaust: Identity, Testimony, Representation, (Oxford: Oxford University Press, 2007), 144 and Geva, "To Collect the Tears of the Jewish People," 81.

49 Waxman, Writing the Holocaust, 114.

50 See Gunhild \& Einar Tegen, De dödsdömda vittna: Enquetesvar och intervjuer, (Stockholm, Wahlström och Widstrand, 1945). Pia-Christina Garde, De Dödsdömda Vittnar-60 Ar Senare (Stockholm: Megilla förlaget, 2004). Swedish historian Lars M Andersson is currently undertaking a research project on the Tegens' collection of camp survivors' testimonies.

51 Garde, De Dödsdömda Vittnar, 25.

52 See Izabela A. Dahl, “' ...this is material arousing interest in common history'. Zygmunt Lakocinski and Polish survivors' protocols”, Jewish History Quarterly, vol. 3, (2007): 319-338.

53 Dahl, "'...this is material arousing interest in common history," 327. 
about the Holocaust. ${ }^{54}$ Most of these concerned the perceived "hypertrophy" of Jewish memory vis-à-vis other groups victimized during the Holocaust such as the Roma, the handicapped as well as victims of other atrocities such as Ukrainian peasants and African-American slaves. One such example was the immanent critique launched by American scholar Norman Finkelstein, himself a child of two Jewish camp survivors, who, in broad strokes, painted a picture of a "Holocaust industry" which was propped up by Holocaust scholars whose Zionism and zealotry, profited off the Jewish victims' suffering. "This backlash against the Holocaust's perceived privilege in academic and cultural contexts", the literature and critical studies scholar Karyn Ball explains, "evokes an economic logic of scarcity. The assumption is that scholarship about the Shoah appropriates time, energy and public attention that would be more urgently invested in the analysis of immediate and ongoing problems". 55

Similarly, the memory studies scholar Michael Rothberg refers to the example of literature critic Walter Benn Michael and his critique of how the Holocaust has been afforded much more attention as compared to the victims of slavery in the United States. The basic assumption of this 'competitive representation' is that "collective memory obeys a logic of scarcity" and that different group-identities scramble for control of defining what the most prominent memory is in the public sphere. This idea, that "as I struggle to achieve recognition of my memories and $m y$ identity, I necessarily exclude the memories and identities of others", is challenged by Rothberg who instead presents the concept of multi-directional memory. ${ }^{56}$ In contrast to competitive memory, "multi-directional" memory,

Encourages us to think of the public sphere as a malleable discursive space in which groups do not simply articulate established positions but actually come into being through their dialogical interactions with others; both the subjects and spaces of the public are open to continual construction. ${ }^{57}$

Thus, memory's "productive" dynamic is, according to Rothberg, a potential source for justice rather than competition as well as the basis for "new forms of

54 See Michael Rothberg, Multi-directional Memory: Remembering the Holocaust in the age of Decolonization,

(Stanford, CA: Stanford University Press, 2009), 1-2. See also Dean, Aversion and Erasure, 1-30.

55 Karyn Ball, Disciplining the Holocaust, (Albany NY: SUNY Press, 2009), 2.

56 Rothberg, Multi-Directional Memory, 5.

57 Rothberg, Multi-Directional Memory, 5. 
solidarity." 58 Yet, as both Ball and Dean have shown in their analyses of critical debates of scholarly and cultural discourse on the Holocaust, the perception that memory is competitive continues to have serious implications for how specific memories are perceived, and more importantly for this dissertation, how the survivor as a public figure has been constructed over time.

\section{The 'How', 'Why' and From What' of Holocaust Survival}

How survivors are (and were) defined and how they have come to define themselves in relation to survivor-hood has depended on their inclusion (or exclusion) from academic, archival, legal and political discourse. The archival discourses and practices discussed above show how an emphasis on experience and utility create a certain 'ideal' survivor type when individuals with Holocaust experience become witnesses to history. However, even though some archival and historical endeavors have problematized the survivor's utility, there have also been attempts to understand the nature and character of survival itself — a process which has led to different categorizations such as 'victims', 'survivors', 'refugees', 'escapees', 'DPs' etc. These categorizations all depend on what I have termed the 'how', 'why' and 'from what' of Holocaust survival. By asking these questions, it is easier to see how the object travels between different categories of meaning. The 'how' refers to different modes of survival, including escape and hiding. Conversely, asking 'why' some people survived over others constitutes a field of study within historiography which focuses specifically on camp survivors, but is also a question that demonstrates victim's own feelings of having survivedfeelings that have sometimes been exacerbated by the framing of collective memory. Lastly, the 'from what' question focuses on the group identity of those surviving, most often asking whether a Holocaust survivor can be a survivor if one's life was not explicitly marked for annihilation on racial grounds.

Today there is a vast historiography aimed at understanding Holocaust survival, both before, during and after the Second World War. In the past two decades much of this historical research on survivors and their post-war lives has focused on the so called surviving remnant or the She'erit Hapletah, referring to the Jewish Holocaust victims who survived the camp system or who survived by 
escaping or hiding in occupied territories. ${ }^{59}$ This scholarly endeavor, emanating out of primarily North American and Israeli scholarship, attempts to understand the reconstruction of these groups' lives and the social, cultural, economic and political contexts which conditioned them, both in DP camps as well as in their new adoptive countries.

Even though the camp survivor is central to historical studies of Holocaust survivors, those who survived in hiding or managed to escape have also been subject to inquiry. The Jews who escaped to the Soviet Union as the German forces were occupying Poland have received particular attention in recent years as evidenced by the extensive anthology Shelter from the Holocaust: rethinking Jewish survival in the Soviet Union published in $2017 .{ }^{60}$ Moreover, escape from the Holocaust has also become its own sub-field since 'refugee studies' has, in many western European countries such as Britain and France, been a way to deal with questions of guilt regarding the restrictive refugee policies which significantly affected the victims of the Holocaust. ${ }^{61}$ The distinction between survivors and 'survival' is sometimes a difficult one to make here as many scholars see themselves as studying refugees, even though these particular refugees also technically survived the Holocaust. For example, although the kindertransport-referring to the rescue in 1938 of approx. 10000 Jewish children from Germany, Austria and Czechoslovakia - was a form of Jewish survival, the rescuees are often referred to, and refer to themselves as kind or kinder rather than survivors. ${ }^{62}$ In the

59 Dalia Ofer, Francoise S. Ouzan \& Judy Tydor Baumel-Schwartz, Holocaust Survivors: Resettlement, Memories, Identities, (New York: Berghahn Books, 2012). Beth B. Cohen, Case Closed: Holocaust Survivors in Post-War America, (New Brunswick, NJ: Rutgers University Press). Hanna Yablonka, Survivors of the Holocaust: Israel after the War, (Basingstoke: Palgrave Macmillan, 1998). Dina Porat, Israeli Society, the Holocaust and its Survivors, (London: Vallentine Mitchell, 2008). Eva Kolinsky, After the Holocaust: Jewish Survivors in Germany after 1945, (London: Pimlico, 2004). Dan Stone, The Liberation of the Camps: The end of the Holocaust and its Aftermath, (New Haven: Yale University Press, 2015).

60 Atina Grossmann, Mark Edele \& Sheila Fitzpatrick, Shelter from the Holocaust: Rethinking Jewish survival in the Soviet Union, (Detroit MI, Wayne State University Press, 2017).

61 See for example, Tony Kushner, The Holocaust and the Liberal Imagination: A Social and Cultural History, (Oxford: Blackwell, 1994). Dan Stone, Responses to Nazism in Britain, 1933-1939, (Basingstoke: Palgrave Macmillan, 2003). Michael Marrus, The Unwanted: European Refugees from the First World War through the Cold War, (Philadelphia: Temple University Press, 2002). Michael Marrus \& Robert O. Paxton, Vichy France and the Jews, (Stanford: Stanford University Press, 1995).

62 Caroline Sharples, "Reconstructing the Past: Refugee Writings on the Kindertransport," Holocaust Studies, vol. 12, no. 3, (2006): 41. See also Rebekka Gopfert \& Andrea Himmel, "Kindertransport: History and Memory," Shofar, vol. 23, no. 1, (2004): 21-27. 
historiographical literature they are also, in most cases, categorized as refugees rather than survivors. In contrast, in his book Survivors Bob Moore labels all those who hid from, and escaped countries occupied by the Nazis, as "survivors". 63 This terminological variation also affects the ways in which individuals with Holocaust experience have been studied. In her research on the Lakocinski material, Izabela Dahl notes that,

Interesting in this context seems to be the fact that in contrast to other countries the survivors in Sweden were viewed as repatriates. They were never viewed as Displaced Persons. In Swedish research the survivors are called refugees (flyktingar), and this has to be read as a clear signal that they were seen as guests even if many of them had lost their homes and did not feel that post-war Poland was a homeland to which to return. ${ }^{64}$

Here, several terminological issues can be discerned. Firstly, not all Swedish research on those rescued by the 'white buses' label the rescuees as flyktingar. In his study of those rescued by the 'white buses' and the Swedish labor market, Lars Olsson, for example, refers to all rescuees irrespective of national, ethnic or religious background as överlevande ("survivors"). ${ }^{65}$ Similar to Dahl, Olsson uses the term överlevande to denote camp survivors specifically. Dahl does the same by calling Polish catholic camp survivors, merely "survivors". She is right, however, in noting that Swedish historiography most often refers to individuals with Holocaust experience as flyktingar or refugees. Olsson, for example, uses the term when referring to the whole group of Jewish rescuees and escapees as evidenced by his discussion on the Jewish aid worker and activist Inga Gottfarb where he states that "in a postscript to her rendition, which amongst other things, is based on a number of interviews with surviving Jews who were rescued to Sweden, [Gottfarb] emphasizes the need for continuing the research on the 'Bernadotte mission' and the admittance of Jewish refugees to Sweden". ${ }^{66}$ Here, Olsson uses the term överlevande to denote camp survival and flykting to denote all those Jews who managed to flee to Sweden in the years before and during the war. Therefore, the

63 Bob Moore, Survivors, (Oxford \& New York: Oxford University Press, 2004).

64 Dahl, "'...this is material arousing interest in common history," 320-321.

65 Lars Olsson, På tröskeln till folkhemmet: Baltiska flyktingar och polska koncentrationslägerfängar som reservarbetskraft $i$ skainsket jordbruk kring shutet av andra världskriget, (Lund: Morgonrodnad, 1995), 13.

66 Olsson, På tröskeln till folkhemmet, 15 ["I en efterskrift till sin skildring, som bl a bygger på ett flertal intervjuer med överlevande judar som räddades till Sverige, poängterar hon behovet av fortsatt forskning om 'Bernadotteaktionen' och de judiska flyktingarnas emottagande i Sverige']. 
distinction made does not take into account the Holocaust as a limited phenomenon meaning that the definition of survivor is not dependent on 'from what' the individuals classified were escaping. Instead the terminology is based on the subjects' camp experience.

Furthermore, the distinctions of survival — whether one hid in a Christian family, escaped to a neutral country or went through ghettoization and several camps-has also been integral in the study of survivors' mental health, again with a particular focus on Jewish survivors. ${ }^{67}$ Because of the vast difference in survivor experience, psychiatrists have been interested in exploring the differences between the various mental responses and coping mechanisms which arose in response to trauma. For example, Rachel Lev Wiesel and Marianne Amir have, in a series of research projects investigated the occurrence of PTSD in Jewish child survivors who had hid in Christian families, at Catholic institutions, in the woods or with partisan groups or survived in camps. Their results showed that child survivors who had been fostered (raised by Christian families) "scored significantly higher on several of the measures of distress, whereas survivors who had been in the woods and/or with partisans scored significantly higher on several of the positive measures, Qol, potency and self-identity". ${ }^{68}$

Explanatory frameworks regarding survival in the camps have also been related to the category of gender. One of the most controversial theses with regards to the question of why some camp victims survived while others perished was presented by Joan Ringelheim at the first conference on the Holocaust and Gender in the early 1980s. In her presentation, Ringelheim argued that female survival in the camps was different from male survival due to female-to-female solidarity. ${ }^{69}$ Although Ringelheim's postulation has since been revised, gender as a classification has maintained its relevance over the decades, although almost always studied as a

67 See for example, Rachel Lev-Wiesel \& Marianne Amir, "Post-traumatic growth among Holocaust Child Survivors," Journal of Loss and Trauma, vol. 8, no. 4, (2003): 229-237. -"Holocaust Child Survivors and Child Sexual Abuse," Journal of Child Sexual Abuse, vol. 14 (2005): 69-83."Posttraumatic Stress Disorder Symptoms, Psychological Distress, Personal Resources, and Quality of Life in Four Groups of Holocaust Child Survivors," Family Process, vol. 39, no. 4, (2000): 445-459.

68 Lev-Wiesel \& Amir, "Posttraumatic Stress Disorder Symptoms, Psychological Distress, Personal Resources, and Quality of Life in Four Groups of Holocaust Child Survivors," 445.

69 See Esther Katz and Joan Miriam Ringelheim (eds.) Women Surviving the Holocaust: Proceedings of the Conference, (New York: Institute for Research on History 1983). For a discussion on the impact and debate that followed the conference, see Sara R. Horowitz, "Gender, Genocide, and Jewish Memory," Prooftexts, vol. 20, no. 1\&2, (Winter/Spring 2000): 158-190). 
separate entity rather than a vital distinguishing factor amongst others. Since much of early research universalized the male experience, gender research of the Holocaust has focused on the experience of women. This, however, has led to a historiography of female Holocaust experience which continuously aims to 'set the record straight' rather than one that pursues its own interests with regards to gender and the Holocaust. In addition, the British historian Zoë Waxman asserts in her work on female survivor writers, that "research on women's experiences is generally presented as an addendum, or corrective, to existing androcentric work on the Holocaust". ${ }^{70}$ Rather than being positioned at the heart of Holocaust experience, gender is seen as a marginal classification, used by those who are interested in a specifically gendered history of the Holocaust rather than just $a$ history of the Holocaust. This is particularly true with regards to studies of gender and Holocaust representation where almost all research is produced by the same scholars within the same sub-field of feminist Holocaust studies. ${ }^{71}$

The 'whys' of survival have also been controversial as those who survived felt like they were guilty for having left the dead behind—a shame and a guilt that then had to be justified to the world in different ways. The camp survivor Bruno Bettelheim explains this feeling by stating that,

Being one of the very few who were saved when millions like oneself perished seems to entail a special obligation to justify one's luck and very existence, since it was allowed to continue when that of so many others exactly like oneself was not. ${ }^{72}$

However, the ubiquity of this emotional response among survivors has also been questioned by scholars such as Aron Hass who claims that guilt has been an assumed part of the survivors' post-war lives even though his own studies indicate that far from all survivors share this feeling. ${ }^{73}$ Perhaps the notion of guilt became

70 Waxman, Writing the Holocaust, 124.

71 For research on gender and representation see for example, Janet Jacobs, "Gender and Collective

Memory: Women and Representation at Auschwitz," Memory Studies, vol. 1, no. 2, (2008): 211 225._- "Women, Genocide, and Memory: the Ethics of Feminist Ethnography in Holocaust Research," Gender \& Society, vol. 18, no. 2, (April, 2004): 223-238._-"Remembering Genocide: Gender Representation and the Objectification of Jewish Women at Majdanek," in eds Oren Baruch Stier \& J. Shawn Landres, Religion, Violence, Memory, and Place, (Indianapolis \& Bloomington: Indiana University Press, 2006): 163-173. I will return to a discussion on their work and on gender in greater detail in section 1.9.

72 Bruno Bettelheim, Surviving and Other Essays, (New York, Alfred A. Knopf, 1979).

73 Aron Hass, The Aftermath: Living with the Holocaust, (Cambridge: Cambridge University Press, 1995). 
increasingly potent in response to different publics' and cultural elites' skepticism regarding the ways in which some had managed to survive the Holocaust. As Waxman notes in relation to the early reception of survivor literature, "survivors had also not realized that their very survival made them objects of suspicion and unease." 74 One of the most sensitive issues seemed to be that of the Jewish victims walking "like lambs to slaughter"- an issue invoked repeatedly and deliberately during the Eichmann trial, and a question that garnered much attention and criticism when posed by Hannah Arendt in her series of articles on Eichmann published in the New Yorker and later in her seminal book Eichmann in Jerusalem. ${ }^{75}$ The idea that the Jewish victims had somehow been culpable in their own death and that survivors were now forced to testify to this presumably shameful passivity, was thus a major obstacle for some survivors who felt obliged to, yet uncomfortable with, testifying to their own wounds. ${ }^{76}$

Further, the categorization of survivors as different types of victims has also been intimately connected with the ways in which specific groups have been publicly acknowledged. One of the most powerful forms of recognition has undoubtedly been legal processes pertaining to restitution and property claims, ensuing in the post-war period. In order to receive restitution for crimes committed against one's life and livelihood, claimants had to 'prove' in various (often complicated and psychologically painful) ways their different experiences. During the Cold War this process often focused specifically on Jewish victims, leaving out other victim groups affected by Nazi policy such as the Roma, Sinti, LGBTQ community, the disabled and non-Jews forced into different forms of slave labor. ${ }^{77}$ Also, possible claimants residing in the Soviet Union or the Eastern communist bloc were refused significant restitution as their property became nationalized and other forms of compensation were refused to them. ${ }^{78}$

74 Waxman, Writing the Holocaust, 111.

75 David Cesarani, “Introduction," Journal of Israeli History, vol. 23, no. 1 (2004): 1-17. Anita Shapira, “The Holocaust: Private Memories, Public Memory," Jewish Social Studies, Vol. 4, No. 2, (1998): 46-58.

76 Waxman, Writing the Holocaust, 111.

77 Larissa Allwork, Holocaust Remembrance between the National and the Transnational: The Stockholm International Forum and the first decade of the International Task Force, (London: Bloomsbury, 2015), 21. See also Michael Marrus, Some Measure of Justice: the Holocaust era Restitution Campaign of the 1990s, (Madison WI, Wisconsin University press, 2009).

78 See Jeffrey Herf's discussion on the restitution debates in West Germany in Divided Memory: The Nari Past in the two Germanys, (Cambridge MA: Harvard University Press, 1997), 267-333. 
Because of this imbalance, the biggest thrust to create a working restitution program in Europe in the post-Cold War era was aimed at former communist states. Some important legal claims actions have also included restitution for other affected victim groups such as those mentioned above as well as Jehovas Witnesses. In the most recent large-scale project for restitution launched by the International Commission on Holocaust era insurance claims (ICHEIC), however, the focus was yet again on Jewish survivors, estimated in 2003 to comprise a population of approx. 1, 2 million individuals with a majority living in North America and Israel. ${ }^{79}$ What the research preceding the claims process attempted to do was to establish the relative neediness of the remaining Jewish Holocaust survivor population. In order to do this, a definition of who constituted a Holocaust survivor first had to be established "based on certain legal criteria" ${ }^{80}$ Although slave labor and flight constituted their own distinct categories, the final category entitled "those disrupted by Nazi endeavors" opened up the definition for any Jewish person who "actually suffered physical or other kinds of persecution, those who escaped from areas in which they were the designated target for persecution, and those who suffered any kind of other limitation of personal freedom, even temporary or potential limitations." 81 In scholarly literature on restitution, the term survivor is most often used to denote Jewish victims of the Holocaust whereas other people who experienced Nazi oppression are denoted as "victims" or "victim groups". Being victimized during the Holocaust then, does not necessarily mean that one is considered a Holocaust survivor.

\section{The Perils of Periodization: 'The thesis of silence' and the Holocaust survivor}

The discursive construction of the Holocaust survivor is intrinsically linked to the greater development of a transnational as well as a national memory culture surrounding the Holocaust as historical event. Waxman postulates that,

the accepted concept of the Holocaust and the role of collective memory place two demands on the survivor. First, they seek to homogenize the survivors' experiences, and secondly, they assume that, in adopting the role of the witness, survivors will adopt a universal identity. But, in negotiating the hegemony of accepted Holocaust narratives, some survivors' experiences are

79 Sergio Della Pergola, “Jewish Shoah Survivors” in eds Dalia Ofer, Francoise S. Ouzan, and Judy Tydor Baumel-Schwartz, Holocaust Survivors: Resettlement, Memories, Identities, (New York: Berghahn Books, 2012), 294.

80 Della Pergola, "Jewish Shoah Survivors," 294.

81 Della Pergola, "Jewish Shoah Survivors,” 294. 
either pushed towards the margins or neglected altogether. ${ }^{82}$

How the Holocaust story is told thus affects they manner in which Holocaust survivor-hood is constituted. Here, different silences arise when one homogenous experience is assumed to apply to all individuals who were victimized during the Holocaust. The case of sexual violence directed toward Jewish women in the Holocaust constitutes but one such example. In early historiography it was assumed that Jewish women were spared instances of sexual violence as there were so called Rassenschande laws in place which prohibited such acts from being carried out by 'Aryan' men. ${ }^{83}$ This assumption, of course, overlooked the possibility of sexual violence being perpetrated by other victims as well as the seemingly obvious point that many guards and other Nazi officials were able to ignore the Rassenschande laws by silencing their victims and any other potential witnesses. This example highlights not only the ways in which survivor-hood has been defined along the lines of those forms of victimization which have belonged to the official record of Holocaust history, but it also presents a historiographical problem concerning how to study silences. If there is little evidence that Jewish women were exposed to instances of sexual violence, do we assume that these memories have been repressed and that the documentation had been destroyed, or do we accept the evidentiary silence as proof that few Jewish women were sexually assaulted?

On the other hand, in historiographical terms, there are silences which have been exposed when finding that a multitude of sources that have yet to be explored. For example, from the early 1980s up until 2009, there was a general consensus among American as well as European scholars that the Holocaust was not present in Western memory culture in any significant way until the 1960s. In presenting a theory for a "global" Holocaust memory, Daniel Levy and Natan Sznaider famously divided Holocaust memory into four different phases; 1945-1960 was characterized by silence, 1960-1978 constituted a period of change and an increase

82 Waxman, Writing the Holocaust, 158.

83 Helene Sinnreich argues that "the suggestion that a German man would not commit Rassenschande by engaging in sexual relations with a Jewish women is as untenable as any argument which insists that the existence of rules against an action prove that it could not or would not take place," See Sinnreich, “'And it was something we didn't talk about': Rape ad Jewish Women during the Holocaust," Holocaust Studies, vol. 14, no. 2, (2008): 2. See also Annabelle Baldwin, "Sexual Violence and the Holocaust: Reflections on Memory and Witness Testimony," Holocaust Studies, vol. 16, no. 3, (2010): 112-134. Katarzyna Person, "Sexual Violence During the Holocaust: the case of forced prostitution in the Warsaw ghetto" Shofar, vol. 33, no. 2, (2015): 103-121. 
of public debates about the Holocaust, the years between 1979 and 1988 saw the "Americanization" of the Holocaust while the years thereafter has seen a "cosmopolitanization" or globalization of Holocaust memory. ${ }^{84}$ This timeline also structures Annette Wieviorka's narrative in her book The Era of the Witness where she contends that the period between the time that the camps were liberated and the time of the Eichmann trial saw few attempts in hearing the survivors, who, although laborious in their quest to document the Holocaust, found few opportunities to publish their testimonies and fewer audiences who were willing to listen. ${ }^{85}$ Like Levy and Sznaider, Wieviorka argues that the Eichmann trial contributed to the circulation and dissemination of Holocaust stories, particularly with regards to the standing of the Holocaust witness. In a chapter entitled "the Advent of the Witness" she argues that,

The Eichmann trial marks a pivotal moment in the history of the memory of the genocide in France and the United States as well as in Israel. It opens up a new era, in which the memory of the genocide becomes central to the way many define Jewish identity, even as the Holocaust demands to be admitted to the public sphere. Scholars from various countries who have studied the evolution of the construction of memory have noticed this shift. ${ }^{86}$

Furthermore, American historian Peter Novick's influential book, The Holocaust in American Life as well as Tony Kushner's The Holocaust and the Liberal Imagination (both published in the late 1990s), have contributed significantly to the maintaining of this consensus - both on the influence of the Eichmann trial and the period of 'silence' which preceded it. ${ }^{87}$ Novick's claims that Jewish-American communities had been disinterested in the Holocaust and its survivors was, however, famously contested by Hasia R Diner in 2009 who, in her book We Remember with Reverence and Love, showed that although the Holocaust and its survivors were not prominent features in non-Jewish discourse, Jewish-American communities were far from silent in the decades before Eichmann and that the survivor as witness had inhabited a central standing in American-Jewish memorial practices surrounding

84 Daniel Levy \& Natan Sznaider, The Holocaust and Memory in the Global Age, (Philadelphia: Temple UP, cop., 2006).

85 Wieviorka, The Era of the Witness, trans. Jared Stark, (Ithaca NY: Cornell University Press, 2006)

86 Wieviorka, The Era of the Witness, 56.

87 Hasia R. Diner, We Remember with Reverence and Love: American Jews and the Myth of Silence after the Holocaust, 1945-1962, (New York: New York University Press, 2009), 8. 
the Holocaust since the end of the war. ${ }^{88}$ Similarly, British historian David Cesarani has shown how survivor publications of memoirs were much more prolific than previously assumed. ${ }^{89}$

The 'thesis of silence' - although successfully contested by Diner and Cesarani among others - continues to influence Western scholarship on the Holocaust, one context feeding into another, sometimes without much empirically based analysis supporting its claims. It thus endures in its potency and can be found in contemporary efforts to synthesize research on the Holocaust in Sweden (see section 1.5). Trying the 'thesis of silence' is, therefore an important task for researchers as the empirical analyses of several decades of memory practices across vast geo-cultural spaces take both time and effort. It is also important to understand the various forms of silence, both those proposed and created by earlier efforts to explain and understand the Holocaust and its place in different national and transnational memory cultures. Contesting 'the thesis of silence' is thus not a scholarly endeavor that is used to disprove all other previous research on the subject, but a way to empirically explore what forms of silence were there to begin with, and what silences were constructed afterwards in the ever-growing work of Holocaust memory's own historiography.

\subsection{Swedish Holocaust Scholarship}

It is doubtful whether there are any actual Swedish 'Holocaust historians'. Even though there are many excellent examples of research conducted within Swedish historiography which elucidate several questions regarding Swedish policy responses to the Holocaust as well as flight and rescue, few Swedish historians or memory studies scholars deal exclusively with the Holocaust. ${ }^{90}$ In Sweden, the

88 Diner, We Remember with Reverence and Love, 365-390.

89 David Cesarani, "Challenging the 'Myth of Silence': Postwar Responses to the destruction of European Jewry," in eds. David Cesarani \& Eric J Sundquist, After the Holocaust: Challenging the Myth of Silence, (Abingdon: Routledge, 2012): 15-38.

90 For historiography on Swedish policy responses to the Holocaust see Paul A. Levine, From Indifference to Activism: Swedish Diplomacy and the Holocaust, 1938-144 (Doctoral diss.: Acta Universitatis Upsaliensis, 1996). Karin Kvist Geverts, Ett Främmande Element $i$ Nationen: Svensk Flyktingpolitik och de Judiska Flyktingarna, (Doctoral diss.: Acta Universitatis Upsaliensis, 2008). Lars M Andersson and Karin Kvist Geverts, (eds) En problematisk relation? Flyktingpolitik och judiska flyktingar i Sverige, 1920-1950, (Uppsala: Historiska Institutionen, Uppsala University, 2008). Lars 
historical discipline's interest in the Holocaust developed as a result of controversies outside of academia relating to moral questions of guilt, responsibility and Sweden's policy of neutrality during the Second World War. This is not to say that academic interest in the Holocaust was absent before this point. What is widely considered to be one of the first attempts to understand Sweden's role in the Holocaust came two years before the first major controversy of the 1990s through the American scholar Steven Koblik's book The Stones Cry out. ${ }^{91}$ Yet, further studies need to be conducted in order to say anything conclusive about the development of Holocaust historiography in Sweden before 1988, not including the attention that has been paid to the SUAV project (Sverige under Andra Världskriget, Sweden during the Second World War) launched in the 1970s which focused on Swedish action during the Second World War. ${ }^{92}$ What can be argued, however, is that professional historians responded to various "Holocaust moments" (to use Atina Grossman's term) of the 1990s, both through the publication of academic texts on the subject, but also by debating non-academic opinion makers and by working with the Living History campaign and subsequently with the Living History Forum (Forum för Levande Historia). ${ }^{93}$

The smoking gun which created this 'Goldhagen effect' amongst Swedish historians in the 1990s was the journalist and feminist activist Maria-Pia Boëthius's

Olsson, På tröskeln till folkhemmet: Baltiska Flyktingar och Polska koncentrationslägerfängar som reservarbetskraft $i$ skänskt jordbruk kring slutet av andra världskriget, (Morgonrodnad: Växjö, 2008). For historiography on Swedish rescue see for example, Hansson, Flykt och överlevnad, Pontus Rudberg, The Swedish Jews and the Victims of Nari Terror, 1933-1945, (Doctoral diss.: Studia Historica Upsaliensia, 2015). Malin Thor Tureby, "Svenska änglar och hyenor möter tacksamma flyktingar. Mottagningen av befriade koncentrationslägerfångar i skånsk press under året 1945”, Historisk Tidsskrift, 135: 2, (2015): 266-300, --“"Swedish Jews and the Jewish survivors: The first Public Narratives about the Survivors in the Swedish-Jewish Press," in eds Mikeal Byström \& Pär Frohnert, Reacbing a State of Hope-Refugees, Immigrants and the Swedish Welfare State, 1930-2000, (Stockholm: Nordic Academic Press, 2013), 145-166.

91 Steven Koblik, The Stones Cry Out: Sweden's Response to the Persecution of Jews 1933-1945, (New York: Holocaust Library cop., 1988).

92 SUAV is an acronym for Sverige under Andra Världskriget (Sweden during the Second World War), a project that spanned the period 1966-1975 and within which approximately twenty new doctoral dissertations, one anthology and one monograph were produced. SUAV was headed by the Stockholm University-based historian Stig Ekman. See Stig Ekman, "Sverige under andra världskriget—erfarenheter från arbetet i ett projekt,” Historisk. Tidsskift, vol. 99, 1979: 152-165.

93 Atina Grossman, "The 'Goldhagen effect': Memory, Repetition, and Responsibility in New Germany" in ed. Geoff Eley, The "Goldhagen Effect": History, Memory, Nazism-Facing the German Past, (Ann Arbor: the University of Michigan Press, 2000). 
book Heder och samvete ("Honor and Conscience"). In Heder och samvete, Boëthius questions Sweden's neutrality policy during the Second World War and the ways in which it had been defended in the following decades by academics and nonacademics alike. Although many historians considered Boethius's argumentation hyperbolic and sensationalist, her critique led to further reflection within the historical discipline. As Östling argues in his doctoral dissertation from 2008, "[Boëthius's] book was a white hot accusation which, although not fully received by all in the scientific community, in extension contributed to the incitement of a self-examination even amongst historians". ${ }^{4}$ This process of 'self-examination' was further facilitated by a speech given by the well-respected historian, Alf W Johansson, at a symposium in the Swedish riksdag (parliament) in 1995. In his speech, Johansson agreed with some of his critical colleagues that the book did not present any new facts and had a sensationalist tone. However, he also argued that this was a good thing-that Boëthius's book was a much-needed contribution to Swedish historiography because it acted as a counterweight to the consensus which had previously reigned supreme about the righteousness of small-state realism. ${ }^{95}$

The second crucial event that involved historians both as critics and as hired experts was the launching of Persson's educational campaign Living History. Although many have speculated around the 'real' reasons for the initiative, the decision to launch this educational program was officially based on a survey conducted by Brottsförebyggande Rådet (BRÅ, the council for crime prevention) and Stockholm University (CEIFO) which indicated that a third of Swedish school youth either knew very little about the Holocaust or denied its existence as historical event all together. Within the Living History campaign, a book entitled Tell Ye Your Children, authored by historian Paul A. Levine and doctoral student Stephane Bruchfeld, was published which received high praise by Swedish critics. Although Living History was surrounded by much controversy, the book's success (both in Sweden and abroad) garnered much good will for Swedish efforts to remember the Holocaust. Subsequently, the Living History campaign took on a

94 Johan Östling, Nazismens sensmoral: Svenska erfarenheter i andra världskrigets efterdyning, (Stockholm; Atlantis, 2008), 22 ["Hennes bok var en vitglödgad anklagelseakt som inte alla i vetenskapssamfundet tog till sig, men i förlängningen bidrog den till att framkalla självrannsakan även i historikerkåren”]. Maria-Pia Boëthius, Heder och samvete: Sverige och andra världskriget, (Stockholm: Norstedt, 1991).

95 Sverker Oredsson, "Tes—antites—syntes? Synen på den svenska politiken under andra världskriget" in ed. Lars M Andersson, Sverige och Nazityskland: skuldfragor och moraldebatt, (Stockholm: Dialogos, 2007), 69. 
permanent shape in the form of a government agency for Holocaust and genocide remembrance and education, the Living History Forum which opened its doors for the first time in 2003. In creating this agency, a handful of Swedish historians were invited to work with the department for culture as experts and advisors. Also, the first head of the Living History Forum, Helene Lööw, was a professional historian who had also been one of the researchers involved in conducting the survey upon which Living History was based. Since its inception, the Living History Forum has invited historians to hold public lectures, write educational materials and work as in-house staff with the development of exhibitions and research. Significantly, the early activities of the Forum were framed by a so called "Swedish perspective", defined according to the agenda set by the debate unleashed by Boethius's book in the early 1990s. This meant that all activities relating to the Holocaust were supposed to connect in some way to questions of Swedish bystanderism and heroism, be it Raoul Wallenberg or the political views of the average Swede.

In conjunction with the Living History Forum opening its doors to the public, a new research project entitled The Holocaust and European Historical Culture published its first anthology. The project, headed by Swedish Lund-based historians, KlasGöran Karlsson and Ulf Zander aimed to "investigate several European post-war Holocaust battlefields" $" 96$ - a project which comprised fourteen different national contexts with monographs written specifically on historical cultures in the Ukraine and Israel. However, although producing three extensive anthologies and three monographs, Holocaust memory culture in Sweden was merely broached. Rather than exploring the same themes as in other national contexts (such as survivor literature, trials and tribunals, the Holocaust in popular culture etc.) Swedish memory culture was confined to events in 1945 pertaining to rescue and heroism and the ways that these had later been debated in the 1990s. Even though Zander also dealt with the issue of Holocaust and its reception in Sweden in 1979, the empirical work undertaken to study this phenomenon never extended beyond this anthology chapter. ${ }^{97}$

Interestingly, later renditions on Swedish memory culture refer to these research findings as comprehensive, thereby undermining any new efforts to study the period between 1945 and 1990. For example, in Östling's oft-cited chapter on 'small-state realism' he asserts that,

96 Klas-Göran Karlsson, The Holocaust on Post-war Battlefields, 11.

97 Ulf Zander, "Holocaust at the limits," in eds Klas-Göran Karlsson \& Ulf Zander, Echoes of the Holocaust: Historical Cultures in Contemporary Europe, (Nordic Academic Press, 2003): 255-292. 
as a dominant narrative, the small-state realistic interpretation recurred whenever the theme of Sweden and the Second World War cropped up. This was the background to the memoirs and biographies published in Sweden, and the perspective permeated textbooks, films and television series. ${ }^{98}$

To support this claim, Östling refers to Zander's chapter on the broadcasting of Holocaust as well as another text in a German anthology, also authored by Zander. Yet, there is nothing in Zander's research on Holocaust which suggests that narratives of Swedish action during the Second World War were integral to the decision to show Holocaust on Swedish TV or the debate that both preceded and followed the broadcast. Similarly, in a chapter entitled "The Holocaust and Memory Culture: the Case of Sweden" published in an anthology in 2007, historian Kristian Gerner asserts that Holocaust was a turning-point in Swedish memory culture surrounding the Holocaust referring to the establishment of the term "Förintelsen" (the Holocaust) after the broadcast. There is nothing that directly contradicts such a statement but neither Gerner's research nor any other research preceding his, has been able to show, through empirically supported analyses, that Holocaust was the most influential cultural production to raise awareness about the Holocaust in Sweden.

The research that was conducted from 1996 onwards, partly as a response to public discussions on Swedish guilt and neutrality, largely focused on Swedish migration policy during the war as well as anti-Semitism and its effects around the same time. ${ }^{99}$ One of the only exceptions to this rule is Henrik Bachner's doctoral research on anti-Semitism in Sweden after 1945, published in 2005 in which the author partly explores themes relating to the Holocaust in Swedish public discourse. Also, Ingrid Lomfors' dissertation on the "child quota" in Sweden, Miriam Sterner Carlberg's study of the Jewish community in Borås, as well as Malin Thor Tureby's dissertation concerning young exiled Jews from the Hechaluz movements constitute some of the only efforts to study victims of the Holocaust from a migrant perspective. ${ }^{100}$

One of the most recent attempts to analyze Swedish memory culture in relation to the Holocaust came in 2016 with an article authored by Karlsson. In his

98 Östling, "Nordic Narratives of the Second World War," 129-130.

99 See note 90 .

100 Lomfors, Förlorad barndom, àtervunnet liv. Thor Tureby, Hechaluz-en rörelse i tid och rum. Sterner

Carlberg's Gemenskap och Överlevnad: om den judiska gruppen i Borås och dess Historia, 
text, Karlsson shows how the Holocaust in Swedish memory culture has been considerably shaped by the small-state realist perspective. He thus states that,

\begin{abstract}
although neutral, non-belligerent Sweden had a particular position in Europe as one of few bystander states in the Second World War, its postwar attitude to the Holocaust did not differ much from a general European one. The general interpretation was that, as a small state, Sweden had luckily, but also through realistic and skillful political adjustments to the warring parties in general and the Nazis in particular, managed to avoid being dragged into the war. ${ }^{101}$
\end{abstract}

What is particularly telling about this quote is how Sweden's "post-war attitude to the Holocaust" is equated with a general consensus on the righteousness of neutrality - as if no other significant opinions, emotions and/or ideas surrounding the Holocaust existed outside of this discursive frame. In more ways than one, Boethius controversial book continues to haunt Swedish historiography, setting boundaries for what Holocaust research in Sweden is or ought to be-boundaries which frame questions of collective/individual memory, testimony and trauma as singularly tied to issues of national identity and nationalist narratives of political history.

This framing is also evident in a special issue from 2011 on "The Histories and Memories of the Holocaust in Scandinavia" published in the Scandinavian Journal of History within which the editors, Karin Kvist Geverts and Antero Holmila, use Levy and Sznaider's framework to describe Scandinavian Holocaust memory. Although they note that there never was a complete silence about the Holocaust between 1945 and 1960, they still maintain that between 1960 and 1978 was "marked by the establishment of deeply held national master narratives". 102 Again, this might very well be the case, but it has not been established empirically that other narratives regarding the Holocaust, whether being framed by discourses on Jewish identity, Israel, universalism and/or justice also contributed to a meaningful communication of Holocaust memory in Sweden.

The fact that no one has questioned this partial blindness to non-nationalist Holocaust memories can perhaps be explained by Kansteiner's contention that "historians often underestimate the interdependencies between popular and elite culture because they seek to distance themselves from what they consider non-

101 Klas-Göran Karlsson, “'Tell Ye Your Children...' The Twisted Road to Swedish Holocaust

Recognition," Scandinavian-Canadian Studies, vol. 23, (2016): 80.

102 Holmila \& Kvist Geverts, “On forgetting and rediscovering the Holocaust in Scandinavia,” 526. 
professional types of historical representation. As a result, they fail to realize to what extent scholarly innovations depend on larger cultural transformations". ${ }^{103}$ What also seems to be lacking from these accounts of Swedish memory culture is some form of transparency with regards to the huge gaps in research which existed then and which continue to exist in relation to the Holocaust in Swedish public discourse today. In short, the historians of Swedish memory culture and the Holocaust were perhaps too quick to synthesize this part of history. In the past couple of years, however, the art historian Tanja Schult has published two articles written within a research project entitled I skuggan av Förintelsen ("In the shadow of the Holocaust") which both focus on Swedish memory culture through Swedish monuments and memorial sites. In this research Schult begins to shift the idea of Swedish Holocaust memory as singularly tied to narratives of small-state realism. ${ }^{104}$ Schult concludes that early efforts to remember the Holocaust were mostly curated by the heterogeneous Swedish-Jewish minority. This, she contends, relates to the fact that the process of collective mourning over the Holocaust's victims largely became a Jewish issue after the war. ${ }^{105}$ However, memorial practices only constitute one part of the vast array of cultural memory practices that surround the Holocaust and can thus not be used as an empirical foundation explaining Swedish Holocaust memory at large.

The critical exploration expounded above regarding Swedish scholarship on the Holocaust, is not supposed to berate or belittle previous efforts at understanding the role of the Holocaust in Swedish memory culture. Rather, they serve as an explanatory framework for the coming methodological discussion in which I account for the ways in which I have tried to locate, not merely the Holocaust survivor, but also the Holocaust itself in Swedish public discourse. The prevailing attitude that Swedish memory culture has been dominated by one nationalist discourse or narrative and that all other discourses relating to this paradigmatic historical event are largely insignificant, has made my own work on understanding the role of the Holocaust survivor all the more difficult. Rather than having a canonical historical narrative to lean on and to contest, I have had to

103 Wulf Kansteiner, "Success, truth and modernism in Holocaust historiography," 34.

104 Tanja Schult, "Gestaltningen och etableringen av Förintelseminnet i Sverige", Nordisk Judaistik, vol. 27, no. 2, (2017): 3-21. -“Gestaltningen och etableringen av Förintelseminnet i Sverige: Förintelsemonument i Sverige, 1990-2009," Nordisk Judaistik, vol. 28, no. 2, (2017): 39-62. See also Tanja Schult, A Hero's Many Faces: Raoul Wallenberg in Contemporary Monuments, (Doctoral Diss.: Stockholm University, 2009).

105 Schult, "Gestaltningen och etablering av Förintelseminnet i Sverige," 5. 
construct my own periods of significance, searching a multitude of archives for discourses on the Holocaust in the period between 1945 and 1990.

\section{6 'Public Discourse', Genealogy and the Question of Archives}

As is evident from the discussion above, survivors have been studied in a variety of ways across the disciplines; studies that range from the epistemologies surrounding survivor expression to the survivor as a historical subject, creating a life after the catastrophe. While the metahistorical narratives that include survivors discuss the ability of survivors to communicate their experiences, historiographies tend to focus on the reconstruction of post-Holocaust lives. The work that this dissertation bases its theoretical and methodological structure on, however, is more concerned with the construction itself-not the communicability of the Holocaust or survivors' post-Holocaust lives but the very category of 'survivor', how it came to be and how it was subsequently disciplined. Dean's inquiry into the inextricable relationship between victimization and "the rhetorical fashioning of the exemplary victim"106 lies nearest to this endeavor. However, an understanding of the construction of the Holocaust survivor also goes beyond the rhetoric of victimization. It includes a deeper comprehension of the discursive practices that create the Holocaust survivor object at different points in time. At the same time, positioning myself along constructivist notions of history, I as the researcher, am also contributing to the construction; the construction is mine, even though I am attempting to locate and understand the constructions of others. In this section I will discuss and disentangle some of the theories and methodologies that underpin the endeavor of locating constructions as well as constructing the Holocaust survivor. First, the notion of 'public discourse' will be discussed and disseminated. This discussion is then followed by a longer methodological explication of how Foucauldian genealogy can be methodologically strengthened by adopting other discourse analytical strategies. Thereafter, I explain how I have constructed my own archive of sources, where my study begins and where it ends (and why) and finally, how, in more practical terms, I have conducted my analyses.

\section{Public Discourse as Media Discourse}

I have previously referred to the construction of Holocaust survivors in 'public discourse' which is a term often used but rarely expounded. When used colloquially

106 Dean, Aversion and Erasure, 8. 
or within the disciplines of law and political science, public discourse most often refers to conversations, discussions or debates held in public fora such as media outlets or the floor of parliament. Yet, within the vast field of critical theory, public discourse is a much more complex concept which encompasses discursive events as well as the implicit and explicit rules which enable and restrict them. In order to define public discourse, let us first turn to the second part of the term: discourse. In Foucauldian terms, discourse or discursive formation simply refers to the systematic dispersion of statements. Statements, in turn, are "positive events that produce existence through enunciation": a text, a gesture or a practice which, together with other statements, constructs the object. ${ }^{107}$ This enunciation has to occur from a subject position, meaning that all objects are created by subjects whose statements also create subjectivities as much as they create the statement. ${ }^{108}$ This occurs within relations of power that determine the relative impact of the statement in contesting or adapting to the discourse. Foucault phrases it thusly in the Archaeology of Knowledge:

whenever one can describe, between a number of statements, such a system of dispersion, whenever between objects, types of statement, concepts, or thematic choices, one can define a regularity (an order, correlations, positions and functionings, transformations), we will say, for the sake of convenience, that we are dealing with a discursive formation. ${ }^{109}$

Identifying the system or ordering of statements thus constitutes the first task facing the discourse analyst. The central question becomes: how do we "formulate [statements'] law of division?" 110 Since discourses are contingent on their historical context, the analyst cannot follow pre-given themes or concepts but has to explore "the space in which various objects emerge and are continuously transformed". 111 This emergence does not refer to objects' origins but to the spaces in which they are re-affirmed, altered, controlled and contested.

Public discourse then, can be understood as one of those spaces; a space in which objects are enunciated and publicly re-affirmed, altered, controlled and contested. If public discourse refers to the space in which objects are affirmed and negotiated, then this space includes a variety of different communicative platforms

107 Niels Åkerström Andersen, Discursive Analytical Strategies: Understanding Foucault, Koselleck, Laclau, Lubmann, (London: The Policy Press, 2003), 11.

108 Andersen, Discursive Analytical Strategies, 14-15.

109 Foucault, The Archaeology of knowledge, (Abingdon: Routledge, 2006), 41.

110 Foucault, The Archaeology of knowledge, 36.

111 Foucault, The Archaeology of knowledge, 36. 
and outlets_-online chat rooms, political speeches and corporate statements just being a few examples. When studying Holocaust memory, public memorials, commemorative days and awards as well as books and memoirs constitute some of the most important communicative forms. For this dissertation, however, I have chosen to define public discourse as media discourse. This was done in order to limit my own collection of sources but also in order to limit the study to a manageable amount of discursive practices-here defined as the contexts in which the events are produced, circulated and consumed. ${ }^{112}$ Although Foucauldian discourse analyses often focus on several different spaces in which the object comes to be, I have chosen to limit my study to "mass-meditated messages", because these clearly demonstrate the workings of disciplinary power, being the space in which 'experts' communicate with larger publics. ${ }^{113}$ Throughout my analyses I will refer to public discourse and media discourse interchangeably; the former denoting a more general idea of how the object forms while the latter is referenced when discussing specific mechanisms of one or several mediums.

\section{Genealogy as Methodological Framework.}

Media discourse has been thoroughly theorized by the most influential scholars of Critical Discourse Analysis (CDA); Teun Van Dijk and Norman Fairclough. Adopting their analytical approaches would therefore seem apt in a study that attempts to understand the construction of the survivor in media discourse. However, in aiming to describe how an object becomes and changes over time, Van Dijks and Fairclough's linguistic analytical practices become much too focused on the intricacies of media language in the present. As this dissertation project is more concerned with the historical construction of an object, a genealogical approach was adopted which, together with some of the methods developed within CDA is used to elucidate discursive transformations over time.

Most historians of Sweden and the Holocaust have adopted conventional methodological approaches to their subjects based on what the American historian Ethan Kleinberg denotes as a "weaker" form of ontological realism. ${ }^{114}$ This means

112 See for example, Fairclough, Critical Discourse Analysis: The Critical study of Language, (London \& New York: Routledge, 2013), 59.

113 Teun Van Dijk, "Introduction: Discourse Analysis in Mass Communications Research", in ed. Teun Van Dijk, Discourse and Communication: New Approaches to the Analysis of Mass Media, (Berlin: De Gruyter, 1985), 1.

114 Ethan Kleinberg, Haunting History: For a Deconstructive approach to the Past, (Stanford, Stanford University Press, 2017), 1. 
that they adhere to the notion that the past is "an ontological reality that we can only approach from limited perspective and incompletely from our own position in the present and thus with epistemological uncertainty about that which is ontologically certain." "115 In adopting such a perspective they have attempted to uncover phenomena such as intentions behind political decision-making, knowledge about the catastrophe amongst the Swedish population and the whys and whens of Swedish responses to the Holocaust both in the past and in contemporary society. ${ }^{116}$ Simultaneously, there has been a historiographical discussion in Sweden about the moral dimensions of Holocaust scholarship that demonstrates some reflexivity with regards to how the historian's endeavors to describe, understand and explain the past are affected by the present. ${ }^{117}$ In Sweden, as elsewhere, however, questions concerning the ontological reality of the past when we cannot reach it methodological have been largely avoided. ${ }^{118}$

By using a genealogical methodological framework, this dissertation diverges somewhat from these previous scholarly endeavors. Rather than attempting to find the essence of the past, what Holocaust survivors thought and felt and how they were treated by the Swedish state, I venture to understand how survivors have

\section{Kleinberg, Haunting History, 2.}

116 See note 90. There is one notable exception to this trend within studies about the Holocaust and Holocaust representation in Sweden and that is Rebecka Katz Thor's doctoral dissertation, Beyond the Witness: Holocaust Representation and the Testimony of Images, (Art and Theory Publishing: Stockholm, 2018). Also, in one of his anthology chapters written under the auspices of the project The Holocaust and European Historical Culture, Klas-Göran Karlsson discusses the importance of a genealogical perspective on the Holocaust as an argument for why it has been attributed meaning in the post-Holocaust world. See, Klas-Göran Karlsson, "Förintelsen som historiekulturellt fenomen-en översikt", Historisk Tidskrift, vol. 125, no. 4, (2005): 721-733. Karlsson, also explores European Holocaust memory from what appears a genealogical perspective in his book from 2010 Europeiska möten med bistorien: historiekulturella perspektiv på andra världskriget, förintelsen och den kommunistiska terrorn (Stockholm: Atlantis, 2010). Unfortunately, Karlsson's book is only available in Swedish.

117 See for example, Lars M Andersson, "Historikerna och moralen”, in ed. Lars M Andersson Sverige och Narityskland: Skuldfragor och moraldebatt, (Stockholm: Dialogos), 9-25 as well as the debate articles penned by Klas-Göran Karlsson, Kristian Gerner and Andersson regarding the spelling of "Förintelsen" with a capital F. Klas-Göran Karlsson \& Kristian Gerner, "Förintelsen—i historien eller över historien," Historisk Tidskrift, vol. 123, no. 2, (2003): 317-318. Lars M Andersson, ”Att moralisera över det moraliska historiebruket," Historisk tidskrift, vol. 123, no. 2, (2003): 319-323.

118 Kleinberg argues that "conventional historians either avoid or defer the question" of what the ontological reality consists of, thus "working purely on the assumption that method is sufficient to bring the past into the present", See Kleinberg, Haunting History, 2. 
come to be constructed as moral, political and cultural subjects. To be sure, these constructions are also located in the past, making them subject to present discourses, affecting my ability to describe, understand and explain the them. This is also why the title of this dissertation uses the word "constructing" rather than "constructions"; the former implying that I am not only discovering constructions in the past but that I, through my analyses, are also complicit in constructing the survivor. Within many humanist disciplines, the idea of "situated knowledges" is old news. ${ }^{119}$ However, the historical discipline in general, and the historiographies that deal with the Holocaust in particular, are still sensitive to such critical engagements with ontology, epistemology and method. ${ }^{120}$ This careful, protective stance of reality's role in the historical construction is understandable, perhaps especially in studies of Holocaust survivors, as the authenticity of their expressions are always under threat from Holocaust deniers and right-wing extremists vying for control over the political message that survivors are seen to communicate. However, this problem does not negate the situatedness of knowledge, nor does it resolve the inherent contradiction in studying a past as past when the present fundamentally shapes it.

The intellectual exercise of this dissertation is thus not one of uncovering the past as it definitively was but, rather, to construct a narrative that presents for inspection and questioning, some of the statements and productive events that enunciated the survivor object and the underlying problematization that determined these statements. While I recognize and acknowledge that these statements were made in the past, their meaning is, in the end, constructed through my historical narrative however much I reflect upon my choices of sources and their inherent flaws. At the same time, the doctoral dissertation is a test that needs to be passed before one can move into the sphere of original and unsupervised research. Thus, if my examiners do not accept the premise that knowledge is situated, my endeavor to-from my own subject-position—construct a narrative

119 The foundational work on "situated knowledges" is Donna Haraway's "Situated knowledges: The Science Question in Feminism and the Privilege of Partial Perspective" Feminist Studies, vol. 14, no. 3, (Autumn 1988): 575-599.

120 This resistance can be gleaned from debates between heavy weights in historiography and metahistory such as that between Hayden White and Saul Friedländer. See also Wulf Kansteiner's assessment that in an Anglo-American context "White's work remains vilified by some mainstream historians, is more frequently cited by narratologists and literary scholars, and retains a faithful following only among a small group pf postmodern-inclined historical theorists". Wulf Kansteiner, "Success, Truth, and Modernism in Holocaust Historiography," 29. 
of others' constructions and warn against the effects of these constructions, I have already failed the test. As a doctoral student writing about a subject that has previously been dominated by conventional historical methods, and within a genre that requires complete transparency with regards to the research process, the 'pressures of positivism' make themselves painfully known. Therefore-despite the fact that I acknowledge the inherent contradiction in trying to know the past when the present always and irrevocably obscures it-I have adopted some of the methodological approaches used by most historians; critiquing my sources in relation to the context in which they were produced being one such central practice.

At the same time, the aim of this dissertation has prevented me from succumbing to the pressures of a "harder" ontological realism. Rather than trying to uncover the essence of human nature or the inevitability of historical progress I have tried to disentangle the multiple ways in which humans are in an ever-evolving process of becoming. ${ }^{121}$ Because my perspective was processual, focusing on how the context of power and discourse produced an object imbued with different meanings, I chose to adopt a genealogical method for my study. Furthermore, the motivation behind my inquiry into the construction of the survivor has always been the exclusionary effects of commonsensical notions about survivors. As discussed in the introduction to this chapter, the creation of a "we" homogenizes Holocaust experience and reduces survival to a singular phenomenon. Rather than the multiple survivals that Holocaust survivors had to endure-racial laws, ghettoization, camps, forced labor, sexual violence, mental fatigue, physical fatigue, starvation, depression-survivors are seen to have lived though one monolithic event. In questioning perspectives on such a homogeneity, I hope to open up more fields of contestation in which further spaces of expression can form. There is, therefore, an ethical sensibility embedded in the ontological and epistemological foundations of this dissertation, based on the destabilizing of concepts that essentialize the object. ${ }^{122}$

Because genealogy is not a prescriptive method with specific rules regarding analytical practice, I took inspiration from CDA when approaching my sources

121 Seantel Anaïs, "Genealogy and Critical Discourse Analysis in Conversation: Texts, Discourse, Critique”, Critical Discourse Studies, vol. 10, no. 2, (2013): 125.

122 See Connolly's discussion on the ethics of Foucault in William E. Connolly, "Beyond Good and Evil: The Ethical Responsibility of Michel Foucault," Political Theory, vol. 21, no. 3, (Aug, 1993): 365-389. For Foucault's own reasoning on truth, power and ethics see "The Ethics of the Concern of the Self as a Practice of Freedom" in ed. Paul Rabinow, Essential Works of Foucault, 1954-1984, vol. 1. Ethics: subjectivity and Truth, (London: Penguin Books, 2000), 281-301. 
while fundamentally focusing on the development of the object over time. In postulating a framework for the combination of Genealogy with $\mathrm{CDA}$, the Canadian sociologist Seantel Anaïs explains that,

genealogy is a methodological process concerned with telling the story of how a set of discursive and non-discursive practices come into being and interact to form a set of political, economic, moral, cultural, and social institutions which define the limits of acceptable speaking, knowing, and acting. ${ }^{123}$

Anaïs thus argues that "genealogy constitutes an ethos of analysis rather than a strict post-structuralist methodology". ${ }^{24}$ Originally a Foucauldian methodology, genealogy has taken on new shapes by scholars such as Ruth Wodak and Ian Hacking who both emphasize the historical aspect of a genealogical perspective. ${ }^{125}$ Hacking refers to his own iteration of genealogy as a 'historical ontology'; a way to understand present ontologies by excavating the past. According to Hacking this method is a historical exercise, albeit one that does not constitute history since it remains focused on present phenomena. Similarly, Wodak uses a form of genealogy which she has termed 'the discourse historical approach' in order to make sociological perspectives on CDA more acutely aware of the historicity inherent in their objects of study. Although the focus remains the present, the discoursehistorical approach points to the historical context as vital to our understanding of the contemporary social world. ${ }^{126}$ The larger framework and structure of the methodology used in this dissertation is inspired by a Foucauldian genealogical approach although parts of the method also borrow from Hacking's concept of "dialectical realism" and Wodak's emphasis on abductive research strategies. ${ }^{127}$

So far, I have referred to the discursive object or the classification of the survivor. However, there are also subjects, subjectivities and subject positions that

123 Anaïs, "Genealogy and Critical Discourse Analysis in Conversation,"125.

124 Anaïs, "Genealogy and Critical Discourse Analysis in Conversation," 124.

125 However, Hacking has also claimed that his notion of a historical ontology perhaps lies closer in aim and focus to Foucault's earlier endeavors with an archaeological approach to knowledge. See Ian Hacking, Historical Ontology, (Cambridge MA: Harvard University Press, 2002). See also Ruth Wodak, "The Discourse-historical approach" in Methods of Critical Discourse Analysis, (London: Sage, 2001): 63-94.

126 Wodak, “The Discourse-historical approach”, 70.

127 See Ian Hacking, "Between Michel Foucault and Erving Goffman: between discourse in the abstract and face-to-face interaction," Economy and Society, vol. 33, no. 3, (2004): 277-302. 
realize the objects through discursive practices. Subjectivities-the result of the classification affecting our understanding of ourselves as human beings-are also intrinsically linked to the object. The object should not be confused with the classified, however, the latter referring to the physical being or physical object. This is an especially important distinction with regards to the study of the Holocaust survivors, since the classified - the physical person with Holocaust experience-is agential and thus actively participates in the construction of the survivor classification as object and as subject. Again, Nelly Sachs is an excellent example of this; her writing reflects and constitutes discourses on Holocaust survivor-hood and victimization meaning that she contributes to the classification of the survivor object-a classification that comes from her own understanding of what a survivor is and thus, who she herself is as a survivor-while simultaneously contributing to her subject position as survivor-witness to the Holocaust. As previously stated, the smallest component of a discursive formation (and thus the analytical focus of both an archaeological and a genealogical analysis) is the statement. Being expressed from a subject position, the statement both contributes to the constitution of the object and reflects as well as constitutes different subjectivities (knowledges about the self) and creates and/or reaffirms subject positions. In other words, in addition to enunciating the object, "the statement articulates the space and possibility of subjects". 128

The distinctive feature of genealogy as compared to Foucault's earlier work on archaeology is its focus on transformation in history. ${ }^{129}$ While archaeology is concerned with understandings of how the object is formed, genealogy elucidates the discursive processes that contribute to the ways in which the object transforms. This is not in reference to chronological ruptures and continuities but, rather, to the ways in which discursive objects alter "through the contingent and complex intersections" of temporal multiplicity "along multiple vectors of practice". 130

This is language borrowed from the American philosophy scholar, Colin Koopman, who argues that genealogy as a methodology of critique, has to be understood as a result of the intellectual work conducted by Foucault on archaeology as well as genealogy. "Temporal multiplicity" refers to the existence of a problematization that underpins discourse and discursive practice across time. A problematization, in turn, is a term that denotes the "depth conditions"- the

128 Andersen, Discursive Analytical Strategies, 11.

129 Colin Koopman, Genealogy as Critique: Foucault and the Problems of Modernity, (Indiana University

Press, 2013), 31.

130 Koopman, Genealogy as Critique, 43. 
assumptions or common-sense notions about the object-that "make possible the various surface practices that are the object of critical inquiry". 131 With "vectors of practice", Koopman is referring to "the way genealogy focuses on neither power nor knowledge alone, but rather on the power-knowledge interplay". ${ }^{32} \mathrm{~A}$ genealogical study is thus essentially a study of the relation between power and knowledge. Power constitutes knowledge and knowledge constitutes power. The "vectors of practice" that I have chosen to focus on to elucidate this relationship are news discourse and culture critique. Both news (immediate and reportage-style) and culture critique constitute exercises in power-therefore they are also productive practices of knowledge. These practices of knowledge, in turn, reinforce the power relations that exist between practitioners (producers and consumers) of news discourse and culture critique. What this means in practical terms for sourceselection and methods of analysis will be the focus of the coming sub-sections.

\section{Source-selection and Authority}

The central problem that a genealogist faces when structuring an analysis is the question of source selection. Even though I have utilized archives that were assembled by others, I also acknowledge my own role as an 'archiver'. The task of locating periods of significance for a genealogical analysis of transformation necessitates these archival ambitions. I cannot, as many doctoral students of history have done before me, refer to a collection of newspaper cuttings or a specific number of volumes in a physical archive pertaining to a person or subject when discussing my method. The most important archives for me were digital and held innumerable documents. In her well-cited essay on archival dust from 2001, the British historian Carolyn Steedman argues that,

The historian's massive authority as a writer derives from two factors: the way archives are, and the conventional rhetoric of history writing, which always asserts (through the footnotes, through the casual reference to PT $\mathrm{S} 2 / 1 / 1$ ) that you know because you have been there. The fiction is that the authority comes from the documents themselves, as well as the historian's obeisance to the limits they impose on any account that employs them. But really it comes from having been there (the train to the distant city, the call number, the bundle opened, the dust), so that then, and only then, you can present yourself as moved and dictated to by those sources, telling a story

131 Koopman, Genealogy as Critique, 33.

132 Koopman, Genealogy as Critique, 34. 
the way it has to be told. ${ }^{133}$

Here, the archive as a physical place becomes "a way of seeing, or a way of knowing" as well "as a symbol or form of power". ${ }^{134}$ The fact that I have been to the National Archives, that I have scoured through digital newspaper files in the basement of the National library in Stockholm, should, together with the genrebased conventions of dissertation writing be enough to legitimize my account, according to Steedman's argument. In addition to discussing my source selection in every empirical chapter, the following discussion will account for how I established my periods of significance.

As noted above, I have adopted an abductive approach to my analysis, meaning that there has been a constant movement between theory, primary sources and secondary literature. As a long-time student of Holocaust and genocide studies, I struggled with not following the canonical Anglo-American narrative of Holocaust memory and its periodization; thus, assuming that certain events would be important to the construction of the survivor. Because I could not step outside of what others had shown to be important for conceptualizations concerning the survivor in other contexts, I chose to interrogate the significance of proposed watershed events such as the Eichmann trial and the publication of Anne Frank: The Diary of a Young Girl.

Anne Frank was, however, not a phenomenon that, at first glance, appeared important to the construction of the Holocaust survivor in Sweden. For some reason, I assumed that the many mediations that surrounded her writings in the 1950s had not been effectual in Swedish public discourse. This attitude was probably a result of my own fatigue with Anne Frank as a symbol and as an elucidating example used to score intellectual points about everything and nothing within both scholarly and non-scholarly discussion. Just as I am critical of perspectives that lament the hypertrophy of memory (Jewish memory in particular), I fell in the same trap myself, thinking that I could uncover something more obscure or marginalized in my search for the survivor. However, after finding several references to Anne Frank in the newspaper archive while searching the

133 Carolyn Steedman, "Something she called a Fever: Michelet, Derrida and Dust," American Historical Review, vol. 106, no. 4, (2001): 1146. Kleinberg critically engages with Steedman's essay in a discussion on the development of American cultural history, see Haunting History, 42-53. See also Dominick LaCapra, History in Transit: Experience, Identity, Critical Theory, (Ithaca, NY: Cornell University Press, 2004), 30.

134 Steedman, "Something she called a Fever", 1146. 
word "concentration camp"- - findings that led to further searches on the first edition of Anne Frank: the Diary of a Young Girl, the play The Diary of Anne Frank, and the film with the same title-I was forced to realize that the Anne Frank phenomenon had been impactful in Sweden as well. Here, there was no scholarly work in Sweden to aid my analyses during the 1950s. It thus appeared that Anne Frank-however symbolic of the Holocaust victim — was, in fact, a marginalized and much neglected subject in Swedish scholarship on the Holocaust.

The Eichmann trial, like Anne Frank, is a much-explored subject within Anglo-American, German and Israeli research. Few studies, however, have been conducted on the trial and the importance of Eichmann to Swedish Holocaust memory. Swedish researchers have thus not engaged with the subject of the Eichmann trial in 1961 or the effects it may have had on discourses pertaining to the Holocaust in Sweden in the following decades. In contrast to Anne Frank, however, the Eichmann trial was one of the first subjects with which I engaged after beginning my searches for the survivor in various archives. Since the French historian Annette Wieviorka, among others, have claimed that the period during and after the Eichmann trial constituted the "advent of the witness" and was a trial that referenced the Nazi's genocide of the Jews in particular, it seemed a period that should not be overlooked. Therefore, I assumed that the Eichmann trial would be a transformative event with regards to Holocaust victimization and survivorwitnessing. Searching the digital newspaper archive I found references to many different mediations of the trial through radio, film and television. This, combined with references to Eichmann in relation to other Holocaust phenomena later in the decade, indicated that Eichmann had been an important, potentially transformative event, with regards to the construction of the survivor in Swedish public discourse. In order to understand how the Eichmann trial had been transformative I also had to study later representations of the survivor-witness which is why I included an analysis of press coverage related to the first Frankfurt Auschwitz trial and debates surrounding the German-Swedish artist and play-wright Peter Weiss's play Die Ermittlung.

Different periods and subject matters were also studied on the basis of their transmediality: a work of literature or art or a political or juridical event creating commentary across mediums. Mostly, due to problems of access, this meant that the commentary came from the newspapers with critics reviewing not only literature, theatre and film, but also other media treatments of a contemporary social, political or cultural issue. Examples of this can be found in chapter 3 when I discuss the news reel Vittnesbördet ("The testimony") and a radio reportage conducted by the 'radio man' Manne Berggren. This chapter, however, and the 
material that is treated therein, was otherwise heavily based on logical experiments and interactions with previous research regarding the exposure of people escaping and being rescued to Sweden, away from Nazi perpetration and the camp system.

The abductive strategy described above can also be characterized as a form of serendipity. ${ }^{135}$ Similar to anthropologists who work in the field, historians or other scholars who labor in archives, serendipitously stumble over information that throws them off their course. However, serendipity only befalls the researcher who is open to it, who shines a light in corners that might seem wholly irrelevant to the quest. Perhaps this is also how one should understand Foucault's imperative to "read everything" - a veritably impossible task for any doctoral student. ${ }^{136}$ Rather than reading everything, I attempted to follow the leads given to me in the material, tracing them even though they did not, in themselves, directly answer my research questions about the discursive object. From a philosophical perspective it is also this aspect of openness and a sometimes aimless wandering that distinguishes genealogy from other discourse analytical approaches in that it "does not limit the contours and growth of a data set", a process which produces "surprising research trajectories and exciting findings that often spawn new projects or extensions of earlier ones".137 However, for me this openness was also a burden as the lack of previous research in almost all of my periods of significance meant that my research was caught in a tension between establishing truths about the past, so as to fill the gaps that historiography had left, and my focus on the research questions of how the survivor object had come to be.

\section{Delimiting the Timespan: The Importance of Origins and Endings}

Although the periodization of this dissertation depended on abduction and serendipity, the beginning and end of the analysis came with their own set of problems. The core premise of a genealogical approach is that the ontological histories constructed in the analysis inform the present. In this study, the present, however, begins in the past. The 'present' that I am interested in understanding-

135 See Robert K. Merton \& Elinor Barber's exploration of serendipity as sociological concept and method in The Travels and Adventures of Serendipity: a study in the historical Semantics and the Sociology of Science, (Princeton, NJ: Princeton University Press, 2004). In her doctoral dissertation from 2012, Swedish cultural studies scholar and anthropologist Johanna Dahlin also discusses serendipity as a form of ethnographic method. See Dahlin, Kriget är inte över förrän den sista soldaten är begraven, (Doctoral diss.: Linköping University Press, 2012), 25-26.

136 Michel Foucault, Etbics: Subjectivity and Truth, 263.

137 Anais, "Genealogy and Critical Discourse Analysis in Conversation," 130. 
a present which also constitutes a transformation—occurred twenty years ago. The creation of the Living History Forum and its establishment of a testimonial archive at the end of the 1990s are historical phenomena at this point in time. What genealogy provides, then, is not just answers to questions regarding why something is happening now but, rather, demonstrates how ontologies come to be, alter, transform, and disappear, a process whose origins (or ending, depending on how one chooses to see it) the researcher finds depending on what she wishes to understand and/or explain. As the nexus of problems that I am interested in examining occurred in the 1990s, my 'present' dwells in the 1990s. My "genealogical work" thus begun "at the question of when, how, and through what relays of power a given practice, behavior, or ethos came to be seen as a problem". ${ }^{138}$

But why not continue to study the phenomenon of the Holocaust survivor beyond this time period? The answer to this question lies in the nature of my sources. Because I wanted to create a dynamic source-base around problematizations of the Holocaust survivor I chose to include both textual and audio-visual sources. This transmedial approach was deemed important since much of Swedish historiography on the subject has mostly made use of newspapers sources. ${ }^{139}$ In recent years a number of media archives have been (at least partially) digitalized meaning that television segments and radio programs are far more accessible than before. Also, the now 'old' media of television and radio were 'new' once which means that their establishment and subsequent transformation greatly impacted the ways in which discourse could be communicated, disseminated and contested. This is of course also true for what is commonly referred to as 'new' media, meaning social media platforms, websites and online chat rooms etc. The development of this 'new' media has completely transformed the way that humans communicate and socialize as well as the manner in which researchers understand social interaction and discourse. As new media scholar José van Dijk explains, "with the advent of Web 2.0, shortly after the turn of the millennium, online services shifted from offering channels for networked communication to becoming

138 Anais, "Genealogy and Critical Discourse Analysis in Conversation," 127.

139 I use the term 'transmedial' here in reference to my treatment of a number of different mediums and how they serve to construct the Holocaust survivor object. The study of transmediality as its own analytical phenomenon, however, entails a more complex theory of media's entanglement. See for example, Marie Cronqvist \& Christoph Hilgert, "Entangled media histories" Media History, vol. 23, no. 1, (2017): 130-141. 
interactive, two-way vehicles for networked sociality". 140 This has also created new forms of media practices that heavily influence the constitution of subjects, subjectpositions and discursive objects including techniques of the self, such as different forms of "mediated self-representation" (b/vlogs, social media, online tutorials etc). ${ }^{141}$ Therefore, if the survivor's becoming had been studied in the period after 2000, the archive created and the methods used would have been diametrically different from those presented above since this paradigm shift constitutes novel forms of discursive practice. Such an endeavor would have made this project too extensive and too nebulous which is why I chose to focus on the period between 1943 and 2000. Hopefully, though, this study will lay the groundwork for future enquiries into survivors of atrocities and the way that they are constructed within a 'new' media landscape.

Another issue when studying a process of becoming is that of origins. Steedman describes Derrida's concept of Archive Fever as partly derived from a "western obsession with finding beginnings, starting places, and origins". ${ }^{142}$ In contrast to this obsession, a genealogical approach instead focuses on the study of descent and emergence. Firstly, descent refers to the notion that beginnings exist in plural and appear, not in planned and calculated patterns, but in the "exteriority of accidents". ${ }^{143}$ Hence, from a genealogical perspective there is no historical continuity to excavate and discover, there is only the dispersion of statements (discourse) which, together with the non-discursive give rise to objects and subjects in unexpected and seemingly haphazard ways. ${ }^{144}$ Beginnings are thus plural and in order to both understand "the initial appearance and achieved dominance" of a particular perspective one also needs to study emergence. ${ }^{145}$ The emergence of the Holocaust survivor as discursive object has little to do with when the Holocaust was first acknowledged as the systematic persecution of Jews and/or other victims groups in Nazi Germany and more to do with the identification of which

140 José Van Dijk, The Culture of Connectivity: A Critical History of Social Media, (New York, Oxford University Press, 2013), 5.

141 Lilie Chouliaraki, "Self-mediation: new media and citizenship," Critical Discourse Studies, vol. 7, no. 4, (2010): 227.

142 Carolyn Steedman, Dust, (Manchester: Manchester University Press, 2001), 5.

143 Michel Foucault, Essential Works of Foucault, 1954-1984: vol. 2 Aesthetics, Method and Epistemology, ed.

James Faubion, (London: Penguin, 2000), 374.

144 Foucault, Aesthetics, Method and Epistemology, 374.

145 C.G. Prado, Starting with Foucault: An Introduction to Genealogy, (Boulder, Colo.: Westview Press, 2000), 36. 
discourses that came to manifest the Holocaust survivor as object (object of care, educating/communicative objects, activist/political object etc).

The third chapter should thus not be viewed as an 'origins' chapter within which the inevitable development of the concept 'Holocaust survivor' begins. It focuses, rather, on the period in which survivors of the Holocaust were first perceived as objects of public interest; as victims and as witnesses to their own survival and the survival of others. Since I have chosen to begin my analyses with a complex of problems pertaining to the Holocaust camp survivor as silent, excessive and a national 'Other', these all have their own beginnings, as well as their own processes of emergence. Thus, it was never inevitable that Holocaust survivors should be considered anything outside of their own experience of survival. Yet, non-discursive and discursive forces constructed them as such, at different times, in different settings and in different ways. When referring to non-discursive forces I mean the social reality that exists outside of discourse. The relation between the discursive and the non-discursive object has been usefully explicated by Hacking through his discussions on "classification" and "classified". In commenting on the "science wars" which famously erupted in the aftermath of Alan Sokal's fake cultural studies article, Hacking underscored the importance of asking the question: "The social construction of what?"146 By posing this question, with an emphasis on the object, Hacking tried to develop a simpler framework for understanding the differences and interrelations between classification (the social construction/discursive object) and the classified (the physical individual/the nondiscursive object). This is also the relationship of becoming that Hacking refers to as "dialectical realism". As Hacking notes, "in some cases our classifications and the classified emerge hand-in-hand, each egging the other on". 147 Indeed, Holocaust survivor-hood constitutes a social reality, yet it is a social reality that cannot be extricated from the classification of "survivor"- a classification located at a nexus of economic, psychiatric/psychological, scholarly, social, cultural and political discourses.

Subscribing to Hacking's notion of a "dialectical realism" also allowed me to delineate a physical survivor object-a person whose life and health had been targeted/affected by Nazi genocidal policy. Through this definition I could trace descriptions and representations of such experiences in public discourse. This, in

146 See Ian Hacking, The Social Construction of What? (Cambridge, MA \& London: Harvard University Press), 1999.

147 Hacking, "Between Michel Foucault and Ervin Goffman”, 280. 
turn, allowed me to examine the historical descent and emergence of the discursive object without any preconceived definition of what that was or had to be, yet with a set of working hypotheses concerning the type of experience it could include. This was especially important as I soon found that the word "överlevande" (survivor) was not used consistently in the decades directly following the war.

\section{Problemativing Digital and Physical Archives}

The source selection for this dissertation began with an open-ended search in the digital newspaper archive at the National Library of Sweden in Stockholm (Kungliga Biblioteket, KB). Beyond being a library, this institution is also an official government agency with a mission that "concerns defending the values of democracy, equality, and free speech". ${ }^{148}$ As a cultural heritage institution, part of this mission has also been to preserve and make accessible both printed and audiovisual source material for public use through digitalization. Due to the ubiquity of digitization processes in Western cultural heritage contexts over the past decade, an inter-disciplinary field of research has developed in order to critically engage with questions such as "archival surrogacy" and "digital noise". ${ }^{149}$ Discussing the latter in relation to the digital newspaper archive at the National Library, Swedish media scholars Pelle Snickars and Johan Jarlbrink argue that "as previous research on digitized newspapers has shown, whenever information is digitalized and transferred, new noisy 'information' will be added with inaccurate OCR as the most observed and common noise category". 150 Through their own study of the digitization processes surrounding some of the evening newspaper Aftonbladet's nineteenth century issues at the National Library, Snickars and Jarlbrink conclude that "the resulting XML files" that were produced from physical copies of the newspaper at the media conversion center in Fränsta outside of Stockholm were "extremely full of noise". This meant that "the scanned, digital collection of

148 “The National Library”, 2019, https://www.kb.se/in-english/about-us.html, (accessed on 21 November, 2019).

149 See for example, Paul Conway, "Digital Transformations and the archival nature of surrogates," Archival Science, vol. 15, (2015): 51-69. Marlene Manoff, "Archive and Database as Metaphor: Theorizing the Historical Record," vol. 10, no. 4, (2010): 385-398. Pelle Snickars \& Johan Jarlbrink, "Cultural Heritage as Digital Noise in Nineteenth Century Newspapers in the Digital Archive," Journal of Documentation, vol. 73, no. 6, (2017): 1228-1243.

150 Snickars \& Jarlbrink, "Cultural Heritage as Digital Noise in Nineteenth Century Newspapers in the Digital Archive," 1231. 
Aftonbladet contain[ed] millions of misinterpreted words, as well as millions of random texts created by the auto-segmentation tool". ${ }^{151}$

Inaccuracies in the OCR (Optical Character Recognition) can thus result in severe problems for researchers who rely on search words and phrases when collecting big data sets in order to establish significant patterns over time. As Snickars and Jarlbrink also contend, however, "the user who is close reading individual texts can overlook the noise as long as they can find what they are looking for". ${ }^{152}$ This is only partly true. In some cases, even when I knew specifically what I was looking for, I could not locate it in the digital newspaper archive. A particularly revealing example of this was when I attempted to locate an article referred to by Ulf Zander. I knew searched the article author's name, all the words in the title and several time periods close to the one given as well as the several newspapers to account for possible errors in the footnote. Still I ended up with nothing. This also occurred, however, when going through single issues of Göteborgs Handels- och Sjöfartstidning as micro-film. Suddenly one of the crucial pages that I was interested in was nowhere to be found. I scrolled back and forth but the page had evidently been lost in the process of making microfilm copies out of the physical copy. These omissions from the archive, affected by the human factor as well faults in the software have to be noted as they might significantly skew research results and conclusions if we-as a research community — do not become more aware and reflexive about, not only our own practices, but about the many physical conditions that condition these practices.

To meet the challenges posed by the fragmentary nature of archives I adopted a multitudinous material approach for my project: while searching the archive by using specific search words provided material that would give 'clues' that could be used for further searches, these initial searches could not assemble significant quantities from which to draw conclusions about Holocaust memory. This is a common misconception that I have encountered, however, in the process of researching and writing this dissertation. It has been proposed to me on more than one occasion that I should use the graphs provided by the digital archive in order to demonstrate how I 'found' my transformative periods. One of the problems with this approach, as exemplified by Snickars and Jarlbrink, lays in the errors produced in the digitization process where the misinterpretation of words by the

151 Snickars \& Jarlbrink, "Cultural Heritage as Digital Noise in Nineteenth Century Newspapers in the Digital Archive," 1240.

152 Snickars \& Jarlbrink, "Cultural Heritage as Digital Noise in Nineteenth Century Newspapers in the Digital Archive," 1231. 
digital software will lead to misrepresentation in the quantified results. Furthermore, as words rather than full phrases ensure a higher accuracy in the OCR function's ability to locate relevant texts, other contexts for these words also serve to distort the graph. For example, the term "koncentrationsläger" was, in the 1950s, used to refer to camps behind the Iron curtain. Also, combining the words "judar" with "utrotning" would produce many article results, to be sure, but since these words were not always used in conjunction with one another, let alone as singular phrases to refer to the Holocaust, they could merely provide a starting point for further searches. In combining search words, different forms of media texts would be included in the results, the word "utrotning" referring to endangered animal species in one article whereas "judar" occurred in an article about Israeli foreign policy. The digital archive at the National Library is thus not a tool that can be used (at least in this case) to demonstrate significance over time. Instead, the searches were conducted in order to find specific instances when a search term had been used in relation to phenomena which was later been found to be significant-not because of the number of times it occured but in relation to who the speaker is, where in the newspaper the term appeared and in which newspaper it was published. In short, quantity is not used in this dissertation to establish significance, only to find periods of possible significance which could later be confirmed or refuted by further contextualization and further searches through different archives.

In practical terms, I began by searching the digital newspaper archive using words such as "Nazisterna/Nazismen" (the Nazis/Nazism), "koncentrationsläger" (concentration camp), "flykt/flykting" (escape/refugee), "Auschwitz" "BergenBelsen", "Majdanek", "Buchenwald" as well as different words connected to various acts (and non-acts) and practices of mediating experience such as "vittna" (testify), "berätta" (tell), "förmedla" (communicate), "tystnat" (fallen silent), "gömd" (hidden). Since the soft-ware is sensitive to the conjugation of the word, meaning that it will not show results pertaining to the possessive form of the word, searches of, for instance, "flyktingarna" (the refugees) would not yield any result where the word "flyktingarnas" (the refugees') was featured. Thus, after my initial searches, which yielded a great number of results, I began to follow statements and their relation to other statements. I also traced the subjects that these statements produced-individuals with and without Holocaust experience, journalists, filmmakers, critics and other experts— to see how they related to the object and how their positions changed over time. These individuals and their changing subject positions also led to a confirmation that certain historical moments were integral to the construction of the Holocaust in Swedish public discourse which, in 
different ways, actualized the role of the Holocaust survivor. The practical steps in this process of assembling material will be further elaborated on in each empirical chapter of this dissertation.

Another issue that I encountered when searching the digital newspaper archive at the National library was that far from all Swedish newspapers had been digitalized. This is especially true for the period before 1950. Since I wanted to be able to focus on more than one medium as well as other archival material, I had little time to go through whole newspapers, issue by issue. I did so, however, when I felt like the argumentation of the chapter hinged on the inclusion of certain newspapers. For example, in chapter three, I went through Stockholmstidningen as well as Göteborgs Handels- och Sjöfartstidning for the period of October when the Danish Jews were given asylum in Sweden as well as the period in November of 1942 when the Norwegian Jews were deported to Poland in order to follow Göran Leth's categorizations of newspapers according to their political standing vis-à-vis the Nazi regime. Since much of chapter three's analytical focus was on news discourse, it seemed crucial that the political attitudes of the newspapers be taken into account-something which was deemed less important in the other chapters where culture critique and foreign correspondence served as the basis for the analysis. In these chapters, SvD, DN, Aftonbladet and Expressen were thus chosen for analysis - all of which existed in digital form throughout the period studied.

All but one of the newspapers studied in the dissertation were Stockholmbased; Dagens Nyheter (DN), Svenska Dagbladet (SvD), Stockholmstidningen, Expressen and Aftonbladet. This was a deliberate choice based on the fact that the Swedish capital produced newspapers that reached outside of the capital. ${ }^{153}$ Even if it might be an overstatement to call them "national" newspapers, a term which has been used in the past to describe them, their number and circulation reached far beyond any other local newspaper in the country. For example, in 1941 Stockholm had five dailies and two "evening" newspapers that were sold in the afternoon. Their total circulation reached over 600000 in 1941, a third of which were sold outside of the Stockholm area. ${ }^{154}$ Throughout the 1950 s and 1960 s, the Stockholm-based evening newspapers also gained further significance and traction, both with regards to their standing as political commentators but also as sources of entertainment and culture critique. I have chosen to term them "evening newspapers" (a direct translation

153 Elisabeth Sandlund, “Beredskap och Repression,” in eds Karl Erik Gustafson \& Per Rydén, Den svenske pressens historia, (Stockholm: Ekerlids förlag, 2001), 316.

154 Sandlund, "Beredskap och Repression,” 316. 
from the Swedish kvällstidningar) because, in the decades that I study, the tabloid format was not fully formed. The evening newspapers, Expressen and Aftonbladet, although distinguishable in both content and form from their daily counterparts, could thus not be compared to today's tabloids-especially if considering the English tabloids from which the term itself stems.

Although the digital newspaper archive undoubtedly presented some real challenges, the digital audio-visual archive (Svensk Mediedatabas, SMDB)—also located at the National Library in Stockholm-was even more problematic in its fragmentary character and seemingly ad hoc composition. Again, Snickars sheds some light on these issues when discussing the project of digitizing Swedish film heritage. In his article "Remarks on a Failed Film Archival Project", Snickars shows how "archival policies have proven difficult to combine with research interests" as scholars prefer to search large data collections while the digitizing institutions often want to "curate" their own collections based on their own notions of what should and should not be preserved. ${ }^{155}$ This was the case, both for the audio-visual archive and the open access, online archive for films-Filmarkivet.se. These archives were particularly important for this project with regards to Chapter 3, in which I study the news reel Vittnesbördet as well as a radio program about Jewish former concentration camp internees coming to Sweden from Bergen-Belsen. I also used the audio-visual archive to study the role of television in mediating the Eichmann trial to Swedish audiences. In this latter case, it proved difficult to study some of the news programs that showed clips from the trial since many of these lacked audio-files. It almost seemed as if the full programs were no longer available, only the short clips that constituted the raw material used to make the news shows. Since I was not able to speak to the archiving institution (Sveriges Television, SVT) directly, it was difficult to establish what had actually been shown from the trial on a daily basis on Swedish television. Also, the archive only included a small selection of sources, evidenced by comparisons made between radio- and TV-tableaus and searches in the digital archive. ${ }^{156}$ Researchers can request to have material included into the collection, but this takes time. For example, in wanting to access the news

155 Pelle Snickars, "Remarks on a Failed Film Archival Project", Journal of Scandinavian Cinema, vol. 5, no. 1, (2017): 64. See also the specific discussion on the Swedish film institute on pages 64-65.

156 No research has been conducted on the process through which Statens ljud- och bildarkiv became the digital archive, Svensk Mediedatabas (SMDB). On a problematizing account of how Statens ljud- och bildarkiv catalogued sound recordings see, Andreas Österberg, Katalogisering av ljudupptagningar: En komparativ studie av Statens ljud-och bildarkiv och Sveriges Radios grammofonarkiv, (Master's Thesis: University of Borås, 2004). 
program Aktuellt for the spring and summer of 1961, I contacted the National Library to see if they could provide me with the digital files. Although accommodating in their reply they also informed me that they could not give me a timeline for when the material could be delivered from the archives of Sveriges Television, (Swedish public service television, SVT) as there was only one person working with digitizing material. In addition, I was told that researchers were not permitted to visit the SVT archives which meant that all I could do was wait and hope that they would be able to provide me the material within the time frame of writing this dissertation. ${ }^{157}$ This made it difficult for me to use audio-visual sources in any consistent way. Nevertheless, in searching the digital newspaper archive I found instances of radio programs and television programs which could, if not found in their original form, be studied in other ways. For example, the radio program "Anne Frank-Spåren av ett barn” by Ernst Schnabel, broadcast in 1958 could be studied through the Swedish translation of the script which was available as a book loan. Yet, in other cases I had to give up my searches and accept that these sources needed to be digitalized in a systematic manner before they could be scrutinized at a later date and as part of a later research project.

In addition to the digital archives, a handful of physical archives were also visited in order to study collections pertaining to The Living History Forum, government administration documents preceding the Living History campaign, and material related to Riksteatern's production of the play, The Diary of Anne Frank, and documents from the Nobel archives regarding Nelly Sachs. Since my study had begun with an investigation into The Living History Forum, this archival work was by far the most extensive; each volume containing hundreds of uncatalogued documents ranging from emails to official reports issued by the Swedish government (Statens offentliga utredningar, SOU). Because The Living History Forum is a government agency, the work leading up to its formation falls under the broadly defined term of "offentlighetsprincipen" ("the principle of public access to official records"), essentially referring to responsibility of all government agencies to make available those documents that fall under the legal definition of public documentation. ${ }^{158}$ What constitutes public documentation ("allmän handling") is

157 See also Snickars, "Remarks on a Failed Film Archival Project," 64, "In addition, Swedish Television has a substantial film archive with copies available for research. (Since the archive was estabished to facilitate television programmes and not for research, academics cannot enter Swedish Television's archival premises)"

158 See Anna Rosengren, "Offentlighetsprincipen i teori och praktik," Arkiv, sambälle och forskning, no. 1, (2017): 37. 
not definitive but is surrounded by criteria that are open to interpretation. 159 Compared to the other collections that I studied, The Living History Forum collections were extensive. Even though the minute notes from official meetings with the first and the second committee for the constitution of the government agency were characteristically brief, other fora for discussion such as seminars with researchers, private meetings between project leaders and special experts as well as emails and material sent in by officials and private citizens filled in many of the blanks left by the official documentation. Also, as my aims progressed and I began to focus solely on The Living History Forum as a source for a problem-complex, many of my needs for completeness of these sources disappeared. What was left, was an ample and rich collection of sources that could not be referenced in full. Rather, I had to leave out many sources that could further elucidate the problem-complex but that were not necessarily needed to demonstrate the underlying problematization of how the "Memory Archive" had been created.

\subsection{Analyzing the Material: A Discussion on Method}

Even though the source selection for this dissertation will be elaborated in each empirical chapter, this section discusses some of the analytical tools that were used across the material studied. Because I chose to focus on media discourse, the sources were selected from different genres as well as different forms of media communication. The primary categories that the material was divided into after being collected were: 1) News (both TV and printed press) 2) Editorials 3) Culture Critique, and 4) narrative news (including news reels, radio and newspaper reportages). The emphasis on news discourse in the form of shorter news articles/programs as well as narrative news in the form of longer reportages, left little room for investigative articles published in weekly magazines and journals. Even though these magazines could also have been included in the larger framework of media discourse they were excluded from the study as their smaller readership, relative to the nationally circulated daily and evening newspapers, constituted a less important source with regards to the construction of the survivor. This is not to say that these were irrelevant in the negotiation of Holocaust memory in Sweden. Yet, for the purposes of limiting an already extensive collection of sources, they were left for future studies on the subject.

159 Rosengren, “Offentlighetsprincipen i teori och praktik," 37-38. 
A similar principle was applied to the categorization of "culture critique". Rather than analyze all autobiographies, fictional books, theatre and radio dramatizations as well as documentaries and fictional films that touched upon the subject of the Holocaust in my chosen periods during the twentieth century, I instead focused on the critique they garnered in the national daily and evening press. This choice was made both for practical reasons and in order to further understand which cultural representations were deemed important to warrant a more extensive commentary. Since expert discourse has a particular role in constituting the object, this limitation also seemed suitable to the aims and research objectives of this dissertation. Each of the categories outlined above contained a number of source materials that required their own or a mixed set of strategies for dissemination and meaning making. These strategies and their methodological inspiration will be briefly explored in this section. Before doing so, however, I would like to clarify that the theoretical language has been largely abandoned in the chapters as it, in my opinion, disrupts the narrative flow, and therefore also abates the readability of the text. Instead the narrative style chosen for the empirical chapters is an academic prose more common to the discipline of history.

\section{Understanding Culture Critique}

In order to separate the theoretical categorization of disciplinary discourses from all practice that regards the intellectual and aesthetic consideration of culture I have termed what is commonly referred to as culture criticism, culture critique. In this dissertation, culture critique signifies the discourses-reflected and constituted in and by the traditional medium of the press-that serve to discipline the object through discursive practices that critically evaluate representations of Holocaustrelated phenomena. As previously discussed, culture critique serves as one of my "vectors of practice" that, together with studies of the underlying problematization contributes to insights into the descent and emergence of the survivor object. In this analysis, the evaluative texts that I have studied—including book, theatre and film reviews, book prefaces and epilogues—all constitute one "vector of practice".

Reading for the underlying problematization of the text also requires a focus on what Anaïs calls the "institutional labor that [texts] perform" meaning that one has to pay attention to the rules and conventions that govern discursive practices. ${ }^{160}$ This is also why I have included discussions on the mediums themselves; how television developed in the late 1950s and early 1960s, how literary, theatre and film

160 Anaïs, "Genealogy and Critical Discourse Analysis in Conversation," 131. 
critics formed as a professional category in the 1950s and how the newspapers changed the layout of the so called "cultural pages" (Kultursidorna) in the 1960s. An analysis of how the object forms and gains dominance is thus an analysis that takes into account the institutional practices that affect enunciations of the object, the subject-position from which the object is enunciated, as well as the systematic argumentation within the text. The latter refers to how the statements made through the text contribute to the enunciation of the object. With regards to critical reviews, these statements are often in reference to the value of either the object or phenomena that relates to the object in one way or another. For example, when Expressen's editor-in-chief, Ivar Harrie, stated in a review of the play, The Diary of Anne Frank, that the director had removed all references to "gruel" with "exemplary discretion", his statement enforced the notion that representations of the Holocaust (although this term was not in use at this point) should be discrete and only allude to the "unbearable horror" of Nazi perpetration. In itself, the statement is just another opinion about what moved an audience, but considering Harrie's position as the editor-in-chief at Expressen, the development of culture critique at the time, culture critique as a crucial part of the newspaper's profile at the time and other similar statements made about a popular and highly visible phenomenon such as Anne Frank, the evaluation becomes a positive, productive event that enunciates the object-that is, it contributes to the survivor's becoming.

A genealogical study of culture critique also focuses on the construction of concepts and the ways in which these concepts organize statements. ${ }^{161}$ As previously discussed, the main concepts that this dissertation focuses on are silence and excess. However, victimization, witnessing and survival are also concepts that have informed the role of the survivor as communicator of moral perspectives of past events. These are not merely expressed through the culture critique but have a function; they are mechanisms of power and knowledge. Because my analysis began by locating a problematization, the analysis of Swedish culture critique in the 1950s and 1960s also entailed a search for how Holocaust representation was problematized. How did the critics argue for the 'proper' way of representing the Holocaust? Were any definitive limits established? And how did their agreements/disagreements relate to their subject positions as critics, as 'discoverers' and as witnesses to the witnesses? These were some of the questions that I posed to my material in order to understand how the texts were organized and how the arguments were structured in the texts. 
Deconstructing the News Story

Although news discourse and its discursive practices, is not as evident an example of disciplinary discourse as culture critique, statements are sometimes enunciated from expert subject positions. Thus, the author of a news article or the newspaper it is published in as well as the form of the news article-potential commentary and editorializing - all contribute to the disciplining of objects, of subjects and subject positions. Furthermore, analyzing the news is as much an exercise in deconstructing the structure of the news story as it is about the content which it presents. In his seminal work on news discourse, Allan Bell, proclaims that stories are "central to news media. Journalists do not write articles, they write storieswith structure, order, viewpoint and values. So, the daily happenings of our societies are expressed in the stories we are told in the media."162 News discourse also makes the object visible to the public by framing it as news-worthy. By studying both culture critique and news discourse, I wanted to see how the presentation of the survivor as relevant and current, coincided with critical evaluations and debates surrounding the propriety of Holocaust representation. Although disciplinary discourses exist within each space, news discourse produces different images of the object depending on the event reported on-framing the object in an immediate news story while the critics focus on situating the object within a more extensive temporal narrative of the past, present and the future. The main difference between studying news discourse and culture critique, therefore, relates to how news discourse narrates the survivor's being in the present, and deconstructing how culture critique disciplines this being in the past, present and future as proper or improper.

Analyzing news discourse thus involves the deconstruction of the story told. In approaching the part of my material that constituted news articles and television news programs I first considered the question: "what does this news story say really happened?". 163 This approach meant that I paid attention to how the headline, lead and any captions or sub-headlines relayed the message presented in the article/program. As Bell clarifies, this is not done to compare the story with 'what really happened' but rather constitutes a process which "seeks chiefly to deduce an 'event' structure for the story". ${ }^{164}$ Furthermore, the deconstruction of

162 Allan Bell, "News Discourse" in eds Allan Bell and Peter Garrett, Approaches to Media Discourse,

(Oxford: Blackwell, 1998), 64. See also Teun Van Dijk, News as Discourse, (New York \& London:

Routledge, 2009).

163 Bell, "News Discourse," 65.

164 Bell, "News Discourse," 65. 
this structure also involves the identification of actors who appear in the story, any background or commentary (editorializing) as well as follow-up details from previous news stories. Part of the story is also relayed through images; cartoons, photographs and portraits. These have been treated as constituent parts of the news story, meaning that their rhetoric - i.e. their persuasive functions - as well as the representational themes that they communicate have been studied in relation to what the story is presented as.

To be sure, Bell's model for analysis is much more complex than simply paying attention to leads and headings. However, as with most approaches to media discourse, the sources used in Bell's studies are fewer and the perspectives narrower, thus warranting closer analyses of the material at hand. As explained above, I aimed to understand the development of the Holocaust survivor object over time as well as the problematization underpinning this development, meaning that I took inspiration from perspectives that emphasized the manner in which arguments were presented to publics and the position of the speaker (be it an individual critic, correspondent or journalist or the newspaper itself) as well as the structure and content of the arguments made in the source. Also, in critical discourse analyses of the news, circulation as well as reception are often presented as important aspects of understanding the construction of an object. While briefly discussing the possible perception of certain texts, and the "institutional labor" that they perform, public reception has not been part of my inquiry. ${ }^{165}$ This is mainly because of the focus on expert discourse, a subject that I will return to in my discussion on culture critique. Most of the news discourse that I analyzed came from daily and evening newspapers. As I discuss further in chapter 3, what I have chosen to term 'evening' newspapers are newspapers that could be likened to the modern tabloids but did not, in the decades scrutinized in this study, have the same layout or tone as the English tabloids of today have. They were, however, distinct from the major daily newspapers and innovative in so far as they dealt with the more controversial issues of the time and included images to a greater extent compared to the daily newspapers. So how should these images be analyzed as part of the news text? In their book, News Discourse, the Australian-based linguistics and journalism scholars, Monika Bednarek and Helen Caple argue that images have a "communicative function" in contributing or constructing meaning through

165 Anaïs, “Genealogy and Critical Discourse Analysis in Conversation,” 131. 
different news media. ${ }^{166}$ These functions serve to sensationalize, to aestheticize, to evoke emotions and to mark an iconic moment in history. ${ }^{167}$ In studying images as news text and in news text (as in the written word) has, for this dissertation, meant that all of these communicative functions have been studied as many the articles that constituted the source base for my analysis included portraits of the person/people written about in the text, drawings or photographs of people having fled or being rescued as well as iconic photographs of the Holocaust. Moreover, the communicative functions mentioned above were also part of the televisual and cinematic representation of news (the latter referring news reels such as Vittnesbördet).

Editorials are also a part of news discourse albeit with a slightly different news structure compared to news articles. Van Dijk describes this difference thusly,

whereas news reports have their characteristic news schema, other news genres may have their own typical schematic organization. Comments, columns and editorials, for instance, often have a persuasive function, and therefore usually exhibit various kinds of argumentative structure, which they share with many other persuasive genres. ${ }^{168}$

This "persuasive function" also contributes to the creation of "common sense frameworks", which help explain different political, cultural, social and economic phenomena to the reader. ${ }^{169}$ Editorials are, therefore, structured in ways that contribute to the construction of social, political and cultural problems, meaning that they actively contribute to the maintaining and reification of problematizations. When analyzing editorials it is, therefore, important to pay attention to these expressions that are presented as 'framing' the problem discussed, when in fact the editorial contributes to the very construction of the problem itself, laying out evidence for the problem and, subsequently also presenting a solution to the audience.

\section{Narrative News: Witnessing in, by and through the Media}

In Media Witnessing, Paul Frosh and Amit Pinchevski present the notion of "Media witnessing" as "a form of witnessing performed in, by and through the media" that involves the "systematic and ongoing reporting of the experiences and realities of

166 Monika Bodnarek \& Helen Caple, News Discourse, (London: Bloomsbury publishing, 2012), 112.

167 Bodnarek \& Caple, News Discourse, 112.

168 Teun A. Van Dijk, Racism and the Press, (London \& New York: Routledge, 1991), 120.

169 Van Dijk, Racism and the Press, 150. 
distant others to mass audiences. ${ }^{170}$ Basing their theory on Dori Laub and Shoshana Felman's concept of the "crisis of witnessing", Frosh and Pinchevski argue that up until the 1980s the Holocaust was without witnesses. They thus assert that the audio-visual technology used in the Yale Fortunoff archives project "constituted a technological surrogate for an audience of the witnessing process underway." 171 Laub and Felman's postulation that the survivors in their project had to "reestablish an inner witness and build a discourse with an interlocutor" describes the process of those who were silent about their experiences until decades later. However, this is also founded on the idea that trauma made a 'true' rendition of Holocaust experience impossible before the 'therapeutic' turn which, in turn, is based on an erroneous assumption that Holocaust survivors remained silent and that the world was unable to listen.

Yet, witnessing through media- the process that Frosh and Pinchevski claim began in the 1980s with regards to the Holocaust-in fact began much earlier. The conception that media technology serves as a surrogate for an actual audience also describes the function of narrative news in communicating Holocaust experience. Just as the testimonies collected in the Fortunoff archives, Berggren's radio reportage and news reels like Vittnesbördet also have the "inexhaustible potential of reiteration, dissemination, and reproduction supplied by media technology." ${ }^{172}$ The latter then becomes the audience, an audience that persists through time and space. Without the innovation of cinema, producing three-dimensional humans on the screen, or the technological revolution that radio constituted, the notion of the Holocaust survivor would not have had the same meaning in the direct aftermath of the war. In Chapter three, then, I analyze Berggren's radio reportage as well as Vittnesbördet, in relation to the understanding that witnessing occurred both by and through the media; a form of witnessing that also demonstrates the conceptualization of the "dismayed spectator" (a concept that will be explored further in section 1.8). ${ }^{173}$

170 Paul Frosh \& Amit Pinchevski, "Introduction: Why Media Witnessing? Why now?" In eds Paul Frosh and Amit Pinchevski, Media Witnessing: Testimony in the Age of Mass Communication, (London: Palgrave Macmillan, 2009), 1.

171 Frosh \& Pinchevski, "Introduction: Why Media Witnessing? Why now?”, 4.

172 Frosh \& Pinchevski, "Introduction: Why Media Witnessing? Why now?”, 4.

173 Dean, The Moral Witness, 2. 
Narrative news or literary journalism do not sit comfortably within any particular news genre. ${ }^{174}$ What sets narrative news apart from the standard news article is that it is presented in a more or less formalized prose. ${ }^{175}$ Reportage news as presented through news reels, radio programs and printed articles, belongs to this vaguely defined genre. Inspired by Cecilia Aare's model of reportage narratology, the analysis of narrative news material—primarily used to understand a news reel and a radio reportage in chapter three-I studied the relationship between the "director", the "narrator", the "first-person character" and the "characters" in the narrative news story. ${ }^{176}$ In Aare's proposed model of analysis, the "narrative perspective" is divided up into the above categorizations as a first step in locating the speaker of the text. The model, according to Aare, is "particularly useful for studying the interplay between voice and point of view in a reportage." 177 The second step involves a an analysis of the "focalization," a tool that allows for the study of the narrator's perspective. In simple terms, focalization involves the question of whether the characters are described from outside or inside of the experience. This focus allows for an understanding of the difference between speaking and seeing. ${ }^{178}$ Even though the narrator speaks for the character, the point of view-if written as an internal focalization-will seem as if it comes from within the character. This is also what connects reportage narratology to the idea of Witnessing in, by and through the media. Few literary news genres only constitute one form of witnessing, but will, rather, switch between the three, thus also switching between the external perspective of the narrator and the internal perspective of the characters - although both are presided over by the director (the overarching point of view, determined by the context in which the source is produced).

In my collection of news sources, I also had some articles that blurred the lines between genres. The articles written on the Eichmann trial by the Swedish foreign

174 For an overview of Literary Journalism and its practices in several different national contexts see John S. Bak and Bill Reynolds (eds), Literary Journalism Across the Globe, (Amherst: University of Massachusetts Press, 2011).

175 Fiona Giles and William Roberts, "Mapping Nonfiction Narrative: A New Theoretical Approach to Analyzing Literary Journalism," Literary Journalism Studies, vo. 6, no. 2, (Fall 2014): 100-117.

176 Cecilia Aare, "A Narratological Approach to Literary Journalism: how an Interplay Between Voice and Point of View may Create Empathy with the Other" Literary Journalism Studies, vol. 8, no. 1, (2016): 108.

177 Aare, "A Narratological Approach to Literary Journalism,” 109.

178 Aare, "A Narratological Approach to Literary Journalism," 111-113. 
correspondent, Agne Hamrin, (analyzed in chapter 4), fall into this category. Through his observations of goings-on in Jerusalem, Hamrin both editorialized more than a 'normal' news article and the language used had the same personal tone as narrative news or literary journalism. This material then, had to be analyzed with all three categories in mind, with an emphasis on the news structure- the relationship between background, commentary, headlines, captions and leads-the persuasive function of the arguments presented in the articles and the "narrative perspective" from which the story was told. ${ }^{179}$

\subsection{This dissertation and its Research Frontier}

Throughout this introduction of the Holocaust survivor as classification, a number of arguments have been presented based on previous research regarding Holocaust representation, the Holocaust witness and Holocaust victimization. These sources have also been integral in structuring my analyses and informing my researchprocess. Scholars like Carolyn Dean, Karyn Ball and Zoë Waxman have thus inspired research questions and inquiries into the practices and ideals that have shaped the Holocaust survivor object. In this concluding section, I would like to bring these strands of thought together by discussing how this dissertationthematically, theoretically and methodologically—contributes to previous attempts at understanding political, cultural, psychological and social phenomena related to the construction of the Holocaust survivor.

\section{Methodological Clarity and Reflexivity}

In Aversion and Erasure, Dean "discusses the now pervasive discourse about the inextricable relationship between suffering, traumatic suffering and identity" in relation to "the motifs of excess and suspicion as part of a complicated affective relationship to victims (distance, aversion, identification) that transcends context but is nonetheless fashioned by its location in particular times and places". ${ }^{180} \mathrm{My}$ study of the construction of the survivor in Sweden builds on Dean's assertions about the "motifs of excess and suspicion". However, I do not simply view them as motifs but as productive mechanisms of disciplinary power within specific "vectors of practice" and in a specific national context. I, therefore, also argue that the assertion that phenomena "transcends context" while, at the same time, being "fashioned by its location in particular times and places" is too simple a description

179 Aare, “A Narratological Approach to Literary Journalism,” 108.

180 Dean, Aversion and Erasure, 6, 8. 
for the historical continuities and discontinuities discursive practices, discourses and problematizations produce. Another problematic aspect of Dean's research is the methodological obscurity that surrounds her study of affect. This is also something that characterizes Ball's research on the disciplining of the Holocaust where she argues that "Foucault's stress on the material impact of the practices that render the subject visible in relation to a network of discursively constructed categories does not offer a satisfying explanation of how the process of becoming a subject of discipline is consolidated by the imaginary and its pleasures". 181

Both Dean and Ball belong to a cadre of primarily north American historians and literature scholars-Dominick LaCapra being one of its pioneers-of postmodern work on the Holocaust and representation that combine Foucauldian notions of power and Freudian concepts of trauma, projection, transmission, anxiety and affect. ${ }^{182}$ While these terms allude to the emotional responses that are connected to collective practices of Holocaust memory, neither Dean nor Ball explicate how these affective relationships should be studied in more practical terms. I am not alone in remaining hesitant concerning the methodological problems that psychoanalytical perspectives on memory present. In his article "Finding Meaning in Memory," Kansteiner argues that "many inquiries into collective memories commit a tempting yet potentially grave methodological error; they perceive and conceptualize collective memory exclusively in terms of the psychological and emotional dynamics of individual remembering". ${ }^{183}$ Although I do not agree with Kansteiner's assertion that these attempts to understand affect as a part of collective responses to the Holocaust should be abandoned, I still remain questioning of psychological approaches to memory and believe that a more defined methodological framework needs to be elaborated before such endeavors can be truly fruitful.

My emphasis on "vectors of practice" in combination with the concept of problematization is also an important aspect of the work that I will present in the coming chapter; primarily because previous attempts at understanding similar phenomena have not necessarily specified the discursive practices beyond the position

181 Ball, Disciplining the Holocaust, 16.

182 Dominick LaCapra has written a number of books on history, the Holocaust and critical theory.

For a selection of his works see, Dominick LaCapra, History \& Criticism, (Ithaca NY: Cornell University Press, 1985).--Representing the Holocaust: History, Theory, Trauma, (Ithaca NY: Cornell University Press, 1994).- - History and Memory after Auschwitz, (Ithaca NY: Cornell University Press, 1998).—History at its Limits, (Ithaca NY: Cornell University Press, 2009).

183 Kansteiner, "Finding Meaning in Memory," 185. 
of the "critic". In Dean's case the context is American and French and the critics are named and their positions explored insofar as they are already known to her scholarly audience. However, the ways in which the discourse also constitutes the subject position is not explored further in Dean's analysis. Similarly, Ball begins her study in the controversial debate surrounding the then Harvard-based historian Daniel Jonah Goldhagen after which she explores the philosophical canon of Holocaust representation from Lyotard to Adorno and LaCapra. In a section entitled "libidinal reflections," Ball argues that LaCapra "stresses the importance of taking the historian's subject position into consideration in judgements of scientific and moral propriety". ${ }^{184}$ This focus on the utility of psychoanalytical concepts in critiquing historiography and the way that it creates boundaries around 'proper' historical practice, she argues, takes away from the endeavor of "fleshing out" the "theoretical density" of the same psychoanalytic terms. ${ }^{185}$ Although I draw on many of Ball's assertions about the disciplinary practices of Holocaust historians in my analyses, as well as her aim to understand "scholars' and critics' endeavors to regulate interpretation," I-like LaCapra—emphasize the importance of the subject position and how critique also serves to strengthen the expert position, especially when it enunciates the 'genius' object. 186

Another distinguishing aspect of this dissertation is its focus on a particular national context in conjunction with a genealogical methodology. In an article from 2009, the media scholar Shani Orgad presents a genealogical analysis of the survivor's construction in a number of "discursive sites" such as child sexual abuse, reality tv and the Holocaust. To be sure, such an analysis lies closer to a Foucauldian methodology as it takes into account the multiple "vectors of practice" that exist within the chosen discursive sites, thus attempting to understand a more general object ("survivor" rather than "Holocaust survivor"). Yet, for the exercise of understanding the transformation of a discursive object within the bounds of one book or, indeed, one academic article—like the work presented by Orgad—this form of analysis also runs the risk of reducing and obscuring rather than elucidating the complexities of how the object comes to be as a result of both the underlying problematization as well as temporally and spatially contingent practices and events. Similarly, in their article "Survivor: Towards a Conceptual History," German historians Alina Bothe and Markus Nesselbrodt argue that since "survivor" is a 
"transnational concept", they concern themselves with the genealogy of the term in different countries. They also argue that "a conceptual history cannot be strictly chronological, for the concept was shaped in different contexts" and their article "introduces four spheres of discourse about the concept of the survivor-academic, politico-institutional, restitution and memory - in order to uncover the content of the concept in detail". ${ }^{187}$ The main problem with this kind of reasoning is the survivor, even as nominal concept, cannot be understood in detail in that many sites of discourse when the contingencies that also help determine the object and subjectivities are not accounted for. Again, there seems to be an insurmountable gap between the widespread practice of humanist research as a largely solitary endeavor, the demands for making extensive claims in rigid and confining formats of academic writing and publishing and an understanding of discourse and genealogy as research practice.

Genealogy, I would argue, is not something that you, as a researcher, undertake on your own. As I stated in the introductory section to this chapter, understanding the construction of the Holocaust survivor, across time and across space, is a joint endeavor. Because it is a huge as well as an important task, it is not perfect adherence with Foucauldian propositions of "reading everything" or spreading our own studies over several geographies and time-periods that will bring us closer to an understanding of the object, but rather, it is about reflection, openness and transparency. Being explicit about the archives we use, the collections we create, the contingencies of our cases, allows us to focus on the smaller constituent parts, while simultaneously letting others into our search so that they can help complete the picture. Thus, to make my task manageable I have focused the object to one "discursive site" (the Holocaust), centering on one national context and using only two, interrelated "vectors or practice". To present my analyses in a persuasive way from the position that I hold as a doctoral student also means that I have to focus on the explicable as well as describe, explain and reflect along the way on what I am doing and how I am doing it. It is thus this ethical, reflexive practice that sets my study apart from previous attempts at understanding the Holocaust survivor object.

187 Alina Bothe \& Markus Nesselrodt, "Survivor: Towards a Conceptual History," Leo Baeck Institute Year Book, vol. 61, (2016): 59. 


\section{Connecting the Dots: Gender in History or History of Gender?}

As previously noted, feminist perspectives on the Holocaust and Holocaust representation have been largely relegated to their own field of studies. Rather than inform individual inquiries into the Holocaust as a historical event or meaningful referent, gender studies or studies with a particular focus on women's experiences and representations of women, have focused on elucidating that which has previously been erased, ignored or made absent from the historical record. This has been a worthwhile endeavor that has led to a deeper understanding of gender differences during extreme circumstances, sexual violence during the Holocaust, the impact of the Holocaust on masculine and feminine ideals and gendered representations at Holocaust memorial sites. The latter constitutes a niche in feminist studies on the Holocaust that lie nearest to the aims of this dissertation. For instance, the American sociologist Janet Jacob's studies of representations at Auschwitz, Ravensbrück and Majdanek highlights the subjugation of the female victim body; insights that have also come to inform my analyses on the news reel Vittnesbördet. ${ }^{188}$ Furthermore, the Israeli historian Judith Tydor Baumel Schwartz has written about gender and iconic photographs, using Anne Frank as one of her examples. As is evident from the discussion above, and will be even more clear in the coming chapters, many of my analyses on gender have also been inspired by Waxman. ${ }^{189}$ Although Waxman has written extensively on gender and the Holocaust as historical event, her writings also includes research on gender and representation that captures the ways in which women survivors' expressions have been understood by critics and scholars in distinctly gendered ways. ${ }^{190}$

188 See for example, Janet Jacobs, "Gender and Collective Memory: Women and Representation at Auschwitz," Memory Studies, vol. 1, no. 2, (2008): 211-225.- "Women, Genocide, and Memory: the Ethics of Feminist Ethnography in Holocaust Research," Gender \& Society, vol. 18, no. 2, (April, 2004): 223-238. - "Remembering Genocide: Gender Representation and the Objectification of Jewish Women at Majdanek," in eds Oren Baruch Stier \& J. Shawn Landres, Religion, Violence, Memory, and Place, (Indianapolis \& Bloomington: Indiana University Press, 2006): 163-173.

189 See for example, Barbie Zelizer, "Gender and Atrocity: women in Holocaust photographs," in ed. Barbie Zelizer, Visual Culture and the Holocaust, (London: The Athlone Press, 2001): 247-274.

190 For Waxman's work on gender and the Holocaust as historical event see Zoë Waxman, Women in the Holocaust: A Feminist History, (Oxford, Oxford University Press, 2017). For Waxman's research on gender and Holocaust representation See for example chapter 4, "Writing Ignored: Reading Women's Holocaust Testimonies," in Writing the Holocaust, 122-151.—“Unheard Testimony, Untold Stories: The Representation of Women's Holocaust Experiences," Women's History Review, vol. 12, no. 4, (2003): 661-677. 
In understanding the survivor object's becoming in a Swedish context, these previous studies were integral; primarily to understandings of the "True Victim" and the "Moral Witness"- two ideals that Dean elaborates in Aversion and Erasure and The Moral Witness. The first ideal—the "True Victim"-is a term first coined by the American political scientist Alyson M. Cole who, in her book, The Cult of True Victimbood, shows how anti-victim discourses of "victimism" constructs individuals and groups as either "True Victims" or false, bogus victims, who use their victim status for personal gain. ${ }^{191}$ The "True Victim," according to Cole, is constructed in relation to notions of propriety, responsibility, individuality and innocence. ${ }^{192}$ Although Cole only briefly discusses anti-victim discourses in relation to the Holocaust survivor, Dean has applied the same understanding to her analysis of "how anti-victimism unfolds on multiple levels of discussion in both Europe and the United States" in debates about the Holocaust. ${ }^{193}$ This is also one of the ways in which I conduct my analyses of gender; leaning on the research conducted by Jacobs, Zelizer, Tydor-Baumel Schwartz and Waxman, I attempt to grasp how the ideal of the "True Victim" has affected the construction of the Holocaust survivor in Sweden in relation to conceptions of gender.

Similarly, Dean's explication of the ideal of the "moral witness" has also been understood in this dissertation as part of a gendered Holocaust history of representation. According to Dean, the "moral witness" is an ideal that has developed from the inter-war period onward, displaying how perspectives on witnessing and genocide have changed over time. ${ }^{194} \mathrm{By}$ focusing her study on a number of War Crimes Trials pertaining to the Holocaust, Dean argues that although the "moral power" of the witness to genocide has been central to the history of witnessing, this power is slowly waning. ${ }^{195}$ In noting that "the definition of who is and is not a moral witness varies from one location to another and is always linked to cultural projections that may have tenuous relationships to real victims," Dean is also emphasizing the importance of the relationship between the classification and the classified as well as the spatial contingencies that determine the status of the "moral witness". Again, as with the "True Victim," I attempt to understand the gendered construction of the survivor in relation to the ideal of the "moral witness" in

191 Alyson M. Cole, The Cult of True Victimbood: From the War on Welfare to the War on Terror, (Standford, California: 2007), 5.

192 Cole, The Cult of True Victimhood, 5-6.

193 Dean, Aversion and Erasure, 7.

194 Dean, The Moral Witness, 2.

195 Dean, The Moral Witness, 3. 
Swedish public discourse. Although Dean contends that the "moral witness" became an "icon of universal human suffering" in the period 1950-1990, I also attempt to understand what meanings moral witnessing as an act, took on during the early decades of Swedish discourses on the Holocaust. ${ }^{196}$

With regards to gender and representation, then, I am not so much filling a gap as I am connecting the dots. Building on the pioneering work of a number of scholars I attempt to incorporate gender into the history of the Holocaust rather than vice versa. Instead of treating gender as "an addendum" to 'real' Holocaust studies, I have viewed it as an integral part in a wider attempt to understand the survivor object within discourses related to the Holocaust.

\section{Filling the Gap: Silence and Excess}

Concerning Sweden as a geographical space in which the Holocaust as event and as memory has taken place, there are plenty of gaps to be filled; especially in the time period between 1945 and 1990. Certainly, more research is under way within Swedish scholarship on this early period; scholarship that will hopefully lead to further studies on the subject. ${ }^{197}$ The task of this dissertation has sometimes been to straddle both a focus on the construction of the Holocaust survivor and creating a context for Holocaust memory that previously did not exist. As such, this dissertation contributes disparate pieces to the puzzle; actors, contexts and sites of memory that have previously not been considered by Swedish scholars of the Holocaust. However, the central contribution that this dissertation aims to make to the study of Holocaust memory in a Swedish context is the identification and empirical scrutiny of the productive concepts of silence and excess.

When examining or tracing arguments of silence while, at the same time, critically engaging with silences created by historiographical narratives, it is important to untangle what the term 'silence' can come to mean in different rhetorical settings. As can be seen from the discussion above I am positioning myself in relation to a perceived silence, arguing that victims' presence in Swedish post-war discourse has not been sufficiently studied by Swedish historiography concerning the Holocaust. Simultaneously, I make the claim that silence, as well as excess, are concepts often used in order to discipline Holocaust memory—creating

196 Dean, The Moral Witness, 173.

197 Currently Pontus Rudberg is working on a project about survivors' restitution claims as testimonies, Lars M. Andersson is conducting research on the testimonies collected by the Tegens and Malin Thor Tureby and Julia Sahlström are currently working on research pertaining to early Swedish-Jewish memory and Holocaust survivors. 
boundaries for speech acts and, in effect, creating new silences. In doing so, it is not my intention to differentiate between the imagined and the real-positioning the actual silences created by previous research against the rhetorical silences in Swedish public discourse. Rather, the point is to identify when silence, whether empirically substantiated or not, is used to argue for an increased focus on a particular aspect of history. Indeed, someone could conduct a similar analysis on this dissertation and find rhetorical strategies used in order to argue for an increased focus on the post-war lives and representation of individuals with Holocaust experience in a Swedish context. In my analyses I search for the ways in which silence has been used as an argument in favor of more Holocaust memory. However, at the same time, I also search for arguments that heed this call for more memory. Of course, arguments of silence and excess are far more complex than the simple rhetoric of 'more' or 'less' memory. In the debate regarding the thesis of silence, it is primarily the survivors' willingness and ability to speak as well as the world's willingness and ability to listen that constitute the problem-nexus of silence as an analytical concept. However, silence can also be understood as coping, as the unintentional or intentional destruction of archival sources, as the most authentic response to the Holocaust as civilizational rupture and catastrophe and as the forcible and, sometimes violent act of being silenced.

Excess, on the other hand, has often been understood through the psychological condition that it purportedly creates-'Holocaust fatigue'. This open-ended term in itself encompasses notions of a general disinterest, indifference and emotionlessness towards the Holocaust although it is commonly referred to in relation to young people and Holocaust education. ${ }^{198}$ The framing of 'Holocaust fatigue' as a young person's problem also feeds into the historiographical progressivism that characterizes many synthesizing accounts of Western Holocaust memory: first there was silence, then with the Eichmann trial both the witness and the Jewish Holocaust came forth, in 1979 the Holocaust became universalized through the TV-series Holocaust and throughout the 1980s and 1990s, interest in the Holocaust grew and Holocaust memory became institutionalized through archives, museums, educational programs and international efforts to commemorate and remember, a 'boom' which invariably led to 'Holocaust fatigue'

198 See for example Simone Schweber, "Holocaust Fatigue in Teaching Today" in ed. Walter C. Parker, Social Studies Today: Research and Practice, (New York: Routledge, 2010): 151-162_ "Holocaust Fatigue," Social Education, vol. 7, no. 1, (2006): 44-50. See also Aleida Assmann, “The Holocaust - a Global Memory? Extensions and Limits of a New Memory Community" in Memory in a Global Age, (Basingstike: Palgrave Macmillan, 2010): 97-117. 
in the young. Excess and its responses ('Holocaust fatigue' being one of them) is not, however, only a quantitative concept but also relates to qualitative aspects of communicating experience. The question of how much an appropriate amount of memory is, is also intrinsically linked to notions of efficiency. If one accepts the progressivist discourse on Holocaust memory, then the response will be to try to remove or erase 'inefficient' forms of Holocaust communication as well as the seemingly overwhelming feeling that is produced by a multitude of representations of the Holocaust. Thus, by default, a perspective on Holocaust memory as excessive and inefficient will lead to disciplining practices of communicative acts relating to Holocaust experience. In relation to Jewish memory, Dean explains it thusly:

The assertion that there is now a surfeit of memory about the Holocaust also constructs a concept of unmastered memory that never defines what mastered memory might be (two commemorative events a year? Three?). Nonetheless, reductive minimalism does rely on an undefined concept of mastery that renders some Jewish memory implicitly overwrought and histrionic, even if it never specifies what normative measure it exceeds. ${ }^{199}$

The ways in which Jewish memory has been evaluated as both excessive and inefficient in relaying Holocaust memory constructs boundaries around the mastery of testimony and other forms of representation as well as what 'too much' memory is. It thus consists of both a quantitative assessment that determines how much, as well as a qualitative assessment of excessive/minimal forms of expression. Both of these assessments present a number of criteria that serve to discipline Holocaust memory. In the coming chapters, I will refer to 'Holocaust fatigue' and 'anxieties', not as psychological concepts of affect, but rather as analogies for discourses surrounding silence and excess. 



\section{Chapter 2 - Prologue: Locating the Problem-Complex}

\subsection{Introduction}

Initially, this study was designed to focus solely on the Living History campaign as well as the resulting government agency, The Living History Forum. The methodology used for this analysis was, as previously mentioned, Carol Bacchi's What's the Problem Represented to be? approach. During the process of researching the government agency's development from idea to project to institution, I found it difficult, however, to situate the discourses that informed different choices of inclusion and exclusion without conducting a more extensive genealogical analysis of the problems found in the government documents. In order to answer questions such as "why were so many members on the first and second project committees so anxious to see a broader profile for the forum?" And, why was the Holocaust viewed as inherently 'un-Swedish', even by experts in the field?", I had to locate the descent and emergence of problematizations regarding Swedish-ness and the Holocaust; an endeavor that has now filled all pages of this dissertation. Although Bacchi's policy analysis perspective was abandoned in order to understand how the Holocaust survivor had been constructed in the decades after the war, some insights gained from Bacchi's methodological framework still informed the research process. Thus, rather than focus on the policy problematizations themselves, I instead chose to only study the "conceptual underpinnings" of them. The problems described in this chapter will, therefore, not be explained through a genealogical analysis that spans the whole period leading up to the late 1990s. What I provide instead is the conceptual beginning and achieved dominance of discourses surrounding the survivor that also manifested themselves in the so-called 'memory boom' era of the 1990s.

In this chapter I examine how the survivor was problematized as a victim and a witness in a Swedish government project aimed at collecting testimonies from the time of the Holocaust. Before exploring this particular theme, however, I briefly discuss some of the context around the Living History campaign: where the impetus for the campaign came from; how it was framed in the media; and how survivors featured in the early media commentary on the campaign. In relation to this discussion I also analyze the cultural critique that surrounded the book Tell Ye Your Children as well as the "Holocaust film package" issued by the campaign alongside the book's release. After this analysis, I proceed to unpack a complex of problems that formed during the process of creating a collection of testimonies for the future forum. 


\subsection{Method and Sources}

As the previous discussion on the Shoah Foundation's visual history archives and the Yale Fortunoff archives demonstrates, testimonial archival processes are always underpinned by epistemological assumptions about the oral narratives and the objects collected. The Dutch archival theorist Eric Ketelaar has attempted to describe this process through the conceptualization of what he refers to as archivalization, denoting "the conscious or unconscious choice (determined by social and cultural factors) to consider something worth archiving". 200 In contrast to archivization which involves the "methods for transmitting information [that] shape the nature of the knowledge that can be produced"201, archivalization centers on the choices that precede these methods. The question that archivalization begs to answer is therefore: what makes something worthy of being archivized?

In studying constructions of the Holocaust survivor, this question is crucial. As Derrida famously postulates, archives do not merely reflect the past, they also create it. In other words, "archivization produces as much as it records the event". ${ }^{202}$ Hence, by studying processes of testimonial archivalization, one can reveal not only what is deemed important for a specific institution but also what discourses effectively discipline the objects collected. In the case of Holocaust archives based on survivor testimony, this means that archivalization reveals underlying assumptions about the individuals being interviewed.

Having already gone through a vast collection of government documents, I proceeded to categorize them in relation to their relevance vis-à-vis Living History's plans for a collection of testimonies related to the Holocaust; a collection that went under the working name the "Documentation Project".203 Of course, some of the discussions held about the Forum and its future profile were also relevant for a greater understanding of the collection of testimonies, which meant that the minutes from meetings with the first committee (working under the mandate of the Prime Minister's office) were also included in my analyses. However, most of the material used for this first empirical chapter was gathered from government documentation that directly pertained to the "Documentation project". These

200 Eric Ketelaar, "Tacit Narratives: The Meaning of Archives," Archival Science, 1, no. 2 (2001): 131.

201 Ketelaar, "Tacit Narratives," 133.

202 Ketelaar, "Tacit Narratives," 17.

203 See Kristin Wagrell, The Common Sense of forgetting: Interrogating the Policy-Process of the Living History

Forum's Testimonial Archive, 1997-2016, (Licentiatexamen 2017). 
documents included memoranda, minutes from meetings, emails, post-meeting reflections and reports. In my initial studies of the Living History campaign and the Forum, I had also gathered that the framing of Holocaust memory as a young person's issue in Sweden came from a long-standing debate regarding neo-Nazi violence in Sweden. This had, of course, been noted by researchers who had studied or, at least commented on, the Living History campaign. Yet, none had looked closer at the institutional connections between this discourse on youth-onyouth violence and Holocaust memory. Therefore, I decided to also include material from "Barn och Ungdoms-delegationens" ("the Child and Youth delegation") archives; a branch of the central government offices which was assembled in the early 1980s and dissolved in the late 1990s. This choice was based on the fact that this branch had first initiated the study (later conducted by CEIFO and $\mathrm{BR} \AA$ ) that would serve as a catalyst for Prime Minister Persson's Living History campaign.

In addition to the archival material, I also wanted to understand this institutional discourse in relation to the culture critique that surrounded both the project and the Holocaust in general at the end of the 1990s. Under the auspices of the campaign, a book about the Holocaust was published and a "film package" was assembled for the educational purposes of each Swedish household. Wanting to understand the arguments expressed in relation to Sweden and Holocaust memory, I postulated that the critique surrounding the campaign's media output would elucidate how the Holocaust was disciplined at this specific point in Swedish history. Therefore, I also searched the digital newspaper archive for reviews of Bruchfeld's and Levine's book Tell Ye Your Cbildren which was by far the most successful venture to come out of the Living History campaign. This material was analyzed in the same manner as the culture critique surrounding Anne Frank, Adolf Eichmann and Nelly Sachs. The analysis thus followed Karyn Ball's example of tracing arguments that served to "regulate interpretation" of the Holocaust. 204 Inspired by Bacchi's first question in her model of policy analysis- "what is the problem represented to be?-I studied the rhetoric, or persuasive arguments of the experts involved in creating the "Memory Archive" as a way to understand how Holocaust survivors were constructed in relation to the archival ambitions that were part of creating a new institution for Holocaust remembrance and the promotion of human rights. 


\subsection{The threat of neo-Nazism, Living History and the Role of the Survivor}

The Living History Forum, a government agency for the promotion of tolerance and human rights, was formed as a continuation of the Social-Democratic Prime Minister Göran Persson's educational campaign Living History; a campaign that was announced in a speech to the Swedish parliament on June 12, 1997. "The Swastika is seen again, Sieg Heil echoes on our streets, neo-Nazis are marching", Persson exclaimed in his speech. With these dire words, the Persson administration launched an educational campaign with the aim to educate the Swedish population on Holocaust history and its relation to a Swedish present and future. ${ }^{205}$ One day prior to the parliamentary debate, the government had published a report, ordered from, and conducted by, the Swedish National Council for Crime Prevention (Brottsförebyggande rådet, BRA) and Stockholm University's Center for Research in International Migration and Ethnic Relations (CEIFO). The report, which included three different studies, seemed to show that almost a third of the adolescent respondents had little to no knowledge of the Holocaust, with a small percentage denying its existence altogether. In addition, almost 28 percent of the respondents had not agreed with the statement "Democracy is the best system of rule." 206 This re-ignited a long-standing debate about the vulnerability of Swedish youth to the corrupting influence of right-wing extremism and neo-Nazi ideology. The society-wide concern regarding a perceived rise in neo-Nazi activity had been present since the early to mid-1980s with a few key events shaping debates on racism and xenophobia in Sweden. As Swedish historian Helene Lööw asserts, up until the 1980s racism was not framed as a Swedish phenomenon at all but was referred to as an international problem, the most prominent examples being segregation in the Southern United States and the Apartheid system in South Africa. ${ }^{207}$ The leading National-Socialist party in Sweden, Nordiska Rikspartiet (NRP), had

205 Partiledardebatt, Sveriges Riksdag, July 12, 1997, Protokoll 1996/97: 119, 22.

https://data.riksdagen.se/fil/62A0CA5E-31EE-4431-BE69-BA7A41688D2A, (accessed on July 2, 2015).

206 The report included a study of exposure to ethnically and politically motivated violence, the spread of racist and anti-racist propaganda, and attitudes to democracy amongst school youth. See Lange et al. Utsatthet För Etniskt Och Politiskt Relaterat Hot Mm: Spridning Av Rasistisk. Och AntiRasistisk Propaganda Samt Attityder Till Demokrati Mm Bland Skolelever, (Ceifo/Brå: Stockholm, 1997), 56.

207 Helene Lööw, Nazismen i Sverige, 1980-1999_den rasistiska undergroundrörelsen: musiken, myterna, riterna, (Stockholm: Ordfront förlag, 2000), 24. 
been marginalized in Swedish politics since the 1940s and as such, they received little media attention in the 1960s and 1970s. According to Lööw, Swedish neoNazi groups were regarded as "unpleasant yet curious elements in the Swedish people's home", ${ }^{208}$ In 1980, however, the campaign-based organization Bevara Sverige Svenskt (BSS, "Keep Sweden Swedish") made its first political appearance. At the same time, crosses burned across Sweden as part of a string of neo-Nazi manifestations garnering massive media attention, finally making racism and xenophobia a "national affair". ${ }^{209}$ BSS's platform was comprised of one essential question: to stop immigration to Sweden. As BSS was not part of any national socialist faction in an official capacity, they were, argues Lööw, perceived as more threatening to Swedish society than the NRP even though their numbers did not exceed 300 in the early 1980s. ${ }^{210}$ However, as the violence wielded by NRP members, including harassment, arson, assault and even murder, led to a series of highly publicized trials between 1985 and 1987, which in turn spawned new national socialist factions (what Lööw has termed a "racial ideological underground movement"211), fears of right-wing extremism in Sweden increased.

Although many of the trial cases of the 1980s involved young offenders, no case led to the framing of racism as a problem particular to youth culture. This changed in 1995, however, with the murders of 18-year-old Gerard Gbeyo, and of fourteen-year-old John Hron. In both of these murder cases, the assailants had been teenage skin heads and neo-Nazis. Although John Hron was a white Swedish citizen and Gerard Gbeyo an Ethiopian asylum seeker, both murders raised questions about the particular vulnerability of Swedish youth to the violence and extremism of neo-Nazi groups. The so-called "Klippan" case (the murder case of Gbeyo) also produced tangible political responses with Barn och Ungdomsdelegationen (the delegation for children and youth, hereafter the DCY) opening up an investigation into the state of affairs in the southern municipality of Klippan-an investigation which primarily focused on public institutions such as schools, the local police department and social services. ${ }^{212}$ Even though many of the national

208 Lööw, Nazismen i Sverige, 24.

209 Lööw, Nazismen i Sverige, 24.

210 Lööw, Nazismen i Sverige, 24.

211 Lööw, Nazismen i Sverige, 59 [“den rasideologiska undergroundkulturen”].

212 Riksarkivet (RA), Barn- och ungdomsdelegationen (1983-1998), vol. 22, "Minnesanteckningar", March 25, 1996. Barn- och Ungdomsdelegationen was an advisory committee formed in 1982 that reported directly to the Swedish government on issues pertaining to Swedish children and youth. 
newspapers framed the Klippan murder as a local phenomenon, the DCY positioned this small community as a central part in a larger effort to understand the spread of racist and neo-Nazi propaganda in Sweden as a whole. ${ }^{213}$ From their investigation into Klippan, the DCY concluded that the municipal workers interviewed perceived the problem of racism to be multi-layered, stemming from growing unemployment in the region, high levels of immigration, low levels of education amongst the local population, a long tradition of Nazi political leanings and "historylessness" in the local community. ${ }^{214}$ It was also this latter argument that came to dominate the debate around BRA's and Ceifo's survey (commissioned by the DCY in 1996) as well as Persson's decision to launch Living History.

The interrelation between this concern for organized right-wing extremism and Holocaust education was thus not a pre-given relationship. Rather, the survey was first meant to only cover perceptions of racist violence and the spread and use of racist propaganda in Swedish schools. ${ }^{215}$ The part about students' knowledge of the Holocaust was added on at a later stage of the study and thus did not naturally relate to the questions which had arisen when the study was requested as a direct response to the murders of Gbeyo and Hron. Furthermore, the survey's results concerning racist propaganda and perceived racist violence received relatively little attention in the debate that followed, which almost singularly circulated around questions concerning Holocaust knowledge, Holocaust denial and the antidemocratic attitudes of some of the respondents. 216 Also, because Living History

213 Berit Wigerfeldt, "Klippan—bilden av en ort som rasisthåla" in eds Göran Rystad \& Svante Lundberg, Att möta främlingar (Lund: Arkiv Förlag, 1999): 193-217. See also, Riksarkivet (RA) Barnoch ungdomsdelegationen, vol. 22, "Protokoll" April 12, 1996. At a meeting held on April 12, 1996, the municipal leader in Klippan expressed a wish to have Barn- och ungdomsdelegationen research his municipality as part of a "national strategy for actions against violence and intolerance" ["nationell strategi för åtgärder mot våld och intolerans".].

214 Riksarkivet (RA), Barn och ungdomsdelegationen, vol. 22, "Minnesanteckningar", March 25, 1996.

215 Riksarkivet (RA), Barn och ungdomsdelegationen, vol. 22, “Minnesanteckningar”, March 25, 1996.

216 See for example, Eva Bäckstedt, "Okunniga tvivlar på Förintelsen—forskare kartlade elevers osäkerhet om judeutrotningen", June 13, 1997, SvD, 10. Hans Bergström, "Skolan har misslyckats", June 13 1997, DN, 6. Eva Parkrud, "Förintelsen ska inte glömmas", June 13, 1997, Göteborgsposten, 2. Britta Svensson, "Jag hoppas Persson vet vad han gör”, June 13, 1997, Expressen, 109. Mats Carlsson, “Ungdomar inte rasistiska” June 27, 1997, Göteborgsposten, 2. Peter Englund, "Ung och totalitär", June 13, 1997, Expressen, 4. 
was launched in response to the survey, Holocaust education came to be understood as the natural remedy to neo-Nazi ideology and violence.

Living History, which was introduced with a full program of learning activities in November 1997, included special pedagogical training for teachers and educational material for all interested Swedish households. The idea was that if parents had better knowledge of the Holocaust, they could communicate this knowledge more efficiently to their children; a transference of history that would protect the latter from neo-Nazi propaganda. High school students and all interested households were given the book Tell Ye Your Children-a brief overview of Holocaust history - authored by the historian Paul A Levine and the PhD candidate Stephane Bruchfeld. ${ }^{217}$ During the autumn of 1997, Persson also initiated talks with the British Prime Minister, Tony Blair, and the President of the United States, Bill Clinton, with regards to further transnational efforts for Holocaust remembrance and education. These talks subsequently resulted in the establishment of the International Taskforce for Holocaust Remembrance (ITF) in May 1998 which, in turn, facilitated the Stockholm International Forum Conferences, held between 2000 and 2004. ${ }^{218}$ In the wake of the looted gold and other Jewish assets controversy, this attention was crucial for the establishment of Sweden's reputation as a country committed to Holocaust remembrance worldwide. Because of the Living History campaign and additional efforts made to remember the Holocaust, Sweden was described in the Eizenstat report as the country that had made the "most significant investment in encouraging its people to learn the lessons of history." 219

The international attention that Living History garnered later led both scholars and opinion makers to attempt to understand the ideological investments embedded in both the campaign and the Forum that was created as its permanent continuation. In an early study of the campaign, Swedish historian Cecilia Trenter

217 Paul A. Levine and Stephane Bruchfeld, Om detta må ni berätta (Stockholm: Regeringskansliet, 1997). The English translation was published in 1998 and received the title Tell Ye Your Children, which is the title used in this dissertation when referring to the book henceforth.

218 See Larissa Allwork, Holocaust Remembrance between the National and the Transnational: The Stockholm International Forum and the First Decade of the International Task Force (London and New York: Bloomsbury Academic, 2015).

219 W. Slany and S.E. Eizenstadt, U.S. and Allied wartime and postwar relations and negotiations with Argentina, Portugal, Spain, Sweden, and Turkey on looted gold and German external assets and U.S. concerns about the fate of the wartime Ustasha Treasury (Washington DC: United States Department of State, June 1998). 
positioned Persson's initiative within a greater national historical culture where Sweden, which had little territorial experience of the Holocaust in terms of ghettos and camps, had to commit to Holocaust remembrance as a "ticket" to enter "a European historical community". 220 Furthermore, in his dissertation on Norwegian Holocaust memory, Kyrre Kverndokk argues that even though Living History has to be understood as a universalist project occurring in a cosmopolitan memory context, it was also a nationally specific project, "promoting Sweden as a responsible and leading nation in upholding a universal Holocaust memory and thereby also [positioning it] as a protector of human rights and democratic values". 221 Although many critics of the project saw it as a political and strategic move to gain influence and international goodwill, the historian David Ludvigsson contended, only a few years after the campaign was launched, that it stemmed from a genuine interest in, and concern for, Holocaust education and remembrance..$^{222}$ Nevertheless, Living History has undeniably become a battleground for ideological struggles over the moral and political value of the Holocaust, the most prominent of these struggles being fought over whether the Living History Forum should also base its activities on the history of atrocities committed by Communist regimes; a topic that has been explored by the Swedish historian Jan Selling. ${ }^{223}$

One of the questions that remains, however, is how victims of the Holocaust featured in these debates at a time when Holocaust remembrance and education was high on the Swedish political and cultural agenda? The debate that arose in the direct aftermath of CEIFO's and BRA's survey centered on the failure of the Swedish educational system. The first media reactions to the study, and to Persson's political response to it, was one which problematized Swedish youth and their lack of knowledge and proper education on the Holocaust. ${ }^{224}$ In this first wave of reactions, several Swedish Holocaust survivors, many of them active in

220 Cecilia Trenter, "I mötet med minnet—historiekulturer i Skandinavien," Historisk tidsskrift, vol. 122 no. 2, (2002): 300.

221 Kyrre Kverndokk, Pilegrim, turist og elev (Norrköping: Linköping studies in Arts and Science, 2007), 26.

222 David Ludvigsson, “Levande Historia Inte Bara Levande Historia,” Mod Nye Historier: Rapporter till det 24. Nordiske Historikermöde 49 (2001): 144-177.

223 Jan Selling, "Between history and politics: the Swedish Living History project as discursive formation" Scandinavian Journal of History 36, no. 6 (2011): 555-569.

224 Hans Bergström, "Skolan har misslyckats", June 13, 1997, DN. Peter Englund, "Ung och totalitär," June 13, 1997, Expressen. Eva Bäckstedt, “Okunniga tvivlar på Förintelsen—forskare kartlade elevers osäkerhet om judeutrotningen”, June 13, 1997, SvD. Eva Parkrud, "Förintelsen ska inte glömmas," June 13, 1997, Göteborgsposten. 
contemporary debates on racism, antisemitism and Holocaust denial, were asked to comment on the report. Emerich Roth, a former social worker and Jewish camp survivor contributed with his insights on Swedish Radio's program Studio 1 while Jewish camp survivors Hédi Fried and Jerzy Einhorn gave statements to $S v D$ and Göteborgsposten. ${ }^{225}$ Moreover, Holocaust education, although viewed as a task for the educational system at large, was also framed in evening newspaper chronicles as a greater societal effort to communicate the past with a particular emphasis on the role played by survivors. 226

This remained a recurrent theme, even as the debate changed in character in November of 1997 when the Persson-led government officially launched Living History. Although the researchers who had conducted the study had always been forthright about the survey's weaknesses, these were 'rediscovered' as the Persson administration presented a more detailed plan for Living History in the autumn. For example, the fact that many of the respondents had been as young as 12 and had not yet received Holocaust education at school, was used to denigrate Living History and label it as a premature response to false or exaggerated claims of forgetfulness and ignorance among Sweden's young. ${ }^{227}$ In most cases, this critique did not invalidate efforts to remember the Holocaust per se but rather made the point that many had been too quick to castigate the Swedish educational system on the basis of a heavily flawed survey. ${ }^{228}$ In the midst of this critical storm, a handful of Jewish camp survivors remained visible in the press, elucidating their role as communicators of Holocaust memory - a visibility which emphasized their importance and marked it as unrelated to any critique against Living History. ${ }^{229}$ Hence, even though Persson's campaign was framed as inherently political, the work that survivors undertook was not seen to be tainted by Living History's memory politics.

225 Eva Parkrud, “Förintelsen ska inte glömmas” June 13, 1997, Göteborgsposten. “Överlevande vill ge alla skolbarn kunskap om Nazismen," June 13, 1997, SvD.

226 Britta Svensson, "Jag hoppas att Persson vet vad han gör," June 13, 1997, Expressen.

227 Already on June 13th, the day after Persson's speech, Bruchfeld explained in an interview in SvD that the results from the study should be understood in relation to the low age of some of the respondents. "Hetsen mot de unga" November 27, Expressen, Albin Rydman,"Persson tolkade larmet fel," November 27, 1997, Expressen. "Ungas svar feltolkade," November 27, 1997, SvD.

228 "Vi behöver historien" November 30, 1997, Göteborgsposten. "Kampanj med risker," November 29, 1997, Expressen.

229 "Studieresa till Förintelselägren", November 27, 1997, SvD. "Upplysningsarbete mot våld och rasism belönas," November 27, 1997, SvD. "Att minnas Förintelsen,” November 28, 1997, Aftonbladet. 
Yet, as the campaign progressed and its content was scrutinized, ideas about the nature and utility of survivor testimonies began to emerge. The culture critique that surrounded the publication of Tell Ye Your Children as well as the film-package presented by Living History in early 1998, demonstrated how perspectives on Holocaust representation could subtly discipline the role of the survivor in general and the utility of Holocaust testimony in particular. The book, which was launched in early 1998, was supposed to be distributed to school children and their parents in order to facilitate a more pedagogical narration of Holocaust history in Swedish homes. Even though the book was primarily distributed in Swedish schools, it could also be obtained by parents, free of charge, from the Swedish government offices (Regeringskansliet). Throughout 1998, the news reported on the book's successes: how distribution exceeded all expectations, and that awards were given to the authors, as well as the book's ever-increasing international spread. ${ }^{230}$

In addition to the news about these successes, the critical reception of the book significantly bolstered the whole Living History campaign, with its successes largely seen to override any earlier controversies regarding the CEIFO/Brå study and Persson's alleged political motives. This narrative-something good which sprung out of something bad-began to influence the campaign even before the book had reached its target audience. Through several congratulatory and jubilant reviews, Tell Ye Your Children was positioned as the qualitative result of a campaign that had, in more ways than one, proved Persson's critics wrong. The essential quality of the book that all reviewers lauded referred particularly to the minimalist style that the authors had adopted in their brief overview of the Holocaust. In Expressen the book was described as "solid, tight and worked-through" and DN's headline read "matter-of-fact, harrowing and personal". ${ }^{231}$ Aftonbladet's critic argued that Levine and Bruchfeld had accomplished "a strange feat— to accessibly and with searing gravity tell about what happened without making schindler's list out of it all; without exploiting and mythologizing in that way which tends to chew

230 See for example, "Strykande åtgång av bok" February 10, 1998, Dagen. "Framgång för bok om Förintelsen," March 17 1998, "Perssons bok sprids över hela världen,” May 24, 1998, Göteborgsposten. "Kampanjbok tvåa efter bibeln," September 20, 1998, DN. "belönad för bok om Förintelsen,” November 26, 1998, Göteborgsposten.

231 Peter Englund, "Som man bäddar..." February 10, 1998, Expressen, 4. Kerstin Vinterhed, "Sakligt, skakande och personligt," February 3, 1998, DN. 
the Holocaust into a sweet-and-sour gruel of guilt". 232 Similarly, SvD's critic complimented the book by highlighting that "the tone [was] muted and facts and eye witness accounts [were] given priority over demonstrative repudiations". ${ }^{233}$ All reviews also emphasized that victim stories were used to personalize the narrative, preventing the victims from becoming "mere statistics". ${ }^{234}$ Also, two of the reviews commented on the moral stringency of the book by claiming that its narrative was not "exploitative". 235 Not making "Schindler's List" of the project was never explained further but likely referred to a critical discussion among western intellectuals about Steven Spielberg's film and how it contributed to the fetishization of the Holocaust. ${ }^{236}$ Similarly, when SvD's critic commended the book's "muted tone" and the fact that testimonies were included in the narrative over "demonstrative repudiations", he also underscored the importance of not politicizing the Holocaust. Here then, survivor testimonies were framed as authentic sources which spoke directly from the past, thus minimizing any possible political or fetishizing undertones in the historical reconstruction.

The style of writing celebrated in these reviews could thus be labelled minimalist. Minimalism, according to Dean, "is a sophisticated style characterized by aesthetic and emotive restraint" that "[resists] hyperbole in order to avoid the potential conversion of suffering into kitsch, voyeurism, or sublimity". ${ }^{237}$ By pointing to the minimalist qualities of Tell Ye Your Children as the one factor that made the book great, the critics positioned it as "an antidote to the alleged media exploitation of the Holocaust and [as an] insurance against the unstable and narcissistic representations of the event associated with overwrought memory". ${ }^{238}$

232 Eva Moberg, “Hur passiv kan man vara utan att bli medskyldig?” February 19, 1998, Aftonbladet.

["En märklig bedrift—att lättillgängligt och med svidande allvar berätta om det som hände, utan att göra schindler's list av alltihopa, utan att exploatera och mytologisera på det där sättet som ibland tenderar att tugga sönder Förintelsen till en enda sötsur skuldgröt.”].

233 Johan Hakelius, "I det ofattbara som var verklighet," February 9, 1998, SvD [“tonen är lågmäld och faktaupplysningar och ögonvittnesskildringar har givits prioritet framför demonstrativa avståndstaganden.”].

234 Englund, "Som man bäddar..." February 10, 1998, Expressen, 4.

235 Eva Moberg also specifically uses the phrase "exploatera" (exploit) in her two reviews of Tell Ye Your Children and the film-package.

236 See Yosheva Loshitskyed, ed., Spielberg's Holocaust: Critical Perspectives on Schindler's List (Bloomington: Indiana University Press, 1997).

237 Carolyn J. Dean, Aversion and Erasure: The Fate of the Victim after the Holocaust (Ithaca:

Cornell University Press, 2017).

238 Dean, Aversion and Erasure, 102. 
Even though the successful integration of witness accounts constituted a central aspect which made, according to the critics, Tell Ye Your Children a qualitative book, seemingly raising the status of the survivor, it also contributed to a disciplining of how personal narratives of the Holocaust should be told and, more importantly, who would be able to tell them.

In the reviews, minimalism was not necessarily combined with notions of a surfeit of Jewish memory. Indeed, it was a specifically Jewish Holocaust that was being narrated in Tell ye your Children, even though other victim groups were also mentioned throughout. However, the examples that have been used for the past four decades to warn against the exploitation, Disneyfication and fetishization of the Holocaust have all been specifically Jewish (Holocaust, Schindler's list, several of the installations at Auschwitz-Birkenau and survivors such as Elie Wiesel, etc.). ${ }^{239}$ The notion of "too much Jewish memory" is thus inherently connected to representations of a Jewish master narrative of the Holocaust, meaning that the structure that most Jewish survivors have learned to follow when narrating their experiences has been continuously deemed at risk of being exploited, Disneyfied or fetishized. Even though there was no explicit critique directed towards this master narrative in the reviews above, the "anxiet[ies] of transmission" that underpinned the whole Living History campaign and later also the work of the Living History Forum, can be gleaned from their appraisals of what makes a historical construction of the Holocaust good. ${ }^{240}$ In the reviews, Holocaust representation was framed as a tight-rope balance between facts and individuals, historical context and identification, rational explanation and emotion; never veering 'too much' to either aspect of representation. All of these appraisals were thus intrinsically linked to notions of utility and propriety where the former involved the effective communication of moral lessons to a younger generation, while the latter pertained to an even more diffuse idea of the proper amount of memory. In short, the reviews guarded Holocaust memory against excess.

As will be explored further in the coming section, these notions of utility and propriety would also permeate the development of the new government agencyThe Living History Forum - making its orientation shift from the Holocaust to the "Swedish perspective"; a perspective which primarily focused on bystanders and

239 See for example, Norman Finkelstein, The Holocaust Industry: Reflections on the Exploitation of Jewish Suffering (New York: Verso Books, 2000). Tim Cole, Selling the Holocaust: From Auschwitz to Schindler; How History is bought, Packagaed and Sold, (New York: Routledge, 2000).

240 Dean, Aversion and Erasure, 150. 
heroes. The discourses responsible this shift also had a significant effect on how Living History dealt with survivor testimony, in particular the testimony given by Jewish Holocaust survivors.

\subsection{Living History's Creation of a "Memory Archive" for the Future}

In 1998, a committee comprising representatives from different academic disciplines, interest groups, Swedish bureaucracy and museum institutions, was appointed by the Swedish government to investigate how, and by what means Persson's educational campaign, Living History, could be re-established in a more permanent form. ${ }^{241}$ One of the points explicated in the first set of directives given to the committee asked that they decide whether or not the collection and archivization of memories (in the form of testimonies as well as objects) from the time of the Holocaust should commence before the establishment of the institution itself. ${ }^{242}$ As a first step in this process, the committee commissioned a survey from The Official Council of Jewish Communities (Judiska Centralradet, heretofore the OCJC) in 1999. One of the primary tasks of the OCJC was to map already existing Holocaust archives in Sweden as well as Swedish material pertaining to the Holocaust abroad. ${ }^{243}$ In addition, it was requested that the OCJC present a set of suggestions for groups whose testimonies could be included into the archive.

241 The members of the project committee were: Sören Ekström (former General Secretary of the Swedish Church), Kristian Berg (head of the National Historical Museums), Malin Berggren (Chairman of Landsrådet för Sveriges Ungdomsorganisationer), Hédi Fried (Psychologist and Holocaust camp Survivor), Stefano Kuzhicov (Chairman of Romernas Riksförbund), Lena Posner Körösi (Chairman of Judiska Församlingen), Marie Rydh (High-school teacher) Per Thullberg (Headmaster of Södertörn Polytechnic University) and Stephane Bruchfeld (Phd student at Uppsala University who asked for his resignation from the committee on November 2, 2000). A group of experts was also appointed and included: Margareta Ahlin (Head of Kulturen Museum in Lund), Ingrid Lomfors (in her role as head of Grundtvig institute at Gothenburg University), Lenke Rothman (Jewish artist and Holocaust camp survivor), Cissi Storck and Jörgen Svidén (both departmental secretaries at the department of culture).

242 Riksarkivet (RA), Kommittén Forum för Levande Historia med Projekt Levande Historia, vol. 19, "Kommittédirektiv, KU 1999: 74".

243 Riksarkivet (RA), Kommittén Forum för Levande Historia med Projekt Levande Historia, vol. 13, "Punkter som kan ingå i kartläggning inför insamlande av vittnesmål". Riksarkivet (the National Archives) was also contracted to do an inventory of existing archives in Sweden relating to the Holocaust, see Riksarkivet (RA), Kommittén Forum för Levande Historia med Projekt Levande Historia, vol. 12, "Inventering av arkivmaterial rörande Förintelsen". 
At this early stage in the planning process it was not yet clear what the new institution was supposed to be-a Holocaust museum? a 'knowledge center'? a research institution? an educational institution? - the list of possibilities seemed endless. Proposals came from Lund, Umeå, Gothenburg and Uppsala, all claiming to have the best competencies for a new institution which could continue the work that had begun during the Living History campaign. ${ }^{244}$ The OCJC's proposal for a collection of memories was thus based on the premise that the new institution would be a Holocaust museum, an option which would never actually come to fruition. However, the fact that the OCJC was first contracted to conduct a survey and present a plan for collection demonstrates that the initial aims of the committee were to create an institution with a particularly Jewish Holocaust memory as its foundation.

This is also what the survey conducted by the OCJC conveyed. In the introduction to its final report it stated that although much had been written about the Holocaust and although Sweden did not technically involve itself in either the war or the genocidal machinery, "we need to understand what happened outside of our borders" and what happened to those who were murdered as well as those who survived. ${ }^{245}$ In addition, the report asserted that a new collection of testimonies and objects needed to account for the general mood in Sweden during the Holocaust, what it was like to live in Sweden during the war, if people knew about the persecution of Jews and if they were complacent or attempted different forms of resistance. The report thus recommended that the largest group of interview subjects should be Jewish survivors, suggesting that ten to fifteen individuals from a large number of sub-groups be interviewed. These sub-groups included Jewish survivors who escaped from the Nazis, survivors who hid in other countries or with partisans, survivors of labor camps, of $\mathrm{KZ}$ camps, survivors who were rescued or arrived as relatives to those rescued, survivors who came through the "child quota" and those who came through the Hechalutz movement. ${ }^{246}$ The report also suggested that the project include individuals from "other victim groups" such as the Roma, HBTQ and Jehovah's witnesses. The OCJC thus recommended to the

244 Riksarkivet (RA), Kommittén Forum för Levande Historia med Projekt Levande Historia, vol. 12, "Levande Historia: ett kunskapscentrum i Lund" and "Levande Historia: Vad Umeå kan bidra".

245 Riksarkivet (RA), Kommittén för Levande Historia, vol. 12, "Kartläggning inför insamlande av vittnesmål rörande offer av Förintelsen," 1.

246 Riksarkivet (RA), Forum för Levande Historia med projekt levande historia, vol. 13, "Kartläggning inför insamlande av vittnesmål rörande offer av Förintelsen,", 5-6. 
committee that a new memory project should attempt to interview people with as many 'surviving' experiences as possible. As is explained in the report,

Even with regards to the Jewish refugees/survivors one should differentiate between them. This is very important when collecting new material. Different groups during different parts of the Jewish persecution (1933-1945) had the possibility and opportunity to bring different things and even the personal witness accounts differ. ${ }^{247}$

This clarification, emphasizing the fact that even Jewish witness accounts differ, shows how prevalent the idea of one, singular Jewish Holocaust experience was at the time. Also, the OCJC uses two words to describe the Jewish group-refugees and survivors. The fact that there is only an oblique stroke between the two categorizations indicate that there might be some overlap, that some refugees could be construed as survivors while some survivors were not refugees. As will be demonstrated later in the collection process, the differentiation between these two categories will only grow more distinct. In addition to these "refugee/survivor" subgroups, "Swedish private persons" and "Swedish Jews" were proposed as other potential interview groups. In regard to these, however, no advice was given on their internal diversity. Rather, the report recommended that ten to fifteen individuals be interviewed from each group. The report also suggested that people who came in contact with 'extraordinary Swedes' such as Folke Bernadotte and Raoul Wallenberg should be interviewed.

As part of its task to 'map' the current state of Holocaust archives in Sweden and abroad, the report listed a number of institutions that could potentially serve as partners to the new Living History institution. The most prominent examples of such partners were Jewish Memories ("Judiska Minnen”) — a project focused on Holocaust memories and the Swedish-Jewish experience conducted by the Nordic $\mathrm{Mu}-$ seum in the mid-1990s — as well as the Shoah Foundation's visual history archives. Also mentioned as potential partners were a number of Swedish survivor organizations including Föreningen Förintelsens Överlevare, Föreningen Förintelsens Minne,

247 Riksarkivet (RA), Forum för Levande Historia med projekt levande historia, vol. 13, "Kartläggning inför insamlande av vittnesmål rörande offer av Förintelsen," 5. [“Även när det gäller de judiska flyktingarna/överlevanden bör man göra en åtskillnad. Detta är mycket viktigt då man skall samla in nytt material. Olika grupper under olika tider av judeförföljelserna (1933-1945) hade möjlighet och tillfälle att ta med sig olika saker och även de personliga vittnesmålen skiljer sig"']. 
Kulturföreningen 1945 års räddade judar, and Föreningen Child Survivors. ${ }^{248}$ In addition to these collections, the report listed 49 institutions world-wide which held collections or testimonies and/or objects pertaining to the Holocaust. ${ }^{249}$ In spite of this comprehensive account of commemorative institutions all holding seemingly expansive collections of testimonies and objects, the report concluded that "today there are survivors in practically all countries, in all parts of the world. They have been a silent generation, they did not have the strength to speak, all energy was spent creating a new life, new beginnings and on forgetting." 250 Hence, even though ample evidence was provided to the contrary, a discourse on survivor silence was reproduced in the report, arguing that survivors themselves chose not to speak of their experiences in order to survive.

While some of the advice given by the OCJC was heeded in the coming documentation process, a significant shift in the focus of the future institution was taking place which would also come to alter the direction and trajectory of the "Memory Archive". Although the Holocaust was initially the sole focus of the Living History campaign, the question of whether to widen the thematic scope of the new institution or not, was raised within the project committee's discussions after the OCJC's report had been received; discussions that later manifested in a more diffuse, open-ended phrasing of the Forum's mission evidenced by the language used in the official government report. ${ }^{251}$ Although Living History had been a campaign for the remembrance of the Holocaust specifically, several of the committee members thought it appropriate to widen the thematic perspective so as to include

248 Riksarkivet (RA), Kommittén Forum för Levande Historia med projekt levande historia, vol. 13, "Kartläggning inför insamlande av vittnesmål rörande offer av Förintelsen," 12.

249 Riksarkivet (RA), Kommittén Forum för Levande Historia med projekt levande historia, vol. 13, "Kartläggning inför insamlande av vittnesmål rörande offer av Förintelsen," 12.

250 Riksarkivet (RA), Kommittén för Levande Historia, vol. 12, "Kartläggning inför insamlande av vittnesmål rörande offer av Förintelsen," ["Idag finns det överlevande i praktiskt taget alla länder, i alla delar av världen. De har varit en tyst generation, man orkade inte prata, all energi gick åt till att skapa ett nytt liv, börja om, att glömma”].

251 Riksarkivet (RA), Kommittén Forum för Levande Historia med projekt levande historia, vol. 17, "Protokoll från kommittémöte den 10 maj 2000," 1-2 [“Arbete pågår att specificera uppläggningen och en discussion uppstod i kommittén om hur viktigt ett sådant breddat seminarium är för kommitténs arbet. Flera uttryckte stöd för seminariet och dess ambition till breddning och koppling till dagsaktuella frågor"] [“Flertalet höll med om att utgångspunkten måste vara nuet, det dagaktuella samhället samt tron på samhällets lika värde"]. "Forum för Levande Historia," SOU 2001: 5. https://www.regeringen.se/rattsliga-dokument/statensoffentliga-utredningar/2001/02/sou-20015/, (accessed on November 18, 2019). 
other genocides in history as well as oppressive ideologies and regimes beyond that of Nazism. ${ }^{252}$ Also, a re-definition of the Holocaust was suggested; one which included groups other than the Jews, such as the Roma, HBTQ individuals and the handicapped. ${ }^{253}$ Although this latter issue was never 'resolved' within the committee itself, the widened focus of the Living History campaign had tangible results; amongst other things, a lecture series including themes such as crimes committed under Communist rule and comparative perspectives on genocide. ${ }^{254}$ Levine and Bruchfeld, authors of Tell Ye Your Children, were two of the most staunch defenders of the so called 'singularity thesis' and argued for the continued effort to define and remember the Holocaust as the attempted annihilation of the Jews, an occurrence so unique that it could not be compared to any other historical event or genocide. ${ }^{255}$ As opposed to Bruchfeld, Levine was not a committee member, but remained vocal in both the Swedish press and in discussions with the committee on his opinions on the matter. ${ }^{256}$

Levine's critique against the future Living History institution's widened scope was also directed towards the second Stockholm International Forum Conference, Combating Intolerance, held in 2001, where issues such as human rights and intolerance took precedence over specific questions regarding the Holocaust. In an opinion piece published in DN, Levine declared that this new focus constituted a "backlash" in Swedish Holocaust remembrance and that the "Holocaust fatigue" that some expressed was most often experienced by those who possessed the least

252 Several of the members, however, protested loudly against this widening of the Forum's profile.

The protesters included Ingrid Lomfors, Lena Posner-Körösi and Lenke Rothman, see for example Riksarkivet (RA), Kommittén Forum för Levande Historia med projekt levande historia, vol. 17, Lenke Rothman, "Inför Kommittémötet den 20-21 juni," 1-4; vol. 19 "Protokoll från extra komittémötet den 5 januari 2001," [“So övrig fråga tillade Per Thullberg att han—med tanke på att de aktuella handlingarna kommer att förvaras i kommitténs arkiv—har för avsikt att till kommittén skicka ett brev i vilket han bemöter den kritik som har riktats mot kommittén dels i det tidigare föreslagna särskilda yttrandet, dels i brev från Ingrid Lomfors”]. Ingrid Lomfors \& Lena Posner-Körösi, "Särskilt yttrande till slutbetänkande om Forum för Levande Historia".

253 Jan Selling, "Between history and politics: the Swedish Living History project as discursive formation" Scandinavian Journal of History 36, no. 6 (2011): 270.

254 Riksarkivet (RA), Kommittén för Levande Historia, vol. 25, "Levande Historias seminarier 2003".

255 Selling, "Between history and politics," 268.

256 Selling, "Between history and politics," 268. 
amount of knowledge on the subject. ${ }^{257}$ Despite these words of warning from Levine, Bruchfeld and other committee members, the establishment of a permanent form for the Living History campaign was to follow in the footsteps of the Stockholm Conferences. In 2001, the same year as Combating Intolerance, the committee presented a proposal for a national center of knowledge, called the Living History Forum, where democracy, tolerance and human rights were to be promoted through information about a history of atrocities. ${ }^{258}$ In the proposal, the committee clarified that the primary historical focus should be the Holocaust. However, it also stated that;

with the Holocaust as a point of departure, one can also discuss the reasons for and the mechanisms of the genocide. One can thereby widen the discussion to other genocides. The Holocaust can also be the point of departure for a discussion on totalitarian systems, and Nazism can thus be compared to Fascism and Communism."259

The latter sentence, pertaining to the issue of comparing Nazism and Communism, was the result of a long-standing critique from conservative and liberal politicians, academics and opinion makers who argued that the left used the Holocaust as a detraction from their own sordid history of oppression, often referring to Stalin's and Mao's reigns of terror. Despite the conflict within the committee and the absence of an actual definition of the Holocaust (as either the extermination of the Jews alone or the extermination of several victim groups), the proposal firmly cemented a universal perspective on the Holocaust and its purpose as a historical example that should not be forgotten but should also not, by itself, dominate the new Forum's activities on human rights promotion.

After the official report for the establishment of the Living History Forum had been published, real work on the so called "documentation project", which later resulted in the "Memory Archive", commenced. In welcoming her 'advisory group 260 to their first meeting, the newly appointed project leader, Eva Fried,

257 G. Eriksson, “Konferens Om Intolerans. Förintelsen i skymundan på årets konferens,” January 29, 2001, DN.

258 SOU 2001: 5.

259 SOU 2001: 5, 10.

260 The advisory group comprised of 'experts', a vast majority being professional historians based at either Uppsala or Stockholm University: Helene Lööw (historian and first chief curator of the 
informed the group that the former committee (which had been dissolved and acceded by another committee) had emphasized that "the memories collected should portray the Holocaust from a Swedish perspective and that the collected memories should have a connection to the Holocaust" (this author's italics). ${ }^{261}$ The process of collecting testimonies and objects from the Holocaust with a predominant focus on Jewish "survivors/refugees" had thus shifted to a much more loosely defined idea of Holocaust memory through the framework of Swedish-ness and with the addition of a "connection" to the Holocaust rather than individuals directly impacted by the Holocaust. This shift followed the greater process of institutional creation with plans for the Living History Forum moving towards a universalized and comparative perspective on the Holocaust. Yet, there were also more concrete steps in the decision-making process that contributed to this concurrent shift in the aims of the "documentation project".

In an attempt to further understand how the collection process should proceed, the first committee had appointed a special advisor to the "documentation project" in early 2000. The new special advisor-Swedish historian and current head of The Living History Forum, Ingrid Lomfors-had previously been in charge of the Nordic Museum's Jewish Memories collection. ${ }^{262}$ Prior to working with this collection, Lomfors had received her doctorate in history at Gothenburg University through a dissertation exploring the history and individual memories of the "child quota" - a subject close to her heart as she was the daughter of a "child quota" rescuee. ${ }^{263}$ As such, she was one of the only Swedish historical professionals to

LHF), Stig Ekman (historian, lead the extensive state-funded project on Sweden and the Second World War, SUAV), Henrik Bachner (historian, primarily focused on research relating to antiSemitism), Paul A Levine (Historian, co-authored Tell ye Your Children), Arne Ruth (journalist and opinion-maker, came to Sweden with the White Buses at the age of 1), Per Frånberg (intellectual historian), Mattias Tydén (historian), Lars M Andersson (historian), Ingrid Lomfors and Yvonne Hirdman (historian and gender historian, respectively). See Riksarkivet (RA), Kommittén för Levande Historia, vol. 14, "Dagordning för möte den 30 maj, 2001".

261 Riksarkivet (RA), Kommittén Forum för Levande Historia med projekt levande historia, vol. 14, "Minnesanteckningar från möte med Rådgivargruppen för Kommittén för Levande Historias Dokumentationsprojekt 2001-05-30," 1. [“Kommittén som var den ursprungliga uppdragsgivaren betonade att de minnen som samlas in bör skildra Förintelsen ur ett svenskt perspektiv och att de insamlade minnena bör ha en koppling till Förintelsen"].

262 Lomfors acted as Eva Fried's mentor, and also served as an advisor to the project. See Riksarkivet (RA), Kommittén Forum för Levande Historia med projekt levande historia, vol. 12 "Bilaga till avtal angående uppdrag som mentor".

263 Ingrid Lomfors, Förlorad barndom - àtervunnet liv: de judiska flyktingbarnen från Narityskland (Historiska institutionen, Univ., Diss. Göteborg: Univ., Göteborg, 1996). 
have dealt with survivors, in a personal, academic as well as a museal context. As special advisor to the committee and as a prominent Swedish expert on survivor memory, her opinion and subsequent advice thus carried much weight. In a plan presented by Lomfors to the project committee in the summer of 2000, Holocaust survivors were problematized as prospective interview subjects in several ways. ${ }^{264}$ Firstly, Lomfors asserted that Swedish survivors had been "offered and, to some extent, had requested to leave witness statements within the framework of a number of different projects" previous to the one planned by the Living History committee. 265 This, she added, had been a good experience for most of them while others felt "pressured and forced to tell their story. Sometimes against their will."266 She therefore suggested that approximately 50 out of 1000 Swedish Jewish survivors should be considered as interview subjects for the project. Beyond those 50 individuals, other Jewish groups should be considered such as Swedish Jews living in Sweden at the time of the Holocaust, Jewish refugee children, Jews saved from Norway, Jews saved from Denmark, second generation survivors and Jewish refugees/survivors leaving Sweden for another country. ${ }^{267}$ Included in the plan was also a motivation for the exclusion (bar these 50 individuals) of Jewish survivors from the project which asserted that,

The Jewish survivors' history must be regarded as most well documented, especially in relation to contemporary source material which has been left from the time around the Holocaust and which exists, first and foremost, in foreign archives. In addition, there are over 50,000 video-taped Jewish witness accounts from the Holocaust. A new Swedish collection of Jewish memories should aim for as many different personal experiences as possible. At the same time, and taking the future forum's profile into account, it is crucial that [the collection] takes as its point of departure, Swedish history and Swedish perspectives. A specifically

264 See Riksarkivet (RA), Kommittén Forum för Levande Historia med projekt levande historia, vol.

12, "Plan för insamling av intervjuer med överlevanden från Förintelsen" vol. 12 projekt.

265 See Riksarkivet (RA), Kommittén Forum för Levande Historia med projekt levande historia, vol.

12, "Plan för insamling av intervjuer med överlevanden från Förintelsen," 4.

266 See Riksarkivet (RA), Kommittén Forum för Levande Historia med projekt levande historia, vol.

12, "Plan för insamling av intervjuer med överlevanden från Förintelsen," 4.

267 See Riksarkivet (RA), Kommittén Forum för Levande Historia med projekt levande historia, vol.

12, "Plan för insamling av intervjuer med överlevanden från Förintelsen," 5. 
Swedish approach would distinguish the new interviews from those already collected, and at the same time give legitimacy to the forum and its future 'visitors'. ${ }^{268}$

Beginning with the first sentence of this quote, it needs to be understood in relation to how the Nordic Museum's collection of Jewish Memories was legitimized when it was first presented to the public in 1996. In Judiska Minnen: Berättelser frän Förintelsen - a book which summarized the collection-Lomfors argued that the Jewish Holocaust survivors who came to Sweden in 1945 were greeted by a "compact silence", a silence which persisted in the decades after liberation. 269 "The surviving Jews were a silent generation" she maintained, "not only in Sweden, but all over the world". ${ }^{270}$ Even though the Nordic Museum, was "an institution with a mission to collect and preserve the history of 'all people in Sweden"'271, the framing of Jewish memories through a greater Holocaust narrative demonstrates that Jewish life in Sweden was deemed interesting to Swedes, in large part, because it related to the Holocaust. Thus, 'silence' as an imperative to listen to Jewish stories in general was used as an argument to legitimize not only the collection of memories from the Holocaust, but the collection of stories from the Swedish Jewish minority at large. ${ }^{272}$

268 See Riksarkivet (RA), Kommittén Forum för Levande Historia med projekt levande historia, vol.

12, "Plan för insamling av intervjuer med överlevanden från Förintelsen," 6. ["De judiska överlevandes historia måste betraktas som ytterst väldokumenterad, i synnerhet i relation till samtida källmaterial som har efterlämnats från tiden kring andra världskriget och som finns i främst utländska arkiv. Dessutom finns över 50000 videofilmade judiska vittnesmål från Förintelsen. En svensk ny insamling av judiska minnen bör ta sikte på så många olika personliga erfarenheter som möjligt. Samtidigt, och med hänsyn till det kommande forumets profil, är det angeläget att utgå ifrån svensk historia och svenska perspektiv. Ett specifikt svenskt förhållningssätt skulle särskilja de nya intervjuerna från de som redan insamlats, och på samma gång ge legitimitet för forumet och dess framtida 'besökare"'].

269 Ingrid Lomfors, "Inledning", in ed. Britta Johansson, Judiska minnen. Berättelser från Förintelsen, (Stockholm: Nordiska Museet, 2000): 8. See also Malin Thor Tureby's discussion on the 'thesis of silence' in Sweden in "Svenska änglar och hyenor möter tacksamma flyktingar. Mottagningen av befriade koncentrationslägerfångar i skånsk press under året 1945," Historisk Tidsskrift, 135, no. 2 (2015): 266-300.

270 Lomfors quoted in Thor Tureby, "Svenska änglar och hyenor möter tacksamma flyktingar," 282 ["De överlevande judarna blev en tyst generation, inte bara i Sverige utan i hela världen"].

271 Malin Thor Tureby, "To Hear with the Collection: The Contextualisation and Recontextualisation of Archived Interviews," Oral History 41, no. 2 (Autumn 2013): 13.

272 See Thor Tureby, "To Hear with the Collection: The Contextualisation and Recontextualisation of Archived Interviews," Oral History 41, no. 2 (Autumn 2013): 63-74. 
Lomfors's assertion in the plan that the Jewish survivors' history was "welldocumented" a mere four years after she contended that they had been "a silent generation" thus appears contradictory at best. It also demonstrates the salience of Levine's argument that many key contributors to the Living History project, and later, the Living History Forum, suffered from an early onset of 'Holocaust fatigue'; questioning the validity of focusing on the Holocaust when it had already received 'so much attention'. ${ }^{273}$ However, in the quote above, Lomfors also referred to "different personal experiences", a classification which, in the plan, denotes other victim experiences. These groups included those who fled to Sweden from Norway and Denmark as well as Jewish children who arrived as refugees before the war began. Even though these individuals survived the Holocaust they are not referred to as "överlevande" (survivors) in the plan-a term which was exclusively used to describe camp survivors. It is thus camp survivors specifically that are being problematized here. According to Lomfors' plan, the history of camp survival was already well-documented even though this particular group purportedly spent most of their lives in silence. Also, their history was not considered "Swedish" enough to have them be included into the new "Documentation Project".

These concerns, first presented in Lomfors plan, continued to influence the "Documentation Project" through contacts between Fried and Lomfors. In her notes from their first official meeting in September 2000, Fried wrote that Lomfors "is very hesitant as to the propriety of going out with an open call to survivors who want to be interviewed. She thinks this would border on 'exploitation' of this group to, for the third time, direct such a call at them." 274 Here, concern for the wellbeing of camp survivors was reiterated by Lomfors who pointed to the fact that many of Sweden's camp survivors had already been interviewed within the frameworks of the Shoah Foundation's Visual History Archives as well as the Nordic Museum's Jewish Memories. However, Fried also noted that Lomfors had identified a great risk in that "many who have already been interviewed would want to be interviewed again in order to adjust their stories for different reasons (have remembered different facts, want to change details etc)."275 This need for certain survivors

273 Paul Levine, "Whither Holocaust Studies in Sweden? Some Thoughts on Levande historia and Other Matters Swedish," Holocaust Studies: A Journal of Culture and History, vol. 11, no. 1 (2005): 95.

274 Riksarkivet (RA), Kommittén Forum för Levande Historia med projekt levande historia, vol. 12,

"Minnesanteckningar från träff med Ingrid Lomfors den 13 September 2000".

275 Riksarkivet (RA), Kommittén Forum för Levande Historia med projekt levande historia, vol. 12, "Minnesanteckningar från träff med Ingrid Lomfors den 13 september, 2000". 
to tell and re-tell their story was thus framed as something that government institutions of remembrance should not encourage. Instead Fried continued, "it is more appropriate to make it so that one gets the interviews one wants, unless a survivor who has not yet been included into an archive wants to be interviewed, in which case this should be arranged." 276

In these notes, the epistemological perspective on survivors as "informants" was articulated, demonstrating a desire to extract 'important' information from the interview subjects in order to cover as much historical ground as possible. Although concern was also expressed for the well-being of camp survivors and their willingness and ability to speak of their Holocaust experiences, limits were put around those who wished to speak beyond the framework of one archival project. Survivor silence was thus first framed as a problem by the OCJC, as well as by Lomfors in conjunction with Jewish Memories, while it was later deemed necessary, both for the continued health of the camp survivors as well as for the aims and ambitions of the Living History 'memory' archive.

Another argument of silence which was used to shift the focus of the archive was that of the "Swedish perspective"; an elusive term which was first explained in a government memo issued by the department of culture in February 2001. The memo, which explicated the official plan for the "documentation project," stated that "the central purpose of gathering witness accounts in Sweden, despite the fact that there are many collections of witness accounts in other countries, is to give the user of the Forum an opportunity to access a material which complements other forms of acquiring knowledge" and that "witness accounts from different groups in Sweden from the time of the Holocaust are meant to complement other interview-based collections through the Swedish perspective."277

The Swedish perspective was positioned as a complementary feature to the wealth of testimonial documentation on the Holocaust that already existed in other

276 Riksarkivet (RA), Kommittén Forum för Levande Historia med projekt levande historia, vol. 12, "Minnesanteckningar från träff med Ingrid Lomfors den 13 september, 2000".

277 Riksarkivet (RA), Kommittén för levande historia, vol. 12, "Planering av dokumentationsprojektet år 2001 för forum för levande historia," 1. ["Det centrala syftet med att samla vittnesmål i Sverige, trots att det finns många vittnesmål insamlade i andra länder, är att ge brukaren av Forum en möjlighet att få tillgång till ett material som kompletterar annat kunskapsinhämtande genom traditionell faktainlärning." "Vittnesmål från olika grupper i Sverige från tiden för Förintelsen syftar till att komplettera andra intervjusamlingar genom det svenska perspektivet']. 
countries. Lomfors's recommendation regarding the inclusion of Jewish camp survivors had been observed, a decision demonstrated by the statement that

Jewish persons who have survived concentration camps should, in so far as these persons contact the project, be interviewed. This should partly be done in respect for the survivor, and partly because these interviews could complement the already existing material from this group. Apart from this, it is not a prioritized group. $^{278}$

Jewish camp survivors were not to be contacted for interviews and were thus largely excluded from the "Documentation Project". Instead, the focus was the "Swedish perspective"; a perspective that centered on the Swedish societal "zeitgeist" during the war. "What was it like to live in Sweden during the war years?", "How was it to be a normal person, one who does not engage?" "Could one "turn off the war and knowledge about the Holocaust?" were some of the questions posed to capture particularly 'Swedish' experiences. According to the memo, the purpose of applying the "Swedish perspective" to a new collection of Holocaust memories was to "minimize people's feeling that what happened during the $30 \mathrm{~s}$ and 40s was something that happened in another part of the world, in another cultural sphere and that this could not have happened in Sweden". 279 'Swedishness' and Swedish experience was thus framed as phenomena that excluded the Jewish (camp) survivor experience, the latter perceived to have already been captured in foreign archives. The Swedish perspective also included a bystanderist view on immigration through questions that focused on the normal Swede's perception of immigration rather than on the migrant experience itself. ${ }^{280}$ This principle of selection was not merely based on the recommendation of Lomfors, but was also

278 Riksarkivet (RA), Kommittén för levande historia, vol. 12, "Planering av dokumentationsprojektet år 2001 för forum för levande historia," 6. ["Judiska personer som överlevt koncentrationsläger bör i den mån som någon av dessa personer söker upp projektet och så önskar bli intervjuad. Dels bör man göra det av respekt för den överlevande, dels bör man göra det för att dessa nya intervjuer kan komplettera det befintliga intervjumaterialet från denna grupp. I övrigt är det inte en prioriterad kategori'].

279 Riksarkivet (RA), Kommittén för levande historia, vol. 12, "Planering av dokumentationsprojektet år 2001 för forum för levande historia," 4 [“Att få in det svenska perspektivet kan sammanfattningsvis bidra till att minimera människors känsla av att det som hände under 30- och 40-talen var något som hände i en annan del av världen, i en annan kultursfär och att detta inte skulle kunna hända här i Sverige"].

280 Riksarkivet (RA), Kommittén för levande historia, vol. 12, "Planering av dokumentationsprojektet år 2001 för forum för levande historia," 4. 
reinforced by the whole advisory board, largely comprised of Swedish historians whose research covered subjects such as anti-Semitism and Nazism as well sterilization and migration policy; all with a focus on Swedish perpetration, bystanderism and/or heroism. ${ }^{281}$ In short, all those who advised the project were already researching questions pertaining to Swedish guilt, a field that had been shaped by the 'moral' turn of Swedish historiography in the early 1990s.

What can also be gleaned from the official documents regarding the "Documentation Project", are concerns regarding utility. In the initial plan for the whole project, the main questions raised regarding the future archive's profile was "what material will be valuable in 50 to 100 years?" The choice of words here-particularly the use of "valuable" (värdefullt) — indicates that utility was one of the leading principles underpinning the project. It is not enough that the archival material might be interesting to future generations, they have to be able to use it for something, or rather, learn something useful. From a national perspective, the lessons Swedes should learn from this archive was how to respond to catastrophe. This aim was also related to the notion of representativity —an issue also raised in discussions with the advisory board. ${ }^{282}$ The fact that there were Swedes with Holocaust victim experience was neither deemed useful nor representative as most Swedes stood by silently as the Holocaust was progressing. However, the minority population who acted on behalf of victims and survivors during the Holocaust remained important to the archival ambition, as it was seen to highlight the Swedish perspective, representative or not. Representativity was thus only of importance in discussions concerning victimization.

281 See for example, Mattias Tydén, Svensk antisemitism 1880-1930, (Uppsala: Reprocentralen, 1986). Mattias Tydén och Gunnar Broberg, Oönskade i folkhemmet: Rashygien och sterilisering $i$ Sverige, (Stockholm: Gidlund, 1991). Mattias Tydén och Ingvar Svanberg, Sverige och Förintelsen: Debatt och dokument om Europas judar 1933-1945, (Stockholm: Arena, 1997). Mattias Tydén, Från politik till praktik: de svenska steriliseringslagarna 1954-1975. Rapport till 1997 års steriliseringsutredning, (Stockholm: Statens Offentliga Utredningar, 2000). Henrik Bachner, Aterkomsten: Antisemitism $i$ Sverige efter 1945, (Stockholm: Natur och Kultur, 1999). - Judefragan: debatt om antisemitism i 1930talets Sverige, (Stockholm: Atlantis, 2009). Lars M Andersson, En jude är en jude är en jude: Representationer av "juden" i svensk skämtpress omkring 1900-1930, (Doctoral diss.: Lund University, 2000). Paul A. Levine, From Indifference to Activism (Doctoral diss.: Acta Universitatis Upsaliensis, 1996). Lööw, Nazismen i Sverige, 1980-1999. As previously mentioned Stig Ekman headed the extensive research project SUAV in the 1960s and the 1970s.

282 Riksarkivet (RA), Kommittén Forum för Levande Historia med projekt levande historia, vol. 17,

"Minnesanteckningar från möte med rådgivargruppen för Kommittén för levande historias Dokumentationsprojekt, 2001-05-30”. 
This is also where the crux of this whole dissertation emanates: why are narratives of Holocaust victimization-especially coming from the perspective of those victimized — not perceived as a significant part of national histories concerning Sweden and the Holocaust? It is true that those camp survivors who came to Sweden, were, at one stage "foreign elements" although some stayed and became Swedish citizens. ${ }^{283}$ Therefore, their histories could be considered as Swedish as a that of a rescue worker or that of Raoul Wallenberg. The central problem here is not the "documentation project's" focus on Sweden, but rather how the project defined 'Swedish-ness' in relation to notions of Holocaust experience. The exclusion of Jewish camp survivors was defended and explained by the principle of complementarity. However, this principle was, at an early stage of the collection process, impossible to adhere to as talks with the Shoah Foundation fell through on account of the high cost of transferring the 330 interviews they had conducted in Sweden to the Living History Forum. ${ }^{284}$ Indeed, in the final stages of the documentation project, Fried expressed a concern that no deal had been made with the Shoah foundation yet since the whole premise of the archival selection was based on the idea that there was a prolific international and national archive of Holocaust memory that could be accessed by the new institution. 285 In addition, as the Living History Forum was to become an official government agency, all documents handled by them needed to be open for public scrutiny, meaning that the largely protected material collected within the Jewish Memories project could not be placed at the disposal of the Forum's "Memory Archive" either. ${ }^{286}$ Suddenly, the abundance of Jewish camp survivor testimonies did not appear as bountiful as previously assumed.

Given the insistence from a cadre of professional historians that the so-called Swedish perspective was marginalized and needed to be explored further, it seems that assumptions underpinning the "documentation project" also reflected greater

283 "Foreign elements" is a term used by the Swedish historian Karin Kvist Geverts, see Karin Kvist

Geverts, Ett Främmande Element i Nationen: Svensk Flyktingpolitik och de Judiska Flyktingarna (Uppsala: Acta Universitatis Upsaliensis, 2008).

284 The "documentation project" did, however, request to review the Shoah Foundation's interview methodologies but did not actually use any of the questionnaires in their own interviews. Riksarkivet (RA), Kommittén Forum för Levande Historia med projekt levande historia, vol. 12, Mail correspondence between Eva Fried and the Shoah Foundation's attorney, Rita Marseille.

285Riksarkivet (RA), Kommittén Forum för Levande Historia med projekt levande historia, vol. 13

"Ang. eventuell fortsättning av dokumentationsprojektet".

286 Riksarkivet (RA), Kommittén Forum för Levande Historia med projekt levande historia, vol. 13 "Insamling av material med anknytning till Förintelsen". 
discursive trends surrounding Holocaust memory and those who survived the Holocaust (Jewish camp survivors in particular); a connection which leads to the second problem: why was Jewish camp survivor history assumed to be "well-documented" when there was a wide consensus that survivors remained silent for most of the twentieth century? There was obviously documentation other than that of survivor testimony which had been collected in countries where the camps were located. The Southern Swedish museum Kulturen in Lund had, for example, received objects and testimonies from the Ravensbrück camp which were used, from 2004 onwards in different displays about the women rescued by the white buses from that particular camp. ${ }^{287}$ One could also argue, as Lomfors did, that Jewish Memories had fully captured the Jewish camp survivor's experience, making it well documented in a Swedish project. The main issue with this line of argumentation is that it does not take into account the inaccessibility of Jewish Memories as well as the fact that this collection was very much constructed as a separate Jewish (here meaning non-Swedish) project at the Nordic Museum. ${ }^{288}$ As Thor Tureby demonstrates, the collectors involved in Jewish Memories, although having the best intentions, created a collection in which 'Swedish-born Jews' were "(re)constructed as non-Swedish" and all Jewish narratives were, in some way, framed by the Holocaust and the Second World War. ${ }^{289}$ As such, the Jewish survivor experience was both connected to Swedish Jews as non-Swedes as well as to a collective survivor identity that was, at the same time, excluded from a Swedish identity. Because of this construction, the Jewish survivor experience became inextricably linked to the Swedish-Jewish minority and to other Jewish survivor groups in other countries, making the Jewish (and Swedish) camp survivor an 'other' in Swedish history. While Thor Tureby problematizes this relationship by highlighting how discourses on the Holocaust led to the reconstruction of the Swedish-Jewish minority as particularly Jewish, I would like to emphasize the ways in which their interrelation also contributed to the construction of the Jewish survivor as non-Swedish-a construction which was reinforced when the Jewish (camp) survivor was excluded from Living History's archive. Thus, the problem did not reside in the archivers' focus on Sweden as a geographical construct, but rather in their insistence that Jewish camp survivors and their narratives were not part of the Swedish perspective.

287 Katrine Tinning, "To Survive Ravensbrück: Considerations on Museum Pedagogy and the Passing on of Holocaust Remembrance," Museum and Society 14, no. 2 (2016): 338-353. 288 Thor Tureby, "Hearing with the collection," 71. 289 Thor Tureby, "Hearing with the collection," 71. 


\section{5 Conclusions: Presenting the Problem-complex}

Beyond reflecting archival choices, the creation of another Swedish Holocaust "Memory Archive" between 1999 and 2003 actualized several contemporary questions about Holocaust survivors in Sweden - who were they and what could they contribute to society? And above all, the archivalization process demonstrated an ambivalence with regards to the treatment of, and space afforded to, Jewish camp survivors in particular-were they silent and forgotten, or too eager to talk and revise their stories, exploited and over-exposed? As Dean points out in Aversion and Erasure, during the 1990s and the 2000s "Jewish claims to have suffered [were] not denied but often deemed excessive". In the same way, the political climate of the 1990s in Sweden was characterized by a palpable fear of neo-Nazis and rightwing extremism while questions regarding the 'proper' representation of the Holocaust, at the same time, permeated cultural discourse. The "anxiet[ies] of transmission" which underpinned arguments of utility—how Swedes could best learn from the Holocaust - were also continuously proffered by political challenges from liberals and conservatives who questioned the relevance of the Holocaust for Swedish history and memory.

Archival practices that make informants out of survivors attempt to do so in response to arguments of utility, which are imposed upon, as well as reinforced by, Holocaust survivors. Both this utility approach and the psychiatric care shown for survivors have been informed and shaped by a long history of people's "affective relationship" to survivors as victims. Discourses on Jewish victimization, especially when invoked by Holocaust survivors, have aroused a variety of responses ranging from the emotional and physical identification w Benjamin Wilkomirski to Norman Finkelstein's infamous thesis on the "Holocaust industry"; an industry within which survivors constitute mere pawns in an economic game set to 'sell' the Holocaust to willing consumers. Referring to examples from American and French intellectual discourse, Dean contends that critics of a Jewish 'victim culture' create a clear distinction between history and memory by arguing that historical experience has been distorted by trauma. For example, in their book Vichy: An everpresent Past, published in 1998, Éric Conan and Henry Rousso argue that most Jews believe that anti-Semitism is on the rise even when surveys and studies show the opposite. This, the authors explain, is due to the fact that "everyone wants his own genocide' including Jews who did not live through the Holocaust." The traumatic distortion of historical experience has, in line with this argument, led to an over-indulgent relationship between Jewish communities/society at large and Holocaust narratives of Jewish victimization, creating an untenable situation where 
"victimization now trumps heroism in conferring identity and prestige". These critics want to separate real victimization (historical experience) from exaggerated or false victim narratives (memory practices), thereby creating a more 'sober' view on the history of identity. As Dean explains, they "presume that the experience of Jews during the Holocaust can be stripped of its iconic status and returned to history' as a means of preserving what happened undistorted by memory, both public and private". Similarly, the exclusion of those camp survivors who had "already been heard" or who might have wanted to change their story in the national record also demonstrates how "over and over, the presumptive cultural demands of false victims...trump any inquiry into how some victims are deemed more credible than others since we are presumed to know that 'real' survivors would by definition be reluctant to seek attention." In this case those excluded were portrayed as false victims insofar as their testimony (if changed) could no longer be trusted. Their victimization was thus perceived to be undermined if they tried to be included over and over again in different testimonial collections.

After this close and detailed analysis of one national effort to remember the Holocaust, it is perhaps necessary to reiterate that the aim of this dissertation is not to answer the specific questions posed above regarding Living History's archival choices. Rather, the purpose of the analysis of a single archivalization process is to elucidate two distinct conceptual relationships which seem to have been crucial in constructions of the Holocaust survivor in Swedish public discourse during the 'memory boom' of the 1990s: that between silence and excess as well as that between 'Swedish-ness' and Jewish Holocaust survivor-hood. Underpinning these conceptual relationships is the problematization of utility. The central question of the coming analyses is therefore: How did the conceptual relationship between silence and excess and 'Swedish-ness' and Jewish Holocaust survivor-hood manifest themselves in Swedish media discourse during the 1940s, 50s and 60s? In order to answer this question, the coming chapters will focus on different points in Swedish history when the Holocaust survivor became a central figure in Swedish media discourse. Because Jewish victim narratives were perceived as un-Swedish in the creation of a "Memory Archive", all chapters include analyses of how notions of Jewish victimization have informed constructions of the survivor. Also, because the survivor has developed into a figure of utility — someone who helps society prevent further catastrophe-the survivor as witness will also be studied throughout. And finally, survival itself — whether active or passive, redemptive or superfluous - will also be analyzed in relation to constructions of the Holocaust survivor. 
Chapter 2 


\section{Chapter 3 - Victimization, Witnessing and Survival: An Origin Story, 1943-1945}

\subsection{Introduction}

Tracing the conceptual relationships identified in the analysis of the "Memory Archive" required some form of beginning. As explicated in the introduction, this beginning can be understood through the term descent. Carlos Prado asserts that "the analysis of descent is incomplete without the complementary analysis of emergence (Enstehung) in the complex sense of both initial appearance and achieved dominance" of certain discourses. The descent/emergence complex is, therefore, not merely concerned with the initial appearance of certain ways of thinking and acting, but also with how this thinking and acting establishes itself; how discourses continue to shape and define what is. In practical methodological terms, however, one needs to begin somewhere. The descent of conceptual phenomena, although elusive, will thus be the focus of this chapter, while the emergence-the "achieved dominance" of discourses surrounding Holocaust victimization, witnessing and survival in relation to silence and excess-will be developed in the following chapters which primarily interrogate the disciplinary discourse of culture critique.

The concepts of Holocaust victimization, witnessing and survival are intrinsically linked to one another. Research on this interrelation has commonly been conducted in reference to periods of assumed significance for each national context with certain events being deemed universally important to Western memory culture surrounding the Holocaust. However, as has been demonstrated by Levy and Sznaider, among others, Holocaust memory is not necessarily tied to national, territorial boundaries, but moves and influences across borders in a multitude of ways. ${ }^{290}$ The same is true for media discourse, where transnational (as well as transmedial) perspectives tend to be overlooked in favor of close analyses of national contexts. ${ }^{291}$ Certainly, many of the most influential symbols of the Holocaust travelled between national contexts and between different media

290 Daniel Levy \& Natan Sznaider, The Holocaust and Memory in the Global Age, (Philadelphia: Temple UP, cop., 2006).

291 See Marie Cronqvist \& Christoph Hilgert, "Entangled media histories" Media History, vol. 23, no. 1, (2017): 130-141. 
forms - the Anne Frank phenomenon moved from Holland via the United States to Sweden, and the mediation of the Eichmann trial and Nelly Sachs were heavily influenced by the German post-war context of remembrance. Yet, the discourses that surround these signifiers of the Holocaust still manifested themselves in specific national, regional and local contexts and were, therefore, also shaped by particularities that can only be identified if one focuses on the case study itself.

This point becomes even more salient when considering the relationship between the classification and the classified. Since ideas about Holocaust victimization, witnessing and survival formed around actual people-witnesses in trials, camp survivors being interviewed in the press and fleeing refugees depicted on film or in magazines - the location and identity of those individuals mattered in the formation of these three concepts. The classified thus impacted the ways in which classifications such as the "True Victim" and the "moral witness" could form. As Dean explains, "the definition of who is and is not a moral witness varies from one location to another and is always linked to cultural projections that may have a tenuous relationship to real victims". 292 The classification of the "moral witness" will be studied in relation to discourses on witnessing in this chapter. Following Dean's definition of the "moral witness" as a figure that "represented the authority of the victim's experience", I examine the victim's position as witness to the suffering of him/herself as well as a witness to the suffering of others. Here, the notion of "true victimhood" also plays a crucial part. Alyson M. Cole's conceptualization of the "True Victim" also inspired the analysis in this chapter.

In attempting to locate the descent of the Holocaust survivor-as a "True Victim" and as a "moral witness" in a Swedish context, I thus searched for contexts in which the concepts of victimization, witnessing and survival could potentially have formed. The most obvious contexts in which the concept of Holocaust witnessing could form were the war crimes trials held in the direct aftermath of the war. Conceptual beginnings for Holocaust victimization and victimhood, on the other hand, depended heavily on how and when the Holocaust was understood in the context of the Nazi's concerted effort to exterminate the Jews; as something beyond the confines of the war itself. And finally, survival was hypothesized to be connected to discourses on flight and rescue. In practice, this meant scrutinizing the points at which the Holocaust was problematized in Swedish news discourse: 1) November 1942, when the Norwegian Jews were deported east; 2) October

292 Carolyn J Dean, The Moral Witness: Trials and Genocide after Genocide, Ithaca; London: Cornell University Press, 2019, 5. 
1943, when the Danish Jews fled to Sweden; 3) the spring and summer of 1945 when the "White Buses" mission and the United Nations Relief and Rehabilitation Association (UNRRA) rescued individuals from German concentration camps; 4) September-November 1945 when survivor-witnesses took the stand to testify against Josef Kramer and 44 others at the Belsen trial. In studying these potential points of conceptual descent, I endeavor to understand how the Holocaust survivor was first constructed in relation to the concepts of victimization, witnessing and survival. By analyzing newspaper articles, as well as film and radio programs, I also attempt to highlight the ways in which different media forms contributed to the descent of the Holocaust survivor. The distinction between witnessing through, by and in the media was therefore applied to the analysis in order to grasp how the press, films and radio programs contributed to the formation of a survivor object.

In this chapter, I thus attempt to answer the following questions: How were

the fleeing Danish Jews represented in the Swedish Stockholm-based press? What camp survival experience was represented and portrayed in the Swedish press, in news reels and in radio programs in the spring and summer of 1945? How were the camp survivors who testified at the Belsen trial made visible in the Swedish press in the autumn of 1945? And finally, how did these representations contribute to the conceptualization of Holocaust victimization, witnessing and survival in Swedish media discourse?

\subsection{Methods and Sources}

Although specified in each empirical chapter, discussing the method and sources for the descent of the Holocaust survivor seems particularly important as this analysis differs from the analysis of disciplinary discourse in the coming chapters. While the periods of significance for chapters four, five and six were established by following statements and events that contributed to the disciplining of different survivor types (a process that depended heavily on clues from the digital newspaper archive), the periods of significance that this chapter deals with instead concerned the very first constructions of these types. These conceptual beginnings were thus located through digital archival searches as well as through the examination of previous research on Swedish refugee policy before and during the war, research on Swedish Holocaust consciousness and research on Swedish rescue missions at the end of the war. The research process underpinning this chapter was, therefore, much different from the other empirical chapters of this dissertation in that it required a constant movement between previous research and archival sources; a 
process which entailed the scrutiny of sources already appearing in scholarly work on Sweden and the Second World War, as well as adding new evidentiary pieces to the puzzle.

As discussed in chapter one, the search words used to find representations of the Holocaust survivor only served as the first step in my research process. Locating discourses on Holocaust victimization, witnessing and survival had little to do with the nominalism of "survivor" ("överlevande") as this term was not always used to refer to Holocaust survival in the early post-war years. Similarly, the term "Holocaust" ("Förintelsen") had not yet come into wide use which meant that other terms needed to be identified in order to locate newspaper articles about Nazi persecution. ${ }^{293}$ The most common search words used were therefore: "utrotningskrig" (extermination war), "utrotning" (extermination), "utrota" (exterminate) "deporterades" (deported), "slavarbete" (slave labor), "Gaskammare(n)/gaskammrarna" (Gas chamber) "krigsindustrin" (the war industry), "jude/judar/judarna(s)" (Jew), "Zigenare” (Roma), "Tattare" (travellers) "arisk" (Aryan) and "Flykting/flyktingar" (Refugees). The search words did not merely yield expected results but also produced findings which led to further inquiries into a person, a geographical location or a specific date. The word 'deported' (specifically in the past tense) was used to search for instances where the press acknowledged and/or highlighted that large groups of people were being displaced for specific reasons (even if these reasons were not always clear in the articles). This is also how I began to search using phrases like 'slave labor' and 'the war industry', the former being a more honest rendition of goings-on while the latter was used to find descriptions of the camps and their 'purpose' which used a more euphemistic language. Finally, and perhaps most importantly, 'refugees' was used to search for descriptions of those who had escaped Nazi persecution to different countries, although most of what was found related to refugees trying to get to, or who were already residing in, Sweden. Of course, the words were also

293 In the material pertaining to the rescue missions launched in the spring and summer of 1945 as well as in relation to the Belsen trial in the autumn that same year one can find references to the word "Förintelse" as a way to describe the act of annihilation. The definite article of the Holocaust ("Förintelsen"), however, cannot be found in the newspaper material studied for the research presented in this chapter. It has been postulated, as it has in many other national contexts, that the term Förintelsen (definitive article) became widespread and commonly used after the TVseries Holocaust aired on Swedish television in 1979. However, no research conducted on the period before 1979, specifically focusing on the language used to describe the Holocaust in Sweden, has been conducted which is why it is difficult to conclude whether or not Holocaust served as a turning point in the language used to denote the Holocaust in Sweden. 
used together with different victim categories such as 'Jews', 'Roma' (although searching the term 'Zigenare' which was commonly used to refer to the Roma at the time) 'Travellers' ("Tattare" and "Zigenare" were often conflated and therefore came to refer to individuals from both groups). The search term 'Aryan' was used on the basis that the Nazi's exterminatory policies could be found through studies of the construction of the norm. Following Foucault's example in studying madness through practices of health, I attempted to study the construction of Jews, Roma, HBTQ persons and the disabled by searching for articles referring to individuals as "Aryan".

Searches in the digital newspaper archives demonstrated that few articles were written about victim groups other than the Jews before 1945. Descriptions of the persecution of LGBTQ persons were rare as homosexuality was a criminal offense in Sweden up until 1944, at which point it was instead medicalized and made into a psychiatric diagnosis. It is, therefore, highly unlikely that individuals from this group would have wanted their fates described in the Swedish press and the newspapers would not have considered their victim stories as noteworthy or important as those of other persecuted groups. This is also true for LGBTQ persons' testimonies in the decades after the war. As Klaus Müller writes in his seminal work The Men with the Pink Triangle, "ours is an empty memory. We have few names, and fewer faces: not more than fifteen gay Holocaust survivors have spoken of their experiences, and many of them have asked for anonymity". 294 Regarding the Roma, some concern was expressed with regards to their fate on behalf of the Swedish press. In February 1940 a handful of newspapers reported that Czech "gypsies" would be sent to a "colony" in Slovakia where some would be used as farmhands while others were going to be sent to labor camps. ${ }^{295}$ Moreover, the question of the Czech Roma was discussed in the Swedish press already in 1938 when Germany occupied the Sudetenland. In an article in DN, published in December 1938, the author described the horrendous conditions of those "gypsies" whom no country wanted to care for. In the article it is described

294 Kai Hammerstein, "Inventing History”, p. 19.

295 "Liten intervju," February 8, 1940, DN, 8. "Tjeckiens romer får ej längre vara nomader," February 7, 1940, SvD. "Arbetsläger hotar zigenarna," February 6, 1940, Aftonbladet, 9. "Protektoratets zigenare skola bli bofasta," February 7, 1940, Provinstidningen Dalsland, 6. See also Svanberg and Tydén's discussion on the Roma in the Swedish press before and during the war. Ingvar Svanberg and Mattias Tydén, Sverige och Förintelsen: Debatt och dokumentation om Europas judar, 1933-1945 (Stockholm: Dialogos, 1997), 351-353. 
that the thousands of Roma that resided in Czechoslovakia were now stuck in the borderlands between Slovakia and Hungary, a desperate, miserable bunch, whose fate was yet unknown. However, as these individuals were never given refugee status and were hindered from entering Sweden even in the years following the war, descriptions of Roma individuals in relation to notions of Holocaust survival and victimization were not found in the digital newspaper archive.

As previously noted, there are no scholars in Sweden who singularly focus on the Holocaust. Most who have researched the Holocaust in relation to Sweden have done so from a migrant or a rescue perspective, defining those who survived the Nazi's genocidal policies and the camps as "refugees", "guests of the Swedish state", "the rescued of 1945" and, in some cases, as "survivors". 296 This scholarly treatment of the first representations of camp survivors has thus primarily focused on how they were constructed as refugees. The Swedish historians Malin Thor Tureby and Mikael Byström, Ulf Zander and the Finnish historian Antero Holmila have contributed the most in-depth insights into these representations of survivorrefugees. In Byström's doctoral dissertation from 2006, he argues that constructions of the refugee in Swedish public debates depended heavily on what he terms "the Nordic Prerogative". 297 The period studied by Byström begins in 1942, a choice partly motivated by prior arguments that Swedish refugee policy shifted during this year as a result of the deportation of the Norwegian Jews. ${ }^{298}$ In attempting to locate representations of Holocaust victimization, witnessing and survival I wanted to explore whether this year was, in fact, crucial for the construction of the Holocaust survivor which is why I began to search the digital newspaper archive for news articles relating to this event in November 1942. By studying both newspaper material as well as parliamentary debates Byström also concludes that the fleeing Danish Jews were constructed as "problematic" refugees;

296 Svante Hansson, Flykt och överlevnad: flyktingverksamhet i mosaiska församlingen i Stockholm, 1933-1950, (Stockholm: Hillelförlaget, 2004.). Pontus Rudberg, The Swedish Jews and the Victims of Nazi Terror, 1933-1945, (Uppsala: Studia Historica Upsaliensia, 2015). Steven Koblik, The Stones Cry Out: Sweden's Response to the Persecution of Jews 1933-1945, (New York: Holocaust Library cop., 1988). Paul A. Levine, From Indifference to Activism (Doctoral diss.: Acta Universitatis Upsaliensis, 1996). Mikeal Byström \& Pär Frohnert, Reaching a State of Hope-Refugees, Immigrants and the Swedish Welfare State, 1930-2000, (Stockholm: Nordic Academic Press, 2013). Mikael Byström, En broder, gäst och parasit: Uppfattningar och föreställningar om utlänningar, flyktingar och flyktingpolitik $i$ svensk offentlig debatt 1942-1947 (Stockholm: Almqvist and Wiksell, 2006). Ingvar Svanberg and Mattias Tydén, Sverige och Förintelsen.

297 Byström, En broder, gäst och parasit, 266.

298 Byström, En broder, gäst och parasit, 15. 
another contention that I wished to examine. ${ }^{299}$ Since Byström makes use of newspaper cuttings from the Swedish Ministry of Foreign Affairs' (Utrikesdepartementet, UD) archive-a rich yet redacted collection of sources-I deemed it important to investigate whether the digital newspaper archive could contribute further articles that could complicate this image. In relation to those rescued in 1945, Malin Thor Tureby has contributed the most detailed insights into how the camp survivors were represented in the local as well as the Swedish-Jewish press. In contrast to Byström, Thor Tureby has chosen to study a smaller amount of newspapers and periodicals in order to create her own collection of news articles. Through these studies she, among other things, concludes that gender was an important signifier in reports of those rescued by both the "White Buses" mission as well as the UNRRA mission. These conclusions, together with the fact that more women arrived with the rescue missions of 1945 compared to men, made me acutely aware of the need to pay attention to the ways in which the press, the radio and film represented female and male camp survivors. This did not affect my searches in the digital newspaper archive and the audio-visual archive, yet it impacted my analysis insofar as it heightened my awareness regarding this classification. Similarly, my study was also impacted by Holmila's research on representations of the Holocaust in the Swedish press during my chosen period. However, Holmila's as well as Byström's research tends to overlook the importance of news structure as well as the different media that affected conceptions related to the Holocaust in the direct aftermath of the war. As Thor Tureby contends in her article on the Southern Swedish press, the wide use of press cuttings has affected the ways in which news discourse has been understood as the position of the article-whether it was a small press item on page 18 or a huge headline on the front page-is often overlooked. ${ }^{300}$

The conclusions that previous research has drawn with regards to public representations of the Holocaust thus guided my searches in the digital archive in terms of which particular time periods to focus on. Not surprisingly, constructing a 'beginning' to the concepts of Holocaust victimization, witnessing and survival heavily depended on when the Holocaust was shown to be, or believed to be, a

299 Byström, En broder gäst och parasit, 120. See also Kvist Geverts, Ett främmande element $i$ nationen, chapter 8 \& 9 where she discusses possible explanations for the restrictiveness of Swedish immigration policy towards the Jews during the war, 211-256.

300 Malin Thor Tureby, "Svenska änglar och hyenor möter tacksamma flyktingar. Mottagningen av befriade koncentrationslägerfångar i skånsk press under året 1945," Historisk. Tidskrift, 135: 2, (2015): 266. 
process that meant certain death for specific groups of people. Of course, these discourses could be traced from 1935 and the Nuremburg laws. ${ }^{301}$ They could also be understood to emanate from representations of some of the first large groups of refugees receiving asylum in Sweden through the so called "child quota" in 1938 and 1939.302 However, before 1942/43, these occurrences were not widely understood as developments in a large-scale genocidal process, even though some commentators had more foresight than others. Similar to my reasoning around the issue of disciplinary or 'expert' discourse, I am not as concerned with the question of whether every Swede knew or acknowledged the Holocaust. Instead, I focus on when the Holocaust was acknowledged by the Stockholm-based newspapers as the Nazi's concerted effort to exterminate the Jews. My endeavor to locate the descent of discourses on Holocaust victimization, witnessing and survival therefore had to begin when the Holocaust was widely accepted as a deadly machinery from which few people returned as well as when the survivor-victims of Nazi perpetration) were represented in the press.

In the first section of this chapter, the choice of newspapers used to study these periods were inspired by Swedish media historian Göran Leth's categorization, established in his study of the Swedish press and the Kristallnacht in 1938. In this study, Leth divides his newspapers into three categories: 1) Protest, 2) Indifference and, 3) Compliance, depending on their political stance vis-à-vis Nazi Germany. While protest and compliance refer respectively to the newspapers that explicitly criticized or supported Nazi Germany (without being overt 'Nazi' newspapers), indifference includes those newspapers that did not take any particular perspective on Nazi policies, most often adhering to Swedish state

301 See also Svanberg \& Tydén's reasoning around early reports on German concentration camps in the 1930s in chapter 5 of Sverige och Förintelsen, 124-135.

302 In her dissertation, Ingrid Lomfors explains that the "child quota" was constituted after a request from the Jewish community in Stockholm and was part of the more extensive Kindertransport program, See Lomfors, Förlorad Barndom: återvunnet liv, 19. It is not altogether clear, however, whether the 500 children that arrived in Sweden through this quota in 1938 and 1939 were, in fact, part of the Kindertransport, as no reference is given by Lomfors to support this claim. In addition, I have not been able to find any other international research conducted on the Kindertransport (which primarily transported children from Germany and Austria to Great Britain) which refer to a Swedish section of the program. See, for example, Wolfgang Benz "Emigration as Rescue and Trauma: The Historical Context of the Kindertransport", Shofar, vol. 23, no. 1, (2004): 2-7; Rebekka Gopfert \& Andrea Hammel, "Kindertransport: History and Memory", Shofar, vol. 23, no. 1, (2004): 21-27; Caroline Sharples, "Reconstructing the Past: Refugee Writings on the Kindertransport”, Holocaust Studies, vol. 12, no. 3, (2006): 40-62. 
censorship which encouraged the press to not publish articles on issues that may injure Swedish foreign relations and Swedish neutrality. ${ }^{303}$ It is also within this latter category that the most radical difference in approaches to the victims and survivors of the Holocaust can be expected as they, in 1938, according to Leth "seem[ed] to have avoided information on the Jewish plight, was intent on keeping the issue at bay, and often conveyed a covert antisemitism". 304 As two "indifferent" newspapers, SvD and DN thus served as examples of how news discourse, in 1942 and 1943 turned from indifference to activism (to borrow Levine's expression). ${ }^{305}$

For the categories of protest and compliance, the daily newspapers Göteborgs Handels- och Sjöfartstidning (protest) and Stockholmstidningen (compliance) were chosen in addition to the evening newspaper Aftonbladet (compliance). Göteborgs Handelsoch Sjöfartstidning's editor-in-chief, Torgny Segerstedt, was one of the most staunch critics of Nazi Germany at the time and was vocal in his disagreement with other liberal editors on the issue of war-time censorship (mainly pertaining to the informal gag order on criticizing Germany). ${ }^{306}$ Stockholmstidningen, in contrast, was a 'German-friendly' daily, at least up until 1943.307 In 1932, the owner of Stockholmstidningen also acquired the evening newspaper, Aftonbladet which would become one of the most important newspapers of its kind. ${ }^{308}$ Like Stockholmstidningen, Aftonbladet remained a supporter of Germany during the 1930s and a majority of the war, keeping intimate connections with Nazi officials in Stockholm. However, with the changing tide of the war in 1943, the paper experienced a process of 'de-nazification' which resulted in the appointment of a new, liberal-minded editor-in-chief. ${ }^{309}$ Even though Leth's categories do not hold true for Aftonbladet and Stockholmstidningen post-1943, they still demonstrate how the liberalization of the printed media landscape affected characterizations of Danish Jewish refugees in the autumn of 1943. Stockholmstidningen's and Aftonbladet's concurrent shift towards more critical expressions against Nazi policy, including

303 See Johnny Wijk, “'Censur och propagandaministeriet' - en översikt av Informationsstyrelsens verksamhet 1940-1945 utifrån dess efterlämnade arkiv," Historisk Tidsskrift 1 (1990): 21-49.

304 Göran Leth "The Construction of Indifference: The Swedish Press and Kristallnacht," Yad Vashem Studies, vol. 36, no. 2, (2008): 160.

305 Levine, From Indifference to Activism.

306 Leth "The construction of indifference," 159.

307 Elisabeth Sandlund, "Beredskap och Repression," in eds Karl Erik Gustafson \& Per Rydén, Den svenska pressens historia, (Stockholm: Ekerlids förlag, 2001): 359.

308 Sandlund, "Beredskap och Repression," 231-232.

309 Sandlund, "Beredskap och Repression," 356-357. 
that which pertained to the Holocaust, meant that a growing section of the Swedish press was more likely to represent victims' suffering when the Danish Jews escaped in 1943. The choice of newspapers was thus not necessarily based on their political profiles, but rather the collective platform which they formed during a crucial point for the descent of the Holocaust as a concept during the war.

With regards to the rescuees of 1945, the digital newspaper archive was specifically searched in the time period before and directly after the 'White Buses' mission as well as during June and July of 1945 in order to catch any references to camp survivors brought to Sweden by the UNRRA mission, when further ships and trains brought rescuees from Buchenwald and Bergen-Belsen to Sweden. The principal search terms used were "flykting/flyktingen(s)/flyktingar(nas)" (Refugee/Refugees), "röda korset" (the Red Cross), Bernadotte, "Gaskammare/kammaren/kammrarna(s)" (gas chamber) and "koncentrationsläger/läger/arbetsläger" (concentration camp/camp/work camp). Because I wished to search for articles across a longer period of time, I excluded Stockholmstidningen and Göteborgs Handels- och Sjöfartstidning from my analysis as these newspapers have not yet been digitalized for the period in question. I did not consider this a significant loss methodologically, however, as a majority of the major newspapers in 1945 were no longer defending Nazi Germany; a task that had been left for the overtly Nazi newspapers such as Dagsposten. In addition to these newspaper sources, the news reel depicting the "White Buses" mission, Vittnesbördet ("the Testimony was studied together with a radio reportage containing interviews with UNRRA rescuees entitled En last med levnadskval ombord ("Aboard a load of life anguish"). Vittnesbördet was found through filmarkivet.se (see discussion on page 57) and En last med levnadskval ombord was located in the audio-visual archive at the National Library after searching the words "koncentrationsläger/koncentrationslägren(s)" (concentration camp).

The Belsen trial—which has never been studied in relation to Swedish news discourse - was studied searching the digital newspaper archive, initially using the search words "Belsen" and "Lüneburg". After this search had yielded a substantive amount of material, further searches were made using the terms "Auschwitz", "Grese", "Kramer", "vittne(n)(na)" (witness). The same search terms were used in the audio-visual archive with only one relevant match; a news reel covering the Belsen trial. Hypothesizing that emblematic perpetrators like Kramer and Grese would be sensationalized in the evening press, Expressen and Aftonbladet were chosen for further scrutiny. Again, considering the searchability of the nationally covering DN and SvD in the digital newspaper archive, these newspapers were chosen to represent the daily newspapers. 


\subsection{The Norwegian Jews and the Swedish Press}

In 1940, the Norwegian Jewish population was made up of approximately 2,100 individuals. In contrast to Denmark, where the government stayed in place after occupation, Norway's king and government was exiled and fled to London in June 1940. A "puppet government" was put in place, led by the Norwegian fascist Vidkun Quisling which, in turn, facilitated the immediate commencing of making Norway Judenrein ("cleansed of Jews")—a process which began directly after the German invasion. Even before the old government had left the country, all Jews were forbidden to own radios, a majority of which were confiscated by Norwegian police forces, serving under the new Nazi apparatus. Jews were also registered and were subjected to further discriminatory measures which culminated in the deportation of some 800 Norwegian Jews in the late autumn and early winter of 1942. 42 percent of Norway's Jewish population perished in the Holocaust, a majority in Auschwitz-Birkenau.

Even though the newspapers represented the Holocaust differently and more vigorously after 1943, it has been widely argued that the deportation of the Norwegian Jews in the late autumn of 1942 was a turning point in Swedish refugee policy. Hence, Swedish attitudes towards the Holocaust in terms of protecting those persecuted, at least those who were of Scandinavian descent, shifted before the press began to highlight the ongoing genocide. In their studies of Swedish bureaucracy and policy-making, Hans Lindberg, Byström and Levine all point to the fundamental impact that the deportation of the Norwegian Jews in November 1942 had on attitudes towards the Holocaust, as well as actual shifts in Swedish refugee policy. ${ }^{310}$ Nuancing this picture somewhat in his recently defended doctoral dissertation, Lars Hansson demonstrates that Swedish refugee policy concerning Norwegian refugees was in fact 'elastic' during the years of occupation before 1942 (1940-1942). Because of the openness of the term 'political refugee', the local police districts admitted refugees in an ad hoc manner, some accepting Jewish heritage as a reason for political flight while others did not. ${ }^{311}$ Thus, refugee policy regarding the Norwegian Jews in particular was never as strict in practice as has previously been argued. In fact, only 5 out of 22 Norwegian Jewish refugees

310 Hans Lindberg, Svensk, flyktingpolitik under internationellt tryck. 1936-1941, (Stockholm, 1973), 127158. Levine, From Indifference to Activism, 279. Kvist Geverts, Byström, En broder, gäst och parasit, 2122.

311 Lars Hansson, Vid gränsen, Mottagningen av flyktingar från Norge, 1940-1945, (Doctoral diss.: 2019), 294. 
were refused entry into Sweden before December 1941. The autumn of 1941, argues Hansson, thus constitutes the unofficial, yet real, turning point in Swedish refugee policy concerning Norwegian refugees. With regards to Jewish asylum seekers, no Jews were refused entry into Sweden after October 1941, this in spite of official statements from Utrikesdepartementet (UD) in December that Jewishness did not qualify an applicant for political refugee status. ${ }^{312}$ In the Western Swedish districts Hansson studied, 742 Jews were allowed to enter Sweden throughout 1942, a majority arriving in the aftermath of the big round ups and deportations in November and early December that year. ${ }^{313}$ Through his research, Hansson thus supports Klas Åmark's contention that "the change in refugee policy had started before the turn of the war" even though Åmark maintains that the turn came in the spring of 1942 rather than in the autumn of $1941 . .^{314}$

For the construction of Scandinavian Jewish refugees as Holocaust survivors, the unofficial/official status of these asylum seekers is crucial. As will be demonstrated in the coming section, the Swedish government's decision to grant refuge to all Danish Jews made big headlines in Swedish newspapers during October 1943 and made human interest stories regarding the thousands of refugees coming onto Swedish shores possible. Although stories of Jewish flight from Norway to Sweden made the local press in the border regions, there were no great news stories written in the Stockholm-based press covering the plight of those Norwegian Jews who had managed to make it over to Sweden in December 1942. One could argue that this was also due to vast differences in the scale of migration between Norway and Denmark-almost 10 times as many Danish Jews came to Sweden in 1943 compared to Norway in 1942. However, the fact that UD or the Swedish government had not officially granted the Norwegian Jews asylum must have meant that stories concerning Norwegian Jewish refugees remained precarious, especially considering the lingering censorship on Swedish news outlets. $^{315}$ The Norwegian refugees' survival was, therefore, not represented in Swedish public discourse at the time.

Furthermore, if compared to the news coverage of the Danish Jews, the attention afforded to the persecution of the Norwegian Jews should be considered

312 Lars Hansson, Vid gränsen, 295.

313 Lars Hansson, Vid gränsen, 172.

314 Klas Åmark, "Sweden and the Refugees, 1933-45" in eds Mikael Byström \& Per Frohnert,

Refugees, Immigrants and the Swedish Welfare State, 1930-2000, (Stockholm: Nordic Academic

Press, 2013), 50.

315 Wijk, “Censur och propagandaministeriet,” 21-49. 
minimal, lacking in pictures of escapees and/or, to the public, well-known victims as well as taking up very little of the news space which was instead given to stories pertaining to other aspects of the war. The media space given to this event as a news story was thus negligible, a surprising fact given that the deportations in 1942 in hindsight have been attributed great import with regards to shifting both attitudes and policy in Sweden. Although many Swedish opinion makers reacted with shock and outrage to the arrests and deportations of Norwegian Jews in late November and early December 1942, the event neither made big nor lasting headlines in the Swedish news. On November 27, DN, SvD and Stockholmstidningen all published the same TT news article explaining that 1000 Jews had been deported to Poland and that eye witnesses attested to the brutal arrests of the elderly and children as well as the wives of already captured men. ${ }^{316}$ In SvD and DN, the news was expanded upon inside the newspaper, albeit briefly and with little information as to the fate awaiting those Jews who had been deported. ${ }^{317}$ Similarly, in a DN editorial, those deported were described as meeting a yet-unknown but surely painful and in many cases lethal fate, as the Nazis continued to show a "complete contempt for human worth". ${ }^{318}$ This was a clear protest against Nazi action in Norway, yet with mere allusions to the extensive and organized character of the Holocaust and, more importantly, without reference to those who had escaped the arrests on November 26.

In the following days, smaller articles appeared in the daily and evening newspapers referencing events in Norway, primarily reporting on different protests amongst Swedish clergy and intellectuals. ${ }^{319}$ Headlines were made on November 2 about renewed efforts to round up and deport Jews. What filled these reports were that elderly individuals, as old as 80 , had been taken and were now awaiting deportation. ${ }^{320}$ Although DN had published articles regarding the deportation of

316 “1000 norska judar föras till Polen,” November 27, 1942 DN, 1. "1000 norska judar ha blivit förda till Polen," November 27, 1942, SvD, 3. "1000 norska judar ha deporterats till Polen," November 27, 1942, Stockholmstidningen. "Ett tusental norska judar sända till Polen," November 27, 1942, Göteborgs Handels- och Sjöfartstidning.

317 “Barn och åldringar fördes bort," November 27, 1942 DN, 3. “Norska judar...," November 27, 1942, SvD, 7.

318 "Barn och åldringar fördes bort," November 27, 1942 DN, 3.

319 "Hjärtslitande scener i Oslo," November 28, 1942, SvD, 7. "Flammande protester mot judeförföljelsen i Norge," November 30, 1942, SvD, 9. "Nya deportationer av judar från Norge," December 2, 1942, SvD, 6. "Flyglarm för att hindra judar fly," December 1, Aftonbladet, 1942, 3. "Varje kristet samfund måste reagera," November 28, 1942, Göteborgs Handels- och Sjöfartstidning. 320 “80-åriga Norska judar och även barn tas för ny deportation," December 2, 1942, DN, 1. 
German Jews to Poland a whole year before these events in Norway, this detailthat Norwegian citizens, old and young and some in a very fragile state, were being deported to horrendous conditions in the east-remained one of the most upsetting and newsworthy aspects of the deportations themselves. ${ }^{321}$ The fact that this was considered newsworthy is also rather surprising considering what was known about measures against the Jews in Germany and other occupied territories. That Jewish individuals of all ages and genders were being deported was nothing new. Rather, the emphasis on the Nazi's targeting the elderly can be interpreted as DN (as well as SvD) attempting to shine a light on aspects of the Holocaust which countered pro-Nazi arguments that the Jews were being deported because they constituted a threat to the security of the Third Reich.

As can perhaps be expected, Göteborgs Handels- och Söfartstidning (known for its continuous critique of Nazi Germany before and throughout the war) were more proactive in their commentary on the situation in Norway, both through news articles and opinion pieces. ${ }^{322}$ For instance, on November 28, an existential and poetic piece written by the freelance journalist Theodor Freeman, discussing the catastrophic yet increasingly normalized news that Jews were being deported, was published in Göteborgs Handels- och Sjöfartstidning. ${ }^{323}$ Directly underneath Freeman's thoughtful musings was a news article which detailed criticisms from two Swedish liberal and clerical organizations of the deportations of Norwegian Jews. ${ }^{324}$ Furthermore, on November 30, one could read about the great cathedral in Gothenburg, how it was filled to the brim with people coming to pray and show their support for Norway's Jews. The headline read: “If They Keep Quiet, the Stones will Cry Out" referring to bible passage in which Jesus enters Jerusalem as the messiah. No mention of the Norwegian Jews' situation can be found in either Aftonbladet or Stockholmstidningen after the initial news of deportation. In the weeks following the second round of arrests, little was written about the remaining Norwegian Jewish community or the probable fate of those deported.

321 "80-åriga Norska judar och även barn tas för ny deportation," December 2, 1942, DN, 1. "Nya deportationer av judar från Norge," December 2, 1942, SvD, 6.

322 "Ett tusental judar sända till Polen” November 27, 1942, Göteborgs Handels- och Sjöfartstidning. "varje kristet samfund måste reagera" 28 November 1942, Göteborgs Handels- och Sjöfartstidning. "Om vi tege skulle stenarna ropa" November 30, 1942, Göteborgs Handels- och Sjöfartstidning. "Angående..." November 30, 1942, Göteborgs Handels- och Sjöfartstidning.

323 Theodor Freeman, “en båt den 27 november 1942," November 28, 1942, Göteborgs Handels- och Sjöfartstidning.

324 “Om vi tege skulle stenarna ropa,” November 28, 1942, Göteborgs Handels- och Sjöfartstidning.. 
The Gallup-survey conducted by DN and published in the same newspaper on New Year's Eve in 1942, however, did reveal that the biggest news event that year (seen from the public's perspective) was, in fact, the deportation of the Norwegian Jews. ${ }^{325}$ According to Swedish historians Ingvar Svanberg and Mattias Tydén, this trend was even more apparent in the regions bordering on Norway, where people had witnessed the plight of the refugees first hand. Thus, even though the news of the deportations were relatively sparse, they made a significant impact on the Swedish population, demonstrating that, in the case of the Norwegian Jews, the newspapers neither reflected nor constituted public opinion. Nevertheless, even though the fate of the Norwegian Jews surely moved many and the protest as well as the Indifferent newspapers commented on the ruthless measures used to round up and arrest Norway's Jews, those who survived this treatment, did not constitute a major news story in any of the daily or evening newspapers studied here. ${ }^{326}$ Considering the reasoning above, this does not necessarily mean that the fleeing Norwegian Jews nor those sent for extermination did not contribute to ideas of Holocaust victimization. In fact, the upset that their plight seem to have created among the Swedish population indicates that the deportation of the Norwegian Jews facilitated for more forceful reactions when news about deportations in Denmark emerged a year later. However, as few Norwegian escapees were represented in the national press, no tangible group had yet emerged either in description or imagery that could procure a cohesive idea of what Holocaust survival was. Who those elusive figures were, hiding out, escaping to safer shores or coping with camp existence were thus yet to appear in Swedish news discourse? 327

325 Svanberg \& Tydén, Sverige och Förintelsen, 260-261.

326 One article in SvD mentioned that there were "tragedies at the border", describing an incident with two Jewish men who, in trying to reach the Swedish border, had been shot by the border police. "Hjärtslitande scener i Oslo", November 28, 1942, SvD.

327 In his dissertation, Lars Hansson uses local newspaper articles to bolster his explanations of how Swedish refugee policy vis-à-vis the Norwegian escapees developed during the Second World War. However, although not elaborated on in the method section of the dissertation, the reference list shows that only two articles from the local newspaper Karlstad Tidning are referenced for the period in 1942 when the Norwegian Jews were deported east. For 1940, Hansson demonstrates an ample collection of articles from the local newspapers reporting on people fleeing Norway over to Sweden. At this point, however, conceptions of the Holocaust-although aspects of the persecution were well-known - had not yet formed as the concerted effort to exterminate all Jews, 


\subsection{The Danish Jewish Escapees, Holocaust Survival and Victimization}

Because the deportation of the Norwegian Jews had stirred emotions in Sweden, news about the arrests and deportations in Denmark in October 1943 elicited forceful reactions from the Swedish Stockholm-based newspapers. However, the most significant difference between the two occurrences for the construction of Holocaust victimization and survival, was not the newspapers' reactions to the deportations themselves, but rather, the representations that followed of the many thousands of refugees that fled across the Öresund sound over to Sweden. As Hansson demonstrates in his doctoral dissertation, some 886 Norwegian Jews managed to flee to Sweden between 1941 and $1945 .{ }^{328}$ In contrast, some 7,742 Danish Jews escaped to Sweden in October 1943. ${ }^{329}$ Also, on October 2, 1943, it was announced that all Danish Jews who could cross the sound would receive asylum in Sweden, thus giving them the legal refugee status that the Jews fleeing Norway in 1942 had lacked.

This status meant that the newspapers could write about the newly arrived refugees without fearing any reprimands from the government censorship agency, Statens Informationsstyrelse (The National Board of Information, SIS). The news coverage-comprising editorials, short news articles and longer news reportagesis the focus of the coming section, in which I attempt to disentangle the ways in which the Stockholm-based newspapers framed the fleeing Danish refugees. Thus, I examine how the editorials contributed to the conceptualization of the Holocaust as the intended extermination of Europe's Jews. I also explore how the Danish refugees were constructed as victims and how they were constructed as witnesses to their own plight, as well as the ongoing genocide at large in an attempt to capture whether they reflected or constituted the ideals of the "True Victim" and the "moral witness".

meaning that the flight of the Norwegian Jews was not directly connected to Holocaust survival. Also, the refugees fleeing Norway before 1942 were, to a great extent, not Jewish as Hansson shows that most Jewish escapees arrived in Sweden between October 1942 and January 1943. Lars Hansson, Vid gränsen, 172.

328 Hansson, Vid Gränsen, 172.

329 Sofie Lene Bak, "Repatriation and Restitution of Holocaust victims in Post-war Denmark," Jewish Studies in the Nordic Countries Today, vol. 27, (2016): 136. 
"We'd rather give up all our possessions than get deported to Poland"

This is a quote taken from a news article published in Aftonbladet on October 4, 1943. Although the notion of "the east" and references to deportations to Poland had been used to describe something ominous and dangerous in the Swedish press since 1940, it was not until the deportations of the Danish Jews in October 1943 that such descriptions were widely understood in relation to those who managed to escape it. This is a crucial point as the conception of the Holocaust survivor implies that one has survived/escaped certain death-not just in relation to 'normal' practices of war, but in the context of the Nazi's specific exterminatory policies toward certain groups in society. This is also why the first instances of Holocaust survival in Swedish news discourse were connected to the Danish rather than Norwegian Jews.

Like in its neighboring Scandinavian countries, the Danish-Jewish population was relatively small and highly assimilated in pre-war Denmark, and a majority of Denmark's Danish Jews lived in and around Copenhagen. ${ }^{330}$ During the period of 'cooperation' between the Danish government and Nazi Germany (from the occupation in 1940 until August 1943), no major actions against the Jewish population had been taken. The Danish authorities continued throughout this time to largely protect its Jewish citizens, and the Jewish community leadership also encouraged its members to "put their trust in the institutions of the Danish state and not draw attention to themselves". ${ }^{331}$ However, due to German losses in the winter and spring of 1943, Danish resistance groups began to increase their activities which culminated in outright battles between these groups and Nazi troops as well as a number of strikes carried out during the summer of 1943.332 Thus, on August 29, the Webrmacht was declared in charge of Danish affairs, making the Danish Jews all the more vulnerable to arrests and deportations. Although the Danish police force and civil courts would be left in charge and some form of cooperation would continue, a state of martial law was instated until October 6; a condition that forced the hand of Dr. Werner Best-Senior Nazi official and

330 Bak, "Repatriation and Restitution of Holocaust victims in Post-war Denmark," 135.

331 Bob Moore, Survivors, (Oxford \& New York: Oxford University Press, 2004), 87.

332 Michael Mogensen, "October 1943 - the Rescue of the Danish Jews" in eds Mette Bastholm Jensen \& Steven L. B. Jensen, Denmark and the Holocaust, (Copenhagen: Institute for International Studies, Department for Holocaust and Genocide Studies, 2003): 37. 
civilian administrator of Denmark — to act against the Jewish population. ${ }^{333}$ As a majority of the Danish Jews lived in the capital, the operation was carried out there first. After night fall on October 1, 1500 German police troops were stationed around Copenhagen and targeted Jewish individuals for arrest. ${ }^{334}$ However, information about the operation had been leaked three days before it occurred, meaning that approximately 500 Danish Jews had already managed to flee to Sweden when the Swedish government, on October 2, declared that all Danish Jews had been granted asylum in Sweden. ${ }^{335}$ Also, as Danish historian Sofie Lene Bak notes in her writings on the action, the resources allocated to the German police force were limited, which, together with the fact that many Jews had already begun moving towards Sweden, meant that only "472 people were deported from Denmark because of their Jewish descent".336 Thousands of Jewish refugees continued throughout the first two weeks after the operation to escape to Sweden, all by boat across the sound. In the middle of October, the influx drastically dropped, and by the end of the month approximately 95 percent of the Danish Jews had fled to Sweden. ${ }^{337}$

In contrast to the news reporting surrounding the deportation of the Norwegian Jews in November 1942, the reports concerning the Danish Jews only grew and became more prominent in Swedish newspapers during the first two weeks of October. The news trajectory in all newspapers studied here (with the exception of Aftonbladet) was one which slowly shifted from details about German action, the new Swedish asylum policy and the so called "Jew Ships" to the tragedies that had befallen the thousands of fleeing Jewish refugees, as well as the Swedish reception of them. Since the operation against the Danish Jews was leaked days before it begun, both Aftonbladet and Göteborgs Handels- och Sjöfartstidning

333 Mogensen, “October 1943-the Rescue of the Danish Jews," 37-38, Mogensen argues that the fact that the action occurred during the state of martial law also was a result of the power struggle between the shrewd cooperatist Dr. Best and the head of the Wehrmacht, General v. Hanneken. The latter would have preferred to postpone the action to after martial law had been suspended so that the responsibility for the deportation was put on Dr Best.

334 Bak, "Repatriation and Restitution of Holocaust victims in Post-war Denmark," 135.

335 Bak, Notbing to Speak of: War-time Experiences of the Danish Jews, (Copenhagen: The Danish Jewish Museum, 2011), 29.

336 Bak, "Repatriation and Restitution of Holocaust victims in Post-war Denmark," 135. For an account of the Danish memory culture surrounding the flight of the Danish Jews see for example also Sofie Lene Bak, Jodeaktionen oktober 1943: Forestillinger i offentlighed og forskning, (Museum Tusculanum, 2001).

337 Bak, "Repatriation and Restitution of Holocaust victims in Post-war Denmark," 136. 
reported on the coming raids and on the "panic" that this information had unleashed among Copenhagen's inhabitants. ${ }^{338}$ In the days directly following the many arrests, DN continuously reported on the whereabouts of a ship purportedly holding 1600 Danish Jews. On October 3, the 1600 on a ship to Poland was the main headline that day, followed up on October 6 with an article claiming that the deportation ships (now in plural) were still at the Copenhagen harbor, only to deliver the detrimental news on October 13 that the first ship left already on October 2. ${ }^{339}$ The deportation ships were also mentioned in captions, sub-headings and summaries in articles found in SvD, Stockholmstidningen and Göteborgs Handelsoch Sjöfartstidning, all speculating about where the ships were and reporting with certainty that they were headed east, most likely to Poland. ${ }^{340}$ In addition, it soon became headline news that saboteurs had blown up two of the ships, meaning that only one was able to bring its Jewish prisoners east.

In Stockholmstidningen, where Germany's official line was first reproduced without comment, Jewish refugees were featured as human beings who had escaped something terrible. On October 3, euphemisms were used to describe the fate of those unfortunate enough to have been rounded up and put on a ship towards "unknown fates in the east". 341 At this point, information about Nazi treatment of the Jews who were deported east was much more extensive and detailed than Stockholmstidningen made it seem. However, when studying the progression of Stockholmstidningen's reporting during October 1943, these euphemisms soon disappeared and were supplanted by more explicit references to German action in Denmark. Already on October 4, the summary of a news article proclaimed that "it seems as if the Germans really are following an extermination

338 “Tyska judeförföljelser befaras i Danmark” October 1, 1943 Göteborgs Handels- och Sjöfartstidning,

"Danska judarna hotas av förföljelse", October 1, 1943, Aftonbladet.

339 "1600 judar på deportationsbåt," October 3, 1943, DN, 1. "Deportationsfartygen kvar i

Köpenhamn," October 6, 1943, DN. "Danskarna sökte förgäves hejda judeförföljelserna.

Deportationsfartyg avgick redan den 2 Oktober," October 13, 1943, DN.

340 "8000 judar i Danmark. 1600 redan deporterade, "October 3, 1943 Stockholmstidningen, 1. "Danska sabotörer sänkte två judefartyg," October 4, 1943, Stockholmstidningen. "Danska judarna till Gdynia och Warsawa," October 4, 1943, Stockholmstidningen, 10. "1600 judar på deportationsbåt," October 3, 1943, DN, 1. "Deportationsfartygen kvar i Köpenhamn," October 6, 1943, DN. "Danskarna sökte förgäves hejda judeförföljelserna. Deportationsfartyg avgick redan den 2 Oktober," October 13, 1943, DN. "Aktionen mot Judarna i Danmark har nu inletts," October 3, 1943, SvD. "Judefartygen ännu i hamn," October 6, 1943, SvD.

341 "Sverige erbjuder Danmarks judar fristad," October 3, 1943, Stockholmstidningen, 1. 
program against the Danish Jews". ${ }^{342}$ In addition, on October 5, the onslaught of refugees on the Danish coast was described as the Jews "storming" all boat owners "in order to save their lives", thereby underscoring the fact that capture meant death. ${ }^{343}$

The almost frenzied preoccupation with the deportation ships, primarily in DN but elsewhere as well, is an important aspect of the early 'follow-up' reporting on the Danish Jews. It expressed a concern, not only for the refugees of Nazi terror but also for its victims. The attention paid to the ships in headlines, summaries and captions also meant that this was a prioritized aspect in the news hierarchy of goings-on in Denmark. More importantly, however, it underscored the particularity of the Nazis' treatment of Europe's Jews-something which had been present in the news but never so forcefully agreed upon by all major daily newspapers. As there were, in fact, no 1600 Jews on a ship headed east, it is also notable that these numbers appeared so prominently in the news, feeding the image that the Danish Jews were going toward the same fate as their Norwegian counterparts. In this sense, reactions to the deportation of the Norwegian Jews seems to have been crucial in making the press more prone to upset and exaggerations when the Danish Jews were targeted for arrests and deportation in October 1943.

\section{The Editor doth Protest}

The early news reports on the situation in Denmark show that by 1943, deportation east was widely acknowledged as something catastrophic. Outrage on behalf of those deported was also expressed in fiery editorials published in DN, SvD. Although all newspapers studied here mentioned German legitimizations for the operation-namely that the Jews were "poisoning the atmosphere" and were behind many of the resistance movement's attempts to sabotage the Nazis' quest for law and order-only a few newspapers openly refuted such attempts at justification. In their editorials, DN, SvD presented German arguments for deportation as ridiculous and wholly without merit. SvD called these attempts "a purely fantastical accusation" while DN characterized them as a "slap aimed at all

342 "Danska judarna till Gdynia och Warsawa," October 4, 1943, Stockholmstidningen, 10. [“det förefaller som om man från tysk sida skulle följa ett verkligt utrotningsprogram mot de danska judarna"].

343 “Tiotusentals judar tiggde förgäves om båtar,” October 5, 1943, Stockholmstidningen, 4. 
that is good reason, normal feeling and basic honor". 344 In SvD's editorial, published on October 3, the author stated that "the accusation that 'the Jews are poisoning the atmosphere' is merely a pretext for the systematic plan-to poison the Jews". 345 'This quote shows both how SvD acknowledged the Nazi's aims to annihilate the Jews and posed an open challenge to German justifications of the operation.

DN's editorial, also published on October 3, refuted German claims that the Jewish population in Denmark had been fuelling sabotage and riots, making a long statement about the absolute assimilation of the Danish Jews into Danish society. "To amputate them out of the Danish social body would be to cut a piece out of the Danish people's healthy, living flesh" the author contended. ${ }^{346}$ Here, the flawed 'logic' of targeting the Danish Jews was elucidated through the use of a religious analogy in which the Nazis have become blind to all reason, all in the name of the "holy mission — the blood mission, the exterminatory mission". 347 The title of the piece, "Sacrificial Offerings" also alludes to this same analogy, where the foregone conclusion is that the Danish Jews had to be sacrificed to the insatiable and allpowerful God of the Nazi party, Adolf Hitler, in spite of such an action being 'unstrategic' for Germany at that time. Here, then, the Holocaust as an "exterminatory mission" is spelled out, and empathy for the Danish Jews expressed. Similarly, SvD's editorial described the Danish Jews as pillars of Danish cultural society with a prominent standing within the Danish bourgeoisie. "Yet, for perspectives against racial fanaticism, the victims' birth, bildung and standing, and wealth carry no

344 "Mot gudomlig och mänsklig ordning," October 3, 1943, SvD, 4. [“"men det är en rent fantastisk beskyllning”]. "Avgudaoffer," October 3, 1943, DN, [”örfilen som måttas åt allt som heter sunt vett, normal känsla och elementär heder bränner bara hårdare för var gång”]. In a forthcoming anthology chapter, Ulf Zander also analyzes an opinion piece published in Aftonbladet, penned by the philosophy scholar and pro-german intellectual, Karl Olivencrona. Olivencrona's sympathetic perspective on Sweden accepting all Danish Jews into the country in 1943, Zander argues, demonstrates how wide the consenus was on the vulnerability of the Danish Jews. Ulf Zander, "Dire Strait? When the Holocaust came to Sweden-A regional Perspective," in eds Johannes Heuman and Pontus Rudberg, Early Holocaust Memory in Sweden, (Palgrave Macmillan, forthcoming).

345 "Mot gudomlig och mänsklig ordning," October 3, 1943, SvD, 4.

346 "Avgudaoffer," October 3, 1943, DN, 4 ["att söka amputera dem ur samhällskroppen blir att skära i danska folkets friska, levande kött.”]

347 “Avgudaoffer," October 3, 1943, DN, 4 [“Det kan också vara så att den högsta ledningen i ett givet ögonblick är blind för allt annat än den heliga missionen-blodsmissionen, utrotningsmissionen"] 
principle meaning" the author spits. Rather it is the "ruthless contempt for humanity's gains for centuries in western history, that these persecutions of Jews expose". ${ }^{348}$

What is particularly striking about these vehement rebuttals of German justifications is that they merely explain why it is ludicrous to deport the Danish Jews. Even though the quote above speaks to a universal critique of the Nazi's "ruthless contempt" for humanism, this argument was made in relation to the utmost crime; to deport the highly assimilated Danish Jews. Thus, by defending the Danish Jews based on their incomparable levels of assimilation into Danish cultural life, this form of argumentation, implicitly posits that Jews in other occupied territories, first and foremost those in the east, were 'rational' or 'strategic' targets of annihilation. Perhaps the rationale of these opinion pieces and other news articles were to sway the diminishing section of Swedish public opinion that remained supportive of German policies towards the Jews in 1943 by showing how utterly ludicrous the persecution of Denmark's Jews was. However, as the Indifferent press had, up until that point, expressed little outrage when faced with news of conditions in the Polish ghettos and deportations of Jews east, it could be argued that the argumentation conceded a form of 'logic' to German measures against Jews in areas where "the Jewish Question" was considered to be real.

How can we understand the outrage expressed in DN's and SvD's editorials with regards to the Danish Jews? The editorials analyzed above reveal a perceived disparity between the Jewish victim groups. In SvD's editorial, the Danish Jews were described as having played a "quantitatively and qualitatively" more important role in Denmark compared to the Jews in Norway. ${ }^{349}$ The deportation of the Norwegian Jews was given as a reference point to impart the gravity of the situation in Denmark but with the added argument that what was seen in 1943, in Copenhagen and on the Danish coast, was much worse than the events that transpired just a year before. Of course, the tragedy of those fleeing Denmark was amplified by the sheer number of refugees, yet the number reportedly on a ship

348 "Mot gudomlig och mänsklig ordning," October 3, 1943, SvD, 4. ["Men för inställningen mot rasfanatismen äro offrens börd, bildning och besuttenhet utan principiell betydelse. Vad det gäller och vad som strider mot all gudomlig och mänsklig ordning är det ohyggliga och hänsynslösa förakt för humanitetens landvinningar under långa sekler av västerländsk historia, som dessa judeförföljelser ådagalägga”].

349 "Mot gudomlig och mänsklig ordning," October 3, 1943, SvD, 4. [“Här kan gestapo få sitt verkliga lystmäte, ty judarna spela i Danmark kvalitativt och kvantitativt en långt större roll än $\mathrm{i}$ Norge"]. 
east were similar in Denmark as to what was reported in November 1942 (1000 in Norway vs. 1600 in Denmark). Even though the deportation of Norwegian Jews might have come as a shock, the powerful words used to describe the deportation of the Danish Jews and the astonishment that this action garnered indicates that the Danish Jews — as was also repeatedly pointed out in these editorials - were of special importance to their home country and thus carried a particular victim status.

Explained by the British historian Tony Kushner as the assimilationist ideals of the "liberal imagination", this hierarchizing discourse which was predicated on the dichotomization between east and west was common throughout the western world before and during the war. ${ }^{350}$ The primacy of this liberal discourse in Sweden during the war is, however, an understudied area of Swedish antisemitism, something which will be discussed further in the section below. When considering the rhetorical function of the argumentation found in these editorials, it can be understood as an attempt to undermine the legitimacy of any Nazi claims that the deportations were either just or necessary. Furthermore, they also confirm what the Indifferent press had long avoided to spell out - the systematic and on-going extermination of Europe's Jews by Nazi Germany. The arguments that remained absent, however, were once aimed at a greater framework of empathy for Eastern Jewish victims, something which would continue to characterize representations on Holocaust victimization and survival in the post-war period. ${ }^{351}$ Although SvD's editorial connected the Danish operation with the deportation of both the Norwegian and the Dutch Jews, these were also highly assimilated minority populations in countries geographically located near Sweden, and were given as background rather than comparable cases. This framing of the Holocaust in Denmark would also come to affect representations of the Danish-Jewish refugees in the autumn of 1943.

In what ways was this hierarchization of Jewish victims important to the early construction of Holocaust survival and victimization? Significantly, these editorials constituted a concerted, collective acknowledgement, as well as a vehement criticism, of the Nazis' exterminatory actions towards the Jews specifically. The outrage was expressed on behalf of the culturally assimilated Jews as cultured, bourgeois and educated Danes, thus humanizing the fleeing Jewish victims and discursively connecting their flight with the Holocaust. Even the previously

350 See Tony Kushner's conclusion in, The Holocaust and the Liberal Imagination, (Oxford: Blackwell, 1994), 270-279.

351 See for example, Timothy Snyder, "Holocaust: The Ignored Reality", New York Review of Books, vol. 56, no. 12, (2009). 
cautious newspapers, $\mathrm{DN}$ and $\mathrm{SvD}$, maintained a staunchly critical and sneering tone against the Nazis' feeble explanations regarding why the Danish Jews had to be removed from Denmark. This negating of any credibility given to Nazi actions also aided in the construction of true Jewish victimhood in terms of removing any doubt that the Jews were complicit in their own demise. This point is underscored by Cole when she comments on victimhood and victimization in the modern age where "the victim's innocence must be complete and incontrovertible." "True Victims", she continues, have not contributed to their injury in any way." 352 As assimilated, cultural Danes, the Danish Jews had done nothing to bring about their own misery and were therefore attributed the status of "True Victims". Predicated on the notion of cultural sameness, the linkage between true victimhood and the Danish Jews was reinforced further through the representation of the foremost symbols of vulnerability at the time: women and children.

\section{Women and Children as "True Victims"}

Although Best declared Denmark Judenrein already on October 5, 1943, DanishJewish refugees continued to escape to Sweden in the week following that in which the action had begun. ${ }^{353}$ According to Bak, "in the course of just a few weeks in October 1943, 1,742 persons had fled to Sweden, including children of mixed marriages and Gentile spouses; all victims of persecution by the Germans" a number which constituted approximately 95 percent of Danish Jewry. ${ }^{354}$ Most often the literature refers to "the rescue" of the Danish Jews. Indeed, the Swedish government giving the Danish Jews asylum on the day after the Nazis' action against them could be interpreted as a form of rescue. Also, Danish and Swedish individuals aided the fleeing Jews in their struggles to get to Sweden. However, there was never a planned, concerted effort to rescue the Danish Jews. Therefore, I have chosen to refer to this historical event as 'escape' or 'flight'. This was a conscious terminological decision based on the differences between how the press represented the 'White Buses' and the UNRRA rescue mission in the spring and summer of 1945 and how they treated the flight of Danish Jews. In the case of the former, much attention was paid to the rescuers and the mission itself, bolstering the image of Sweden as a rescue nation. The press coverage of the flight of the Danish Jews, however, focused more on the escapees as well as their needs and the 
logistical problems that they caused. The notion of the Danish Jews as "rescued" is thus a post-war construction that does not fit well with how the Danish Jews were portrayed in the Swedish press in October 1943.

Even though the Danish Jewish refugees were problematized by the Swedish newspapers as economic burdens on Swedish society and, in some instances, as an ethnic 'other', the most prominent representation of this group constructed them as vulnerable victims. This was, by all accounts, an effect of the antisemitic perspective on Danish Jews explored above-because of their cultural inclusion into Danish society, they were humanized in the Swedish press, their strife and need positioned as a counter weight against arguments of the imposition they caused Swedish society. However, through the absence of personal narratives, they were never subjectivized but remained objects onto which a multitude of emotions could be projected.

What is particularly interesting in the news reports surrounding the DanishJewish refugees is the ways in which they were constructed as both Danish and 'Other'. For instance, and as Byström also shows in his dissertation, the Jewish refugees were distinguished from 'normal' Danish refugees. ${ }^{355}$ Articles in SvD, $\mathrm{DN}$, Stockholmstidningen and Aftonbladet informed their readers that even though the onslaught of destitute cohorts of refugees created logistical and financial problems for Skåne, the Mosaiska församling (the Jewish congregation in Stockholm) had swiftly been sent down to aid their 'brethren' ("trosfränder"). Byström also argues that representatives from the Jewish community in Sweden felt obliged to thank Swedish authorities for helping the Danish Jews. ${ }^{356}$ This notion, that the DanishJewish refugees were somehow the responsibility of the Swedish Jews, shows how the Jewish refugees were distinguished from non-Jewish Danish refugees. Yet, some of the terms referring to the refugees_ "Danish refugees", "refugees" and "Danes", although further specified inside the article, showed at least some form of inclusion of the Danish Jews into the idea of Denmark and 'Danishness'. In DN, for example, all articles referred to "refugees," "Jews" and "The Danisg Jews" in headlines and captions. In Stockholmstidningen they were also referred to as "refugees" or "Danish Jews" when the piece was about both those captured and 
those who were attempting to flee. ${ }^{357}$ In an article published on October 6, "Danish citizens with Jewish heritage" was used in Stockholmstidningen to denote the refugees which, considering the newspaper and its prior leanings, speaks to at least a formal political inclusion of the Jews into the conception of 'Norden', if not one based on ethnicity and/or race. ${ }^{358} \mathrm{SvD}$ was the only newspaper during this period to use the term "Aryan Refugees" albeit only in one of their first articles. 359

The inclusion of Danish Jews into the cultural notion of Denmark is, however, the most prominent feature in how the refugees were denoted, especially when considering the captions accompanying pictures published of the refugees. On October 5 in Aftonbladet's 'picture-spread'-a news format which Aftonbladet revolutionized during the 1930s-two photographs of Jewish refugees were included, one depicting a young girl and her mother being registered in Malmö and the other showing a woman on a gurney smiling up at a male aid worker. The caption stated that these were "some pictures of Danish Jews in Malmö" only to,

357 “1600 judar på deportationsbåt," October 3, 1943, DN, 1. "1700 judar från Danmark har räddat sig till Sverige," October 4, 1943, DN. "Växande flyktingskaror räddar sig över sundet," October 5, 1943, DN, 1. "Dolde sig i skogar för Gestapo," October 6, 1943, DN, 14. ”161 flyktingar i land enbart på en liten ort," October 6, 1943, DN, 14. "Danska flyktingar i kamp för livet," October 7, 1943, DN, 1. "Över 5000 flyktingar har anlänt," October 10, 1943, DN, 1. "1700 judar...tyskarna försökte i det längsta hålla förberedelserna hemliga," October 4, 1943, DN. "Aktionen mot judarna i Danmark har nu inletts," October 3, 1943, SvD. "Båtar med danska flyktingar i jämn ström till Sverige," October 4, 1943, SvD. "Flyktingströmmen visar ingen tendens att avtaga," October 5, 1943, SvD, 9. "Danska flyktingarna få hälp på löpande band," October 6, 1943, SvD. "Skräcknätter över Danmark då judarna arresterades," October 6, 1943, SvD. "Flyktingbåt påseglad av svensk vedettbåt," Svenska Dagbladet, October 16, 1943, SvD. "Tusentalet danska judar här," October 3, 1943, Aftonbladet. "Danska judarna...," October 5, 1943, Aftonbladet, 2. "Danskarna se rött då judiska kvinnor häktas," October 5, 1943, Aftonbladet, 8 . "15 000 kr. bjöds för båtfärd över Öresund," October 5, 1943, Aftonbladet, 1. "Storm och regn stoppa ej flyktingarna," October 6, 1943, Aftonbladet, 1. "Fiskarna vågade inte ut, flyktingarna köpte båten," October 6, 1943, Aftonbladet, 19. "Otröstlig sorg blandas med glädje åt livet," October 7, Aftonbladet, 1. "Danska flyktingarna söva småbarnen före avfärden," October 6, 1943, Göteborgs Handels- och Sjöfartstidning, 12. "Danska Flyktingarna," October 6, 1943, Göteborgs Handels- och Sjöfartstidning. "Flyktingarna hårt ansatta av gestapo," October 7, 1943, Göteborgs Handels- och Sjöfartstidning. "Tiotusentals judar tiggde förgäves om båtar," October 5, 1943, Stockholmstidningen, 4. "3000 gestapomän finkammar alla Köpenhamns hus," October 6, 1943, Stockbolmstidningen, 6. "Två månaders barn bland förolyckade danska flyende," October 10, 1943, Stockholmstidningen.

“Terrorvåg över Danmark—Öresundskusten spärrad," October 3, 1943, Stockholmstidningen.

358 “3000 gestapomän finkammar alla Köpenhamns hus," October 6, 1943, Stockholmstidningen, 6

[“Danska medborgare av judisk härkomst”].

359 "Båtar med danska flyktingar i jämn ström till Sverige," October 4, 1943, SvD. 
in the next sentence, refer to the woman on the gurney as "a sick Danish woman ("en sjuk danska")". ${ }^{360}$ Similarly, in SvD the caption to a set of pictures showing refugees (women and a small child) at Ramlösa brunn, read "involuntary Danish 'Brunns'-guests at Ramlösa". ${ }^{361}$ Underneath, the summary accounted for the trials of the Jewish refugees who were nervously awaiting the arrival of their relatives, asking continuously "is he coming tonight?". ${ }^{362}$ Right next to this depiction was a short intro to an interview with a "Danish refugee" referring to a non-Jewish refugee. The text thus distinguishes between Jewish and non-Jewish refugees, but the caption's umbrella term "involuntary Danish guests" indicates that they are all Danes. Byström's contention that "Jews-even Danish ones-were seen as different, problematic and were not obviously included into the idea of 'Norden"' is thus only partly true. Yes, Jewish refugees were problematized and were, in some ways, represented as an 'other' but were not portrayed as 'un-Nordic'. Considering the editorials above, there was no ambivalence with regards to the cultural Danishness of the Jews, even if the Jewish identity of the refugees remained a distinguishing factor in some of the news discourse surrounding the refugees.

Although the Nordic Jews were included in a political and cultural definition of 'Norden', 'Eastern' Jews were still considered a problem; both in terms of their perceived inability to assimilate into Swedish society, as well as through the idea that they created more anti-Semitic feeling by merely existing. In his dissertation, Carl-Henrik Carlsson shows how between 1880 and 1920, 'Eastern' Jews were discriminated against by Swedish authorities to a greater degree than 'Western' Jews. ${ }^{363}$ This discrimination was also largely supported by leading segments of the Swedish-Jewish community, consisting of assimilated Jews who had immigrated to Sweden during the 1700s. In a chapter entitled 'The construction of the 'Eastern' Jew", Carlsson demonstrates how Jews from Tsarist Russia, including the kingdom of Poland, were distinguished in the Swedish press from the "aristocratic" Jews, meaning the assimilated Jewish families who, by 1915, had lived in Sweden for generations. In the DN article that Carlsson refers to, 'Eastern' Jews were described as illiterate, sickly and poor, thus having little in common with the Swedish "aristocratic" Jews. ${ }^{364}$ Although this distinction between 'Eastern' and 'Western'

360 October, 5, 1943, Aftonbladet.

361 "Danska flyktingar få hjälp på löpande band" October 6, 1943, SvD.

362 "Danska flyktingar få hjälp på löpande band" October 6, 1943, SvD.

363 Carl-Henrik Carlsson, Medborgarskap och diskriminering: Östjudar och andra invandrare i Sverige, 1860-

1920, (Doctoral diss.: Studia Historica Upsaliensia, 2004).

364 Carlsson, Medborgarskap och diskriminering, 57. 
Jews is a well-studied area in German historiography, it remains largely unexplored in Swedish research. Indeed, in his book on antisemitism in Sweden after 1945, Henrik Bachner laments the fact that little research has been conducted on antisemitism in Sweden during the Second World War. To be sure, Kvist Geverts, Levine and Byström all discuss anti-Semitism and anti-Semitic attitudes in relation to policy directed towards the Jews both before and during the war. However, because these studies focus more on tangible policies and political rhetoric, they provide little empirical evidence regarding the changing dynamics of anti-Semitic discourse during the war.

Therefore, it is difficult to explain the construction of the Jewish escapees as cultural Danes in reference to a greater discursive system. However, and perhaps more importantly, the distinction made between non-Jewish Danish and DanishJewish refugees was not only indicative of an ethnic differentiation between them, but also served to construct the latter as "True Victims," given the acknowledgement of their particular vulnerability. Returning to the content of the pictures portraying the refugees, a vast majority of these showed women and children. Even when photographs were not part of the article, the refugees were represented as women and children. An example of this can be found in Göteborgs Handels- och Sjöfartstidning on October 8, when an article describing the dramatic flight of Denmark's Jews was accompanied by a cartoon of a woman holding a sleeping toddler, and a young female child carrying a teddy bear. ${ }^{365}$

Depicting women and children rather than young males could be interpreted as an attempt to construct the "True Victim"- someone weak, defenseless and non-threatening. In exploring the trajectory of refugee representations from 1945 until today, Heather L. Johnson claims that "as the complexity of the perceived threat posed by refugees has increased, and as restrictive asylum policies have arisen in response, the imagined figure of the refugee has also become that of a victim."366 Here, Johnson is describing portrayals of refugees in a post $9 / 11$ world where ideas about economic and 'strategic' migrants as well as hidden 'terrorist' migrants have led to harsher distinctions between the authentic victimized refugee and the opportunistic 'unworthy' refugee. However, her contentions can also be applied to representations of Jewish refugees in Sweden before 1945, as this group was often problematized and portrayed as an economic threat as well as an economic burden

365 October 8, 1943, Göteborgs Handels- och Sjöfartstidning.

366 Heather L. Johnson, "Click to Donate: Visual Images, Constructing Victims and Imagining the Female Refugee,” Third World Quarterly, vol. 32, no. 6: 1027. 
and, by the Nazi- friendly press, as violent instigators of political unrest. By representing them as women and children, describing their dangerous escape across the sound, and showing them to be vulnerable and defenceless, the Swedish press constructed the Danish Jewish refugees as "True Victims". These people could not have contributed to their strife in any way and their suffering, again, signified the "complete and incontrovertible" victimhood of Western Jews under Nazi rule. ${ }^{367}$ These portrayals of "True Victims" were also juxtaposed with descriptions of 'fake' refugees, referring, for instance, to people who hid in boats and other vessels in order to escape Denmark. The newspapers never gave the reasons as to why these 'fake' refugees had wanted to leave their country. In DN it was stated that they had "un-blistered hands", meaning that they had ridden on the coat tails of the 'real' refugees who arrived, wet, cold and with bleeding palms from their long burdensome travels by row boat. ${ }^{368}$ As all Danish Jews had been given asylum in Sweden, these alleged 'imposters' were most likely non-Jewish Danes. Other reasons for non-Jewish Danes fleeing were rarely given, other than through vague descriptions of them helping others (probably Jewish refugees) to flee.

The Danish Jews were thus constructed as cultural kin whose vulnerability had not distinguished them from non-Jewish Danes until the Nazi action launched in the autumn of 1943. The image-based portrayal of Jewish refugees as women and children were also added to a general news discourse which focused on dramatic stories where mothers, whole families, and lone children fought to get across the sound. ${ }^{369}$ In conjunction with headlines and news texts about the deportation ships, a sense that these people escaped certain death can be read between the lines. Although the word 'survivor' was never used to denote the Danish Jews, the acknowledgement by all newspapers studied here - that the Nazis were waging an exterminatory war against Europe's Jews - brought a new meaning to the fleeing Jews. This, in conjunction with the fact that the Danish Jews were perceived as a social, economic and cultural kin also contributed to the construction of them as 'authentic' victims—a notion which did not only justify their stay in Sweden, but

367 Cole, The Cult of True Victimhood, 5.

368 “Rodde så händerna blödde," October 6, 1943, DN. "Fiskarna vågade sig inte ut, flyktingarna köpte båten," October 6, 1943, Aftonbladet. "flyktingbåt påseglad av svensk vedettbåt," October 10, 1943, SvD.

369 On a single page in Aftonbladet, no less than three articles describing the plight of families, mothers and children were published on October 6 in Aftonbladet alone, see "Fiskarna vågade inte ut, flyktingarna köpte båten", "Ung mor simmade i land med barnet på ryggen", "Genomvåta flyktingbarn kläs upp från topp till tå”, October 6, 1943, Aftonbladet, 19. 
also positioned them as true survivors of a fate inevitable to all Jews subjected to Nazi rule.

The bridging of the dichotomy Danish/Jewish, as well as the entrenching of the dichotomy authentic/fake both served to legitimize humanitarian action on behalf of potential victims of the Holocaust. Although Jews had been constructed as authentic victims of the Nazi regime before, this was the first time that this victimization was so forcefully connected to discourses on asylum and a Swedish imperative to help. This does not mean, however, that economic concerns were not aired in the press, as has already been shown in regard to representations of Swedish-Jewish aid and financial support for the refugees. Many articles referred to the future situation of employment for the refugees, singling out the Jewish refugees as particularly problematic as they might not be able to return home after the war. ${ }^{370}$ As opposed to before, however, such argumentation was not used to delegitimize the government's new asylum policy towards the Danish Jews, but rather addressed issues that were assumed important to public opinion. Furthermore, the refugees were described as both destitute and people of means, some having to flee with only what they had on their body while others had paid huge fees to the boatmen bringing them across the sound.

Rather than representing refugees as poor and thus a financial burden on Swedish society, many newspapers described them as people who had lost everything because of the war and because of the Nazi occupational forces' treatment of Jews in particular. On October 4, the sub-headline on the front page of Aftonbladet read "Malmö full to the brim with destitute refugees". ${ }^{371}$ From the headline it seems that the article problematizes the flight of the Danish Jews by pointing to their number and financial situation. However, already in the subheading, the article pointed to the desperate situation of the refugees themselves by stating that "Hotels and boarding-houses overcrowded-the fleeing feel like hunted animals". ${ }^{372}$ In the introductory paragraph to the article, this point was reiterated as the text explained that many of the estimated 1700 Danish Jews that had fled to Sweden in the first few days after the arrests had begun had "endured

370 "Flyktingproblem," October 15, 1943, Aftonbladet. "Hela Ramlösa Brunn blir koloni för flyktingar," October 5, 1943, Stockholmstidningen. "Danska flyktningarna söva småbarnen före avfärden," October 4, 1943 Göteborgs Handels- och Sjöfartstidning. "Dolde sig i skogar för Gestapo," October 6, 1943, DN.

371 "Röda korset till judarnas hjälp," October 4, 1943, Aftonbladet, 1. See also, "Tusentals danska judar här," October 3, 1943, Aftonbladet, 1.

372 “Röda korset till judarnas hjälp," October 4, 1943, Aftonbladet, 1. 
immense hardships and [had] felt like hunted animals". ${ }^{373}$ The hoteliers and owners of boarding houses were also described as having a difficult time with the onslaught of refugees seeking shelter-something which was, at the same time, explained as a necessary burden since the refugees were in real need. Similarly, the headline on the front page of DN, published on October 5, showed how the financial 'problem' that the refugees were also positioned as was weighed against the righteousness of Sweden acting as a safe haven. The headline, which read "growing refugee cohorts save themselves across the sound", first introduced the reader to the concept that these refugees had fled a real danger by using the phrase "save themselves". By phrasing it thusly, the newspaper had already established that these refugees had escaped a sure death. Moreover, the sub-heading supported the Swedish government's choice to give these refugees asylum by informing the reader about the staunch critique that the Nazis' actions had received in Finland. Although the introductory paragraph spoke of all the problems the sudden influx of refugees had caused to various establishments in the southern city of Helsingborg, the led had already reassured the reader that the head of the National board of health and welfare (Socialstyrelsen) had travelled down to Helsingborg in order to provide assistance to the growing group of needy refugees. ${ }^{374}$ Thus, the newspapers both presented the problems that the refugees caused while at the same time reinforcing the perspective that this chaos was warranted because of the great need that these refugees were in.

While SvD maintained a critical stance toward the refugees in the first couple of days after the action against the Jews in Denmark, the reporting quickly shifted in tone as more news about events emanated from Copenhagen. ${ }^{375}$ On October 4, SvD reported in a headline that a "steady stream" of boats holding "Danish Refugees" were coming onto Swedish shores. The sub-heading specified that 1000 of those refugees were Jews, and in the lead the word "invasion" was used twice to describe goings-on in Skåne and the city of Helsingborg in particular. Furthermore, in the first paragraph of the article it was stated that a majority of the refugees were

373 "Röda korset till judarnas hjälp," October 4, 1943, Aftonbladet, 1.

374 "Växande flyktingskaror räddar sig över sundet," October 5, 1943, DN.

375 SvD, 3 October "Aktionen mot judarna i Danmark har nu inletts," October 3, 1943, SvD. "Båtar med danska flyktingar i jämn ström till Sverige," October 4, 1943, SvD. "Direkta order från Berlin anses ha utlöst pogromerna," October 5, 1943, SvD. "Flyktingströmmen visar ingen tendens att avtaga," 6 October 1943, SvD. "Danska flyktingar få hjälp på löpande band” October 6, 1943, SvD. "Skräcknätter över Danmark då judarna arresterades," October 6, 1943, SvD. "Flyktingbåt påseglad av svensk vedettbåt," SvD, October 16, 1943, SvD. 
Jewish with a mere 2 percent of the refugees being "Aryan". 376 As previously noted, SvD was the only newspaper studied here which used the term "Aryan" to differentiate between the Danish refugees. This was also the only article which does not communicate some form of refugee experience or criticism of Nazi actions in the headline, sub-heading, lead or first paragraph of the news article. However, only two days later, the news article depicting the "involuntary guests" from Denmark at Ramlösa Brunn appeared in SvD, showing women and children in two photographs with descriptions of the refugees' anxieties and worries about having been separated from their loved ones and all their property. In addition, in the very same issue, SvD also reported on the "Terror Nights over Denmark when Jews were arrested", a news article published next to news about the "Jew ship" reportedly headed to Gdynia, Poland. ${ }^{377}$ Although the term "Aryan" continued to be used in order to distinguish between Jewish and non-Jewish Danes, the context in which it was used after October 4 changed - descriptions of refugees giving their children to stay with "Aryan" families before they fled being one such example. Moreover, the word "invasion" was never used after October 4 to describe the number of refugees arriving to Skåne but was instead supplanted for the word "stream". Also, in the article about the Brunns-guests where a child could be seen in one picture and a group of women in another, an adjacent article bore the heading "Strangers became friends for life"; thereby underscoring the friendly spirit that existed between the escapees. ${ }^{378}$

Although both victims and survivors of Nazi persecution, the Danish Jews were sometimes mistrusted as witnesses to their own strife. Indeed, in this regard they were sometimes perceived as unreliable and subjective-as if they were the legitimate adversaries of Nazi Germany. Evidence of such presumptions can be found in an article published in Stockholmstidningen on October 5, with the headline "Hundreds of Jews Begged in Vain for Boats". "A Danish witness tells us:" begins the lead of an article within which can be read that "an incredibly reliable refugeehimself not a Jew" has made many trips along the Zealand coast since the action

376 SvD 4/10 "Det överväldigande antalet är judar. De senaste dagarna har det inte kommit mer än två procent ariska flyktingar till Helsingborg!’].

377 SvD 6 October "Skräcknätter över Danmark då judarna arresterades."

378 SvD, 6 October "Danska flyktingarna få hjälp på löpande band," [“Obekanta blevo vänner för livet"]. See also "Otröstlig sorg blandas med glädje åt livet," October 7, 1943, Aftonbladet, 1. The lead stated "90 year old relinquished space for younger people". 
began and can attest to the desperation and panic of the fleeing Jews. ${ }^{379}$ Assuming that their readers would not trust Jewish narratives of Nazi persecution, the article relayed the horrific scenes on the coast of Denmark through a reliable non-Jewish witness who could give his objective perspective on these events. Furthermore, in the other newspapers, articles communicated the refugees' experiences through second-hand narratives based on interviews with the refugees, seldom letting these speak directly through the article. In the few cases that the refugees were quoted in the news articles, they spoke to the bravery of their non-Jewish helpers as well as their own gratitude towards these people. For example, in the article accompanied by the cartoon of the women with the sleeping toddler and the little girl, the lead stated that "Danes who have found a safe haven tell their stories" followed by an account of how the Danish coastal population risked their lives to save their Jewish brothers and sisters. ${ }^{380}$ Similarly, on October 6 a Danish-Jewish man was interviewed for Göteborgs Handels- och Sjöfarts Tidning, telling its readers about the difficulty of bringing children on the boat, lest they make a sound and expose the whole company to Nazi officials. However, aside from this part of the story (first presented in the headline "Danish refugees sedate their children before departing") the cost of the journey and the sacrifice of those who took them was central to the narrative. ${ }^{381}$ The refugees were thus seldom quoted in reference to their own experiences of being persecuted but were instead allowed to give testimony to the selflessness and bravery of their non-Jewish Danish brethren as well as their gratitude toward the Swedish people.

One of the first groups onto which the concept of Holocaust survival was attached in Swedish news discourse was the fleeing Danish Jews. The victim status of the Danish-Jewish escapees was intimately linked with representations of them as "True Victims" which, in turn, contributed to the idea of a Jewish survivor of Nazi persecution who both deserved and should receive Swedish protection and care. Rather than being personalized or individualized in the news articles, the refugees' arrival was framed by problematizations regarding the immediate needs of the escapees in relation to the logistical and economic issues that their presence brought. By portraying the refugees as women and children, however, the

379 "Tusentals judar tiggde förgäves om båtar," October 5, 1943, Stockholmstidningen [“En ytterst trovärdig flykting—själv icke jude"].

380 "Tyskar hjälpte judar fly. Priset: alla deras pengar," October 8, 1943, Göteborgs Handels- och Sjöfartstidning. See also "Danskarna se rött då judiska kvinnor häktas," October 5, 1943 Aftonbladet and "Gråtande flyktingar belägrades i svenska legationen i Köpenhamn," October 7, 1943, DN. 381 "Danska flyktingarna," October 6, 1943, Göteborgs Handels- och Sjöfartstidning. 
neediness of the refugees as well as their absolute victimhood justified this temporary burden. With the editors establishing a clear boundary between right and wrong in their staunch critiques of the Nazis' actions against the Danish Jews, Swedish responsibilities to care for the refugees became a moral imperative. Although the attention paid to Swedish-Jewish aid in these articles could be interpreted as a problematization of the Danish Jews as economic burdens, it could also be viewed as a way to further appease the critical voices that did not think the Danish Jews should have received Swedish aid. Thus, by assuring these readers that officials from the Jewish community in Stockholm as well as central representatives of Swedish welfare-oriented government agencies had travelled down south to aid in efforts to care for the newly arrived refugees, the newspapers also mitigated any malcontent concerning the shift in Swedish asylum policy on behalf of the Danish Jews. Primarily, however, this news discourse demonstrated a broad consensus between the newspapers on the responsibility that should be taken on behalf of the refugees who had been forced to flee their native country. They were not subjects with agency and will, but objects onto which pity and notions of Swedish generosity could be projected. What is more, the Danish Jews were not engaged as "moral witnesses" by the Swedish press. Instead, they were treated as victims whose stories only elucidated parts of their own struggles; primarily communicating how these had been alleviated by their Swedish neighbors. The reporters and correspondents who wrote about the refugees as well as non-Jewish Danes and Swedish rescue workers who were quoted in the articles were, as Dean terms them, "dismayed spectators" whose testimonies were perceived as credible, and therefore also effective, in creating sympathy for the victims. As we shall see in the coming sections, the end of the war would produce similar forms of media representations where non-Jewish camp survivors testified to Jewish suffering in the concentration camps; a relationship between witnessing and victimization which also affected the concept of survival. 


\section{5 1945: Guests of the Swedish State}

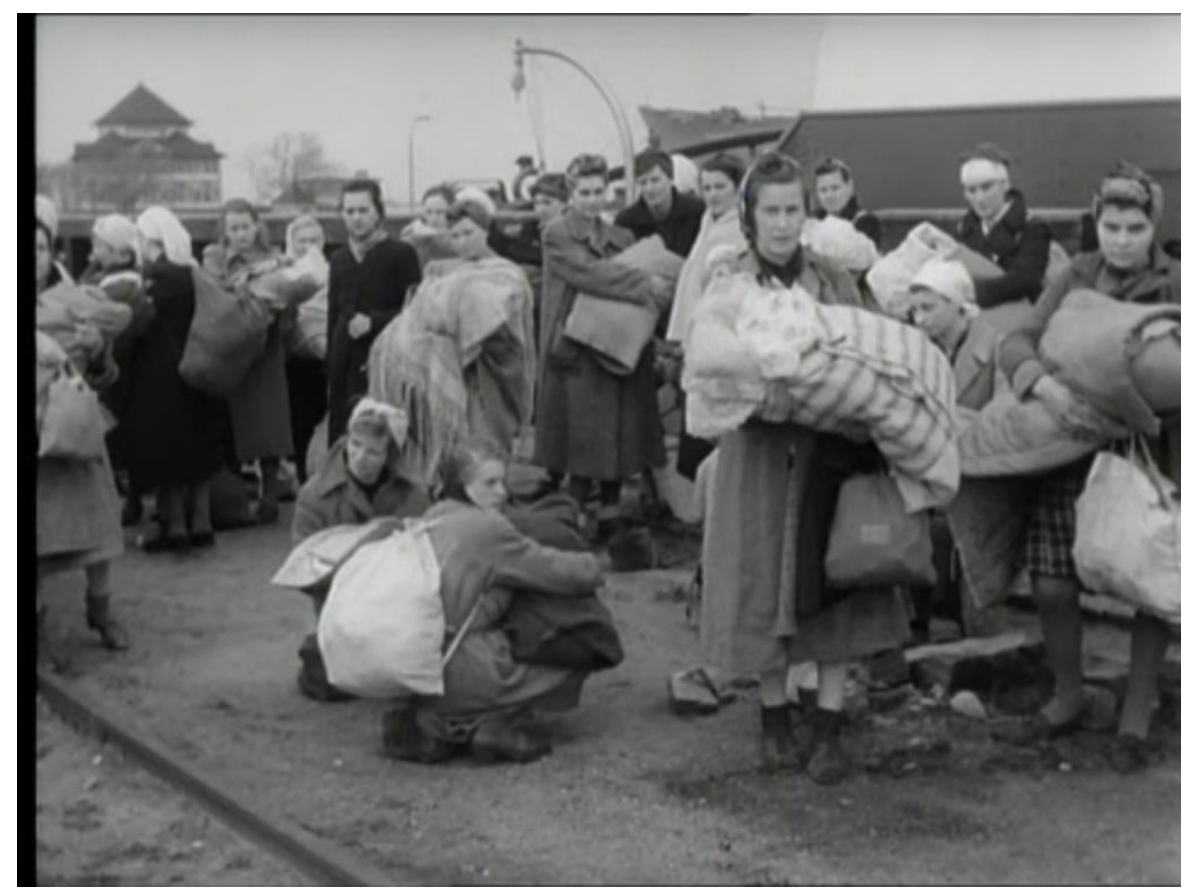

Still photograph taken from the news reel Vittnesbördet ("the Testimony"), directed by Nils Jerring, 1945.

The Swedish population's first encounter with great numbers of camp survivors came during the late spring and early summer of 1945. As opposed to those rescued from Denmark in 1943, these were the remnants of the full force of Nazi terror; those who had not been able to escape or go into hiding. They thus represented another form of survival and were more heterogeneous with regards to national, religious and social background, carrying with them stories of unimaginable atrocities at the hands of Nazi officials, the effects of which were also visible on their faces, bodies and the clothes they arrived in. Through the forbearance of the Swedish and Danish Red Cross as well as UNRRA, thousands of camp survivors came to Sweden in April, May, June and July of 1945. In addition, more camp survivors arrived under quotas specified for relatives of those rescued through these missions, as well as other special circumstances relating to further migration, severe illness and labor shortages. ${ }^{382}$ After initially being interned at various 
locations around Sweden, some were repatriated, some stayed and made a life for themselves, while others migrated elsewhere. ${ }^{383}$

In the early news discourse surrounding the rescuees of the "White Buses" mission, Scandinavian camp survivors testified to their own victimization as well as to the exceptional victimization of the Jews at the hands of Nazi guards and camp officials. The Jewish camp survivors that arrived with the "White Buses" were rarely quoted in the news articles and, as in the case of the Danish Jews, reporters' descriptions served as the foremost form of witnessing to the Jewish victims' experiences. Similarly, Vittnesbördet ("The testimony")—a news reel depicting the "White Buses" mission — excluded any interviews with those rescued, making the footage and narration speak for the individuals shown on the screen. It was not until the radio reportage Med en last av levnadskval ombord ("With a load of life anguish aboard") — recorded on a "White Ship" as part of the UNRRA mission-that Jewish camp survivors were heard speaking at length about their own victimization and the crimes that had been committed against them. In this section, I attempt to understand how these different mediums contributed to the conceptualization of victimization, witnessing and survival in relation to camp experience. Were these rescuees constructed as "moral witnesses"? How was their victimization related to their nationalities, their gender and their Jewishness? And, finally, how did these concepts affect discourses on Holocaust survival?

\section{Swedish Rescue Missions during the Second World War Revisited}

The "White Buses" mission and the UNRRA mission were by far the biggest reasons for the arrival of survivors in Sweden at the end of the war. ${ }^{384}$ The first

383 There is no research or reliable statistics regarding the numbers that stayed or the numbers of those who migrated elsewhere after having spent some time recovering in Sweden. Through various lists, there is some idea of how many individuals reached Sweden in 1945 as well as how many of these individuals died in the suites of their camp experiences. In the 1970s the PolishJewish camp survivor Adam Lezniewski conducted a survey with camp survivors of the Holocaust and estimated in his report that 21000 refugees who had survived the camps resided in Sweden in 1972. From his phrasing it seems that he acquired this information from the Jewish community in Stockholm's member registers and documents from the Stockholm city archive, but he does not specify his estimates further. See Riksarkivet (RA), Adam Lesniewskis samling, vol. 2, “Acklimatisering av judar f.d. koncentrationslägers fångar till det Svenska samhället," 1.

384 Hansson also presents seven different categories of survivors who came to Sweden outside of these two rescue missions: 1) close relatives to those rescued (parents over the age of 60 , spouses, 
large-scale initiative to rescue prisoners from German concentration camps was launched in the early spring of 1945, when Count Folke Bernadotte, the vice president of the Swedish Red Cross, negotiated with Heinrich Himmler for the release of Scandinavian concentration camp internees. In cooperation with representatives of the World Jewish Congress and the Danish Red Cross, the Swedish Red Cross rescued approximately 15,000 individuals from German concentration camps and work houses through what was later named the 'White Buses' mission. ${ }^{385}$ The mission was initially primarily aimed at the rescue and repatriation of Norwegian and Danish internees (both Jewish and non-Jewish), but later also included the rescue of primarily French, Belgian and Polish women, some of whom were Jewish, from Ravensbrück concentration camp. In the 1990s and early 2000s, the selection-process of prisoners and the logistical organization of the mission came under scrutiny. In Bosse Lindqvist's radio program from 1998 entitled Take the Jews Last, the mission was criticized for prioritizing Scandinavians before Jewish internees, especially considering the fact that Scandinavian prisoners had a relatively high standing in the camps' victim hierarchy already. The historian Ingrid Lomfors later built on this argument in her book Blind Fläck from 2004, where she addresses an episode during the mission when the 'White Buses' had to move sick prisoners to another camp in order to make more room for Scandinavian prisoners.

Even though the "White Buses" mission holds a central place in Swedish memory culture and became a contentious example of Swedish realpolitik vs humanitarianism in the 1990s, few academic attempts have been made to establish how many survivors it brought to Sweden in the spring of 1945. In fact, up until 2004, only the popular historian Sune Persson and the former rescue worker Inga Gottfarb had presented any real figures pertaining to numbers rescued. However, in his book Flykt och överlevnad ("Flight and Survival") from 2004_requested by the Jewish community in Stockholm as a study of Swedish-Jewish rescue work during the war - the Swedish historian Svante Hansson estimates that the number of Jews arriving with the white buses was approximately 4500 individuals (from both Scandinavian and non-Scandinavian countries), most of them women. ${ }^{386}$ This is

children under the age of 16);2) migrants who were presumed to continue onto a third country in the near future; 3) labor migrants; 4) Very sick DPs; 5) refugees from areas occupied by the red army; 6) survivors with special permission to enter Sweden; and, 7) illegal immigrants. See Svante Hansson, Flykt och överlevnad, 281-282.

385 Sune Persson, Vi åker till Sverige: De vita bussarna 1945, (Rimbo: Fischer \& Co, 2002), 436. 386 Hansson, Flykt och överlevnad, 279. 
more than Gottfarb's estimate (3112) (37 $^{387}$ and less than the figures given by Persson who refers to Gilel Storch's estimates of 6000 to 7000 Jews saved. ${ }^{388}$ The great difference between Hansson's and Persson's figures lies in a discussion on the number of unrecorded Jews - those who had been left out of the official statistics due to definitional problems (whether the survivor had two Jewish parents or had been labelled a 'mischlinge', etc.) and those who had feared further anti-Semitic measures and concealed their Jewish heritage/identity. ${ }^{389}$ While Persson believes that this number could be as high as 2000 to3000 individuals, Hansson counters this contention by arguing that since most Jewish survivors came from Central and Eastern Europe and were thus likely to have full Jewish parentage, the figure should be much more modest than what Persson suggests. In addition, Hansson concedes that many Jews were perhaps hesitant to admit to their Jewish heritage in fear of reprisals, but the number, he adds, is likely to be much less than what Persson has argued. Thus, whereas Hansson contributes some nuance to earlier estimates of rescued Jews, there are no certain figures regarding the total number of camp survivors rescued.

In promising to help the allies in their humanitarian efforts, the Swedish government also agreed to take in and care for approximately 10,000 very ill camp survivors from Bergen-Belsen; a rescue operation which was later referred to as the UNRRA mission. If the "White Buses" mission remains an understudied area within Swedish academic historiography, the "White Ships", bringing individuals suffering from typhoid and relatives to those already rescued to Sweden, can easily be considered an almost completely forgotten piece of Swedish history. Although Byström discusses parliamentary reactions to the mission and Hansson concludes that approximately 6900 Jews (a majority of which were women) were saved by the mission, no in-depth analysis has been undertaken with regards to the fate of those rescued or the organization of the mission itself (selection process of prisoners, economic incentives, rehabilitation and care, etc.). ${ }^{390}$ As such, UNRRA remains a blind spot in Swedish historiography on rescue and the survivors it brought in 1945. It should also be noted that both Hansson's discussions on numbers saved focus primarily on Jews versus non-Jews; an understandable focus considering that Hansson's book was written on behalf of the Jewish community in Stockholm.

387 Gottfarb, Den livsfarliga glömskan, (Stockholm: Langenskiöld, 1986), 276.

388 Persson, Vi åker till Sverige, p. 437.

389 Hansson, Flykt och överlevnad, 279. Persson, Vi åker till Sverige, 436-437.

390 Hansson, Flykt och överlevnad, 285. 
Thus, Hansson's study is underpinned by a definition of the Holocaust that denotes the total destruction of the Jews, making 'the survivor' ("överlevande") de facto Jewish. The problem does not lie in Hansson's focus—an important one, indeedbut rather, in the fact that few historians have taken an interest in other potential Holocaust victims who came to Sweden with the "White Buses" mission such as the Roma or gay camp survivors. These numbers are likely low, primarily because no representative at the Red Cross negotiated to have such prisoners released from the camps. Also, those prisoners who were able to get on a bus or boat to Sweden despite not making it onto a rescue list, would, similar to some Jewish victims, not divulge their true identity as either Roma or queer after their arrival. There might thus also be non-Jewish Holocaust survivors hidden in the statistics as Belgian, French, Polish and Jewish rescuees that have yet to be accounted for.

As was discussed in the introduction to this dissertation, historical analyses of how the Holocaust was represented at the end of the war grew in number when issues of guilt, heroism and Swedish migration policy during the war came under public scrutiny. The questions that many Swedish historians have attempted to answer when studying Swedish rescue missions in 1945 thus center on issues relating to Holocaust consciousness and constructions of the refugee. ${ }^{391}$ Thor Tureby has, as previously mentioned, also studied survivor representation, focusing on both the Southern Swedish press as well as the Swedish-Jewish press. ${ }^{392}$ Representations of camp survivors in the Stockholm-based press have also been studied in Antero Holmila's Reporting the Holocaust in the British, Swedish and Finnish press, 1945-1950.393 One of the key issues that both Holmila and Thor Tureby emphasize in their research is the distinction between how Jewish camp survivors were represented vis-à-vis other survivor/refugee groups. With regards to representations of both Jewish victims and Jewish refugees found in the Swedish press in the spring and summer of 1945, Holmila argues that Jewish camp survivors were more visible than previously assumed, especially when compared to the British context. In contrast, Thor Tureby demonstrates that although the southern press did not shy away from descriptions of Jewish refugees, they received relatively little media space in relation to their numbers (estimated by Thor Tureby as approximately 33 percent of those rescued by the White Buses and the UNRRA

391 Svanberg and Tyden's Sverige and Förintelsen is an example of the former while Byström's En broder, gäst, och parasit is an example of the latter.

392 Thor Tureby, "Svenska änglar och hyenor möter tacksamma flyktingar, 266-300.

393 Antero Holmila, Reporting the Holocaust in the British, Swedish and Finnish Press, 1945-1950

(Basingstoke: Palgrave Macmillan, 2011). 
mission). ${ }^{394}$ How did this relative marginalization of Jewish voices affect the construction of camp survivors as "moral witnesses" to genocide? What form of survival was attached to those survivors who were represented? And if Jewish suffering was still visible to some extent, how did the portrayal of this victimization compare to that of other victim categories?

\section{Camp Survivors: Scandinavian Resilience and Jewish Suffering in the Stockbolm-based Press}

The newspaper coverage from the liberated camps presented some of the first representations of camp survivors in Swedish media. Moving from what Holmila describes as a "a certain aloofness" concerning reports from the liberated camps, to a heightened awareness and concern when confronted with the camp survivors rescued to Sweden in April and May, the Swedish press' interest in the subsequent waves of camp survivors coming to Sweden soon died down, meaning that the arrival of rescuees through the UNRRA mission never made any significant headlines in the Stockholm-based newspapers. In the initial coverage from the liberated camps, most newspapers avoided publishing the graphic images taken by British and American war photographers. ${ }^{395}$ Indeed, as Holmila elucidates, DN's Daniel Viklund even "argued that it was unpleasant and unsuitable for the Swedish press to expose this disgusting photographic material as evidence of Nazi cruelty". ${ }^{396}$ Yet, one evening newspaper, Expressen, and the image-based biweekly magazine, $S e$, did not adhere to this tacit agreement amongst the dailies. A liberal newspaper, Expressen was born in 1944 as a part of the press conglomerate to which DN belonged. Although Expressen remained far behind Aftonbladet in terms of its circulation, it was innovative and pioneering in its more tabloid-like format which was expressly aimed at young people and women who, by joining the work-force during the war, had "become involved in the societal process in a more active way than before." 397 On April 26, Expressen published a full spread depicting scenes from Bergen-Belsen. As Holmila also points out, a survey was later conducted which aimed to show how Expressen's readership had reacted to the images. Given the people that had been asked, a small sample from the general public and known

394 Thor Tureby, "Svenska änglar och hyenor," 279.

395 Holmila, Reporting the Holocaust in the British, Swedish and Finnish Press, 37-38.

396 Holmila, Reporting the Holocaust in the British, Swedish and Finnish Press, 38.

397 Editor-in-chief of Expressen, Carl-Adam Nykop cited in Elisabeth Sandlund, "Beredskap och

Repression," in eds Karl Erik Gustafson \& Per Rydén, Den svenska pressens historia, (Stockholm: Ekerlids förlag, 2001), 378. 
public figures with different political leanings, it is not necessarily surprising that responses were ambivalent-some expressing disgust and abhorrence, others showing sympathy for the victims, while Sven Hedin, a known Hitlerite, questioned the veracity of the pictures. ${ }^{398}$

When considering the text which accompanied the images, however, it was the camp survivor-witness rather than the depicted victims that was central to the story given in the article. The most harrowing picture published in Expressen on April 26 showed a pile of corpses, loosely covered by blankets. Next to the bodies stood a man and his son, the latter reaching down towards the exposed and emaciated legs of the victims. The caption quoted the father exclaiming that "the Germans cannot touch our own!" and continued to explain that the father and son were Poles who had found some of their relatives among the corpses and were covering them up in preparation for their burial. As the dead bodies were partially covered and wholly anonymized, it was the father and son caring for their relatives that made up the meaningful object of the picture. Above the picture, the headline read in bold, large letters: "Witness account about the perpetration". In the lead, the article's author defended the publication of the pictures by stating that "they forever are going to establish and prove what Nazi barbarity has meant for Europe with regards to a cultural eclipse and a systematic undermining of the concept of humanity". ${ }^{399}$ However, the author continues, the pictures will also be narrated by one who has lived through the camps. Thus, the "Austrian shoe-maker" Otto Wilhelm and his story from Dachau and Buchenwald was featured along with the pictures, as well as a headshot of Wilhelm himself. In his story, there were no references to victim groups, only to the camaraderie between the different political prisoners. From his narrative, one can also assume that Otto himself had become a prisoner due to his communist/social democratic views. The camp survivor voice is here posited as a crucial accompaniment to the pictures, filling in the blanks and lending authenticity to what is shown in them. This also supports Holmila's contention with regards to later Swedish reporting on the Holocaust that "photographic evidence was not seen as the main component of establishing an authentic record. Instead, survivor interviews occupied the prime place in the Swedish reporting, therefore placing the survivor experience at the heart of a wide range of issues that the camps had raised." ${ }^{400}$

398 Holmila, Reporting the Holocaust in the British, Swedish and Finnish Press, 39.

399 "Vittnesmål om förbrytelsen," April 26, 1945, Expressen, 14.

400 Holmila, Reporting the Holocaust in the British, Swedish and Finnish Press, 42. 
In the article, the camp survivor-witness was not only a central figure but also a valiant and almost martyr-like person-someone who was punished because of his resistance to the Nazis rather than someone who was marked for annihilation due to his/her race. In contrast, the perpetrators were described as criminal prisoners and one of the camp's officers, in the article called obersturmbanführer Jonny, is described as a "homosexual figure whose brutality was incomparable". 401 Rather than being something which would have marked a prisoner for destruction, homosexuality was instead an aspect used to further vilify and pathologize the Nazi tormentors. Here, the victims and survivors were depicted as honorable men, whereas the perpetrators were portrayed as sadistic and criminal beasts with perverse leanings. Conversely, the survivor-witness described in the article had agency and spirit, moving him out of the passive victimhood category and into something more powerful—survivor-hood.

Holmila contends that even though Jewish victims and Jewish suffering were more prominent themes in the Swedish press compared to the British press, "the narrative was predominantly constructed along the lines of 'Nordic victimhood', which was, in a sense, diverted Nationalism". 402 To be sure, the Nordic narrative, which primarily focused on the excellence of Swedish rescue, dominated the press coverage on the "White Buses" mission. ${ }^{403}$ This did not mean that Jewish suffering was not visible in the Swedish press, particularly in relation to the Scandinavian Jews. DN was, by far, the newspaper that emphasized Jewish suffering the most in its early coverage of the mission. Indeed, even before the government's media censorship on the mission had been lifted, DN published articles about numbers saved and the progression of the mission, including interviews with rescued Norwegian Jewish men, giving names and places of origin. ${ }^{404}$ Yet, when considering the news structure of the articles that were written, even in DN, about the camp survivors in the first few days after the censorship had been lifted, one

401 "Vittnesmål om förbrytelsen," April 26, 1945, Expressen, 14.

402 Holmila, Reporting the Holocaust in the British, Swedish and Finnish Press, 46.

403 “Du gamla du fria—ett visslat tack," May 2, 1945, DN. "Nya Kläder åt 16000 fångar,” May 3, 1945, DN. "16 000 fångar till Sverige—24 nationaliteter,” May 5, 1945, SvD. "Utan Röda Korset hade jag inte varit i livet," May 6, 1945, SvD. “19 000 räddades,” May 5, 1945, Expressen. "21 500 flyktingar till Sverige, betydligt fler än vad som väntades," May 1, 1945, Aftonbladet. "Röda korsets arbete i Tyskland nu slutfört," May 1, 1945, Aftonbladet, 1. "Fantastiska scener vid Köpenhamnsfärjan," May 2, 1945, Aftonbladet, 1.

404 See Holmila, Reporting the Holocaust in the British, Swedish and Finnish Press, 42 as well "Sverige räddar Hitlers fångar," April 29, 1945, DN. 
can detect a clear hierarchy in the news coverage. For example, on the front page of the newspaper on May 3, a photograph showed female prisoners stepping off a ship at Malmö harbor. The headline read, "16,000 Prisoners to Sweden-24 different nationalities". The article continued on page 6 under the headline "New Clothes for 16,000 prisoners" under which two smaller articles were situated, one of which stated that "Red Cross packages relieved Jews". 405 In the article it could be read that the Danish Jews who had been deported in 1943 had been rescued from a camp in Böhmen-Mären, where they had stayed in private rooms, vacated especially for them. The only reference made to their victimization was that 50 of them had died in the camp. Thus, all headlines concerned the act of rescue itself, rather than specifics of those rescued. No Jewish survivor testimonies were included into these articles and in the headline for the short article dealing with the Danish Jews, the headline concerned the way that they had been helped by the Red Cross.

Moreover, on May 5, three articles about the "White Buses" mission were published in DN on pages 6,9 and 16. On page 6, the headline read "Rescued from Torture and Guillotine" above pictures of a Danish male rescuee and a Norwegian female rescuee. ${ }^{406}$ On page 9, a longer article on other rescuees was published under the headline "It is a Miracle that I am here" next to a picture of Charlotte Jackson; an American nurse and member of the French resistance who had been deported in 1944. ${ }^{407}$ Finally, on page 16, the headline read "Jewish orchestra played for the Red Cross", again emphasizing the gratitude expressed by the Danish Jewish rescuees towards the Red Cross. In this final article, it was reiterated that the Danish Jews had been treated well in Theresienstadt; something which was highlighted in this recounting of an interview with Captain Harald Folke:

It was an experience to see Theresienstadt with its 60,000 Jews, continues Captain Folke. There was no barbed wire around them. The Jews had their own agencies with their own bank and money, police corps, theatre and an

405 “16 000 fångar till Sverige—24 nationaliteter,” May 3, 1945 DN. "Nya Kläder åt 16000 fångar."

“Nya Kläder åt 16000 fångar," May 3, 1945, DN.

406 “Räddade från tortyr och giljotin,” May 5, 1945, DN, 6. "Det är ett under att jag är här,” May 5,

1945, DN, 9. “Judisk orkester spelade för röda korset,” May 5, 1945, DN, 19.

407 “Det är ett under att jag är här,” May 5, 1945, DN, 9. 
orchestra that played when we left—an unforgettable memory". ${ }^{408}$

Also, the pictures accompanying the article did not show the rescued Jews but, rather, a portrait of Major Sven Frykman who had led the expedition, as well as a picture portraying Danish policemen arriving at the train station in Copenhagen framed the text. The whole article, although headlined by information on a Jewish orchestra, concerned the rescuers and not the rescuees. In addition, testimonies of Theresienstadt came from the rescuers which meant that the victims themselves could not testify to the treatment of them in the camp. Instead, the implication underlying the interviews conducted with Captain Folke, was that the Nazi's 'model ghetto' had spared the Danish Jews from any hardship during the war. As will be argued throughout this section, this witnessing by the media contributed to a marginalization of the Jewish camp survivor witness, even in relation to the Scandinavian Jews, indicating that the concept of a "moral witness" of Genocide had not yet been born. ${ }^{409}$

Even in the article in which camp survivor testimonies were a central feature, the Jewish accounts tended to disappear in the news structure. In the article from May 5, on page 9, the headline cited a British Franciscan nun and the picture showed the American Charlotte Jackson. Also, in the article, albeit further into the article text, Polish-Jewish women were featured: one of them was quoted stating that Jewish women had been sent straight to the gas chambers, before even receiving a tattooed number on their arms. The Polish-Jewish woman's voice, however, was only one of many voices - a voice that was not prioritized in the news story. ${ }^{410}$ Again, this did not mean that Jewish suffering was not a significant part of the newspaper discourse, only that their testimonies were not afforded the space or placement in the text which would have underscored the particularity of their suffering. Even though the article text stated this particularity, it was never reflected in the news structure. It was also uncommon in these news articles that Jewish camp survivors were quoted in the text. In an article in DN, published the same day as that which described the Polish-Jewish women, non-Jewish female

408 “Judisk orkester spelade för röda korset," May 5, 1945, DN, 19. ["Det var en upplevelse att se Therienstadt med dess 60000 judar, fortsätter kapten Folke. Ingen taggtråd fanns omkring dem. Judarna hade självförvaltning med egen bank och egna sedlar, poliskår, teater och ett operakapell, som spelade då vi for vår väg-ett oförglömligt minne”].

409 Dean, The Moral Witness, 2.

410 “Det är ett under att jag är här," May 5, 1945, DN, 9. 
Norwegian and Danish camp survivors testified that "Jewesses" had been "'sorted" to crematories". The text itself described how "naked Jewesses" had to parade in front of a "commission" before they were selected for death. ${ }^{411}$ The reference to hordes of naked female victims would later become an important symbol for Nazi cruelty during the Belsen trial, a subject which will be dealt with further in section 3.6. More importantly in this context, however, was that non-Jewish camp survivors, yet again, testified to Jewish suffering, thus supporting the conclusion that a particular Jewish survivor-witness, with the moral authority to speak for Jewish suffering had not yet been formed as a concept. Instead, others-rescue workers and fellow prisoners - testified to the exceptional victimization of the Jews in the camps.

One of the main narratives in the Stockholm-based press during the first week of arrivals regarded the different conditions that the camp survivors seemed to be in. Indeed, in an article in DN, published on May 12, the correspondent reflected on the fact that these later arrivals showed rescuees who looked thinner, sicker and more worn than previous contingents seen stepping off the ships. In the lead, the article declared that "it was a gloomy caravan [of people] who wandered over the ship's gangplanks, gaunt, sick people, dressed in indescribable rags, and nowhere a happy face". "The character" of this later transport, the lead continued, was of a different kind to that of earlier transports, where the rescuees had been relatively well kept and put together. ${ }^{412}$ This was also one of the main narratives in the early reporting on the mission where one of the underlying questions was: how come the Scandinavians had fared so well and survived in such great numbers in the concentration camps? As an answer to this question, the resilient spirit of those who had survived the camps was underscored in several of the newspaper articles; a form of survival which was primarily attributed to non-Jewish Scandinavians. For example, in Aftonbladet, a Norwegian female camp survivor was described as "healthy, happy and strong", explained by the woman herself as a result of her dedication to "outdoor life and exercise". 413 "The camp uniform will surely be

411 “Märg sögs ur benpiporna, levande låg i likhögar,” May 5, 1945, DN.

412 “1400 trasiga, sjuka fångar till Malmö från Tyskland,” May 12, 1945, DN [“Det var en dyster karavan som vandrade över fartygets landgångar, magra, sjuka människor, klädda i obeskrivliga paltor, och ingenstans såg man ett glatt ansikte. Denna transport var överhuvudtaget av en helt annan karaktär än de kontingenter av flyktingar som hittills kommit hit till landet”].

413 "Fantastiska scener..." May 2, 1945, Aftonbladet, 2 [“Hon var frisk, glad och stark. 'Men det beror på att jag alltid älskat friluftsliv och kroppsrörelse" "Hennes lägerdräkt blir säkerligen något av en hedersuniform när hon kommer till sitt land igen”]. 
somewhat of a badge of honor when she returns to her own country" the correspondent suggested. The jauntiness of the Norwegian woman stood in stark contrast with the ways in which other victim groups were portrayed. The Jews were, for instance, said to have been "treated with particular sadism", and a Red Cross worker was cited as saying that "there is no doubt that the Jews have been put through the roughest treatment". In addition, the correspondent described how "all Jews, without exception, generally made up a ghastly sight", many of whom were mere skin and bones. ${ }^{414}$ Although the Norwegian woman was mentioned as a fine specimen of vivaciousness and life, the female camp survivors were, as a group, said to make a "disheartening impression" with "fate having put his harsh stamp on them". 415 Hence, the Scandinavian camp survivors (of which a majority were men) symbolized survival and agency, while the Jewish camp survivors were primarily represented through descriptions of exceptional victimization in the camps; making the former a survivor ("överlevare") whereas the latter became a surviving remnant (“överlevande”).

Another example that highlights this framing of survival was that of the Danish police office whose photograph was published in several newspapers on May 5. ${ }^{416}$ In DN, a sub-headline to the article featuring the Danish Police officer read "eyes burned on silent patriot" after which it was described how the former prisoner had refused to give up the whereabouts of his friends to the gestapo; an act of bravery that had meant that one gestapo officer had "lifted his eyelid and pressed a burning cigarette against his cornea". ${ }^{417}$ Although denoted as a "victim of gestapo terror", the story of how the man's corneas and eardrums were mutilated also relates to his choice not to comply with Nazi orders, thus making him an active, heroic victim. The same article also described how a Norwegian man smiled out of a train window with a "weather worn face on a pair of broad shoulders, a body that not even three years in prison and concentration camps could destroy",

414 "Fångnumren brändes in i huden," May 5, 1945, Aftonbladet, 10 ["Det är ingen tvekan om att judarna varit utsatta för den mest hårdhänta behandlingen. Alla utan undantag utgjorde $i$ allmänhet en anskrämlig syn"].

415 “Fantastiska scener...” May 2, 1945, Aftonbladet, 2 [“Ödet har satt sin hårda stämpel på dem, och i sina trasiga lappade dräkter...har de gjort ett beklämmande intryck"].

416 "Räddade från tortyr och giljotin," May 5, 1945, DN. "Utan Röda Korset hade vi inte varit i livet," May 5, 1945, SvD. These photographs were also published in the local press, see for example “Autentisk berättelseexposé över den Nazistiska 'fångvården,"” May 5, 1945 Trelleborgstidningen. "Ohygglig Sadism och råhet i tyska koncentrationsläger," May 5, 1945 Sölvesborgstidningen.

417 “Räddade från tortyr och giljotin,” May 5, 1945, DN, 6. 
again extending the narrative of Scandinavian heroism to encompass resilience and active forms of survival. ${ }^{418}$ In the lead to SvD's article depicting the Danish man, it was stated that those who survived did so because of their extraordinary resilience: "from their long years in captivity they bring with them horrific memories; that so many have been able to survive could perhaps be explained by, as a doctor put it, "those who can stand it, can stand almost anything". 419 The man's picture and story were connected to the notion that survival was an inherent strength - if you could withstand torture by the gestapo you could also withstand years in a camp. The man who was featured in both the Stockholm-based and the local press as well as in Vittnesbördet became a symbol for the toughness and resilience of the Scandinavian people. The message communicated was that only those who were strongest, both mentally and physically, could withstand the Nazis. ${ }^{420}$ Rather than position the Scandinavian camp survivors as lucky or fortunate in having been treated better than other inmates, their survival was attributed to their tenacity and resilience.

However, not all newspapers expounded this perspective on camp survival. Expressen, for instance, contributed to a nuancing of this framing of camp survival in an article with the headline, "Norwegian and Danish Prisoners 'Upper Class' when Care Packages from Sweden Arrived". ${ }^{421}$ The importance of these care packages for the survival of Scandinavian camp prisoners was significant, but never to the extent as in the full-page article published in Expressen on May 6. In DN, the correspondent writing from Malmö stated that in his conversation with the rescued women he had gathered that the Norwegian women's survival had depended on solidarity between these prisoners, their self-discipline, and the care packages received from the Swedish Red Cross. ${ }^{422}$ Here then, survival was partly attributed to help given to Scandinavian prisoners, but also to their own characteristics, that they were mentally strong and took care of each other. Rather than positioning the Scandinavian camp survivors as lucky or fortunate in having been treated better than other inmates, their survival was attributed to their tenacity and resilience.

418 "Räddade från tortyr och giljotin,” May 5, 1945, DN, 6.

419 "Utan Röda Korset skulle vi inte vara i livet," May 5, 1945, SvD [“Från fångenskapens långa år föra de med sig förfärande minnen; att så många ändå överlevat förklaras måhända med, som en svensk läkare sade, 'de som tål, de tål nästan vad som helst"].

420 "Utan Röda Korset hade vi inte varit i livet," May 5, 1945, SvD

421 “Norska och danska fångar 'överklass' när gåvopaketen från Sverige anlände,” May 6, 1945, Expressen.

422 “Märg sögs ur benpiporna, levande låg i likhögar,” May 5, 1945, DN. 
As can be gathered from the examples expounded above, witnessing, victimization and survival were all related to ideas of gender in the early reporting on the "White Buses" mission. From late April into the first week of May, different figures regarding those rescued circulated in the national press. In SvD it was reported that an estimated 19,000 individuals had been saved, while DN proclaimed that 16,000 had been brought to Sweden by May 3. ${ }^{423}$ On May 5, Expressen declared in a headline that "21,500 refugees" had come to Sweden, which was "considerably more than expected". ${ }^{424}$ These figures were then deconstructed in the news discourse according to nationality and gender. As women often arrived separately from the male rescuees, it is not surprising that these reports differentiated between men and women. However, this differentiation also meant that notions of victimhood and survival developed in relation to ideas of a gendered suffering. In the case of the non-Jewish Scandinavian women, their high survival rates and healthy looks were explained by care packages, their solidarity and their character. At the same time, in many of the articles featuring the Danish Police officer, a photograph of a Norwegian woman, holding up her tattooed arm to the camera was also shown. ${ }^{425}$ Together, these two individuals symbolized both the survival and the victimization of the Scandinavian rescuees; a balancing act which simultaneously positioned Scandinavian men and women as pitiful victims and courageous resistance fighters. For example, in an article in DN, the rescued Norwegian and Danish women (said to be 120 in number) were described as a "miniature women's army" as they walked off their ship at Malmö harbor. ${ }^{426}$ The non-Scandinavian women and their suffering were, on the other hand, only framed in relation to victimhood. These women were thus featured as the ultimate proof that the camps had not been intended for enemies of the Nazi state; a representation made possible by the addition of details in descriptions of women's

423 “Röda korset har befriat 19,000 fångar i Tyskland,” May 6, 1945, SvD. "Nya kläder till 16,000 fångar," May 3, 1945, DN.

424 “21 500 flyktingar till Sverige, betydligt fler än som väntades," May 5, 1945, Expressen, 10.

425 "Fångnumren brändes in i huden," May 5, 1945, Aftonbladet. "Räddade från tortyr och giljotin,"

May 5, 1945, DN, 6. "Ohygglig Sadism och råhet i tyska koncentrationsläger," May 5, 1945

Sölvesborgstidningen.

426 “Kända norska namn bland de lössläppta," May 3, 1945, DN: 
suffering; that they had to parade "naked", never received numbers, or that they were subjected to medical experiments. ${ }^{427}$

The marginalization of the Jewish witness, together with the gendered representation of Jewish and non-Jewish/non-Scandinavian victimization, proffered a construction of camp survival which was based on the passive victim/active resistor dichotomy. Scandinavian testimonies were thus used to elucidate all other suffering in the camps; in practical terms this seems unsurprising since language issues likely complicated interviews with non-Scandinavian camp survivors. Still, this inclusion of Scandinavian witness narratives into the news discourse meant that the Holocaust witness—a subject position with moral authority-was Scandinavian (including both rescuers and rescuees), whereas the "unproblematic", passive victim was non-Scandinavian and female. Added to this was the victim group described as most vulnerable: the Jewish women. Jewish men hardly appeared in the news articles, except in relation to general statistics over dead Jewish victims. ${ }^{428}$ Interestingly, the Danish-Jewish camp survivors were neither interviewed nor described at any great length, even though their survival was miraculous in comparison to the deported Norwegian Jews, where all except a small number had perished in Auschwitz. This tragic fact regarding the Norwegian Jews appeared in the news during the period studied but were not included to a great extent in the news discourse on the rescue mission. ${ }^{429}$

These conclusions related to the early news coverage of the "White Buses" mission all indicate that the witnessing conducted by the Stockholm-based press never contributed to conceptions of a Jewish "moral witness" testifying to a specific genocide of the Jews. Rather, the press facilitated the witnessing of camp torture, death and survival. However, this did not mean that camp survival was framed in the same way for all victim groups. While the survival of non-Jewish Scandinavian women and men was framed by arguments relating to Swedish aid and good character, Jewish and non-Scandinavian survival was only related to the rescue mission itself. This distinction between active and passive survival would become even more apparent when those rescued with the "White Buses" mission were shown on screen in the news reel film Vittnesbördet.

427 “Märg sögs ur benpiporna, levande låg i likhögar," May 5, 1945. "Det är ett under att jag är här," May 5, 1945, DN, 9. "Fångar byggde Hamburgkanal, 40,000 dog," May 5, 1945, Expressen. "Utan röda korset skulle vi inte vara i livet," May 5, 1945, SvD.

428 "1400 trasiga, sjuka fångar till Malmö från Tyskland," May 12, 1945, DN.

429 "5 av 700 överlevde," May 24, 1945, SvD. "I rapporter från Buchenwald berättades att bara 5....," May 3, 1945, DN. 


\section{Visual Encounters: The Case of Vittnesbördet}

In the spring and summer of 1945, the newspapers advertised that horrific scenes from Buchenwald and Belsen would be shown at the cinemas Röda Kvarn and Sagabiografen in Stockholm. ${ }^{430}$ In addition to these films that primarily depicted mass death, Svensk Filmindustri (SF) had been contracted to document the "White Buses" mission for Swedish cinema audiences. The result was a 21-minute news reel in which the director, Nils Jerring, presented both the organization of the mission and the state of those it had saved from the camps. This news reel, entitled Vittnesbördet ("The Testimony"), was shown in Swedish cinemas in May 1945, as the grand finale of a number of other short films, all featuring Swedish rescue efforts, including the four-minute-long Flykten över Sundet ("the Escape Across the Sound") depicting the rescue of the Danish Jews in 1943. Although Vittnesbördet was not a direct result of state propaganda, it reproduced the same narrative of earlier films whose express purpose had been to convey Swedish humanitarianism and solidarity with Europe's refugees, especially those escaping from Norway, Denmark and Finland. As images of survivors had been sparse in the daily newspapers, Vittnesbördet constituted one of the first visual encounters between Swedish audiences and Holocaust survivors.

Notably, Vittnesbördet did not contain any references to the religious/ethnic identity of any of its subjects, with the narrator only mentioning the various nationalities of those who were arriving in late April 1945. Vittnesbördet follows a narrative structure in which Folke Bernadotte is first shown flying off to South Germany to negotiate for the release of concentration camp prisoners from Germany. In these scenes, the narrator does not comment on the nationality of the intended rescuees. In the following footage, buses are shown preparing for departure. Even though the mission was purely humanitarian, Franz Schubert's Marsh Militaries (recognized by a majority of Swedes as the soundtrack to Disney's short film Santa's Workshop, which is shown on SVT each Christmas Eve) plays in the background to these scenes of preparation and departure. This piece of music together with the images of military vehicles (which are shown as camouflaged vehicles with red crosses painted on them rather than the white buses that are

430 "Buchenwald och Belsen, de fruktansvärda tyska koncentrationslägren,” May 16, 1945, Aftonbladet, 18. The headline is taken from the cinema and radio tableau page in Aftonbladet merely to exemplify how these films were advertised in the national press. Although I have not studied the local press systematically, I have found instances of the same form of advertisements in local newspapers such as Hudiksvallstidningen and Trelleborgstidningen indicating that these films were also shown in smaller cities and towns across Sweden. 
shown later in the film) travelling through Sweden on their way toward the continent communicates that Swedish involvement in the war was both important and righteous. After this opening scene, the rescued camp survivors are shown as they arrive on a ship to Malmö Harbor. First, both men and women are shown at the harbor, the men waiting in line outside a great ship, reading the paper while the women can be seen standing in groups, some with babies in make-shift cots. ${ }^{431}$ In passing, the narrator mentions that the interpreters hired by the Red Cross struggle with the religious strife amongst the former prisoners, alluding to the conflictridden relationship between Catholic Poles and Jews. Beyond this comment, however, the refugees are only attributed a gender and/or a nationality.

As in the case of the Danish Jews and the representation of them as both Danish and Jewish, it is difficult to say anything conclusive about why no mention was made of the Jewish victims in Vittnesbördet since little research has been conducted on antisemitism as discourse in Sweden during the war years. However, in a forthcoming article about representations of gender and victimization in $V$ ittnesbördet, I suggest that the silence regarding Jewish victims in the film shows both a tendency towards what Kvist Geverts terms an "Antisemitic background noise" as well as a concern for the vulnerability of the Jewish camp survivors. As Kvist Geverts expounds in her doctoral dissertation, opinion-makers such as the economist Karin Kock protested during the war against the differentiation between Jewish and non-Jewish Norwegian refugees; arguments which were exacerbated by the subsequent flight of the Danish Jews. ${ }^{432}$ The critique launched at this time concerned the reproduction of Nazi categorizations that were believed to lead to the furthering of Aryan/Untermensch dichotomies. Such concerns might then also have informed the way that the Nazi's victims were represented in Vittnesbördet. However, the Jewish identity of the camp survivors were secondary to their ability to demonstrate how well they were being cared for by the Swedish government. They were survivors whose victimization did not necessarily reflect Jewish suffering during the war but were, rather, symbols of Nazi cruelty and Swedish benevolence. It is this reduction of Jewish victimization that I attribute to an "Antisemitic background noise"; the Jewish catastrophe was not important enough to trump the excellence of Swedish rescue operations in the News discourse.

431 This is a representational phenomenon that Barie Zelizer has labelled the "overgendering of women" a strategy which reproduces "stereotypes of women as nurturing, domesticated, fragile, and vulnerable." See Zelizer, "Gender and Atrocity: Women in Holocaust Photographs" in ed. Barbie Zelizer, Visualizing the Holocaust, (London: the Athlone Press, 2001), 256.

432 Kvist Geverts, Ett främmande element i nationen, 221-222. 
The way that Vittnesbördet portrays female camp survivors in comparison to male camp survivors is also significant in this regard. In the film, women were shown in their most vulnerable states during the initial process of inspection and disinfection-naked in front of the Red Cross' medical staff and in the shower before receiving new clothes. In front of the camera, these women were thus transformed from former concentration camp prisoners into 'objects of care'. Showing these women going through a process of sanitation communicated a sense of responsibility and propriety in the Swedish reception of the camp survivors. As most non-Scandinavian survivors rescued by the 'White Buses' were women, it was most likely important to demonstrate that they did not bring any diseases with them. However, in several scenes the women were also shown when exposing their wounds, as well as the numbers tattooed on their arms and the effects starvation and unsanitary conditions had left on their bodies. Their physical appearance embodied Nazi cruelty; an aspect that made their apparent discomfort at being exposed to the camera in the nude insignificant in the greater framework of testifying to the violence that had caused them so much harm. In one of the scenes showing women showering, being sprayed with DDT and receiving new clothes, a little girl is shown. In one of the shots, she holds her small hands over her chest and smiles shyly into the camera as one of the male medical professionals stretches out a hand to shake hers. The little girl—a Dutch-Jewish woman named Irene Krausz-Feinman, who later emigrated to South Africa with her mother-was in 2011 interviewed for the Swedish film-maker Magnus Gertten's documentary film Hoppets hamn ("Harbor of hope"). ${ }^{433}$ In an interview with Gertten, Irene stated that her mother had been upset about how the delousing treatment had happened and "that there were men there, Swedish soldiers". ${ }^{434}$ She continued by explaining that these soldiers had been "in charge of the inspection, but [they] had been through similar things with the Germans and it felt degrading for the women to undress and be naked in front of these men". 435 The fact that the feelings of these women

433 Magnus Gertten, Hoppets hamn, (Auto Images AB, 2011).

434 Åberg \& Gertten, Hoppets hamn. När överlevarna kom till Sverige, (Malmö: Roos och Tegnér, 2012),

10. (see translated quote below). The book with the same title as the film was developed in connection with the documentary project and contains more comprehensive transcripts of the interviews with survivors.

435 Åberg \& Gertten, Hoppets hamn, 10, [“Men jag minns också att hon blev upprörd över avlusningen och över att det fanns manspersoner där, svenska soldater. De hade hand om kontrollen, men vi hade varit med om liknande saker hos tyskarna och det kändes förnedrande för kvinnorna att klä av sig nakna inför de här männen’]. 
was not considered by the Red Cross staff is perhaps not surprising under the circumstances, yet the fact that these female camp survivors were put on display for the greater part of the Swedish population to see is, on the other hand, deeply significant in that it demonstrates a tendency to overlook their humanity even after the rescue mission had been successfully completed. According to the American Holocaust historian Rochelle Saidel "girls were brought up to be modest, and many women were traumatized when forced to parade naked before men and even other women." Furthermore, she contends that women were "taught to be submissive and 'the weaker sex,", something which "they had to overcome... in order to stay alive. ${ }^{436}$ The female camp survivors had thus been dehumanized by being ordered to appear naked in front of the guards for orders and selection. In addition, they had been defeminized by taking on the role of 'the stronger sex' as a way of surviving the camps. In Sweden, they continued to be shown as dehumanized victims with the addition of becoming feminine objects in need of care and protection. In a way, this gendered representation serves as an early preamble to what Waxman has referred to as the construction of "unproblematic" female victims in studies of women and the Holocaust where "women's testimonies are often used to show us what we already want to see". ${ }^{437}$ By having their bodies displayed onscreen, these women both confirmed the Nazi cruelty that was already known at this point, as well as the organized and structured manner in which they were cared for by the Swedish state. What is more, contrary to what the title of the film implies, it was not the women witnessing through the medium of film but, rather, the film-makers witnessing by the medium; a fact which, when conflated, made it seem as if the women were, in fact, testifying with their own bodies.

In contrast to these female 'objects of care', the male subjects of the filmdescribed as Danish and Norwegian men-were represented lying in bed reading the newspaper and regaining their strength in a convalescent home. To be sure, the Scandinavian men who had been rescued also had to go through a process of sanitation, but this was not deemed necessary to show on screen. Instead, their "pristine pyjamas" and the newspapers "allude to images of the father, lying in bed on Sunday morning with his paper and breakfast tray". 438 The juxtaposition of

436 Rochelle G. Saidel, The Jewish Women of Ravensbruck Concentration Camp (Madison: University of Wisconsin Press, 1999), 210.

437 Waxman, "Unheard testimonies" p. 662.

438 Kristin Wagrell, "Jews, Gender, and the Scandinavian Subject: Understanding the Context and Content of the Film Vittnesbördet [The Testimony]," Early Holocaust Memory in Sweden, Palgrave Macmillan, Forthcoming. 
these two images - cowering naked women in the shower and content, relaxed men in clean beds-display a gendered construction of the camp survivor. ${ }^{439}$ While the female non-Scandinavian object is physically (and involuntarily) testifying to crimes already made known through other sources, the male Scandinavian subject is demonstrating the swift recovery of newly liberated Denmark and Norway. This representation of the Scandinavian men also shows that Holmila's contention about the concern for the restoration of the dignity of the survivors expressed in the Swedish press did not necessarily apply to the entire Swedish media landscape. Or, rather, that the act of establishing the humanity and dignity Scandinavian camp survivors did not seem to extend to all categories of camp survivors. Some also had to embody the cruelty of the Nazi regime as well as the benevolent nature of the neutral, humanitarian state; a task which fell to the female non-Scandinavians. As 'objects of care', the women were blank canvases onto which Swedish benevolence and Nazi cruelty could be projected.

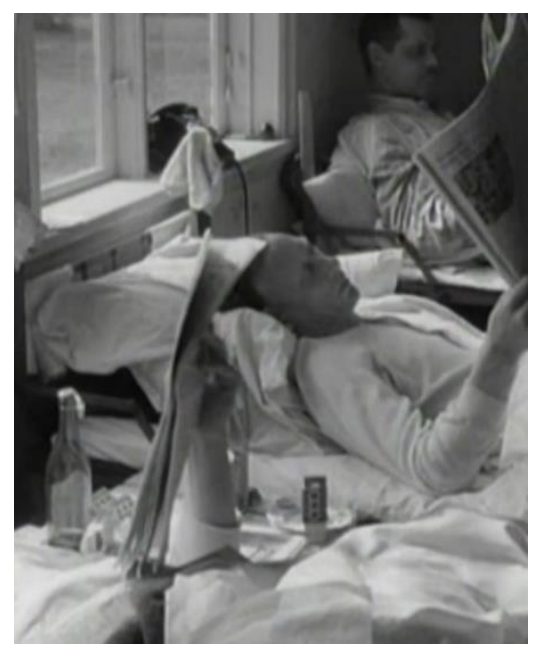

Still photograph from Vittnesbördet.

Men reading the newspaper at

Ramlösa Convalescent Center.

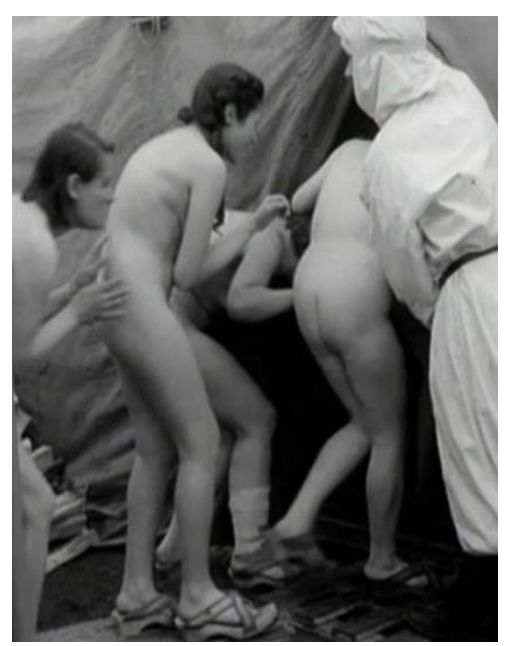

Still photograph from Vittnesbördet. Women let back into a tent after having showered outdoors.

439 For an in-depth analysis of the film and an elaboration of the gendered construction of survivors in it see Wagrell, "Jews, Gender and the Scandinavian Subject". 
How important was Vittnesbördet in the greater development of Holocaust discourse in 1945? As the final film in a long series of news reels created under the auspices of the National Board of Information (Statens Informationsstyrelse, SIS) and as a depiction of the most extensive humanitarian mission to save camp survivors to Sweden in 1945, Vittnesbördet constituted the piéce du resistance in a long line of films directly or indirectly produced as a result of state propaganda and media censorship. ${ }^{440}$ SIS had been created in 1940 in order to monitor and control media outlets as well as work to educate Swedes on Beredskap ("readiness") during the war. ${ }^{441}$ In 1945, the film medium had already developed into "a communicative platform with great social, didactic, and propagandistic impact". ${ }^{442}$ Because of this, media scholar Mats Jönsson proclaims that "Swedish citizens have never been as visually and audio-visually disciplined" as they were in the first half of the twentieth century. ${ }^{443}$ This also relates to Barbie Zelizer's contention that western epistemology is "ocular-centric", making images of the Holocaust an important part of the meaning-making process, particularly with regards to early representations of the Holocaust. It could therefore be argued that Vittnesbördet shaped the notion of camp survival and victimization to as great an extent as the printed press, given that it showed the embodiment of Nazi cruelty in threedimensional form rather than presenting mere descriptions of it. With regards to witnessing, however, Vittnesbördet did not deliver what the title promised. Instead of letting the subjects speak through the film, they were projected onto the screen from the film-makers' perspective.

440 On the May 22, 1945, it was advertised in the daily newspaper Svenska Dagbladet that the cinema Röda Kvarn in central Stockholm would be showing a number of newsreels pertaining to the liberation of Oslo as well as Swedish rescue work. The first two films on the schedule were Flyktingar finner en hamn ("Refugees find a harbor") and De kom över fjällen ("They came across the mountains") as well as Då Norge blev fritt ("When Norway became free"). These were presented in smaller type, while a filmed speech by Folke Bernadotte and Vittnesbördet were presented in large, bold type. Vittnesbördet's title was also accompanied by a description of the film's content. As such, being the last film on the list, in significantly larger and bolder type (including a description), Vittnesbördet was presented as the film in a series depicting current events in a newly liberated Europe.

441 Johnny Wijk, “'Censur och propagandaministeriet'-en översikt av Informationsstyrelsens verksamhet 1940-1945 utifrån dess efterlämnade arkiv," Historisk Tidsskrift 1 (1990): 21.

442 Jönsson, "Non-fiction Film Culture in Sweden," 125.

443 Jönsson, "Non-Fiction Film Culture in Sweden," 125. 
Although this perspective was almost exclusively framed by the printed press as admirable and important, the female subjects of the film were also problematized as disloyal and selfish in an editorial penned by the German-Jewish exiled journalist Lisa Matthias. ${ }^{444}$ In her editorial headlined "The women should be ashamed", Matthias argued that "among the deathly ill and skeleton-like old men and women shown in the film were masses of round-cheeked, smiling and laughing people, both men and women-primarily women-who even jostled in front of the camera". ${ }^{445}$ After this, Matthias noted that the narrator told of the Norwegian policemen's survival which had primarily been due to the Red Cross care packages they had received as well as their camaraderie. In contrast, she continued, the same did not seem to have applied to the women, some of whom were severely damaged by their experiences while others seemed healthy and happy. "It seemed" she stated "that all the strong, brutal and ruthless [women] managed to steal both food and clothing while the weak had been forced to starve their way [through the war] as best they could" without any help from the other women. ${ }^{446}$ The women in $V$ ittnesbördet, described by Jerring as being of French, Belgian and Polish descentwere, in contrast to the Scandinavian women, problematized as selfish and selfserving. Even though Matthias directed her message to all womenkind, who in her opinion lacked a sense of solidarity and chivalry, the statement was still made in reference to the women in the film. Since DN and Aftonbladet had already positioned female Scandinavian survival as a form of active resistance to the Nazis as well as an effect of Scandinavian solidarity (see argument on p. ?), Matthias' critique only served to further distinguish between Scandinavian and nonScandinavian camp survival.

Matthias's critique, although not necessarily representative of Swedish news discourse as a whole, still clearly demonstrates how different camp survivor groups were cast in distinct roles as survivors with (or without) moral character or as innocent 'objects of care'. When Norwegian women were seen to exit the camp

444 “Vittnesbördet m.m.," May 8, 1945, SvD. 19. "Vittnesbördet," May 8, 1945, Experessen. 19. "Kvinnorna bör skämmas," May 18, 1945, Expressen.

445 “Kvinnorna bör skämmas," May 18, 1945, Expressen ["Men bland de dödssjuka och skelettaktiga gubbar och gummor som filmen visade, fanns det massvis med rundkindade, leende och skrattande människor, både män och kvinnor, mest kvinnor, som t.o.m. trängde sig fram vid kameran"] 17.

446 “Kvinnorna bör skämmas,” May 18, 1945, Expressen [“det såg ut som om alla starka, brutala och hänsynslösa, lyckats roffa åt sig både mat och kläder, medan de svaga fått svälta sig fram bäst de kunde'] 17. 
system as healthy and jaunty, this was explained as a result of their resilience and in-group solidarity. In contrast, when non-Scandinavian women could be seen onscreen, round-faced and laughing, they evoked suspicion and criticism for not having protected each other enough against their tormentors. The testimony given by the medium of film was thus not principally about camp experience, but rather, it concerned the nature of suffering. The exclusion of Jewish victims from the narrative also meant that the female subject became the main object of sympathy for Swedish audiences; an object that had to appear and act in certain ways in order to fit into the role of "True Victim". Like the allied films of liberated concentration camps, Vittnesbördet seemed a document in itself, mediating only that which was in front of the camera man as he followed those rescued on their journey, from their first steps on Swedish soil, to their recuperating at Ramlösa convalescent center. There was no appeal to listen or see, no call to remember or 'never forget'. Such imperatives would, however, come a month later through a different medium; the radio.

\section{Witnessing the Witness: Radio news and Reports from a "White Ship"}

Although perhaps not as impactful as visual media, radio became influential in its role as a democratizing medium during the early twentieth century in Sweden. The Swedish radio historian Göran Elgemyr argues that "as a medium [radio] surpassed even the printing press. Once the radio infrastructure was fully in place, it could reach most of the residents of the country at the same time and at great distances, which was something entirely unprecedented" 447 . Although radio news journalism had been under the thumb of the newspapers since its inception in the 1920s, the final days of the war signified a great shift in its power to relay goings-on first hand to Swedish listeners; a victory won as radio journalists began to report directly from the center of events in Copenhagen and Oslo, thus surpassing the mere regurgitation of TT news messages. TT (Tidningarnas Telegrambyrå) had monopolized all news reports in order to protect the newspapers from unfair competition by the radio. 448 Therefore, prior to April 1945, the radio news had never contributed anything new to its listeners in terms of current events. Dagens Eko, which later became Swedish radio's foremost news program, began in 1937,

447 Göran Elgemyr, "Inventiveness and a Desire to Experiment: The Development of Production Technology in Swedish Radio 1925-1955," in eds Monica Djerf Pierre \& Mats Ekström, Swedish

Broadcasting: Communicative Ethos, Genres and Institutional Change, (Gothenburg: Nordicom, 2013), 62. 448 Peter Dahlén, "En säregen radioreporter: Ett yrkesporträtt av Manne Berggren," Presshistorisk. årsbok, (2015): 8 . 
but was, up until the end of the war, produced as shorter human-interest stories rather than up-to-date news stories. ${ }^{449}$

Because of the new-found independence that radio had conquered for itself and the extent to which the Swedish public had become regular radio listeners during the war, radio news became important for representations of camp survivors. In the spring of 1945, with German troops retreating from Denmark and Norway, some of Swedish radio's most prominent voices ventured to Skåne, Copenhagen and Oslo to capture the final days before peace was proclaimed. In doing so, Sven Jerring - perhaps the most well-known voice on Swedish radio in the medium's early days-narrated the arrival of concentration camp internees to Malmö harbor on May 2, 1945. Jerring's reports were so extensive that they garnered two news programs, including a segment in Dagens eko. ${ }^{450}$ The latter included interviews with former camp internees rescued by the "White Buses". 451 The interview conducted with a group of Norwegian men focused primarily on the last moments in the camp and the men's feelings at being rescued. Jerring asked how the men reacted when they found out that Red Cross buses were coming to bring them to safety. The answers received were (perhaps expectedly) ones of gratitude, although one of the men underscored that he was grateful for the aid he had received from the Danish Red Cross, thus omitting any words of appreciation towards Sweden or the Swedish Red Cross. It might seem a minor detail but should be understood in light of many Norwegian refugees' critical views on the Swedish government, which had managed to keep Sweden out of the war, partly by allowing German transfers of troops and material through Sweden and into Norway. This concern about Norwegian criticism also explains why Jerring only asked the Norwegian men about their memories of liberation, rather than the darker parts of their experience in German concentration camps; not wanting to emphasize that which could be construed as the result of Swedish collusion with Germany.

In interviewing a large group of Polish women, speaking through an interpreter, Jerring was also quick to change the subject from the camp horrors to how the women felt now. In contrast to the Norwegian men, who sounded tired and worn, the Polish women can be heard laughing and breaking into song whilst

449 Göran Elgemyr, "Maktkampen kring dagens eko—uppkomst och utveckling" in eds Kerstin Brunnberg \& Göran Elgemyr Dagens Eko. Nyheter i radio under 50 år, (Stockholm, Sveriges radios förlag, 187), 69.

450 Svensk Mediedatabas (SMDB), “koncentrationslägerfångar anländer till Malmö: om stämningen

i Köpenhamn kort före tyskarnas kapitulation,” May 2, 1945.

451 Svensk Mediedatabas (SMDB) “Dagens eko," May 4, 1945. 
constantly trying to get the interpreter to convey their stories. The interpreter states that no one could imagine what the Germans had done to these women and that they were so happy and grateful to have come to Sweden. As the interpreter utters these words, "gasovna e crematorium" float through the intermingled voices and hang in the air, without being translated. Instead the interpreter mentioned that most of these women were arrested during the Warsaw uprising and could not wait to return to their beloved city. In these early reports on rescue and liberation, it was the present and the future, gratitude and joy, that became the focus of the news reports. No Jewish camp survivors were interviewed and even though the radio programs were recorded on a day when 800 female camp survivors arrived in Malmö, the time spent interviewing them is negligible compared to the focus given to the male Norwegian rescuees, as well as on officials involved in the rescue mission. Therefore, the radio news reports did not add any new perspectives on the camp survivors that arrived in Malmö during early May 1945. Just like in the newspaper coverage, the Scandinavian perspective dominated discourses on the rescuees, and descriptions of the mission itself were gathered from personnel involved in the mission.

The examples presented above all show media representations of camp survivors who were rescued through the "White Buses" mission. As previously mentioned, the "White Buses" mission has received more scholarly attention in comparison to the UNRRA mission in Swedish historiography on the Second World War and the Holocaust. Although Byström argues that the daily newspapers described in detail those brought to Sweden with the UNRRA mission, he also states that few articles were written about this group of people. This relative silence is surprising, argues Byström, as news reports on Swedish aid to sick concentration camp prisoners would have garnered much good will for the Swedish state. Byström presents a few hypotheses for this difference in press attention. Firstly, as a majority of those who came to Sweden through the UNRRA mission were Jews, they were given less attention because the government feared a flare up in antiSemitic sentiment. Secondly, Byström cautiously postulates that because the refugees were mostly women, they as a group lay outside the 'normative' refugeetype which was male. ${ }^{452}$ This seems a less likely hypothesis given what has been presented above with regards to representations of the Danish Jews in 1943, where depictions of female refugees were the norm. In contrast, Thor Tureby suggests that the news market was saturated with all the stories written about the heroic 
mission of the Red Cross and that there was little journalistic interest left for the UNNRA refugees when they arrived in late June and early July. ${ }^{453}$ This appears a more likely explanation for the relative silence around the mission. Thor Tureby also demonstrates that the local daily newspapers published fervently on the arrival of former concentration camp prisoners from May onwards; indicating that the notion of a silence around UNRRA has been overstated in previous research. Nevertheless, much of the focus was on numbers rescued rather than life stories, which meant that more detailed representations of the refugees remained absent in the later reception of camp survivors from the European continent. This distinction in what the papers reported on is a crucial one for the construction of Holocaust victimization, witnessing and survival. The fact that the papers noted that more refugees were arriving did not necessarily contribute to a greater understanding for what these individuals had been through and who they were. The only study that has shed some light on portrayals of the UNRRA survivors themselves is an article authored by the Swedish historian Lena Roos in which she studies press clippings from Sigtunastiftelsen, a literary retreat which, in 1945, was made into a caring facility for former concentration camp prisoners. ${ }^{454}$ Through her analysis of the press clippings, Roos concludes that most of the press coverage of the rescued UNRRA survivors primarily focused on Swedish humanitarianism and how grateful the survivors were to have such devoted medical personnel dedicated to their lives and health.

However, in addition to the rather sparse newspaper coverage of the UNRRA survivors, an interview reportage-conducted and produced by the early enfant terrible of radio, Manne Berggren—was broadcast on July 10 on Swedish radio. Arguably, this program contributed far more to discourses on Holocaust victimization, witnessing and survival than any of the newspaper discourse since it, to a greater extent, presented witnessing through a medium rather than simply by a medium. In 1945, Berggren's voice was one of the most recognizable on Swedish radio. Berggren was a 'radio man' who was best known for his wallraffian reportages, pushing the boundaries of what radio could do at the time. ${ }^{455}$ In addition, Berggren narrated the history of the rise and fall of the Third Reich in a radio program in May 1945, making him an early radio authority on Hitler and the Nazi party. More importantly, however, Berggren pioneered the genre of the

453 Thor Tureby, "Svenska änglar och hyenor möter tacksamma flyktingar," 294.

454 Roos "Barmhärtiga svenskar och tacksamma flyktingar: Ett beredskapssjukhus sommaren 1945

i svensk press," Nordisk Judaistik, vol. 26, no. 1-2, (2008):133-156.

455 Dahlén, "En säregen radioreporter: Ett yrkesporträtt av Manne Berggren," 8. 
interview reportage. According to the Swedish media historian Karin Nordberg, interview reportages constituted one of the most influential genres for radio as an educator of the people (folkbildare). By the end of the 1940s, Berggren had created three separate categories for the radio interview: the unplanned/informal interview, the "carefully structured dialogue" and the "prepared interview". ${ }^{456}$ The informal language used in this interview genre meant that more people could understand what was said, which increased the chance of them feeling included in the greater political, social and cultural conversation. This, in turn, meant that the genre allowed for the inclusion of normal people into radio's programming; something that was unusual in the first decades of radio. ${ }^{457}$

The program that presented the fates of the UNRRA refugees to Swedish listeners was entitled Med en last av levnadskval ombord ("With a load of life anguish onboard") and was broadcast on July 10, 1945. As a news reportage which had been recorded only days before it aired, it disrupted the regular tableau by replacing a program chronicling the life and deeds of Charles Nicolle, the famed Nobel Laureate most known for his findings on typhoid fever. Instead of hearing about Nicolle, Swedish listeners became privy to the stories of those who were currently suffering from typhoid fever, all on their way to Sweden on the white ship SS Rönnskär. This change in the radio tableau is significant as it indicates the relative importance of the reportage. Even though the arrival of camp survivors to Sweden no longer constituted breaking news, the changes in the tableau underscored the immediacy and urgency of Berggren's program; something which was also emphasized in the introduction to the program.

Most of the reportage consisted of interviews with the sick camp survivors, communicated first through the survivors' own voices-most of whom spoke German - as well as a summary of the testimonies in Swedish provided by Berggren. Before these testimonies were heard, however, the program was introduced by a short monologue in which Berggren, among other things, highlighted the moral imperative of listening to the camp survivors. In his monologue, Berggren proclaimed that even though people may have felt overwhelmed with the amount of testimonies from the camps, they were obliged to hear them. Mimicking a sceptical audience he asked: "should one, during a tranquil summer evening disturb one's peace of mind with immeasurable tragedies,

456 Karin Nordberg, Folkhemmets Röst: Radion som folkbildare 1925-1950, (Brutus Östlings Bokförlag

Symposion, Stockholm/Stehag, 1998), 148.

457 Nordberg, Folkhemmets Röst: Radion som folkbildare, 148. 
what purpose does it serve?" After which he answered his own rhetorical question by stating that the truth can never be heard enough times and that if people could go to the cinema for thrilling entertainment they could just as well listen to the "horrific drama that was, until just recently, playing out in our 'great neighbor' in the South". ${ }^{458} \mathrm{He}$ also added that the exposure of the Nazi camp system during the spring had exposed nothing new, rather it served to finally expel all talk of "gruelpropaganda" which had circulated in the final months of the war. 459 "The witnesses are many, far too many", Berggren declared, for anyone to claim that falsehoods are being spread about Nazi perpetration. There are two aspects of these parts of the monologue that are worthy of special note. First, in stating that his program presented "nothing new", Berggren introduced the notion that all facts regarding the Nazi's crimes against humanity were already known. Second, the manner in which Berggren addressed his audience-as if they were reluctant to listen, fatigued even, with the continuous news about Nazi perpetrationdemonstrates how an innate resistance to Holocaust testimony was, already in 1945 , perceived as a problem. With regards to the camp survivors themselves, Berggren explained that the patients on the ship had been eager to tell him about their experiences and that when he came near "they wave[d] him closer to them". The camp survivors were thus described as brimming over with stories and with a burning wish to share them. Also in the monologue, Berggren asserted that although war and its effects were horrible indeed, it remained something to which people had become accustomed and therefore served as a "logical reality". ${ }^{460}$ What

458 Svensk Mediedatabas (SMDB), Manne Berggren, “En last med levnadskval ombord,” June 28, 1945 [Ska man under en fridfull sommarkväll störa sinnesron med omätliga tragedier, vad tjänar det till? Jag tror att sanningen kan man inte höra för ofta och kan man gå på teater eller bio och se och höra så att säga konstgjorda tragedier och lidanden så kan man också lyssna till några av de överlevande personerna i det fruktansvärda drama som tills helt nyligen utspelats hos, som det hette, vårt stora grannland $\mathrm{i}$ söder.].

459 Svensk Mediedatabas (SMDB), Manne Berggren, ”En last med levnadskval ombord,” June 28, 1945 [De tyska koncentrationslägrens fasor går inte att skildra i full utsträckning men ett är säkert, det är inte möjligt att överdriva och indignationen blir stum när sanningen efter det tyska nederlaget framstod i full dager var det dock inga nya och överraskande ting som blottades. Allt var tidigare bekant men hysteriet och den metodiskt utportionerade lögnens livskraft var länge starkare än sanningen. $\mathrm{Nu}$ är emellertid allt tal om Gruelpropaganda utan fotfäste.] Aftonbladet in particular.

460Svensk Mediedatabas (SMDB), Manne Berggren, ”En last med levnadskval ombord," June 28, 1945 [Ingen kan mäta eller fatta vidden eller graden av de lidande och den nöd som följer i krigets 
was less fathomable, however, Berggren continued, was the killing of millions for no other reason than to extinguish these people from the earth. Berggren thus clearly distinguished between 'normal' casualties of war and German genocidal policy.

Berggren's monologue, which framed the subsequent interviews with primarily Jewish camp survivors, constituted a behest to witness the witnesses and to hear their stories. Compared to the early news stories written about the "White Buses" rescuees, hearing these testimonies constituted a civic duty. "Millions have been silenced but of those who remain 10,000 are coming, in this month, to our country in order to regain their lives" Berggren declares. He is, in contrast to the newspapers, attempting to evoke an interest for the survivors as people who know something that no one else knows, a particular group of people with extraordinary experiences. Here, then, the Jewish camp survivor takes center stage for the first time as a "moral witness" to the Holocaust. At the same time, the monologue responds to a perceived fatigue regarding horrible details about the camps and Nazi terror. Because of this perceived fatigue, Berggren has to appeal to them by clarifying why listening to survivors is important. Yet, the only reason that Berggren gives is that "you can never hear the truth enough times". Hence, before the Holocaust turned into memory, the moral imperative to witness existed in Swedish media discourse, albeit without any developed argumentation regarding the utility or value of such an act.

So how did Berggren mediate the voices of the survivors? As previously mentioned, the interview subjects can be heard testifying in either German or Polish, after which Berggren provides a summary of the testimony in Swedish. All survivors, except for two Polish women, give their stories in German, a language most middle-class Swedes spoke and understood at an adequate level during this time. Between the interviews, Berggren described the scene in both physical and emotional terms: "I don't know how to express what I see around me. It is so horrendous wherever one turns one's gaze. A head, an emaciated, worn head and then a blanket with hardly anything underneath but skin and bone". In all, seven survivors were interviewed in the program. Through Berggren's narrative, the

spår men tanken har ändå vant sig att syssla med krigshandlingar och krigets direkta verkningar som en visserligen fruktansvärd men ändå logisk realitet. Däremot är det omöjligt för fantasin och däri ligger kanske en sinnets självbevarelsedrift att få ett grepp om, och ens tillnärmelsevis återspegla, åt minnet och eftertanken fixera det obeskrivliga onda som tillfogats miljoner och åter miljoner människor inte som en direkt eller nödvändig följd av kriget utan som ett vidrigt självändamål]. 
choice of interview subjects appeared accidental, based on whom he passed by. At the end of the program he also assured his listeners that what they had just heard was far from the worst "horror stories" that existed about the Nazi's camps and ghettos. "They are a handful of people that we, by coincidence, happened upon on a ship with life anguish aboard" Berggren asserted. The interviews included in the program cover a range of nationalities, gender, ages and social backgrounds. The only constant is that most of the subjects are Jewish. The stories told are also different in detail and geographical location. An Austrian Jewish man testified to his experiences in Birkenau, of gas chambers and the giant crematoria, while another man — who had his legs amputated at the hip—testifies to having escaped from a camp, an act for which he was shot by SS guards in both legs. A 15 -yearold Jewish-Hungarian boy, referred to as the youngest on the ship, was described as the only survivor of his family, with his mother dead of typhoid fever and his brothers and father deported elsewhere. "Now he smiles at the prospect of regaining his health in Sweden", Berggren narrates. It seems then, that Berggren had included the testimonies that best represented a wide range of experiences, camps, ages, genders and nationalities.

The women interviewed included two young Polish-Jewish sisters and a Hungarian-Jewish woman. The sisters were interviewed using an interpreter who recounted the girls' testimonies. One of the sisters testified to the collection of children and the elderly in the ghetto (who were then brought to a "factory for corpses"). The same sister also stated that she never thought she would be rescued and emphasized how happy she was to have her sister alive and that they were afforded the opportunity to rebuild their lives in Sweden. To this testimony, Berggren added that "they [were] two, and despite all they've been through, very beautiful, girls." Such characterizations of the camp survivors' appearance as well their intelligence and professional identities permeated the reportage. For example, the man with amputated legs were referred to as "a very educated and intelligent man" and the Hungarian-Jewish woman was presented to the listeners as a medical doctor who received her degree from the University of Prague in 1930. One of the aid workers mentioned to Berggren that she spoke "excellent" German and Berggren addressed her throughout the interview as "Frau doktor". He also characterized her as a "woman with an open intelligent face and with deep dark eyes". As a counterweight to descriptions of emaciated, mutilated, sick bodies, the camp survivors were, in the radio reportage, also constructed as people with intellects, professional identities and beauty. The latter might seem trite in comparison with the other traits. However, the description of beauty served to restore some of these young women's humanity. Similar to what British culture 
scholar Anna Reading discusses in "Scarlet lips in Belsen", descriptions of beauty here allowed the female camp survivors to, at least representationally, "return to gender"; an aspect of their humanity that had been severely maimed by Nazi cultural policy. ${ }^{461}$

The prevailing style of Berggren's reportage was one where his direct experience was conveyed to the listeners, seemingly without redaction or further reflection. The reportage was thus communicated as an ongoing observation, where Berggren, as observer and narrator was neither absent nor the focal point. He was merely a witness to the witnesses; testifying to the authenticity of their experiences by describing what he saw while also letting them testify without much interruption. The notion of Berggren as an exemplary witness to the witnesses was constructed by several write-ups about the radio program published in $\mathrm{DN}, \mathrm{SvD}$ and Expressen in the week following its broadcast. ${ }^{462} \mathrm{In} \mathrm{SvD}$, the article author described how "one could hear on his voice that [Berggren] was touched and upset by the human misery that he saw". ${ }^{463}$ The author also commended Berggren for having interviewed the very sick below deck even though the seas had been rough. Similarly, Expressen's and DN's critics praised Berggren's skillful interview technique and his ability to catch the substance of every testimony through his questions, translations and summaries. ${ }^{464}$ Although part of the program's content was recounted in these article, most of the focus was on Berggren himself and the excellent ways in which he had framed the testimonies. In DN, Berggren's contention that the testimonies had not contributed anything new was reiterated through this statement:

Perhaps there was nothing new in what was said. At least not for those who, during the past years, have come in contact with Jewish stateless refugees: we have known or guessed this even before correspondents and films presented their revelations. Not even the story of cannibalism in the camps

461 Anna Reading, "Scarlet lips in Belsen: culture, gender and ethnicity in the policies of the Holocaust," Media, Culture \& Society, 21, no. 4, (1999): 497.

462 "Med en last av levnadskval” July 11, 1945, SvD. "Sanningen” July 11, 1945 DN. "Plock ut etern" July 16, 1945, Expressen.

463 “Med en last av levnadskval” July 11, 1945, SvD ["Man hörde på rösten att han var gripen och upprörd av vad han såg av mänskligt elände"].

464 “Sanningen” July 11, 1945 DN. "Plock ut etern” July 16, 1945 Expressen. 
seems surprising anymore. ${ }^{465}$

Instead of new information, the importance of the program was attributed to the effective "confrontation" with the witnesses that Berggren had created. The author in DN also concluded that "the microphone does not lie; the voices, the testimonies that reached us through the noise of the ship, didn't exaggerate anything". 466 According to these articles, Berggren is the exemplary witness to genocide; the person who made already-known facts about the Holocaust more accessible to the world. At the same time, the technology itself-the microphone through which the camp survivors testify-was positioned as an objective communicator, speaking the truth about Nazi crimes. This seeming contradiction between the positioning of Berggren as a subjective witness and the objective technology of the radio microphone shows how the conflation of witnessing through media and witnessing by media contributed to the conceptualization of the authentic and effective witness. Although Berggren clearly framed and guided the testimonies given through his questions and the introductory monologuesomething which was perceived as necessary and good by the press-the radio medium was also understood to communicate unedited and unredacted testimonies.

Berggren's reportage from SS Rönnskär contributed to the construction of Jewish camp survivors as "moral witnesses" to the Nazi's attempts at exterminating the Jews. Rather than being objectified like in Vittnesbördet, both male and female survivors were humanized though descriptions of their professional lives before they were arrested and deported, as well as through references to beauty and intelligent features, etc. The newspapers' praise of the program-primarily focusing on the excellence of the interviewer rather than the tragic fates of the interviewees - also positioned Berggren as an exemplary witness to Holocaust experience, thus enforcing the moral stature of the "dismayed spectator". Berggren's position as a "dismayed spectator" of the Holocaust was also further strengthened by the critical discussions that surrounded the program in the

465 "Sanningen" July 11, 1945, DN, ["kanske det egentligen inte var så mycket nytt i det som sades. Åtminstone inte för dem som under gångna år haft närmare kontakt med judiska statslösa flyktingar: vi har vetat eller anat detta redan innan korrespondenter och filmer kom med sina avslöjanden. Inte ens berättelsen om formlig kannibalism i fånglägren innebär numera något överraskande. Helt visst reagerar man på olika vis. I varje fall bör nog sanningar av detta slag inverka på det som kallas vår livsåskådning”].

466 "Sanningen" July 11, 1945, DN. 
newspapers; overshadowing the importance of the Holocaust survivor-witness as a communicator of Holocaust experience.

\section{6 Accusation and Recovery: The Belsen Trial, the Witnesses and the Refugees}

The Belsen Trial was held between September 17 and November 17 of 1945 in Lüneburg, Germany. ${ }^{467}$ The indictment was directed against Josef Kramer (former commandant of Auschwitz and Bergen-Belsen) and 44 others; among them highranking camp officials, SS camp guards and Kapos. ${ }^{468}$ In previous research on Holocaust representation in Sweden, the earliest war crimes trials have been largely overlooked. ${ }^{469}$ This gap in research on the Holocaust in Sweden has meant that the Belsen Trial, which preceded the Nuremburg Trials, has not been studied in relation to Swedish Holocaust history. Presumably, this is because British historiography (primarily the historians Donald Bloxham and Tony Kushner) has argued that the Belsen trial never contributed in any significant way to the exposure of Jewish suffering. ${ }^{470}$ Even though the Jewish genocide was not elucidated in its full extent through the Belsen trial, however, the use of survivor witnesses in the prosecution of Josef Kramer and 44 other camp officials, still contributed a space within which the Holocaust witness could appear, both inside and outside of the court room. As Dean argues through her analyses of five court proceedings between 1920 and 1960, trials pertaining to genocide "recast victims' survival as a redemptive force, placing their suffering and their perspective center stage in place of humanitarian spectators and their dismay, and making the restoration of victims' dignity eventually vital to an international global image of the right and good". ${ }^{471}$ In this section I will investigate the first part of this assertion-the recasting of “victims' survival as a redemptive force, placing their suffering and their

467 Raymond Phillips (ed.), War Crimes Trials. Vol. 2: Trial of Josef Kramer and 44 others, (London:

William Hodge, 1949), xxiv-xxv.

468 Phillips, Trial of Josef Kramer and 44 others, $\mathrm{xxx}$.

469 For studies on the Swedish press and the Nuremburg trials see Holmila, Reporting the Holocaust in the British, Swedish and Finnish Press. Also, Swedish doctoral candidate, Julia Sahlström, has studied representations of the Nuremburg trials in the Swedish-Jewish press. See, "Recognition, Justice and Memory: Swedish Jewish Reactions to the Holocaust and the Major Trials" in eds Johannes Heuman \& Pontus Rudberg, Early Holocaust Memory in Sweden, (Palgrave Macmillan, Forthcoming). 470 Donald Bloxham, Genocide on Trial: War Crimes Trial and the formation of Holocaust Memory, (Oxford:

Oxford University Press, 2001). Tony Kushner, The Holocaust and the Liberal Imagination, 221.

471 Dean, The Moral Witness, 4. 
perspective center stage in place of humanitarian spectators and their dismay"-in relation to how the Belsen trial witnesses were represented in the Stockholm-based press. I also ask whether the camp survivor as witness to Nazi atrocities was shaped in relation to particular identities, focusing specifically on the female Jewish witness.

\section{The Survivor-Witnesses: Sensation and Accusation}

From a cursory search in the digital newspaper archive, it became evident that Belsen was an important point of reference from which a wide variety of phenomena could be discussed in Swedish newspaper discourse. In Aftonbladet, an East Karelian camp was referred to as a "miniature Belsen", and in SvD a small news article detailed how a drunken local politician had hollered "Belsen, Belsen!" when put in a police cell to sober up. ${ }^{472}$ Belsen was thus used, in the autumn of 1945, to draw attention to other instances of suffering during the war, as well as a reference of perceived injustice. As will be explored further in the coming section, one of the most notorious female SS-Aufseherinnen, Irma Grese, also became the object of aversion and fascination in the Swedish press; something that was expressed with particular fervor in the evening newspapers. On the 'women's pages' of Expressen, she thus appeared among news about the latest corset and different ways to settle the nerves in the autumn darkness; further demonstrating how the Belsen trial entered all levels of discourse. ${ }^{473}$

Even though the trial of Kramer and 44 other camp officials is often referred to as the "Belsen Trial", the charge against the defendants was dual in nature, referring to both brutality and murder (by ill-treatment and neglect) in Belsen and Auschwitz, as well as to the murders perpetrated through the gassing and burning of prisoners in Auschwitz. ${ }^{474}$ In attempting to understand how the concentration camp as a symbol of evil formed through representations of the trials, British historian Donald Bloxham argues that American, British and German reporting from the Belsen trial often confused these charges and therefore inflated the numbers dead as well as misconstrued the ways in which these victims had died. ${ }^{475}$ Bloxham also demonstrates how the major American, British and German

472 "Belsen-läger i miniatyr i Finland," October 5, 1945, Aftonbladet, 1. "Finskt koncentrationslägerett Belsen i miniatyr", October 15, 1945, 3. "Fylleristen var ledamot i nykterhetsnämnd!," October 25,1945, SvD, 5.

473 “Mitt i strömmen," September 16, 1945, Expressen.

474 Phillips, Trial of Josef Kramer and 44 others, $\mathrm{xxx}$.

475 Bloxham, Genocide on Trial, 97-98. 
newspapers downplayed or failed to report on Jewish victims in particular. For example, he contends that in addressing the defense, the prosecutor, Colonel Backhouse,

introduced the idea of millions of deaths at Auschwitz, promising to bring forward a witness who would testify to 4 million murders at the camp (a number far in excess of current expert estimates of the total of dead at Auschwitz-Birkenau), but the Frankfurter Rundschau was again true to the tone of the proceedings when, amidst its detailing of the scale of the Auschwitz gas chambers, the Jews were notable by their absence. ${ }^{476}$

These figures of four million dead were also reported in the New York Times and the Times but only referred to people in general and, therefore, did not mention Jews. ${ }^{477}$ The confusion between the camps — of whether victims had been gassed at Belsen or Auschwitz and how many these victims were — can also be seen in Swedish news reports from the trial. For example, reporting from the second day of proceedings in Lüneburg, an article in DN asserted that "the British Brigadier Hughes summarized his assessments about conditions in Belsen, where four million human beings were gassed". ${ }^{478}$ Rather than distinguish between the indictment relating specifically to Belsen and that which referred to Auschwitz I, the article confused the two camps, reporting that Belsen had gas chambers where millions were killed. SvD, in contrast, clearly differentiated between the camps in its reporting, referring to "death and suffering in Belsen as well as death in the gas chambers at Auschwitz". ${ }^{479}$ Furthermore, Auschwitz was, in one article, denoted as a "death camp" whereas "the Belsen camp" or "the concentration camp" were used to refer to Bergen-Belsen. ${ }^{480}$ SvD also highlighted Jewish suffering in relation to the Belsen trial to a greater extent compared to DN. In contrast to the British, American and German newspapers studied by Bloxham, SvD specified that the figure of four million dead at Auschwitz in fact referred to four million murdered Jews in an article headlined: "4 Million Jews were Gassed in the Death Camp in

476 Bloxham, Genocide on trial, 97-98.

477 Bloxham, Genocide on trial, 98.

478 "Leende bödlar från Belsen inför domstolen i Lüneburg," September 19, 1945, DN, 1.

479 "Lägerfånge fick injektioner med fotgen," September 26, 1945, SvD [“Rättegången mot Josef

Kramer, befälhavaren i Belsen-lägret, och 44 av hans medhjälpare, vilka åtalas för att ha vållat död i gaskamrarna i Auschwitz i Polen fortsatte idag för åttonde dagen'”.

480 “4 miljoner judar blevo gasade i dödslägret i Auschwitz," September 22, 1945, SvD. 
Auschwitz". ${ }^{481}$ Although restating these figures on October 19 with a mere reference to 4 million dead, the same article also noted in a caption that "only remnants [were] left of Europe's Jewish population". In bold letters in the middle of the article, it was also asserted that "the bill of indictment [at Lüneberg] treats the German myth about a master people and shows that the accused... united in a plan to extinguish Europe's Jewish population." The news article also mentioned the estimated number of murdered Jews when quoting the bill of indictment: "out of 9 million Jews 5,700,000 have disappeared. Only remnants of the Jewish people remain." 482 Hence, SvD communicated the specificity of Jewish suffering, and contributed to the early construction of the Holocaust as an event that was separate from other crimes committed by the Nazis during the war.

In the first two weeks of the proceedings, SvD published stories about the indictment, the defendants and the witnesses on an almost daily basis. Even though the history of the Holocaust had been slowly unfolding in greater detail throughout the spring and summer of 1945 via newspapers, radio programs, short films and news reels, SvD's reporting framed the trial as a dramatic disclosure of the worst crimes committed by the Nazis. In the first headline presenting the proceedings to Swedish readers, it was printed in bold capital letters that the prosecutor, Colonel Backhouse, would come to expose "Gruesome Details". 483 Also on page 3, another article entitled "Polish Jews Smuggled in Secret to Hungary," detailed how Jews in Slovakia endeavored to rescue Jews in Poland. This story was told through an interview with a camp survivor referred to in the article as Dr. Oscar Neumann. In the text, Neumann was described as a "dark-haired, scrawny man" who sat back in his chair, nervously toking on a cigarette. ${ }^{484}$ Just as the story about Belsen, the story told by Neumann continued on page 9, thus juxtaposing the headlines "Belsen..." and "Jews...". This juxtaposition created a visual connection between Jewish suffering and the concentration camp. Even though they were two different articles, albeit covering related phenomena, the strife and suffering of the Jews who escaped from Poland to Hungary were fundamentally connected to Colonel Backhouse's explication of the crimes committed in Belsen as well as Auschwitz. Importantly, the only victims to be singled out in the article about the Belsen trial were Jewish: "at one point 1400 persons were sent [to Auschwitz], out of which

481 “4 miljoner judar blevo gasade i dödslägret i Auschwitz,” September 22, 1945, SvD.

482 "Kylig statistik över miljoner oskyldiga döda," October 19, 1945, DN.

483 "Belsenrättegången blottar hemska detaljer" September 18, 1945 SvD, 3.

484 "Belsenrättegången blottar hemska detaljer," September 18, 1945 SvD, 3. 
1000 never made it inside. 45000 Jews were brought there and when the camp was overrun only 60 were found left in there". ${ }^{485}$ According to Bloxham, these numbers given in Backhouse's opening statement had a marginal impact on exposing the specificity of Jewish suffering. ${ }^{486}$ It was, however, significant in the article that the Jews were the only victim group singled out for a special mention, especially when considering Neumann's interview, which was placed in the next column over.

Neuman was also positioned in the article as a representative for the remnants that had been left of "the Jewish people" after the catastrophe. Under the subheadline that read "the fate of the survivors", Neumann stated that it was now his "task to work for the survivors" as they had been scattered all over Europe. ${ }^{487} \mathrm{He}$ added that "the Jewish people are a grateful people and they never forget" referring to the Swedish reception of camp survivors during 1945. After making this statement he also pleaded to the Swedish population to continue their charitable work, since the survivors did not have the same "nerve and resilience as ordinary people". ${ }^{488}$ Here, in contrast to the news discourse surrounding the "White Buses" mission, a Jewish survivor testified both to the specific victimization of the Jews during the war, as well as to the vulnerability of Jewish camp survivors in war-torn Europe. This article also contributed to a concept of post-war Jewish solidarity; a concept that, in turn, homogenized the Jewish survivor experience.

In contrast to SvD's reports on the trial, the evening newspapers focused almost exclusively on the infamous defendant Irma Grese, meaning that any suffering that was not connected to her passed by unnoticed. ${ }^{489}$ This fascination

485 “Judar...”, September 18, 1945, SvD, 9. [Vid ett tillfälle sändes 1400 personer dit, av vilka 1000 aldrig släpptes in. 45,000 judar fördes dit och då lägret överflyglades funnos endast 60 kvar”]. The word "överflyglades" translates as "outflanked" and is used in reference to the actual camp being outflanked (indeed the Red Army did outflank German forces in order to reach the camp). However, as the sentence refers to the discovery of Jewish camp survivors, I am assuming that the author was referring to when Red Army forces liberated Auschwitz-Birkenau in January of 1945 , which is why the word "overrun" has been used in the translation instead.

486 Bloxham, Genocide on Trial, 97.

487 “Judar...," September 18, SvD, 9. Subheadline [“De överlevandes öde”] quote ["Det är nu min uppgift att arbeta för de överlevande"].

488 "Judar...," September 18, SvD, 9.

489 “"Onödigt! Tyckte Amerikanerna”, September 17, 1945, Aftonbladet. "Belsen-Irma knäckt, grät öppet," September 28, 1945 Aftonbladet. "Sadist”" September 18, 1945 Expressen. “Trivdes bäst som bödel," September 20, 1945 Expressen. "Belsens bödlar inför rätta i Lüneberg," September 22, 1945 Expressen, "Grese i tårar", October 18, 1945 Expressen, "Belsen-Irma nekar," October 21, 1945, Expressen. 
with Grese also related to discourses surrounding women and violence. Before the trial began and in the first few days of its proceedings, all newspapers published pictures of Grese, as well as of Kramer with captions that described the former as a "sadist", "executioner" and a "helper to the "beast of Belsen". 490 The particular fascination with the special brand of female perpetration that Grese symbolized was also evident in a number of articles published in both daily and evening newspapers, although most obvious and prolific in the latter. During the first week of the trial, the newspapers wrote about Grese's looks, her demeanor, and any emotional responses that the witnesses' testimonies and the film shown from the Belsen camp elicited from her, focusing especially on whether she cried or smiled. ${ }^{491}$ In her book Mothers in the Fatherland, Claudia Koonz argues that even though the female camp guards "were statistically insignificant, descriptions of them fairly leap from the pages of survivors' memoirs". ${ }^{492}$ This emphasis on female cruelty in survivors' narratives is, Koonz postulates, a result of expectations put on these guards as women; their violence being perceived as unfeminine and, thereby, as unnatural. 493

Already in 1945, the survivor witness was given a central role in feeding the public interest with stories of female deviance and perpetration in the Nazi camps. In a near full-page reportage in Expressen, headlined, "Whistling and Elegant, Irma Grese Arrived at her Frightful Nightly Expeditions”, Grese’s crimes were exposed by a Czech camp survivor, said to reside in Norrköping, Sweden. ${ }^{494}$ In the lead, the

490 “Grese i tårar", October 18, 1945 Expressen. "Belsen...," September 19, 1945, SvD, 11. "17000 sjuka kvinnor hade 474 kojer bland likhögar," September 19, 1945, DN, 8. "En ljungande straffpredikan," September 17, 1945, Aftonbladet.

491 “'Onödigt! Tyckte Amerikanerna," September 17, 1945 Aftonbladet, "Belsen-Irma knäckt, grät öppet," September 28, 1945 Aftonbladet, "Sadist," September 18, 1945 Expressen. "Trivdes bäst som bödel," September 20, 1945 Expressen. "Belsens bödlar inför rätta i Lüneberg," September 22, 1945 Expressen. "Grese i tårar," October 18, 1945 Expressen. "Belsen-Irma nekar," October 21, 1945, Expressen. "Belsen-Irma' har erkänt," October 6, 1945 DN. "Kvinnoavdelningen värst i Belsen," October 17, 1945 DN. "Belsenfilmen skakade de kvinnliga fångarna," September 21, 1945 DN. "4 miljoner judar blevo gasade i dödslägret i Auschwitz," September 21, 1945, DN "Där är den mördare som dödat så många!” September 25, 1945, SvD.

492 Claudia Koonz, Mothers in the Fatherland: Women, the Family and Nari Politics, (London: Jonathan Cape, 1987), 404.

493 Koonz, Mothers in the Fatherland, 404.

494 "Visslande, elegant kom Irma Grese till sina fruktade nattexpeditioner," September 20, 1945 Expressen. 
Czech survivor, who had spent time in both Auschwitz and Belsen, was quoted stating that

To beat women senseless was Irma Grese's favorite hobby, and she was her happiest when she got to beat naked, beautiful, young girls. Elegantly dressed and with shining black boots she came whistling to her nightly inspections in the camp. She often commanded a thousand women at a time to stand in the yard, where they, on their knees, had to stand with great rocks in their outstretched hands from half three until ten in the morning. She loved the days when the victims for the gas chambers were selected. She went ahead of a troop of SA-men together with the chief physician along the long lines of naked women and picked the ones she wanted. One time she took everyone with rashes on their bodies - another time she took all who looked skinny. 495

In concluding the article, the Czech woman also stated that, "everything that I have told you about Irma Grese is true. It is not founded on hearsay. I have, on the contrary, seen and experienced everything myself. Before an older English major I have put two fingers on the bible and told everything I know about the Sadist German woman". ${ }^{496}$ Expressen's publication of this woman's testimony not only served to fetishize and sensationalize female perpetration during the Holocaust, but also positioned the female victim as an object of torture rather than as a human subject. In order to understand the female perpetrator and her sadism, images of naked, marching, beautiful, starving women had to be conjured. At the same time, the Czech woman, who testified through the newspaper, remained nameless and the rest of her story was left uncontextualized. Nevertheless, the notion of the survivor witness 'having been there', thus speaking from her own, her sisters' and her fellow prisoners' experience, lent power and authenticity to the story. The special nature of women-on-women violence also meant that the most intriguing,

495 "Visslande, elegant kom Irma Grese till sina fruktade nattexpeditioner," September 20, 1945 Expressen [“Att slå kvinnor medvetslösa var Irma Greses favorithobby, och mest trivdes hon när hon fick slå nakna, vackra, unga flickor. Elegant klädd och med skinande blanka, svarta stövlar kom hon visslande till sina nattliga expeditioner i lägret. Hon kommenderade ofta ut 1000 kvinnor i taget på gården, där de på knä fick stå med stora stenar i de uppsträckta händerna från halv fyra till tio på morgonen. Hon älskade de dagar då offren till gaskamrarna skulle tas ut. Hon gick i spetsen för en trupp SA-män tillsammans med chefsläkaren längs de långa leden ned nakna kvinnor och plockade ut dem hon ville. En gång tog hon alla som hade utslag på kroppen-en annan gång de som såg magra ut”].

496 "Visslande, elegant kom Irma Grese till sina fruktade nattexpeditioner," September 20, 1945, Expressen. 
yet unfathomable stories were communicated by female camp survivors; a fact that made them a particular point of interest.

The daily newspapers' focus on the testimonies given during the first two weeks of the trial also contributed to a construction of a Holocaust witness type that was primarily female and Jewish. Like in the evening press, these representations did not necessarily mean that the suffering of the victims was a central theme in itself. Rather, the perpetrators remained a focal point with testimonies speaking to the evil of the Nazis rather than the suffering of the victims. If considering the news structure of the articles published in $\mathrm{DN}$ and $\mathrm{SvD}$, a majority of the headlines referred to either the content of the testimonies themselves (more prominent in $\mathrm{SvD}$ than $\mathrm{DN}$ ) or the defendants (more prominent in $\mathrm{DN}$ than $\mathrm{SvD}$ ). Also, in $\mathrm{DN}$, the witnesses' identities and roles in the trial were further marginalized by being excluded from the lead. The framing of the trial in $\mathrm{DN}$ was thus structured with the perpetrators at the top of the pyramid, followed by details about the trial itself, and then, at the bottom, the witnesses' gender, ethnicity, nationality and emotional expressions. So, how much weight should be afforded these representations of the female Jewish witnesses at the Belsen trial?

Even though DN's news articles did not place the female Jewish witnesses high in the news hierarchy, the articles still underscored the role of these witnesses, positioning them as both righteous and vindictive accusers whose words bore much weight on issues of justice and punishment. Bloxham argues that the choice to let non-Jewish survivors take the stand before crimes against the Jews were developed further in the accusation meant that the impact of Jewish testimony diminished with the waning public interest in the trial. Bloxham thus claims that "the Jewish witnesses, who had seen far worse than had Le Druillenac, or indeed the British soldiers, were relegated to later appearances, when the initial impact of the trial had diminished" ${ }^{497}$ However, even though the press' interest waned after the first two weeks of trial proceedings in Sweden as well, the most well-covered testimonies were given by Jewish women. These witnesses were Ada Bimko (a Polish-Jewish woman who attested to 4 million dead at Auschwitz), Zofia Litwinska (a Polish-Jewish woman who had, according to her own testimony, been saved from the gas chamber due to her husband being Catholic) and the Hungarian-Jewish girl Dora Szafran (whose testimony was said to have made Grese 
"blush"). ${ }^{498}$ In all headlines for the articles with the exception of the testimony given by Szafran, the main information came from these camp survivor-witnesses. In SvD, the witnesses Bimko and Litwinska were also identified as Jewish, directly in the lead. Although other, non-Jewish, witnesses were also mentioned and their testimonies recounted, there was little that connected them and their experiences to each other, other than having been victimized by the defendants or having witnessed the destructive nature of their deeds. ${ }^{499}$ The female Jewish survivorwitnesses, on the other hand, were unified as a group, both by their gender and by their Jewishness.

Still, the most sensational Jewish witness - Ada Bimko-was represented as both important and dangerous in SvD and DN. In DN, she was referred to in the lead as "the prosecution's sensational witness" who went along the bench of the accused "like a goddess of vengeance", whereas the article in SvD described her as "one of the few survivors from the death camp at Auschwitz" who gave her "gruesome testimony" to the court. 500 Thus, while SvD remained more neutral in their description of Bimko_although calling the day she witnessed "the most dramatic day so far"-DN painted her as a symbol of Jewish vengeance whose testimony was sensational rather than poignant and powerful. Interestingly, Bimko's testimony did not even make the headline of DN's article that day, which instead proclaimed: "Belsen Executioners Shepherded among the Ruins of the Death Camp". ${ }^{501}$ Rather than focus on Bimko's "dramatic testimony", the article covered some of its content in a single paragraph and then swiftly moved on to the fact that the defendants had been forced to revisit the Bergen-Belsen concentration camp (erroneously labelled a death camp in the headline).

With regards to Litwinska's testimony, the Swedish newspapers studied here primarily focused on her dramatic rescue from inside the gas chamber at Auschwitz. ${ }^{502}$ Despite the fact that the French survivor-witness Charles Bendel had

498 "Belsenbödlarna vallade bland dödslägrets ruiner," September 22, 1945, DN “4 miljoner judar blevo gasade i dödslägret i Auschwitz," September 22, 1945, SvD. "Gaskammarvittne avslöjar juldagsmorden i Auschwitz," September 25, 1945 SvD. "Där är den mördare som dödat så många!"' September 25, 1945 SvD. "Olja sprutades in i blodet på de dödssjuka i Auschwitz," September 26, 1945 DN. "Lägerfånge fick injektioner med fotogen," September 26, 1945 SvD.

499 The Jersey star witness, the English military man, a Polish woman and a Hungarian woman.

500 “Belsenbödlarna vallade bland dödslägrets ruiner," September 22, 1945, DN.

501 "Belsenbödlarna vallade bland dödslägrets ruiner," September 22, 1945, DN.

502 “'Gaskammarvittne’ avslöjar juldagsmorden i Auschwitz," September 25, 1945. “'Där är den mördare som dödat så många!”' September 25, 1945 SvD. 
testified the same day to the transport and selection of Jews to be gassed at Birkenau, Litwinska's near-death experience took center stage in reports from the trial. 503 In DN's headline, she was referred to as the "Gas chamber witness" who had "Exposed" the "Christmas Day Murders", and in SvD the headline quoted her when exclaiming to the defendant Franz Hössler: "'There is the murderer who has killed so many!" The lead in SvD detailed how Litwinska, characterized as a "young Jewess from Lublin", had pointed out Hössler, then "collapsed" after which she had to "be helped out of the court room" for a few minutes to compose herself. 504 The news article also included a part of Litwinska's testimony in which she spoke of a particular selection process to the gas chambers. The victims, she stated, had to stand naked in front of their beds (this occurred while Litwinska was in the infirmary) while selected. This degrading state of nudity was repeated in the article when Litwinska was quoted saying that "we were commanded out of the hospital, still naked". ${ }^{05}$ In the lead in DN, Litwinska's effect on Hössler took precedence over any descriptions of her testimony, the text describing him as "a small, stocky man with an imbecilic appearance" who tried to hide his reddened face when pointed out by Litwinska. At the same time, DN's correspondent in Lüneburg, ended the article by asserting that the most memorable moment of that day had been when Colonel Backhouse asked whether Litwinska's husband died in the camp, to which she was described to respond with a "wailing and accusatory voice": "Yes he died-we all died in Auschwitz".506

Considering the news structure of DN and SvD, it thus seems an overstatement to claim that the Jewish female trial witnesses' victimization and suffering was placed "center stage" in the reports from the trial. The witnesses' suffering was central to the news story in SvD and to a certain extent in the other Stockholm-based newspapers, but only insofar as this suffering revealed and expounded Nazi atrocity. Interestingly, however, the female Jewish witness came to be a particular point of interest; both as an exposer of the (at the time) most sensational details about life in the camps, but also as "true victims" of the deviant female perpetrators. What were seen to contribute to the trial theatre, however, was life and drama. Litwinska's collapse when faced with the camp officials was recounted in several newspapers, and DN's dramatic closing to their news story of

503 See Bloxham, Genocide on Trial, 98.

504 “"Där är den mördare som dödat så många!"' September 25, 1945, SvD.

505 “'Gaskammarvittne’ avslöjar juldagsmorden i Auschwitz,” September 25, 1945, DN.

506 “'Gaskammarvittne’ avslöjar juldagsmorden i Auschwitz,” September 25, 1945 DN. 
her testimony - that they all, the living and the dead, died in Auschwitz-also underscored that the witnesses could tie the audience, emotionally, to the Nazi's crimes. Furthermore, Bimko, Litwinska and Szafran were not merely accusers of the Nazis, they were also witnesses to the Nazi's perpetration against the Jewish people as a whole; their testimonies were connected by both their gender and their Jewish identities. Like the Danish-Jewish women, they represented a specific kind of victimhood with the added vulnerability that came with camp experience.

\section{The Survivor-Refugees: On the mend through the Grace of a Benevolent Country}

As the newspapers reported on the suffering that had been inflicted in BergenBelsen and Auschwitz, another figure that contributed to the conceptualization of Holocaust victimization, witnessing and survival appeared in the press: the camp survivor refugee. Technically, not all those mentioned in the articles discussed herein held refugee status as most were considered "guests of the Swedish state" and were, consequently, supposed to either migrate or be repatriated back to their home countries. ${ }^{507}$ In Swedish newspapers, however, they were referred to as both refugees ("flyktingar") and survivors ("överlevande(n)"). Through articles published on the situation for camp survivor refugees in Sweden, the newspapers connected the idea of a Swedish 'safe haven' to the Belsen trial. These representations, which principally concerned female camp survivor refugees, thus added the new role of recovery to that of witnessing. The symbols of Belsen and Auschwitz also provided epithets which were used to contextualize the camp survivor refugees and connect them to known horrors of the camps without having to mention these experiences directly in the text.

This was the case for the so-called "Angel of Belsen" who appeared in DN and SvD during September of 1945. The headline in DN read "The Angel of Belsen lives in Bergsjö" and the subheading in SvD stated that "The Angel of Belsen' is in Sweden", both alluding to the extraordinariness of such a 'celebrity' residing in a small community up in the Swedish north. ${ }^{508}$ In the DN article, which was the more extensive of the two, it was told that Mrs Luba Fryschynska, a Polish nurse who was deported to Bergen-Belsen where she escaped the gas chamber once and the crematoria no less than four times, now resided in Swedish Bergsjö. In the camp, the article text continued, Fryschynska had asked Kramer himself if she

507 Hansson, Flykt och överlevnad, 275.

508 “Belsens ängel bor i Bergsjö,” September 29, 1945, DN. “Undan döden 5 gånger," September 29, 1945, SvD. 
could care for the children in the camp, a request that had later been granted by the camp physician. What these articles demonstrated, other than further confusion between Belsen and Auschwitz, was a fascination with, and a reverence for, the Holocaust survivor-refugee. Although Ada Bimko and Sofia Litwinska testified to similar experiences, "the Angel of Belsen" was there, in Sweden, in the flesh, being cared for by Swedes. Just as Grese was being positioned as the antithesis to feminine values, this symbol of motherly warmth and kindness, demonstrated the inert characteristics of a 'true' woman. Furthermore, in recounting the story of Luba Fryschynska, the SvD article also told the story of her husband, a Polish Jew who had blown up one of the crematory chimneys at Auschwitz and attempted to escape. Thus, the story of Fryschynska's "true womanhood" was also accompanied by descriptions of her husband's masculine courage and resistance; both narratives fitting neatly into the gender norms of the time.

The same themes were also present in a full-page article entitled "Convalescent in Sweden", published in Aftonbladet a week into the Belsen trial. In the article, a female survivor of Belsen described her encounter with Swedish nature, Swedish culture and the Swedish people. ${ }^{509}$ In a cartoon placed in the middle of the text, what can be presumed as the author of the text can be seen sitting leisurely in a deck chair smoking a cigarette. Behind the woman lies a beautiful house out of which a small girl seems to be running towards her. The article, written in a diarylike, confessional narrative, began with a passage in which the survivor introduced the reader to her current mental and physical state:

I am sitting in a comfortable chair, dreaming while awake, with smoke rings from my cigarette dancing in front of me; just like I have been sitting many times before. Yet I can't remember that I've ever felt such a deep physical contentment as I do now. Is this really me; am I living this or is it a treacherous dream that will dissolve into nothing just like the smoke rings of my cigarette? No, now I hear a joyous, girlish laughter right next to me. In the hell that I come from they didn't laugh. In that place there were only tears. Relieved, I lean back in my chair and close my eyes in gratitude while events from the past few years whoosh past in my memory. 510

509 "Konvalescent i Sverige," September 29, 1945, Aftonbladet.

510 "Konvalescent i Sverige," September 23, 1945, Aftonbladet, [“Jag sitter i en bekväm fåtölj och drömmer vaken, medan rökringarna från min cigarett dansar framför mig. Precis så som jag suttit så många gånger förr i världen. Men jag kan inte påminna mig att jag någonsin känt ett så intensivt 
In the article, the reader learned how the woman-whose only identifier was the letter G., signed at the end of the article — had been sent from Prague to a ghetto in Poland, after which she was deported to Auschwitz and finally also to BergenBelsen. In this brief outline of her experiences, the author described how "Auschwitz was horrendous. Bergen-Belsen is hell", thereby not merely equating the two, but stating that the latter was even worse than the former. The article was not principally concerned with these experiences, however, but instead focused on the period of rescue and recovery in Sweden. As a caption in the middle of the text explained; "There is no barren north... says a sick refugee that has come to Sweden. Here she tells us how it feels to recover". 511 Thus, in the article, the women attempted to dispel the myth of a "barren North"; a misconception that had been disproven by her own experiences of "warm-hearted, helpful, honest people" who had assisted her in recovering and gaining "new strength". "It is like having experienced a difficult operation" she wrote, "the wounds still hurt, but I know that I will be better". 512 The difference in descriptions between survivor refugees and survivor witnesses at the trial is significant here, because it underscores the separate roles these two categories of camp survivors were given to fill. While the women in Vittnesbördet had been made to bear witness by baring their bodies to Swedish audiences in May and June of 1945, they had now joined the ranks of the Scandinavian refugees in attesting to Sweden's ability to nourish their bodies as well as their souls. Thus, the survivor-witnesses' accusations as well as their open suffering in German courts, was framed as legitimate and useful, whereas the role of the survivor-refugee was framed as one of recovery. In simpler terms, the role of the survivor-witnesses was to rip at their wounds, while the survivor refugees were to let them heal.

This narrative was reinforced in a series of news articles about UNRRA officials coming to visit Swedish internment camps published in DN. On the front page of DN on October 4, a headline read that "UNRRA delegates visit[ed] the

kroppsligt välbefinnande som i denna stund. Är detta verkligen jag, lever jag eller är det en förrädisk dröm, som jag snart skall växa ur, och som kommer att upplösas i intet, precis som rökringarna från min cigarett? Nej, nu hör jag ett glatt flickskratt strax bredvid mig. I helvetet jag kommer ifrån skrattar man inte. Där fanns det bara tårar. Jag lutar mig lättad tillbaka och sluter tacksamt ögonen, medan de senaste årens händelser åter drar förbi i mitt minne”].

511 "Konvalescent i Sverige," September 23, 1945, Aftonbladet ["Det finns inget kargt Norden...säger en flykting som kommit till Sverige. Hon berättar hur det känns att bli bra"].

512 "Konvalescent i Sverige," September 23, 1945, Aftonbladet ["Det är som att ha gått igenom en svår operation: såren smärtar ännu men jag vet att jag kommer att bli bra”]. 
camps for the Belsen victims". ${ }^{513}$ The two delegates were also depicted in photographs and it was described how their first task was to help Polish refugees return home. The headline to the following article on the last page of the newspaper declared how the children were recovering "surprisingly quickly" and that they had received the best care while in Sweden. ${ }^{514}$ Similarly, on October 11, a front page headline reiterated this message by stating that an "UNRRA-delegate" was "impressed by Swedish refugee camps". ${ }^{515}$ Inside the newspaper the headline declared that "small camps and paid labor" was the "best psycho-therapy for refugees" who, in the article text, were described as diligent workers who were on the mend due to the excellence of Swedish care. ${ }^{516}$ As Byström has shown in his analyses of discourses surrounding different refugee groups, the question of Jewish repatriation was controversial; some opinion makers argued that they should be awarded asylum, while it was opined in Aftonbladet that all Germans should be repatriated; both "Aryans" and Jews. ${ }^{517}$ Byström argues that this particular editorial, beyond being highly insensitive to the issues discussed, also relativized Jewish suffering by comparing it to German victimization. ${ }^{518}$

513 “UNRRA-delegater besöker lägren för Belsenoffren,” October 4, 1945, DN, 1.

514 "Barnen repar sig förvånansvärt fort," October 4, 1945, DN.

515 “UNRRA-delegat imponerad av svenska flyktingläger," October 11, 1945 DN.

516 "Små läger och betalt arbete bästa psykoterapi för flyktingar," October 11, 1945 DN.

517 Byström, Broder, gäst och parasit, 199-200.

518 Byström, Broder, gäst och parasit, 200. 


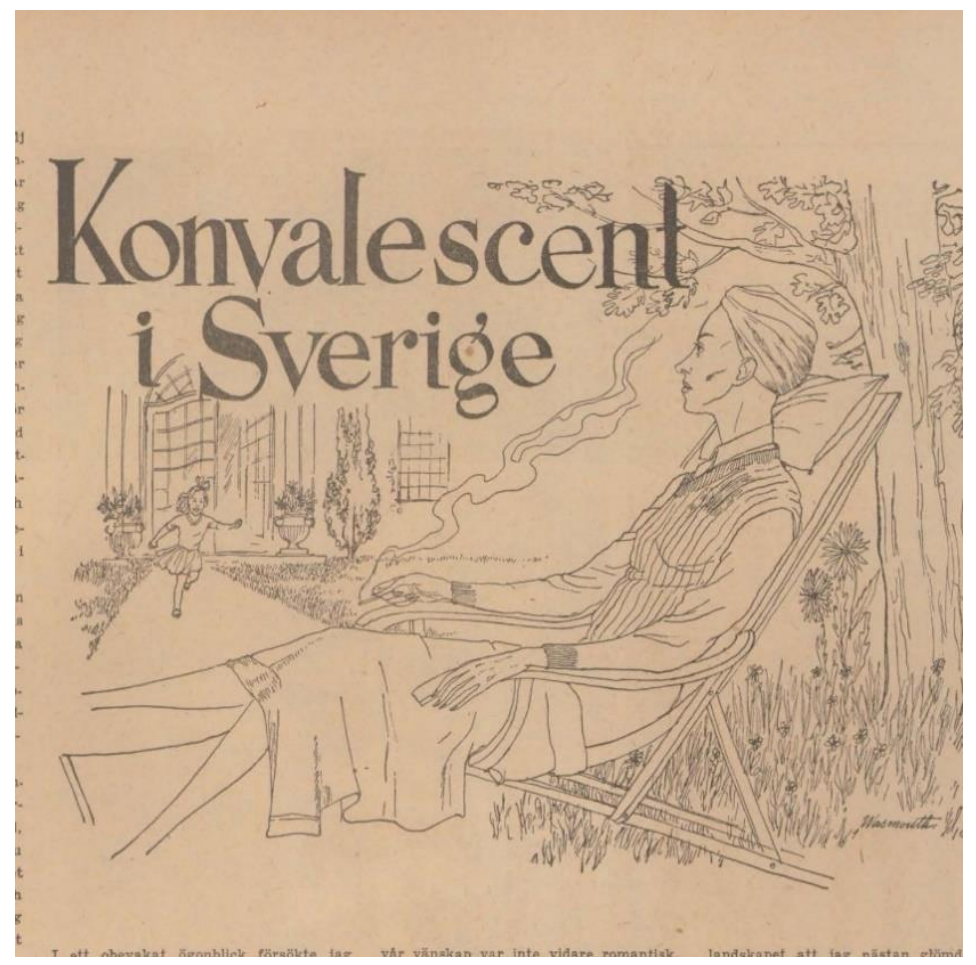

"Convalescent in Sweden," ("Konvalescent i Sverige"), September 23, 1945, Aftonbladet

The issue of German victimization was also part of the news discourse during the Belsen trial, with DN, SvD and Aftonbladet publishing articles about the strife of German citizens living in the rubble and economic crisis caused by the war. ${ }^{519}$ News articles reported that starving Germans were dying each day, creating scenes that were reminiscent of Belsen. "The dead are driven in piles in cars and on carts from the platforms" at the railways stations in Berlin, one news article in Aftonbladet reported, while an article in SvD declared that no child born in Germany that year would survive the winter. ${ }^{520}$ In an editorial in Aftonbladet, it was also argued that

519 "Fruktansvärd barnadödlighet i Tyskland," October 5, 1945, SvD. "Massmord' i Tyskland" October 5, 1945, Aftonbladet. "Medlidandet" October 1, 1945, Aftonbladet. "I kö till livet," October 14, 1945 DN.

520 "Fruktansvärd barnadödlighet i Tyskland," October 5, 1945, SvD. "Massmord' i Tyskland" October 5, 1945, Aftonbladet. 
the allied press, which had previously only shown those who suffered under occupation or in concentration camps, were now showing how the German "population must live under the most primitive conditions; there is not enough food, the children die in their mothers' arms and soon winter's cold and the inflation of hunger is upon them". ${ }^{221}$ In the editorial, it was argued that although sympathy should be withheld from German militarism, the German population needed to be pitied and aided so that peace and culture could prosper yet again. Similarly, in DN, it was asked whether Germany would be able to recover if "the methods that the Nazi's applied" would also be applied to the German people. ${ }^{522}$ It was not merely former concentration camp prisoners that needed to be restored to life, Germany as a whole had to be rebuilt and its people deserved compassion and help in order to survive. In these articles that positioned German suffering as equal to the suffering of the Nazi's victims, Belsen and Auschwitz were also present as symbols; not just of Nazi perpetration but also of a universal evil that could be repeated by anyone and against anyone.

This discourse on German suffering served to relativize Jewish survivorrefugee suffering during the time of the Belsen trial. Belsen became a symbol of suffering for all, not merely the Jewish survivor-victims who were testifying in the trial. Significantly, however, both the Jewish survivor-witness and the survivorrefugee were constructed through the representation of women camp survivors. This meant that the image of the Holocaust survivor became distinctly female. The fainting, angry, vindictive witness, the recovering refugee, the vulnerable victim, the 'object of care', were all survivor types that came to be embodied by women.

\section{7 Conclusions: The Descent of the "True Victim" and the "moral witness" in Swedish Media Discourse}

The descent of the survivor in Swedish media discourse can be found in multiple places. The deportation of the Norwegian Jews-although not contributing to the representation of Jewish refugees in the newspapers studied here-still likely affected the press' response to the deportation of the Danish Jews a year later by facilitating representations of the Danish-Jewish escapees. In representing the specific vulnerability of the Danish Jews, women and children were prominently featured in the news coverage; an aspect that added to the conceptualization of the

521 "Medlidandet," October 1, 1945, Aftonbladet.

522 "I kö till livet," October 14, 1945 DN. 
Danish-Jewish escapees as "True Victims". Considering the headlines and leads together with the images, also shows how the vulnerability of the victims was prioritized in news discourse on the flight of the Danish Jews. Although the early news reports communicated Swedish action on behalf of the escapees, later articles focused on the struggles of the flight itself. In his doctoral dissertation, Byström argues for the importance of the deportation of the Norwegian Jews in 1942 in shifting attitudes towards refugees coming to Sweden. Certainly, the way that those fleeing or being rescued to Sweden were constructed as refugees also mattered to how they were constructed as Holocaust survivors. However, survival from something more specific_like the Nazi's concerted effort to exterminate the Jews - only applied to certain groups of refugees. Therefore, the deportation of the Danish Jews in 1943 served as a pivotal point in the construction of the Holocaust survivor as the historical moment when the representation of the Holocaust as something separate from the war and representations of the classified, coincided.

Yet, the escape of the Danish Jews only constitutes the descent of the Holocaust survivor as a "True Victim". The concept of witnessing, which is also intimately connected to the Holocaust survivor, formed in relation to the increasing visibility of camp survivors in media discourse. Here, witnessing in, by and through the media affected the ways in which the "moral witness", as a passive object and an agential subject, could form. In the early representations of camp survivors in the press, non-Jewish Norwegian survivor-witnesses were more prominent than non-Scandinavian Jewish witnesses. In addition to testifying to their own victimization in the camps, the Norwegian camp survivors also acted as "dismayed spectators", joining the rescuers and other external witnesses in reporting on the extreme suffering that Jews had endured in the camps. Camp survival was also explained differently depending on the survivors' identities; Scandinavian men and women being portrayed as more resilient and loyal to each other compared to other survivor categories. The short documentary film, Vittnesbördet, reinforced these themes while also further gendering the rescuees by representing non-Scandinavian women as 'objects of care' while Scandinavian men were represented as human subjects whose normal lives were but another cup of coffee and a morning paper away. In critiquing the women in the film for being too plump while others appeared starved, Lisa Matthias portrayed the female rescuees as lacking in solidarity and moral character; thus placing even more pressure on female camp survivors to appear and act 'victim-like' in order to be perceived as "True Victims". $V$ ittnesbördet signified a witnessing by the film medium; the bodies of the rescued testifying on camera. Through an external focalization, the survivors and their camp experiences were made largely invisible to audiences. Thus, the "dismayed 
spectators" in the form of the director and the camera man were the only witnesses to their strife; a strife, it seemed, that could easily be used and abused by contemporary commentators.

In contrast, Berggren's interview reportage-constituting both a witnessing through and by the medium-provided a deeper insight into camp experience while also allowing non-Scandinavian Jewish camp survivors to testify to specific experiences related to the Holocaust such as ghetto life and the extinction of whole families. At the same time, the reportage also included descriptions of the survivors that served to proffer the validity and authenticity of the testimonies. All survivor passengers aboard SS Rönnskär were described as sick and wounded as well as starved and weakened. These qualities of victimization also contributed to their standing as "true witnesses" to the Holocaust, speaking from within the experience itself. This is also what constitutes the main difference between the construction of camp survival as a general concept in 1945 and the construction of the Holocaust survivor; the former including many nationalities as well as Jews and non-Jews, while the latter was specifically tied to the particular victimization of the Jews. As evidenced by Berggren's references to "gruel propaganda", the proof of this victimization lay in the wounds exposed by the Jewish camp survivors. The more wounded they appeared, the more reliable their testimony would seem. Even though this exposure of vulnerability created a position for Jewish camp survivors from which they could speak about Jewish victimization, this position soon became disciplined by the need to demonstrate that Sweden was helping all camp survivors to recover, not only the Scandinavian repatriandi. Simultaneously, their victimization was also indirectly compared to German victimization under the occupation of the Allied powers. Also, through the Belsen trial, female Jewish survivor witnesses both constituted an object of interest—-being able to testify to the unnatural and particularly gruesome aspects of female-on-female perpetration—and as an object of suspicion; their vindictiveness and accusatory role as witnesses making them less credible as "true victims".

This chapter has primarily focused on a single "vector of practice" in studying news discourse. However, within this vector, several discursive practices exist which, in different ways contributed to the formation of a survivor object. Even though disciplinary practices involving experts commenting on survivor expression had not necessarily developed at this point given that the event had not yet entered the realm of memory, traces of utility as the underlying problematization can still be detected in the material. Lisa Matthias' commentary on Vittnesbördet constitutes one such example where the women portrayed were being problematized rather than the director who was witnessing in their stead. The latter, in contrast, was 
lauded as an ideal witness to the witnesses, meaning that Berggren's ability to frame the Jewish camp survivors' stories in an effective way was emphasized over the vulnerability of the victims. Even in 1945-before any trial had begun-Swedish commentators thought themselves all-knowing about Jewish victimization, one critic stating that even cannibalism in the camps did not come as a surprise anymore. Utility, then, was the problematization or the "depth condition" that determined the different formulations of the survivor object in 1943 and 1945the object of care showing Swedish excellence while the "moral witness" in the form of a "dismayed spectator" had to effectively communicate Holocaust experience.

Importantly, the female Jewish victim and the female Jewish witness were crucial figures in the descent of the Holocaust survivor in Swedish media discourse during and directly after the war. Partly as a result of the large number of women arriving from Ravensbrück to Sweden in 1945 and partly because of gendered notions of passive victimization and vulnerability, women, to a greater degree than men, became particularly useful symbols of Holocaust survival. As will be explored in the coming chapters, female Holocaust victims and survivors would continue to dominate discourses on the Holocaust, many times embodying the concepts of Holocaust victimization, witnessing and survival. Thus, even though the Jewish "moral witness" to the Holocaust never emerged during and in the direct aftermath of the war, the development of a true Holocaust victim had contributed to the establishment of a figure-female, Jewish and Western-who would come to dominate Holocaust memory in the 1950s. That figure was Anne Frank. 



\section{Chapter 4 - Anne Frank: The Exemplary Witness and the Survivors, 1953-1960}

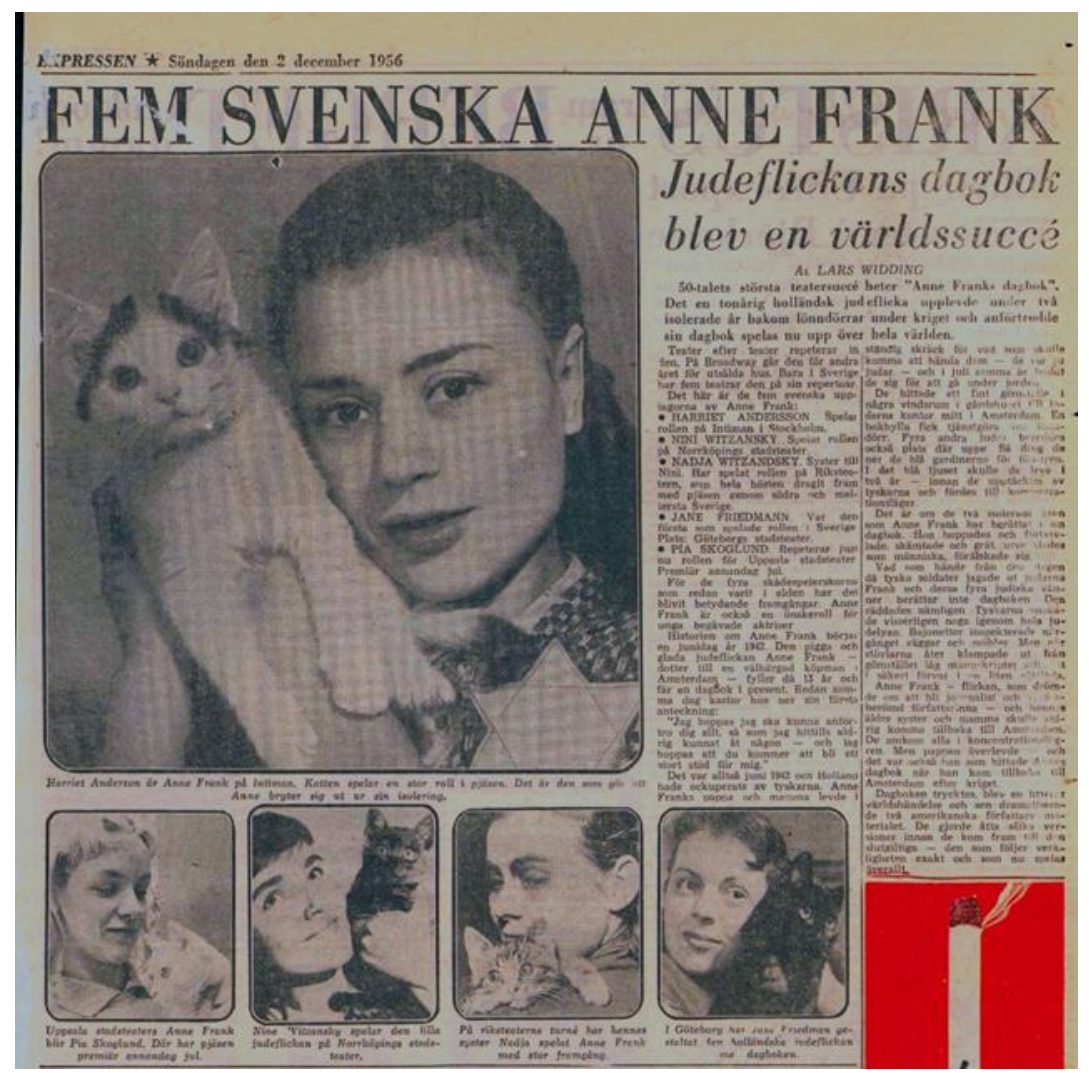

"With the touching letters to 'Kitty' the world had received its catharsis at much too cheap a price-and pretty young actresses were being given a rewarding part to play on the stage and in the movies. The thought filled her with feelings of hatred."1

- Cordelia Edvardson, Burned Child Seeks the Fire

\subsection{Introduction}

This quote, taken from Swedish Jewish writer and journalist Cordelia Edvardson's memoir Burned Child Seeks the Fire, highlights the dark emotional response of a camp survivor when realizing the ease with which the world's conscience could be 
washed clean. These feelings arose in response to the glamourization of the Holocaust in the shape of Anne Frank on stage; a role that could make or reignite the career of any actress in the mid to late 1950s. The Expressen article, depicting five Swedish actresses all playing Anne Frank, shows the foremost symbol of Holocaust victimization and witnessing of the 1950s in Sweden; young and female, sweet and innocent as well as precocious and forthright. If the "True Victim" had been Danish Jewish women and children in 1943, Anne Frank-the Dutch teenage girl whose family were assimilated Jews in a country occupied by the Nazis just south of the Danish border-fit neatly into this conception of true victimization. Perhaps this was also the reason why Swedish newspapers did not, in contrast to their Anglo-American counterparts, shy away from the Jewish identities of the Frank family and their neighbors in the Achterbuis on Prinsengracht in Amsterdam.

Reading and seeing Anne Frank was, from the very beginning, no ordinary cultural experience, but was positioned as one that could change the moral fiber of society. As the American theatre and drama scholar, Edna Nahson, notes in her contribution to the anthology Anne Frank Unbound, "the notion that seeing The Diary of Anne Frank is an exceptional, morally galvanizing experience has a considerable history, dating back to the play's first production".523 What distinguished Anne Frank's testimony from that of survivors who wrote and spoke of their experiences in the same decade (Cordelia Edvardson being one of them), was the fact that she was dead; her story was not based on recollections and was therefore perceived as more authentic than the stories provided by those writing a decade after events had passed. In addition, Anne Frank's story was not one of blood and gore but lingered on the relative dignity of a family in hiding, stopping short before capture and deportation to Auschwitz-Birkenau. However, with the final large-scale American mediation of Anne Frank in the 1950s - the film entitled The Diary of Anne Frank-Anne Frank's fate had been thoroughly explored and her fate significantly attached to the final solution and Jewish suffering in the camp system. Thus, although the dominant figure of Anne Frank hindered the construction of survivors as "moral witnesses" (just like the "dismayed spectator" of the 1940s had done), the historicization of her fate in the late 1950s also served to strengthen the position of the survivor-witness.

523 Edna Nahson, “Anne Frank from Page to Stage,” in eds Jeffrey Shandler \& Barbara KischenblattGimblett, Anne Frank. Unbound: Media, Imagination, Memory, (Indiana University Press, 2012), Ebook, 59 . 
The phenomenon of Anne Frank is a well-explored subject in AngloAmerican research. Interestingly, however, the first iterations pertaining to Anne Frank's writings are completely absent from Swedish scholarship. Even some of the internal histories of the theatres who set up The Diary of Anne Frank during the autumn season of 1956 fail to mention the play. ${ }^{524}$ Also, no studies of Swedish Holocaust memory engage with Anne Frank; as book, as play or as film. As previously discussed, the 1950s are commonly considered to be the 'silent' decade of Holocaust memory when most of the Western world tried to forget its traumatic past and move into the future. ${ }^{525}$ Receptions of Anne Frank: The Diary of a Young girl as well as the play and film adaptations of the book, although enthusiastic and warm, have not necessarily been perceived as breaching this silence. Many studies of this period argue that the mediations of Anne Frank's story never engaged in any meaningful way with the Holocaust as a genocidal process. ${ }^{526}$ This conclusion has, perhaps, affected further study into the impact of Anne Frank in national and regional contexts outside of the US, the UK, Germany and Israel.

Keeping the previous chapter's conclusions in mind regarding gender, age and notions of the "True Victim" and the "moral witness" it is likely significant that Anne Frank was a young girl; her position as an exemplary victim and witness further affecting expectations on how the Holocaust story should be told. The manner in which Anne Frank was received by critics and commented on by cultural and political opinion makers also show a disciplining of Anne Frank as symbol and as a concept; a disciplining process that has been left out of historiographical narratives on Swedish Holocaust memory. Therefore, in this chapter, I examine

524 In a 75 year anniversary book for Rikteatern; a theatre that toured with The Diary of Anne Frank, all over Sweden in the autumn season of 1956, does not mention the play at all. This, in spite of the fact that Anne Frank dominated that theatre seasons. See Christopher Mair (ed.), Riksteatern, 75 arr, (Norsborg: Riksteatern, 2008).

525 Antero Holmila \& Karin Kvist Geverts, "On forgetting and rediscovering the Holocaust in Scandinavia," Scandinavian Journal of History, vol. 36 no. 5 (2011): 526.

526 See for example, Langer, Admitting the Holocaust: Collected Essays, (Oxford: Oxford University Press, 1995), 157-177; “The Uses_and Misuses_of a Young Girl's Diary: 'if Anne Frank could return from among the murdered, she would be appalled," in eds Hyman A. Enzer and Sandra Solotaroff-Enzer, Anne Frank: Reflections on her Life and Legacy, (Urbana-Champaign: University of Illinois Press, 2000): 203-205. James E. Young, Writing and Re-Writing the Holocaust: Narrative and the Consequences of Interpretation, (Indianapolis: Indiana University Press, 1988). Rachel Feldhay Brenner, Writing as Resistance: Four women confronting the Holocaust: Edith Stein, Simone Weil, Anne Frank and Etty Hillesum, (University Park, Pa: Pennsylvania State University Press, 1997), 5. 
how the first mediations of Anne Frank-the book, the play, and the filmreflected and affected discourses on Holocaust victimization and witnessing in Sweden from 1953 until 1960. If we assume that Anne Frank was used as a way to "manage" Holocaust memory in the decades directly following the war, this management is important to understand; not merely because of what it excludes but also in how it was productive. The purpose of this chapter is also to explore how silence and excess as well as conceptions of 'Swedish-ness' and 'Jewishness' informed the construction of Anne Frank during the 1950s and, in extension, how these conceptions informed constructions of the Holocaust survivor. What images of the Holocaust victim and witness did the culture critique of Anne Frank create? And, how did these images affect notions of the Holocaust survivor?

\subsection{Methods and Sources}

In attempting to answer these questions I have primarily studied the critical reception of the first Swedish edition of the book entitled Anne Franks Dagbok (published in 1953), the five theatre productions based on the American playwrights Frances Goodrich and Albert Hackett's play The Diary of Anne Frank (staged during the autumn season in 1956) and the film adaptation of the Broadway play also entitled The Diary of Anne Frank (released in 1959). The Swedish literature scholar Johan Svedjedal argues that research on culture critique is often confused with studies of "reception". ${ }^{27}$ Certainly, the ways in which critics 'receive' a book only account for a small part of its greater reception - the other parts, as Svedjedal points out, being created in different encounters between the text and its readers, between the book and commercial institutions, between the book and libraries etc. ${ }^{528}$ However, critics, in their positions as experts, still play a vital role in affecting how a particular work should be received. Although such disciplinary practices may not control how every reader/viewer/listener perceives a work, they still significantly affect the ways in which the work is framed in relation to greater political, social and cultural discourses, thus affecting how the literary work is perceived over time.

Moreover, the critical reception of a cultural product, be it a book a play or a film, is also intrinsically linked to its physicality. Because of this conditioning of the critique, I have chosen to also include analyses of various aspects of the book itself.

527 Johan Svedjedal, "Kritiska tankar: Om litteraturkritiken och det litterära systemet," Tidskrift för litteraturvetenskap, no. 1, (1998): 50.

528 Svedjedal, "Kritiska tankar," 50. 
In practical terms, this means that I have paid attention to the cover page, the preface and the epilogue as well as the redactions made to the first Swedish edition of Anne Frank: Diary of a Young Girl. With regards to the section on the stage adaptation of the book, I have primarily focused on theatre reviews in the Stockholm-based daily and evening press. However, as previous research on theatre productions of The Diary of Anne Frank in Sweden were wholly lacking I also made use of Riksteatern's (a touring theatre company with national reach) archives in order to establish some form of knowledge base for ticket sales, number of performances, as well as touring dates and places for the autumn (premiere) season of 1956. In addition to the critical reception of the film itself, I have also explored the chronicle series and theatre play created by Ernst Schnabel as well as how these were discussed in the Swedish press.

As with all chapters in this dissertation, the various mediations of Anne Frank first appeared in the digital newspaper archive at the National library. When using the search word "koncentrationsläger" a multitude of results cropped up for the late 1940s and the 1950s. Looking closer at the years in the middle of the latter decade - 1955 and 1956-I found several articles that used the term to describe camps that existed behind the "iron curtain". ${ }^{229}$ In addition, I found a longer article about the current use of Dachau in DN as well as an article describing how former Jewish concentration camp prisoners were, yet again, housed in camps (similar to shanty towns) outside of Munich after having returned from Israel where they, reportedly, had not liked either the climate or the working conditions. ${ }^{530}$ In 1956 the government also published their white papers on the 'White Buses' mission which garnered some attention from the Swedish press; especially due to the critique that Himmler's Finnish masseur, Felix Kersten, received from the esteemed British historian Hugh Trevor-Roper. ${ }^{531}$ However, that very same year I also found a large number of advertisements displaying a cartoon picture of Anne Frank's face. The advertisement was for the weekly magazine Folket $i$ Bild (FIB)

529 See for example, “25 000 fångar i blodig lägerrevolt," July 30, 1956 Expressen.

530 "Barackerna fylls av tyskar från östzonen,” April 29, 1955 DN, 8-9. "Flyktingselände i nazismens huvudstad," April 28, 1955, DN.

531 “Hur Sverige räddade 19000 Hitlerfångar," April 26, 1956, Expressen, 24. "Personligt tack till Himmler från Gustav V," April 26, 1956, DN, 8. 
which was publishing the book Anne Frank's Dagbok as a chronicle series. ${ }^{532}$ One of the advertisements, dominating the newspaper page of Aftonbladet with Anne's face, presented the story as "the most gripping fate of our time"; a phrase that indicated that the story of Anne Frank had caught the attention of Swedish readers and audiences. ${ }^{533}$ Thus, I began searching articles that discussed Anne, her family, the book, the play and the film and found that this was the most consistent theme through which Nazism, the Holocaust as well as its victims and witnesses was discussed over nearly the entire decade.

When searching the audio-visual archive, the first post found searching the term "Anne Frank" was a radio program made and broadcast in 1968. Since searches in the newspaper archive had shown that a play, a chronicle series as well as a documentary about the house in which Anne Frank and her family hid, were broadcast on Swedish radio beginning in 1953, the audio-visual archive simply seemed to lack this material. Thus, because of the fragmentary character of this archive, it was difficult to say anything about the audio-visual output regarding Anne Frank before 1968, outside of what I found in the tableaus published in the daily and evening press. What is more, television had not yet established itself as a medium and was just beginning to appear in 1956, meaning that most Swedish households did not have a television set. ${ }^{534}$ Therefore, I decided to focus solely on the material found in the newspaper archives as well as contextualizing material found in Riksteatern's archive.

After this decision was made, several daily newspapers were chosen based on their positions as platforms for culture critique during the period between 1953 and 1959. Here, Lina Samuelsson's doctoral dissertation The Order of Criticism: A Study of Reviews in Sweden in 1906, 1956, 2006 was helpful in delimiting some of the more influential daily newspapers and evening newspapers of the time. As in the previous chapter, DN seemed an obvious choice for scrutiny since it published more literature reviews than any other daily or evening newspaper in $1956 .{ }^{535}$ Quoting Tomas Forser, Samuelsson also points out that, other than being the most prolific

532 The advertisement was published in DN on October 13, 20 and November 2; in SvD on October

27; in Aftonbladet twice on October 20, once on October 26 and November 3; in Expressen on

October 20 and November 13. Often, the advertisement was bigger than any of the other adds or it covered the whole page.

533 October 20, 1956, Aftonbladet.

534 See discussion in section 5.4 on the establishment of the television medium in Sweden.

535 Lina Samuelsson, Kritikens ordning: Svenska bokerecensioner 1906, 1956, 2006, (Doctoral diss: Bild, text \& form, 2013), 64. 
newspaper in the cultural field, DN also dominated the market and was the most "coveted place for cultural debate and for culture critics". 536 Furthermore, in the early 1950s, Olof Lagercrantz stepped up as the editor for DN's cultural pagessomething which furthered the newspaper's "quality and status". ${ }^{537} \mathrm{SvD}$ was also selected in addition to DN; a choice founded on its established cultural profile. Compared to the other Stockholm-based newspapers, SvD had a smaller circulation than, for example, Stockholmstidningen and DN, yet as opposed to the former, SvD had a clear cultural profile and actively promoted itself as an authority on matters of culture. ${ }^{538}$

Also, as the Anne Frank phenomenon seemed to be promoted as a universal story aimed at the general population, two evening newspapers-Aftonbladet and Expressen — were included as well, hypothesizing that they would frame the phenomenon of Anne's Frank in different ways compared to the daily newspapers. Again, according to Samuelsson, Expressen's "cultural journalism differed from that of the daily newspapers". The editor-in-chief, Ivar Harrie wanted the newspaper's cultural pages to "keep a 'a straight line', be clear, sharp and popular in [their] tone, focus on debate and not be scared to bring up controversial issues". ${ }^{539} \mathrm{I}$ therefore expected Expressen to be more forthright about Anne Frank's genocidal context with aspects of sensationalism informing the tone and framing of the critical content.

Finally, in order to understand the relationship between Anne Frank as witness and the Jewish camp survivor as witness, I chose to analyze the literature critique of the Polish-Jewish and Swedish camp survivor Zenia Larsson's debut novel Skuggorna vid träbron ("The Shadows at the Wooden Bridge"), published in 1960. This choice was made based on the timing of Larsson's debut, occurring at the beginning of a new decade following the Anne Frank-dominated 1950s, yet entering the literary scene before the Eichmann trial.

\section{3 The Dead vs. the Living}

When the American writer Cynthia Ozick, in her New Yorker article from 1997, asked "Who owns Anne Frank?" she was alluding to a process of disciplining the

536 Samuelsson quoting Tomas Forser, Kritikens ordning, 64. See Tomas Forser, Kritik av kritiken: 1900-

talets svenska litteraturkritik, (Gråbo: Anthropos, 2002), 56.

537 Samuelsson, Kritikens ordning, 64.

538 Samuelsson, Kritikens ordning, 64.

539 Samuelsson, Kritikens ordning, 63. 
Holocaust. Owning means controlling the narrative of who Anne Frank was, what her story contributes to the greater story of the Holocaust, and what kind of victim and witness she was in relation to ideals of representing and communicating the Holocaust. Ozick calls it the "shamelessness of appropriation", building on a long tradition of critique against the many uses and abuses of Anne Frank's diary notes. Anne Frank was not a Holocaust survivor, yet as the symbol of spiritual survival, her story created important ideals for witnessing and for victimization. As will be demonstrated in these coming sections, these ideals became impossible for any survivor to live up to as they circulated around the notion that true objectivity and efficiency of narrative came with death. Thus, the authenticity of Anne's story came from the notion that her diary entries had been left untouched—her witnessing was from inside the experience and had never been tainted with ambition, greed, feelings of revenge or hatred. In her book Writing as Resistance, Rachel Feldhay Brenner explains that postwar reconstructions of dead victim-witnesses became ways of alleviating some of the pressure felt when faced with the totality of the catastrophe. She thus contends that,

posthumous, hagiographical treatments of [Edith Stein, Simone Weil, Anne Frank and Etty Hillesum] signal the postwar tendency to mitigate the horror. Stein, the Carmelite, was beatified as a Christian martyr; Frank became the universal icon of victimized children; Weil and Hillesum entered the pantheon of saintly altruists. ${ }^{540}$

Furthermore, she concludes that "the idolization of testimonies of the women's final moments is symptomatic of the post-Holocaust proclivity to make Holocaust suffering more manageable". ${ }^{541}$ In Anne Frank's case, these final moments were not those before she died in Bergen-Belsen but rather the final lines of her diary in which she famously writes: "A voice within me is sobbing...I get cross, then sad.... and keep trying to find a way to become what I'd like to be and what I could be if...if only there were no other people in the world". 542 As Zoe Waxman reminds us, however, Frank's most commonly cited phrase does not consist of these final words but, rather, the phrase, "I still believe, in spite of everything, that

540 Rachel Feldhay Brenner, Writing as Resistance: Four Women Confronting the Holocaust, (University park, PA: Pennsylvania State University, 1997), 5.

541 Feldhay Brenner, Writing as Resistance, 5.

542 Anne Frank, The Diary of a Young Girl, (London: Vallentine Mitchell, 1952), 336. 
people are truly good at heart". 543 'The choice to interpret Anne's story as hopeful and redemptive came under heavy critique in the 1980s and 1990s, primarily and most ferociously by the American Holocaust scholar Laurence L. Langer. In his 1995 book of collected essays, Langer asked the question "how much darkness must we acknowledge before we will be able to confess that the story cannot be told in terms of heroic dignity, moral courage, and the triumph of the human spirit in adversity?" 544

Langer's critique is a significant contribution to the discussion on how the Holocaust should be understood and, perhaps more importantly, how it should be represented. This long-standing discussion was especially potent in the decades before the ascent of the internet when a small number of mediums controlled how the Holocaust was portrayed. The fact that Anne Frank became the spokesperson for victims' suffering during the Holocaust is only one example of how Holocaust experience became homogenized. What was, and to some degree still is, at stake in the mediation of Anne Frank is the possibility for stories other than that of Anne to be afforded space in public discourse. The issue is thus not Anne herselfwhether she is Jewish enough, or if she was wise beyond her years, a good writer or truthful in her narration-but, rather, the use and abuse of her memory over the decades when most Western countries were coming to terms with the Holocaust.

The Post-Holocaust construction of Anne Frank and the reception of the book, play and film based on her writings has, of course, been subject to much scholarly scrutiny, especially in the United States. Because interest in Anne Frank has been so great for decades, however, some efforts to contextualize the book, play and film have sometimes lacked scholarly stringency. For example, David Barnouw's The Phenomenon of Anne Frank, although containing a well-written and fascinating narrative about all three mediations, does not contain a system of references, thus making it impossible to trace where the author has received all his information. ${ }^{545}$ Furthermore, most works that discuss the post-Holocaust

543 Zoë Waxman, Writing the Holocaust: Identity, Testimony, Representation, (Oxford, Oxford University Press, 2007), 131.

544 Langer, Admitting the Holocaust, 158.

545 David Barnaouw, The Phenomenon of Anne Frank, trans. Jeanette K. Ringold (Indianapolis: Indiana University Press, 2018). In the author's note on page viii, Barnouw explains that “in order to make [his] book more readable, no footnotes have been used, but where necessary, the text refers to the sources." In reading Barnouw's narrative, however, there are a few crucial points where footnotes would have been necessary in order to substantiate his account of Anne Frank as an early phenomenon. 
representation of witnessing, victimization and survivors tend to refer to Anne Frank as an enlightening example of the points being made. As a contested symbol of Holocaust memory this is not surprising. However, rather than reference these discussions I have made extensive use of two works which both provide novel perspectives on, as well as contexts for, the different mediations of Anne Frank in the 1950s. The first of these, the anthology Anne Frank Unbound, edited by media scholar Jeffrey Shandler and drama and Jewish studies scholar Barbara Kirschenblatt-Gimblett, focuses on the "phenomenon of Anne Frank as a subject of interest in itself", an endeavor which takes all mediations at face value-as meaningful cultural productions on their own, both in relation to Anne Frank's biographical writings as well as outside of them. ${ }^{546}$ Due to the temporal frame of this dissertation, the first three chapters of the anthology, authored by Shandler, Nahson and the British film studies scholar Leshu Torchin, were helpful to my analysis as they focus on the first mediations of the book, the play and the film respectively. In addition, the American novelist and critic Francine Prose's book Anne Frank: the Book, the Life, the Afterlife, has also guided my studies, especially in regards to Prose's contextualization of the publication of Anne Frank: the Diary of a Young Girl in the United States. ${ }^{547}$ These works both belong to an American scholarly tradition and were also partly chosen because of this fact with both the Swedish translation of the book, the play and the film being American imports. However, in addition to these two works, Waxman's chapter on women's Holocaust testimony in Writing the Holocaust has been helpful in contributing insight into the construction of the female Holocaust witness in relation to discourses on Anne Frank. ${ }^{548}$

With such qualitative work already being conducted on Anne Frank-as person, victim and symbol — it may seem a futile endeavor to revisit her yet again, especially when considering the critique that her dominance in the Holocaust diary genre has served to obscure other forms of Holocaust memory. Yet, considering the fact that no scholarly work has been conducted on the Anne Frank phenomenon in a Swedish context and given that she has been deemed important

546 Jeffrey Shandler \& Barbara Kirschenblatt-Gimblett, "Introduction: Anne Frank, the Phenomenon," in eds Jeffrey Shandler \& Barbara Kischenblatt-Gimblett, Anne Frank Unbound: Media, Imagination, Memory, (Indiana University Press, 2012), E-book, 7.

547 Francine Prose, Anne Frank: The Book, the Life, the Afterlife, (New York: Harper, 2009).

548 See chapter 4, "Writing Ignored: Reading Women's Holocaust Testimonies," in Writing to Remember, 122-151 Waxman has also authored a brief companion to Anne Frank, see Zoë Waxman, Anne Frank, (Stroud: The History Press, 2015). 
(although in ways that have been perceived unseemly) to Holocaust memory elsewhere, it appeared relevant to investigate the effects that the book, play and film had on public discourses on the Holocaust survivor in Sweden. In addition, bar Waxman's feminist perspective on Anne Frank, the 1950s culture critique that first 'created' this phenomenon has not been understood in relation to conceptions of gender. ${ }^{549}$ The purpose of this chapter is thus also to explore these dimensions of the Anne Frank phenomenon-as an effectual presence contributing to specifically gendered notions of the Holocaust victim and witness in Swedish public discourse.

\subsection{The Diary of a Young Girl: A Subject of Gender and Age}

The book with the English title, Anne Frank: The Diary of a Young Girl (heretofore Anne Frank) remains the most famous and prolific of all mediations of Anne Frank's writings. First published in Dutch in 1947 under the title Het Acbterbuis, the book had already reached a world audience by the time that the Swedish translation was published in 1953 under the title Anne Franks dagbok. ${ }^{550}$ Looking almost identical to the first American edition, the first Swedish edition of Anne Frank was published and distributed by the relatively small publishing house Hökerbergs förlag. In this section of the chapter I will explore this first Swedish edition of the book, focusing mainly on how the story was framed through an analysis of the cover, the prologue and the epilogue of the book. As Shandler contends in his contribution to Anne Frank Unbound, "examining the diary's redaction, publication, and materialization reveals a complex of obscured or easily overlooked mediations between Anne's original writings and her millions of readers, shaping their encounter with her life and work." ${ }^{551}$ Even though there is not enough space in this dissertation to undertake a full investigation into the publishing process of Anne Frank's first Swedish edition, inclusions into, and exclusions from, the existing editions will still elucidate some of the publishing choices made and, thereby also,

549Waxman, Writing the Holocaust, 122-151. Of course, Judith Tydor Baumel Schwartz seminal book,

Double Jeopardy, may also seem pertinent contribution to this analysis of Anne Frank and gender. However, since Baumel Schwartz focuses on the didactic aspects of Anne Frank as a gendered symbol of Holocaust victimization, it does not significantly inform the coming analysis of Anne Frank as the ideal victim-witness.

550 Shandler \& Kirschenblatt-Gimblett, "Introduction," Anne Frank Unbound, 2.

551 Jeffrey Shandler, "From Diary to Book: Text, Object, Structure," in eds Jeffrey Shandler \&

Barbara Kischenblatt-Gimblett, Anne Frank Unbound: Media, Imagination, Memory, (Indiana University Press, 2012), E-book, 26. 
of how Anne Frank was first presented to the Swedish public. Furthermore, the critical reception of the first Swedish edition will be examined in order to understand how Anne Frank as victim and as witness was shaped by literary experts, which audience she was presented to and what the main themes of the book were made to be.

\section{The Book's Swedish Becoming}

Early perceptions of Anne Frank were shaped by the conception that the book contained the largely unredacted diary notes of an adolescent Dutch Jewish girl; a girl who, without intention or foresight, had jutted down her thoughts during the final years of her short life. ${ }^{552}$ As has been shown in later research on the diary as well as in later editions of the book itself, many layers of changes were made to Anne Frank's diary notes, both by the author herself, her father Otto Frank, as well as by various publishing houses, before it was first published in Dutch in 1947. Anne consciously revised and improved upon her diary notes after hearing a plea from the Dutch government in exile, speaking to the Dutch people via the radio channel Radio Oranje, to keep records of any acts of resistance to the occupying Nazi regime. ${ }^{553}$ It was, from that point onwards, Anne's intention to have her writings published, as evidenced by the ways in which she edited her diary notes, creating a prologue and a title page, including what would also become the first Dutch title of the book, Het Achterhuis. ${ }^{554}$ Furthermore, the book manuscript was altered by different publishing houses. ${ }^{555}$ For instance, in the original Dutch edition, the publishing house Uitgiverij Contact, asked to have any references to menstruation and sexuality removed from the manuscript. In contrast, such descriptions were included in the German edition, American and Swedish editions. ${ }^{556}$ Also, even before the book was submitted to a publishing house, both

552 All reviews of the book that have been studied here referred to the story behind the book as being limited to the discovery of the diary pages. No references were made to redactions, changes or rewrites and Anne's intentions of publishing her diary after the war was never noted or described. In a book notice published in DN on August 31 the introduction stated that "The diary that the Jewish girl Anne Frank wrote during the German occupation of Holland and which garnered much attention all over the world has now also been translated into Swedish". Here, the text portrayed one, singular diary being written, discovered and then published; a portrayal that largely fits with the descriptions given in the book reviews that I will refer to henceforth.

553 Shandler, "From Diary to Book: Text, Object, Structure," 28.

554 Shandler, "From Diary to Book: Text, Object, Structure," 28.

555 Shandler, "From Diary to Book: Text, Object, Structure," 31.

556 Shandler, "From Diary to Book: Text, Object, Structure," 31. 
Anne herself and Otto Frank had synthesized and altered Anne's diary annotations so that they would fit into a single work of writing, changing the names of some of the characters and rewriting passages in order to improve on the language. ${ }^{557}$ The notion that the diaries as well as the fictional stories found in the abandoned house on Prinsengracht were the unedited and unintentional notes of a young girl was thus a fundamental misconception.

Shandler argues that "each translation and each edition [of Anne Frank] is distinguished by different framing images and texts, which mediate readers' encounter with the published diary itself'. ${ }^{558}$ On many of the first edition's covers, the image of a very young Anne Frank can be seen, making the author seem even more precocious than what was already expressed on the pages of the diary. As Shandler notes, "among the range of photographs of Anne to appear on the covers of her published diary, there seems to be a greater tendency for earlier editions to use an image that emphasizes her youthfulness" while later editions have chosen photographs of an older Anne, catching her in the act of writing. ${ }^{559}$ Furthermore, Shandler contends that "although this trend may reflect changes in what images have been available to the publishers, it also evinces a shift in how Anne Frank has been presented to the public". ${ }^{560}$ Indeed, the ways in which Anne Frank was presented to the Swedish public in the late summer and autumn of 1953, contributed to an image of Anne as younger and more innocent than later shown in the critical editions published decades later.

The photograph used on the first Swedish edition of Anne Frank, depicts Anne smiling big into the camera. Anne is sitting at what appears to be a desk with her arms neatly laid in front of a blank notebook. This was the same photograph that was later used on the cover of more recent American editions of the book. ${ }^{561}$ Interestingly, however, on the Swedish cover, credited to the Swedish artist Jurgen von Konow, the notebook and desk have both been cropped out of the picture. What is more, there is little saturation in the photograph; an effect that makes Anne appear younger than she looks in the original version of the photograph where her adolescent features - a growing nose, darker skin around her eyes, the protrusion of a bone structure-are more prominent. The choice to crop out the desk and the notebook seems odd as the inclusion of a photograph rather than an illustration

557 Shandler, "From Diary to Book: Text, Object, Structure," 30-31.

558 Shandler, "From Diary to Book: Text, Object, Structure," 33.

559 Shandler, "From Diary to Book: Text, Object, Structure," 36.

560 Shandler, "From Diary to Book: Text, Object, Structure," 36.

561 Prose, Anne Frank, 79. 
(as some of the early German, Israeli and Dutch editions did) demonstrates a willingness to underscore the authenticity of the book-its direct connection to a once living author and subject speaking to her audience from a not so distant past. Making Anne seem younger at the time of writing the diary, however, does serve to soften the words spoken in the book. Her portrayal through photographs from a young age thus makes her seem less dangerous and less of a threat to the status quo. As will be discussed in chapter 6 regarding representations of Nelly Sachs, age and gender were two vital factors in discourses on Holocaust victimization and witnessing during the 1950s and 1960s in Swedish media discourse. The younger Anne appeared, the greater her achievement would seem. Thus, the emphasis on her youth bolstered her image as a genial writer, talented far beyond her years, while it also rendered her narrative even more innocent and unthreatening.

The epilogue of the first Swedish edition of Anne Frank consists of three brief paragraphs with information about what happened to the characters of the book and how the pages of the diary notes were discovered. The first paragraph thus informs the reader that the inhabitants of the attic at Prinsengracht were arrested by the Gestapo on August 4, 1944, while the final and third paragraph briefly discloses who perished and who survived. In three sentences, the second paragraph discloses the fate of the diary notes, stating that "with the exception of a few places, which were of little value to the reader, the original text has been printed." 562 Although brief, the epilogue constitutes an important part of the text in establishing the authenticity of the story just told as well as in communicating and cementing the notion that Anne's diary notes had been published, to a great extent, without redaction or editing. Similarly, some of the prefaces published in other language editions also emphasized the authenticity of the book. For example, according to Prose, Annie Romein-Veershoor's preface to the first Dutch edition "praised the book while dismissing it as the unaffected, unpolished scribblings of an unusually gifted child" thus further entrenching the notion that the book was an authentic, unedited, unintentional document from the war. ${ }^{563}$

The innocence of Anne Frank's young face was also added to by her gender. Another aspect of the book's composition that contributed to the gendering of the book was the decision to keep Eleanor Roosevelt's American preface in the Swedish edition of the book. In the preface, Roosevelt attested that she had been

562 Anne Frank, Anne Franks dagbok, trans. Ella Wilcke, (Stockholm: Hökerberg, 1953), 324. [Så när som på några enstaka ställen, som är av ringa värde för läsaren, har den ursprungliga texten blivit tryckt"].

563 Prose, Anne Frank, 79. 
made cognizant of the "war's worst evil—the human spirit's degradation" through Anne Frank's story. Directly after this statement Roosevelt praised the strength and resilience of Anne and emphasized the fact that the diary was a "testimony" to the dignity that the human spirit was capable of. ${ }^{564} \mathrm{It}$ is, of course, interesting that Roosevelt attested to being made aware of the Holocaust through Anne Frank when its narrative never broached neither ghettos nor camps. Also, the word "testimony" was not used as a reference to witnessing but rather, was used to describe the resilience of humanity in withstanding "the worst evil". ${ }^{565}$ As Shandler explains, "Roosevelt praises Anne's spiritual resolve, while ignoring her physical suffering, and emphasizing her familiarity, while marginalizing her Europeanness and eliding her Jewishness". ${ }^{566}$ All these aspects demonstrate "an enduring American approach to the diary as accessible and ennobling" - an approach which, as will be demonstrated in the culture critique of the play and the film, would easily be translated in a Swedish context.

If also considering the speaker of the manuscript as well as those who took it upon themselves or were chosen to present the book to the public, this approach of spiritual resolve and redemption also becomes distinctly gendered. After the American edition had been published, Otto Frank sent a letter to Eleanor Roosevelt, thanking her for giving him "comfort and the conviction that Anne's wish is fulfilled: to live still after her death and to have done something for mankind". ${ }^{567}$ Both the book's American editor, Barbara Zimmerman's and Otto Frank's delight at Roosevelt's preface most likely had to do with both its contentits universalization of Anne's story — as well as its ability to garner a greater interest in the book, thus spreading Anne's words to more readers. However, Eleanor Roosevelt, a well-respected human rights advocate and UN-delegate, had also, during her husband's twelve years as President been the first lady of the United States, a position that had made her the ultimate role model for American women. The fact that she, and not another, male representative of human rights discourse or someone that carried more literary weight, was given the opportunity to write a preface for the American edition of Anne Frank demonstrates how Anne Frank, albeit universalized in the preface, was still a gendered subject. Her story was the story of a private, domestic realm as well as that of the inner life of a little girl-

564 Anne Frank, Anne Franks dagbok, (1953), front cover.

565 Quoted in Prose, Anne Frank, 86.

566 Shandler, "From Diary to Book: Text, Object, Structure," 38.

567 Prose, Anne Frank, 86. 
both spaces which were presided over by the female sex. Because Anne's story was domestic (perhaps even perceived as a little dull at times), it was by default a female story, which, in turn, made it inherently apolitical. Even though Eleanor Roosevelt was a political heavy weight who had, arguably, wielded much power as an active first lady (especially after the paralysis of her husband), she remained a symbol of a decidedly female power and strength. Added to this was the fact that the two most significant editions of the book-the Dutch and the German editions-were also prefaced by women: Annie Romein-Veershoor (Het Acbterbuis) and Marie Baum (Das Tagebuch der Anne Frank). ${ }^{568}$ As will be further elucidated in the coming discussion on the book's critical reception, the gendering and de-gendering of Anne was intimately connected to those writing about her. In the case of the first Dutch edition, Romein-Vershoor's husband, Jan Romein had written an essay about Otto Frank's manuscript entitled "A Child's Voice" which had subsequently led to its publication in 1947. Here, Jan Romein's role had been to 'sell' the manuscript as a viable and worthy piece of literature as well as an important document from the German occupation of Holland during the Second World War. In contrast, Annie Romein-Vershoor's role had been to relay what Anne Frank was, her essence and the essence of the story she had contributed to the world. This was also the gendered division of labor which would come to characterize the critical reception of Anne Frank in Sweden.

Prose argues that in the adaptation from book to play, "the particular was replaced by the so-called universal, and universal was interpreted to mean American —or, in any case, not Jewish, since Jewish was understood to signify a smaller audience, more limited earnings, and, more disturbingly, subject matter that might alienate a non-Jewish audience". ${ }^{569}$ This universalization process has been widely discussed and criticized by scholars in relation to Anne Frank, both as book and as play. ${ }^{570}$ Yet, in all these discussions, the particular/universal dichotomy refers to the differentiation between a Jewish particularism and a non-Jewish universalism. The argumentation presented above, which will continue with the analysis of the critical reception of the book in Sweden, means to complicate this dichotomy further by introducing an understanding of the particular to mean both Jewish and female and the universal to mean a distinctly male non-Jewish perspective. The shift of Anne Frank, from a particular to a universal subject, is thus two-fold: when

568 Shandler, "From Diary to Book: Text, Object, Structure," 37.

569 Prose, Anne Frank, 76.

570 See for example Langer, Admitting the Holocaust, 70. Young, Writing and Re-Writing the Holocaust, 3. 
her story became a commercial success, she also became a viable political subject worthy of universal (male) attention. Therefore, through the first Swedish edition of the book, Anne Frank was both gendered and universalized. Even though Eleanor Roosevelt wrote in her preface that Anne Frank "says a lot about ourselves and about our own children" (this author's italics), this message, delivered by a woman about a young girl's thoughts, were more likely to engage other women.

\section{The Critical Reception of Anne Frank}

The critical reception of the Swedish edition of Anne Frank was both warm and enthusiastic. If Roosevelt's preface had effaced the Jewishness of the books' characters, this aspect was now being reinforced and highlighted. However, the critical response also echoed much of the preface in emphasizing the brilliance, strength and soulfulness of young Anne while trying to restore some hope to her story. In addition, the book was further gendered by this critical reception-not necessarily through the content of the reviews but, rather, through the people who presented Anne to Swedish publics.

During the autumn of 1953, several reviews of Anne Frank were published in Swedish daily and evening newspapers. A great majority of these were penned by female journalists, writers and translators who also worked as literary critics. In her dissertation, Samuelsson shows how most literary critics in the 1950s worked as freelance writers and 40 percent of the critics in her study were also active as fictional writers. In addition, many critics had academic degrees such as $\mathrm{PhDs}$ and licentiates. ${ }^{571}$ In quoting Swedish literary scholars Stina Otterberg and Tomas Forser, Samuelsson contends that the literary criticism of the 1950s, as expressed on the still somewhat fluid and ad-hoc "cultural pages" of newspapers, was produced by a collection of academic and literary experts who were hired to comment on contemporary issues according to their own tastes and personal interests. ${ }^{572}$ Although many different experts had access to the cultural pages, there were significant differences in status between those who delivered this literary criticism. Since the female critics, who constituted approximately 16 percent of Samuelsson's sample (18 out of 113), were more likely to announce female writers than were their male counterparts, they were often seen as being part of a "female literary sub-culture". 573 As Samuelsson writes, "literature criticism was a male

571 Samuelsson, Kritikens ordning, 67.

572 Samuelsson, Kritikens ordning, 67-68.

573 A term coined by Karl-Erik Rosengren in the 1950s. See Samuelsson, Kritikens ordning, 70. 
culture: 84 percent of the critics were men, it was men who wrote 86 percent of the reviews and 79 percent of the announcements treated work written by men. 71 percent of all the reviews were written by men about other men's work". 574 The famous critics critiqued the famous writers and vice-versa, meaning that when women were given the opportunity to review great works by men, their status as critics increased. 575

The foremost reviewers of Anne Frank were women: Ann Boleau, Ven Nyberg and Maud Adlercreutz. The last two were prolific journalists and literary critics whereas Bouleau was a professional translator who also wrote about literature. ${ }^{576}$ Although Nyberg (whose signatures were Ven, Vogue and Elle) and Adlercreutz (whose signature was simply Maud) held high positions at their respective newspapers, Nyberg at SvD and Adlercreutz at Aftonbladet, they have not been recognized in previous research as prominent literary critics of their time. In Per Rydén's Domedagar: Svensk litteraturkritik efter 1880, which, as the title suggests, portends to be an overview over Swedish literature criticism from 1880 onwards, Nyberg is never mentioned. Furthermore, in Tomas Forser's seminal work Kritik av kritiken, Adlercreutz does is not featured at all, while Nyberg has been added in an endnote on page 147.577 Even though this might say more about the patriarchal thinking underlying academic writing on Swedish literature criticism than it does these women's respective positions in 1953, it remains indicative of the structures that held these women in the lower echelons of the hierarchy of 'making' and 'discovering' new authors.

574 Samuelsson, Kritikens ordning, 70. [“Litteraturkritiken var en manlig kultur: 84 procent av kritikerna var män, det var män som skrev 86 procent av recensionerna och 79 procent av anmälningarna behandlade verk skrivna av män. 71 procent av recensionerna var skrivna av män om andra mäns verk.'].

575 Samuelsson, Kritikens ordning, 70. Samuelsson gives the example of Abenius and Nyman who reviewed Harry Martinsson's book Aniara in 1956.

576 Samuelsson, Kritikens ordning, 69.

577 Per Rydén, Domedagar: Svensk litteraturkritik efter 1880, (Lund: Lund University, 1987). Tomas Forser, Kritik av kritiken: 1900-talets Svenska litteraturkritik, (Gråbo: Anthropos, 2002). Rather than being included in these seminal works on Swedish literature criticism, scholars such as Kristina Lundgren have attempted to rectify the exclusion of women critics from the academic canon through works that focus specifically on them. See for example, Kristina Lundgren, Alltfor mycket kvinna: En biografi om Else Kleen och den nya kvinnan som sambällsförbättrande journalist, (Stockholm, Carlssons, 2010).—Attis, Bang, Maud: Solister i maingfalden, (Doctoral diss.: Stockholm University, 2002. 
Several months before Anne Frank had been published in Swedish, however, its English edition was reviewed in DN by the renowned literary critic Knut Jaensson. Although debuting as a critic in his late 30s, Jaensson maintained a particularly elevated position within the Swedish cultural elites throughout the 1930s, 40s and 50s. ${ }^{578}$ Himself a writer, he spent most of his time critiquing the works of others, and his and his wife-the renowned Swedish author Tora Dahl's-home in the Stockholm archipelago served as a meeting place for young, up-and-coming poets and writers during the 1930s. In 1946 he was given a fulltime position at DN but continued to write for different literary journals until his death in $1958 .{ }^{579}$ His review of Anne Frank, which dominated the page of DN on May 4, began with the dramatic opening statement that there were not many books, "nor diaries for that matter", that could boast being "unique" and "one of a kind". 580 Jaensson continued by proclaiming that many "of Jewish heritage" had previously described how it was to live (and die) under "occupation" during the war. Yet, none had, according to Jaensson, described it quite like this young girl had, whose rendition was "humanely harrowing, artistically perfect, relentlessly revealing, exceptionally frank and highly intelligent". 581 Jaensson also underscored the fact that Anne was "objective and possesse[d] a great deal of self-awareness". ${ }^{582}$ As the first critic to present the book to Swedish audiences, Jaensson contributed to its framing as an action-packed thrilling read, even if it took place inside the mind of a young girl. Because Jaensson wrote his review before the Swedish edition had been published, the photograph used for the article was the same as the one featured on the first American edition of the book, showing a young Anne Frank with, as Prose describes it, a "beautiful face [that] convey[ed] a wistful intelligence and a piercing sweetness". ${ }^{583}$ The photograph was taken by her father Otto in 1939, three years before she even began writing in her diary. This was, Prose asserts, the way that Anne wished to be represented, "a serious, lovely girl" rather than smiling and animated as the photograph on the cover of the Swedish edition showed. ${ }^{584}$ Again, the first contacts that Swedish audiences had with Anne Frank were related

578 Samuelsson, Kritikens ordning, 68-69, See also Göran Lundstedt, Till bords med de bästa: om kritikern Knut Jaensson, (Lund: Nova Press, 1997).

579 Lundstedt, Till bords med de bästa, 20.

580 Knut Jaensson, “Anne Franks Dagbok,” May 4, 1953, DN.

581 Jaensson, “Anne Franks Dagbok,” May 4, 1953, DN.

582 Jaensson, “Anne Franks Dagbok," May 4, 1953, DN.

583 Prose, Anne Frank, 84.

584 Prose, Anne Frank, 84. 
to the American mediation of her writings. Rather than come directly from its country of origin, the book travelled across the Atlantic and back again, before reaching Sweden.

There had also been a considerable amount of scepticism around the book in the US where the manuscript was repeatedly refused by the large publishing houses for being "very dull" and too domestic, too Jewish and, above all, too likely to remind readers of what they wished to forget". 585 Even after it was published in the United States, and after it had received rave reviews and was said to have been widely read by the greater public, there remained an "unconscious" resistance to the book. This notion of an "unconscious resistance" was formulated by the famous American theatre critic Walter Kerr who had noticed that people, although enthusiastic about the book and play in theory, had failed to pick up a copy of the book or purchase tickets for the play. ${ }^{586}$ The perception that such an "unconscious resistance" would also exist amongst Swedish readers is evidenced by the ways in which Hökerbergs advertised the book. Citing a review by Erna Holmboe Bang in Göteborgsposten, Hökerberg assured the reader that the story presented by Anne Frank was "most varied. There is a continuous stream of exciting events...she is dead but yet she lives". ${ }^{587}$ As if the publishing house was expecting prospective readers to hesitate before the monotonous story of a young Jewish girl stuck in an attic, Hökerbergs sold the book as an endless adventure with multiple twists and turns. They also cited Jaensson's review, once again printing the words "humanely harrowing, artistically perfect, relentlessly revealing, exceptionally frank and highly intelligent". 588 Also, in the lead to Jaensson's review article, following a repetition of the bombastic language used in the first paragraph, Jaensson stated that "the book was written in Dutch and has been translated into, amongst other languages, Norwegian and Danish. Any Swedish publisher has, on the other hand, not yet taken an interest in this strange book". ${ }^{589}$ Here, Jaensson was not merely noting the absence of a Swedish edition but was also, through his enthusiastic promotion of the American edition, inciting Swedish publishers to follow their Scandinavian

585 Prose, Anne Frank, 81.

586 Nahson, “Anne Frank from Page to Stage,” 69.

587 “Anne Franks Dagbok,” August 31, 1953 DN, [“Den är ytterst omväxlande. Ideligen händer spännande saker...hon är död men hon lever'].

588 “Anne Franks Dagbok," August 31, 1953 DN.

589 Jaensson, “Anne Franks Dagbok,” May 4, 1953, DN [“Boken skrevs på holländska och har översatts till bl.a. norska och danska. Någon svensk förläggare har däremot ännu inte intresserat sig för denna märkliga bok’]. 
counter-parts and publish Anne Frank in Swedish. Whether Jaensson's review was that which incited Hökerbergs to acquire the rights to the book is not known. However, it is likely that Jaensson's presentation of Anne Frank legitimized a Swedish edition of it and validated the book as a serious and worthy literary endeavor with an extraordinarily talented authoress to boot.

Moreover, Jaensson was a staunch critic of 1940s modernist literature with its bleak outlook on the future and with its complex and avant-garde language. ${ }^{590}$ In a letter to the Swedish philosopher Ingvar Hedenius, Jaensson wrote that

Nowadays it is modern to be a 'cellar human'=angry, querulous, displeased, pessimistic, cynical and unhappy through one's intelligent hysteria, which, on the other hand, is perceived as that which is singularly true and humanly dignified. Oh those poor suckers who are dumb enough to believe in a certain measure of good or those who naively try to orient themselves towards the kind side of things! ${ }^{591}$

The irony of the final sentence is expressed to underscore the ridiculousness of not having any hope in the future or in humanity - a comment on the pessimism that defined the modernism of the late 1940s. The way that Anne Frank was presented to the public was, therefore, positioned as an antidote to this gloom and disbelief. Rather than finish his review with expressions of despair regarding the death of Anne Frank and all but one of her family members, Jaensson instead informed his readers that when the Gestapo came to arrest the hiding Jews, they "missed" the diary ("hennes dagbok" in singular) making her "wish come true at least: to live on after her death". ${ }^{592}$ Other than praising the book, Jaensson also presented it as a

\section{Lundstedt, Till bords med de bästa, 45.}

591 Jaensson quoted in Lundstedt, Till bords med de bästa, 47. ["Nuförtiden är det modernt att vara 'källarmänniska'= ilsken, kverulantisk, misslynt, pessimistisk, cynisk och olycklig genom sin intelligenta hysteri, som å andra sidan uppfattas som det ända sanna och människovärdiga. Stackars alla djävlar som är dumma nog att tro på en viss godhet eller helt naivt försöka orientera sig åt den snälla sidan!"

592Jaensson, “Anne Franks Dagbok," May 4, 1953, DN. Rather ironically, Forser also describes Jaensson as someone who detested "trendiness, opportunism, commercialism, the fixation on personas, and flock mentality," all things that are today intrinsically linked to Anne Frank and every mediation of her. ["Den akademiska miljöns pedanteri sådan som han mötte den i Uppsala avskydde han. Men också trendighet, opportunism, kommersialism, person-fixering och flockmentalitet representerade det som en kritik av hans slag försökte bekämpa"]. See Forser, Kritik av Kritiken, 13. 
success story, the tragedy of Anne's untimely and cruel death disappearing in the triumph of her achievements as a witness and as a writer.

So, if Jaensson set the stage by framing the important themes of Anne Frank before its Swedish edition had been published, what did the reviews of the first Swedish edition contribute when commenting on the book in the autumn of 1953? Although Nyberg, Adlercreutz and Bouleau joined Jaensson in praising Anne's objectivity and wisdom, they also added descriptions of how one would feel when reading the book. Such expressions of feelings and personal reflections were, according to Samuelsson, becoming increasingly common in Swedish literature critique during the 1950s. "The critic legitimizes her/himself [in this period]", Samuelsson argues, "by being a sensitive and perceptive recipient; rather than laud or denounce he or she should explain". 593 The fact that female critics were reviewing a book written by a young girl whose life ended in tragedy, further imposed a need to show an emotional connection to the subject. Adlercreutz described her experience thusly: "there is a thickness in the throat the entire time when one turns the page, and many times while reading one has to clench one's fists in anger and shame at being an adult in a world where it is this hard being a child". ${ }^{594}$ Similarly, Nyberg explained how Anne recounted the microcosm of the attic with such "intimacy and detailed lucidity" that it completely immersed the reader in it. ${ }^{595}$ She also finished her review by informing the reader of the lasting emotional impact that this book would have: "[Anne Frank's] characterization of the small circle of people around her is farsighted and accurate. But the anxiety and longing after a little girl's usual delights are intertwined [and transforms into] a leitmotif of agonizing intensity which becomes a tone that continues to sing in one's heart". 596

593 Samuelsson, Kritikens ordning, 82 ["kritikern legitimerar sig genom att vara en känslig och lyhörd mottagare; istället för att hylla eller fördöma ska han eller hon förklara"].

594 Maud Adlercreutz, "Annes dagbok," September 30, 1953, Aftonbladet [“Det sitter en tjock klump i halsen hela tiden medan man vänder bladen, och många gånger under läsningen måste man lägga ifrån sig boken för att knyta händerna i vrede och skamsenhet över att vara vuxen $i$ en värld där det är så svårt att vara barn”].

595 Ven Nyberg, "Ur en stormig värld," September 7, 1953, Aftonbladet ["hon återger denna besynnerliga vardag i gårdshuset med en intimitet och detaljskarp åskådlighet som gör läsaren fullkomligt delaktig av den"].

596 Nyberg, "Ur en stormig värld,” September 7, 1953, Aftonbladet [“Hennes karakteristik av den lilla kretsen omkring henne är kvickögd och träffsäker. Men ångesten och längtan efter en liten flickas vanliga glädjeämnen tvinnas samman till ett ledmotiv av plågsam intensitet, blir en ton som fortsätter ljuda i ens hjärta”]. 
As presented in the reviews, these descriptions appear to be spontaneous outbursts of feeling, experienced by these critics while reading the book. However, the formulations of emotion also position Anne Frank's narrative against other forms of witnessing, putting aesthetic boundaries around the most 'effective' way of mediating the horrors of the Holocaust. These feelings that the reviewers describe are thus of a nobler kind than the "gruel" that many other testimonies at this time were characterized as. This is especially apparent in the review written by Bouleau in which she states that "the feelings one experiences before a document like [Anne Frank] are considerably more heart-wrenching than the gagging sensations that one automatically associates with the thought of Hitler's pogroms" ${ }^{597}$ The reader's emotional connection to Anne Frank is thus described as something different to those feelings experienced while seeing images of concentration camps, or hearing stories of death, torture and despair. It is also a sentence which comments on the inefficiency of those survivor narratives that deal explicitly with the ghettos and camps. This reasoning also underscores that which is perceived as the excessiveness of all those narratives that cannot effectively move the audience. Even Adlercreutz's bleak characterization of her own emotional response while reading the book was tempered by her final sentences in which she assured the reader that they, and the world, have "so much to learn from little, wise, brave, warm Anne". ${ }^{598}$ Hence, although Adlercreutz affirmed that one would feel anger and shame while reading the book it was an anger and shame on behalf of the rest of the world, as the book contained no pointed fingers or vindictiveness. The critics never spoke of revulsion or disgust, but rather of a more melancholic longing for improvement, a yearning for making the world a better place for its children. As Waxman argues, "it is the suggestion of emotion, albeit not of traumatic emotion, that holds the possibility of providing a bond between witness and reader. Women, and particularly young women, are often seen as fulfilling this role. Anne Frank is the most obvious example of this." 599

The emotional connections expressed by these critics also reflect some form of motherly protectionism and concern for the child Anne Frank, rather than a greater concern about antisemitism, racism and xenophobia. At the same time,

597 Ann Bouleau, “Att vara judebarn,” September 7, 1953, Expressen [“De känslor man erfar inför ett sådant dokument är betydligt mera hjärtslitande än de mer eller mindre kväljningssensationer man automatiskt förknippar med tanken på Hitlertidens pogromer’].

598 “Annes dagbok," September 30, 1953, Aftonbladet [“och därifrån har den gått ut till en värld som har så mycket att lära av lilla, kloka, tappra, varma Anne"].

599 Waxman, Writing the Holocaust, 129. 
these reviews also, in contrast to Roosevelt's preface, emphasize the fact that Anne was Jewish. Nyberg, Adlercreutz and Bouleau all mention early on in their texts that Anne was Jewish and that the book reflects her fate because of this fact. Nyberg, for instance, used the term rasfränder ("racial kin") when describing the identity of the "Dutch-Jewish" girl Anne and those who hid with her in the attic. However, Anne's and her family's Jewishness became most apparent in Bouleau's review which had the precarious title "To be a Jew Child". ${ }^{600}$ Bouleau's whole article was framed by the Jewish genocide, something that made it stand out in relation to the other reviews which identified and relayed other central themes to the book such as the importance of family under duress and the growing pains of an adolescent girl. In contrast, Bouleau contended that

it is not the facts about daily life which sets the diary apart. No, it is the background to these facts, the very relationships that have been forcibly created, and which make Anne's experiences so diametrically different from that of our own young ones. It is the reality of the Jewish star that this, otherwise ordinary, child has had to live through in all its cruelty, while we cannot even explain what this means to our own thirteen-year olds. ${ }^{601}$

The most important aspect of the book, according to Bouleau, was thus the ways in which it highlighted the specific trials of Europe's Jewish population during the Second World War; a perspective which she, alone, presented to Swedish readers. Even Jaenssen's review article, which made great claims about the importance and uniqueness of Anne Frank, never connected its themes directly to the Holocaust. Rather, Jaensson described the book as a rendition of Dutch life under occupation, although comparing Anne's writings to other specifically Jewish attempts to portray life in hiding in Germany as well as the German-occupied countries during the war. ${ }^{602}$ Even though he did not name any specific title, this subtle reference to other attempts at describing the same period from a Jewish perspective also captures the dynamic between silence and excess: Jaensson's message being that previous renditions of Nazi persecution from a Jewish perspective were prolific

600 Bouleau, “Att vara judebarn,” September 7, 1953, Expressen [“Att vara judebarn”].

601 Bouleau, “Att vara judebarn,” September 7, 1953, Expressen ["Men inte är det väl dagsfakta som gör dagboken märkvärdig. Nej, det är bakgrunden till dem, själva de förhållanden som har tvingat fram situationen, som gör skillnaden så enorm mellan Annes erfarenheter och våra så snarlika ungdomars. Det är judestjärnans realitet, som detta vanliga barn har fått uppleva $i$ hela dess grymhet, medan vi inte ens lyckas förklara dess innebörd för våra tretton-åringar].

602 Jaensson, “Anne Franks Dagbok,” May 4, 1953, DN. 
but they had not managed to reach their audience in the same way as Anne Frank had.

The importance of the characters' Jewish identities was also hierarchized in a news article, written by the writer and journalist Lars Widding. Widding's article, published in Expressen at the end of August, was not written as a review but read more like a sensational write-up of the book, citing Jaensson's review and giving Expressen's readers contextual information about Anne, her story and how the book had been received so far. The sensationalist character of the article can be gathered, not only from the content of the article but from its structure. Every paragraph began with a statement that was supposed to grab the reader's attention. The first paragraph thus began, "This girl is dead", the second paragraph with the words "Today this girl is world famous" and the third paragraph with the statement that "Anne Frank was her name. She was heljudinna ("fully Jewish")". This structure could be read as a presentation of facts about Anne Frank in order of their perceived importance; Anne Frank was a victim, Anne Frank was vindicated by becoming recognized worldwide as a brilliant authoress, and finally, Anne Frank was Jewish (not half Jewish, but 100 percent Jewish). That Expressen was the only newspaper to contextualize Anne Frank thusly in 1953 is not surprising as its editor-in-chief, as previously mentioned, encouraged a more popular tone as well as the paper's active participation in controversial issues of the day.

Adlercreutz, Nyberg, Bouleau, Jaensson (and to some extent, Widding) played different roles in presenting Anne Frank to Swedish publics. While Jaensson presented her as a world sensation, and as a brilliant writer whose words were worthy of literary consumption, the female reviewers emphasized Anne's capability to create an emotional bond with the reader. Although the newspapers that these critics published their work in were widely read by both men and women, it is likely that the reviews penned by women about female authors interested female readers more than they did male readers. Samuelsson explains that "the women [critics] read both men and women while 83 percent of the men's reviews treated other men". ${ }^{603}$ Although we know little of how men vis-à-vis women consumed literature at the time, it is reasonable to suggest that, because women's positions as writers were overshadowed by the authorships of men, reviews about their work were more likely to be ignored by male readers, especially if reviewed by another woman.

603 Samuelsson, Kritikens ordning, 70. 
Moreover, the head of Hökerbergs-Folke Hökerberg — was married to Eva Hökerberg who, at the time of the publication of Anne Frank, was the editor-inchief of the women's magazine IDUN. Even though Anne Frank in its book form was reviewed in all the major daily and evening newspapers, a more in-depth engagement with Anne Frank as a historical subject, was taken by IDUN. This, in turn, meant that the story of Anne Frank, beyond that of her brilliance, youth and the hope her story inspired, was left to the female segment of Swedish society who were the foremost consumers of this magazine. IDUN was a weekly magazine directed towards women. Founded in the 1880s, IDUN was by the 1950s, a powerhouse in its genre albeit with a limited readership. ${ }^{604}$ The fact that IDUN became responsible for mediating the history of Anne Frank also signaled that the story of the "little Jewish girl" was a woman's issue rather than something that belonged to everyone. No less than five issues of IDUN in 1953 featured Anne Frank in its articles. ${ }^{605}$ Furthermore, Margit Vinberg—a female journalist whose prolific writings mainly dealt with issues pertaining to recipes, fashion and "household tips" 606 - also conducted a reportage about Anne Frank's house which contained interviews with people that had known the young Anne. Although the story of Anne Frank was fundamentally different from the usual mundane "how to" reportages that could also be found in IDUN, the juxtaposition was not uncommon as the women's magazines of the day had struggled to find their identity, meaning that politics, culture and the everyday of domesticity all coexisted on the pages of these magazines. ${ }^{607}$ Vinberg's reportage was also advertised during the autumn of 1953 as a way to promote issues of the magazine. In the advertisement the headline read, "A close up of Anne Frank" followed by a short text explaining that "the 15year old Anne Frank's diary is already a classic and belongs to all the world"; a text that presented the reasons why IDUN had visited the house in Amsterdam where she lived "under-ground". ${ }^{008}$ Furthermore, a few months after the reportage was

604 Monika Djerf-Pierre, "Journalistikens kön. Fältets struktur och logik under 1900-talet," Kvinnovetenskaplig tidsskrift, vol. 2 no. 3, (2003): 32.

605 “Innehållsregister," Idun, (Digitalized Copy: Gothenburg University Library, 1953)

606 Margit Vinberg also won the prestigious journalism prize, Stora Journalistpriset, for her contributions to several weekly magazines in 1958. See Gullan Sköld, Med känsla för klass: Thea Oljelund och Marianne Höok i femtiotalets folkhem och finrum (Stockholm: Leopard förlag, 2006), 33.

607 Sverker Jonsson, “TV förändrar världen (1958-1975)," in eds Lars-Åke Engblom, Sverker Jonsson \& Karl-Erik Gustafsson, Den Svenska pressens historia: Bland andra massmedier (efter 1945), (Stockholm: Ekerlids, 2002): 243.

608 "Anne Frank i närbild," September 5, 1953. Anne Frank is also featured in an advertisement in

DN on October 17 under the headline, "För kvinnan och kärleken". 
published, it also became a radio program which was broadcast on Christmas Day in 1953. ${ }^{609}$ Perhaps this had always been the plan, yet the fact that Vinberg's reportage became a radio program that could be widely consumed by the general public also demonstrates the beginning of a shift in how Anne Frank was being represented. As we shall see in the coming section, the adaptation of the book into a stage production and its subsequent success on Broadway, would position Anne Frank as a cultural subject (and commercial product) of huge significance, far beyond the private, emotional spheres dealt with by the "female literary subculture". ${ }^{610}$

Importantly, all the critics as well as Widding reproduced the story of Anne Frank's diary as the unredacted version of Anne's thoughts, speaking directly to them through time and space. While Jaensson and Bouleau referred to the diary as a wartime "document", Adlercreutz, Nyberg and Widding included a brief account of how Anne's writings were found by chance and published for all the world to read. Significantly, Nyberg referred to "diaries" in plural when telling the story of how Anne's writings were discovered. However, in the next sentence "the diary" in singular reappeared with no explanation as to how the many became only one. Although not explicated in these book reviews, the notion of a testimony from inside the experience-a description of war-time life without the post-war judgements, agendas or memory gaps that were assumed to tarnish other accounts of Jewish suffering during the war-would come to affect the position of the survivor witness in the years to come. As Dean explains, "when the topic is victims' suffering, discussions about proper style often begin with the premise that the victim who proclaims his injuries loudly may have dubious motives, implicit in the cliché that only the dead are the true witnesses". ${ }^{611}$ Thus, by making the ghost of Anne Frank the exemplary survivor witness-someone who procured noble feelings of sadness and hope in her readers, whose rendition was not of the past but of her own present and whose very appearance exuded both wisdom and innocence- the critics contributed to the construction of an impossible ideal for survivors to live up to. In contrast, the latter would be deemed ineffectual, unnecessary and therefore, excessive. Although silence would come to be used as an argument to encourage more people to read, watch and experience Anne Frank, this argument never extended beyond her as a singular figure.

609 Shown in the radio tableau on December 24, 1953, DN, 16.

610 Samuelsson, Kritikens ordning, 70.

611 Dean, Aversion and Erasure, 111. 
In 1953, Anne Frank was still a foreign subject - a Dutch and Jewish girl whose story was prefaced by an American woman. It is difficult to know why Roosevelt's preface remained in the first Swedish translated edition of Anne Frank. Perhaps, the publisher wanted to publish the book as soon as possible, therefore leaving little time for any changes to the copy. However, it is also plausible that Hökerbergs did not deem it important enough to have a Swedish person write a preface as the book's subject was not considered significant to Swedish wartime or post-war experience. Of course, there were many Swedish citizens who could potentially have written a preface to the book - adult survivors of the camps, child survivors of Nazi genocidal policy, Jewish and non-Jewish scholars, authors and rescue workers; the list goes on and on. It would, nevertheless, take another American success for Anne Frank to become Swedish. In 1956, the stage production of Anne Frank created a situation where Swedish directors and actresses framed the story of the young Dutch Jewish girl, thus making the phenomenon of Anne Frank, if not relevant to Swedish post-war experiences, then at least a significant part of the Swedish cultural landscape.

\subsection{The Survivor as Witness and Accuser}

Yet another interesting find from my searches in the digital newspaper archive, which did not directly relate to Anne Frank but was relevant to discourses on Holocaust survivors all the same, led me to a series of articles, published in DN in June 1955, little more than a year before the play about Anne Frank was to appear on stages all over Sweden. The articles demonstrated a rather heated debate between the editor-in-chief of DN, Herbert Tingsten, the then medical professor and critically acclaimed author, Lars Gyllensten, and the camp survivor, writer and journalist Cordelia Edvardson, then working for the daily newspaper MorgonTidningen. ${ }^{612}$ The reason for the upset was a decision made by the Swedish school board ("skolöverstyrelsen") to include an essay topic for its final exams taken by all Swedish high school students which dealt with the "the German wonder", referring to the swift rehabilitation and reconstruction of West Germany. The debate is relevant to the context of Anne Frank as it elucidates the position of the camp survivor as a witness to German perpetration in the middle of the decade. As will be briefly explored in this section, Edvardson was denigrated by one of

612 Gyllensten was later chosen to join the Swedish academy and became its permanent secretary in 1977; a position that he vacated as a protest against the Academy's unwillingness to take a stance against the fatwah issued against Salman Rushdie in 1986. 
Sweden's most prominent newspaper men when entering the debate- something that demonstrated how individuals with "personal memories" were not seen fit to comment on important phenomena such as post-war memory and human rights discourse.

In his initial article, published in DN in early June 1955, Gyllensten marvelled over how "the German wonder" had been chosen as a subject for school youth to discuss; a topic that he argued was tainted with "nationalist accents". He also scolded "die dummen Schweden" for bolstering an image of Germany as technically and organizationally proficient while, at the same time, ignoring the atrocities that the Germans committed during the war. He added that for those who remembered "the biggest catastrophe that humanity [had] witnessed in a long time", "the German wonder" meant something different. ${ }^{613}$ As an example he referred to another fellow medical doctor by the name of Elie A. Cohen, a Dutch Jewish camp survivor whose book Human Behavior in the Concentration Camp was also referenced in the article. Cohen was used as an example of a survivor-witness, whose detailed research and own testimony put into question any wonderment at German recovery. Tingsten responded in a calm and collected manner by pointing out that Gyllensten's opinion piece was characterized by the misconceptions and misrepresentations that all such pieces were based on. In a painstaking scrutiny of Gyllensten's article, Tingsten then proceeded to deconstruct Gyllensten's arguments. Significantly, Tingsten refuted Gyllensten's contention that many Swedes believed most Germans to be innocent of the crimes committed during the war. Contrastingly, he claimed to never have encountered such opinions. However, only a few lines later, Tingsten himself presented the core argument for such an apologetic perspective as he stated that "it is true that most [Germans] did not protest, most people do not protest when a protest means death"- thus negating the fact that German civilians enjoyed or actively engaged in the persecution of Jews. ${ }^{614}$ After this statement Tingsten spent the rest of his rebuttal railing against perspectives that proposed that the Germans were more evil than any other nationality, proclaiming that he hated communism and Nazism equally—a hatred that did not extend to the people of Russia or Germany. In conclusion, Tingsten delivered a backhanded compliment to Gyllensten with the words: "Dr Gyllensten

613 Lars Gyllensten, "Det tyska undret", June 7, 1955, DN, 4. [“Den största katastrof som mänskligheten bevittnat på lång tid"]

614 Herbert Tingsten, “Det tyska undret”, June 8, 1955, DN, 4. [“det är sant att det flesta inte protesterade, de flesta protesterar aldrig då en protest betyder döden”]. 
has so brilliantly written about the conditions of human-kind that he does not need to construct a difference between Germans and people". ${ }^{615}$

Tingsten's response to the opinion piece, although delivered with a considerable amount of condescension, still presented its arguments in a respectful and systematic manner. However, the very next day, in a response to Cordelia Edvardson, Tingsten put his foot down. In entering the debate, Edvardson conceded that the latter seemed to speak from an honest and good place when he took "on the role of St: George". Yet, it seemed to Edvardson that he defended the dragon rather than the princess. In her piece, Edvardson extended her examples beyond the Jewish case, arguing that "this people's suffering is so old and so familiar that it has almost been accepted as inevitable". ${ }^{616}$ Thereafter, Edvardson continued to give examples of how the Polish concentration and extermination camp prisoners were treated, and how Ukranian children were used as footballs for the German soldiers. She also argued that it seemed that resistance to the Nazis in Germany was not as widespread as in other countries such as Norway, where people would rather "rip off their fingernails" than betray the resistance or relinquish Jewish victims to the occupational powers. In Tingsten's response to Edvardson he accused her of having written an article which served as a "confession to volks hatred or racial hatred or a hatred of the collective" - a confession which, according to Tingsten, resembled "the propaganda that the Nazis directed towards the Jews". ${ }^{617} \mathrm{He}$ added that it was "this way of thinking that (he) attempt[ed] to fight, not primarily because it ruin[ed] relations between people-but because [he] believe[ed] the thinking to be wrong, aroused by personal memories or the knowledge of the horrible things that happened during Nazism". 618 In one fell swoop, Edvardson's contribution to the debate was denounced by being attributed to the unfortunate consequence of "personal memories".

615 Tingsten, “Det tyska undret," 1955, DN, 4. [“Dr Gyllensten har så lysande skrivit om människans villkor att han inte behöver konstruera någon skillnad mellan tyskar och människor”].

616 Cordelia Edvardson, “'Det tyska undret,”'June 10, 1955, 5. [“Detta folks lidande är ju så gammalt och välkänt att det nästan har blivit accepterat såsom oundvikligt”].

617 Tingsten, (Rebuttal of Edvardson's article) June 10, 1955, DN, 4. ["Fru Edvardsons inlägg är, säkerligen omedvetet, i än högre grad än dr Gyllenstens artikel en bekännelse till folkhar eller rashat eller kollektivhat_den för rent tanken på den propaganda nazismen riktade mot judar'].

618 Tingsten, (Rebuttal of Edvardson's article) June 10, 1955, DN, 4. [“Detta sätt att tänka söker jag bekämpa, inte i första rummet därför att det fördärvar sammanlevnaden människor emellanden konsekvensen är uppenbar-utan därför att jag tror att man tänker fel, upphetsad av personliga minnen om de fruktansvärda saker som hände under Nazismen”]. 
Tingsten, arguably the most powerful editor-in-chief at the time, put both Edvardson and Gyllensten in their places, making it seem as if their arguments were led by the, according to him, simple and low-standing emotions of anger and hatred. That Tingsten could compare Edvardson to a Nazi-equating her assumed hatred of the Germans with the Nazi's hatred of the Jews—also demonstrates the weak position of the survivor as accuser in the mid-1950s. As a survivor-witness her arguments did not carry more weight than those presented by Gyllensten. Rather, her experiences incriminated her, and made her a more conspicuous witness whose motives could not be trusted in such an important debate about the 'actuality' of German guilt. Edvardson's proclamation that the Jewish tragedy seemed a toothless example in arguments about German guilt also shows a sense of defeatism with regards to bringing attention to the Jewish genocide; something which indicates a perceived level of 'Holocaust fatigue' among the Swedish population, at least in relation to the subject of Jewish victimization. Everyone knew, yet no one seemed to care about Jewish suffering as history had shown that nothing could be done to stave off the world's long-standing hatred against the Jews.

As will be demonstrated in the coming sections, this attitude towards Holocaust survivors with camp experience-as conspicuous witnesses with agendas tainted by feelings of hate and vengeance-was reflected in discourses about Anne Frank throughout the decade only to shift slightly in 1958 through the contextualization of Anne and her families' journey through the camp system. What the debate contributes to the coming analysis is thus an indication of the position of 'those who had been there'- the camp survivors of the Holocaust-in newspaper discourse in the same decade as Anne Frank dominated the cultural scene.

\subsection{Staging Anne Frank in Sweden}

If the publication of the book in Swedish had trailed behind other Nordic editions, the play about Anne Frank, her family and their neighbors was swiftly scooped up by Swedish theatres, the first production premiering already in August of 1956. On August 25, the theatre critic Per Erik Wahlund announced to SvD's readers that the Gothenburg city theatre (Göteborgs Stadsteater) had "won the eternal race towards the first European performance" of Goodrich and Hackett's stage adaptation of 
Anne Frank. ${ }^{619}$ Indeed, it seemed that a Swedish theatre had been the first to introduce the popular play to a European audience. Since the American performance at the esteemed Paris International Theatre Festival had been cancelled earlier that summer in order to ensure good relations between France and West Germany, the Gothenburg city theatre could boast an early (if not the earliest) first performance of the popular and sought after play. ${ }^{620}$ As many European renditions of the play came soon after its Broadway premiere and many countries scrambled to be the first to the ball, snatching the European premiere must have been a feather in the cap for the small, and in cultural as well as geographical terms, peripheral, country of Sweden.

The play continued to be set up throughout the 1950s and into the 1960s but soon lost its news value and disappeared amongst the classic pieces that continued to return each season. Although The Diary of Anne Frank is not considered a lasting success in the history of Swedish theatre, its impact on Swedish cultural life in 1956 is difficult to ignore. In this section of the chapter I thus explore in more detail the promotion and public success of Riksteatern's stage production of the play. This is done in order to gage the impact of the play-how many people it reached and who it was aimed at. However, a majority of this section focuses on the culture critique surrounding the five different theatre companies' versions of Goodrich and Hackett's The Diary of Anne Frank in order to understand how the figure of Anne Frank was shaped in relation to how the play and its themes were disciplined by culture experts at the time. In contrast to the book reviews, the plays were reviewed almost exclusively by men. Because of the successful play, Anne Frank had become a bona fide phenomenon which was both profitable and politically important-Anne had thus stepped out of the female domestic sphere, and into the public realm.

That Anne Frank had become a household name in Sweden by 1956 when the first stage performance was set up is also evidenced by the fact that her name was used in the promotion of other literary works. For example, both the SwedishJewish writer Jules Berman's Arvet frä Sinai ("the inheritance from Sinai") and Hungarian author Christine Arnothy's I am fifteen and I do not want to die were

619 Per Erik Wahlund, “Anne Franks dagbok på Göteborgs Stadsteater,” August 25, 1956, SvD, 9. 620 Nahson, “Anne Frank from Page to Stage,” 80. 
advertised in relation to Anne Frank. ${ }^{621}$ Arnothy, who had based her novel on her own diary notes (kept while living in Budapest during the Second World War) was advertised by the publishing house Bonnier as "a Hungarian Anne Frank" while Berman's story-which did not resemble Anne's in the least-was said to have "the same message as that found in Anne Frank's Diary". ${ }^{622}$ This latter comparison also underscores the fact that Anne Frank was perceived as a distinctly Jewish subject as the only connection between Anne Frank's story and Berman's story was that they dealt with Jewish suffering. By being compared to Arnothy, Anne Frank also became connected with the Soviet occupation of Hungary which was one of the most well-covered international crises in 1956. Also, in the news, Anne Frank was used to highlight different issues. For instance, in Expressen it was reported that many Jewish organizations had protested Hans Globke's position as undersecretary of state in West Germany. The article began by setting the stage using Anne Frank. It thus stated that: "in the summer of 1942 a 13-year old Jewish girl sits in an annex on Prinsengracht in Amsterdam, hunted and outcast... At the same time a middle-aged man sits at his desk at the ministry of interiors in Berlin. It was he who, in 1935, authored the commentary to Hitler's Jew-laws, the so called Nuremburg laws, the laws that made 13 year old Anne into a hunted animal". ${ }^{223}$ In less controversial news, Anne was also connected to a burglar who, according to the article headline, was a convicted "international thief" that had been "the neighbor of Anne Frank". ${ }^{224}$ In 1956, the figure of Anne Frank was thus used to facilitate for the public's understanding of injustices still occurring in West

621 See Jules Berman, Arvet frän Sinai, (Stockholm \& London: C. E. Fritzes bokförlag). Christine Arnothy, Jag ärfemton och jag vill inte dö, trans. Eva Alexanderson, (Stockholm: Bonnier, 1956). While Arnothy's book resembles Anne Frank by being based on the diary notes of a young girl in hiding, Berman's book does not resemble Anne Frank at all, making it likely that it was the Jewish identity of the author and the themes of Jewish persecution in Russia that were constituted as the main connections between the books.

622 "En ungersk Anne Frank," November 30, 1956, Expressen, 5. “Arvet från Sinai-'Budskap av samma sort som Anne Franks dagbok," November 2, 1956, SvD, 11. Anne Frank was also mentioned in a review of Arnothy's book written by Sven Stolpe entitled "Ungerskt Protokoll" which was published in Aftonbladet on December 6, 1956, 3.

623 D.M. Winter, “Adenauers grå eminens," March 7, 1956, Expressen. [“Sommaren 1942 sitter en 13-årig judisk flicka i ett gårdsrum vid Prinzengracht i Amsterdam. Jagad och utstött...Samtidigt sitter en medelålders herre vid sitt skrivbord i inrikesdepartementet i Berlin. Det var han som 1935 1935 författade kommentarerna till Hitlers judelagar, de s.k. Nürnberglagarna, de lagar som gjorde 13-åriga Anne Frank till ett jagat djur.’]

624 "Internationell tjuv dömd, var granne med Anne Frank," October 31, 1956, DN. 
Germany and to heighten the value of a news-story as well as to sell other writers' novels and books. In addition, her story was published as a chronicle series in a weekly magazine and in the autumn of 1956, The Diary of Anne Frank would be set up by no less than five different theatres in Sweden. The Anne Frank phenomenon had begun to root itself in Swedish public discourse.

Yet, beyond being a point of reference for a wide variety of phenomena, what did the figure of Anne Frank signify in 1956? And how did the culture critique that surrounded the play shape conceptions of Holocaust victimization and witnessing? In the previous section, I concluded that the book reviews contributed to a distancing between the dead victim, writing from inside the experience, and the survivor witness, whose post-Holocaust reconstruction was met with suspicion and skepticism. Did the critics of the play contest this dichotomy between victimwitness and survivor-witness in any way or did their words merely serve to perpetuate and entrench it?

\section{Riksteatern and the Many Successes of The Diary of Anne Frank}

The prestige of being the second theatre to show The Diary of Anne Frank in Sweden was palpable in the press releases sent out by Riksteatern in the autumn of 1956. In a press release it was thus proudly declared that the play, that had been a "world success already", had now premiered on a Riksteatern stage in Eskilstuna, the second stage in Sweden to present the American production. ${ }^{625}$ Wahlund, SvD's foremost theatre critic who reviewed two out of the five Anne Frank performances that season, also asserted that "Riksteatern [had] stayed out in front of the competition for the American dramatization of the Diary of Anne Frank, a mere month after the Nordic premiere in Gothenburg, and with a good head start before Norrköping". 626

Riksteatern was formed in 1933 on the initiative of the Social-democratic led Swedish government in order to spread the theatrical arts to smaller towns as well

625 Riksarkivet (RA), Svenska Riksteatern, del 1, B: 2 Pressmeddelanden. The message was iterated in two different press releases. The first release opened with the sentence, "as the second theatre in the country, Riksteatern on Sunday presented The Diary of Anne Frank."

626 “Anne Frank i Eskilstuna," October 1, 1956, SvD ["Riksteatern har hållit sig väl framme i konkurrensen om den Amerikanska dramatiseringen av Anne Franks dagbok; bara någon månad efter den Nordiska premiären i Göteborg_-och med gott försprång före Norrköping, som härnäst står på tur-är Sandra Malmquist färdig att låta sin föreställning gå ut över landet”]. Wahlund had, by October, altered his statement about the European premiere to the more modest, "Nordic premiere," referring to the Gothenburg production. 
as the countryside. ${ }^{627}$ As the then minister of ecclesiastics, Arthur Engberg, noted in a government report on theatre policy from 1933, "it is not merely the capital's population that are entitled to enjoy first-class theatrical arts". ${ }^{628}$ Further explaining this perspective, theatre scholar Rikard Hoogland writes that the point of theatres such as Riksteatern was to "distribute the scenic arts over the whole country and provide a quality assurance" to its audiences. ${ }^{629}$ This endeavor was also driven by an ambition to shape the lower classes' cultural tastes by introducing them, not only to theatre, literature and the fine arts, but also to the classics within each discipline. ${ }^{630}$ However, Hoogland continues, through the sociologist Harald Swedner's studies, conducted during the 1960s, this endeavor was shown to have been largely unsuccessful as the lower classes, after thirty years of this cultural policy, showed little interest in the theatre classics.

Nevertheless, although the government was not successful in inciting the working poor to appreciate the theatrical arts, Riksteatern's records over attendance between 1947 and 1957 show a significant increase in theatre goers all over Sweden. Also, in considering these figures there seems to be little difference in attendance between the classics and newer stage productions such as The Diary of Anne Frank. According to the figures, most plays that were set up during the season 1956/57 were well attended by the general public. ${ }^{631}$ Obviously, these documents do not disclose which social classes the attendees represented. However, from the numbers it is safe to assume that the middle classes, at least, were attending the theatre in increasing numbers. It can thus also be deduced that, even if the public's interest in the theatre waned in the 1960s (perhaps due to the introduction of

627 There is no comprehensive scholarly work that deals with the early period of Rikesteatern's history. However, for a shorter commentary on the formation of Riksteatern in 1933 see for example, Gösta M Bergman, "Riksteatern—ett folkbildningsintresse," A.B.F: Tidning för Arbetarnes Bildningsförbund, vol. 9 (1935): 116-117. For a general overview of the organization and its activities see for example Christopher Mair (ed.) Riksteatern 75 år and Carl-Gustaf Petterson \& Therese Lagerlöf Smids (eds), Teaterbistoria, (Stockholm: Natur och Kultur, 1995). Rikard Hoogland, Spelet om teaterpolitiken: det svenska regionsystemet: frän statligt initiativ till lokal realitet, (Stockholm: Teatertidningens bokförlag, 2005).

628 Hoogland, Spelet om teaterpolitiken, 37.

629 Hoogland, Spelet om teaterpolitiken, 37. ["huvudfrågan var här att distribuera teaterkonsten över hela landet och att den skulle ha en kvalitetsstämpel'].

630 Hogland quoting Li Bennech Björkman about how cultural policy aimed at shaping tastes. Hogland, Spelet om teaterpolitiken, 37.

631 Riksarkivet (RA), Svenska Riksteatern, del 1, B3: vol. 1 "Berättelse över Riksteaterns verksamhet," 4-5. 
television in the late 1950s), the medium was still going strong when Riksteatern set up The Diary of Anne Frank, the stage production premiering in the city of Eskilstuna on September 30, 1956.

Between late September and late November in 1956 Riksteatern performed The Diary of Anne Frank over 50 times in 25 different cities and towns across Sweden, from Ystad and Karlskrona in the South to Östersund and Sundsvall in the North. ${ }^{632}$ During this period, the play premiered at the Norrköping city theatre, Intiman in Stockholm and, finally, in December 1956, the play also premiered at Uppsala City Theatre (the first premiere, as previously mentioned, being in Gothenburg). It is therefore a fair assessment that most Swedes who nurtured an interest in, or a curiosity of, the play were afforded an opportunity to see it, regardless of where they lived in the country. Furthermore, already at the end of September, SvD announced that Riksteatern's tour, which would have ended on November 19, was to be prolonged for ten days, travelling back to a handful of cities on the West coast as well as adding the cities of Borås and Landskrona to its touring schedule. ${ }^{633}$ Even though the play had already been shown for a couple of weeks in Gothenburg by this point, the critical reception of the following stage productions of The Diary of Anne Frank were no less enthusiastic, albeit more focused on the production itself rather than the story of Anne Frank. However, the more premieres the play accumulated, the more news-worthy it seemed to become with the evening newspapers writing longer articles about current and prospective cast members as well as cute anecdotes and facts about the main stars; the actresses playing Anne Frank being of particular interest. ${ }^{634}$

\section{The Diary of Anne Frank: Gruel-free Jewish Theatre}

It also seems as if the coveted play was an instant hit with Swedish audiences. In an internal communication to members of Riksteatern it was asserted that The Diary

632 Riksarkivet (RA), Svenska Riksteatern, del 1, F6C: vol. 5 "Spelschema". Riksteatern toured Eskilstuna, Nyköping, Västerås, Fagersta, Arboga, Karlstad, Lidköping, Tidaholm, Vänersborg, Uddevalla, Varberg, Falkenberg, Halmstad, Ystad, Kristianstad, Karlshamn, Karlskrona, Växsjö, Oskarshamn, Kalmar, Jönköping, Köping, Sandviken, Sundsvall and Östersund.

633 "Förlängd turné," November 15, 1956, SvD, 15.

634 See for example, "Strååt spelar pappa Frank,” September 14, 1956, DN, 16. "Lördagsskvaller," August 26, 1956, Aftonbladet, 10. [“Anne Frank ska på intiman spelas av Harriet Andersson”]. "'Dagbokspojken' funnen," September 26, 1956, Aftonbladet. Lars Widding, "Fem Svenska Anne Frank," December 2, 1956, Expressen. Clas Brunius, "Lillflickans krigsdagbok: flärdfri teater runt hela världen," October 11, 1956, Expressen, 4. 
of Anne Frank had been a "big success... wherever the tour [went]" ${ }^{635}$ Furthermore, in a press release to the Stockholm based press it stated that "the biggest success is The Diary of Anne Frank that, so far, has been shown before overcrowded houses with many requests about extra performances". 636 This message was also reiterated in Expressen on September 30 when the newspaper proclaimed that The Diary of Anne Frank was the "play of the autumn" season and "[would] be played in all theatres". ${ }^{637}$ In his article, also in Expressen, entitled "Five Swedish Anne Franks", penned at the end of the 1956 theatre season, Lars Widding declared in the lead that "the greatest theatre success of the 1950s is The Diary of Anne Frank". ${ }^{638}$ Hence, the message of the play's success was not merely relayed through the critical reception of the different stage productions, actor performances and/or directing achievements, but also through news reports of the impact that the play had made on the Swedish population. As previously mentioned, most of these articles focused primarily on the performances of the actresses playing Anne. The evening press, with Expressen in the lead, wrote extensively on the different actresses with a particular focus on the sisters Nadja and Nini Witzansky who played Anne at Riksteatern and the Norrköping City Theatre respectively, as well as on Harriet Andersson, who played Anne at Intiman. ${ }^{639}$ While Nadja Witzansky's performance was declared "the birth of an actress" by Aftonbladet's editor-in-chief and foremost literature/theatre expert, Per-Gustaf Peterson, Andersson was said to have made her "comeback" in the role of Anne. ${ }^{640}$ The play, and Anne's character in

635 Riksarkivet (RA), Svenska Riksteatern, del 1, B2 Pressmeddelanden [“Stor succé gör Anne Franks dagbok var den än går'].

636 Riksarkivet (RA), Svenska Riksteatern, del 1, B2 Pressmeddelanden [“Största succén är Anne

Franks dagbok, som hittills gått för överfyllda hus och givit anledning till många önskemål om reprisföreställningar"].

637 “Två systrar i en pjäs,” September 30, 1956, Expressen, 15 [“Anne Franks dagbok är höstens pjäs_-den spelas eller skall spelas på alla teatrar’].

638 Lars Widding, "Fem Svenska Anne Frank," December 2, 1956, Expressen, [“"50-talets största teatersuccé heter' Anne Franks dagbik"']

639 Lars Widding, "Fem Svenska Anne Frank," December 2, 1956, Expressen. Clas Brunius, "Lillflickans krigsdagbok: flärdfri teater runt hela världen," October 11, 1956, Expressen. Bengt Olsson, "Harriet A. Jag vet vad Anne Franks dagbok betyder för världen," November 4, 1956, Aftonbladet, 7. "Harriets comeback," October 27, 1956, Expressen, 10.

640 Per-Gustaf Peterson, "En skådespelerskas födelse," October 1, 1956, Aftonbladet, 2. Per-Gustaf Peterson, “Anne Frank på Intiman,” October 27, 1956, Expressen, 3. For an account of PGP’s position in the newspaper landscape see Per Rydén, "Guldåldern (1919-1936)," in eds Karl Erik Gustafson \& Per Rydén, Den svenska pressens historia, (Stockholm: Ekerlids förlag, 2001): 231. 
particular, could thus both make and remake an actress. It was a role that was deemed to define these actresses' careers_-an assessment which demonstrates the perceived importance of the play in 1956.

Also, most of the evening newspaper critiques analyzed in this section commented on the overwhelming applause that had showered the casts at the end of their respective premieres. Intiman's production "received all the cheer it was entitled to" according to Peterson who also characterized the Eskilstuna audience's response to the play by describing how the "curtain hauler tired before the audience did" which demonstrated that it had been "an undisputable triumphant start for The Diary of Anne Frank" at Riksteatern.641 In Expressen, the theatre critic Carl Brunius described the "wild applause" that followed the performance at Intiman and in Aftonbladet the mood in Norrköping's auditorium was said to have been "so intense that it completely killed the cold-induced [sneezes and coughs] that had previously threatened to ruin the whole thing". ${ }^{642}$ Moreover, Expressen's editor-inchief, Ivar Harrie, described in his review how the Gothenburg audience was "touched-deeply touched" and that the "the play-and the performancereject[ed] loud final effects, it literally end[ed] in the middle of a sentence. The rest [was] silence". 643 This notion of the propriety of silence was later reiterated by Brunius who, although describing the "wild applause" also called these "almost blasphemous under the circumstances". ${ }^{644}$ Although Brunius clarified that the applause were well-deserved and had to do with Andersson's "captivating" performance, his comment nevertheless captures an important theme of the play's general reception. Even though the play was popular amongst Swedish audiences and an import from Broadway with all its connotations of glitz and glamour, it also dealt with a deeply serious and dark subject. The silence that fell over the audience after the play premiered in West Berlin was also characterized in Expressen, the

641 Peterson, “Anne Frank på Intiman,” October 27, 1956, Expressen, 3. ["Premiären var en stor framgång för Intima teatern. Pjäs och föreställning fick allt det bifall de var berättigade till, och Stockholmarna har fått en viktig teaterkväll att ta vara på”]. Peterson, "En skådespelerskas födelse," October 1, 1956, Aftonbladet, 2. [“det var en obestridlig triumf-start för 'Anne Franks dagbok' i riksteaterversion. Ridåhalaren tröttnade före publiken”].

642 "Den tredje Anne," October 11, 1956, Aftonbladet, 11 [“Stämningen i salongen i går blev till sist så intensiv att den fullständigt tog kål på förkylningseruptioner som till att börja med såg ut att vilja äventyra alltihop”].

643 Ivar Harrie, “Tysk Anne Frank gjorde genombrott,” October 3, 1956, Expressen, 11 [“Publiken var gripen_hårt gripen. Pjäsen_och föreställningen_ratar fulltoniga sluteffekter, den slutar bokstavligen mitt i en mening. Vad övrigt är, är tystnad. Den tystnad som får en att inte glömma”]. 644 Clas Brunius, “'Trettonåriga Anne Frank blev Harriets stora roll,” October 27, 1956, Expressen. 
author's perception being that the audience members had been "moved but [were] still, somehow, liberated". ${ }^{445}$ The article also included a citation from the play's program in the words of the West German President Theodor Hoess: "We cannot forget the collective shame, we cannot make it too easy for ourselves". ${ }^{646}$ The juxtaposition of these statements-that the German audience had been absolved ("liberated") after one viewing of The Diary of Anne Frank and Hoess's words about a collective shame-demonstrates a perception of the play as a form of necessary evil that was, at the same time, effective in purging its audience of any guilt.

The immediate success of Anne Frank, both critically and commercially, had not been a given when the play was first presented to American audiences. As Nahson explains, in the beginning, ticket sales were down and there was widespread anxiety amongst the play's writers and producers whether such a "serious" stage adaptation would become a successful financial venture. ${ }^{647}$ Therefore, in order to up the dramatic aspects of the play, an extra scene in which a piece of bread is stolen, was added. ${ }^{648}$ Part of the concern that the play would not be a financial success also stemmed from "a cluster of larger anxieties" regarding the play being "'too Jewish" and therefore "too upsetting for a Broadway audience". ${ }^{449}$ This anxiety was also shared by Otto Frank who expressed to the producers that he did not want "the dramatization of his daughter's diary to be either too sectarian or too despairing". ${ }^{650}$ It was not the first time that the 'Jewishness' of the book's dramatization had come up. Indeed, the first attempt at dramatizing Anne Frank had been made by the literary critic, staunch Zionist and playwright Meyer Levin who had lauded the first American edition of Anne Frank in the New York. Times in 1952. Although Levin's adaption of Anne Frank was made for radio and broadcast on NBC in December 1952, Otto Frank, who owned the rights to the book and controlled any further mediations of it, rejected Levin's first attempt at a play adaptation. Part of the issue, according to Nahson, was that Otto did not approve of "how [Levin] foregrounded Anne's (and other characters')

645 Harrie,"Tysk Anne Frank gjorde genombrott," October 3, 1956, Expressen, 11 [“Några enstaka applåder hördes. Sedan gick man ut, tyst, gripen och ändå på något sätt befriad”].

646 Harrie, "Tysk Anne Frank gjorde genombrott," October 3, 1956, Expressen, 11 [“"Vi får inte glömma kollektivskammen, vi får inte göra det för lätt för oss”'].

647 Nahson, “Anne Frank from Page to Stage," 68.

648 Nahson, "Anne Frank from Page to Stage," 68.

649 Nahson, "Anne Frank from Page to Stage," 66.

650 Nahson, "Anne Frank from Page to Stage," 66. 
Jewishness". ${ }^{651}$ Thus, the script that was subsequently used in the Swedish stage productions of The Diary of Anne Frank was one that, after having been revised a total of eight times by Goodwin and Hackett, eschewed perspectives which pointed to the particular persecution of the Jews during the Holocaust.

The 'Jewishness' of the play and the characters' Jewish identity were not avoided in the Swedish press, however, and themes of Nazism and victimization were used to contextualize the story of Anne Frank. Still, there were significant differences between the newspapers as well as the different article authors in how they treated these themes. Significantly, Wahlund and Expressen's editor-in-chief, Ivar Harrie, although commenting on the historical background of the play, also trivialized the Jewish Genocide in their reviews. Firstly, in his review of the Gothenburg premiere, Wahlund downplayed the importance of the play's connection to the Holocaust by referring to "what happened to bundreds of thousands of defenceless people in the countries occupied by Germany" (this author's italics) while at the same time emphasizing the point that the play was also about the inner life of a young person. ${ }^{652}$ While Wahlund did not shy away from the subject of Jewish strife during the Holocaust—quoting a segment of the play where Anne speaks through her diary about the living conditions of the group of Jews hiding in the attic as well as referring to "the situation of the Jews during the Dutch occupation"- - his words also served to trivialize and minimize the Holocaust by referring to "hundreds of thousands" as well as using the term "people" rather than referring directly to Jewish victimization. Also, in announcing Wahlund's review inside the paper, the front page of $S v D$ that day described the play as a theatrical work which reacquainted the audience with "the Jews" situation in Germany during the war". ${ }^{653}$ Using the euphemism "situation" and only referring to the German Jews thus further entrenched Wahlund's trivializing of the Holocaust inside the paper. In addition, Harrie's review in Expressen of the Gothenburg performance was less about the play than it treated the greater theme of forgetfulness. The article with the telling title "Anne Frank Forces us to Remember the threat of Nazism" began with a verse. It read: “'Not be forgotten, not forget!' Not forget, poor twenty years after, how it was once upon a time when Germany was a Nazi-country, what

651 Nahson, “Anne Frank from Page to Stage," 77.

652 Wahlund, “Anne Franks Dagbok på Göteborgs stadsteater,” August 25, 1956, SvD, 9. [”Det är chockerande men hälsosamt att bli påmind om gårdagens historia; vad som hände 100000-tals försvarslösa människor i de tyskockuperade länderna fram till 40-talets mitt är sådant som händer fortfarande och kan hända igen, och som vårt diskreta minne inte borde ha rätt att stöta ifrån sig”] 653 "En generations samvete," August 25, 1956, SvD, 1. 
was planned in Hitler's Europe for Northerners, Dutchmen and Jews, not to speak of the Latin and Slavic peoples. Not forget that these plans were supported by most Germans-passively, of course, without engaging much, with a way out of the tangible horrors: 'of that we knew nothing..." ${ }^{654}$ Although Harrie declared himself an unapologetic critic of the Nazis as well as of the German people who, according to him, lived in denial, his identification of different victim groups had a similar effect on the message conveyed as Wahlund's assessment of the play. Jewish victims were placed among other nationally and regionally defined groups like "Northeners" and "Dutchmen" and what Harrie termed "latin and Slavic peoples" were presented as more prominent victim categories than the Jews through the phrase "not to speak of'. The only review that clearly positioned the play in relation to the Nazi's persecution of Jews was Brunius's article in which he compared the performances of the Witzansky sisters. ${ }^{655}$ In his review, Brunius declared that the "dramatization of the diary...is now played all over the world - a world that we with much certainty know has not put away its hatred of the Jews, in spite of everything that has happened". ${ }^{656}$

The most interesting aspect of Harrie's review, nonetheless, is how it positioned the play as an ample antidote against forgetfulness. In the verse he chided the Germans for wanting to forget "the threat of Nazism". This forgetfulness was not only a problem in Germany, according to Harrie, but as he stated, "we have all been about to forget". But, he continued, "then it happens that one is awakened, intimately reminded of what has happened; that which really and irrevocably has happened...The performance penetrated you like the reminder of a dark threat, like a desperate plea-there echoed a formula from the first World War: 'lest we forget"'. Reminders that break the silence around Nazism and its victims was, according to Harrie, pivotal in order to ward off the ever-looming

654 Harrie, “Anne Frank tvingar oss minnas Nazismens hot," August 25, 1956, Expressen, 5 [“'Inte glömmas, inte glömma!' Inte glömma, fattiga tjugu år efteråt, hur det var den gången Tyskland var Naziland, vad som planerades för nordbor, Holländare och judar, för att inte tala om de latinska och slaviska folken. Inte glömma att de planerna var en överväldigande del av tyska folket med på-passivt förstås, utan att engagera sig farligt, med utvägen tillhands svära sig fria från de påtagliga ruskigheterna:'det där visste vi inget om...”'].

655 Clas Brunius, "Lillflickans krigsdagbok: flärdfri teater runt hela världen," October 11, 1956, Expressen, 4.

656 Brunius, "Lillflickans krigsdagbok: flärdfri teater runt hela världen," October 11, 1956, Expressen, 4 [“dramatiseringen av dagboken, enkelt och flärdfritt gjord av ett par amerikanska filmskribenter, spelas nu över hela världen—den värld som vi med visshet vet ännu inte har lagt av sitt judehat, trots allt som hänt']. 
Nazi threat. However, the reminder needed to be of a certain kind so as not to frighten people or put them off the cause of remembrance; it needed to be exemplary just like the play about Anne Frank. Thus, Harrie contended,

in the play, which was based on the diary of Anne Frank, not a single Nazi or Gestapo man is seen on the stage; there is no greuel whatsoever, such things are not even spoken of. And Ake Falck held, with exemplary discretion, the terror, evil and unbearable horror in the background as something invisible, indecipherable; an atmosphere. ${ }^{657}$

Here, Harrie positioned Anne Frank, and the treatment of her story in the play, in contrast to those individuals and documents that testified to torture, starvation, disease and mass death-what Harrie refers to as "greuel". The absence of shocking images and imageries-what the American writer Susan Sontag has described as "means of making 'real' (or 'more real') matters that the privileged and the merely safe might prefer to ignore"-is, according to Harrie, an appropriate absence as it makes the narrative more effective in keeping memory of Nazi perpetration alive.

Even though Jewish suffering was trivialized in critical assessments of the play, the Jewish identity of the characters on stage was never obscured. In the evening press, the epithets "Jew-girl" or "Jewish girl" were commonly used to refer to Anne Frank and the Jewish identity of the other characters were also frequently underscored. ${ }^{658}$ For example, in his article for Expressen, Widding consistently referred to Anne as "the Jew girl" (Judeflickan) and reiterated the fact that the family Frank were Jews and so were the people with which they were in hiding. ${ }^{659}$ Even as a point of drama in the middle of the text, Widding informed the reader that "Anne Frank's father and mother lived in constant fear of what was to befall them-they were Jews after all—and in July that same year they went

657 Harrie, "Anne Frank tvingar oss minnas Nazismens hot," August 25, 1956, Expressen, 5 [“I teaterpjäsen som tillverkats med Anne Franks dagbok som förlaga syns inte en enda Nazist eller Gestapoman på scenen, där redovisas ingen Gruel alls. Talas knappt om sånt en gång. Och Åke Falcks föreställning höll mönstergillt diskret skräcken, ondskan, den outhärdliga fasan i bakgrunden som något osynligt och ogripligt, en atmosfär"].

658 Harrie, "Anne Frank tvingar oss minnas Nazismens hot," August 25, 1956, Expressen, 5. Clas Brunius, "Lillflickans krigsdagbok: flärdfri teater runt hela världen," October 11, 1956, Expressen, 4. Widding, "Fem Svenska Anne Frank," December 2, 1956, Expressen.

659 Widding, "Fem Svenska Anne Frank," December 2, 1956, Expressen. 
underground". 660 This would have been a reasonable reminder were it not for the sub-heading which declared that "The Jew Girl's Diary Became a World Success" followed by the lead stating that "what a teenaged Dutch Jew girl experienced during two isolated years behind secret doors during the war and confided to her diary is now being acted out over the entire world". 661 The article was accompanied by five pictures of the Swedish actresses playing Anne Frank, all holding up a kitten to the camera (see photograph at beginning of chapter). The biggest photograph showed Harriet Andersson, the breast of her dress displaying a large sown-on Jewish star. The fact that the story of Anne Frank was a story about Jews and the persecution of Jews during the Second World War was thus established early on in the article, making the comment "they were Jews after all" wholly superfluous. Widding's repetition of "Jew", "Jews" and "Jewish" created a dramatic tension between the hunted protagonists of the story and the newspaper's readers. In the cultural critic Ebbe Linde's (DN) review of the Norrköping production of The Diary of Anne Frank the subject of the characters' Jewishness was also broached in his critiquing the choice of performing the "Chanukah-feast's ritual completely in Hebrew"; a choice that, according to Linde, may have "contribute[d] to an exotic mood" in the play. ${ }^{662}$ What is interesting about this, otherwise peripheral, comment, is that it inadvertently points to a tendency within the non-Jewish Swedish community to view Jewish religious rituals as something exotic. This was also demonstrated by another article published in DN about the rehearsals of Riksteatern's production, the headline declaring: "The Anne Frank Ensemble learn Hebrew Songs". ${ }^{663}$ The article text explained that a man referred to as Dr Abraham Brody had visited the set to teach the whole ensemble sing Hebrew songs for their performance of the Chanukah-feast. ${ }^{664}$ The fact that this detail was deemed newsworthy demonstrates how unusual and "exotic" Jewish traditions were and how 'foreign' certain parts of Anne Frank's story was to Swedish actors and

660 Widding, "Fem Svenska Anne Frank," December 2, 1956, Expressen, [“Anne Franks pappa och mamma levde i ständig skräck för vad som skulle kunna komma att hända dem—de var ju judaroch i juli samma år beslöt de sig för att gå under jorden”].

$6612 / 121956$.

662 Ebbe linde, “Anne Frank nu i Norrköping," October 11, 1956, DN, 16 [“Det ger förstås ökad exotisk stämning, men är det verkligen vad som är viktigast? Är det inte viktigare att vi lär oss förstå denna lilla beträngda grupp? 99 procent av publiken gick nu miste om det meningsfulla innehållet i texterna, och det är synd, framför allt beträffande orden om mackabéernas kamp, som ger en så blixtlik vision av styrkan $i$ judisk tradition och senare blir föremål för anspelning”].

663 “Anne Franks ensemble lär sig hebreiska sånger," September 23, 1956, DN, 21.

664 “Anne Franks ensemble lär sig hebreiska sånger," September 23, 1956, DN, 21. 
audiences. The notion of The Diary of Anne Frank as a Jewish, and thus by default an 'un-Swedish' play, also became evident when the blond and blue-eyed actress Pia Skoglund was cast in the lead of Anne at the Uppsala City Theatre. In a review in $\mathrm{SvD}$, three of the four paragraphs focused on how the theatre had solved the problem of Pia's hair color. ${ }^{665}$ In the article Skoglund was described as "blond and blue-eyed just like the glitter on a Swedish lake". The article continued, "sure, Jews and Jewesses can be blond, but Swedish theatrical convention decidedly say: Anne Frank shall be dark. And, therefore, the consequences are that Uppsala city theatre will present a new Pia Skoglund, a dark and 'Jewish' one-with some technical help". ${ }^{666}$

Even though the Jewish characters of the play were described as "exotic" and 'un-Swedish', the attention that some critics paid to the ways in which the play was interpreted and set up by Swedish theatres, also contributed to the nationalization of Anne Frank. The original stage setting for The Diary of Anne Frank had been created by Boris Aronson and, according to Nahson, it "garnered much praise and was replicated in productions of the play world-wide". ${ }^{667}$ In Sweden, the scenographer Sandro Malmquist, who had also directed the play for Riksteatern, created a stage setting which received more critical attention than the scenery of the other Swedish productions. Malmquist, known for his long career as a producer, director and scenographer at Riksteatern, had, similar to Aronson designed a set where the main part of the stage mimicked an attic space, (according to the set description "formerly used as a laboratory"), with small storage rooms on either side of it and an extra attic space above. ${ }^{668}$ The part of Aronson's setting that drew most critics' attention was the "cyclorama depicting Amsterdam" that the Broadway set was surrounded by. According to Nahson "the cyclorama was visible to the audience but not to the inhabitants of the Annex, thereby emphasizing their isolation and contrasting the city's architectural splendor with

665 "Pia Skoglund gör stor Uppsalaroll,” December 20, 1956, SvD, 15.

666 "Pia Skoglund gör stor Uppsalaroll," December 20, 1956, SvD, 15.

667 Nahson, “Anne Frank from Page to Stage," 72.

668 Riksarkivet (RA), Huvudarkivet, del 1, B 2 Pressmeddelanden. All I was able to find with regards to Malmquist's scenery was a play sheat with a short description of the acts and scenes as well as a list of characters and a brief description of the stage setting. Ann-Margret Liljequist has been through riksteatern's archive, both at riksarkivet and drottningholms teatermuseum-she has also interviewed Sandro Malmquist with regards to his most memorable stage productions. However, Liljequist does not mention Anne Frank. See Ann-Margret Liljequist, Sandro Malmquist och hans verksambet som scenograf, (Doctoral diss.: Stockholm University, 1985). 
their deprivation". ${ }^{669}$ From the short description of Riksteatern's set provided by a play sheet, it seems that Malmquist's stage was rather like the original version. The praise that Malmquist received from Swedish critics for his stage set was, however, more about the propriety of the scenery than it was its efficacy in conveying the cramped and claustrophobic quarters of the characters. For example, the theatre critic Sven Barthel for DN and Per Erik Wahlund for SvD both emphasized the "suggestive" character of Malmquist's scenery, the former stating that "out of the discretely colored, but profoundly atmospheric environment, images and situations unfold with a suggestive clarity". ${ }^{670}$ Wahlund called the set "both practical and suggestive" and attributed these qualities to Malmquist's own expertise and innovative mind. ${ }^{671}$

Importantly, Wahlund's praise of Malmquist's set was one of the only positive aspects in the former's critique of the play. For example, in his review of the Gothenburg production, Wahlund bemoaned the "doomed project" of the play since "the introverted notes of a young girl who [was] in the middle of a maturing process" was not fit for the "art of the extroverted". ${ }^{672}$ Furthermore, he castigated the adaptation for being "shallow" with a "complete tone deafness of the nuances in the psychological mood" that permeated the book. ${ }^{673}$ Wahlund also noted that there were moments during the play when "one wanted to stand up and leave, as if in protest against the exploitation and forgery". ${ }^{674}$ What this exploitation consisted of was never elaborated on by Wahlund, but it appeared that he found the whole endeavor morally reprehensible-effective theatre, but fundamentally

669 Nahson, “Anne Frank from Page to Stage," 72.

670 Sven Barthel, ““Anne Frank’ på Riksteatern,” October 1, 1956, DN, 15 [“Ur den diskret färgsatta, men starkt stämningsskapande miljöskildringen utvecklar sig bilder och situationer med suggestiv självfallenhet”].

671 Wahlund, “Anne Frank i Eskilstuna,” October 1, 1956, SvD, 13 [“Dessutom är scenversionen en lämplig turnépjäs, en flyhänt transposition av dagbokens mer påtagliga sidor, med få och föga komplicerade personer och med stående dekor (för övrigt både praktisk och suggestiv i Malmquists egen utformning)"].

672 Wahlund, “Anne Franks Dagbok på Göteborgs stadsteater,” August 25, 1956, SvD, 9. ["Däremot har det varit ett på förhand dödsdömt företag. Inåtvända anteckningar av en ung flicka mitt inne i en mognadsprocess är inte stoff för det utåtriktades konst"].

673 Wahlund, “Anne Franks Dagbok på Göteborgs stadsteater,” August 25, 1956, SvD, 9. [“total tondövhet för nyanserna i den psykologiska stämföringen”].

674 Wahlund, “Anne Franks Dagbok på Göteborgs stadsteater," August 25, 1956, SvD, 9. [“det gives ögonblick under föreställningen då man får lust att resa sig och gå, som protest mot exploatering och förfalskning”]. 
wrong. This abhorrence was connected to Wahlund's wish to keep the story of Anne Frank focused on the subject of a young girl's adolescent journey. In finishing his review, he stated that "onlookers who venture out to watch efficient and extroverted theatre will, in the grand scheme of things have their needs met. But the Diary of Anne Frank, the wonderful story of a child's early growth into an exceptional human being, they will never learn". 675 Wahlund's off the cuff comment about Malmquist's set may seem a negligible side note in the critical response to the play. Yet, it subtly contributed to the notion that the garish American endeavor of making Anne's diary into a play, was much improved by the skill and know-how of the Swedish theatre. None of the other Swedish productions of the play received any attention with regards to their sets. Malmquist was a wellknown scenographer and therefore critics took notice of his set, even though it most likely looked very similar to the original set design, meaning that it probably looked similar to the set designs of the other Swedish plays as well. The attention paid to the set design of Riksteatern production was thus a rhetorical strategy used to emphasize the fact that The Diary of Anne Frank, when handled by a true, Swedish master of the theatrical arts, was an immersive experience with nuances and considerable dramatic weight. When American excess ruined the truth conveyed by Holocaust witnesses, Swedish decorum and representational restraint would mitigate the disaster.

Furthermore, it was not Anne's Jewishness that made her an exceptional witness in the eyes of the Swedish critics. Rather, it was the story, and its theatrical mediation, that managed to convey memories of the war that had a 'real' emotional impact on the audience, far away from the detailed horrors of ghetto and camp existence. Returning again to Brunius's review of Riksteatern's production, the introduction of his article asserted that

many tons of documents lay collected in the archives, cubic meters of eyewitness accounts of the Nazi's atrocities during the war. There cannot be anyone who would claim to have a full overview of what has been saved in the archives of the Nuremburg trials. Still it would be surprising if there was one single depiction therein that had the same ability to shake the indifferent, wake the sleeping and keep those who struggle to stay asleep, awake against

675 Wahlund, “Anne Franks Dagbok på Göteborgs stadsteater,” August 25, 1956, SvD, 9. [“åskådare som går ut för att se effektiv och utåtriktad teater, blir på det hela taget väl tillgodosedda. Men Anne Franks dagbok, den underbara berättelsen om ett barns brådmognad till undantagsmänniska, får de inte lära känna”]. 
their will. ${ }^{676}$

In addition, the caption accompanying a photograph of a very young Anne Frank read: "Anne Frank, the young serious Jewish girl, wrote the most efficient story of the Second World War". ${ }^{677}$ Here, Anne was positioned as a much more effective witness if compared to all those survivors who communicated their stories in the direct aftermath of the war. The introduction to the article also speaks of an excess of memories in referring to "tons" and "cubic meters", somehow assuming that this documentation was created in order to maintain people's interest in the Nazi's crimes.

The effectiveness of the story and the play were also emphasized by other critics; Barthel for DN calling it "truly engaging" on account of the characters' "very quiet, collected manner before the ultimate catastrophe" and Peterson for Aftonbladet pointing to the "authenticity and the deeply human tone" of the book, which, according to him, had been preserved in the stage adaptation. ${ }^{678}$ Peterson also wrote that the play was not a "hate-play", something that, according to him, had been one of the many "pit-falls" for Goodrich and Hackett when adapting the book for the stage. ${ }^{679}$ Also referring to these "pitfalls", Linde wrote that "how near must not the risk of sentimentality have been, or the risk of a glorification of the

676 Brunius, "Lillflickans krigsdagbok: flärdfri teater runt hela världen,” October 11, 1956, Expressen, 4. ["Många ton dokument ligger samlade i arkiven, kubikmeter med ögonvittnesskildringar av nazistiska ohyggligheter under kriget. Det finns väl ingen som kan säga sig ha full överblick ens över de skildringar som är bevarade i Nürnbergrättegångens arkiv. Ändå skulle det förvåna om där fanns, oupptäckt, en skildring som har samma övertygande kraft som 'Anne Franks dagbok', samma förmåga att skaka om de likgiltiga, väcka de sovande och hålla dem som försöker sova vakna mot deras vilja”].

677 Brunius, "Lillflickans krigsdagbok: flärdfri teater runt hela världen," October 11, 1956, Expressen, 4. [“Anne Frank, den lilla allvarliga judiska flickan, skrev den verksammaste berättelsen om världskriget”].

678 Brunius, "Lillflickans krigsdagbok: flärdfri teater runt hela världen," October 11, 1956, Expressen, 4. [“den blir sant engagerande. Och att människogruppens ytterst stillsamma, fattade uppträdande inför den slutgiltiga katastrofen gör en så patetisk verkan är det vackra beviset på föreställningens äkthet och styrka"].

679 Per-Gustaf Peterson,'Konsten att vara människa," August 25, 1956, Aftonbladet, 2 [“det underbara med pjäsen är att den inte i första hand, ja inte alls om man så vill, är en hatpjäs trots att ämnet naturligtvis tillhandahållit den allra djupaste och bredaste fallgrop åt de båda amerikanska dramaturgerna Frances Goodrich och Albert Hacket']. 
allied powers, in an American reconstruction" of the young Anne Frank's diary. ${ }^{680}$ These "pitfalls" - expressions of hatred, sentimentalizing the past and glorifying the allied powers - were identified as potential problems of the play that were also related to the act of witnessing. Being objective, fair and balanced as well as emotional in the 'correct' way were all characteristics that were deemed effective theatre in the case of Anne Frank.

Yet, what does sentimentality signify in this context? Certainly, the emotional response that Anne Frank elicited from her readers and theatre audiences was never framed as untoward or unsuitable. On the contrary, there seemed to be a difference between expressions of anger-either by those interpreting Anne Frank or by Anne Frank herself - and the anger elicited from readers and theatre goers. Just as Edvardson's involvement in the debate about Germany was denigrated as a kneejerk reaction based on "personal memories", the stage production of Anne Frank was evaluated based on its emotional detachment from the subject it treated. In order for the audience to be moved in the right way, the play had to remove itself from any negative feelings such as hatred, vengeance, dismay and indignation. Sentimentality thus signified a 'revelling' in these emotions; survivors and other affected parties lingering gratuitously on that which could only cause more pain and further rifts in the Western fabric of life. As such, the theatre critique mirrored the criticism surrounding the book where the reader's emotional response was different from the "gagging sensations" felt when reading about or seeing depictions of Nazi perpetration (perhaps especially the camps). What is more, the effectiveness of the book and the play to elicit the right emotions from its readers and spectators was also positioned as the antidote to forgetfulness. As demonstrated above, Harrie undercored this point in his review of the Gothenburg production, where he, although trivializing Jewish suffering, argued that Anne Frank "forced" the theatre goers to remember Nazi perpetration-even without any gestapo uniforms on stage or references to "gruel". At the same time, Harrie commented that Belsen and Auschwitz (where the protagonists of the play were later sent) needed to be remembered as well; a seeming contradiction when considering that the play ends where camp experience begins.

680 Ebbe Linde, “Anne Franks dagbok,” August 25, 1956, DN, 10. [”Och hur nära måste inte risken för sentimentalitet ha legat, eller för osant västmaktförhärligande i en amerikansk efterdiktning. Så sade man sig själv. Men Frances Goodrich och Albert Hackett har undvikit de båda sista fallgroparna på ett i stort sett berömvärt sätt och har därtill gått i land med att göra en genomgripande nydiktning...”]. 
Similar to the culture critique surrounding Tell Ye Your Children and the Living History campaign's film package, Swedish theatre critics in the 1950s were quick to laud what they perceived as a form of minimalism in the narrating of Anne's story. However, the "emotive restraint" that was seen to characterize The Diary of Anne Frank was not preventative of the conversion of suffering into sublimity but rather contributed to setting Anne Frank apart from other victims of the Holocaust. 681 Her particularity as young and precocious as well as brave and wise beyond her years made her an exemplary witness; a witness beyond any others who had tried before her. The minimalism of mediating Anne Frank, however, was predicated on the absence of "gruel" and "sentimentality". This aspect of Anne Frank's story, however, would soon come to be explored in Swedish news discourse.

\subsection{Gruel and Glamour: Ernst Schnabel and Anne Frank on Screen}

Even though neither the book nor the stage adaptation of Anne Frank ventured into Anne and her family's camp experiences, the German writer and radio documentarian Ernst Schnabel soon filled these gaps in the story of Anne Frank. The most well-known of Schnabel's iterations concerning Anne's camp experiences is the book Anne Frank: A Portrait in Courage which was published in West Germany under the title Anne Frank: Spur Eines Kindes: ein Bericht and in Swedish under the title Vem är Anne Frank? En bok om flickan som blev legend ("who is Anne Frank? A book about the girl who became legend) in 1958. In Sweden, Schnabel's book was also published as a newspaper chronicle series in Expressen, published during Easter the same year. ${ }^{682}$ Through testimonies and archival work, Schnabel had constructed a narrative that retraced the steps of Anne Frank from her arrest by the Gestapo in the autumn of 1944 to her untimely death in BergenBelsen in early 1945. In Anglo-American research on the various mediations of Anne Frank, Schnabel's deeds remain lacking; perhaps because his book and documentary program did not make a significant impact in a British or an American context. However, in overlooking Schnabel and his narrating of Anne's journey through the camp system, previous research has missed the ways in which Anne Frank was constructed as a camp victim; a construction that relied heavily on

681 Dean, Aversion and Erasure, 101.

682 “Anne Franks dagbok var starkare än döden,” April 3, 1958 Expressen, 14. "Gestapo Bryter sig in”, April 5, 1958, Expressen, 13. "Med den sista transporten...från Holland till Auschwitz," April 
survivor testimony and therefore actualized the role of the survivor-witness. Moreover, the story of these last months of Anne's life were also relayed through a radio play which in Swedish bore the title Anne Frank: Sparen efter ett barn ("Anne Frank: the traces of a child"), broadcast in March 1959. ${ }^{683}$ Sweden thus saw three different mediations of Schnabel's work during 1958 and 1959 which made Anne's fate far more accessible than it had been, were it only for the book and the play.

The documentary interest demonstrated by these mediations of Anne Frank's final months also impacted how the film adaptation of the play was received by Swedish critics. The film which had the same title as the Broadway play (The Diary of Anne Frank) premiered in Sweden during the autumn of $1959 .{ }^{684}$ Understandably, much of the news discourse surrounding the film pertained to the young, beautiful and glamorous Millie Perkins who starred in the film as Anne Frank. However, the film was also-to a greater degree than the book and the play-framed as a document of Holocaust history. Before 1958 Anne Frank had been positioned as an effective witness to Nazi perpetration. With Schnabel's historicization of the literary figure of Anne, the film could be understood as something more specific; as a document of the Nazi' persecution of the Jews. In this section I thus investigate this transformation of Anne Frank from an autobiographical character to a historical figure as well as the effects that this transformation had on discourses pertaining to the survivor as a witness.

\section{The Importance of Documentation}

Through Schnabel's work, the "gruel" that had previously been avoided in the story of Anne Frank was suddenly introduced to Swedish audiences. On April 3, 1958 (two days before the newspaper chronicle's first article was to be published) Expressen announced that they had acquired the exclusive rights to Schnabel's story. On the front page the headline read: "Expressen Publishes a Continuation of Anne Frank's Diary". ${ }^{685}$ Not only could Expressen take credit for being the first to present this part of Anne's story to Swedish readers but they were also mere weeks after the publication of the first German edition of Schnabel's book. Rather than wait for a Swedish translation (which would come months later), Expressen was able to

683 “Anne Frank i Auschwitz," April 8, 1958 Expressen, 11. "Anne Frank dog av sin systers död," April 9, 1958, Expressen, 18. "Radio och TV", March 18, 1959, 20.25, Aftonbladet. See also Ernst Schnabel, Anne Frank sparen efter ett barn: ettprogram, trans. Herbert Grevenius, (Stockholm: Sveriges Radio, 1959).

684 “Anne Frank i filmpremiär," September 15, 1959, SvD, 1.

685 “'Anne Frank—spåren av ett barn’. Börjar idag,” April 3, 1958, Expressen, 1. 
keep up with the buzz that surrounded the book in its country of origin. Schnabel's narrative contained, according to one of the articles in Expressen, testimonies from 42 individuals who had known or encountered Anne and/or her family members as they had been transported first to Auschwitz and later to Belsen (Anne and her sister Margot). Thus, while Schnabel expanded on Anne's Holocaust story and brought it into the camps, his interview subjects' testimonies existed as mere vessels for Anne's continued story rather than as additions of new information about Holocaust experience. ${ }^{686}$ Schnabel's research and the narrative that came thereof focused on the extraordinary behavior of Anne in the camp. Two of the four articles in the chronicle series were told from the perspectives of female survivors who encountered Anne in Auschwitz and Belsen respectively. In the first of these articles the main headline read, "Anne Frank in Auschwitz" followed by two subheadings, one of which quoted a woman survivor stating that "[Anne Frank] was the only one who could still cry" while the other sub-heading stated that "[Anne Frank] saw the children queue in front of the gas chamber". In the article a woman described how Anne maintained her human emotion long after her friends had lost theirs, the woman survivor describing how "she could still see [Anne] standing in the door looking out on the camp street where a herd of gipsy children were driven toward the crematorium. Anne looked at them and wept". ${ }^{687}$ The survivor also recounted how Anne had managed to procure a cup of coffee for her when she was dying of thirst and that Anne had only become more beautiful for every day that passed in the camp. ${ }^{688}$ Also, in the final article of the series, Anne's death was described by another woman survivor as a consequence of Anne's sister dying, a conclusion that also informed the article headline. The article thus explained, through the survivor, that "they did not tell Anne about her sister's death, for Anne was also very ill. But after a few days she understood what had happened anyway. Shortly thereafter she herself died, calm and with the feeling that nothing bad would befall her". ${ }^{689}$ This comforting description allowed the readers to enter Anne's mind in the moments before her death, mimicking the diary as a document to the inner thoughts of the Holocaust victim. Also, just as the end of her diary had been interpreted as hopeful and full of compassion with the world, the final sections of this text communicated redemption and peace rather than darkness and

686 “Anne Franks dagbok var starkare än döden,” April 3, 1958, Expressen, 14.

687 “Anne Frank i Auschwitz," April 8, 1958, Expressen, 11.

688 “Anne Frank i Auschwitz,” April 8, 1958 Expressen, 11.

689 “Anne Frank dog av sin systers död," April 9, 1958, Expressen, 18. 
despair. Through this narrative of a girl whose spirit never lessened, the notion of Anne as the exemplary victim was perpetuated; a victim who never gave up hope, was self-sacrificing, never relinquished her beauty and who died in peace.

The survivors were witnesses to Anne's victimization. On the other hand, Anne herself had also been a compassionate witness to the suffering of others in the camps; to the Roma children and to the plight of her own sister. This relationship brought the exemplary witness closer to those whose narratives of suffering and survival had previously been deemed excessive. Even when placed in a context of suffering, Anne's story-as told by survivor witnesses-was not critiqued as overwrought with emotion or as voyeuristic. Rather, the accusation, albeit still diffuse in what it entailed, now seemed a natural part of the Holocaust narrative surrounding Anne Frank's story. For instance, in a review of Schnabel's radio play, DN's critic claimed that,

The fate of Anne Frank has, for an infinite amount of people, become the tangible symbol for the incomprehensible that happened in the Nazi's systematized extermination of six million Jews. The little girl from Amsterdam has grown close to us. We have gotten to know the individual of the diary and therefore, she can accuse in a way that the horrifying millions cannot. Where fantasy fails and the thought has no strength to follow, there a child speaks so that we understand something of that which occurred. ${ }^{690}$

Also significant in this review is that Anne was explicitly referred to as a symbol of Jewish suffering; a perspective that was broached but never explicated in the critical reception of the book and the play. Rather than solely being about the occupation of Holland or the Nazi's persecution of "hundreds of thousands" or "Northeners" and "Slavs", the story of Anne Frank had now become about the "Nazi's systematized extermination of six million Jews". This shift toward a more specific context for Anne's story can also be detected in a review of the writers and critics Ann Birstein and Alfred Kazin's The Works of Anne Frank, published in Expressen on Christmas Day, 1959. The review was penned by the famous Norwegian journalist, author and literature critic, Johan Borgen, who had used his journalistic platform during the War to criticize Nazism. In the review, headlined with the

690 “Filmen om Anne Frank—drama och historia,” March 28, DN, 1959, [“Anne Franks öde har för oändligt många blivit den fattbara symbolen för det ofattbara som skedde vid nazisternas systematiska utrotning av sex miljoner judar. Den lilla flickan från Amsterdam har kommit oss nära. Vi har lärt känna dagbokens Anne som individ, och därför kan hon gripa och anklaga på ett sätt som de förfärande miljonsiffrorna inte förmår’]. 
question, "Do we Have a Right to be Left Alone by Anne Frank?", Borgen argued that "the survivors" (i.e. everyone who was not victimized by the Holocaust) should live "with a worry in [their] minds". "Without this active worry" he continued, "we have no right to be survivors. What happened to Germany's Jews and Poland's Jews and all countries' Jews-Norway's Jews... Not only should we never 'forget', we shall also never let our consciousness rest". ${ }^{691}$ In Borgen's review, it was not only the Dutch Jews or the German Jews who were referenced but all Jews who were murdered in the Holocaust. Also, according to Borgen, Anne Frank was not merely a figure who helped her readers and audiences remember, but was someone whose story explained the entire genocide in a graspable way. Knowledge about the horrible conditions under which Anne lived before her death did not weaken her position as victim or as witness. Being the exemplary witness instead meant that she could accuse and berate in a way that "the horrifying millions" could not. This message was also communicated in the culture critic Barbro Hähnel's critique of Schnabel's book where she stated that the "immense" perpetration that happened to "millions of Jews" was never clearer then when told through the lens of the young girl, Anne Frank. ${ }^{692}$ Hähnel also asserted that Anne Frank "gave a face and a name to one of the innumerable victims, so that the slow minds of outsiders could suddenly grasp the scope of what had happened". 693

These discourses concerning the specificity of Jewish suffering during the war and Anne Frank as a symbol for the many was also a significant part of the culture critique that surrounded the film, The Diary of Anne Frank. Soon after the film had premiered in New York (the Swedish premiere came six months later), DN published a full-page article about The Diary of Anne Frank as "drama and history". ${ }^{694}$ Under this headline, two photographs depicting Millie Perkins and a very young Anne Frank were placed next to each other so as to reiterate the message relayed in the headline; Anne Frank was both real and fictional. Central to the article text, however, was the documentary work conducted behind the scenes of the film, both by Schnabel and by the Riksinstituut voor Oorlogsdocumentatie- the latter being a Dutch research institute that had reportedly acted as a "history advisor" to the film's director, George Stevens. The documentation mentioned in the article was comprised of survivor testimonies and registers of Jews deported

691 Johan Borgen, “Har vi rätt att vara ifred för Anne Frank?” December 26, 1959, Expressen, 4.

692 “Vandring till Inferno," December 17, 1958, DN, 5.

693 "Vandring till Inferno," December 17, 1958, DN, 5. [“Hon ger ett namn och ett ansikte åt ett av

de otaliga offren, så att utomståendes tröga sinnen plötsligt kan fatta vidden av det som skedde"]. 694 "Filmen om Anne Frank—drama och historia," March 22, 1959. 
East. Below the photographs of Millie Perkins and Anne Frank, a section of such a list — displaying the names of the Frank family_-had been inserted with a caption that explained that "the Nazis held registers of all Jews who were deported from the "'transit camp' Westerbork to the extermination camps in the East". Although focused on the Frank family, the caption also stated that "for long periods of time approximately 2000 Jews a week were deported. For some transports there [were] only a few survivors, but through interrogations with them it [had] been possible for the institute to localize practically every transport and follow a majority of the Jews all the way to the gruesome end". ${ }^{695}$ Here, camp survivors were positioned as documentary sources of knowledge akin to the registers that listed the Frank family and other Dutch Jewish victims. In the quote as well as when describing the work of Schnabel, the article referred to the "interrogation" ("Förhör") of survivors rather than interviews or conversations with survivors. Even in the news discourse surrounding the Belsen trial, survivors were described in less objectivistic terms.

However, considering what was at stake in the representation of Anne Frank in the late 1950s, it seems plausible to suggest that solid documentation of Anne's life and Holocaust experience became increasingly important as she continued to be constructed as the symbol of six million dead. Displaying the documentation of her journey though the camp system thus became synonymous with documenting the Holocaust at large. Echoing the message relayed by the critics of Schnabel, the DN article referenced above also quoted the German film maker and writer Erich Lüth stating that,

Anne Frank's diary, written without intention, to afford the author some relief from her own inner life — a dialogue with death anxiety—has shown an ability to, in a comprehensible way, mirror a fate that has become the key to the whole Jewish tragedy. Anne Frank becomes a stand-in for everyone that had to suffer the same fate. ${ }^{696}$

695 “Filmen om Anne Frank—drama och historia,” March 22, 1959, DN, [“Långa tider deporterades ungefär 2000 judar i veckan. Från vissa transporter finns det bara ett par överlevande, men genom förhör med dem har det för institutet varit möjligt att lokalisera praktiskt taget varje transport och följa flertalet judar ända till det ohyggliga slutet”].

696 "Filmen om Anne Frank—drama och historia”, March 22, 1959, DN, [“Anne Franks dagbok, nedskriven utan avsikt, för att skänka författarinnan en lättnad av sitt eget innersta, en dialog med dödsångesten, har visat sig på ett begripligt sätt kunna spegla ett öde som ger nyckeln till hela den judiska tragedin. Anne Frank blir en ställföreträdare för alla som måste lida samma öde’]. 
This argument about Anne Frank as a "stand-in" for "the whole Jewish tragedy" also reoccurred in SvD's critique of the film after the Swedish premiere, where the critic explained that,

Thousands and thousands of pens have described the Nazi nightmarish epoch in our part of the world. Knowledgably, documentarily, objectively or with flaming indignation it has been described on millions upon millions of book pages, in newspaper articles, plays and films, and in exposing photographic reproductions. The strange thing is that almost no one has been able to vivify these years of terror with a more powerful effect than the little girl in Amsterdam, when she, in simple words, wrote down her diary notes during the years as a prisoner in the attic space above the spice factory. The success probably depends partly on the fact that the individual fate always manages to rouse more feeling than that of the hundreds and thousands and partly because the martyred death of the innocent child seems more awful than that of the adult. 697

According to this critic, no one had been able to communicate Holocaust experience as effectively as Anne Frank even though many had tried. Interestingly, this critical assessment of the film also presented the view that representations of the Holocaust were prolific. Like Brunius's review of the play, SvD's film critic reinforced the notion that there was a plethora of information about the Holocaust—not just in archives, but through various artistic expressions, books and articles. Again, discourses on forgetfulness and silence (intentional and unintentional)—as presented in Harrie's review—were thus reinforced alongside discourses on hypertrophy and excess; the former serving as a reason for Anne Frank's survival in popular culture, the latter being an argument for the prevention of conflict inefficient witnessing. Also, the recurring theme of excess-not just referring to excessive forms of representation but also to the number of representations-also highlights how, even in a decade that has often been referred

697 "Park: Anne Franks dagbok," September 15, 1959, SvD, [“Tusen och åter tusen pennor har skildrat den nazistiska mardrömsepoken i vår världsdel. Initierat, dokumenterat, sakligt eller flammande indignerat har den beskrivits på miljoner och åter miljoner boksidor, i tidningsartiklar, pjäser och filmer, i nakna fotografiska reproduktioner. Det underliga är att nästan ingen kunnat levandegöra skräckens år med starkare verkan än den lilla flickan i Amsterdam, när hon i enkla ord nedskrev sina dagboksanteckningar om åren som fånge i vindskamrarna ovanpå kryddfabriken. Framgången beror väl dels på det faktum att det enskilda ödet alltid förmår uppröra mer än de hundrades och tusendes, dels på att det oskuldsfulla barnets martyrdöd synes ohyggligare än de vuxnas"]. 
to as 'silent' or as reluctant to deal with the memory of the Holocaust, the perception was that the Holocaust was constantly and continuously discussed and represented.

So, what effect did the discourses surrounding Anne Frank have on the construction of the survivor? An answer to this question can be gleaned from a handful of reviews concerning the Swedish camp survivor and author Zenia Larsson who, in her debut novel from 1960, Skuggorna vid träbron ("The Shadows by the Wooden Bridge"), depicts life in the Lodz ghetto. Although receiving rave reviews in the major dailies as well as being portrayed in a full-page feature in Expressen, Larsson's writings were characterized in ways that reflect some of the discourses discussed above. For example, in DN Larsson's novel was compared to Pamietnik Dawida Rubinowicza (published in Swedish under the title Davids Dagbok in 1960) as well as Erwin Leiser's seminal documentary Mein Kampf. DN's critic thus stated that "if one compares with the authentic — with David's Diary or with the images from the Warsaw-ghetto in the film Mein Kampf_Skuggorna vid träbron must seem like a reconstruction. The authoresses' powers have not been enough to give life to the reality that is her childhood memories". ${ }^{698}$ Although the critic finished his review by stating that this made Larsson's novel no less important, this assessment still re-affirmed the conception that Holocaust representation should be as documentarian as possible; a feat that Anne Frank had achieved on the basis of writing from within the experience. The purpose of the representation did not seem to matter here; all expressions of Holocaust experience were to abide by the documentarian ideal.

In addition to this ideal, the notion that all survivors were receptacles of facts waiting to be shared was also expressed in the literary critique surrounding Larsson's debut. In SvD, the critic stated that it had taken almost fifteen years for Larsson to "present her experiences from the ghetto during the war"; thus assuming that these experiences had always meant to be presented. ${ }^{699}$ This notion was also reaffirmed by Larsson herself in the feature published in Expressen. In her interview with the Swedish-Jewish culture journalist, Madeleine Kats, she asserted that,

one always has it inside of oneself. One does the dishes, walks the dog. But it is always inside of oneself. In the end one has to express it. One does not have the right to not do one's best, to try to find one's own distinctive character and express that which one has lived through. Everything was already

698 “De instängdas hopp," November 11, 1960, DN, 7.

699 "Krigets getto," November 4, 1960, SvD, 12. 
ready inside of me. It came out when I began to feel the language in my hands. ${ }^{700}$

The imperative to tell the world about the Holocaust—as it had been rather than how it had been experienced-was thus expressed both by survivors as well as by critics. Just like Anne Frank-whose literary talents were established by Swedish critics early on-survivor writers were also assessed on the basis of being able to effectively express that which had always been there and would always be there. Interestingly in Larsson's case, the temporal distance created by her 'delayed' debut was also perceived as something positive. In SvD the critic asserted that "if she had written the book earlier on, the tone would likely have been more agitated; the faith in the victory of the human spirit in the middle of the Nazi's murderous zealotry and depravity, that is now displayed in the story, would perhaps not have been there". ${ }^{701}$ Just as with Anne Frank, the hopeful redemptive messages-the continued belief in humanity and the resilience of the human spirit-were also aspects that were emphasized in the literary critique of Larsson's debut novel. Also, it is possible that these themes in Skuggorna vid träbron-of hope, love and community — were highlighted in the reviews as a way to relieve a perceived Holocaust fatigue. In the feature, Kats postulated that her readers would think Larsson's book superfluous; as yet another book in a long line of books written about Nazi perpetration. Mimicking her readers' thoughts, she stated, "yet another book...an inner resistance grows. Not much but enough to make one scared. A feeling of fatigue even before the book has been opened. Do we have to? Again..."702 The answer to these imagined questions were provided in the next paragraph and also framed the whole article through the headline: "People cannot

700 “Människor får inte bli statistik," November 27, 1960, Expressen, 17. [“Man har det alltid inom sig. Man diskar, städar, går ut med hunden. Men det finns alltid inom en. Till sist måste man ge uttryck åt det. Man har inte rätt att inte göra sitt bästa, försöka finna sin egenart och ge uttryck för den, för vad man själv upplevt. Allt fanns redan färdigt inuti mig. Det kom när jag började känna språket i mina händer'].

701 "Krigets getto," November 4, 1960, SvD, 12. [“Hade hon skrivit boken tidigare skulle tonen sannolikt varit mer upprörd; den tro på människoandens seger mitt $i$ anloppet av nazistisk mordlust och gemenhet, som nu i alla fall finns med i berättelsen, skulle kanske haft svårare att inställa sig'].

702 “Människor får inte bli statistik," November 27, 1960, Expressen, 17. [“En bok till...det tar emot. Inte mycket men tillräckligt för att göra en rädd. En trötthetskänsla redan innan man öppnat boken. Måste vi? Nu igen...”]. 
become statistics". ${ }^{703}$ To let human beings become statistics, Larsson asserted in the article, was to kill each dead victim again. "Statistics are dead, innocuous. No one has the mind to think in millions" she added. Effective Holocaust witnessing was thus connected to the imperative to listen to the individualized stories of Holocaust experience.

With Schnabel's book, radio play and chronicle series, the fate of Anne Frank became legible to Swedish media consumers. The subsequent framing of Holocaust survivors as historical documents of Anne's untimely death also strengthened the survivor's position as witness to the Holocaust (albeit primarily to the tragedy of Anne and her family). Beyond the trials of the 1940s, then, Anne Frank provided conceptions of Holocaust witnessing both from within and from without of the experience; Anne's narrative in the attic on Prinsengracht contributing details on the inner life of a Jewish girl in hiding and the anonymous camp survivors testifying to Anne's life after being arrested and deported. If Anne Frank's Jewish identity was made more visible through the theatre critique of the many stage productions set up in 1956, the critique of Schnabel's book and radio play as well as the critique of the film contributed to a more specific formulation of the Holocaust as the concerted effort to exterminate the Jews during the war. The concept of excess also became increasingly prominent in the latter half of the 1950s with many critics asserting that so much had already been written, acted out, and said about the Holocaust. Even so, forgetfulness and silence concerning the victimization of the Jews under Nazi occupation was also positioned as an ever-looming threat. The solution to this problem, then, was not more expression but rather the effective expression of Holocaust memory; something which, during the Anne Frankdecade, was defined as hopeful, future-oriented narratives that reminded people of why Nazism was bad while, at the same time, absolving them from any lingering feelings of guilt, shame and anger.

\subsection{Conclusions: Anne Frank and the Survivors}

The difference between the descent and emergence of the Holocaust survivor in Swedish public discourse lies in the fact that the descent was marked by the immediacy of events-the concept forming as a result of news discourse containing information about survival and victimization in the here and nowwhereas the emergence of the object was intrinsically linked to the memory of the 
event. The disciplinary or expert discourse that formed around the subject of Anne Frank was thus both interested in establishing the facts of the past as well as with finding the most effective witness - the former actualizing the role of the survivor as historical document while the latter served to marginalize the survivor-witness. Also, in the 1950s the perception was that survivors wanted to, and indeed did speak, through a variety of mediums, about their experiences during the war. The problem was not their silence but the rest of the world's difficulty to listen to their stories; especially those stories that concerned the darkest chapters of the Holocaust.

Although perhaps the least important mediation of Anne Frank's writings during the 1950s, the book Anne Franks dagbok created an initial encounter between critics and the author and figure of Anne Frank. The women and men who constructed her, did so in different ways depending on their gendered positions as critics. Whereas Jaensson underscored Anne's genius, Adlercreutz, Bouleau and Nyberg described the emotional connection that they made with the young authoress; her words making an emotional impact on them as well as a moral impact on the world. Discussing the importance of gender in representations of Holocaust experience, Waxman argues that "what is often overlooked" in scholarly work on gender and the Holocaust "is the importance of gender difference in the narration of experience". ${ }^{704}$ Female survivors (and diseased victims) formulate their thoughts in ways that are different to the writings of male survivors. ${ }^{705}$ However, gender norms about how women should write have also affected who the ideal Holocaust witness has been in different decades. Although many female survivor writers were overlooked and ignored because of standards set in relation to male writers such as Primo Levi and Elie Wiesel, in the early decades of Swedish Holocaust writing, almost all prominent survivors-poets or survivor-authors were women. Just as the "True Victim" had been Jewish, young, female and Danish in 1943, the exemplary witness in the 1950s was Jewish, young female and Dutch. Also, representations of the Danish Jewish victims, crossing the sound in row boats until their hands blistered, had framed them as tenacious as well as vulnerable; two qualities that Anne Frank was also seen to have. In contrast to the Danish Jewish refugees and the women shown in Vittnesbördet, however, Anne Frank was not an object of care but an agential subject whose words and perspectives mattered. At 
the same time, they only mattered in so far as they were effective in moving others to remember.

In the reviews of the book, this notion of Anne Frank as an effective witness had been presented and was merely further developed in the theatre critique of the play during the autumn of 1956 . Even though the critics were not necessarily clear about what was supposed to be remembered through the play about Anne Frank (the Nazi's occupation of Holland, the camp system at large, the persecution of the Jews?), the importance of the story could not be emphasized enough. The undesirable results of such a remembrance were, however, clear; no undue accusations against Germany as a whole should be given the space to breathe as this kind of vindictive, reactionary response only led to more conflict and strife. This attitude was plainly visible in Tingsten's response to Edvardson's critique of the "German wonder" in 1955; her personal experience of Nazi cruelty being more of a hindrance to her argument than an aid in establishing her authority as an expert on the subject. Remembrance was thus positioned as important, but the feelings that came thereof had to be honed and disciplined so as not to cause a deeper rift between countries and between people. This concept of a non-accusatory witness was further developed by the theatre critics who praised the play for not showing any "gruel" on stage; an assessment that also demonstrated how representations of the camps and the details of disease, violence and death were deemed excessive. This, in turn, meant that the camp survivor as witness, by default, became excessive and deemed unsuccessful in effectively communicating the memory of the Holocaust.

However, with Schnabel's historicization of Anne's Holocaust experiences, the "gruel" that had so thankfully been excluded in the book and the play, was introduced into the story of Anne Frank. This shift in the narrative around Anne led to a re-actualization of survivor testimony as well as its ability to shed light on particular details of the Holocaust. Similar to the epistemological perspective on survivors as informants, survivors were yet again viewed as documents of the Holocaust; not necessarily contributing completely new knowledge, but rather, authenticating the victimization of others. It is also at the end of the decade that discourses around Anne Frank can be seen to be productive; occluding interest in the multi-dimensionality of survivor-hood, to be sure, yet also creating spaces for narration that would perhaps not have received much attention were it not for a reignited interest in the victims of Auschwitz and Belsen. Although Anne Frank was never referenced in relation to Zenia Larsson's debut, the symbols of Auschwitz and Belsen were present as part of Larsson's own Holocaust experience, thus drawing a straight line from the deportation of the Norwegian Jews, through 
the "White Buses" and UNRRA missions, through the Belsen trial and lastly through Anne Frank and onto, as shall be explored in the next chapter, the Eichmann and first Frankfurt Auschwitz trials. What these events and figures also had in common in Swedish public discourse was their Jewish character, Zenia Larsson's debut being no different with critics explicating that her book was "a book about Jews". ${ }^{706}$ In contrast to Edvardson's weak position as survivor commentator in 1955, Larsson was afforded more room to speak on issues other than her own book; her feature in Expressen quoting her wish to communicate her Holocaust experiences to children as well as the importance of individualizing the Holocaust through narrations of everyday life under extreme conditions. This shift in the position of the survivor was not necessarily only a result of Anne Frank and the attention that the mediations of her garnered but perhaps still an indication of what the ideal for Holocaust witnessing was at the time. Edvardson, who debuted as a published author in 1958 under the pseudonym "Maria Heller", wrote about her camp experiences and was-as evidenced by her involvement in the debate about the "German wonder" - vocal about her feelings towards her former countrymen. ${ }^{707}$ Interestingly, Edvardson did not receive the same amount of critical attention for her first novel compared to Larsson. Larsson's debut was framed as a hopeful love-story, set in the everyday of ghetto life, which meant that it (and Larsson herself) fit more neatly into the concept of effective witnessing - a form of testimony that created an appropriate, manageable emotional connection between the writer and the reader.

These conclusions have been made before by scholars studying other local, national and regional contexts. In 1995, Langer argued that mediations of the Holocaust such as Goodrich and Hackett's The Diary of Anne Frank allowed "the imagination to cope with the idea of the Holocaust without forcing a confrontation with its grim details". ${ }^{708}$ However, Anne Frank has also widely been recognized as an Americanized and universalized figure; someone whose "traumatic story" adopted "an innocuous form, the message being that everyone was in some respects a victim of world war II". ${ }^{709}$ In Sweden, however, this Americanization

706 “De instängdas hopp,” November 11, 1960, DN, 7.

707 Edvardson's debut was also reviewed in the daily and evening newspapers but made much less of a "splash" with brief critical accounts of the storyline and the value of the book's narrative. See for example, "Minnen av inferno", April 8, 1958 DN, 5. "I gaskammarens skugga," July 28, 1958 SvD, 5. "Flyktingliv i fin debutbok," May 20, 1958, Expressen, 4.

708 Langer, "The Americanization of the Holocaust on Stage and Screen," 159.

709 Levy and Sznaider, The Holocaust and Memory in the Global Age, 62. 
and universalization of Anne Frank was only partly present and mostly evident in the theatre critique of the play. Considering all three mediations and Swedish Holocaust memory across the entire decade, however, the particularity of Jewish suffering becomes a much more prominent theme in relation to Anne Frank and the culture critique that disciplined representations of her. Furthermore, in a Swedish context, more in-depth research on this period in Swedish Holocaust memory is needed in order to understand how the Holocaust featured in different public fora. What the enquiry presented here can firmly establish, nonetheless, is that the concepts of silence and excess were present even in the first decade after the war ended. As will be explored further in the coming chapters, the perception of a hypertrophy of Holocaust memory — especially that which dealt with Jewish camp experiences - existed in the earliest decades of Holocaust memory. Although this insight does not negate the proliferation of Holocaust representation in the 1980s and 1990s, it does open up for the questioning of how discourses on the Holocaust continue to affect perspectives on absences and excesses in public forms of remembrance; the Living History's "Memory Archive" being but one example. 


\section{Chapter 5 - The era of Holocaust Trials}

\subsection{Introduction}

In the 1960s the survivor-witness was reintroduced into Swedish news discourse through the high profiled trials of Adolf Eichmann in Jerusalem in 1961 and 22 Auschwitz officials (including one Kapo) in Frankfurt am Main in 1963-1965. Understandably, the Eichmann trial has been perceived as a turning point in Western Holocaust memory with regards to constructing the Holocaust as specifically Jewish. The fact that the trial was held in Jerusalem and featured 111 witnesses meant that both the Holocaust witness and the Holocaust survivor were both defined by Israeli narratives and notions of specifically Jewish Holocaust experiences. As we have seen in the previous chapter, however, these themes were already well established in Swedish public discourse. In addition, critiques of, and contextualizing texts about, Anne Frank and her writings also introduced a particularly Western Jewish Holocaust experience into Swedish homes-an experience that was defined by stories from Auschwitz survivors rather than representations of the majority of Jews who suffered and died during the Holocaust. So, if these aspects of what the Holocaust meant had already been established in Sweden by 1961, then what effect did the Eichmann trial have on the construction of the survivor? In more specific terms, how did the mediation of the trial affect the Holocaust survivor's particular visibility and status in Swedish public discourse? And how was the survivor disciplined by journalists and cultural critics in their commenting on, and interpretation of, different expressions of Holocaust experience in relation to the trial?

These are some of the questions that will be explored in the coming sections beginning with the examination of the Eichmann trial on Swedish television in order to establish whether the televising of the trial significantly affected constructions of the survivor in a Swedish context. The second part of the analysis centers on the printed press with a specific focus on foreign correspondence and news discourse. Because television was still in its cradle, foreign correspondents and news outlets remained vital in explaining world events to Swedish citizens. The same can be said for the cinematic medium. Although declared dead in the early 1960s by many contemporary scholars and critics, films (both fictional and documentary) continued to inspire and engage Swedish audiences. The so called 
'Eichmann films', that came out in the spring of 1961 thus constitute an example of Holocaust representations that brought drama to the Eichmann trial.

The Eichmann trial is often identified as the main juridical event that helped shape conceptualizations of the Holocaust witness. However, the first Frankfurt Auschwitz trial-held in Frankfurt am Main between 1963 and 1965-also made extensive use of testimony (350 as compared to the 111 who testified during the Eichmann trial). Therefore, the media attention surrounding the first Frankfurt Auschwitz trial will also be scrutinized along with the cultural critique of Peter Weiss's play Die Ermittlung (The Investigation).

\subsection{Methods and Sources}

The Eichmann trial has, as noted above, been positioned as an integral event to Holocaust memory by most (primarily Anglo-American) scholars who have asserted that it constituted a turning-point in the collective understanding of the Holocaust as a Jewish event. In searching the digital newspaper archive using search words such as "Auschwitz", "koncentrationsläger", "utrotning" and "Nazist/Nazisterna/Nazisternas" I also found Eichmann referenced years after the trial had ended together with other Holocaust-related phenomena, indicating that the trial had an impact on the whole decade. For example, in 1963 an article commemorating the rescue of the Danish Jews published in DN appeared when searching the word "Auschwitz". One of the sub-headings in the middle of the article stated: "Eichmann disappointed", after which the article declared that during "one week" in October "nearly all of Denmark's Jews were rescued." 710 Eichmann was not otherwise mentioned in the text, but the single reference to Eichmann as the person who would have been disappointed at the successful rescue of the Danish Jews suggests that he alone had come to represent the Nazi's endeavors to exterminate the Jews in Denmark. Another revealing example was the fact that DN referred the trial against the former SD-officer Wilhelm Horster and his two aides in Munich in 1967, as "The Eichmann Proceedings of the Netherlands". 711 Thus it seemed that the Eichmann trial colored understandings of many different aspects of Holocaust memory during the 1960s; both as a referent of Nazism as well as the model trial upon which all subsequent trials were compared.

710 “Nätter på Öresund Räddade 7500 judar,” October 20, 1963, DN, 28.

711 "Hollands Eichmannprocess: väl avvägd bekännelse av tränade nazijuristen," January 25, 1967, DN, 15. "Hitlers bödlar i Holland åtalas," January 23, 1967, DN. 
After having established that the Eichmann trial impacted news discourse on the Holocaust throughout the decade, I searched the newspaper archive from the days before Eichmann was indicted, although focusing primarily on the period in which the witnesses took the stand (April 24 until June 12) to see how their testimonies were characterized both in terms of their content as well as their form. The Eichmann trial is, in part, famous for being the first televised Holocaust trial. Researchers like the American media historian Jeffrey Shandler have thus studied the trial as a particular "Media Event," emphasizing as well as questioning previous conceptions regarding the ways in which the television medium contributed to the communication of Holocaust experience in the early 1960s. ${ }^{712}$ Because the Eichmann trial had been on television, I wanted to explore if, and how, the trial had been included into the Swedish television-tableau. In my initial searches of the audio-visual archives at the National library I found little of import relating to the Eichmann trial. What I could conclude was that the trial did not constitute its own program in the tableau. Because I was particularly interested in whether the testimonies had been broadcast on Swedish television, I requested to have the news show Aktuellt digitalized from late April to the end of May. This process took time and I soon realized that I could not rely on this particular method of sourcecollection since only one person at the responsible archiving institution, Sveriges Television (SVT), worked to digitalize reels when requested by the National Library. Importantly, however, from studying the television tableaus in newspapers together with my searches in the audio-visual archive I detected a surprising absence of Eichmann from Swedish television's daily content. Rather than being broadcast every day, it seemed that snippets of the proceedings were included into other programs, Aktuellt being one such show. I included what I found into my analysis in order to problematize this absence as well as the trial's fragmented presence (see section 5. 4) but, more than anything, these findings made me realize the importance of the newspapers and particularly, the importance of the foreign correspondents who were stationed in Jerusalem and reported directly from the events.

712 See for example, Jeffrey Shandler, "The Man in the Glass-box: Watching the Eichmann Trial on American Television," in ed. Barbie Zelizer, Visual Culture and the Holocaust, (London: Athlone, 2001). Judith Kielbach, "The Eichmann Trial on East German Television: On (not) Reporting about a Transnational Media Event," Journal of European Television, History and Culture, vol. 3, no. 5, (2014): 17-22. Amit Pinchevski, Tamar Liebes \& Ora Herman, "Eichmann on the Air: Radio and the Making of an Historic Trial", Historical Journal of Film, Radio and Television, vol. 27, no. 1, (2007): $1-25$. 
Since Expressen, SvD and DN all had their own correspondents in Jerusalem during parts of the trial, I chose to examine articles in these particular newspapers. As Jessika Fredriksson has demonstrated in her master's thesis, the local Northern daily newspaper Norrbottens-Kuriren had also employed a foreign correspondent, stationed in Jerusalem; something that demonstrated the reach of the Eichmann trial's perceived importance outside of the metropolitan areas in Sweden. ${ }^{713}$ However, as this correspondent only published one article in Norrbottens-Kuriren during the trial, this local newspaper was not included into my analyses. Furthermore, since I was particularly interested in the time period in which the witnesses took the stand in Beit Ha'am, I also chose to focus on DN's correspondent Agne Hamrin—both due to his prolific writings during the trial, his prominent position as a long-time Mediterranean correspondent for DN as well as his position as a Swedish expert on Israel and the Levant.

Furthermore, as will be discussed in the next section, the late British historian David Cesarani suggests, in an introduction to a special issue about the Eichmann Trial from 2004, that it was primarily the debates that preceded and followed the proceedings in Jerusalem that were impactful on discourses regarding the Holocaust. ${ }^{714}$ Arendt, he argues, was one of the central actors in, as well as a crucial subject of, these debates. ${ }^{715}$ When searching for discussions on Hannah Arendt's writings on the Eichmann trial after her book Eichmann in Jerusalem was published in 1963 (Swedish trans. 1964), however, I found only a handful of articles that, in different ways, engaged with Arendt's arguments—none of them positioning the trial in relation to the witnesses. ${ }^{716}$ The one article that discussed the controversial arguments made in Arendt's book about the Jewish victims and their role in the genocide was not an argumentative opinion piece, but rather, had the character of

713 Jessica Fredriksson, 'Europas bödel' fast efter 15 år': En kvalitativ presstudie av den svenska pressens rapportering om Eichmannrättegaingen 1961, (Master's thesis, Uppsala University), 10.

714 David Cesarani, “Introduction,” Journal of Israeli History, vol. 23, no. 1 (2004): 1.

715 Cesarani, "Introduction," Journal of Israeli History, 6.

716 Ulf Brandell, "Var Judarna medskyldiga?” January 26, 1964, DN, 4. "Nazismen—en vålnad," August 1, 1965, DN, 4. "Själavård invid galgen," September 4, 1965, SvD, 5. "'Den slutgiltiga lösningen," February 26, 1965, SvD, 4. For the first English language edition of Arendt's book, see Hannah Arendt, Eichmann in Jerusalem: A report on the Banality of Evil, (New York: Viking Press, 1963). For the first Swedish translation of the book see, Hanna Arendt, Den Banala Ondskan: Eichmann i Jerusalem, (Stockholm: Aldus/Bonnier, 1964). 
a news article reporting on a new and noteworthy book. ${ }^{717}$ Therefore, I looked elsewhere for actual debates about Holocaust related phenomena in general in the first half of the 1960s and found, through searches of "Auschwitz", several review articles of Peter Weiss's play Die Ermittlung. Being an exiled German Swede, Weiss was positioned as a famous figure that Swedes could be proud to call their own, making his ideas and the expert opinion regarding his work more relevant than the lukewarm discussions that surrounded Arendt and Eichmann in Jerusalem. It was thus Weiss's play, rather than the first Frankfurt Auschwitz trial, that determined the period of inquiry for the second part of this chapter. To be sure, the Swedish newspapers also reported on the Sobibor trial, the Treblinka trial, the subsequent Frankfurt Auschwitz trials, which may all have reflected and constituted the survivor object in Swedish public discourse. Yet, my interest was not to cover all news discourse regarding Holocaust trial witnesses in the 1960s, but rather, to find instances in which the role of the witnesses might have been questioned or contested. In relation to Die Ermittlung, this ambition was also added to by an aim to understand how the critics' opinions about Weiss's play-even if they did not directly refer to survivors, victimization or witnessing-served to discipline Holocaust representation in general.

As can be garnered from the discussion above, the research process concerning the "era of Holocaust trials" was abductive insofar as previous research from primarily an Anglo-American perspective was interrogated by searching for references that a postulated importance, as well as by searching more openly for unexpected, yet related points of significance. It also entailed an understanding of how debates about Holocaust representation informed notions of the survivor, as well as how representations of survivors informed notions of the Holocaust and Holocaust justice. In the coming sections these relationships will be further elucidated.

717 The DN article with the the headline "Were the Jews complicit?" is an example of this. See Ulf Brandell, "Var Judarna medskyldiga?" January 26, 1964, DN, 4. It should be noted, however, that Cordelia Edvardson discussed most likely did discuss Jewish victimization in a radio program called "Martyrs and resisters" in April of 1963. Whether this discussion contained any commentary regarding Arendt is difficult to say since I have not been able to access the recording. See "Martyrer och motståndsmän—ett samtal mellan Cordelia Edvardson and Tore Zetterholm," TV och Radio, April 22, 1963, DN, 47. 


\section{3 The Impact of the Trials}

Adolf Eichmann, formerly an SS-obersturmbannführer, was abducted in Buenos Aires, Argentina by the Israeli intelligence organization, Mossad, and brought to Jerusalem in May 1960. Almost a year after his arrest, Eichmann was charged with crimes against the Jewish people. On May 29,1962, Eichmann was sentenced to death and was subsequently executed shortly after his sentencing. ${ }^{718}$ Although the focus of the trial was Eichmann himself and, through his figure, the content and form of evil at large, it was also a trial which provided a forum for the Holocaust's victims; both those who had survived as well as those who had perished. In addition to the 111 witnesses brought to the stand by the prosecution (102 of which were camp survivors), the prosecutor, Gideon Hausner, claimed in his opening statement that he accused Eichmann on behalf of "six million prosecutors". ${ }^{719}$ Hence, the victims were not only part of the evidence launched at the defendant but they were also stated as his true accusers. The whole trial was, as the Israeli historians Hanna Yablonka and Tom Segev have elucidated, framed by political strategy with both prime minister David Ben-Gurion and foreign minister Golda Meir intervening in the process to construct narratives which would bolster Israel's diplomatic relations with the West and sub-Saharan Arica. ${ }^{720}$

In a scholarly context, the Eichmann trial has been held as a watershed in the cultural memory of the Holocaust. ${ }^{721}$ Cesarani has noted that "the capture, trial and execution of Adolf Eichmann were sensational events that for short periods dominated the news media of the time and forever changed perceptions of the Nazi's persecution and mass murder of the Jews." "722 However, while some have argued that the trial broke a "deep silence" on the Jewish genocide, others have asserted that it merely altered the narrative around the Holocaust; providing a context, a name, explanations and, not least, drama to an already existing memory

718 David Cesarani, “Introduction,” Journal of Israeli History, vol. 23, no. 1 (2004): 1.

719 The Israeli attorney-general and chief prosecutor in the Eichmann trial Gideon Hausner, cited in Hanna Yablonka, The State of Israel vs. Adolf Eichmann, (New York: Schocken books, 2004), 82.

720 Yablonka, The State of Israel vs. Adolf Eichmann, 83-87. See also Tom Segev, The Seventh Million: the

Israelis and the Holocaust, trans. Haim Watzman, (New York: Henry Holt, 2000), 323-367.

721 Daniel Levy \& Natan Sznaider, The Holocaust and Memory in the Global Age, (Philadelphia: Temple UP, cop., 2006). Peter Novick, The Holocaust in American Life, (Boston: Houghton Mifflin, 1999). Shoshana Felman, The Juridical Unconscious: Trials and Traumas in the Twentieth Century, (Cambridge, Mass.: Harvard University Press, 2002) Deborah E. Lipstadt, The Eichmann Trial, (New York:

Nextbook/Schocken, 2011).

722 Cesarani, "Introduction," Journal of Israeli History, 1. 
culture. ${ }^{723}$ Many scholars who have commented on, or studied the importance of the Eichmann trial in greater memory processes have also contended that the notion of the Holocaust witness was fundamentally altered by the trial and the commentary it garnered. ${ }^{724}$ For example, the American historian Deborah Lipstadt argues, that in taking on the role to speak for six million dead, the survivor witnesses also gained "an iconic, almost mythic authority". ${ }^{725}$ Similarly, in an Israeli context, Hanna Yablonka has shown that the testimonies given during the trial were integral in changing the position of the survivor in Israeli society. ${ }^{726}$ "For the survivors", Yablonka argues, "the trial was a decisive milestone in their integration into Israeli society, a way for that society to tell them, 'Your heritage is part of our culture". ${ }^{727}$ Similar arguments have been made for other national contexts such as the British and the French. For example, the British historian Peter Novick contends that the Eichmann trial was pivotal in exposing the survivor witness to the British public imagination and the French historian Annette Wieviorka has termed the era of the Eichmann trial, "the advent of the witness". ${ }^{728}$ However, in responding to Novick's contention in particular, Zoë Waxman emphasizes that,

it is important not to overstate the significance of the trial in the developing position of the Holocaust witness. Unlike the Nuremburg trials, which were predominantly concerned with establishing the fact and extent of the crimes of Nazism, the trial of Eichmann in Jerusalem was specifically concerned

723 Tom Segev has argued that there was a "deep silence" about the Holocaust in Israel before the Eichmann trial; a contention that Deborah Lipstadt questions in The Eichmann Trial on page 189, Anita Shapira, Dalia Ofer, Yehiam Weitz and Hannah Yablonka have also refuted such claims. See for example Anita Shapira, "The Holocaust: Private Memories, Public Memory," Jewish Social Studies, Vol. 4, No. 2, (1998): 46-58. Yechiam Weitz, "Political Dimensions of Holocaust Memory in Israel during the 1950s," Israel Affairs, vol. 1, (1995): 129-145. Dalia Ofer, "The Strength of Remembrance: Commemorating the Holocaust during the First Decade of Israel," Jewish Social Studies, Vol. 6 No. 2 (2000): 24-55 and Hanna Yablonka, Survivors of the Holocaust: Israel after the War, (Basingstoke: Palgrave Macmillan, 1998).

724 See for example, Novick, The Holocaust in American Life, 133-145. Cesarani, "Introduction," Journal of Israeli history, 1-17. Lipstadt, The Eichmann Trial, xx. Wieviorka, The Era of the Witness, 56-95. Levy \& Sznaider, The Holocaust and Memory in the Global Age, 96-130.

725 Lipstadt, The Eichmann Trial, xx.

726 Yablonka, The State of Israel vs Adolf Eichmann, 155.

727 Yablonka, The State of Israel vs Adolf Eichmann, 155.

728 Wieviorka, The Era of the Witness, 56-95. Novick, The Holocaust in American Life, 133-145. For a scholarly discussions on the role of the Eichmann trial in a French context see Wieviorka, The Era of the Witness, 56-95 and Johannes Heuman, The Quest for Recognition: the Holocaust and French Historical Culture, 1945-1965, (Doctoral Diss.: Stockholm University), 164-171. 
with what happened to Jews; however, the vulnerability of survivors was still not fully appreciated. ${ }^{729}$

According to Waxman, it was the force of the collective accusation that garnered public attention in Britain during the Eichmann trial, not the personal stakes and emotional struggles of the individuals giving their testimony.

Central to these discussions is the intricate relationship between survivorhood and witnessing. Not all trial witnesses were survivors, and understandings of 'the witness' were not always conducive to in-depth and nuanced understandings of survivor-hood. Tracing the transformation of the Holocaust survivor into the Holocaust witness in an American cultural context, Carolyn Dean explains that "the survivor as a figure emerged in a Western and especially US cultural field that sought above all —in a replay of the Eichmann trial—to re-evaluate the meaning of survival in the context not only of industrialized genocide and murder, but also the victim blaming that was pervasive in the 1960s, and against which the witness testimony so forcefully protested". ${ }^{730}$ Through questions directed at the witnesses of the Eichmann trial regarding their lack of resistance, and the responses this produced - both from the witnesses themselves and the debates that followedthe survivor-witness became the antidote to such accusations of victim culpability as well as a symbol for how "the most extreme suffering" could be transformed "into survival on behalf of the greater good". ${ }^{731}$ The establishment of the dead victims' absolute vulnerability thus transformed the survivors into heroic defenders of the dead. ${ }^{732}$ However, as will be demonstrated in the coming section, the visibility of Jewish suffering during the Eichmann trial did not necessarily provide a greater understanding of survival in Swedish public discourse. Rather, it involved a complex of representations that transformed past vulnerability into a potentially destructive power in the present.

729 Waxman, Writing the Holocaust, 115.

730 Carolyn J. Dean, The Moral Witness: Trials and Testimony After Genocide, (Ithaca; London: Cornell University Press, 2019), 117-118.

731 Dean, The Moral Witness, 130.

732 Dean refers to Yablonka's notion of a "new kind of heroism" where survival was reimagined, not as something shameful, ugly and desperate, but as something that required an admirable endurance under duress and an exceptional solidarity with others. See Dean, The Moral Witness, 106-108. 
Understandably, a majority of the research undertaken on the Eichmann trial has focused on the Israeli, US, British, French and German contexts. ${ }^{733}$ However, the special issue of the Journal of Israeli History entitled "After Eichmann: Collective Memory and the Holocaust after 1961" from 2004 also includes explorations of the Italian context. ${ }^{734}$ In her article, the Italian historian Manuella Consonni shows how the Eichmann trial, although extensively covered and embraced as a reminder of the fascist era, did little to spark national memories of Jewish persecution in Italy. Previous research on the mediation and reception of the Eichmann trial in Sweden is sparse. Ulf Zander, who is the most prolific Swedish historian with regards to mediations of the Holocaust in Sweden during the twentieth century, has explored audio and visual representations of Eichmann using internationally acclaimed films such as Holocaust, Conspiracy and God Afton Herr Wallenberg. ${ }^{735} \mathrm{~A}$ project that more directly engages with the immediate media attention that the Eichmann trial garnered, however, is Jessika Fredriksson's master's thesis "Europas bödel' fast efter 15 arr'” from 2014. Fredriksson's study of the Swedish press shows that Swedish newspapers wrote both extensively and consistently about the Eichmann trial from 1960 until $1962 .{ }^{736}$ Fredriksson does highlight some aspects that concern the survivor-witnesses but only in so far as they regard portrayals of victimization. In other words, her thesis does not engage with descriptions of the witnesses themselves but rather, with characterizations of victim suffering during the war. Her conclusions are thus that reports on the Eichmann trial showed the victims as innocent and helpless as well as mere statistics rather than individuals who were "brothers, sisters, mothers and fathers who [had] been murdered or deprived of their relatives". ${ }^{737}$ Although Fredriksson's study greatly contributes to

733 For examples American research on the Eichmann Trial see Lipstadt, The Eichmann Trial. Felman, The Juridical Unconscious. -Holocaust: An American Understanding, (New Brunswick: Rutgers University Press, 2016), 46-108. Levy and Sznaider, The Holocaust and Memory in the Global Age, For British research on the Eichmann trial see for example, David Cesarani, Becoming Eichmann: Rethinking the life, Crimes, and Trial of a "desk murderer", (Cambridge mass.: Da Capo Press, 2007). "Introduction," Journal of Israeli History, 1-17.

734 Manuella Consonni, “The Impact of the 'Eichmann Event' in Italy, 1961,” Journal of Israeli History, vol. 23, (2003): 91-99.

735 Zander, "I våldets virvelvind-representationer av Adolf Eichmann i förintelsens historiekulturer," in eds Eva Österberg and Marie Lindstedt Cronberg, Vald: Representation och Verklighet, (Lund: Nordic Academic Press, 2006): 303-322.

736 Fredriksson, 'Europas bödel' fast efter 15 år, 54-62.

737 Jessika Fredriksson, 'Europas bödel' fast efter 15 år, 62. ["Mycket sällan omtalas dessa människor som bröder, systrar, mödrar, och fäder som blivit mördade eller berövade sina släktingar"] 
an understanding of how much attention the Eichmann trial received from the Swedish press through her quantitative analysis, her qualitative analysis does not provide any further insight into reports on the trial witnesses, nor does it explore other mediums following the trial proceedings.

The importance of television in the mediation of the Eichmann trial has been discussed in previous research although few studies outside of the American, German and Israeli contexts exist regarding this aspect of the trial. In focusing on how the Eichmann trial as a televised event was treated and received in an American context, Jeffrey Shandler argues that "the Israeli government conceived the trial as an occasion for presenting the Holocaust as a distinctly Jewish phenomenon and as a public event that would validate the new state's political agenda". 738 Thus, "the arrangements to televise the trial specifically targeted foreign audiences; in Hausner's words, this was done 'so that the whole world could watch". ${ }^{739}$ But how successful were these ambitions to have "the whole world watch"? In the American case, Shandler demonstrates that television was only important insofar as it contributed a sense of immediacy to the trial in addition to constituting a "moral act of witnessing", similar to watching the news reels of newly liberated concentration camps in 1945 or, as Nahson argues, watching Anne Frank on stage. Although the Eichmann trial as televised event was supposed to contribute drama, it, according to Shandler, "often proved disappointing as dramatic spectacle" and the people who engaged most with the trial "'[relied] on the written word, rather than the broadcast media, as a source of information". ${ }^{740}$

Not only is it questionable whether the television medium was effective in communicating the intended messages of the trial, the American literature scholar Shoshana Felman as well as Cesarani have argued that it was the debates surrounding the trial, rather than the proceedings themselves, that made the most profound impact on later conceptualizations of the Holocaust. Cesarani, for example, contends that due to the drawn-out proceedings, a large portion of the journalist corps grew weary and left the court room and, in some cases, Jerusalem and Israel, in the early stages of the trial. Therefore, "only a fraction of the investigation or the complex debate in the courtroom reached the general public" and only a "few journalists stayed the course and many missed the most shattering

738 Shandler, "The Man in the Glass-box," 92.

739 Shandler, "The Man in the Glass-box," 93.

740 Shandler, "The Man in the Glass-box," 102, 104. 
moments of testimony". ${ }^{741}$ Cesarani thus argues that it was not necessarily the press coverage of the trial that sparked controversy and thereby the publics' interest, but rather that the "instant biographies published before the trial and the reportage that appeared afterwards" - the most impactful of these being Hannah Arendt's Eichmann in Jerusalem. ${ }^{742}$ Similarly, in her seminal book The Juridical Unconscious: Trials and Traumas in the Twentieth Century, Felman shows how Hannah Arendt's rendition of the trial as well as Claude Lanzmann's documentary film Shoah, contributed to new conceptual understandings of ethics and human behavior in relation to the Holocaust. In critically engaging with Arendt's writings on the trial, Felman contends that "both the Eichmann trial and Arendt's critical rehearsal of it are preoccupied - albeit in different styles - with the translation of grief into justice". ${ }^{743}$ Central to this "translation" were the 102 survivor-witnesses who (9 out of the 111 witnesses were not survivors), in various ways, performed their suffering on the stand; performances that Arendt critiqued as a form of "Jewish self-centeredness". 744

This focus on Arendt in discussions of the Eichmann trial are understandable, especially if considered from an Anglo-American perspective since Arendt published her reports in the American weekly magazine The New Yorker and in her influential work Eichmann in Jerusalem. For a Swedish context, however, another commentator on the Holocaust trials of the 1960s has shown to be much more significant in terms of how the Holocaust, its victims and survivors were discussed and conceptualized: the exiled writer, play-write and film-maker, Peter Weiss. Weiss's play Die Ermittlung ("The Investigation" in English, "Rannsakningen" in Swedish) premiered in West and East Berlin as well as 14 other West and East German cities in 1965, an occasion that garnered much attention in the Swedish press. ${ }^{745}$ The surrealist play which, according to the American drama scholar Robert Cohen belongs to a "genre of German post-war documentary theatre", is based on reports from the first Frankfurt Auschwitz trial. ${ }^{746}$ On December 20, 1963, 21 former Auschwitz officials as well as one 'Kapo' were put on trial “for

741 Cesarani, "Introduction," Journal of Israeli History, 5.

742 Cesarani, "Introduction," Journal of Israeli History, 5.

743 Felman, The Juridical Unconscious, 158.

744 Felman, The Juridical Unconscious, 138. See also Marianne Hirsch \& Leo Spitzer, "The Witness in the Archive: Holocaust Studies/Memory Studies,” Memory Studies, vol. 2, no. 2 (2009): 154.

745 Robert Cohen, "The Political Aesthetics of Holocaust Literature: Peter Weiss's The Investigation and its Critics," History \& Memory, vol. 10, no. 2 (Fall, 1998): 51.

746 Cohen, "The Political Aesthetics of Holocaust Literature," 45. 
crimes committed at Auschwitz, specifically for first degree murder"' ${ }^{747}$ The trial ended in August, 1965 after little less than two years of trial proceedings during which time 350 witnesses in total had testified against the defendants. As such it was a momentous legal event which drew a lot of media attention both nationally and internationally. ${ }^{748}$ In West Germany alone, American historian Robert Pendas estimates that "1400 articles from seventy newspapers" were written about the trial, "meaning that almost every newspaper in the Federal Republic carried at least sporadic coverage of the trial's 183 sessions". ${ }^{749}$ As Pendas also shows in his research, however, this did not mean that the trial was significant in terms of changing the West German population's perspective on Germany's Nazi past. Indeed, Pendas concludes that public responses to the trial were ambivalent with the newspapers both exacerbating and "[helping] to generate an "inner resistance" to its intended pedagogical message. ${ }^{750}$

In this regard, Weiss's play was no exception. Rather than focus on the theme of how the lives of many perpetrators continued without disruption in the Federal Republic, most of the Swedish debate around the play concerned Weiss's critique of capitalism. Weiss had, in 1939, emigrated to Sweden following his parents who had fled some years prior due to his father being Jewish. ${ }^{751}$ Because of the attention that Weiss and Die Ermittlung received in Sweden in 1965 and 1966 (when the play was set up at The Royal Dramatic Theatre in Stockholm), Weiss's critique could thus be understood in the same manner that Arendt's critique of the Eichmann trial has been understood-as a commentary that was affectual on conceptualizations of the Holocaust.

747 Devin O. Pendas, “'I didn’t know what Auschwitz was': The Frankfurt Auschwitz Trial and the German Press, 1963-1965," Yale Journal of Law and the Humanities, vol.12, no. 2 (Summer 2000): 399.

748 Pendas, “I didnt know what Auschwitz was," 399.

749 Pendas, "I didnt know what Auschwitz was," 399.

750 Pendas, "II didn't know what Auschwitz was," 443.

751 Sture Packalén, “'Som om det under varje ord låg en skugga’ Peter Weiss—författare mellan två språk", Samlaren: tidskrift för svensk litteraturvetenskaplig forskning, 113, (1992): 27. See also, Sture Packalén, "From the 'Third Reich' to the 'Third Space': Paul Celan, Erich Fried, and Peter Weiss," in ed. Alexander Stephan, Exile and Otherness: New Approaches to the Experience of the Nari Refugees, (Berlin: Peter Lang, 2005): 121-134._-"Peter Weiss—Brevskrivaren,” Samlaren: Tidskrift för svensk litteraturvetenskaplig forskning, 111, (1990): 5-31. 


\section{4 The Eichmann Trial on Swedish Television}

On the opening day of the Eichmann trial the newly built civic center, Beit Ha'am in Jerusalem, was packed to the brim with people from all over the world. Journalists from far and away had come to report on the spectacle that the trial was expected to become. It was not only the defendant himself that was the subject of news reports leading up to the trial. Israel's right to try Eichmann, his abduction, his treatment by the Israelis and how the trial was to be held was widely discussed in world news in the months leading up to the trial. ${ }^{752}$ These were also issues that the Swedish daily newspapers reported on. ${ }^{753}$ Another aspect that featured prominently in the evening newspapers was that the trial was to be televised. On January 3 Aftonbladet declared that "the trial against Eichmann [would] be on Swedish TV!". ${ }^{754}$ The article reported that all four Nordic heads of state-run television had flown to Copenhagen to acquire the television rights to the Eichmann-trial. The day before his first day in court, Expressen also put Eichmann on their front page with the caption "Time for the Jew-Drama" underneath a caption reading "Time for the Eye-Drama" referring to a televised eye-surgery. ${ }^{755}$ The evening newspapers thus framed the trial not only as a juridical matter but also as a dramatic television event. The fact that Expressen commented on the trial in this manner was no coincidence. Ever since television had established itself, the printed press had been forced to adapt its content to this new, modern medium, often acting as an announcer and expert commentator on television's, still rather sparse, programming. ${ }^{756}$ Hence, "Time for the Jew-drama" referred both to the actual proceedings in Beit Ha'am but also to the way that these would be dramatized on screen. The front-page headline served as an announcer for that evening's news-program about Eichmann: a program apparently filled with dramatic content, twists and turns. However, the drama that was promised by the evening press would not be delivered in the form of broadcasts from Beit Ha'am. Instead, reportage segments that incorporated footage from the Warsaw ghetto and from Auschwitz, Belsen and Buchenwald as well as clips from Hollywood

752 Cesarani, "Introduction," Journal of Israeli History, 3-5.

753 "Eichmannrättegången skall skapa bättre förståelse mellan Israels tre huvudgrupper," March 27, 1961, SvD, 17. "Kritik mot domare i Eichmannmålet," April 6, 1961, SvD, 9.

754 “Rättegången mot Eichmann kommer i svensk TV!” January 3, 1961, Aftonbladet, 1.

755 “Dags för jude-dramat," April 10, 1961, Expressen, 1.

756 Sverker Jonsson, “TV förändrar världen (1958-1975),” in eds Lars-Åke Engblom, Sverker Jonsson \& Karl-Erik Gustafsson, Den Svenska pressens historia: Bland andra massmedier (efter 1945), (Stockholm: Ekerlids, 2002): 134-136. 
produced motion pictures depicting arrests and arrivals at Auschwitz were broadcast as a historical contextualization of the trial. ${ }^{757}$ The survivor-witness only played a minor part in this drama, however, and remained an objective informant of the effects of Nazi genocidal policy. Even though the television broadcast of the Eichmann trial in Sweden can be described as limited at best I have analyzed three of the reportage segments about the Holocaust and about the trial in order to understand if and how the medium contributed to constructions of the survivor in 1961.

Although it is difficult to say anything about most European countries and their broadcasts of the Eichmann trial Shandler has shown that in the United States, "broadcasters presented no more than one hour of trial footage daily; most offered much less." ${ }^{\prime 58}$ Even though the express purpose of televising the trial was to spread its message across the European and North-American continents, the interest from most countries was not enough to fulfil this ambition. ${ }^{759}$ Hence, not only was the trial mediated through what was at the time deemed 'live television', but the format itself-the trial as a media spectacle-also became part of the news-content reported by the media. In comparison to the rest of the world, the US had the most comprehensive coverage of the trial, broadcasting material daily as well as showing programs "focusing on the case itself as well as documentary and dramatic programs offering background on Nazism and the Holocaust". ${ }^{760}$ Although Swedish television also created documentaries about Nazism and the Holocaust to contextualize the trial, these were not outstanding from the regular programming schedule. Rather, they were incorporated into news programs such as Aktuellt and Skol-TV ("School TV"). ${ }^{761}$ In her analyses of TV program schedules and tableaus as text, Swedish media scholar Anna Edin declares that "historically it is only very specific events that can disturb the well-organized programming schedules—which are based on routines and established habits—and push out the already announced

757 Svensk Mediedatabas (SMDB), "Skol-TV," April 14, 1961. Svensk mediedatabas (SMDB)

“Aktuellt,” April 10, 1961. Svensk Mediedatabas (SMDB), “Aktuellt,” April 28, 1961.

758 Shandler, "The Man in the Glass-box,” 95.

759 Shandler, "The Man in the Glass-box," 93.

760 Shandler, "The Man in the Glass-box," 95.

761 For an analysis of how Skol-TV as a program developed in the 1960s see for example, Margareta

Borg, Skol-TV - traditioner, visioner och former: En studie av skol-TV:s förutsättningar, framväxt och utveckling under 1960-talet, (Doctoral diss.: Lund University, 2006). 
programs." 762 The Eichmann trial was thus not deemed important enough to disturb the schedule of Swedish public broadcasting. Although parts of the trial were shown on the news program Aktuellt throughout 1961, no extra time was allotted to the proceedings as its 'own' television program. ${ }^{763}$ In order to understand Swedish television's broadcasting of the Eichmann trial it is also vital to understand the development of the television medium in Sweden during the late 1950s and early 1960s. In comparison to its Scandinavian neighbors, Sweden was relatively late in introducing television to Swedish homes. Tests with broadcasting began in 1954 although a set schedule was not under way until 1956. ${ }^{764}$ Even though far from every household owned a television set in the 1950s, two major sports events - the ice hockey world cup and the world cup in football (hosted by Sweden) -both held in 1958, made the purchasing of televisions sky-rocket. ${ }^{765}$ As Swedish media historian Lennart Weibull has shown, in 195725000 television licenses had been sold, a number which had increased to 800000 in 1960. The new medium was welcomed with both excitement and caution. In contrast to the inception of radio, television was not viewed with the same awe as a technological advancement. Rather, it was the content that interested both the audience and the political elites. ${ }^{766}$

As Swedish television remained an exclusively public broadcasting medium up until the 1990s, the aesthetics and interests of the political elites came to shape both programming and the ways in which other media related to television. Although television was supposed to also provide entertainment, its role as a democratizing,

762 Anna Edin, "I takt med tiden: Om Tv-tablån som mediehistorisk text," in eds Anna Edin \& Per Vesterlund, Svensk television: En mediehistoria, vol. 6 (Mediehistoriskt arkiv, 2008), 100. ["Historiskt sett är det endast mycket specifika händelser som kan störa de välorganiserade tablåerna, som bygger på rutiner och etablerade vanor, och slå ut de förannonserade programn”].

763 Out of the programs that I received from the National library after requesting Aktuellt for the period April 24 to May 12, only one had a legible clip from the Eichmann trial (images and narrative). In addition to this clip, two documentary-like segments were shown on Swedish television regarding the Eichmann trial. See Svensk Mediedatabas (SMDB), "Skol-TV," April 14, 1961. Svensk mediedatabas (SMDB) "Aktuellt," April 10, 1961. Svensk Mediedatabas (SMDB), “Aktuellt," April 28, 1961.

764 Torsten Thurén, Medier i Bläsväder: Den svenska radion och televisionen som sambällsbevarare och sambällskritiker, (Stockholm: Norstedt, 1997), 15.

765 Lennart Weibull, "New Media between Technology and Content. The Introduction of Radio and Television in Sweden," in eds Monika Djerf-Pierre \& Mats Ekström, A History of Swedish Broadcasting: Communicative Ethos, Genres and Institutional Change, (Nordicom: University of Gothenburg, 2013), 47.

766 Weibull, "New Media between Technology and Content," 47. 
educational and bildungs-institution was heavily enforced in its early days. In more ways than one, television was charged with the task to popularize political, social, economic and cultural questions, disseminate them and make them understandable to the average viewer. ${ }^{767}$ However, there was also a strong sense that television would inhibit socialization and make the Swede lazy and complacent. ${ }^{768}$ As Edin explains, “it wasn't supposed to be too easy to watch TV. The medium was to offer the audience both information and experiences whilst at the same time encouraging a limited and selective use" of the programs offered. ${ }^{769}$ Therefore, many of the early programs had an expressed educational purpose; Skol-TV, directed toward school children and broadcast in the late afternoons in 1961, was one of these programs. ${ }^{770}$ Also, in the late 1950 s the program that had previously dealt with current events through reportage segments-Bild-journalen-was replaced by the new, American-styled news program Aktuellt where a studio newsman announced and commented on segments as well as interviewed guests. ${ }^{771}$

The first of these Aktuellt reportages pertaining to the Eichmann trial aired on April 10, the day before Eichmann's indictment. ${ }^{772}$ In the ten minute segment, the crimes of Eichmann were communicated through intermingling clips of documents signed by Eichmann, a map with deportation routes, posters with names of concentration camps including pictures and clips from a motion picture showing the arrest of Jews and their arrival at a camp. After such a clip-where Jews were seen disembarking train cars, having their things taken from them, and being ordered either left or right — an interview with the camp survivor Ferenc Göndör had been included. Göndör, who came to Sweden in 1949 from Hungary, was an Auschwitz and Mauthausen survivor who, in 1961 worked as a radio

767 Edin, “Tillbaka till framtiden: Om publiken som public service-problem," in Mats Hyvönen, Pelle Snickars \& Per Vesterlund, Medieproblem: Mediestudiets formering, (Mediehistoria: Lund University, 2015), 117.

768 Edin, Den föreställda publiken: programpolitik, publikbilder och tilltalsformer i svensk. public service-television, (Eslöv: B Östlings bokförlag, 2000), 83.

769 Edin, Den föreställda publiken, 83. ["Det fick inte vara för enkelt att titta på TV. Mediet skulle erbjuda publiken information och upplevelser, men samtidigt mana till en begränsad och selektiv användning”].

770 See Edin, Den föreställda publiken, 78-83.

771 Monika Djerf-Pierre \& Lennart Weibull, Spegla, granska, tolka: Aktualitetsjournalistik i svensk radio och tv under 1900-talet, (Stockholm: Prisma), 126-131.

772 Svensk mediedatabas (SMDB) “Aktuellt," April 10, 1961. 
technician for Sveriges Radio (Swedish public broadcasting). ${ }^{773}$ Before answering any questions posed to him in the documentary segment, Göndör held up his tattooed arm to the camera showing the number A6171; a number which would be subsequently be known to many Swedes in the 1980s and 1990s. In the Aktuellt segment Göndör's testimony was matter-of-fact and emotionless, an account that included details about the ghetto, cattle cars and Auschwitz. Even though testimonies of Auschwitz had been disseminated through radio programs, newspaper articles and published works written by survivors as well as through Schnabel's story about Anne Frank, Göndör was one of the first (if not the first) to recount his Holocaust experiences on television in Swedish. In contrast to Anne Frank, Zenia Larsson or Cordelia Edvardson, Göndör revealed no emotion in the interview, and was never asked about how he felt about his past or about Eichmann and the upcoming trial. Rather, the interviewer queried about what Göndör had thought when he arrived in Auschwitz, if he had known that Auschwitz was a death camp, if Göndör had known prior to his deportation who Eichmann was and about what Göndör thought of Eichmann's forthcoming trial. After describing how Eichmann's role in the deportation of the Hungarian Jews had been known to all Hungarian Jews, Göndör continued to explain that he was unsure whether he had ever seen Eichmann in person. Göndör thus seemed aware that the audience expected his testimony to relate directly to the defendant in Jerusalem; the rest of his narrative being less important and interesting if it did not connect to this symbol of Nazi perpetration. He was also prompted by the interviewer after his disclaimer of not being sure that he had witnessed Eichmann in person, to still connect his own and his family's fate to Eichmann. The interviewer asked; "But you and your family were still Eichmann's victims?”. The establishment of Göndör's victimization was not to rouse sympathy but to establish a Swedish connection to the sensational trial of Adolf Eichmann. The same was continuously done by the daily and evening newspapers, Expressen and SvD in particular reporting on the trial in relation to evidence that Sweden had acted either in defense of the Jewish victims

773 Göndör shared his experiences in multiple fora and mediums over the decades before his death in 2010. See for example Svensk Mediedatabas (SMDB), "Ferenc Göndör: A6171," Film, 1987. Svensk mediedatabas (SMDB), "Från Mauthausen till Liljeholmen," September 28, 1980. "Förintelsen. Berättelser och nutida perspektiv ur radioarkivet," Sveriges Radio, https://web.archive.org/web/20070930232012/http://www.sr.se/cgibin/mall/artikel.asp?programID $=1602 \&$ Artikel=782837 (Accessed on December 18, 2019). 
or as indirect executioners by not issuing visas to those trying to escape the Nazis. ${ }^{774}$

However, as Eichmann's victim, Göndör was still asked to comment on the trial; what were his thoughts before the trial the next day, the interviewer asked. To this final question Göndör responded that he believed that it was not only Eichmann who was being indicted but the "whole Nazi regime". He added that he thought that it was good that the past was not forgotten and that the trial could serve as a reminder for the world, and a call that this should never happen again. This 'never again' slogan had of course been invoked before. As discussed in the previous chapter, Expressen's editor-in-chief had expressed the same sentiment in his review article of The Diary of Anne Frank and Zenia Larsson had communicated the importance of intergenerational remembrance of the event in her feature in the same newspaper. While Harrie had been a "dismayed spectator", Larsson had acted as a "moral witness" witness to genocide, just like Göndör in his interview for Aktuellt. A fundamental difference between Larsson and Göndör's testimonies, however, was that Larsson contributed an emotional dimension to her testimony; both in the passionate delivery of her message and through the genre that framed her words. Göndör, as part of the news discourse on Eichmann, was an impassioned witness to genocide, stating the facts as he knew them and was also prompted to give his thoughts, reflections and opinions rather than explicate how he felt.

The second program dealing with Eichmann and the Holocaust was included into the series Skol-TV: behind the headlines, which was aimed at Swedish youth. The series covered a wide range of contemporary issues that were deemed particularly relevant to school children, ages seven to nineteen. The segment began by showing still pictures from the Kristallnacbt, describing it as "the last act in the Jewish drama". ${ }^{775}$ After this introduction, clips from the Warsaw ghetto were shown with a particular focus on children. Emaciated, dirty faces peered into the camera and the narrator informed the young audience that these moving images were recorded by the Nazis themselves to use for training purposes. This was followed by panoramic pictures over the vast areas covering Auschwitz-Birkenau as well as footage of the "Arbeit Macht Frei" archway leading into the camp. The narrator

774 See for example, “Tyska judar ej önskvärda i Sverige," April 10, 1961, Expressen, 14. "Nazisterna sköt anställd vid svensk ambassad. Lam svensk protest: 'Inte göra så,” April 13, 1961, Expressen, 11. "Dokument om svensk vädjan framläggs i Eichmannprocessen," April 11, 1961, SvD, 21. "Sverige fick rapport. Ansåg utrotning känd," June 21, 1961, SvD.

775 Svensk Mediedatabas (SMDB), "Skol-TV,” April 14, 1961. 
remarked that "Jews, Roma, Poles, and Russians" all died here, thereby both acknowledging and equalizing the suffering of several different victim categories. "The victims were a nameless mass" the narrator continued as the camera showed a prisoner baring their breast upon which a number had been tattooed. Similar to the documentary shown on Aktuellt, Holocaust experience was, in this program, defined by what was referred to as "the great Jew pogrom" of Kristallnatten, the Warsaw ghetto, deportation and Auschwitz.

In a survey of the program, conducted by its directors and a number of teachers from the city of Norrköping, the Eichmann documentary was voted the best episode of Skol-TV that season. In Aftonbladet it was reported that the students had appreciated the "excitement and drama" that the documentary had provided. ${ }^{776}$ Again, as with the announcement of the Eichmann trial (both as legal procedure and televised event), the tabloids commenting on TV-programming surrounding Eichmann, demonstrates how not only the story about Eichmann and his crimes was considered to be important, but also how dramatizations and documentary narrations about the trial spoke to parts of the population. The combination of Swedish television's educational credo and the framing of the Eichmann trial as a televised drama meant that the Holocaust-as the Nazi's extermination of the Jews-became an important part of the history subject even before it officially entered any national curriculum. Even though no survivors were included in this program for Swedish youth, it can be seen as laying the foundation for the Holocaust survivor as educator, especially considering the fact that students appreciated the 'dramatic' aspect of the documentary. What television provided, that no other medium had been able to before, was the sense of here and now. ${ }^{777}$ Documentaries about historical events thus coincided with this ability to emphasize the present and created a temporal paradox which can also be found in the survivor witness - a physical being in the present which at the same time embodies the past. It is this sense of here and now, together with the new technology's ability to make the world come closer and seem more real, that established a communicative 'ideal' that would also come to affect the position of the survivor as the most effective communicator of Holocaust memory in the coming decades.

One of the longest segments shown from the Eichmann trial itself, aired as part of Aktuellt on April 28, four days into the prosecution's hearing of the 111

776 "Program om Eichmann höstens bästa skol-TV," May 18, 1961, Aftonbladet, 13.

777 Anna Edin \& Per Vesterlund, "Svensk television och mediehistoria—en inledning," in eds Anna Edin \& Per Vesterlund, Svensk television: en mediehistoria, vol. 6, (Statens Ljud och Bildarkiv, 2008), 12. 
witnesses. As the camera panned over the court room that day, showing Judge Landau, prosecutor Hausner and several witnesses, the narrator described that the "process proceeds slowly and with consideration of all legal formalities making the trial, in spite of all the dramatic and tragic content making up its foundations, a tad monotonous". 778 The first survivor-witness to be shown on screen was Zynder Grynszpan described by the narrator as the father of a "young Jew who, in 1938, shot the German state secretary Ernst vom Rath"—an occurrence which was used by the Germans to justify the pogroms of the Kristallnacht. ${ }^{779}$ This was not, the narrator continued, what Grynszpan had been called to testify on, however, but rather Grynszpan told the prosecutor "about the deportation of German Jews to Poland and he said, amongst other things, that the Germans treated the Jews in barbarous ways". 780 The narrator also quoted Grynszpan in saying that "it was the first time I saw the wild barbarity of Nazism". ${ }^{781}$ The narrator paused and the camera rested on Grynszpan as he spoke in Yiddish to the judges and the prosecutor who were later shown in the frame. As other snippets of the witnesses taking the stand were shown, the narrator gave some background information as to why all these survivor-witnesses had been called to testify. "The prosecutor Gideon Hausner", the narrator stated,

wants, through these witnesses, first to give a background to the witness accounts which will come later with more direct descriptions of the extermination camps. And so, the parade of witnesses will continue to appear before the court for several days to come, in spite of judge Landau trying to hurry this up so that the process will not continue for too many months. ${ }^{782}$

778 Svensk Mediedatabas (SMDB), “Aktuellt”, April 28, 1961. [“processen fortskrider sakta och med iakttagande av alla juridiska formaliteter så att den till trots allt det dramatiska och tragiska stoffet som bildar underlag får ett visst inslag av monotoni över sig”].

779 Svensk Mediedatabas (SMDB), “Aktuellt,” April 28, 1961. [“Han är far till den unge jude som 1938 sköt den tyska stadssekreteraren Ernst vom Rath].

780 Svensk Mediedatabas (SMDB), “Aktuellt,” April 28, 1961. [“Grynszpan berättade på Jiddisch om deportationerna av tyska judar till Polen och han sade bland annat att Nazisterna behandlade judarna på de mest barbariska sätt'].

781 Svensk Mediedatabas (SMDB), “Aktuellt,” April 28, 1961. [““det var första gången jag såg Nazismens vilda barabari'"'].

782 Svensk Mediedatabas (SMDB), “Aktuellt,” April 28, 1961. [“Åklagaren Gideon Hausner vill genom dessa vittnen först ge en bakgrund till de vittnesmål som kommer senare med direkta 
The only other instance of the Eichmann trial during the period in question (early April until early June) found in the Aktuellt material was shown on May 9. Due to the poor quality of the recording where the Swedish narration is missing, it is difficult to say anything about the structure of the story told. From the moving images, however, it can be discerned that the footage was taken on a day in court which would later be characterized at length by DN's foreign correspondent in Jerusalem, Agne Hamrin. On this day, several testimonies were given. In the middle of one such testimony, a man in the audience stood up and yelled "Blood-hound, blood-hound!" at the defendant—an occurrence which would, in the daily press come to signify the rising tension in Beit Ha'am during the period of witnessing.

As can be gathered from the discussion above, the news coverage of the trial was fragmentary at best. The most significant findings in the audio-visual archive were the reportages about Eichmann and his crimes, both shown on Swedish television in preparation for the trial. The documentary which was part of Aktuellt is particularly interesting because it includes the testimony of a Swedish survivorsomething that did not occur in any other medium during the first months of the trial. Indeed, no survivor was interviewed in relation to the period when the witnesses took the stand in Jerusalem, indicating that it was the trial itself and not the evidence of Eichmann's crimes that dominated discourses on Eichmann in Sweden. As shall be explored further in the next section, the notion that everything was already known about the camps and thus, by default, that everything was known about the Holocaust at large, would come to express itself in Swedish public discourse during the trial. Of course, the nature of evil through the figure of Eichmann was centrally featured in much of the news coverage. Yet, those discussions which occurred in other national contexts about the culpability of victims - whether they had walked like "lamb to slaughter"-were never broached in Swedish newspapers or in the news documentaries or news sections that were broadcast on Swedish television. In the program shown as part of Skol-TV, the tattooed chest, in addition to Göndör's tattooed arm, demonstrates how the number continued to be used to verify the Holocaust as a historical event. Just like the woman's arm was held up to the camera in Vittnesbördet in 1945, survivors 20 years later bared their bodies to prove what happened.

skildringar från utrotningslägren. Och så kommer paraden av vittnen inför domstolen att fortsätta ännu åtskilliga dagar trots att domaren Landau försökt skynda på så mycket som möjligt för att inte processen ska dra ut i allt för många månader’]. 
The images from the court room, although most lacked audio and can therefore not be analyzed regarding narrative, were all brief and never lingered on any particular part of either the questions asked by the prosecution or the answers given by the witnesses. The longest news segment included into Aktuellt on April 28 , however, demonstrates a sense of fatigue with regards to the many witnesses. Described as a "parade" and one that would continue for several days in defiance of Judge Landau's protestations, the witnesses were never positioned as either dramatic (a source of entertainment) or as important to the accusation itself. Instead, they were perceived a necessary yet excessive aspects of the trial, a tedious tirade of individuals whose role was to repeat what others had already confirmed before them. This perspective was also prevalent among Swedish foreign correspondents stationed in Jerusalem during the trial.

\subsection{Foreign Correspondence and Representations of the Eichmann Trial in TT-news}

With the growing influence of television during the early 1960s, the newspapers worked tirelessly to maintain their authority over reportage journalism as well as their position as the expert medium that could contribute in-depth commentary on contemporary political, cultural and social issues of the day. ${ }^{783}$ Even in countries like the United States, where the televised coverage was more extensive compared to Sweden, people received most of their information from printed sources such as the daily press. $^{784}$ Indeed, the mass media communication of the trial was specifically aimed at foreign audiences but only a fraction of what was filmed actually reached European and North American homes. ${ }^{785}$ As previously noted, Swedish public broadcasting included footage of the trial into the regular programming schedule, making it even more fragmentary and less of its own 'media event' as clips from Beit Ha'am were juxtaposed with footage from other world events, wars and crises. Thus, in order to understand what was occurring in Jerusalem in 1961, Swedish television audiences had to rely on other mediums such as radio and newspapers. Here then, contemporary commentators on foreign political events became key figures in explaining the trial to the public - the most important of which were the foreign correspondents. In this section, news

783 Jonsson, “TV förändrar världen”, 134-136.

784 Shandler, "The man in the Glass-box," 104.

785 Shandler, "The man in the Glass-box," 104. 
discourse through foreign correspondence is analyzed with a particular focus on DN's correspondent, Agne Hamrin, in order to establish how this particular genre of news contributed to notions of the survivor-witness as a "moral witness" and as "True Victim".

In their book Understanding Foreign Correspondence, Peter Gross and Gerd G. Kopper claim that the role of the foreign correspondent is

to minimize 'geopolitical and geocultural distance'... [a] task [which] emphasizes the crucial importance of the foreign correspondents' interpretation function. They have to frame and contextualize current affairs and events happening abroad in order to help media consumers at home evaluate and order them in a particular context to avoid misunderstandings and misperceptions. $^{786}$

The media 'consumer' of the 1960s was even more reliant on this interpretive function as few had travelled outside of Sweden. Because television remained a new medium, the direct audio-visual communication of world events was still limited as well as structured by moral principles of bildung and the aesthetic values of Swedish elites. Gross and Kopper's assertion also implies that the foreign correspondent is a mere conduit of information—one which is 'truer' to the object than news delivered through other agents. This is a highly simplified notion of the work of correspondents and the institutional labor that 'their' texts perform. Rather than "avoiding misunderstandings and misperceptions", the foreign correspondent constructs an account of current events, a construction shaped by the social world as well as preconceived notions of what that world means, how it should be represented and what the recipients of these representations need/want to know.

Throughout the 1950s and 1960s, the daily and evening newspapers employed a number of influential foreign correspondents who shaped the news-reports from the areas in which they were stationed. ${ }^{787}$ The newspapers that are analyzed in this section-Expressen, $\mathrm{SvD}$ and DN—all employed foreign correspondents who were either already stationed in, or sent to, Jerusalem for the purpose of covering the Eichmann trial. Expressen's Gunnar Nilsson, SvD's Mogens Kofod-Hansen and DN's Agne Hamrin thus had direct access to the everyday goings-on of the trial

786 Peter Gross and Gerd G. Kopper, Understanding Foreign Correspondence: A Euro-American handbook of Concepts, Methodologies and Theories, (New York: Peter Lang, 2011), 130.

787 Lars- $\AA$ ke Engblom, “Tidningar dör men pressen lever vidare,” Den svenska pressens historia (Efter 1945), eds Lars-Erik Engblom, Sverker Jonsson \& Karl-Erik Gustafsson, (Stockholm: Ekerlids, 2002), 69. 
proceedings and the life that went on inside and outside of the courtroom. The fact that the newspapers competed with television for the inside scoop was further evidenced by how Nilsson was introduced to Expressen's readers in April 1961. Underneath the big, bold headline on April 11, a head shot of Nilsson was accompanied by an introductory text stating that Nilsson, the most "routinized watcher of world events", was now sitting among "500 top journalists from all corners of the world". He would help Expressen's readers follow the trial and detect things that "the TV cameras [could not] see" and hear what "the microphones [could not] hear". ${ }^{788}$ This characterization of Nilsson's work likened him to a spy trying to uncover the seedy underbelly of the trial; aspects that the cameras and microphones deliberately excluded. Expressen was also the newspaper that covered the trial in most detail during the weeks preceding the indictment. ${ }^{789}$ DN's Mediterranean correspondent, Agne Hamrin, did not need the same introduction that Nilsson had received, however. ${ }^{790}$ As a foreign correspondent who had both published books and written numerous articles for DN on the situation in Palestine between 1948-1955, Hamrin was a well-known name to the newspaper's readers. If Nilsson was the insider detective for Expressen, Hamrin was the utmost expert on the context outside of the court room. Lastly, although Kofod-Hansen-a Danish journalist and foreign correspondent-was SvD's inside man in Beit Ha'am, his position vis-à-vis Nilsson and Hamrin was weak at best. Not only was he not a recurrent name in SvD's reporting, his articles from Jerusalem were far fewer if compared to those published by Nilsson and Hamrin during the period in question. ${ }^{791}$

More importantly, all newspaper coverage of the trial dropped considerably in May 1961. As the witnesses were put on the stand, less articles were describing the goings-on in Beit Ha'am. While the month of April had been characterized by reportage-style news articles that included detailed descriptions of the defendant as

788 "Blek Eichmann inför domarna hörde anklagelseakten stående," April 11, 1961, Expressen, 6 ["Bland de 500 toppjournalister från alla världens hörn som på tisdagsmorgonen befann sig i en ytterligt välbevakad rättegångssal i Jerusalem befann sig också Expressens Gunnar Nilsson, rutinerad bevakare av världshändelser. Med hans hjälp kan Expressenläsarna följa rättegången—se vad tv-kamerorna inte ser, höra vad mikrofonerna inte hör. Expressen är där"].

789 Between April 6-12, two articles signed Gunnar Nilsson were published in the newspaper each day, many of which also made the front page.

790 See Agne Hamrin, Bokslut i Jerusalem, (Stockholm: Bonnier, 1961).

791 During the month of April 1961, Nilsson had 15 articles published in Expressen, Hamrin had 19 articles in DN, and Kofod-Hansern had 6 in SvD. 
well as exposés on how Sweden and Swedish actors had been involved in the Nazi's persecution of Jews during the war, May signified the month of fatigue and disillusionment. At this point, SvD did not proceed to publish articles by KofodHansen, meaning that the only articles relaying the witness accounts in SvD came from the Swedish news agency, Tidningarnas telegrambura (TT). The excitement that had built by references to phone calls between Raoul Wallenberg and Eichmann as well as through documents that reportedly demonstrated Swedish involvement in both the attempted rescue, and the abandonment of Jewish victims, slowly but surely died down in the newspapers' reporting from Jerusalem. ${ }^{792}$

Therefore, the only correspondent who stayed the course and contributed any form of commentary to the witness accounts against Eichmann, was DN's correspondent, Agne Hamrin. What makes Hamrin's reports from Jerusalem stand out in the news-flow regarding the trial was his particular interest in the Israeli context, the impact of the testimonies, and how the latter threatened to exacerbate tensions between Israelis and Germans. In one of his first reports from the proceedings, the headline roughly translated as "A quiet Dignity Characterizes the Israeli people's Reaction". ${ }^{793}$ Rather than writing about the pale figure in the glassbox and the fate that awaited him, Hamrin instead interviewed a number of people watching the trial from the Ratisbonne institute. In the article, Hamrin stated that he divided his interview subjects into two groups-Holocaust survivors and Jews from Asia and Africa who had no experience from the ghettos and camps. In the article an interview with an Auschwitz survivor and a Yemeni Jewish man were included. Hamrin asked the former what Israel should do with their captive. The survivor's answer was made into a caption in the middle of the text: "not kill him". The non-vindictive answer given by the survivor-that Israel should neither extradite nor kill Eichmann but give him life in prison-follows a greater theme in the daily newspapers' reports from the trial. In order to support Israeli claims to try Eichmann, it was important that the representatives of the court and the Israeli people watching were not perceived as vengeful or acting out of anger or rage. In

792 Both Expressen and SvD published articles which concerned court evidence that related to Swedish action during the war. Between April 6 and April 13, four full-page articles were published in Expressen regarding Swedish connections to trial documents, the headlines reading; "Raoul Wallenberg Wrote to Eichmann,” April 7, 1961. “'German Jews Persona non Grata in Sweden,” April 10, 1961. "Threatening Eichmann-letter after Swedish Attempt to Rescue Jews," April 11, 1961. "The Nazi's Shot Employee at Swedish Embassy. Lame Swedish protest: 'don't do that."' April 13, 1961.

793 Agne Hamrin, “Stilla värdighet Israeliska folkets reaktion,” April 13, 1961, DN, 10. 
SvD, the objectivity and emotive restraint of the trial proceedings were also emphasized in a description of the two Israeli guards sitting behind Eichmann on the second day of the trial; they were "two dark-hued men" who "[had] been chosen with care and [came] from oriental Jewish communities, that did not directly suffer under the Nazi regime". ${ }^{794}$ Similarly, in a news article just adjacent to the article that described Eichmann's guards, the atmosphere in the courtroom was described as "muted" and the proceedings "dignified"; "There was no theatre, no rhetoric and no appeal to the passions" the article declared. ${ }^{795}$

This concern with regards to the decorum of the trial proceedings also mirrored Israeli and US debates taking place before, during and after the trial. Commentators such as Karl Jaspers, Hannah Arendt and Richard Crossman presented different arguments concerning the impropriety of abducting and trying Eichmann, still a German citizen, in Israel. ${ }^{796}$ Arendt, in particular, expressed a wish for Eichmann to be tried in Germany and "was upset that the Bonn government had not requested his extradition". ${ }^{797}$ Indeed, as the Israeli historian Anita Shapira argues, "while all the states under former Nazi occupation had tried and sentenced war criminals and none doubted their fundamental right to do so, the Jews were suspected of vindictiveness: they were bent on vengeance, not justice."798 The Swedish daily newspapers studied here, however, did not problematize this aspect of the trial at all, but, rather, reiterated the message that Ben-Gurion had been so keen to communicate; that "as a sovereign Jewish state, Israel was now able to protect its citizens, and was qualified to try and to punish anyone who acted against the Jewish people". 799

However, underlying anxieties of how Germany and the German people would respond to the trial seemed, nevertheless, to inform Swedish news discourse on the trial. SvD's foreign correspondent in Bonn, Per Forslind, reported continuously on West-German responses to the trial. In one such report, Forslind

794 “"Världen har väntat i 15 år,”’ April 12, 1961, SvD, 7, [“Bakom honom sitter två israeliska poliser.

Dessa mörkhyade män har utvalts med stor urskillning och kommer från orientaliska judiska samfund, vilka inte direkt behövde lida under nazisternas förföljelser. De kan därför väntas behandla den anklagade på ett oklanderligt korrekt sätt och inte falla för frestelsen att genom fysisk hårdhänthet markera ett personligt känt hat'].

795 “Samtliga åhörare grundligt visiterade” April 12, 1961, SvD, 7. [“Atmosfären var dämpad och allt gick värdigt till. Det förekom ingen teater, ingen retorik och ingen vädjan till passionerna”].

796 Shapira, "The Eichmann Trial: Changing Perspectives," 19.

797 Shapira, "The Eichmann Trial: Changing Perspectives," 19.

798 Shapira, "The Eichmann Trial: Changing Perspectives," 19.

799 Yablonka, The State vs. Adolf Eichmann, 54. 
described the embarrassment of Adenauer's closest man, Hans Globke, for having to admit, under the pressure of the world press, that he indeed had been responsible for creating the law which ordered all Jews to change their names. 800 Further, on April 12 (the day Eichmann was formally presented with the accusation against him) Forslind reported that the population of West-Germany had been exposed to a "graphic" documentary about the destruction of the European Jewry. Thus, German households had to suffer through a "harrowing depiction of the Nazi's systematic annihilation of six million Jews, in which there was always an undertone of accusation against the older generation of Germans." 801 Forslind was never explicit in his commentary on whether such an exposure to past horrors was either good or bad but the attention paid to these matters still demonstrates a concern for how the trial against Eichmann, especially the parts that implicated German civilian collusion in Nazi crimes, would come to affect several generations of Germans. Hamrin also clearly expressed his concerns for the seemingly deepening rift between Israelis and Germans. In an article entitled "Eichmann trial sharpens anti-German sentiment in Israel" Hamrin wrote that he himself was privy to Israeli-German tensions when attending a ball where a German journalist had asked an Israeli girl to dance. While dancing, the Israeli girl had asked the journalist whether he was English or American. At his reply—-that he was, in fact, Germanthe girl had abruptly torn away from him exclaiming: "do you think I want to dance with someone like...my father and mother and all my siblings were left behind in Auschwitz!" After this symbolic anecdote Hamrin noted that he "didn't know who to feel sorrier for, the Jew-girl or the German youth". 802 This notion of German victimization was also echoed in Hamrin's book based on his writings on the trial, Bokslut i Jerusalem, in which Hamrin recounted a conversation with a young female survivor named Annie. She had been the only Jewish girl in her German schoolclass and told Hamrin about the time when her Christianity teacher asked the whole class who the biggest enemy of the German state was. The answer, later delivered by the teacher as_- "die Juden"-made the whole class turn and look at Annie. Hamrin recalled the character Mr Geek, (a character from the Polish Jewish writer André Schwartz-Bart's novel, The Last of the Just, from 1959), who as a teacher

800 Per Forslind "Eichmann-processen pinsam för Globke," May 4, 1961, SvD, 9. Per Forslind

“Globke försvaras, ny Adenaueraktion,” May 15, 1961, SvD, 8.

801 Per Forslind, "Västtyska Tv-tittarna fick se skakande film om Nazist-tiden,” April 12, 1961, SvD, 7.

802 Agne Hamrin, “Eichmann-rättegången skärper antityska stämningar i Israel,” April 12, 1961, DN. 
spread his antisemitism and hatred of Jews to the children he taught. ${ }^{803}$ Hamrin described Schwartz-Bart's characterization of the antisemite teacher as "poisoning the German youths' soul" and responded to Annie, that "sometimes [he] wonder[ed] who Eichmann...[had] hurt the most: the Jews or the German youth?". 804

Throughout the two decades following the end of the Second World War, the dominant discourse in West Germany was that the German population had also been victims during the war. They had been victimized by the 'mad-man', Adolf Hitler, and his henchmen and they had become prisoners of war and been bombed by the allies. ${ }^{805}$ This narrative was also facilitated by concurrent ideas about the nature of totalitarianism and intentionalist perspectives on genocide. Furthermore, the notion that Versailles had 'created' the Nazi party, and as a consequence, the whole war, made contemporary commentators wary of any harshness against Germany that might create another rise in right-wing extremist politics. Hence, the number of witness accounts and their collective accusation against Eichmann was, by some, perceived as Israel 'poking the bear'.

Simultaneously, however, DN and Hamrin showed their support for Israel in trying Eichmann and reports on the testimonies given in the later spring and early summer of 1961 were also used demonstrate the righteousness of the trial. On the day following Hamrin's first characterization of the witnesses, an article on Meir's upcoming visit to Stockholm was published in DN in which Hamrin painted a picture of an extraordinary woman who fought hard to "give Israel a future". 806 The article about Meir was situated next to a T'T news article about a testimony given at the Eichmann trial. The title read "Witness about the Death Camps: Victims Burned Alive". 807 The message conveyed was one that the Israeli government was carefully fashioning at the time: that the future of Judaism depended on the future of Israel_outside of the Israeli state, no Jew was safe. This was one of the two "foundational myths" that David Ben-Gurion, expounded in

803 See Andre Schwartz-Bart, The last of the Just, (Secker \& Warburg, 1961). The novel won the prestigious Prix de councourts in 1959.

804 Hamrin, Bokslut i Jerusalem, 84-85.

805 See for example Jeffrey Herf, Divided Memory: The Nari Past in the two Germanys, (Cambridge MA:

Harvard University Press, 1997), 276-334.

806 Agne Hamrin, "Golda Meir praktisk idealist," May 2, 1961, DN, 3.

807 "Vittne om dödslägren: offren brändes levande," May 2, 1961, DN, 3. 
his independence-day speech a couple of days into the Eichmann trial. As Anita Shapira contends,

In that speech, two founding myths of the state of Israel symbolically met: the myth of heroism of the Jewish people in its ancestral land, and the myth of the Holocaust. One underscores the historical bond between the people and the land, forging a vital link with the age old landscape and the nation's pristine youth. The other inscribes the Jewish people's unique fate, the bloody reckoning between Jews and non-Jews, from the past and pledge for the future. ${ }^{808}$

The juxtaposition of the article conveying horrors in Auschwitz and the feature article on Meir and her vision for Israeli foreign policy thus mirrored this message. In his doctoral dissertation, Henrik Bachner argues that the Eichmann trial was important in strengthening public support for Israel. Throughout the 1950s, the liberal press, spearheaded by DN and its pro-Israeli editor-in-chief, Herbert Tingsten, were central actors in creating the image of Israel as the country of "pioneers, kibbutzes and flourishing desserts" rather than one of conflict and Palestinian strife. ${ }^{809}$ This was not a controversial perspective in the 1950 s as there was already, according to Bachner, a "strong pro-Israeli atmosphere, not least within the social democratic party". 810 Though not controversial, Hamrin's and DN's focus on Israel during the Eichmann trial contributed to the idea that the Holocaust was first and foremost an issue pertaining to the Jewish people and thus also to the state of Israel. Both the survivors themselves and their act of witnessing constituted a corner stone in the foundation of the Israeli state, but they had little to do with Sweden and Swedish life.

In his writings Hamrin also demonstrated an ambivalence towards the meaning of the great number of testimonies given during the trial proceedings. In the first days of the witnesses taking the stand, Hamrin lamented the fact that so few had stayed to hear their testimonies:

many colleagues have already gotten the deposit for their transistor radio back, a radio out of which they could no longer discern a 'story', why they

808 Shapira, “The Eichmann Trial: Changing Perspectives," 18.

809 Henrik Bachner, Aterkomsten: Antisemitism i Sverige efter 1945, (Stockholm: Natur och Kultur, 1999),

91. [“Ofta var det pionjärernas, kibbutzernas och de blommande öknarnas Israel som framhölls, mer sällan Palestiniernas eller de orientaliska judarnas”].

810 Stig Hadenius, Dagens nyheters historia: Tidningen och makten 1864-2000, (Stockholm: Bokförlaget

DN, 2002), 316. 
left Jerusalem and Israel. They should have been here today. Sure, we did not get to hear any 'hot news', it was all well-known things, stories of evil and of limitless suffering. But it is this that has to be told, over and over again. So that we don't forget. 811

This statement was to impress upon the reader the importance of listening to the witnesses. However, the critique launched against his colleagues also reflects an early sense of 'Holocaust fatigue' - that there was nothing new about the witnesses' stories. According to Hamrin, the details might be the same, but they need to be heard over and over again. Hamrin's observation was not without cause. Indeed, Cesarani notes that the world's journalists had come "in search of shocking 'news' and soon became weary of the legal routine" and one by one, left the hall of justice (whose seats were later filled by locals). ${ }^{812}$ Here, both silence and excess were drawn upon as arguments for the inherent utility of Holocaust remembrance. Even though the excessiveness shown by the exposure of 111 witnesses, all telling the same story, was cause for fatigue, these voices needed to continue speaking in order to keep the memory of the Jewish genocide alive. Also, in late June 1961, in the final days of survivor testimony, Hamrin seemed to have fallen victim to a form of 'Holocaust fatigue' himself. In an article entitled, "The dilemma of Servatius", he questioned what the real connection was between all the survivor testimonies and the accused-few of them, it seemed to Hamrin, had ever met Eichmann or attested to crimes that he had committed in person. Hamrin thus concluded that the indictment against Eichmann had also been directed against a whole "historical epoch" - an important task, indeed. Yet, another such monumental trial would surely be insufferable, mused Hamrin, not just to the Israeli people and the Jewish diaspora, but to the rest of the world as well. It was up to the historians now, he contended, if they wished to administer further guilt and judgement.

Because of the weariness demonstrated by the journalist corps, both with the slow-moving proceedings and the many witness accounts, the survivor-witnesses became little more than a contour-less mass whose pain was being put on display. In extension, although represented by 111 witnesses, "the six million' remained elusive". 813 From this elusiveness emanated a conception of a homogenous

811 Agne Hamrin, "Vittnesmål om terrorns vardag framkallade gråt bland åhörare," May 2, 1961, DN, 12. The growing disinterest in the trial was also reported on in Aftonbladet "Eichmann-målet för utdraget, världen har tappat intresset" May 7, 1961, and Expressen, Gunnar Nilsson

"Nazirörelsen. Med Eichmann i glasburen" May 8, 1961.

812 Cesarani, "Introduction," Journal of Israeli History, 20.

813 Shandler, "The Man in the Glass-Box," 102. 
Holocaust experience. This notion of homogeneity was also demonstrated in a chapter of Hamrin's book Bokslut i Jerusalem, published in 1961, entitled "The girl who wanted to bathe" (Flickan som ville bada). In this chapter Hamrin recounted the story of Rakel who survived the same gas chamber where her sister perished. In the book Hamrin stated that "her name is Rakel—and if that's not her name, then I guess it is Sara or Mirjam". He continued by describing Rakel's husband "David, and if that's not his name, it must be Benjamin or Isak" thus communicating to the reader that Rakel could be any other Jewish woman and David any other Jewish man. ${ }^{814}$ Rakel is a Holocaust survivor and David is the companion that tells the story that she no longer has the strength to tell. Hamrin's point was that there were tens of thousands of Rakels and tens of thousands of Davids in Israel alone. It is an emphasis on the magnitude of the Jewish catastrophe but together with the fading interest in the witnesses and their stories, the meaning of Hamrin's words becomes one of homogenization—all survivors tell the same story, they have lived through ghettoization, avoided death in the gas chamber and all have numbers on their arms which show their fate. Both the focus on German responses to the trial and Hamrin's characterization of the witnesses signifies an ambivalence towards the form of the accusation; the power of the many witnesses being both necessary and potentially destructive.

The vigilance against accusatory moods amongst the audience at Beit Ha'am, the characterization of testimony as homogenous and a general focus on the German people's exposure to the trial all contribute to a construction of the survivor as potentially dangerous while at the same time an indispensable force against forgetfulness of the Nazi's crimes. The power of testimony to move people was both constructed as a problem as well as a necessity in relation to the Israeli audience. In the same article where Hamrin lamented his colleagues' absence, the title read, "Witness Account of everyday Terror brought out Tears among the Spectators". ${ }^{815}$ In the article, Hamrin detailed how Golda Meir sat with "tears streaming down her face" as the witness delivered his horrific account. This is the same witness account that incited one of the spectators to lose his composure and shout "blood-hound, blood-hound!" at the defendant-a scene which was also recounted in a TT news article in SvD as well as on Aktuellt. ${ }^{816}$ The witnesses that had managed to procure such raw emotion from the spectators were said to have

814 Hamrin, Bokslut i Jerusalem, 65.

815 Hamrin, "Vittnesmål om terrorns vardag framkallade gråt bland åhörare," May 2, 1961, DN, 12. 816 "Vaggsång i lägerhögtalarna när barnen fördes ut att dö," May 2, 1961, SvD, 8. 
told stories of "the everyday" rather than speak of the "gas chambers and crematoria". 817 Hamrin also characterized these testimonies as "artless stories, but with the truthful character of lived experience" and the testimony given by the survivor Leon Wells as "ruthlessly dispassionate". ${ }^{818}$ As Hamrin seems to have been the only Swedish correspondent that reported from Beit Ha'am as these testimonies were given, this characterization was also unique in its kind. In The Moral Witness, Dean asserts that during the Eichmann trial "critics interpreted survivors' testimony as free of sentimentality, let alone self-indulgent, and rather as a form of self-surrender and an exercise in humility". ${ }^{819}$ In emphasizing that these testimonies were given in a calm and dignified manner, Hamrin's characterization thus echoed a perception of the witnesses that was shared by his Anglo-American colleagues at the time. According to Dean, descriptions of the survivor-witnesses as emotionally restrained contributed to the notion of them belonging to "the living dead"- - a concept which "describes the survivor who returned from the massacres and camps miraculously intact but still among the dead". ${ }^{820}$ In a Swedish context, however, the portrayal of artlessness and truthfulness in Jewish survivor testimony signified a shift in the perspective of the survivor; from the antithesis of the innocent female victim who could effectively create an emotional bond with the listener-as expressed in the cultural critique of Anne Frank-to an eventempered, objective vessel of truth.

As previously noted, Hamrin's positioning of the survivor-witness as both accusing and dangerous while, at the same time, emphasizing their importance, shows some form of ambivalence towards the survivor as witness. Yet, even though Hamrin's writings on the Eichmann trial in April and May of 1961 could very well demonstrate an ambivalence in the reporting itself, the institutional labor that Hamrin's texts perform, contributes to the dichotomization of credible/noncredible witnesses; an assessment made as a result of the witness' emotional performance. Just like Felman argues in relation to Arendt's characterization of the witness K-Zetnik's testimony, Hamrin's descriptions do not take the survivor's own experience into account as an emotional performance; a perspective that is critical to understanding Holocaust witnessing itself. Rather, his texts are

817 Hamrin, "Vittnesmål om terrorns vardag framkallade gråt bland åhörare," May 2, 1961, DN, 12. 818 Hamrin, "Vittnesmål om terrorns vardag framkallade gråt bland åhörare," May 2, 1961, DN, 12. [“Konstlösa berättelser, men med det självupplevdas sanningsprägel”].

819 Dean, The Moral Witness, 116-117. Dean makes this claim in relation to an example about the critique of Martha Gellhorn.

820 Dean, The Moral Witness, 117. 
preoccupied with the communicability of the testimony, its ability to effectively relay past experiences. Thus, the articles penned by Hamrin discipline the act of witnessing performed by survivors by only affording it value-both emotional and documentary-when given without excesses. Here, silence and excess are expressed, yet again, as imperatives to speak with performative moderation according to certain aesthetic principles. The survivors were encouraged to speak through Hamrin's invocation of the already worn out phrase "lest we forget", while, simultaneously, communicating that the ideal survivor testimony should be unemotional, coherent, and to the point.

The danger of emotions were also further emphasized in an article, also penned by Hamrin, concerning Israeli Holocaust survivors as psychiatric subjects. In the article with the headline, "'Eichmann psychosis' a problem amongst the rescued Nazi victims", Hamrin described responses elicited by the witness accounts by reiterating the incident with the spectator yelling "blood-hound-blood hound!" at Eichmann during one of the first days of testimony. In the first part of the article, Hamrin stated that,

the episode is characteristic in at least two respects. In its dramatic provocation it illustrates, in an extraordinarily convincing way, the spiritual strain that comes with listening to the witnesses' descriptions of what they have experienced in Auschwitz, in Treblinka, in the Warsaw ghetto, on the deportation trains, on the death marches...Even us non-Jews feel this strain incredibly fiercely, in our heart, in our whole nervous system. ${ }^{821}$

Hamrin continued the article by characterizing the Jewish audiences' "taut faces", their "cramped, tightly held hands" and eyes that had cried until their tears ran dry. ${ }^{822}$ "it is surprising", he stated, "that there haven't been more nervous break downs" considering that the Israelis have "been forced to live with a violent psychological tension" for an entire year. ${ }^{823}$ After lamenting this fact the article moved onto its true subject- the Israeli camp survivors. According to Hamrin,

821 “Eichmannpsykos’ problem bland räddade nazioffer," May 13, 1961, DN, 11, [“I sin dramatiska tillspetsning illustrerar den utomordentligt övertygande den själsliga påfrestning det innebär att åhöra vittnenas skildringar av vad de upplevat i Auschwitz, i Treblinka, i Warsawas ghetto, i deportationstågen, på dödsmarscherna...Även vi icke-judar känner denna påfrestning oerhört starkt, $\mathrm{i}$ vårt hjärta, $\mathrm{i}$ hela vårt nervsystem”].

822 “Eichmannpsykos' problem bland räddade nazioffer," May 13, 1961, DN, 11, [“spända ansikten, förgråtna ögon och krampaktigt sammanpressade händer'].

823 “Eichmannpsykos” problem bland räddade nazioffer," May 13, 1961, DN, 11. 
these individuals felt the "drama in Beit Ha'am" even more fiercely than the other spectators. In introducing this "distinctive group" to his readers, Hamrin described what he termed the "former KZ prisoners" as representatives of "a whole complex of social and mental- hygienic problems". Arriving in Israel, these individuals "brought a special refugee mentality" while at the same time harboring "exaggerated expectations", which is why they were "to a great extent, disillusioned" with their new homeland. Hamrin compared the relatively easy integration, however, of the camp survivors into Israeli society to the obstacleridden road that those emigrating to the United States had encountered; describing them as unfortunate individuals who had been thrown into a "murderous individualistic competitive struggle". 824 In contrast, the Jewish "home-bound" survivors "were surrounded by human understanding, by warmth, by national loyalty" in Israel whose inhabitants "spontaneously identified" with the survivors. As Yablonka has shown in her studies on Israeli Holocaust consciousness and Israeli survivors this was far from the case, as "the Holocaust story...totally overshadowed the story of survivors as survivors. To a large extent they were not considered part of this story." 825

Again, Hamrin romanticized the state of Israel while, at the same time, problematizing its Holocaust survivors, framing them as social and psychiatric subjects who, in spite of their luck at receiving a home in Israel, remained questioning and critical toward the state and the opportunities afforded to them in their new country. Also, survivors' social adjustment and mental illnesses were explicitly connected to the act of witnessing. As opposed to the argument that witnessing can be harmful to the witnesses themselves, the argument presented by Hamrin was that descriptions about ghettos and camps were detrimental to peoples' health. Witnessing was thus pathologized by Hamrin, its effects not merely said to deepen conflict as in the culture critique of Anne Frank, but to create physical harm. Through the reportage style articles written by Hamrin, the survivor-witness became both vulnerable figures whose psychiatric health was dependent on a space between forgetting and remembering, as well as a dangerous figure who, when speaking as part of a larger group of survivor-witnesses, could damage individuals as well as society as a whole. Even though the survivor-witness was not so overtly gendered in reports on the Eichmann trial if compared to

824 “Eichmannpsykos’ problem bland räddade nazioffer," May 13, 1961, DN, 11, [“I motsats till de flyktingar som fann asyl i exempelvis Förenta Staterna kastades dessa hemvända människovrak inte omedelbart in en mördande individuell konkurrenskamp"]

825 Yablonka, The State vs Adolf Eichmann, 159. 
representations of the witnesses in the Belsen trial, the construction of the ideal trial witness as unemotional and objective, still invoked images of the male witness; as embodied by Göndör in his interview for Aktuellt. Features of the prosecution's main witnesses were published in Expressen in the earliest days of the trial and like in the longest Aktuellt segment from the trial itself, all witnesses were male. ${ }^{826}$ This position of the survivor-witness contrasted with the news discourse on Jewish victimization, where women and children were still representing the "True Victims" of the Holocaust.

\section{TT News: Jewish Victimization Revisited}

Although foreign correspondents were prominent commentators on, and meaningmakers of the Eichmann trial, the everyday procedure of the courtroom also constituted news. As previously noted, television news did not follow the trial with any particular dedication. However, descriptions of the trial via the national news bureau Tidningarnas Telegrambyra (TT) and Reuters were regularly published in Swedish daily and evening newspapers. Despite the death of many local newspapers in the late 1950s, the daily press's circulation increased by a fourth between 1958 and 1975, making Swedes the world's most newspaper-reading people at that time. ${ }^{827}$ In a majority of the testimonies that were recounted from the Eichmann trial in TT articles, murdered and tortured children were one of the most prominent themes. ${ }^{828}$ Another central theme was mass-graves, gas-chambers and victims having to witness, or take part in, the killing of their own kin. ${ }^{829}$ In testimonies where children were mentioned as victims, this part of the narrative became central to the newspaper article, even if the testimony itself covered a range of Holocaust experiences. For instance, in an article concerning a testimony about Lidice, a Czech town which was completely eradicated by the Nazis, the focus was on the 53 orphans that were deported rather than on the hundreds of men who

826 "Pojken som slapp ut ur gaskammaren...och tre andra vittnen som avslöjar massmördaren" February 18, 1961, Aftonbladet.

827 Jonsson, “TV förändrar världen,” 137.

828 “Skakande judiskt vittnesmål: Mamma får jag gåta nu?” May 5, 1961, DN. ”Eichmann medskyldig till mord på Lidicebarn" May 25, 1961, DN. "Eichmann dödade pojke för stöld av körsbär," May 27, 1961, DN. "Fångar i Auschwitz sprängde brännugn,” June 3, 1961, SvD, 6. "Vaggsång i lägerhögtalarna när barnen fördes ut att dö," May 2, 1961, SvD, 8. "Räddad ur massgrav från SSmäns kulor," May 9, 1961, 9.

829 "Räddad ur massgrav," May 9, 1961, SvD. "Vi har skjutit 28000 ryssar för att bereda plats åt er," May 6, 1961, DN, 6. "Vittne om dödslägren: offren brändes levande," 
were murdered as the town was burned to the ground. ${ }^{830}$ Furthermore, in a report from the trial proceedings where the Warsaw uprising was discussed, DN chose to use the Lithuanian resistance leader Aba Kovner's story about a girl who had learnt not to cry while in hiding as the headline to the article, rather than information presented about the violent quelling of the actual uprising. ${ }^{831}$ Testimonies about victimized children were thus used to demonstrate the Nazi's most heinous crimes against humanity. The child, as a symbol of the most vulnerable and innocent of victims, was thus deemed more important than relaying details about the witness and her/his act of witnessing.

Such representations - where women, children and the elderly were centrally featured-constitute a significant part in Holocaust discourse where testimony and documentation is utilized to highlight the inhumanity of perpetrators' actions rather than on the multiple ways in which the victims suffered. ${ }^{832}$ In an attempt to grasp evil as a universal concept the survivors' carefully recounted narratives were given value based on what they could contribute to the general understanding of that very concept. Therefore, rather than a human with a past, present and future, the survivors become a mere depository of knowledge about the crimes committed against them. It should be noted that none of the testimonies were reported on in the evening press, something which indicates that Cesarani's contention that the trial was not deemed as dramatically interesting as first anticipated, also applied to the Swedish evening newspapers. Although Hamrin lamented this fact and stayed the course to continue his commentary on the trial and the 111 witnesses, the 'spectacle' expected by the world press was nowhere to be found. Even if reports from TT and Reuters on the testimonies given shows that this part of the trial was at least considered news-worthy, nothing that the survivors recounted was considered 'sensational'. The enlivening of the Eichmann trial instead had to come from the dramatic medium of film.

\subsection{The "Eichmann Films"}

As Hamrin noted in one of his articles, the trial had not become the spectacle that everyone had expected. The documents presented by the prosecution led to long, tedious legal discussions and the testimonies given, although moving to the Israeli spectators, were only partially mediated to Swedish audiences. Instead it was the

830 “Eichmann medskyldig till mord på Lidicebarn,” May 25, 1961, DN.

831 "Skakande judiskt vittnesmål: 'mamma får jag gråta nu?”' May 5, 1961, DN.

832 Shapira, "The Eichmann Trial: Changing Perspectives," 23. 
documentaries and films, depicting the time of the Holocaust, which brought drama to the story of Eichmann's life, his career and his subsequent demise. As a review in SvD phrased it, "the continuous current of documentary, semidocumentary and fictional films" coming out this spring are "aimed at resurrecting the reality behind the dry, matter-of-fact accounts given in the Eichmann trial". 833 During the spring of 1961, three films relating to Eichmann and the Holocaust were shown in Swedish cinemas: Operation Eichmann, Kapo and Eichmann und Das Dritte Reich (Eichmann and the Third Reich). ${ }^{834}$ Although moving within different film genres and focusing on various aspects of the Holocaust, these films were all categorized as depictions of "Eichmann's Butchery" in a full spread in Expressen. 835 The caption below the title in the article read; "The Jew killer knew what awaited him if arrested. Tried to destroy all pictures". In dramatizing the Holocaust, these films helped fill a gap in the Swedish imagination of the Holocaust and thereby also served to define the camp survivor as a historical phenomenon. This was not just accomplished through representations of the Holocaust in these films, but also through the ways in which the films were critiqued in the daily and evening newspapers.

It has been widely acknowledged that the rise of television meant the slow (but sure) decline of cinema. As Weibull explains, "the losing medium in Sweden, as in most other countries, was the cinema. Between 1956 and 1963 the number of cinema attendances declined from 80 million per annum to 40 million per annum." "836 This may seem a dramatic drop, yet television, as any new medium, was also inextricably bound to its media predecessors in various ways. ${ }^{837}$ One of the earliest programs on Swedish public broadcast television was a show called Filmkrönikan - a program dedicated to the discussion about, and critique of, contemporary world cinema. ${ }^{838}$ In reviewing and critiquing films, Filmkrönikan also further entrenched the growing sense that film was a form of art, a notion which

833 “Saga: Kapo,” April 18, 1961, SvD, [“den strida strömmen av dokumentära, halvdokumentära och helt fiktiva filmer som syftar till att återuppliva verkligheten bakom de torrt sakliga referaten av Eichmannrättegången].

834 Operation Eichmann, directed by R.G. Springsteen, (United States: Allied Artists Pictures, 1961). Kapo, directed by Gillo Pontevcorvo, (Italy, France, Yugoslavia: Cineriz, 1960). Eichmann und das

Dritte Reich, directed by Erwin Leiser, (Switzerland, West Germany: Praesens Film, 1961).

835 "Nu kommer filmerna om Eichmann's Bödelsverk," April 5, 1961, Expressen.

836 Weibull, "New Media between Technology and Content," 48.

837 See Per Vesterlund, "Filmkrönika—filmkritik i ljud och bild," in eds Anna Edin \& Per

Vesterlund, Svensk Television: En Mediebistoria, (Statens ljud- och bildarkiv, 2008): 108-134.

838 Vesterlund, "Filmkrönika—filmkritik i ljud och bild," 108-134. 
was facilitated by understandings of the new TV-medium as frivolous and trite. Thus, although the 'Eichmann films' may not have reached as many people as the short documentary segments about Eichmann and his crimes that were shown on television, their standing, as meaningful, artistic depictions of past horrors, made them perhaps even more powerful in communicating Holocaust. In addition, the daily and evening newspapers continued to announce film premieres, publish reviews and report on news-worthy events behind the scenes and in relation to the films' wider reception by audiences. As in the relationship between television and cinema, film 'experts' writing for the press served to discipline both the subject matters that film dealt with as well as the medium through which the content was presented.

Although announced as one of the coming films about Eichmann's deeds in April 1961, Operation Eichmann had already premiered six months earlier, in December 1960. The two films which were showing during the time of the trial and which became extensively discussed and reviewed, were therefore Kapo and Eichmann und das Dritte Reich. The former premiered in late April and the latter came out in early June. In this section I attempt to understand how Kapo and Eichmann und das Dritte Reich portrayed survival and how these themes as well as Leiser's background were treated in the critical response that the films garnered in the Swedish press.

\section{Leiser's Documentary Film About the Victims}

Eichmann und das dritte Reich, created by the Swedish journalist Erwin Leiser, can be described as an archival assemblage, including images of Nazi mass rallies, ghetto life and mass killings as well as photos of documents tying Eichmann to the crimes of the Holocaust. The film received less reviews and 'talk' in the newspapers compared to Kapo, most likely because it constituted a form of sequel to Mein Kampf —Leiser's first film about Hitler and the Third Reich which had created a lot of 'buzz' both before and after it premiered in Swedish cinemas during the spring of $1960 .{ }^{839}$ Even though Eichmann und das dritte Reich differed from Mein Kampfin that it centered on the Holocaust story rather than on the rise of the Nazi party, both films were discussed especially in reference to their inclusion of images from the Warsaw ghetto. Significantly, the proceeds of Leiser's second film went to the

839 "Leisers film om Hitlertiden en bragd," May 3, 1960, DN. "Svenskar har sammanställt unik film om Tredje Riket,” April 4, 1960, SvD. "Måndagens filmpremiärer," May 3, 1960, SvD. "Svensk film om Hitlertiden väcker tysk uppmärksamhet," July 16, 1960, Expressen. "Den blodiga tiden....," April 30, 1960, Aftonbladet. 
Kibbutz Lochamei Hagetao't — the place where the first Holocaust museum, the Ghetto Fighters' Museum, was established in $1949 .{ }^{840}$ In addition, the head curator for the museum, Miriam Novitch, was also included as a special advisor to the project.

The importance of the images included into Leiser's film from the Warsaw ghetto cannot be understated in an Israeli context. To be sure, the Warsaw ghetto uprising was already an iconic example of Jewish resistance in Israeli memory culture in 1961, yet the question of passivity and docility in the face of mass death and near extinction also haunted the Eichmann trial. ${ }^{841}$ For instance, Shapira notes that Gideon Hausner “repeatedly asked the witnesses: why didn't you resist?"-an unfair question in hindsight, although seemingly important to the Israeli prosecutors. Both Yablonka and Shapira suggest that this was done in order to once and for all settle this delicate question in front of the Israeli public; a query posed to finally establish that the Jews had acted as any victim would in order to protect themselves and their loved ones from more pain and agony. ${ }^{842}$

The images from the ghetto shown in the Aktuellt documentary and in Leiser's film depict this ultimate form of victimization. In one particularly graphic clip from Eichmann und das Dritte Reich, the camera fixates on two half-dressed emaciated corpses laying in the street in front of an apartment building in the Warsaw ghetto. People pass without stopping to look or help (making it evident that such a sight was part of everyday life in the ghetto) and after a while a cart, pushed by two adolescent boys, comes to collect the bodies. Although the corpses are basically skin and bone, it is difficult for the boys to keep them on the cart and at one point, one body falls off and one of the boys struggles to get it back onto the cart. The next frame shows the boys unloading the corpses onto a heap of similar skeletonlike bodies inside what appears to be an old bicycle shed. The camera closes in on the pile, so much so that the viewer can see the wrinkles in the skin, tufts of hair and the outline of noses, ears and teeth. It is a horrifying sequence of moving images, where the apathy and matter-of-factness of the living is almost as unnerving as the dead bodies. ${ }^{843}$

Leiser later stated in an interview with $\mathrm{SvD}$ that as opposed to the footage taken in the Warsaw ghetto in Mein Kampf, which was filmed by Nazi officials, Eichmann und das Dritte Reich included clips which were filmed by the ghetto's own

840 Geva, "To Collect the Tears of the Jewish People," 74.

841 Yablonka, "The Development of Holocaust Consciousness in Israel: The Nuremburg, Kapos,

Kastner, and Eichmann Trials," Israel Studies, vol. 8, no. 3 (Fall 2003): 15-22.

842 Shapira, "The Eichmann Trial: Changing Perspectives," 24.

843 Leiser, Eichmann und das Dritte Reich. 
inhabitants (although they remained anonymous). In quoting Lucy Davidowitz' critique of Warsaw ghetto portrayals in the 1968 BBC documentary The Warsaw Ghetto, film scholar Annette Insdorf reminds us that "although the British film was clearly intended to condemn German treatment of the Jews, 'the images of the Jews which persist in our minds... are the very images which the Nazi propagandists originally wished to impress on the minds of their viewers." "844 This is then also what was reproduced in Mein $\operatorname{Kampf}$ where portrayals of the ghetto came from a purely Nazi perspective. In Eichmann und das dritte Reich, however, the audience received representations of the ghetto produced by those who actually lived there, thus partially removing the occupiers' filter and showing a different reality of ghetto experience. Nazi footage of the Warsaw ghetto would often include racist and antiSemitic stereotypes of Jews, something which would not be reinforced in images produced by ghetto inhabitants. Moreover, for the film, Leiser interviewed survivors of the Warsaw ghetto uprising, adding their interviews to the end of the film, thus both individualizing the faces on the screen and conveying the message that those who had once been victims had arisen and produced good lives for themselves in Israel. Furthermore, this dual depiction of the ghetto-a place of death and despair and a place of ferocious resistance also communicated that those who survived fought to live. They were not merely passive victim-survivors but agential, powerful and courageous survivors.

Although Leiser was Jewish and escaped Nazi Germany at the age of 15 through the forbearance of the head of the Jewish community in Stockholm (Mosaiska församlingen i Stockholm), his background was never explicated in the Swedish press. ${ }^{845}$ In fact, neither his Jewish identity nor his own experiences of Nazi persecution were ever even mentioned. This may not have been a deliberate absence, however, as Leiser was a known figure in Sweden at the time, serving as editor for the Stockholm-based daily newspaper Morgontidningen and having received much attention for $M e i n \operatorname{Kampf}$ a mere year prior to the Eichmann trial.

844 Annette Insdorf, Indelible Shadows: Film and the Holocaust, (Cambridge: Cambridge University press, 2003), 140.

845 For Background on Leiser see chapter 1 in Erwin Leiser, Samtal i Berlin, (Stockholm: Pan/Norstedt, 1969). See also Erwin Leiser, Gott hat kein kleingeld: Erinnerungen, (Colon: Kiepenheuer \& Witsch, 1993). For research on Leiser's work see Tobias Ebbrecht-Hartmann, "Trophy, Evidence, Document: Appropriating an Archive Film from Liepaja, 1941," Historical Journal of Film, Radio and Television, vol. 36, no. 4: 509-528.—-Dokumentarfilm als Gerichtverfahren: Erwin Leisers Eichmann und das Dritte Reich (1961)", Filmblatt, vol. 51, (2013): 47-57. 
Thus, Leiser's Jewish identity and history may have been so obvious to Swedish readers that it need not be explored further in reviews of his work. However, even when Mein Kampf was discussed on the pages of the daily and evening newspapers and Leiser was being presented as a documentary film maker for the first time, he was still merely referred to as a Swede with "roots in Germany". 846

Also, as much of the writing surrounding the Eichmann trial took special care to underscore the neutrality and general composure of those guarding and accusing the defendant, it also seems likely that Leiser's background and Jewishness was obscured as a result of the documentarian ideal that governed Holocaust mediations at the time. This can, for example, be seen in SvD's review of the film where the critic agreed with the hypothetical protest that any film made before Eichmann had been convicted, would commit a serious error in judgement. Yet, the critic continued, "if it is necessary to make a film about Eichmann in this situation it should be done as in Erwin Leiser's Eichmann and the Third Reich". ${ }^{847}$ In this review, Leiser's documentary was also positioned as the complete opposite to the "partly naïve, partly mendacious" film Operation Eichmann. Eichmann und das Dritte Reich was thus described as exemplary in its strictness—or, as the critic added, "as strict as one can ask for" in that context. ${ }^{848}$ The strict, undramatic presentation of authentic footage was thus given as the ideal form of representing Eichmann and his crimes - an idealized form that may have been compromised if Leiser was 'exposed' as a vindictive survivor who merely wanted revenge on his former oppressors. Therefore, in order to let the film rest in this exemplary category of Holocaust representation, Leiser's own background, his personal motivations for making the film and his feelings towards Eichmann had to be ignored.

Furthermore, in an article in DN, the film's becoming was described as the "intense chase through the archives after new documentary stuff", the author adding that Leiser had "gone on month-long research trips to the United States, Germany, Poland, England, France and many other countries" 849 and had viewed "60000 meters of film" and "gone through 700 documents and read 4000

846 "Leisers film om Eichmann vållade tumult i Tyskland," June 2, 1961, DN.

847 “Eichmann—dödens agent," June 6, 1961, SvD, [“Men om det nu nödvändigtvis skall göras film om Eichmann i detta läge så skall det göras som Erwin Leiser gjort i sin 'Eichmann-dödens agent"'].

848 “Eichmann—dödens agent," June 6, 1961, SvD..

849 Agne Hamrin, "Eichmann och nazismen i dokumentärfilm om Leiser," April 19, 1961, DN. 
pages" ${ }^{\circ 50}$. These descriptions positioned Leiser more as a researcher than as a filmmaker, and as an objective truth-teller rather than as a passionate victim and survivor whose own story related directly to that of the six million dead. His actions - his labors in the archives, the hours of film that he had collected, the time spent abroad researching-was what made him the most appropriate communicator of Holocaust experience. This positioning of Leiser is not merely reflective of the position of the survivor at the time but also reflects discourses surrounding the documentary film genre. As film-studies scholar Aron Kerner comments,

Traditionally, the documentary film-maker has been viewed as a humble conduit, through which unmediated facts are conveyed, the connotations being that it is not the film-maker who speaks but the event itself that speaks through the film. .851

Hence, both the form through which Leiser had chosen to express himself and the absence of his own Holocaust experiences from narratives about his film contributed to the notion of Leiser as an objective and distanced observer.

Moreover, the SvD critic concluded his article by stating that even though Leiser's most recent film could not compare to Mein Kampf, it remained effectual in serving as a "reminder of the incredible suffering that untermench, who believe themselves to be übermench, can cause their fellow human beings". 852 Therefore, in its documentary form the film was said to highlight the crimes committed by the Nazis, not necessarily the victims themselves and their stories. Interestingly, in a write up on the film prior to its premier, signed Hamrin, Leiser was quoted stating the opposite- that he took care to highlight some individual survivor stories in the film in order to "translate the Eichmannian murder statistic into flesh and blood". ${ }^{853}$ However, even this article posed the perpetrator as the most important feature of Leiser's film through the headline: "Eichmann and Nazism in Documentary Film by Leiser" as well as a lead which sensationalized the content

850 “Leisers film om Eichmann vållade tumult i Tyskland," June 2, 1961, DN.

851 Aron Kerner, Film and the Holocaust. New Perspectives on Dramas, Documentaries, and Experimental Films, (London: Continuum, 2011), 18. See also Elizabeth Cowie, "Seeing and hearing for ourselves: the spectacle of reality in the Holocaust documentary" in eds Toby Haggith and Joanna Newman, Holocaust and the Moving Image, (London: Wallflower, 2005).

852 “Eichmann—dödens agent," June 6, 1961, SvD.

853 Hamrin, "Eichmann och nazismen i dokumentärfilm om Leiser," April 19, 1961, DN. 
of the film through the description "a piping hot and fresh documentary film about Eichmann and the Third Reich". ${ }^{854}$ Even in a film where the stated intention was to individualize the victims, the impetus to explain perpetration overshadowed this aim, further reiterating the point made in relation to representations of victimization in TT news: that witnessing was only important insofar as it highlighted the wounds inflicted by perpetration. This is also telling of how individuals with Holocaust experience-although successful in their mediations of the Holocaust and although highly visible in public discourse—had little power to themselves define the importance of Holocaust representation. This was also further demonstrated in the critical reception of Kapo.

\section{Kapo and the Credibility of a Victim's Trajectory}

The film that received the most attention in the Swedish press during the spring of 1961 was the French/Italian motion picture Kapo. In Expressen's presentation of the "films about Eichmann's butchery", a still from Kapo dominated the right page of the spread. The image showed two women in striped prison dresses, one holding a baton ready to strike the other. In the article the film was described as "a very powerful film" that "despite a few somewhat melodramatic episodes is a harrowing film about the activities that Eichmann facilitated". 855 This notion of the melodramatic character of the film and conceptions of what constituted its core purpose became central themes in the critical reception of Kapo in Swedish public discourse.

A much discussed film in studies on Holocaust cinema, Kapo constitutes one of the first motion pictures which garnered harsh criticisms regarding its euphemistic cinematic language- the most famous being Jacques Rivette's critical review in Cabiérs du Cinema. ${ }^{856}$ Kapo, directed by Italian director Gillo Pontecorvo and starring Susan Strasberg, chronicles the journey of the Jewish girl Edith as she, under the false identity of non-Jewish Nicole escapes her parents' deadly fate and becomes a feared Kapo. In the camp, Edith encounters the Russian POW Sasha with whom she falls in love. Through Sasha, Edith becomes involved in an escape plan and, with dozens of other internees, perishes. She knows that she will not survive as she has taken it upon herself to turn off the power to the fence, making her one of the last people to attempt her escape. In the final scene with Strasberg,

854 Hamrin, "Eichmann och nazismen i dokumentärfilm om Leiser," April 19, 1961, DN.

855 "Nu kommer filmerna om Eichmann’s Bödelsverk," April 5, 1961, Expressen.

856 Libby Saxton, Haunted Images: Film, Ethics, Testimony and the Holocaust, (London: Wallflower Press, 2008), 18. 
Edith makes one of the guards (Karl, who made her Kapo) remove her Swastika arm band and before she dies, "reassumes her Jewish identity by reciting a Hebrew prayer". 857

In Insdorf's words, “Kapo traces Nicole's transformation from a frightened, orphaned, and selfish victim into a political heroine who ultimately embraces her heritage and sacrifices herself." 858 Insdorf also poignantly argues that Sasha's survival, shown by him climbing out of a mass-grave, also "suggests that survival means stepping over dead bodies" 859 . "Kapo thus questions the price of individual safety and celebrates a collective spirit as the means to heroism." 860 Furthermore, the film communicates a notion of the "True Victim" as self-sacrificial and dedicated to his/her own identity. Survival becomes something conspicuous, something that comes at a great cost and something that constitutes an almost immoral act. This narrative ran counter to all other representations of survivors in the Swedish media landscape where neither their actions during the war nor their survival was contested.

The trajectory of Edith was also questioned in a majority of the Swedish reviews of the film. For example, in a review in Aftonbladet the critic deemed Edith's "metamorphosis" from human to "animal back to human again" less than credible. 861 This, in conjunction with her love for Sasha, made the film "slip into a melodrama" that disrupted the pathos of the story, argued the critic. This critique of the film's melodramatic character was also shared by the critics writing in DN and Expressen, where the latter denounced the film's artistic value and the former called the "melodramatic" storyline "cinematically [and] ably mendacious!" However, all reviews, including that in SvD, claimed that the film remained important and that its depiction of camp life was true to historical reality. Thus, the film's melodramatic undertones were said to inhibit the film's artistic ambitions while, at the same time, not distorting the truth which the film attempted to convey. This is an important distinction since the film's relevance was said to be the horrific story-the crucial content that trumped the lacking form. The subject matter of the film is survival and the grey zones of victimization, yet the reviewers attempt

857 Insdorf, Indelible Shadows, 148.

858 Insdorf, Indelible Shadows, 148.

859 Insdorf, Indelible Shadows, 149.

860 Insdorf, Indelible Shadows, 148.

861 “"Den är halvvägs till storheten,” April 18, 1961, Aftonbladet, 15 ["Han låter judeflickanövertygande spelad av Susan Strasberg så långt rollen tillåter det—från människa förvandlas till djur och sedan till människa igen. Och den metamorfosen är inte trovärdig’']. 
to refocus this aim, so that the real subject matter, the one that the audience should pay attention to, is the horrible ways in which the Nazi's treated the Jews. As the critic in SvD declared:

The question [of Edith's trajectory] is irrelevant. The whole storyline is, strictly speaking, irrelevant. The relevance is precisely the stark light that the film casts over the inhuman conditions in which people can be thrown by other people, the unfathomable cruel reality in our time, just now, that cannot and should not be forgotten. ${ }^{862}$

This quote is telling of the critical perception on Holocaust representation and remembrance as wholly connected to the utility of explaining and understanding the horrors of Nazism. A film that was about survival and victimization was labelled "irrelevant" in its aims while inherently important because of the theme with which it dealt. Although Edith dies in the camp and survival is not depicted as life after the catastrophe, the survivor — as victim and as a person living among other Swedes, could have been actualized through the depiction of camp life. Redirecting the focus from the victim story to that of the perpetrator, therefore led to the erasure of Swedish survivors' experiences-the critics removing any possibilities shutting down a discussion on Holocaust survival that could have engaged Swedish camp survivors.

How did the 'Eichmann films' contribute to the construction of the Holocaust survivor in Swedish public discourse? While the films themselves-through representations of both camp horrors and the individuals who experienced themopened up for discussion and debate on victimization and survival, these themes were swiftly disregarded or ignored by Swedish critics. The fact that Leiser's background as a Jewish child survivor was never broached or his work with other survivors such as Miriam Novitch, barely mentioned, also shows how the mediator of Holocaust history had to be a neutral actor as well as a zealous documentarian. In contrast to figures such as Simon Wiesenthal, whose face recurred in the Swedish press throughout the Eichmann trial, the documentarian of Nazi crimes for the sake of saving these for posterity, could not be seen as either vindictive or self-serving. Wiesenthal's work was neither criticized nor denigrated by the Swedish press — quite the opposite-but the role of the survivor Nazi-hunter and the role

862 “Saga: Kapo,” April 18, 1961, SvD, [“Frågan är ovidkommande. Hela storyn är strängt taget ovidkommande. Det väsentliga är just det bjärta sken filmen kastar över omänskliga förhållanden vari människor kan kastas av människor, den ofattbart grymma verklighet $i$ vår tid, helt nyss, som inte kan glömmas och inte får glömmas”]. 
of the survivor historian/documentarian were very different in the early 1960s; a difference that contributed to the notion of survivor-witnesses as excessive and Holocaust historians as fair, objective and suitable for the task of documenting the Holocaust.

\subsection{The first Frankfurt Auschwitz Trial and Peter Weiss's Die Ermittlung}

The first Frankfurt Auschwitz trial has been widely understood as a process through which a number of contemporary political and juridical issues pertaining to the Holocaust were actualized and contested. ${ }^{863}$ Indeed, the trial itself, just like the Eichmann trial, was an inherently political endeavor that addressed questions relevant to the Cold War and West German democracy. ${ }^{864}$ As the American historian Devin O. Pendas argues, however, this did not mean that the first Frankfurt Auschwitz trial "was an illegitimate attempt to use legal forms to pursue extra-legal ends" but first and foremost consisted of a concerted juridical attempt to afford the victims of Auschwitz justice. ${ }^{865}$ In contrast to the Eichmann trial where the 6 million victims had indicted the defendant, the survivor-witnesses were the true accusers in the first Frankfurt Auschwitz trial. ${ }^{866}$

The Canadian historian Rebecca Wittman has argued that with most of the evidence in the trial being based on testimonies, "the descriptions of everyday life in Auschwitz became part of the public consciousness about the camp and provided invaluable factual information for historical reconstruction of the crimes

863 Devin O. Pendas, The Frankfurt Auscbwitz Trial, 1963-1965: Genocide, History, and the Limits of the Law, (Cambridge: Cambridge University Press, 2006). -“I didn't know what Auschwitz was': The Frankfurt Auschwitz Trial and the German Press, 1963-1965," Yale Journal of Law and the Humanities, vol. 12, no. 2 (Summer 2000): 397-446.— "Eichmann in Jerusalem', Arendt in Frankfurt: The Eichmann Trial, the Auschwitz Trial, and the Banality of Justice," New German Critique, no. 100, (Winter, 2007): 77-109. Rebecca Wittmann, Beyond Justice: The Auscbwitz Trial, (Cambridge, Mass., Harvard University Press, 2005). - "Indicting Auschwitz? The Paradox of the Frankfurt Auschwitz Trial," German History, vol. 21, no. 4, (2003): 506-532._-"Telling the Story: Survivor Testimony and the Narration of the Frankfurt Auschwitz Trial," Bulletin of the GHI Washington, issue 32, (Spring, 2003): 94-101.

864 Pendas, The Frankfurt Auschwitz Trial, 2.

865 Pendas, The Frankfurt Auschwitz Trial, 2.

866 In "Telling the Story," (2003) Wittman explains that "while the Nuremburg trials relied heavily on documentary evidence, West German postwar trials hinged almost exclusively on witness testimony", 94. 
of the Holocaust" ${ }^{867}$ However, in studying the West German press, Pendas has shown that the trial did not have the didactic impact as previously assumed. 868 Nonetheless, even though the 'learning' effects of the trial were negligible, or, at least, difficult to ascertain, the survivor testimonies served to inform further reconstructions of Holocaust history pertaining to camp experience in general and Auschwitz in particular. Of course, in public debates on the trial in Swedish media discourse, the question of guilt rather than the question of Jewish suffering was at the top of the agenda. Still, the trial as well as the mini trials in other German cities in the early 1960s, afforded an opportunity for the newspapers to explore human interest stories. The drama of Eichmann being over, new angles with regards to Germany's Nazi past were found in relation to the West German trials. These points of interest also had a clear connection to Sweden. Except for Göndör, the 'Swedish connection' to the Eichmann trial had been made through evidence presented in the case against Eichmann; documents that tied government action and Raoul Wallenberg to Nazi perpetration and Jewish victimization in different ways. In 1963, when the first Frankfurt Auschwitz trial began, the 'Swedish connection' had, however, already begun to establish itself through camp survivors living in Sweden; a connection that would be further strengthened through the debates surrounding Weiss and his play based on the trial. In this section I attempt to understand how Auschwitz, as a point of reference, strengthened in relation to the first Frankfurt Auschwitz trial and how Auschwitz as a Holocaust symbol contributed to constructions of the Holocaust survivor in the early to mid-1960s.

\section{Swedes in the Auschwitz Trial: Reluctant yet Heroic Witnesses}

Both before and during the first Frankfurt Auschwitz trial, camp survivors were becoming subject to human interest stories, primarily in the evening newspapers. For example, in Expressen's Sunday issue in May 1963, a full-page article portrayed — in photographs and text-how a young woman could finally be reunited with her elderly mother after being separated in Auschwitz some twenty years earlier. In the lead the article described how "in the glare from the bright lights of a Moscow TV-studio, the women looked at each other, curiously but with tears in their eyes. The first meeting between Lydia, once a child in Auschwitz, and her now grey-haired mother was witnessed by TV-viewers all over the Soviet

867 Wittman, "Telling the Story," 94.

868 Pendas, “'I didn’t know what Auschwitz was,” 397-446. 
Union". ${ }^{869}$ This Soviet story of reconciliation was later replicated in a Swedish context with Aftonbladet reporting that the Hungarian Jewish survivor, Mrs Iréne Wächter, then residing in Uppsala Sweden, had recently discovered that her son, Schlomo, was alive and well in Jerusalem. ${ }^{870}$ Mother and son had reportedly been separated when the former was forced to march to the concentration camp Lichtenwört in Austria. Next to the article text, Iréne and Schlomo could be seen in two photographs; a smaller picture taken before the war and a larger picture showing the pair smiling into the camera after being reunited in Nathanya, Israel. During 1961, the Jewish survivor-witness and Jewish victimization were largely framed as Israeli or German phenomena. On February 21, 1964, however, Aftonbladet dedicated all of page six to two of the individuals who had been asked to testify in the first Frankfurt Auschwitz trial. The headline read: "Swedes bear Witness in Nazi Process". 871 In the lead it was also reiterated that "two Swedes, Albert Ehrenfeldt and Sylvia Norrman, have been called to testify in the trial against 22 of death's helpers at the concentration camp, Auschwitz". ${ }^{872}$ Under the subheading, "300 witnesses", the article explained that the trial was, that week, moving towards its "dramatic climax" through the "parade of witnesses". "They are approximately 300", the article continued, "men and women who survived the hell of Auschwitz. They arrive, travelling to Frankfurt from Europe, Israel and America to, yet again, stand face to face with their executioners. In the name of justice they submit to gruesome and upsetting hours in this sober court of justice." 873 The mental tole that witnessing took on camp survivors was rarely commented on during the Eichmann trial where the focus had either been on Eichmann himself

869 "Nu har hon fått henne tillbaka," May 26, 1963, Expressen, 13 [“I skenet från de starka lamporna i en TV-studio i Moskva såg de båda kvinnorna på varandra, lite nyfiket men med tårar i ögonen. Det första mötet mellan Lydia och hennes nu grånade mor bevittnades av TV-tittare i hela Sovjetunionen"].

870 "För 19 år sedan försvann 2-årige sonen i ett koncentrationsläger: Nu har de åter mötts," January 10, 1964, Aftonbladet, 7.

871 “Svenskar vittnar i nazistprocessen," February 21, 1964, Aftonbladet, 6.

872 “Svenskar vittnar i nazistprocessen,” February 21, 1964, Aftonbladet, 6 [“Två svenskar, Albert Ehrenfeldt, Hägersten, Stockholm, och Sylvia Norrman, Malmö, har kallats att vittna i rättegången mot dödens 22 hantlangare i koncentrationslägret Auschwitz'].

873 "Svenskar vittnar i nazistprocessen," February 21, 1964, Aftonbladet, 6 [“Med sakkunnigutlåtande segar sig nu veckans tre rättegångsdagar i Frankfurt långsamt fram mot processens dramatiska höjdpunkt, vittnenas parad. De är cirka 300, män och kvinnor som överlevde Auschwitz helvete. De kommer resande till Frankfurt från Europa, Israel och Amerika för att återigen stå ansikte mot ansikte med sina bödlar']. 
or on the conduct of the witness and the spectators. As discussed in relation to Hamrin's writings, witnessing in the Eichmann trial was also framed as something noble yet dangerous because of the pain it caused those on the receiving end of the testimony. In 1963 and 1964, however, witnessing's effect on the witnesses themselves became a central aspect of the news discourse surrounding the Auschwitz trial.

Interestingly, the article gave two different accounts of Norrman's Holocaust history, the framing article (signed Sonja Westling) claiming that Norrman's father died in a Nazi raid whereas the personal story (signed Gunnar Printz) stated that her father died after the whole family had been deported to Auschwitz. Even the headline read "Her Father was Killed as the Rescue Arrived". 874 The interview recounted from the paper's meeting with Ehrenfeld (signed Thore Davidson) had the headline "They Gassed my Wife and my Children". In this human-interest story, the introductory or framing narrative, presented by Westling, communicated the bravery and steadfastness of the witnesses while the actual interviews focused more on the most sensational details of the survivors' Holocaust experience. This is interesting because, even though the discourse about survivors as living deposits of juridically viable documentation was strong, if not to say dominating at this time, the details of the survivors' own as well as their families' deaths were not treated with much care. It thus seems that, in the evening press, trial witnesses had become subjects of drama, in addition to their roles as objective recounters of facts. This interest in the trial witnesses had also manifested in the daily press even before the first Frankfurt Auschwitz trial had commenced. In an article in SvD, the "main witness" against Obersturmbannführer, Otto Bradfisch, at a Nazi trial in Hannover during the autumn of 1963, was presented. Even though the indictment regarded events in the Lodz ghetto, Auschwitz figured prominently in the text with one of the photographs depicting a baby with a tattooed arm, described in the text as "the only surviving child from Auschwitz". 875 The witness was further described as a "Polish-born Swede" who was quoted stating that it was "gruesome to have to

874 "Svenskar vittnar i nazistprocessen," February 21, 1964, Aftonbladet, 6 [“Hennes far dödades när räddningen kom"].

875 "Min plikt att avslöja det jag sett," August 24, 1963, SvD [“Ett porträtt bränner sig fast i minnet: det förebrående pojkansiktet, det enda överlevande barnet från Auschwitz”]. 
scratch at the wounds" but that he also thought it his "duty" to reveal what he had seen, "both to those still living and to those who died". 876

During the years that the first Frankfurt Auschwitz trial progressed, Cordelia Edvardson and Zenia Larsson were also becoming more prominent symbols of Sweden and the Holocaust and as particular survivor voices from within Swedish society. Rather than being framed as migrants or as outsiders looking in, they were constructed as Swedes, bringing invaluable perspectives on Swedish society to their fellow citizens due to the extraordinary things they had experienced and survived during the war. In a review of Cordelia Edvardson's novel Kärlekens Vittne (Witness to Love), published in 1964, the writer, translator and critic Gunnel Vallquist characterized Edvardson's book as one of the first depictions of the camps coming to readers in the original language, since such stories of survival usually came from foreign authors. "This time" Vallquist explained, "a voice comes out of our very own language, out of our people's home". ${ }^{877}$ Even though Edvardson and Larsson had been active writers who had published books since the end of the 1950s, Vallquist made it sound as if Edvardson's Swedish book was the very first attempt at representing camp experience in Swedish. One might also wonder why it mattered whether these experiences were expressed in the original language or as a translation? It thus seems that the notion of Swedes witnessing was becoming increasingly important in the aftermath of Eichmann and in relation to the first Frankfurt Auschwitz trial. Another example that underscores this point is an article series in Expressen, published in the late summer of 1965, (at the same time as the first Auschwitz trial was concluded) that provided literary perspectives on the Swedish people's home; a series to which Larsson contributed the first reflection. ${ }^{878}$ In an introduction to the series-under the headline, "writers scrutinize the people's home"-Larsson's perspective was said to receive its "special tone from her memories of the ghetto, from Auschwitz and from Bergen-

876 "Min plikt att avslöja det jag sett," August 24, 1963, SvD, [“För mig är det ohyggligt att behöva riva i såren. Mardrömmarna jagar mig ännu och genom det här skärps detaljerna igen. Men jag tycker att det är min plikt att avslöja vad jag sett—min plikt både mot dem som lever och mot dem som dog'].

877 Gunnel Vallquist, “Kärleken i Inferno,” April 29, 1963, SvD, 5.

878 Zenia Larsson, “Anklagelsen var en gång min,” August 4, 1964, Aftonbladet. The "People’s home” is a translation of Folkhemmet; a concept coined in a speech by the conservatives at the beginning of the twentieth century but was later coopted by the Social Democrats to express their vision for a new society that should feel like a home to all its citizens. 
Belsen". ${ }^{879}$ Furthermore, in her reflection, Larsson presented herself, not as a Swede, for "one can never escape one's origins", but as a Swedish "societal citizen". ${ }^{880}$ In her narrative, Larsson also discussed how she had become like all other Swedes and how, while the accusation used to be hers (the headline of the article read "the accusation was once mine"), she could now understand the apathy and passivity that arose when one encountered the misery and suffering of others. In her final passage of the article she thus stated;

I understand the silence that grew into a wall around the ghetto in Warsaw and Lodz; I understand how everything could move towards its completion in Majdanek. And I don't know how one can activate one's commitment beyond the crumbs that scantily patch up one's conscience. TV shows the faces of children that have never learned how to laugh, a poet that dared to dream about freedom is thrown in prison; daily, every hour, every second, people die from starvation and will continue to die. Spain is left, South Africa is left. And the war has never ended, it continues-it has only moved far enough to not trigger immediate worry in my safe world. I sit down and direct my eyes stubbornly at my pot of boiling potatoes. Even though I remember and know. ${ }^{881}$

The reference to the boiling pot of potatoes serves in the text as an image of how normalcy dominates the everyday life of survivors; how they have grown accustomed to living in a safe place, largely removed from their memories of pain and suffering. It thus describes a struggle between the role of the victim and the role of the survivor-witnesses who are supposed to remind their fellow human

879 Zenia Larsson, “Anklagelsen var en gång min,” August 4, 1964, Aftonbladet. [“Hennes syn på den svenska idyllen får sin speciella ton av hennes minnen från ghettot, från Auschwitz och BergenBelsen"].

880 Zenia Larsson, “Anklagelsen var en gång min,” August 4, 1964, Aftonbladet. [“De när 20 åren i Sverige har visserligen inte förmått att förvandla mig till en svensk—sitt ursprung kommer man inte ifrån—men de har gjort en samhällsmedborgare av mig, och det räcker gott”].

881 Zenia Larsson, “Anklagelsen var en gång min,” August 4, 1964, Aftonbladet. [“Jag förstår den tystnad som bildade muren omkring ghettot $\mathrm{i}$ Warsawa och Lodz, jag förstår hur allt kunde gå mot sin fullbordan i Majdanek. Och jag vet inte hur man kan aktivera sitt engagemang utöver de smulor, som nödtorftigt lappar ihop ens samvete. TV visar barnansikten som aldrig lärt sig skratt, en diktare som vågat drömma om friheten kastas i fängelse; dagligen, varje timma, varje sekund dör människor av svält och kommer fortsätta att dö. Spanien är kvar. Sydafrika är kvar. Och kriget har aldrig slutat, det fortsätter- det har bara flyttat på sig, tillräckligt långt bort för att inte väcka omedelbar oro i min trygga värld. Jag slår mig till ro och riktar blicken envist mot potatisgrytan. Trots att jag minns och vet']. 
beings to act on behalf of others who are in need. At the same time, it is also a text about becoming Swedish, seeing the world in the same way that Larsson imagined that Swedes saw the Holocaust during the war. Therefore, although Larsson does not claim to be Swedish, she has become part of the Swedish soul; acting like all other Swedes in the face of adversity.

The fact that Edvardson and Larsson were seen, and, to some extent, saw themselves, as part of the Swedish people's home, demonstrates a shift in the position of the survivor in the wake of the Eichmann trial. This position becomes even more significant when considering the fact that there were many groups that were perceived as foreign to, or unwanted by, the Swedish people's home in the 1960 s. $^{882}$ It seems then, that by 1963 , Jewish camp survivors had been elevated to a position of great social and political import; their opinions about the world and about Swedish society carrying much weight in contemporary debates about social and political issues of the day. More importantly, this shift also signifies the emergence of the survivor as a "moral witness" to genocide; symbolizing and expressing "how and why victims" suffering mattered". 883

\section{Die Ermittlung and the Utility of Holocaust Representation}

If the survivor-witness had become a sensation and an object of fascination and respect in the evening press, the survivor-witness as strictly documentarian would re-emerge through the debate that surrounded Die Ermittlung in 1965. As previously mentioned, Weiss's play, premiered across West and East Germany in 1965. Although known to Swedish publics through reportages of Germany during the late 1940s as well as through his own books written in Swedish, Weiss was not proclaimed a great artiste until his play Marat/Sade premiered in Germany in early $1965 .{ }^{884}$ After the play premiered in Paris, Expressen's Sunday issue proclaimed that "We" (presumably referring to Sweden) "have received a world class dramatist!". 885 During 1965 and 1966 Weiss figured in the press as the German playwright who was also Swedish but whose reputation and relevance reached all four corners of

882 For critical perspectives on the exclusion of different groups from the idea of the people's home and the social and political effects of these exclusions se till exempel Mattias Tydén och Gunnar Broberg, Oönskade i folkhemmet: Rashygien och sterilisering i Sverige, (Stockholm: Gidlund, 1991). Maija Runcis, Sterilieringar i folkhemmet, (Stockholm: Ordfront, 1998). Yvonne Hirdman, Att lägga livet till rätta: Studier i svensk folkhemspolitik, (Stockholm: Carlsson, 1989).

883 Dean, The Moral Witness, 4.

884 Packalén, “'Som om det under varje ord låg en skugga,” 28.

885 "Vi har fått en dramatiker i världsklass!" May 2, 1965, Expressen. 
the world. As Aftonbladet's critic Kerstin Bergström presented him to her readers; "Peter Weiss (German author with a Swedish passport and an international conscience)". 886 As such, Weiss constituted another Swedish connection to the first Frankfurt Auschwitz trial, making representations of the Holocaust relevant to Swedish culture critique.

When Die Ermittlung premiered in East and West Berlin on the same night, Swedish critics were present to experience and evaluate the play that had created so much buzz. The critiques that were produced at this time reveal how Holocaust representation had entered a realm with strict aesthetic boundaries in Swedish public discourse. Arguments that both praised and criticized Weiss's play all related to notions of authenticity and truth. In DN it was stated, for example, that Weiss presented the details of Auschwitz with absolute exactness and that this was a necessity for one's conscience to "see the truth in the gruesome descriptions". ${ }^{887}$ Similarly, Expressen's foreign correspondent, Svante Löfgren, argued that the play had been gripping and that the lines of the witnesses and the accused had been "authentic" as well as "fairly and representatively chosen". 888

In SvD, two diametrically different appraisals of the play were presented; first through an interview with the director Erwin Piscator, conducted by the journalist and writer Sigrid Kahle, and secondly, through a review by the critic Per Erik Wahlund (who had also reviewed two of the Anne Frank plays, staged in 1956). In Kahle's article, the play's impact and importance was underscored through the concluding statement that "the camp grows on stage, and continues to grow into the auditorium, over all of Berlin, over Germany and all of life; there is no escape or absolution. We are to sit there and the camp should grow inside us, establish roots in us and never let go." 889 In contrast to this dramatic assessment of Weiss's play, Wahlund's review framed it as a cheap attempt to make money and critical acclaim off a subject that had already - and to greater effect-been explored by

886 Kerstin Bergström, "Han är i strid med väst," July 7, 1965, Aftonbladet. ["Peter Weiss (tysk författare med ett svenskt pass och ett internationellt samvete"].

887 Bengt Jansson, “Peter Weiss drama en moralisk bragd,” October 20, 1965, DN. [“detaljerna måste ges exakt och konsekvent $\mathrm{i}$ alla sammanhang för att ens medvetande skall kunna inse sanningen i de ohyggliga beskrivningarna"].

888 Svante Löfgren, "Gripande Weiss-premiärer i Berlin_tyst förstämning efter ridåfall," October 20, 1965, Expressen.

889 “Att medvetandegöra—_et är min uppgift," October 13, 1965, SvD. [“Lägret växer fram på scenen, växer ut över salongen, över hela Berlin, över Tyskland och hela livet, det finns ingen undanflykt och ingen pardon. Vi skall sitta där och lägret ska växa in i oss, slå rot där och aldrig komma loss"']. 
others. He thus claimed that Die Ermittlung was not even a dramatic achievement, but a dubious selection of witness statements and statements from the accused in the first Frankfurt Auschwitz trial. 890 "In reality", Wahlund contended, "everything that is said in Peter Weiss's dramatic montage, except the beautiful moving episode about Lili Tofler, has been said before with the same, or an even greater emphasis in other contexts; from Koestler's Arrival and Departure to Erwin Leiser's documentaries and the detailed court records that have also been published in the Swedish press". 891 Of course, this latter critique was not necessarily concerned with the content of the play but with the form, arguing repeatedly that Die Ermittlung was not theatre, let alone art. Hence, while Kahle saw Weiss's play as effectively communicating the truth of Auschwitz, step by step, through the audience and out into the world, Wahlund saw it as a mere ploy for attention.

This latter critique also mirrors some of the Anglo-American and Israeli critiques that dominated literary perspectives on Die Ermittlung in the 1970s and 1980s. In his article, “The Political Aesthetics of Holocaust literature: Peter Weiss's The Investigation and its critics," Robert Cohen explores how prominent Holocaust scholars and literary critics such as Laurence Langer, Alvin H. Rosenfeld, Sidra Dekoven Ezrahi and James E. Young, with "startling...ferocity" disparaged Weiss's play as an ideological "distortion and exploitation" of the Holocaust; a distortion that was also "artless, lifeless and mechanical". ${ }^{892}$ According to Cohen, these opinions were part of a more extensive "process of institutionalization" where a "politics of inclusion and exclusion" led to narrow definitions of what 'good' Holocaust art should be. As Cohen asserts, "these politics are most apparent in the discussions, uniquely central to the literature of Auschwitz, of facticity and authenticity, and of legitimacy; who is allowed to speak for the victims? The perpetrators? Who defines the victims and perpetrators?" 893

In addition to the notion that Weiss's play simply was not real theatre or art, some critics also questioned whether the play was relevant or not. When the play had premiered at the Royal Dramatic Theatre in Stockholm, in the spring of 1966,

890 "Bestialisk tragik men absolut inget diktverk," October 20, 1965, SvD.

891 "Bestialisk tragik men absolut inget diktverk," October 20, 1965, SvD. [“i själva verket har allt som sägs i Peter Weiss dramatiska montage, den fina gripande episoden om Lili Tofler undantagen, sagts förut med lika stark eller starkare emfas på skilda håll; från Koestlers 'Domens dag’ över Erwin Leisers dokumentärfilmer till de ingående rättegångsreferat som publicerats även i svensk press"].

892 Cohen, "The Political Aesthetics of Holocaust Literature," 43.

893 Cohen, "The Political Aesthetics of Holocaust Literature," 44. 
the philosophy professor Harald Ofstad contributed to the debate with a piece entitled "Penetration or documentation?". ${ }^{894}$ In the article, Ofstad drew from all of the previous arguments presented in the critiques of the West German production, contending that even though Weiss's play may have been useful ("nyttig") it brought no innovative or novel perspectives on Nazi perpetration. The main question asked in the article was thus; is Die Ermittlung "interesting"? Furthermore, Ofstad asked, "what is it that Weiss has found out about Nazism that he thinks is so important to relay to the world?" 895 Here, the authenticity of the testimonies on stage were both expressed as useful (although it was never explicated in what ways) as well as excessive. The underlying argument was; do we need another play about the Holocaust? Implicit in this argument was also that the Holocaust, and witnesses to the Holocaust, should only be afforded space in culture and politics (which at this time were intimately connected public spheres) if it brought any new insights into the 'whys' of Nazi perpetration. In contrast to Langer and Rosenfeld, Ofstad did not question the play for trying to make sense of the incomprehensible, but rather positioned it as useful and useless at the same time. Just like Hamrin had done before him, as well the other critics of the playhe emphasized the importance of witnessing but also contributed to a perspective on the witnesses as the old and somewhat tired aspect of the play.

Hence, while the evening newspapers relished in the human-interest stories of witnesses and victims who were reunited twenty years after the war, Swedish critics were more than ready to move on from the survivor-witness. Interestingly, however, there appears to be two parallel arguments in the Swedish critique of Die Ermittlung; one that emphasized the survivor-witnesses' importance as a communicator of emotion, and another that underscored the importance of facts and authenticity. Perhaps these were not contesting discourses but were based on an implicit consensus on the 'right kind' of emotion. In all critical accounts of the West German performance, the music was considered grating, too loud, and overemotional. Lily Tofler's gripping and beautiful part, on the other hand, was, at the same time praised for its soft emotional, authentic tone. It thus seems that, just like with Anne Frank, it was a question of a nobler kind of emotion. What had changed between the mid-1950s and the mid-1960s, however, were the multiple trials that continued to indict individuals and hold them accountable - together with an entire

894 Harald Ofstad, "Penetrasjon eller dokumentasjon?” March 16, 1966, DN.

895 Harald Ofstad, "Penetrasjon eller dokumentasjon?” March 16, 1966, DN. ["Hva är det han har funnet ut om nazismen som han synes det er viktig å meddele?’]. 
population-for crimes committed during the war. While the many had been accusatory - the trial format insisting that everyone should be heard-a new canon of Holocaust writers was being constructed; a canon that could not fit the many stories and details of the survivors, only those that could effectively move as well as explain without accusing or placing blame.

In an opinion piece in SvD, Kahle summed up German and Swedish responses to the trial by referring to "West German historians and political scholars" who agreed that "the era of guilt and confession is over: it is never the ones who should feel guilty who confess, in any case". 896 This, however, did not mean that the era of witnessing had passed. Instead Kahle asserted,

the Germans have every reason to be deeply grateful to Peter Weiss. He has accomplished what no other writer or play has accomplished even though many have tried to break a taboo. To open the flood gates and let the fresh water surge in. Only that full realization can hinder a new Auschwitz. ${ }^{897}$

Yet, the era of witnessing did not necessarily mean the "era of the witness". 898 Concurrently with Kahle's article, a new ideal for the survivor-witness had been born through the Nobel laureate, poet and writer Nelly Sachs.

In the critique surrounding Weiss's play there seems to have been two distinct ideological camps-not merely in terms of leftist and conservative commentators who either appreciated Weiss's Marxist perspectives or refuted them-but in terms of ideas regarding the use of Die Ermittlung. While critics such as Kahle, Svante Löfgren and Bengt Jansson underscored the importance of the play based on its exactitude and commitment to exploring the pain of Auschwitz so that society was not allowed to forget, Wahlund and Ofstad largely rejected the play; Wahlund thought it a sordid attempt at fame and fortune and Ofstad based his rejection on the play's perceived inability to explain Nazism. As a professor of philosophy at Stockholm polytechnic university, Ofstad — who had also penned a prologue for the first Swedish translated edition of Arendt's Eichmann in Jerusalem-inhabited an

896 Sigrid Kahle, "Under Strecket," December 12, 1966, SvD. [“Tyskarna har all anledning att vara

Peter Weiss djupt tacksamma. Han har förmått vad ingen annan författare och ingen annan pjäs förmått fastän många försökt; att bryta ett tabu. Att öppna dammarna och låta det friska vattnet forsa in. Bara den fulla insikten kan förhindra ett nytt Auschwitz"].

897 Sigrid Kahle, “Under Strecket," December 12, 1966, SvD.

898 Wieviorka, The Era of the Witness. 
effective subject-position. ${ }^{899}$ In a way, he seemingly stood on the sideline of politics in a decade when politics was everywhere. Rather than polemicizing like Wahlund about the disgraceful act of making bad art about the Holocaust, Ofstad simply asked the question of whether one should care deeper about the themes of the play since it had no satisfactory explanatory framework that could contribute to a collective understanding of $w h y$ this crime against humanity and the Jews had taken place. At the same time, Ofstad also opened his article by asserting that the play was very useful. The problematization of utility thus informs the debate with arguments relating to both silence and excess. As with Anne Frank and the witnesses of the Eichmann trial, however, no one significantly engages with the question of why it is important to remember. Rather, it is implicit in the positive reviews of Die Ermittlung, that 'never forget' equals genocide prevention. Similarly, Ofstad's questioning of the play's importance is based on the same argument; why talk about the Holocaust if we cannot prevent it from happening again? Understandings of the act of witnessing were thus determined by the problematization of utility-Peter Weiss is a witness to the witnesses, whose only role is to explain Nazism and prevent genocide.

\subsection{Conclusions: The Eichmann Trial as Transformative: Idealizing the Survivor Witness}

The era of the trials led to a transformation of the Holocaust survivor. From being an excessive witness whose main task consisted in testifying to the demise of Anne Frank, the understanding of survivor-witnessing, as something that was crucial in processes of accountability and punishment, led to the elevation of the survivor's position as truthteller and social commentator. As evidenced by the construction of camp survivors as Swedes in the aftermath of the Eichmann trial—as well as the inclusion of Zenia Larsson and Cordelia Edvardson into the notion of the People's home- the survivor had gone from ineffective yet necessary part of dealing with the past, to a prominent piece in the moral fabric of Swedish society. Hence, even though little attention was paid to the witnesses themselves during the Eichmann trial, their role as his indictors and accusers had still impressed upon the world that they were a force to be reckoned with.

899 Harald Ofstad, "Vem var Eichmann?" in Hannah Arendt, Den banala ondskan, (Aldus Aktuellt, 1964): 8-11. 
Yet, their collective strength was also problematized. Through Hamrin's writings, a problematic image of the survivor-witness emerged; their witnessing entrenched conflict, made themselves sick, and tested the nerves of those who were "forced" to listen. Again, their stories were deemed necessary for justice to run its course. Still, as the German critics mentioned by Kahle, Hamrin also seemed to agree at the end of the trial proceedings around Eichmann's crimes would settle the matter of guilt. Indeed, it appears that in every decade, a limit was set for how much the Holocaust could be discussed and disseminated. In the 1950s this limit was set by the ideal victim witness whose perfect emotional tone was enough to shame those who needed to be ashamed and remind those who needed to be reminded. In the 1960s, the Holocaust trials, although continuing into the next decade, were always seen as the final settlement with the Nazi past. This was, then, how the Holocaust survivor - as victim and as witness - was dealt with in public discourse; as a construct between silence and excess.

Because television did not provide the drama that the newspapers has promised, and because the newspapers were continuously struggling to stay relevant vis-à-vis newer mediums, the foreign correspondents received an important platform as commentators of the trial. Hamrin was thus inhabited an important subject position as communicator of world events as well as a critic of witnessing. Similarly, the critics of the 'Eichmann films' as well as the critics of Die Ermittlung (particularly Ofstad), strengthened their own positions by attaching themselves to an object (the Holocaust) that seemed to elicit interest-be it fascination or abjection-from cultural consumers. Thus, by opining on what the Holocaust really meant, and also what the survivor's role was in the construction of such meaning, the critics became subjects while the camp survivor trial witnesses remained an elusive mass.

The documentarian ideal also continued to inform constructions of the survivor-witness. Anne Frank's diary had been framed as a document of the Dutch occupation as well as to the Jewish genocide, yet it was the emotional connection that her writings established that had garnered the most attention throughout the 1950s. The trials of the 1960s, however, reified the importance of documentation and a performance of witnessing that was not excessive in itself or led to excessive emotional responses of the audience. Ofstad's question of whether Die Ermittlung was interesting also echoed the film critique of Pontecorvo's Kapo. The notion that the Edith's trajectory was irrelevant clearly demonstrates any explorations into the grey zones of victimization were not seen as usefulinformation about the Holocaust. Rather, the Holocaust victim was framed as an impression stamped by evil and it was this evil that needed further exploration. Thus, this chapter supports Waxman's 
contention that the Eichmann trial did not necessarily lead to further interest in the particular "vulnerabilities" of the camp survivors. ${ }^{900}$ Although the many witnesses testifying in the Holocaust trials of the 1960s did contribute to strengthening the ideal of the "moral witness," they did not constitute the classified in this regard. In The Moral Witness, Dean concludes that,

by bringing their experience into being, survivors cast their suffering as a dramatic caesura between a familiarized, natural world of death and dying and another world of planned and targeted murder in Soviet and especially Nazi camps; by bearing witness survivors testified to the destruction of the concept of humanity and redeemed it at once. ${ }^{901}$

Indeed, trial survivors testified to the Holocaust as a rupture in the human body, yet their role as universal redeemers were not as clear cut as Dean suggests in her genealogy of the "moral witness". Just like Anne Frank had been positioned as a stand in for all witnesses, dead and alive in the 1950s, the Holocaust trials of the 1960s served to both elevate and discipline the camp survivor trial witness. While Edvardson and Larsson became "moral witnesses" of sorts, the ideal "moral witness" would be Nelly Sachs—a construction that redeemed humanity by overlooking the wounds of camp survivors and the expressions that these wounds could take. It was thus not the trial witnesses themselves that were "moral witnesses"; through their accusation they garnered a critique of witnessing as accusation which, in turn, promoted a new vision for a Holocaust survivor witness, steeped in the image of Anne Frank, but alive and active in her testimony. 



\section{Chapter 6 - The Poet after Auschwitz: The Genius of the Exemplary Survivor Nelly Sachs}

\subsection{Introduction}

One of the main problematizations underpinning the research questions of this dissertation is that of the Jewish Holocaust survivor as either silent or excessive; notions that are intimately connected with the idea of one, singular and homogenous Jewish Holocaust history. When discussing the inclusion of interview subjects for the "Memory Archive" in the 1990s, the Jewish survivors were said to have one history; a history that was in no need of any further documentation. In the previous two chapters, this notion of singularity and homogeneity has been explored in relation to the Anne Frank phenomenon and the Holocaust trials of the 1960s. In the theatre critique of Anne Frank, the camp survivors were one voice, excessive yet necessary for the understanding of Anne's journey through the camp system. During the Eichmann trial, the "parade of trial witnesses" and their experiences-told before the emotional audience in Beit $\mathrm{Ha}$ 'am-were homogenized through the writings of Hamrin. Up until 1966, these survivorwitnesses thus remained an elusive mass with only a few breaking the surface to have their contours defined. Examples of such individuals were Cordelia Edvardson and Zenia Larsson. Through the first Frankfurt Auschwitz trial, the Holocaust had also been made relevant in Sweden through Swedes witnessing in the trial and through the inclusion of camp survivors into the notion of the people's home. The common denominator for these Swedish Holocaust witnesses (including Peter Weiss) was that they accused others, nations and economic systems for what had transpired in Germany and the countries that Germany had occupied during the war. When Sachs was awarded the Nobel Prize in 1966, then, a new figure emerged who could alleviate all the heaviness and guilt caused by these accusations.

The attention that Sachs received as she won this highly esteemed prize created a platform from which some critics could elevate her to an almost divine status. This was not least true in the Federal Republic where she was made to play an important role as the conciliatory medium between Germany and the Jews who suffered during the Holocaust. The construction of Sachs's work as non-accusatory and forgiving would also be reproduced in Swedish public discourse. Here, as opposed to in 1961, Ben-Gurion's credo presented in the New York Times that 
the world was to be "made ashamed of itself" 902 no longer applied. The shame and culpability that had been Germany's as well the rest of the world's to bear since the Eichmann trial was now alleviated by one small, mild-mannered woman living in a tiny apartment on Bergsundsstrand in Stockholm. Like the victim-witness, Anne Frank, Nelly Sachs became known as the most effective voice of six million dead; taking over the task from those survivor-witnesses who had testified against Eichmann in 1961. Their excesses were disciplined by Sachs's absence from debates regarding the guilt of others.

In this chapter I thus examine the construction of Nelly Sachs as the exemplary Holocaust survivor. This includes an analysis of the ways in which Sachs and her work were deconstructed by the author, influential cultural critic and editor-in-chief of DN, Olof Lagercrantz. I also investigate how Swedish news discourse positioned her and her work in relation to the Nobel Prize announcement, and in relation to the festivities that surrounded the awarding ceremony in Stockholm.

\section{2 Methods and Sources}

Sachs's early life has been well documented by several biographers, including the Danish writer Ruth Dinesen, Swedish writer, translator and literature scholar, Aris Fioretos, the Swedish literature critic, newspaper editor and writer Olof Lagercrantz and the Swedish literature critic, writer, journalist and Sachs's close friend, Bengt Holmqvist. ${ }^{903}$ Although receiving world-wide attention in the $1950 \mathrm{~s}$ and 1960s, the American literature scholar Jennifer Hoyer argues that real scholarship on Sachs's life as well as her work first began in the early 1970s. ${ }^{904}$ This early research, however, was heavily influenced by the politically colored appraisals Sachs's work received in the 1960s which meant that the focus remained on Sachs's post-war poetry with little attention paid to her early work and how this showed literary continuity, a subject which I will return to in my analysis of how Sachs's was constructed in 1966. Indeed, as Hoyer discusses in her 2014 book "The space of words": Exile and Diaspora in the Works of Nelly Sachs, the first 'real' critical exploration

902 Segev, The Seventh Million, 327.

903 Ruth Dinesen, Nelly Sachs: En biografi (Ringkøbing: After Hand, 1993). Aris Fioretos, Flykt och förvandling: Nelly Sachs, forfattare, Berlin/Stockholm (Stockholm: Ersatz, 2010). Bengt Holmqvist, Das Buch der Nelly Sachs (Frankfurt am Main: Suhrkamp, 1968)

904 Jennifer Miller Hoyer, "The Space of Words": exile and diaspora in the works of Nelly Sachs, (Rochester, NY: Camden House, 2014), 2. 
of Sachs's life and poetry came in 1992 with Ruth Dinesen's biography entitled Nelly Sachs. Eine Biographie. ${ }^{905}$ In her book Dinesen presents archival material of Sachs's earlier unpublished works as well as critical commentary of these writings. ${ }^{906}$ However, Dinesen's analysis is far from exhaustive and more in-depth literary scholarship on Sachs's early work did not come until the late 2010s with Swedish literature scholar Daniel Pedersen and Hoyer's examination of exile and diaspora in Sachs's work (pre and post exile). ${ }^{907}$ If the early biographers and literary critics saw Sachs's post-war poetry—seen as being unleashed by the Holocaustas the only significant work produced by Sachs, this latter scholarship has focused more on identifying continuity in Sachs's authorship; something which has had significant implications for how Sachs's poetry has come to be understood as a vessel of Holocaust memory.

Sachs's name had cropped up in my searches for articles pertaining to Eichmann and Anne Frank. Because of this recurrence she became a point of interest that, after having read Hoyer's and Martin's analyses of her critical reception in Germany, only grew. I began searching the digital newspaper archive for culture critique pertaining to her work before and directly after the 1966 Nobel Prize announcement. Knowing that she was a figure who had been important for mitigating collective feelings of guilt in Germany, I wondered whether her position in Swedish cultural life had been of a similar character. Although Pedersen's dissertation had dealt with Sachs from a literature studies perspective in a Swedish context, her construction as a witness to the Holocaust, perhaps even a survivorwitness—although rarely being referred to as an "överlevande" in the 1960s—had been left unexplored by Swedish scholarship. As previously discussed, the 1960s have been largely neglected by Swedish historians of the Holocaust, who have instead taken an interest in the period during and directly following the war as well as the 1990s and early 2000s. Understanding the place of Nelly Sachs in Swedish public discourse about the Holocaust thus became an important endeavor in and

905 Hoyer, "The Space of Words," 2. For scholarship conducted on Sachs in the 1960s, 1970s and 1980s see for example, Olof Lagercrantz, Nelly Sachs (Stuttgart: Richard Boorberg Vlg, 1969). Erhard Bahr, Nelly Sachs (München: C.H. Beck, 1980). Henning Falkenstein, Nelly Sachs (Berlin: Colloquium, 1984).

906 Dinesen, Nelly Sachs: En biografi.

907 Daniel Pedersen, Tårarnas Poetik: Nelly Sachs författarskap fram till och med In den Wobnungen des Todes (Doctoral diss.: University of Stockholm, 2016). See also Katherine M Bower, Ethics and Remembrance in the Poetry of Nelly Sachs and Rose Ausländer (Columbia SC: Camden House, 2000). 
of itself; not least because of her elevated position among the Swedish literature elite. ${ }^{908}$

In searching the newspaper archive I found a series of articles signed Olof Lagercrantz, the much debated and prolific writer, translator and editor-in-chief, who was a central cultural and political figure in Sweden during the 1960s. Because of Lagercrantz' prominent position, these articles became part of the empirical foundation for my analyses. In addition, newspaper articles including features, reviews, interviews and news articles were chosen for analysis as well as a television interview with Sachs in relation to the announcement. Using the same newspapers as in chapters 4 and 5-SvD, DN, Expressen and Aftonbladet-I wished to understand how the figure of Sachs had been portrayed, both in imagery and text, in relation to notions of victimization and witnessing. Here, as in previous chapters, the ideals of the "True Victim", the "moral witness" and the "heroic witness" guided my analyses of the newspapers' representation of Sachs.

Although the televised Nobel ceremony from 1966 could be accessed from the audio-visual archive at the National library, the footage lacked commentary. For this reason, I decided to exclude this piece of material from my analysis. However, it should be noted that this footage demonstrates how the Nobel ceremony was staged with references to the Holocaust through presenters and speakers who both represented camp survival and humanitarian work in combination with the natural sciences. The ceremony could thus be understood as part of a performance in Swedish Holocaust memory - a point tha did not, however, fit into the scope of this dissertation. Nevertheless, televised material of an interview between the journalist and poet Matts Rying and Sachs was also found in the audio-visual archive; a find that was included into the analysis of Sachs and the media after the Nobel prize announcement.

\subsection{The Reception of Sachs' work in Germany and Sweden}

Both Germany and Sweden are particularly interesting national contexts with regards to Sachs and her work; the first being her country of birth, providing her with her language of expression while the second constituted her adoptive country, a place with literary traditions that inspired her later work. The politicization of Sachs's poetry in West Germany is also relevant to the Swedish context whose

908 See for example, Anders Olsson (ed.) Bokstäverna jag färdas i: En antologi om Nelly Sacbs, (Stockholm: Themis, 2001). 
most prominent cultural figures mirrored the German context by emphasizing the conciliatory aspects of Sachs's persona as well as her poetry. In this section I thus sketch a background to the critical reception of Sachs in West Germany and in Sweden in order to create a context through which the following analyses of Lagercrantz' critique as well as Swedish news discourse can be understood.

\section{Mitigating a Painful Past in West Germany}

Leonie (Nelly) Sachs was born in 1891 in Schöneberg, Germany. She was the only child of William and Margarete Sachs, both assimilated Jews who, together with their daughter enjoyed the wealth and cultural capital which came with bourgeois life in early Weimar Germany. Harder times awaited, however, with her father growing sickly in the 1920s; a sickness which subsequently led to his death in 1930. When the Nazis came into power three years later, Sachs and her mother were stripped of their German citizenship and lived as stateless Jews until Sachs acquired Swedish citizenship in 1951 (her mother passed away in 1950). As a child, Sachs started a letter exchange with the renowned Swedish author Selma Lagerlöf and it was through her contacts that Sachs and her mother were able to escape Nazi Germany to Sweden in $1940 .{ }^{909}$

Although writing from an early age, Sachs's first publication in Germany came out in 1921 and consisted of a two part collection of fairy-tales entitled Legenden und Erzählungen. ${ }^{910}$ It would take another thirty-five years before Sachs received any real recognition for her writing in her native country. In more ways than one, the subject-matter of her post-war writing which was primarily focused on exploring the bodily and spiritual pain that Jewish victims suffered during the Holocaust, both hindered and facilitated this process of reception and recognition. Forgetting Nazi atrocities was, in the early years of the Federal Republic, perceived as a prerequisite for the successful reconstruction of a peaceful and democratic country. As Jeffrey Herf has shown, Konrad Adenauer's approach to nation-building was one of selective remembering. ${ }^{911}$ In a speech to the Reichstag in 1949, Adenauer proclaimed that "the government of the Federal Republic, in the belief that many have subjectively atoned for a guilt that was not heavy, is determined where it appears acceptable to put the past behind us". ${ }^{912}$ Integral to Adenauer's new West

909Fioretos, Flykt och forvandling, 35-38; 104.

910 Hoyer, "The Space of Words," 18.

911 Jeffrey Herf, Divided Memory: The Nazipast in the two Germanys (Cambridge, MA: Harvard University Press, 1997), 267-333.

912 Herf, Divided Memory, 271. 
Germany was thus the relinquishing of individual guilt, a movement 'forward' which assumed that those who were really at fault had either been punished or were, in other, alternative ways, atoning for their crimes. At the same time, crimes committed by the red army and other communist groups were to be remembered in order to strengthen resistance against the un-democratic forces at work in the German Democratic Republic (GDR). ${ }^{913}$

Furthermore, based on Herbert Marcuse's discussion about the "three illusory longings" Martin argues that attitudes towards Holocaust memory during these years were founded on the myths of "German victimization, ignorance and resistance". ${ }^{914}$ The victimization of the German people was viewed as double in nature as the Germans had been subjected to the madness of Hitler and his henchmen as well as the "vengeful" tactics of the allied forces, including the ferocious bombings of German cities at the end of the war. ${ }^{915}$ The second myth asserted that the German people had been unaware of what the Nazis were doing during the war, thus exonerating them from any responsibility for what happened to the victims of Nazism. In a sense, the third myth was intricately connected to this idea about ignorance as it presented a notion of a different Germany held intact by the strength of its long-standing civilization and culture. Goethe became one of the main symbols for this "other" Germany and commemorative practices surrounding his life and work served to remind the German people that their 'real' nation had withstood the forceful, albeit temporary, intrusion of Nazism. ${ }^{916}$

These three myths also permeated the post-war literary scene in the Federal Republic. The three genres which dominated West German society at the time were Kriegsliteratur (war literature), Trümmerliterature (Rubble literature) and Heimkehererliteratur, ('Return' literature). ${ }^{917}$ Although all three contributed to the creation of different forms of silence surrounding the Holocaust, Martin argues that the latter was particularly potent in exculpating the German population from any crimes committed during the war. With prisoners of war and former soldiers writing from a so called "worms eye view", ordinary Germans could relate to the

913 Herf, Divided Memory, 271.

914 Martin, Nelly Sachs, 9.

915 Martin, Nelly Sacbs, 10. See also Bill Niven (ed.) Germans as Victims: Remembering the Past in

Contemporary Germany (Houndmills, Basingstoke, Hampshire: Palgrave Macmillan, 2006).

916 Martin, Nelly Sachs, 13.

917 William Rasch, "Introduction: looking again at the rubble" in German Postwar Films. Studies in European Culture and History (Palgrave Macmillan: New York, 2008). 
idea of having little to no knowledge of over-arching Nazi ambitions. ${ }^{918}$ This, according to Martin, created a hostile environment for Sachs's post-war literature which demanded too much from a populace who wished to accept the narrative of German victimization and move forward into the future rather than dwell on the past. As Martin asserts about this period; "the condemnatory message that permeated Sachs's poetry was also unwelcome; the German public was more concerned with cultural restoration than with having the pangs of guilty collective consciousness roused". ${ }^{919}$ Moreover, Martin points to a few key occurrences which helped turn this trend in the 1950s and 60s. Beginning with the Ulm Einsatigruppen trial in 1958 and continuing onto the Eichmann trial in 1961, swiftly followed by the first Auschwitz trial in 1963-1965, and the media attention that these garnered, memories of the Holocaust could no longer be kept at bay. Also, instances of antisemitism were seen around Germany, most notably in Cologne where the Synagogue was desecrated in 1959. Something that Martin fails to mention but which, according to Harold Marcuse, had a great impact on the younger generation in Germany was the publication of the Diary of Anne Frank. According to Marcuse, Frank's fate led to a heightened interest in the Nazi's crimes and he shows how the before neglected memorial site at Buchenwald became a well visited place by youths in Germany after 1956. ${ }^{920}$ Although references to German perpetrators were edited out of the German edition of the book, Frank's narration of her thoughts and dreams as well as the fate of those around her, awakened a keen interest amongst German youth in the lives and deaths of Jewish Holocaust victims. Many still argue that the successful reception of the Diary of Anne Frank in Germany was due to its personal character, taking place in a small familial world with few references to perpetrators and their deeds. ${ }^{921}$ Also, the subsequent dramatizations of the book were especially focused on the hopeful themes of the book which obfuscated the very real and horrible deaths of Anne Frank and her family. As Sachs would also later become, Anne Frank became a means for German

918 Martin, Nelly Sacbs, 25.

919 Martin, Nelly Sacbs, 35.

920 Harold Marcuse, Legacies of Dachau: uses and abuses of a concentration camp, 1933-2001, (Cambridge: Cambridge University Press, 2001), 201.

921 Sture Packalén, Tyska minnesgemenskaper: Nazism, krig, förföljelse och folkmord i tyskspräkig litteratur efter 1945 (Stockholm: Carlssons Bokförlag, 2010), 153-155. See also Alvin Rosenfeld, Bruno Bettelheim and Thaler \& Wiedemann "Hauntings of Anne Frank: Sightings in Germany" in eds Barbara Kirschenblatt-Gimblett \& Jeffrey Shandler Anne Frank Unbound: Media, imagination, memory, (Bloomington: Indiana University Press, 2012). 
publics to ignore any real confrontation with the Nazi past and a way to quickly find absolution and forgiveness in her story.

The Holocaust literature of the 1950s thus had to be reinterpreted into something hopeful, redemptive and forgiving in order to be accepted in the Federal Republic. Therefore, rather than becoming a figure used to pierce further into the complicated web of perpetration and guilt, Sachs was posed as the remedy to all such issues. As Martin notes, the accolades and prizes Sachs received in the late 1950s and 1960s were "based less on the merit of her work- that would come with critical scholarship which really only began in the 1970s-than on avoiding a genuine attempt at 'vergangenheitsbewältigung"'. ${ }^{222}$ In other words, the interpretation of Sachs's work as conciliatory was a political tool used to absolve all Germans of responsibility and free them from the uncomfortable questions raised in the Holocaust trials of the 1950s and 1960s. The first step towards such an instrumentalization was exhibited when a prize in Sachs's name was instituted in the city of Dortmund. In introducing Sachs as the first recipient of the Nelly Sachs-preis, the mayor of Dortmund praised her "'exemplary message of forgiveness". ${ }^{923}$ Although Sachs never involved herself in any of the debates surrounding Eichmann or spoke on issues of justice or retribution, it is a far stretch to call her work forgiving. In one of her most famous collection of poems from 1947 entitled In den wohnungen des Todes Sachs, for instance, presents a most damning image of the Bystander. In one of the poems, Katherine Bower asserts that "the poetic voice $[\ldots]$ addresses the bystanders, who by their very apathy are to be judged as complicitous in the murder of the victims." 924 There were of course other themes in Sachs's work that could be read as conciliatory, but the neglect of Sachs's accusatory voice also demonstrates that it was not her work alone that solicited the attention she received in the Federal Republic at the end of the 1950s and the early 1960s. Indeed, Martin poignantly argues that "what the various prizes, honors and the attendant public discourse attests to is an attempt to have Sachs perform the task of mourning on behalf of the German people, to applaud her for doing so and to return to "business as usual"'. 925

922 Martin, Nelly Sachs, 35.

923 Martin, Nelly Sachs, 39.

924 Bower, Ethics and Remembrance, 22

925 Martin, Nelly Sachs, 47. 


\section{Sachs and the Swedish Cultural Elites}

Even though there were a handful of individuals within the Swedish literary elite who had read most of Sachs's poetry by 1966 and wrote extensively on her work in newspapers and books, none strayed far from the image of the West German perspective of her as a the conciliatory figure whose main ambition was to explore the pain of the victims rather than to point fingers at perpetrators or passive bystanders. The struggle to maintain that image is understandable in a German context where the population was seen to be 'under attack'. In Sweden, however, such motives are more difficult to explain. One crucial context, however, is the pro-Israeli feeling that dominated Swedish public discourse during the 1950s and 1960s. Although a critical debate regarding Israel grew throughout the 1960s, the hegemonic discourse, characterized by "deep sympathies" for Israeli ambitions to grow as a country and a "near unconditional support for the Jewish part of the Arab-Israeli conflict" remained largely uncontested until 1967.926 As discussed in the previous chapter on the Eichmann trial, the editor-in-chief of DN until 1959, Herbert Tingsten, was a staunch pro-Israeli liberal newspaper man and intellectual. Other liberal and social-democratic newspapers followed a similar line in questions regarding Israel and often described it as a collectivist and liberal utopia, built on egalitarian ideals. ${ }^{927}$ The Holocaust was also posed as a reason for supporting the Israeli project and was explained as the price that the western world had to pay for its crimes against Europe's Jews. ${ }^{928}$

After arriving in Sweden with her mother in the winter of 1940, Sachs soon began to work as a translator of modern Swedish poetry. In 1941 she requested to translate the work of the already established Swedish poet Johannes Edfeldt who, in turn, promised to help her with her own work. ${ }^{929}$ That same year Edfeldt managed to arrange for Sachs's first Swedish publication in the weekly magazine $V i{ }^{930}$ For the next three decades, Edfeldt worked tirelessly to call attention to

926 Bachner shows that there was some resistance to this discourse, especially with the growth of a new left in the 1960s which served to highlight the plight of the Palestinians to a greater degree than had been visible in public discourse before. Henrik Bachner, Aterkomsten: Antisemitism i Sverige efter 1945, (Stockholm: Natur och Kultur, 1999), 90.

927 Bachner, Aterkomsten, 96.

928 Bachner, Aterkomsten, 97.

929 Dinesen, Nelly Sachs: En biografi, 256-257.

930 Dinesen, Nelly Sachs: En biografi, 257. 
Sachs and her work in the public sphere. ${ }^{931} \mathrm{He}$ was thus one of the first to know Sachs's talents and served as a key figure in elevating her to the position of the Holocaust survivor in 1966. Through Edfeldt and through her own translating work Sachs also came in contact with other authors, poets and Swedish cultural profiles throughout the 1940s, most notably Bengt and Margareta Holmqvist, the Jewish exiled literature professor Walter A Berendsohn, the Finnish-Jewish composer Moses Pergament and the prominent writer and cultural critic Erik Lindegren. ${ }^{932}$ Because of their promoting her work, Sachs was already considered a rising star at the end of the decade. On the cultural pages of Aftonbladet in 1949, it was, for example, advertised that Sachs's yet unpublished play Eli was going to be published as a "bibliophile edition" by Edfeldt, Berendsohn and Gunnar Berkow. In a parenthesis after this declaration the article presented Sachs as "the famous German-Jewish poet who through Selma Lagerlöfs personal involvement was rescued over to Sweden and who has, amongst other things, produced a number of translations of Swedish poetry". 933 Where this notion of her fame came from is unclear as Sachs had not reached any notable renown either inside or outside of Sweden at this point in time. Most likely, Sachs was well-known to a rather small Swedish cultural elite, within which many of its members worked to provide her with the profile of an exiled literary celebrity.

In 1958 and 1959, a handful of articles were published in DN and Aftonbladet on Sachs and her work. In an article in Aftonbladet, the writer and cultural critic Birgitta Trotzig provided a "loving analysis" of Sachs's literary deed using phrases such as "burning purity" and "timeless". 934 Trotzig began her article with the perfunctory statement that "the German-Jewish poet Nelly Sachs should not be a strange name to the Swedish public"; thus assuming that Swedish audiencespresumably referring to a high-culture consuming middle class rather than the working masses-knew Sachs and her work well.935 This assumption is rather surprising when considering the fact that Sachs received relatively little attention in

931 Dinesen, Nelly Sachs: En biografi, ["I skrift och tale påkalder han gjennem årene outraetteligt offentlighedens opmaerksomhed på hende"].

932 Lindegren was also a member of the Swedish Academy between 1962-1968.

933 "Supskription på mysteriespel," June 5, 1949, Aftonbladet [“(Nelly Sachs är den berömda tyskjudiska skaldinnan som genom Selma Lagerlöfs personliga ingripande räddades över till Sverige och som här bl.a. verkställt en rad översättningar av svensk lyrik)’].

934 She later became a member of the Swedish academy (1993-2011).

935 "Flyktens bröd," August 18, 1958, Aftonbladet ["Den tysk-judiska poeten Nelly Sachs bör inte vara något obekant namn för svensk publik”]. 
the major dailies and evening newspapers during the 1950s. Indeed, Trotzig's review article in Aftonbladet as well as a review by Edfelt in DN (published a month prior) were two of the first real critical articles within which Sachs's persona and work were presented to Swedish publics, both through textual descriptions as well as pictures of Sachs. In these reviews, however, some crucial ideas about Sachs and her writings were introduced. For instance, in his review Edfelt described her poems as "purified from hatred" while also arguing that Sachs attempted to "build a bridge of love over the river of death". ${ }^{936} \mathrm{He}$ also asked whether "any now living poet has more whole-heartedly identified themselves with the suffering of an entire people". 937 Trotzig also asks the rhetorical question of whether Sachs's ability/willingness to create came only after her flight to Sweden. These review articles thus served to plant the seeds which later grew to become established truths about Sachs-1) that she harbored no feelings of resentment, hatred or vindication towards the Nazis and German bystanders, 2) that she was Jewish suffering incarnate and, 3) that her escape/survival unleashed her talents and made her a poet.

As will be demonstrated later in the culture critique presented by Lagercrantz, these three perceptions of Sachs and her work would serve as cornerstones in the construction of her as a conciliatory figure whose thoughts and actions moved beyond mere human feeling. In addition, Sachs's work could also be heard on Swedish radio. As early as 1946, Sachs's words were read on Swedish radio, then in German by Herman Greid with an introduction by Edfeldt.938 A decade later, in 1959, the play Eli-made into an opera with music by Moses Pergament—would be broadcast as part of the radio program Radioteatern ("the radio theatre"). Hence, both Edfelt and Pergament also contributed to Sachs's work being heard as well as read. Schnabel's radio documentary Anne Frank: Sparren av ett barn was presented together with Eli on the basis of being "Jewish" works in the 1959 tableau for the month of March. ${ }^{939}$ Even though they had little in common with regards to content and form, they were singled out as separate from the 'normal' tableau; an act which tied Sachs's work to the hugely successful and well-known narrative of Anne Frank's diary.

936 "Rekviem för hemlösa," July 7, 1958, DN.

937 “Rekviem för hemlösa," July 7, 1958, DN [“Man kan fråga sig om någon nu levande lyriker mer

helhjärtat än Nelly Sachs identifierat sig med ett helt folks lidanden”].

938 "Riksprogramt," November 5, 1946, Aftonbladet.

939 "Radioteatern ger ny opera av Pergament," February 26, 1959, Aftonbladet. 
Although mostly lauded and celebrated throughout the 1950s, Sachs's translations of Swedish poetry did, in some instances, garner critique. In an issue of the literary magazine Lyrikvännen ("friends of poetry"), the German exiled writer Karl Kern expressed his discontent with how some of Sachs's translations were rather "reckless" in their interpretations of the "metric, syntactic and rhythmic structure" of the poetry. This critical engagement with Sachs's translations led to a longer, and rather heated, debate between Lyrikvännens editor, Stig Carlson and Bengt Holmqvist. In a rebuttal to Carlson's defense of his publishing Kern's critique, Holmqvist maintained that the criticism of Sachs's impeccable translating work was bad enough, but it was nothing compared to Kern's understated acknowledgments of Sachs's own poetry. Holmqvist's indignant tone resulted from Kern stating that Sachs's work had grown "stronger" over the years. "It was strong enough already in 1947" Holmqvist furiously finished his rebuttal, "when she put 'In den Wohnungen des Todes' to her resumé- the great poetic work about the demise of European Jewry". 940 According to Holmqvist, the most insulting aspect of Kern's article was not that it criticized Sachs's translation but, rather, that it did not sufficiently recognize her own accomplishments as the voice of Jewish suffering. The same argument-that the value of Sachs's poetry lay in the serious subject-matter of her work - could also be found in official statements made by the Swedish academy relating to individuals were being considered for the Nobel Prize in literature. In the permanent secretary Anders Österling's special statement for 1963 he wrote:

It has been established through expert opinion that the German-Jewish poet has illustrated her tribe's tragic destiny with suggestive and moving symbolism. The Committee can largely share in this esteemed evaluation, even when disregarding the purely humanitarian sympathies which rightly befall the writer in her Swedish exile. The thought of a Nobel Prize seems, however, premature and requires further consideration. ${ }^{941}$

940 Bengt Holmquist, “Undret Nelly Sachs: Ett replikskifte,” May 10, 1963, DN.

941 Anders Österling, "Utlåtande av Svenska Akademiens Nobelkommitté: Särskilt yttrande," 1963 Nobelkommitténs arkiv. ["av sakkunnighetsutlåtandet framgår, att den tysk-judiska skaldinnan har gestaltat sin folkstams tragiska öde med suggestiv och gripande symbolik. Kommittén kan i mycket dela den höga värdesättningen, även bortsett från de rent mänskliga sympatier som med rätta tillkommer författarinnan i hennes svenska exil. Tanken på ett nobelpris synes dock för tidigt väckt och förutsätter närmare prövning”]. 
In 1965, a similar set of arguments were presented by the Academy and its permanent secretary. At this point, however, Sachs was not considered as accomplished a writer as Agnon, whose "Hebrew authorship seem[ed] to [Österling], singular in its character, whereas Nelly Sachs's poetry, however highly held, could be compared to other significant performances in German language poetry from the last decades". ${ }^{942}$ Nevertheless, what made this proposal more potent than other suggestions for a "split" Nobel Prize was, according to Österling, the fact that Agnon and Sachs "together represent[ed] the Jewish people's tragic destiny in our time". 943 This phrasing was later used in 1966 to justify the choice of Sachs as one of the Nobel Laureates for literature that year. While Agnon was said to "give a promising expression of the Jewish spirit and its distinctiveness", Sachs was described as a poet of "great and deep calling" who had, "with moving empathy and inspiration, interpreted the tragedy of the Jewish tribe in our time". 944 Agnon and Sachs were thus positioned as the great bearers of both a Jewish history (in Europe) and a Jewish future (in Israel); a potentially controversial position given the fact that Sachs had never visited Israel. Indeed, in his statement given in 1966, Österling attempted to forestall some of the critique which were anticipated for the choice of laureates that year. In his statement he clarified that "if a Nobel Prize to these two would be perceived as a Zionist gesture and procure political comments, the academy should be able to calmly defend this humanist tribute, which also has to be seen to fully live up to the testator's purpose and goals". 945 There was thus a sense that the awarding of the Nobel Prize to Sachs and Agnon would be perceived as inherently political.

This was also something that German critics picked up on, some of whom wondered why Sachs should receive the life-time achievement award that the Nobel Prize constituted when she had been virtually unknown to Western publics

942 Anders Österling, "Utlåtande av Svenska Akademiens Nobelkomitté: Särskilt yttrande," 1965 Nobelkommitténs arkiv. [“Agnons hebreiska författarskap synes mig ensamstående i sin art, medan Nelly Sachs poesi, hur högt man än vill värdera den, påkallar jämförelser med andra betydande prestationer i tyskspråkig diktning från senaste årtionden"].

943 Anders Österling, "Utlåtande av Svenska Akademiens Nobelkomitté: Särskilt yttrande," 1965

["Samuel Agnon—Nelly Sachs representerar tillsammans det judiska folködets patetik i vår tid”]. 944 Anders Österling, "Utlåtande av Svenska Akademiens Nobelkomitté, Särskilt yttrande," 1966 Nobelkommitténs arkiv.

945 Anders Österling, "Utlåtande av Svenska Akademiens Nobelkommitté: Särskilt yttrande,” 1966, Nobelkommitténs arkiv [“Om ett nobelpris till dessa båda skulle uppfattas som en zionistisk gest och framkalla politiska kommentarer, torde akademien med lugn kunna försvara en human hedersbetygelse, som även får anses till fullo motsvara testators syftesmål']. 
only ten years before. ${ }^{946}$ Also, some questioned the ideological motivations behind the choice of recipients and why their Jewishness was emphasized as part of the motivation. ${ }^{947}$ Finally, the prize was, by some German literary critics, viewed as a sort of "obsequious reverence" for her work, a reverence which did not engage with the language, structure and content of Sachs's poetry in any meaningful way. ${ }^{948}$ In Sweden, however, no such critique could be detected on any of the larger newspapers' so called cultural pages. Instead, the inflated conceptions of Nelly Sachs outlined above were further entrenched by cultural critics and opinion makers, making her the new spokesperson for the Holocaust's Jewish victims as well as the Jewish conscience of the world; a task that she was carrying simultaneously with camp survivor-witnesses, concurrently giving their testimonies in different court rooms around Germany.

\section{4 The Beauty of Pain: Olof Lagercrantz Constructs Nelly Sachs}

One of the key figures involved in constructing Sachs as the spokesperson for six million dead in the preamble to her receiving the Nobel prize as well as in the direct aftermath of the Swedish Academy's announcement, was DN's editor in chief, Olof Lagercrantz. Lagercrantz played an especially important role in the story of how Nelly Sachs was constructed as the genial Holocaust survivor in Swedish media discourse. As a well-received writer and poet and as the coeditor-in-chief of DN between 1960 and 1975, Lagercrantz dominated the highly politicized cultural scene of the 1960s. As a practitioner (writer and poet) and an influential literary critic he was both the subject of critique while also setting the agenda for what proper cultural critique should be. In addition, Lagercrantz worked as a publisher and translator, two positions which furthered his influence in the Swedish literary sphere. ${ }^{949}$ In this section of the chapter I examine the ways in which Lagercrantz constructed Sachs, primarily through an analysis of his six-part article series,

946 Martin, Nelly Sachs, 43.

947 Martin, Nelly Sachs, 43.

948 Martin, Nelly Sachs, 44.

949 Stina Otterberg, Klädd i sitt språk: Kritikern Olof Lagercrantz, (Lund: Ellerström, 2010), 14. 
published in DN in the months leading up to Sachs being awarded the Nobel Prize for literature. ${ }^{950}$

Lagercrantz's most powerful position was undeniably that of editor-in-chief of DN, a newspaper which had dominated the daily press since the early 1940s. ${ }^{951}$ He shared this position with Sven-Erik Larsson and Sten Hedman. The former had been appointed as the political spear-head of the paper with Lagercrantz as the cultural expert although the responsibility for the political editorial pages and the so called 'cultural pages' was contractually split down the middle. ${ }^{952}$ In his dissertation from 1975, Sven Nilsson investigates how the cultural pages in the daily press developed from their inception in the 1920s up until the early 1970s. During the 1960s, Nilsson argues, the dominating perception of the newspapers' societal role was that they were to offer distinct and differing political, moral and aesthetic opinions to the public, independent of official government politics. ${ }^{953}$ Despite a widespread consensus on this fundamental goal, attitudes differed with regards to the relative autonomy of the cultural pages. Should they toe the line of the political editorial pages? Or could they create their own political profile, even if it sometimes contradicted the official political profile of the newspaper? The schism that formed between Lagercrantz and Larsson—a conflict that culminated in 1968 with a reorganization of the editorial responsibility—was partly due to differences in attitude toward these questions. Larsson, a strict Folkpartist (the liberal party) considered it his duty to express liberal values on the editorial pages of the paper and held the view that politics and culture were separate entities, meaning that the cultural pages should not involve themselves in the political issues of the day. Lagercrantz, on the other hand, believed that culture and politics were

950 Olof Lagercrantz, "Nelly Sachs och de döende," August 14, 1966, DN. "Såret mellan natt och dag," August 21, 1966, DN. "Den förstenade ängeln," September 3, 1966, DN. "Det lidande folket," August 17, 1966, DN. "'Ingen vet mer," September 11, 1966, DN. "Den pågående skapelsen," October 21, 1966, DN.

951 Lars-Åke Engblom, “Tidningar dör men pressen lever vidare,” Den svenska pressens bistoria: Bland andra massmedier (efter 1945), in eds Lars-Åke Engblom, Sverker Jonsson \& Karl-Erik Gustafsson, (Stockholm: Ekerlids, 2002), 67-71.

952 Sven Nycander, Makten över åsikterna: DN under Olof Lagercrantz och Sven-Erik Larsson (Stockholm: Atlantis, 2014), 7. Hedman was not directly involved in creating the content for the newspaper but was appointed as acting publisher, meaning that he worked as a direct link between his editorial colleagues and the newspaper's owner.

953 Nilsson, Det offentliga samtalet: Storstadspressen som medium för kulturinformation och kulturdebatt, (Phd diss., Lund University, 1975), 107. 
one and the same. ${ }^{954}$ Added to this belief, Lagercrantz never thought that politics had to adhere to liberal discourse but rather that the cultural pages could offer a space for more avant-garde views or what the previous editor in chief of DN, Herbert Tingsten, referred to as "leftist-radical" and "new-left" opinions. In offering the cultural pages as a space for political 'radicalism' and differing political views to the official newspaper profile, Lagercrantz did not necessarily break any norms. Rather, he was a man of his time; a time in which the politically active younger generation in Sweden had all moved further to the left and a time in which the concept of culture expanded to include more than mere aesthetics. ${ }^{955}$ Because of Lagercrantz' active politicization of the cultural pages during the 1960s, it has been widely argued that traditional culture such as literature had to give way for political opinion-making during this decade. ${ }^{956}$ Contesting this perception, however, the Swedish literature scholar, Stina Otterberg, argues that one did not exclude the other. Because Lagercrantz did not separate culture and politics but wanted one to inform the other, literature and its practices were used as tools to understand the political issues of the day. ${ }^{957}$ This perception and the literary critique it produced throughout the 1960s would come to shape the image of Nelly Sachs and her poetry in 1966.

From August until November 1966, Lagercrantz published a series of articles on Sachs that covered her life, her work and the impact her work had on greater philosophies of pain and death. In his six piece article series-which were also published as a book under the title Den pågående skapelsen: en studie $i$ Nelly Sachs diktning ("The Continuous Creation: A Study in the Poetry of Nelly Sachs") in December the same year-Lagercrantz presented as well as manifested Sachs as the Holocaust survivor, someone who was uninterested in guilt and justice, a 'seer' of the world beyond time and space and a universal symbol of righteousness in the face of unimaginable pain and suffering. There is a clear progression in the disposition of the article series, moving from more detailed analyses of Sachs's poetry to larger complexes of her political impact. This progression also follows a logic of both particularism and universalism, with Sachs as both specifically Jewish

954 Otterberg, Klädd i sitt språk, 69.

955 Otterberg, Klädd i sitt språk, 12-14.

956 See for example Sven Nilsson, Det offentliga samtalet, 139. Sven Nilsson \& Rolf Yrlid (eds), Svensk litteratur $i$ kritike och debatt 1957-1970: en antologi, (Stockholm: Prisma, 1972), 39. Sverker Jonsson \& Karl-Erik Gustafsson, Den Svenska pressens historia: Bland andra massmedier (efter 1945), (Stockholm: Ekerlids, 2002), 163-165.

957 Otterberg, Klädd $i$ sitt språk, 72. 
and German while, at the same time, a universal symbol for all mankind. Before delving into an analysis of Lagercrantz's article series, however, it is important to note that what Lagercrantz expressed in his writings on Sachs during the autumn of 1966, was not only his own thoughts and musings but, rather, constituted a collection of ideas based on interviews and conversations with Sachs herself. In addition, other experts on Sachs and her poetry acted as editors to the text; a list that included Berendsohn, Pergament and Edfeldt. In addition, Lagercrantz credited Margareta and Bengt Holmqvist, both close friends of Sachs's and the latter her biographer, with having contributed insightful comments on his analysis of her work and the intentions behind it. ${ }^{958}$ Although it is difficult to ascertain to which degree these different individuals influenced Lagercrantz' writings on Sachs, they all constituted a closely knit circle of people who propagated for the publication and spread of Sachs's work both within and outside of Sweden. ${ }^{959}$ Also, there are aspects about Sachs's childhood and her time at Beckomberga psychiatric hospital which most likely came from Sachs herself. In the foreword to his book Lagercrantz states that beyond "great generosity" and "friendship", Sachs had helped him decipher especially difficult passages in her work. Through the voice of Lagercrantz, Sachs was, therefore, integral in the construction of her own persona and her work on the cultural pages of DN in the late summer and autumn of 1966. I want to underscore this point so as not to perpetuate an object/subject dichotomy where the former is always inhabited by individuals with survivor experience. As with all subjects, survivors' positions and their ability to act was conditioned by power relations which, in turn, determined the order of discourse. Yet, survivors' actions in constructing images of the Holocaust and their own communication of it, were still acted out from specific subject-positions. In other words, Jews with survivor experience were never mere objects, as little as nonsurvivors were always subjects with significant subject-positions.

In his biography of Sachs, Fioretos characterizes Sachs's influence on the perception that others had on her and her history through the example of the "dead bride groom". This is a recurrent feature in writings on Sachs with many attributing her poetic birth to the moment she lost the love of her life. Yet, there are three different men who feature in Sachs's narratives on the "dead bridegroom" —all of whom have been pointed out as the direct inspiration of her work. These potential

958 All were mentioned as crucial to the process of writing the articles and the book in the Lagercrantz' preface. Olof Lagercrantz, Den pågående skapelsen: en studie $i$ Nelly Sachs diktning, (Stockholm: Wahlström \& Widstrand, 1966).

959 See Dinesen, Nelly Sachs: en biografi, 156-179. 
bridegrooms include a boy who died at seventeen, a man who perished as part of resisting the Nazis in the 1930s and a man who died in a gas chamber. From Berendsohn's notes, scribbled down after a meeting with Sachs in which the inspiration of her writings was discussed, Fioretos concludes that Sachs,

put equal signs between the anonymous infatuation of youth, the man she met in the 1930s and the person who died during the war: $x=x=x$. By attributing the whole work to a source so overwhelming that it did not leave room for anything else, she provided these tragic events with a story known from chivalrous poetry as well as romance novels. The implication of a living pain [surrounding these memories] made further inquiry impossible. A tactful conversational partner such as Berendsohn could only meet her trust with pious silence. No one wanted to cause Sachs further harm by posing follow up questions. ${ }^{960}$

Although this is taken from one interview with Sachs it seems reasonable to suggest that most of her relationships were characterized by this level of respect. In her seeming frailty and with a poetic language that left many questions unanswered, Sachs could create notions of her own authorship that were connected to symbols of love and loss as well as to stories of the Holocaust that seemed lived but that she, herself, had never experienced. These love stories-often held as authentic parts of Sachs's own Holocaust testimony-could never be fully excavated due to the respect that those around her had for her position as a true Holocaust victim and "moral witness". This reverence for Sachs's writing as a form of witnessing as well as a form of post-Holocaust survival can also be found in Lagercrantz' texts, in which the Holocaust was positioned as the force that unleashed Sachs's poetic genius.

The first article published by Lagercrantz on Sachs in the late summer of 1966 carried the title "Nelly Sachs and the dying"961. The story that Lagercrantz created in this analytical feature of Sachs began with a discussion about what Sachs did not

960 Fioretos, Flykt och förvandling, 57. [Av samtalet med Berendsohn framgår att hon satte likhetstecken mellan den anonyma ungdomsförälskelsen, mannen hon träffade på 1930-talet och personen som $\operatorname{dog}$ under kriget: $x=x=x$. Genom att återföra hela verket på en källa så överväldigande att det inte gavs utrymme för andra, försåg hon de tragiska upplevelserna med en story bekant från såväl hövisk diktning som romanser. Den ännu levande smärtan som antyddes omöjliggjorde ytterligare upplysningar. En taktfull samtalspartner som Berendsohn kunde bara bemöta förtroendet med pietetsfull tystnad. Ingen ville åsamka Sachs ytterligare skada genom att ställa följdfrågor'].

961 Lagercrantz "Nelly Sachs och de döende," August 14, 1966, DN. 
do through her poetry. As previously discussed in relation to the Eichmann trial, the early and mid-1960s were permeated by debates surrounding issues of collective guilt, justice and retribution. The Ulm Einzatsgruppen trial, the Eichmann trial and the Frankfurt Auschwitz trials had all contributed to placing the Holocaust on the political agenda with heated debates regarding the propriety of representation. In mirroring Sachs's symbolic language, Lagercrantz gave these events biblical proportions in stating that "the mass murder of the Jews during the Second World War has been followed by trials no less fierce than that started by Job". ${ }^{962}$ Nelly Sachs, however, Lagercrantz contended, has been silent in the debates surrounding these trials. In the lead to the article and in a summarizing introduction to the whole article series the text reiterates this fact about Sachs: "She is a victim of Nazism but does not belong to those [victims] who hold others accountable for the Nazi cruelties". ${ }^{963}$ In the article text Lagercrantz also argued that Sachs's deliberate absence from accusatory debates was also reflected in her work: "the victims in Sachs's poetry have no accusations to launch-they live in relation to the concept of righteousness in a state of innocence". ${ }^{964}$ To be sure, Lagercrantz conceded, Sachs laments the fate of the Jewish victims, but she does not "rouse up in anger" in reaction to how they were treated and subsequently murdered. This lead Lagercrantz to the conclusion that Sachs had moved beyond the human concept of justice. He thus proclaimed that,

it was a relief for Job that he could make God answer for his actions. He sought to restore order. Such a restoration should be a necessary precondition for the possibility of human life on earth. Nelly Sachs chooses a different way than that of the judicial process. The alleviation she seeks is not without, but within suffering. ${ }^{965}$

962 Lagercrantz “Nelly Sachs och de döende," August 14, 1966, DN. [“Massmorden på judarna under andra världskriget har följts av rättegångar inte mindre häftiga än den Job startade"].

963 Lagercrantz "Nelly Sachs och de döende," August 14, 1966, DN. [“Hon är ett av nazismens offer, men hör inte till dem som ställer någon till svars för de nazistiska grymheterna”].

964 Lagercrantz "Nelly Sachs och de döende," August 14, 1966, DN [“Offren i Sachs' dikting har inga anklagelser att ställa—de lever i förhållande till begreppet rättfärdighet i ett oskuldstillstånd”]. 965 Lagercrantz "Nelly Sachs och de döende," August 14, 1966, DN [“Det betydde en lindring för Job att han fick ställa Gud till svars. Han sökte återställa ordningen. Ett sådant återställande torde vara en nödvändig förutsättning för att människans liv på jorden skall vara möjligt. Nelly Sachs väljer en annan väg än processens. Den lindring hon söker ligger inte utanför, utan innanför lidandet']. 
This perspective on Sachs and her work mirrors the master narrative on Sachs in West Germany at the time. She was accepted because her work lacked anger and accusation and she was embraced as a Holocaust victim and survivor whose main ambition was to mourn the dead and not to admonish the living. As previously noted, this view also permeated the critical consensus on Sachs's approach to the Holocaust in Swedish literary discourse. For instance, in his introduction to one of Sachs's most well-known works, Flykt och förvandling, published in 1959, Edfeldt commented that "in songs and hymns that have been purged from hatred but carries a sorrow for human kind's deep degradation, she emphasizes the memory of those who were hunted; their anxiety and disgraceful deaths". ${ }^{966}$ This forgiving quality - to mourn without hatred and to seek answers inside the pain rather than outside of it - was conveyed in order to communicate the forgiving and humble character of Nelly Sachs. These descriptions also position her as the opposite to all those witnesses who testified against Eichmann and the Nazi officials who worked in Auschwitz. She is the deity who sees beyond justice, who recognizes the futility of anger and vengeance, the one who 'turns the other cheek' while the trial witnesses - the camp survivors-become trite human beings who squabble over earthly questions such as guilt and justice.

The concept of pain and suffering "from within" was also something that permeated Lagercrantz's discussion on Sachs's work throughout his article series. In his third article this theme dominated the narrative and Lagercrantz asserted repeatedly that suffering and even death were, to Nelly Sachs, signs of new beginnings. Even though he introduced the article subject by explaining Sachs's differentiation between death as hopeful and mass murder as a "false" and "unreal" death, he continuously returned to the redemptory message that death brought in Sachs's poems. For instance, Lagercrantz claimed that although wounds were signs of suffering, Nelly Sachs transformed them into opportunities of enlightenment and new beginnings. As Lagercrantz poetically phrased it,

Wounds are admittedly signs of suffering, but from the first moment in Nelly Sachs's lyricism they are attached to the sunset, with its transition from darkness to light; with a birth. The wound is a window into another world. The wound is the moment when a light pours over the fragments and people see the right context. The wound is sometimes almost identical to another of

966 Johannes Edfeldt, "Inledning," Flykt och förvandling: ett dikturval, Nelly Sachs, ed. Erwin Leiser, (Stockholm: FIB:s lyrikklubb), 5. [“I sånger och hymner, som är renade från hat men burna av sorgen över människans djupa förnedring, lyfter hon minnet av de jagades ångest och skymfliga död']. 
Nelly Sachs's continuously used imageries — the seed-because just as the day is born from the wound of the sunset, a new plant grows from the entombed seed. ${ }^{967}$

Even the more tragic aspects of Sach's own life were made brighter by her poetry, argued Lagercrantz. For periods of her life Sachs had to spend time at a psychiatric hospital in western Stockholm called Beckomberga. Sachs's mental health has been a controversial subject, with early scholars and critics (including Lagercrantz) believing that it was the stress of exile and the painful memories of Nazi Germany that made her spirit fragile and her mind sick. However, later scholarship has shown that part of Sachs's mental illness-including anorexia, depression and delusions-were present throughout her life, with continuous visits to different health institutions in her early teens. ${ }^{968}$ While at Beckomberga, Sachs drew inspiration from the other elderly female patients walking the halls and eating in the cafeteria. She describes these figures in a collection of poetry entitled "Än hyllar döden livet" where she, according to Lagercrantz, "sees creativity and vitality in those zones of human life from which most people turn away in shivers". 969 She thus identifies meaningful life where other people only see decay and death -an aspect of her poetic 'sight' which distinguished her from normal people. In her book Den sarade divan ("The Wounded Diva"), the late Swedish intellectual historian, Karin Johannison, argues that even though "the mythical connection between madness and genius" remains a prominent feature in the elevated position of male poets, female writers and poets, such as Nelly Sachs, have never garnered any positive critical attention on account of their psychiatric diagnoses. ${ }^{970}$ However, in Sachs's case, her visits at Beckomberga were, in fact, used by Lagercrantz as a way to underscore her genius and superhuman ability to identify life in places where others only saw death.

967 Lagercrantz, "Såret mellan natt och dag,” August 21, 1966, DN. [“Såren är visserligen lidandets signa, men från första stund i Nelly Sachs lyrik är de förbundna med soluppgången, med övergången från mörker till ljus, med en födelse. Såret är ett fönster in till en annan värld. Såret är det ögonblick då ett ljus strömmar över skärvorna och människorna ser det rätta sammanhanget. Såret är ibland nästan identiskt med en annan av Nelly Sachs ständigt använd bild—sädeskornet, ty liksom ur soluppgångens sår dagen föds, spirar ur det gravlagda kornet en ny växt’].

968 See Johannison's discussion on Sachs's anorexia, Den sårade divan, 306-311.

969 Lagercrantz, "Den förstenade ängeln," September 3, 1966, DN. ["Här bland de gamla och sjuka framstår det ännu klarare hur Nelly Sachs ser det skapande och livskraftiga i de zoner av människolivet inför vilka flertalet människor rysande vänder sig bort'].

970 Johannison, Den sårade divan, 301-302. 
There are several aspects of this construction that are significant to the conceptualization of Sachs as the ideal or the emblematic Holocaust survivor. First, Lagercrantz emphasized throughout his articles that there was a before and an after in Sachs's work; a distinction which has lived on in scholarship on Sachs into the present day. ${ }^{971}$ Sachs's early work is thus dismissed by Lagercrantz as naïve and insignificant, displaying it as nothing more than an affinity for story-telling and make-believe. For instance, he described Sachs's pre-war work, Legenden und Erzäblungen, as being untouched by the world turned to ruins by World War I. In Sachs's world there is a "sleeping beauty ambiance and the prince with the waking kiss is still far away", according to Lagercrantz. ${ }^{972}$ In discussing this differentiation between Sachs before and after the Holocaust, Hoyer asserts that "scholars and critics adopted the position that her early work is negligible, either based on Sachs's own views or because they found her early texts merely conventional." 973 As Hoyer goes on to show, Sachs herself often contributed to the idea that her poetry was dependent on her need to survive after the catastrophe, a theme that would also permeate Swedish news discourse surrounding Sachs as a Nobel Laureate. This narrative thus emphasized that it was only after having fled Nazi Germany that Sachs's talents were unleashed and that she became a great poet. Embedded in this narrative were also Sachs's own assertions that "she was never a poet, that she was merely a frail woman, that she wrote to combat melancholia or trauma, that her person was unimportant, and that she wanted to disappear behind her work". 974 Channeling critical assessments of Anne Frank, Sachs thus presented herself as a conduit, and as a Holocaust witness without intent; an image that was also entrenched by her absence from debates on justice and retribution. The understanding of Sachs's mental illness as a result of her Holocaust experience also served to construct the image of Sachs as the "heroic witness". In her active, healthy periods she became a phoenix, rising from the ashes and when she caved from the pressure of her nerves, taunted by the memories of her past, this was a necessary and temporary relapse, needed for her in order to recover her strengths. In this duality — strong and brave/weak and fragile—Sachs was made to embody all the ideals attributed to Holocaust survivors at the time; "true victimization", the "heroic witnessing" and "moral witnessing". Mental illness did not necessarily fit

971 Hoyer, The Space of Words, 1-15.

972 "Det lidande folket," August 17, 1966, DN.

973 Hoyer, "The Space of Words," 1.

974 Hoyer, "The Space of Words", 16. 
neatly into the image of the "moral witness" however as this witness, according to Dean, considers "false testimony... a sacrilege". ${ }^{975}$ Therefore, Sachs's mental illness was constructed as something that emanated from her Holocaust experience; a construction that made her a credible Holocaust witness because (in contrast to genetically induced mental illness), her Holocaust experiences were seen to merely open up her vision to the collective trauma rather than affect her ability to speak truthfully about it.

Through this notion of Sachs's talents being born by her Holocaust experience and subsequent exile the concept of her as an almost omnipotent 'seer' was born. The pain that she had suffered was thus perceived to given her a newer, clearer vision of human life. This notion was repeated in Lagercrantz's article series where he stressed how pain made one's perspective more lucid as well as how Sachs's biblical inspiration lead her to visions of the future. His fourth article, for example, had the title "No one knows more". 976 The title referred to Sachs's collection of poetry with the same name ("Ingen vet mer") although through his discussion on Sachs's use of biblical imagery Lagercrantz also positioned her as the omnipotent survivor. Or, rather, he stated that she had placed herselfin that position. In adopting the "prophetic, apocalyptic [and] visionary" aspects of the bible, Sachs had found in herself the "seer power that characterized the biblical ecstatics". ${ }^{977}$ Similarly, in his third article, in which he outlined the Christian and Judaic inspiration for Sachs's work, Lagercrantz also subtly suggested that Sachs, like Mikael (a character from her play Eli) could see evil for what it really was and could, thereby, create a divine justice in never letting this evil pass unnoticed. Lagercrantz explained that,

Mikael is one of the thirty-six holy figures who, according to Jewish folklore, keeps the world up-right and whose gaze remains unbroken so that they can see the context. It is when this image no longer exists that evil retains unlimited power. When Mikael looks upon the murderer the latter seizes to exist. ${ }^{978}$

975 Dean, The Moral Witness, 1.

976 Lagercrantz “'Ingen vet mer," September 11, 1966, DN.

977 Lagercrantz, "Den förstenade ängeln,” September 3, 1966, DN.

978 Lagercrantz, "Den förstenade ängeln,” September 3, 1966, DN. [“Mikael är en av trettisex heliga, vilka enligt judisk folktro håller världen upprätt och vilkas blick är obruten så att de ser sammanhanget. Det är när den bilden inte längre finns som det onda får obegränsad makt. När Mikael ser på mördaren upphör denne att existera”]. 
Significantly, before this allusion Lagercrantz also asserted that "everything and everyone cry out for release. The evil that we find through legal processes are so to speak only the recognized, bourgeois evil; that which is on the surface. But regarded on a deeper level, evil such as death, is something entirely different". ${ }^{979}$ To Lagercrantz, Sachs's poetry identified an evil that lay beyond human juridical justice and, by keeping her eyes on this 'truer' evil, she became one of the "holy figures" portrayed in her play-someone whose gaze was unbroken and therefore understood how to counteract evil acts without resorting to trials and accusations. As argued above, Sachs's vulnerability was thus positioned as a form of superhuman strength; a madness that made her genius. However, it is part of an ideal that relates to the utility and effectiveness of Holocaust witnessing. According to this ideal, the Holocaust survivor has received a wisdom beyond the personal experience- a wisdom that will help society grow and become better.

This super-human quality was further emphasized in Lagercrantz's lengthy discussions on Sachs's identity and national belonging. In the second article, entitled "The Suffering People" Lagercrantz attempted to sketch Sachs's Jewish becoming. He describes how she was born into an assimilated home with a father whose interests lay in humanism and Goethe. As previously discussed in relation to the reception of Sachs's work in West Germany, Goethe was a figure who symbolized the 'other' Germany, a country unsullied by the Nazis. Lagercrantz's mention of him here in relation to Sachs's father serves to illustrate Sachs's background as no less German than that of a Christian family. Sachs, according to Lagercrantz, was not born a Jew but chose Judaism as an effect of Nazi policy and her forced exile. In this, Lagercrantz continues, she was not alone. All Jews under Nazi rule had but two choices: to accept one's Jewishness and support the project of an Israeli state or to question the Judepolitik of the Nazis. ${ }^{980}$ Lagercrantz' narrative points to some essential aspects of how new Jewish identities amongst assimilated Jews were constructed in Germany after 1933. Indeed, referring to Itta Shedletzky, Dagmar Lorenz asserts that "after 1933 many Jewish writers felt the need to reconsider their Jewish heritage and recast it in a way meaningful and

979 Lagercrantz, "Den förstenade ängeln," September 3, 1966, DN. [“allt och alla ropar efter förlösning. Det onda som vi kommer åt genom processer är så att säga bara det erkända, borgerliga onda, det som ligger på ytan. Men djupare betraktat är det onda liksom också döden någonting annat'].

980 Lagercrantz, "Det lidande folket", August 17, 1966, DN. 
appropriate to their historical situation". ${ }^{981}$ It is not so much that Lagercrantz is erroneous in his contextualization of how Sachs's became Jewish but rather that he uses this argumentation to cast her as something separate or 'above' other writerssomething which contributes to the construction of her as both super-human but also as the 'right kind' of Jewish.

In Lagercrantz' narrative, Sachs is positioned as distinctly German, Swedish in that her post-war poetic language was unleashed by Swedish poetry ${ }^{982}$ as well as Jewish - a taken identity, yet crucial to her writings on the Holocaust. Lagercrantz accounts for all the struggles Sachs continues to have with her various identitiesa stranger in Germany because of her Jewishness, a stranger in Israel because of her German language, a stranger in Sweden because of her foreignness. ${ }^{983}$ These are all insightful reflections on the identarian struggles that many Jewish survivors experienced throughout their lives. However, amongst these discussions Lagercrantz also asserted that "in a deeper sense, [Sachs] stands outside of all national and local categories, since that which most interests her are those universal concerns that are untouched by racial or national concepts". ${ }^{984}$ Hence, in spite of Israel's, Germany's and Sweden's failure to adopt Sachs as their own, she remained, according to Lagercrantz, profoundly relevant to all national and religious contexts. By staying inside the pain and avoiding the worldly, 'bourgeois' system of justice and retribution Sachs superseded all geographical and ethnic boundaries-she was everything and nothing all at the same time, her vision fixed on evil such as it manifested itself in all contexts.

Johannison also describes Lagercrantz's personal view on Sachs as "ambivalent: between admiration and irritation over what he himself [perceived] as her increasingly queen-like self-representation, especially in the years around the Nobel Prize". ${ }^{985}$ This ambivalence never bled into his writings on Sachs during the autumn of 1966. Nevertheless, it is interesting to note this attitude as it speaks to

981 Dagmar C.G. Lorenz, "Jewish women authors and the exile experience: Claire Goll, Veza Canetti, Else Lasker-Schuler, Nelly Sachs, Cordelia Edvardson," German Life and Letters, vol. 58 no. 2 (April 1998): 228 .

982 “'Ingen vet mer," September 11, 1966, DN.

983 “Den förstenade ängeln," September 3, 1966, DN. "Det lidande folket," August 17, 1966, DN.

“"Ingen vet mer,"' September 11, 1966, DN. "Den pågående skapelsen,” October 21, 1966, DN. 984 "Det lidande folket," August 17, 1966, DN.

985 Johannison, Den sårade divan: om psykets estetik (och om Agnes von K, Sirid H och Nelly S) (Stockholm: Bonnier, 2015), 300. [“hans blick på henne är ambivalent: mellan beundran och irritation över vad han uppfattar som en alltmer drottninglik självrepresentation, särskilt åren kring Nobelpriset']. 
the expectations that the 'discoverers' of Sachs had on her as the ideal survivor. Indeed, it seems a contradiction in terms to marvel at the growing ego of a person whose pedestal was built by oneself. Lagercrantz's expectation on Sachs to remain humble through all the attention she received in Sweden and abroad in the 1960, thus further demonstrates how Sachs was supposed to live up to the construction of her as a person without ego, selfishness, pride or vanity. Humility-a constituent component of the minimalist aesthetic for victim testimony - was thus made to be an integral part of survivor-hood. ${ }^{986} \mathrm{~A}$ pressure that Sachs seemed aware of as evidenced in her insistence on only being an unintentional conduit of Holocaust experience.

Why does Lagercrantz's lengthy analysis of Sachs and her work matter? As explicated above, Lagercrantz was a prominent and influential cultural authority at the largest national daily newspaper in Sweden in 1966. It would, nevertheless, be safe to say that due to the poetic language and the complicated twists and turns of Lagercrantz's prose, many Swedes would not have grasped the full (or any) meaning of his words. However, it is not only the words in the text that contribute to the construction of Sachs as a particularly important Holocaust survivor. As previously mentioned, in the 1960s the cultural pages grew to be more influential in the greater political conversation. This was facilitated by a renewal of the layout and the widespread use of pictures. Between 1920 and 1960 the cultural pages were characterized by tight columns of text, lacking in captions, catchy headlines or leads. Between 1960 and 1965, however, new principles were applied to the layout of the cultural pages that came to radically alter the ways in which culture was presented to readers. ${ }^{977}$ As Nilsson argues, "to not disappear in the ruthless editing process which characterized other sections of the newspaper, the cultural pages had to have a more extroverted, selling layout". ${ }^{988}$ Also, in order to prevent the cultural pages from being mixed up with the news section of the paper, different measures were also taken to emphasize their distinctive character. Included in this was the setting of "witty" headlines which were supposed to "tease one's curiosity rather than satisfy it". ${ }^{989}$ The article series feature was also part of this renewal and new distinctiveness of the cultural pages. In order to show the reader that the article

986 For a discussion on humility and the minimalist aesthetic see Dean, Aversion and Erasure, 105-106. 987 Nilsson, Det offentliga samtalet, 198.

988 Nilsson, Det offentliga samtalet, 199. ["För att inte komma bort i den hårda redigering som präglade andra avdelningar i tidningarna, måste kultursidan få en mer utåtriktad, säljande utformning; här kom de typografiska medlen in"].

989 Nilsson, Det offentliga samtalet, 199. 
was part of such a series the font would be the same in all articles or there would be a reoccurring vignette attached to each article. 990

In Lagercrantz's article series the vignette was a small headshot of Nelly Sachs next to which her name was typed in bold-faced, large letters. Each article was accompanied by at least one large image, positioned in the middle of the text. This image worked to reinforce the theme of the article in general and the headline in particular. For example, the second article entitled "The Suffering People" was accompanied by a large photograph of a shopkeeper cleaning up the streets after the Kristallnacht. The caption read, "a picture from 1930s Berlin: a Jewish shopkeeper sweeps the street clean of glass shards after an attack on his shop". 991 Portraits of the Jewish religious philosopher Martin Buber, a recurring figure in Lagercrantz's writings on Sachs, and the German philosopher Theodor Adorno were also placed amid the text columns. Reading the text, the inclusion of Buber's portrait makes sense as his philosophies regarding the constitution of a Jewish identity were described inside the text and related to Sachs's "saying yes to Judaism". Adorno, on the other hand, is nowhere to be found in Lagercrantz' narrative. The inclusion of his picture is most likely a reference to Adorno's oftcited credo that "nasch Auschwitz ein Gedicht zu schreiben ist barbarisch"- - statement that ignited a debate in which Sachs was used as a counter-argument which maintained that her "work provided concrete evidence that poetry could and indeed should be written 'after Auschwitz"' ${ }^{992}$ The headline and the pictures included in the article thus all point to Sachs's relation to all things Jewish: the Nazi's persecution of the Jews, her own religious/ethnic identity and her ability to restore faith in 'poetry after Auschwitz'. However, the article lead-another distinct feature of the 'new' cultural pages—read,

\footnotetext{
All poetry comes out of the environment it describes. Through the local runs the road towards the universal. In Nelly Sachs's case it is twice as urgent to underscore that her poetry is not merely a monument of Jewish suffering, writes Olof Lagercrantz in his second article on the German author. Nelly Sachs's main theme is something wholly different, and even when she has
}

990 Nilsson, Det offentliga samtalet, 199.

991 "Det lidande folket," August 17, 1966, DN.

992 Martin, Nelly Sachs, 47. 
the Jewish people in her gaze the complications are many. ${ }^{993}$

Although the headline and the pictures all discursively tie Sachs to the Jewish catastrophe and Judaism at large, the lead told the reader that the main theme of the article was the universal message of Sachs's poetry. Just as the structure of news stories, the 'new' structure of the cultural pages were "replete with ambiguity, unclarity, discrepancy and cavity". ${ }^{994}$ The point of the headline was to draw people in or to "tease" their "curiosity", to use Nilsson's words. The choice of the main image in the article-depicting the aftermath of the Kristallnacht—demonstrated a distinctly Jewish aspect of the Holocaust, albeit without having to utilize the gruesome pictures of a liberated Belsen or Auschwitz-Birkenau. In 'selling' the article, which is all that the 'superficial' reader would consume, Sachs's poetry was the Holocaust and the Holocaust was specifically about Jewish suffering; her headshot, the headline, the picture of the shop-keeper and the pictures of Buber and Adorno all confirmed this—even though the lead stated otherwise.

Although little is known of newspaper readers' consumptive patterns during the mid-1960s it remains important to demonstrate the various ways in which the text could potentially have been read. In other words, the discursive practices surrounding the text is, in this context, pivotal in understanding Sachs's becoming in Swedish public discourse. As the cultural pages changed their layout in the 1960s it is not unreasonable to think that this was at least partly in response to the perceived need for a more 'readable' section of the newspaper. Also, Lagercrantz' ambition to show the inextricable link between politics and culture spurred a change of the cultural pages where DN's readers were afforded the opportunity to disseminate political issues of the day through discussions of culture. ${ }^{95}$ Again, how this dissemination worked in practice is difficult to ascertain. It is not unlikely that readers disseminated the text differently depending on level of education and familiarity with the subject-matter at hand. Some might have read 'superficially', only browsing the headlines, leads, captions and pictures while others read 'deeper', pulled into the narrative through special interest or these new layout features.

993 Lagercrantz, "Det lidande folket,” August 17, 1966, DN. [“All dikt strävar ur den miljö den skildrar. Genom det lokala går vägen mot det universella. I Nelly Sachs fall är det dubbelt angeläget att betona att hennes diktning inte blott är ett monument över judarnas lidande, skriver Olof Lagercrantz i sin andra artikel om den tyska författarinnan. Nelly Sachs huvudtema är ett helt annat, och även när hon har det judiska folket i sitt blickfält är komplikationerna många”].

994 Bell, The Language of News Media, 66.

995 See Otterberg, Klädd $i$ sitt språk, 70-72. 
Therefore, it could be argued that Lagercrantz produced one Holocaust survivor in his writings on Nelly Sachs while "the systematic nature of [the] text" produced a slightly different version. ${ }^{996}$ The same can be said for article five where the headline "No one knows more" was accompanied by a picture of Sachs standing in front of a book-shelf full of books. As previously discussed, the headline referred to one of Sachs's poetry collections. Yet for the uninitiated, 'superficial' reader the headline and image communicated the message that "No one knows more" than Nelly Sachs'; reinforcing the idea of her as an omniscient, super- human figure, yet in a different manner than that expressed by Lagercrantz in the text. The cultural page as material text thus also held a subject position from which a slightly different, somewhat simpler, survivor object could be formed.

Lagercrantz' writings on Sachs in the months leading up to the Nobel prize demonstrate how the Swedish cultural elites steeped Sachs's person and her accomplishments in an aura of mysticism and transcendentalism. As will be discussed further in the coming section, Sachs's appearance-her small body and beautiful, delicate features-was, however, also part of this construction; constituting the tangible pre-requisite for the more ethereal qualities ascribed to Sachs. Interestingly, her distinctly female figure and feminine qualities were both integral parts of her genius; an epithet almost exclusively used for male poets and writers at this time. In the press coverage that followed the announcement that Sachs, together with Agnon, would receive the Nobel Prize for literature, this construction was further entrenched; Sachs's genius made inseparable from her own survival of the Holocaust. The simpler survivor object formed through the layout of the cultural pages would be the one that was further reproduced in the coverage of the Nobel festivities.

\section{5 "The Queen of the Nobel Banquette": Sachs in the Media}

All but one of Lagercrantz' articles were published before the Swedish academy announced that the 1966 Nobel Laureates in literature were Samuel J. Agnon and Nelly Sachs. Because of Lagercrantz' keen attention to her work and person during the late summer and autumn of 1966, Sachs had become introduced to a significant portion of DN's readers. The fact that the prize was split between an Israeli author and a Jewish German poet was also not a wholly uncontroversial choice as evidenced by debates in Germany at the time. In Sweden, however, Sachs 
continued to be constructed as a fragile, bird-like, yet spiritually powerful being whose poetry allowed for mourning and identification without any danger of hatred or thoughts of retribution. In his final article in the 6-part series, published on the day after the Swedish academy's announcement, Lagercrantz described Sachs as a "fragile human, small and tender" while also cautioning the reader that, "behind the frail body is hidden a genius power" ${ }^{997}$ Half the article treated the ways in which the Holocaust shaped Sachs while the other half dealt with the overarching themes of her poetry. In this final article, in which Sachs's life and work was summarized, Lagercrantz constructed a person who was just as much a survivor of the Holocaust as she was a literary genius. Sachs's survivor-hood continued to be connected to her literary deed in writings on her poetry surrounding the announcement that she was one of the Nobel Laureates for 1966; thus further strengthening Sachs's position as the ideal Holocaust survivor.

The day after the announcement, Sachs received a full page dedicated to her in $\mathrm{SvD}$ with a personal feature authored by the Swedish journalist and writer, Marianne Höök, and a literary exposé by the poet and literature critic Björn Julén. The headline of Höök's feature of Sachs speaks to the overarching theme of both articles- "Nelly Sachs began to write as a means to survive". ${ }^{998}$ In this headline there is not even a before in Sachs's literary career, instead her de facto writing began as a means to survive the Holocaust. Like Lagercrantz, Höök also characterized Sachs as fragile, stating that she was both "beautiful and very delicate." She also added that

people who want to talk to her, and there are many who would like to do that on a day like today, have to bend down. It's a touching sight to behold. She could move a stone. And she has. Once upon a time in the age of persecution there was a Gestapo man who lowered both his eyes and his tone when faced with this delicacy and said almost mildly-come closer little one, I won't bite. ${ }^{999}$

997 “Två delar Nobels litteraturpris. Lagerlöf räddade Nelly Sachs 1940”, October 21, 1966, DN, 1. 998 Marianne Höök, "Nelly Sachs började skriva för att överleva," October 21, 1966, SvD, 5. 999 Höök, "Nelly Sachs började skriva för att överleva," October 21, 1966, SvD, 5. ["Hon är mycket vacker och mycket spröd. Människor som vill tala med henne och det är många som vill det en sån här dag, måste böja sig ned. Det ser rörande ut. Hon kan röra en sten. Hon har gjort det. En gång i förföljelsens tid var det en Gestapoman som slog ned både blick och ton inför denna sprödhet och sade nästan milt—kom närmare lilla. Jag bits inte']. 
There was thus something inherently disarming about Sachs's appearance; beautiful features and a sweet nature that created a sense of reverence in the people who encountered her. Her pre-war writings were "conventional and well-behaved", Höök explained and it was only when Sachs arrived in Sweden that she began to really write, "write to survive". ${ }^{1000}$ In finishing the feature Höök also stated that "Nelly Sachs [smiled] her bright smile, her eyes [were] light and transparent in spite of all that they [had] seen". ${ }^{1001}$ This final comment is interesting as few actually know what Sachs witnessed during her seven years under Nazi rule, yet many still allude to her experiences; both as something which fundamentally shaped her writing and as something that made her mentally unstable and sick. However, when Sachs fled to Sweden in 1940, her own testimonies of Nazi genocidal policy remained fixed on the 1930s. The information about her flight in 1940 is an important part of the drama that surrounded Sachs and, to be sure, her Gestapo hearing, being searched for assets before leaving Nazi Germany, and the fact that she bore the name "Sara" in her passport, were all tangible examples of Sachs's encounters with the Holocaust. However, because of the way that she used the camp as a symbol in her poetry, she was also, at times, mistaken for a camp witness. For instance, Julén stated that he thought it difficult to enjoy the poems of In den wohnungen des todes as art since they constituted "testimonies from inside the gas chamber's hermetically sealed walls". ${ }^{1002}$ However, Sachs never witnessed the inside of a gas chamber, neither did she ever smell its fumes, nor see the smoke rise towards the sky. Everything that she wrote about the camps and the gas chambers was based on the accounts of others; of their experiences during the Holocaust. This distinction between flight and camp survival was never emphasized by Swedish critics. The fact that Sachs escaped and survived a certain death made her a survivor and thus an authentic voice with the ability to speak of all aspects of the Holocaust as if she was speaking - like Anne Frank-form inside the experience. Even though Julén was more subtle in his characterization of a before and after in Sachs's poetry and merely stated that her arriving in Sweden offered new "opportunities" to write, he also stated that "over the years her poetry

1000 Höök, "Nelly Sachs började skriva för att överleva," October 21, 1966, SvD, 5. 1001 Höök, "Nelly Sachs började skriva för att överleva," October 21, 1966, SvD, 5.

1002 Björn Julén, "Flykt och hem-Motiv hos Nelly Sachs," October 21, 1966, SvD, [“Det är svårt att idag läsa dessa dikter, dessa vittnesbörd inifrån gaskammarens hermetiskt tillslutna väggar, och samtidigt uppleva dem som konstverk"]. 
has grown in breadth and intensity, but the smoking gas ovens still create the amalgamation of pain out of which her poetry rises". ${ }^{1003}$

Although Sachs's literary deed was clearly and repeatedly attributed to her Holocaust experience, her own answers in interviews after the announcement shows a form of ambivalence towards such characterizations. As previously discussed, Sachs contributed to the image of herself as the ideal Holocaust survivor. As Jennifer M Hoyer explains in the opening paragraphs of "the Space of Words":

Nelly Sachs herself sought to put distance between her postwar poetry and her earlier works; indeed, it seems that Sachs feared her early work would distract from the significance of her postwar poetry. ${ }^{1004}$

It thus appears that Sachs wished to be perceived a Holocaust poet; something that was also evidenced by the ways in which she fueled stories of "the dead bride groom" as the definitive spark that lit her writing talent. However, in snippets of interviews with Sachs, both on television and in the newspapers in late 1966, she began to waver with regards to the idea of a 'before' and an 'after' in her authorship. In a TV-interview conducted by the radio journalist and poet Matts Rying, she, for example, stated that everyone reacted to her gruesome literary themes even as a child, that she had horrifying visions that she tried to keep at bay. ${ }^{1005}$ This part of the interview, however, never seemed to have aired. In the clip discovered in the National library's audio-visual archive the interview ends with Sachs stating that she decided to publish her poems for the sake of the future, so that children would know what had happened during the Holocaust. It is thus from a saved audiorecording of the interview that the quote above is taken. In the audio recording, Rying can be heard asking Sachs whether she wrote even before she came to Sweden. ${ }^{1006}$ Sachs answered that she did and that everyone thought that her writings were horrifying and that she burned them all. However, she continued, it was not all in vain because it served as a kind of preparation for later writings. She also stated that she had great depth even as a child but that "she did not dare speak from her own inner experiences" then in the same way as she could after the

1003 Julén, "Flykt och hem-Motiv hos Nelly Sachs," October 21, 1966, SvD [“med åren har hennes lyrik vuxit i bredd och intensitet, men de rykande gasugnarna skapar alltjämt den smärtans legering ur vilken hennes dikt stiger"].

1004 Hoyer, "The space of words," 1.

1005 Svensk Mediedatabas (SMDB), "Intervju med Nelly Sachs hemma hos Holmqvists". Visual material.

1006 Svensk Mediedatabas (SMDB), "Intervju med Nelly Sachs," audio-recording. 
war. ${ }^{1007}$ Furthermore, in an interview with the journalist and writer Bo Grandien for DN, Sachs first stated that her sparse, precise language came from a sense of responsibility that every person who has been through trauma and writes to survive has to have. ${ }^{1008}$ As if catching herself in a lie she, a moment later, added that in reality she always wrote like this. What made her change her style to a more formalized prose was peer pressure, or in her own words, "everybody laughing" at her. ${ }^{1009}$

When given the opportunity to speak about her own inspiration in 1966, Sachs thus gave both the expected answers; that she wrote to survive and that she wrote for future generations. However, her answers also point to an expression of pain and rupture, even in childhood. The fact that Sachs adopted pain as the main theme in her post-war poetry was thus not a coincidence, according to herself. She had never seen the gas chambers but still described their character with such great affect that no one would doubt that she also experienced the camps. With regards to the style of writing and the thematic content of her poetry there was certainly a difference between Sachs's early published writing and that which was written in exile. ${ }^{1010}$ The idea about a before and after in Sachs's authorship is therefore not false. Yet, the fact that this distinction was repeatedly emphasized and, thereby attributed special meaning, demonstrates how Sachs's being made by the Holocaust constituted the most important truth about her. The effect of this truth was that Sachs was a survivor and nothing else. Her aptitude for writing, and writing 'horrifying' stories, even as a child, was no longer important as it was the Holocaust that fundamentally shaped Sachs and made her who she was; defined her very essence. Very little of the human being beyond survivor-hood was acknowledged in the news discourse around Sachs, making Sachs the Holocaust survivor; even in ways that her own experiences did not create. Her poetry was never as conciliatory as many Swedish and West-German critics made it seem, but it was easy to construct her thusly because she was a soft-spoken woman of slight frame who wrote beautifully about pain and death. In Aversion and Erasure Dean asserts that "the more 'innocent' the speaker $[\ldots]$ the more dramatic the injury inflicted will

1007 Svensk Mediedatabas (SMDB), "Intervju med Nelly Sachs hemma hos Holmqvists".

1008 Bo Grandien, "Då Agnon mötte Nelly Sachs," December 7, 1961, 1.

1009 Grandien, "Då Agnon mötte Nelly Sachs," December 7, 1961, 1. ["Fast egentligen, fortsatte

hon, skrev jag på detta formellt frigjorda sätt redan när jag var ung flicka och bodde i Berlin. Men då skrattade min omgivning åt mig, hemma och bland vännerna, och så fick jag använda de traditionella formerna istället]

1010 See Hoyer, "The Space of words," Martin, Nelly Sachs. Pedersen, Tårarnas Poetik. 
seem to be, and yet presumptions of victims' innocence and powerlessness may also be defenses against or anxieties about their rage"1011. Her appearance thus made Sachs the truest of victims; an aspect of her being that was continuously tied to her poetry, perhaps because it made her writings appear less dangerous. Even though Sachs was not a camp survivor, her small, female, fragile body, her large brown, doe-like eyes and her old age when winning the Nobel Prize all contributed to the idea of her as a "True Victim" and an ideal witness. Sachs being constructed thusly may not only be an expression of an anxiety about her rage, but rather the rage and vindictiveness of all survivors, and Jewish survivors in particular. As seen the news discourse surrounding the Eichmann trial there was a wish to bridge the conflict between Germans and Jews, as well as between Germany and Israel. This road to reconciliation began and ended with the accusers; the survivors of the Holocaust.

Therefore, Sachs's physical being—-her embodiment of the "True Victim"was discursively connected to her spiritual prowess (inhabiting forgiveness, wisdom and grace) and thus, consequently, to the construction of her as a literary genius. In the evening press especially, Sachs's winning the Nobel Prize was told as a Cinderella story, the aging author in the role as a struggling, poor maid finally getting to attend the ball. On the front page of Aftonbladet on December 11, the headline read "Nelly Sachs-Yesterday she was the queen of the Nobel Banquette, on Tuesday she will be crowning Sweden's lucia". ${ }^{1012}$ Later, Aftonbladet also reported from this momentous occasion that the newspaper's editor-in-chiefdepicted arm in arm with the Nobel Laureate—was "chivalrously escorting" Sachs to the door and helping her with her "fur coat". ${ }^{1013}$ The editor was thus positioned as the prince charming to Sachs's Cinderella. In the picture Sachs can be seen smiling big into the camera. In fact, in a majority of the photographs taken of Sachs accompanying articles about the Nobel banquet she was captured in a smile or a laughter. In DN's reporting from the Nobel banquet, for example, Sachs's face dominated the news page with two pictures of her-in one she is seen laughing with the Swedish king, Gustav VI Adolf and the other consists of a portrait where she is seen smiling next to a portrait of Agnon. ${ }^{1014}$

1011 Dean, Aversion and Erasure, 151.

1012 "Nelly Sachs_igår var hon Nobelfestens drottning_på tisdag kröner hon Sveriges Lucia,"

December 11, 1966, Aftonbladet, 1.

1013 "Vilken dag för Lucian,” December 14, 1966, Aftonbladet, 24.

1014 "Sagan har blivit verklighet," December 11, 1966, DN. 
Sachs's Cinderella image was also further enhanced by the ways in which Agnon was represented by the Swedish press. Often portrayed next to Sachs, Agnon was described as her polar opposite: the burly, jovial father-figure to Sachs's demure school girl appearance. ${ }^{1015}$ Reporting from a Channukah celebration at the Judaica center in Stockholm to which both Sachs and Agnon were invited as honored guests, SvD's reporter described the scene thusly: "the delicate authoress looked like something out of a fairy tale where she sat below the podium in a midnight blue velvet dress and with the silver grey hair like a halo around the finely chiseled pale bird-like face. At her side she had the steady Samuel Agnon." ${ }^{1016}$ The article's picture depicts Sachs and Agnon seated next to each other, the latter made larger by being in the foreground, with a shrinking Sachs almost behind him in the background. The caption accompanying the picture reiterated Agnon's characteristics as described in the article: "Nelly Sachs smiled serenely when Evalisa Lennartsson read her poems. At her side she had the steady Josef Agnon". 1017 While descriptions of Sachs were lengthy and detailed, Agnon was merely described with one word- "steady" — as if his only role during the celebrations was to prop up and support the small figure next to him. Returning to Hamrin's characterization of Israel caring for their survivor population, Agnon was portrayed as the embodiment of Israel, caring for the embodiment of the Holocaust-Nelly Sachs. In DN, Bo Grandien's characterization of Sachs and Agnon's first encounter in her small apartment on Bergsundsstrand also positioned Agnon as Sachs's essential opposite:

Two temperaments, completely different, met each other on Tuesday in Stockholm. Nelly Sachs and Samuel Josef Agnon, this year's Nobel

1015 "Sagan har blivit verklighet," December 11, 1966, DN. Bo Grandien, “Då Agnon mötte Nelly Sachs," December 7, 1961, 1. "Vilken dag för Lucian," December 14, 1966, Aftonbladet, 24. Bernt Nilsson, "Nobelprisare skapar i ett rum på fyra kvm," December 12, 1966, Aftonbladet. Ingemar Leckius, "Nattens Modersmjölk," December 9, 1966, Aftonbladet, 4. "Nelly Sachs—igår var hon Nobelfestens drottning — på tisdag kröner hon Sveriges Lucia," December 11, 1966, Aftonbladet, 1. "Glada barn satte färg på stilla Nobelmottagning utan Agnon och Huggins," December 10, 1966, DN, 1.

1016 "Sachs och Agnon på Judisk fest," December 9, 1966, SvD. The Swedish word used to describe Agnon was "trygg" which does not have a satisfactory translation using one word but could be described as steady, secure and confident. [“den spröda författarinnan såg ut som en sagofigur där hon satt nedanför podiet. I djupblå sammetsklänning och med det silvergrå håret som en gloria kring det finskurna bleka fågelansiktet. Vid sidan hade hon den trygge Samuel Agnon"].

1017 "Sachs och Agnon på Judisk fest," December 9, 1966, SvD., the same word "trygg" is used in the caption as well. 
Laureates in literature. It was their first encounter and the meeting took place in Nelly Sachs's small one-bedroom apartment on Bergsundsstrand on Söder. Agnon stormed in like a whirlwind amongst the poetess's little furniture, sea shells and books, carrying a bouquet of red roses and a black yarmulke on his head. Nelly Sachs, small, tender, ethereal with big bright eyes, received him—and after a mere ten minutes they were on a first name basis with each other. ${ }^{1018}$

Here, Agnon takes on the shape of Sachs's suitor, taking her by storm with flowers and charm. In the picture accompanying the article, placed high and dominating the page with its size and focus, Sachs and Agnon can be seen sitting on a sofa, bodies half-turned towards each other and half turned to the camera, both smiling. Their hands reach for each other in a gentle gesture, Agnon's palm turned up to receive Sachs's outstretched fingers. The picture is reminiscent of those taken of royalty after having announced their engagement. This meeting between Sachs and Agnon was also briefly recounted in Expressen where Agnon was described to have "told long stories from his youth, as old gentlemen tend to do" while "Nelly could not get a word in edge wise". ${ }^{1019}$ In the two images depicting their meeting, Sachs and Agnon both embrace and stand smiling, holding each other's hands. These traditional gender roles attributed to Sachs and Agnon, and the positioning of them as a couple or as father and daughter, created a rosy, romantic shimmer around them. It also made Sachs an even less threatening figure-her poetry spoke of dangerous things, but the fragility of her body and her ethereal presence counteracted any notions of hatred and accusation. Her poetry could be read as conciliatory and lacking in hatred and vengeance because no feminine, elderly woman such as Nelly Sachs could hold such dark and destructive feelings.

By being female as well as feminine, Sachs was perhaps the most unlikely person to receive the epithet of 'genius'. In Gender and Genius, the British philosopher Christine Battersby contends that the development of 'genius' as a

1018 Grandien, “Då Agnon mötte Nelly Sachs,” December 7, 1961, 1. [“Två temperament, helt olika, möttes på tisdagen i Stockholm. Nelly Sachs och Samuel Agnon, årets båda Nobelpristagare i litteratur. Det var första gången de träffades och mötet ägde rum i Nelly Sachs lilla enrummare vid Bergsundsstrand på Söder. Agnon stormade in som en virvelvind bland diktarinnans små möbler , snäckor och böcker, och han bar en bukett röda rosor i handen och hade svart kalott på huvudet. Nelly Sachs, liten, späd, eterisk, med stora lysande ögon tog emot—och efter bara tio minuter var de du med varandra"].

1019 "Nu kommer dom,” December 7, 1966, Expressen, 7. [“De möttes i fröken Sachs enrummare, Bergsundstrand 23, kramade varandra i farstun, la bort titlarna, drack sherry och pratade, han mest, långa historier från sin ungdom som gamla herrar brukar, och Nelly fick knappt en syl i vädret”]. 
concept in nineteenth century Europe was intrinsically linked to notions of the male, disembodied creative spirit. Distinguishing between the feminine (gender) and the female (sex), Battersby also argues that while genius has been constructed as both feminine and male ("in male geniuses femininity has been transformed into a virtue"), genius has not been attributed to the feminine female. ${ }^{1020}$ At the same time, she explains that "to call someone a genius seems to imply a social consensus or, at least, recognition by some persons whose opinions have weight in terms of the history of culture." 1021 The many male poets, authors and literature critics that surrounded Sachs from the 1940s onwards were the ones who afforded her that consensus; they constructed her as a genius. At first it was just a close circle around Sachs who argued that she was already famous and an established poet whose genial writings made her the spokesperson for 6 million dead. Thus, the genius survivor in 1966 was both female with distinctly feminine qualities. Perhaps this can be explained by the fact that the ideal of "True Victim" which was intrinsically linked to idealized forms of witnessing, required innocence, fragility and beauty from the person inhabiting this position. Genius in relation to Holocaust witnessing and survivor-hood was thus bound up with notions of femininity as well as images of the female body - the object of torture that verified victimization at the hands of the Nazis. The Holocaust witness genius thus had to be both female and feminine in the 1960s - a perspective that seems to have shifted in the 1970s, 80 s and 90 s with a growing emphasis on the male survivor genius, evidenced by the continuous referencing in scholarly work and popular culture to Primo Levi and Elie Wiesel.

Simultaneously, the discoverer of the survivor genius also became a figure of interest in 1960s media discourse; a figure that was created through the concepts of silence and excess. In two review articles of Lagercrantz's book about Sachs, it was argued that nothing had been written about the poetess until that point. In the first review published in DN, Ulf Linde, for example, stated that Lagercrantz had spent two whole years on the book, a behemoth endeavor since nothing had previously been written about Nelly Sachs except for "a few short essays", according to Linde. ${ }^{1022}$ However, the Swedish cultural elites had long claimed that Sachs had been and international star; an argument that relied on the opposite of

1020 Christine Battersby, Gender and Genius: Towards a Feminist Aesthetics, (London: Women's Press, 1989), 10. See also Battersby's discussion of her earlier work in The Phenomenal Woman: Feminist Metaphysics and the Patterns of Identity, (Routledge, 2013), 9-10.

1021 Battersby, Gender and Genius, 125.

1022 Linde, “En bok om smärtan,” December 9, 1966, DN. 
silence. The prolific attention purportedly given to Sachs's deed in other countries meant that she should also be accepted as a great and famous poet in Sweden. Silence and excess were thus used to both make and unmake Sachs; the former solidifying the expert position of Lagercrantz while the latter strengthened Sachs's position as a genial poet.

Because Sachs was 'discovered' as a genius, she also had to be distinguished from other survivor writers who were visible in public discourse at the time. Writers such as Zenia Larsson and Cordelia Edvardson had established themselves as significant presences in Sweden's cultural landscape. As evidenced by the critical assessments that both Larsson and Edvardson received (see chapters 4 and 5), their writings were, similar to Sachs's, understood as a form of compulsion; their Holocaust experience forcibly establishing itself in their artistic expression. These authors, however, did not feature as comparative examples to Sachs and they were never referenced in 1966 as female victims and witnesses to the Holocaust. It thus seems that it was important that Sachs stood on the pedestal alone and undisturbed by other voices who could, potentially, complicate the image of the omnipotent, genial poet "Nach Auschwitz". Through the disciplining of witnessing, Jewish camp survivors were marginalized in the buzz surrounding Sachs during the autumn of 1966; the latter constructed as a distinct animal from these other voices that detailed the horrors of the camp and sometimes expressed anger and pressured society to act according to certain moral principles (see discussion on Edvardson and Tingsten in chapter 4).

If Lagercrantz's writings on Sachs were dense and inaccessible, the representations discussed above were simple, categorical and overstated. Photographs of a smiling Sachs adorned the front pages of the evening newspapers making her Cinderella story with the Swedish King, newspaper editors and Agnon clearly visible to all. The cameras that followed her slight frame up and into her apartment in preparation of her interview with Rying and the audio of the interview—projecting her careful, quavering voice, speaking in a heavily accented Swedish-also contributed to the clear representation of Sachs's vulnerability.

\subsection{Conclusions: Nelly Sachs as the Exemplary Jewish Survivor}

The construction of Nelly Sachs was a result of a consensus among Swedish cultural elites that she was a genius poet. Like the ethics of representation that developed within historiographies of the Holocaust, Sachs's construction in the 1960s also depended on internally held expert norms and rules that governed her ability to be in public spaces. These norms and rules were also internalized by Sachs 
who, although ambivalent at times, continuously asserted herself as a mere conduit of Holocaust experience, even in relation to events that she had not personally lived through. However, this expert discourse also helped construct Sachs in simpler ways through descriptions of her encounters with Agnon and in imagery that showed the demure, doe-eyed, slight Sachs as she attended Nobel events and took the stage to receive her prize from the king. As in 1943 and 1945, these portrayals contributed to the notion of the female survivor victim and witness as an object of care. Her vulnerabilities recognizable through age and gender, Sachs became the Danish-Jewish women and children and the women from Ravensbrück; all cared for by the Swedish nation. In resembling Anne Frank through her unassuming brilliance, and her non-accusatory yet emotive expressions of Holocaust experience, the figure of Sachs also allowed Swedes to assume the imaginary role of 'carers' for Anne Frank as well.

Just as the true victimization of Anne Frank had initially positioned the camp survivor witness as an excessive aspect of Holocaust memory in the 1950s, Sachs's construction as a "True Victim" and the most effective witness to the Holocaust, also made other Holocaust victims-especially those who contributed with their testimonies in Holocaust trials-seem like "victimists" who relished the opportunity to burden the world with their own pain. It might also have been this tension between the "True Victim" and the "bogus victim" that created a distance between the camp survivor-witness and Sachs. Lagercrantz' positioning of Sachs as a survivor who found meaning and light in suffering also contrasts with the perception expressed by Vallquist, in her review of Edvardson's Kärlekens Vittne ("Witness to Love") in 1963, that the most tragic aspect of a survivor's existence was the fact that she could never step into the light but was forced to keep living in the shadow of the Holocaust. ${ }^{1023}$ In more recent writings on Sachs in Sweden the different perspectives on pain and suffering expressed by Sachs compared to other survivor writers and artists have been understood as a result of their different experiences. For example, in discussing the relationship between the visual artist and camp survivor, Lenke Rothman, and Nelly Sachs, the author and literature scholar Anders Olsson writes that, "to Rothman there was never a way to tell [her story], there wasn't even an alphabet", while Sachs's ability to find reconciliation in

1023 Gunnel Vallquist, “Kärleken i Inferno,” April 29, 1963, SvD, 5 [“Den överlevandes tragik är att kunna bli levande bara i lidandet, i hopplösheten, att inte kunna fungera i det ljusa, enkla, vänliga och lillla livet']. 
suffering was likely the result of never having to experience the camps. ${ }^{1024}$ Whether this characterization of Rothman's inability to express herself is another myth of silence needs further investigation but it still speaks to a difficulty for camp survivors to find solace in suffering in the same way that Sachs arguably did.

Thus, the classification of the exemplary survivor made it impossible for some of the classified - the camp survivors in particular-to speak from this position. Being tailor made for Sachs, the position instead became a place from which Sachs's male discoverers could speak, making further claims about the nature of pain, suffering, accusation and punishment. In this regard it was not just Sachs as a survivor object that travelled between silence and excess. The discoverers-Olof Lagercrantz being the most prominent among them-were also created through arguments of silence (no one had ever written about Sachs before) and excess (she was a famous and critically appraised poet before she became well-known in Sweden). The disciplinary discourse that the critique of Sachs's poetry constituted, therefore strengthened the subject position of the critic as well as the subject position of the ideal survivor witness in the form of a 'true' "moral witness," while simultaneously obscuring the multitudinous expressions that Holocaust testimony (or, to use Greenspan's phrase, recounting) could take.

1024 Anders Olsson, "Nelly Sachs och Lenke Rothman, några fragment”, Bokstäverna jag färdas i: en antologi om Nelly Sachs, 185-191. 


\section{Chapter 7 - Conclusion: The early Survivor Object, Gender and the Mechanisms of Silence and Excess}

\section{1 Introduction}

As stated in chapter one, the aim of this dissertation is threefold; a plurality that developed throughout the research process. First, the aim was to understand how the Holocaust survivor had come to be in Swedish public discourse. This aim was further elaborated on when I noted in all my sources that gender-the construction of femininity and/or masculinity_was integral to this becoming. The aim, then, also included an understanding of the gendering processes surrounding the survivor object. During my empirical work, another problem unfolded regarding the sheer amount of material found. This meant that the time period had to be limited to the 1940s, 50s and 60s, thus creating a gap in the genealogy of the survivor object from the 1970s until the 1990s. Even though I could not explain attitudes toward Holocaust representation and the survivor's role as victim and witness in the 1990s through my analyses, I could still demonstrate how the same mechanisms of silence and excess had governed perspectives on the survivorvictim and the survivor-witness since the earliest decades of Holocaust memory. This is also where the third aim of the project emerged. What I discovered during my research process was that the progressivist historical perspective on Holocaust survivors and memory was not empirically sound. Complete silence had not inevitably turned into excess through the "advent" and "era of the witness". 1025 Rather, conceptions of silence and excess had always, at least in a Swedish context, been used to discipline Holocaust memory; thereby also creating silences and excesses in every decade. In the coming concluding chapter of my dissertation, I attempt to bring together all the different analytical threads identified in each chapter, beginning with the descent and emergence of the survivor object during the 1940s, 50s and 60s. In the second section, I summarize my analyses on the mechanisms of silence and excess, after which I explain how gender has informed the construction of the survivor. Finally, I will provide some examples of persisting research gaps regarding survivors in order to open up new vistas for future scholarship on the subject. 


\section{2 The Descent and Emergence of the Survivor}

What I have attempted in my analyses of the descent and emergence of the survivor in Swedish public discourse is to establish how the formulation of different survivor types through news discourse and culture critique have contributed to a disciplining of the survivor in Sweden. In methodological terms this meant that I paid attention to the subject-position of the 'enunciator' of the object, the context of the medium and the genre as well as the meanings found in the text itself and the "institutional labor" that it performed.

Analyzing the descent of the Holocaust survivor in Swedish public discourse meant locating a "miscellany of beginnings". 1026 These beginnings depended on conceptualizations of Holocaust survival, victimization and witnessing, as all three concepts have fundamentally affected perspectives on survivors in the media landscapes of post-Holocaust representation. The Holocaust as an occurrence separate from the Second World War in combination with physical escapees from Nazi terror provided the crucial framework in Swedish newspaper discourse for the construction of a Jewish survivor-victim in 1943. Although sometimes asked to comment on their own situation and vulnerability, these victims were primarily objects of care; mere reflections of the heroism and altruism of non-Jewish Danes and non-Jewish Swedes and Swedish institutions. Witnesses to the Danish-Jewish flight were thus primarily "dismayed spectators", with the newspaper correspondents themselves primarily filling this role. In some instances, Jewish victims were even problematized as unreliable witnesses; a problematization that both reflected and fed into the idea that Jewish victims exaggerated their wounds in order to exact revenge on their German oppressors. Even though this view was not pervasive across the newspapers studied, it shows that Danish Jews — although the first victims to symbolize Holocaust survival—were not yet "True Victims" in Swedish public discourse.

With the arrival of camp survivors in the spring and summer of 1945, suspicion toward the Jewish survivors and their construction as false victims or witnesses could no longer be detected in the Stockholm-based press. However, even though this group was rather large, they received relatively little space in the newspapers to speak about their experiences. Non-Jewish Scandinavian camp survivors were, on the other hand, included into the news coverage of the "White Buses" mission and testified to the particular cruelty with which the Jews had been treated in German camps. These Scandinavian camp survivors also became 
symbols of resistance and resilience through portrayals of spiritedness in the face of hardship. This narrative was reproduced in the short documentary film Vittnesbördet, in which male Scandinavians clearly represented resilience and recovery while non-Scandinavian women had to expose their bodies in order to demonstrate Nazi cruelty. Just like the Danish Jews in 1943, women enforced the idea of true victimization. Still, the camera and the narrator spoke about the victims, making the "dismayed spectator" the foremost witness to camp survival and Nazi cruelty in the spring of 1945.

Through Manne Berggren's radio program, however, Jewish victimization as well as a form of Jewish Holocaust witnessing first appeared in Swedish news discourse. The interview-reportage genre that Berggren pioneered for Swedish radio helped establish an early form of witnessing through the medium. Nevertheless, with attention primarily paid to Berggren himself as the exemplary witness to the witnesses, it appears that the foremost ideal for witnessing was still steeped in the form of the "dismayed spectator". The Jewish survivor-witness was not a central figure in the Belsen trial either, even though the Stockholm-based press highlighted Jewish suffering in their coverage to a greater extent than other Anglo-American and German news outlets. Here, the survivor-witnesses were obscured by a burning interest in the perpetrators; female camp guards such as Irma Grese being the prime subject. The Jewish camp survivor as victim and witness to the victimization of others was thus only deemed interesting insofar as she/he highlighted the particular cruelty and deviance of the Nazi perpetrators. Here, discourses on German victimization pertaining to the suffering of German civilians in the aftermath of the war also served to curtail any efforts to make the Jewish survivor-victim stand out as a witness to the particular atrocities that had been committed toward the Jews. During and in the direct aftermath of the war, concepts of Holocaust victimization, survival and witnessing first appeared in Swedish news discourse. At this point, the disciplinary discourse that would later shape the survivor object had not yet come into play, as the event was still current and had not entered the realm of memory and representation. Still, the different roles played by Holocaust victims in the media contributed to different perspectives on the Jewish survivor in particular; as vulnerable victims, as objects of care, as vindictive as well as righteous and sensational witnesses.

A decade later, however, through the many mediations of Anne Frank, a more clearly defined survivor appeared. Through Anne Franks Dagbok and Goodrich and Hackett's The Diary of Anne Frank, the notion of an ideal "moral witness" to the Jewish genocide began to form. In contrast to the American context, Anne and her family's Jewishness were not elided by Swedish critics but were, instead, highlighted 
as part of the authentic aspects of the book and the play. Also, with Sweden having such a small Jewish minority, the Jewish rituals connected to the Chanukah celebrations were seen as exotic and exciting features of the play. Simultaneously however, in 1956, the theatre critics constructed different contexts for Anne's plight, referring to the German occupation of Holland and the special victimization of several victim-categories beyond Jewish suffering. It was thus not until the end of the decade that the context of the Holocaust as the Nazi's concerted effort to annihilate Europe's Jews became much more prominent in Swedish news discourse through Schnabel's historicization of Anne's camp experience and through the film adaptation of the play. Suddenly, both Anne Frank and the survivor-witnesses who testified to her journey through the camps, were "moral witnesses"- the former an ideal witness whose non-accusatory and redemptive voice came from within the experience and the latter an indispensable "special" source of "knowledge about human degradation". ${ }^{1027}$ Therefore, I argue that Anne Frank facilitated the emergence of the camp-survivor as a "moral witness" in Swedish public discourse. Even though the court witnesses of the Eichmann trial solidified the notion of a Jewish camp survivor-witness, the widespread conceptualization of the Holocaust as the Nazi's extermination of 6 million Jews in the late 1950s, also meant that camp survivors were understood as witnesses to this definition of the Holocaust, even if they were not Jewish.

At the same time, the Eichmann trial signified a shift in the visibility of Jewish camp survivor-witnesses. Understandably, the Eichmann trial-being an indictment against the logistical overhead of the Jewish genocide-meant that specifically Jewish witnesses were exposed to the world through different media forms. In Sweden, this meant that the Jewish camp survivor Ferenc Göndör, as one of the first witnesses to the Holocaust shown on television, would testify to his experiences through this new medium. It also meant that Jewish survivor witnesses would be discussed in relation to their performance in the court-roomwhether they were emotional or not, or if what they said exposed anything new. Hamrin's writings from Jerusalem also demonstrate how witnessing was increasingly perceived as something dangerous and physically damaging to those forced or compelled to listen to it. If the decade of Anne Frank had led to the descent of the Jewish camp survivor, this figure also emerged and gained dominance in the early 1960s through the news discourse surrounding the Eichmann trial and the first Frankfurt Auschwitz trial. Hamrin's writings especially, 


\section{Conclusion}

together with the culture critique of Peter Weiss's Die Ermittlung, contributed to a homogenization of the Jewish camp survivor group; all victims and victimsurvivors shared the same history, suffered the same illnesses and anxieties and experienced the act of witnessing in the same way.

Nevertheless, the Eichmann trial, together with the first Frankfurt Auschwitz trial, also produced a new interest in the histories of survivors, albeit only as a way to mitigate the death and despair communicated in different court rooms. Stories of reconciliation with loved ones after twenty years apart thus appeared in the evening newspapers. In the same time-period (1963-1965), Holocaust writers such as Cordelia Edvardson and Zenia Larsson were not merely subject to culture critique, but were positioned as particularly incisive commentators on social and philosophical issues because of their camp experiences. Holocaust witnessing was thus exiting the court room, making the camp survivor an asset in debates about a wide range of societal and existential issues_-something that had not been possible in the previous decade as evidenced by the debate between Edvardson, Herbert Tingsten and Lars Gyllensten.

Interestingly, however, the exemplary survivor of the 1960 s had no camp experience at all. Instead, she inhabited qualities that few other survivors were seen to have; she was both meek and powerful, a woman and a genius poet, otherworldly yet all body with her great brown eyes and shy smile. The construction of Nelly Sachs as the exemplary survivor in 1966 set an impossible standard for survivors; especially for those who were struggling with wounds inflicted in the camps. Forgiveness and meaning did not come as easily to them as it seemed to come to Sachs. Through the writings of Olof Lagercrantz and other contemporary critics as well as the newspapers' portrayals of Sachs, the survivor ideal that had emerged with Anne Frank was entrenched and solidified in 1966. This is not to say that Jewish camp survivors were deemed uninteresting or lacking utility. Rather, several roles were created for Jewish survivors_ — roles that were disciplined by the concepts of silence and excess.

\section{3 The Mechanisms of Silence and Excess}

As communicators of Holocaust experience, survivors have continuously been disciplined by implicit rules concerning "acceptable approaches to the Holocaust". 1028 The rules regarding what should be deemed acceptable, is in turn, 
determined by expert discourse: scientific, professional and institutional. Although the survivor came into being through a great number of discourses and therefore took on a multitude of shapes and roles, the ideals of true victimization, moral witnessing and the effective/useful Holocaust victim and witness have fundamentally affected the ways in which survivors—as those who were classified-have been able to speak, act and behave in public spaces. Thus, even though the Jewish Holocaust survivor has been constructed as a performer or entertainer of sorts - as someone who can shock and awe an audience or a reader, make them cry or sigh with sadness or relief-this position has also been continuously critiqued.

Through documentarian ideals where facts, figures and authenticity have been emphasized as well as aesthetic ideals of minimalism and emotive restraint, the survivor has become a figure that exists between silence and excess. Survivor expressions have been deemed too emotional, or the wrong kind of emotional, as stepping outside of the survivor's realm of knowledge, or as unnecessary and superfluous; even as detrimental to the health of others. All of these perceived excesses of survivors' communicating their own or others' experiences, have simultaneously been countered by arguments of silence. Silence, or the absence of expression, was also, throughout the 1950s and 1960s (when the Holocaust had become a more distant memory) positioned as dangerous, albeit with less specificity regarding what this danger entailed. 'Never forget' was also a potent argument in the 1950s. Yet, because the perceived danger of silence was never fully explained or explored, utility also became crucial to the disciplining of survivor expression. How could the space afforded to Jewish survivors in public discourse be justified if they did not contribute something invaluable to society? This seemed to be the question implicitly asked by commentators in the 1950s and 1960s. The problematization of utility-informing representations of the survivor since 1945constitutes the "depth condition" that is continuous in the Holocaust survivor's construction. Because of their construction as 'strange birds' they were both called upon to witness and comment on a wide range of political and social phenomena, while, at the same time, having to balance the tight-rope between silence and excess.

In creating a "Memory Archive" for the future, the experts working under the auspices of Living History deemed Jewish camp survivors excessive because they were assumed to perform their testimonies in ways that were not useful. Rather than viewing Jewish camp survivors' expressions as a process of working-through their memories, the project's epistemological perspective positioned survivors as informants; individuals that one could procure useful information from. Also, even 
though the history of Jewish survivor-hood in a Swedish context is a fundamentally understudied area, the camp survivors' history was claimed to be "welldocumented" with references made to one other Swedish museum collection as well as the USC Shoah Foundation's visual history archives. The Jewish camp survivor as un-Swedish and Jewish camp survivor expressions as excessive were thus two conceptions that underpinned this government-based project during the memory 'boom' era in Sweden. It is understandable that the utility of survivors was emphasized during the process of creating a "Memory Archive" as well as The Living History Forum, since the impetus for the Living History campaign had been to educate Swedish youth on the Holocaust and the importance of upholding democratic ideals. The individuals included in the archive therefore had a specific purpose. However, the whole process of developing an educational campaign into a government agency also elucidated how expert discourse formed around the subjects of Holocaust representation and Holocaust survivors when the stakes were high. Aesthetic ideals of minimalism and emotive restraint permeated the culture critique of Tellye your Children and the film package that was issued as a part of the campaign. "Making Schindler's List" of a book about the Holocaust was an argument that captured a common critique against the sentimentality and emotional excessiveness of Holocaust narratives at the time. Most of the examples used to refer to these transgressions of 'proper' Holocaust representations were also connected to Jewish survivors-Spielberg's Shoah foundation project of 50,000 testimonies contributing to the perception of excessive forms of witnessing.

The problematization concerning utility and conceptions of the hypertrophy of Jewish memory can be traced back to 1945 when objects of care, on screen in $V$ ittnesbördet, testified with their bodies to the horrors of the camps. In her critique of these bodies as too round and happy, Lisa Matthias contributed to the marginalization of the healthy-looking victim, while Berggren's victims lived up to the figure that could elicit appropriate emotion from its listeners. Similarly, the culture critique surrounding Anne Frank served to discipline the survivor by referring to the effectiveness of Anne's testimony. Through the culture critique of the book and the play, the perception that no one could move the hearts of others like Anne Frank, even though "thousands and thousands of pens" had tried, emerged in Swedish media discourse. The utility of the witnesses testifying at the Eichmann trial were similarly critiqued by Hamrin, who characterized their voices as important yet dangerous for their ability to upset others and make the world feel ashamed of itself. Conversely, Sachs's genius could be established in relation to assessments of her work as conciliatory. She saw meaning in suffering where others 
could not and wrote about it with such beauty that she could elicit emotion in her readers or listeners that mended rather than ripped at sorely healed wounds.

Thus, the problematization of utility was the continuous "depth condition" that shaped the survivor object. Yet, simultaneously, the survivor object, subject and subject position also transformed in relation to non-discursive and discursive forces that worked on the object. Anne Frank, the Eichmann trial and Nelly Sachs's Nobel Prize all served to heighten an interest in the survivor as victim and as witness. Two ideals_one documentarian and one emotive-created an expert subject position for the survivor from which their own survivor-hood could be actualized and their perceived expertise on phenomena beyond the Holocaust could be strengthened. What is particularly important then, in the history of the survivor as classification, is the parallel existence of survivor types. In 1945, the Holocaust survivor was defined by discourses on Swedish care. The period of Anne Frank introduced survivors as an agential group who were keen to document what they had experienced as well as witnesses to the ideal victim-witness of Anne Frank. In the era of the trials, the Holocaust survivor became a Swedish witness in German trials and a part of the Swedish people's home; two events that further elevated the position of the survivor-witness. There were thus breaks and discontinuities, created by discursive and non-discursive events that helped shape the survivor object, subject-position and subject. The latter is also evidenced by the ways in which the survivors themselves expressed different truths about victimization, witnessing and survivor-hood in this period; Zenia Larsson arguing that survivors should help individualize the victims in order to prevent a second death, and Cordelia Edvardson claiming in general term that "one" had to express oneself, that this was both an inner need, and a moral duty.

The relationship that most scholars pay attention to when studying Holocaust memory - the progressivist historical narrative of silence and excess-has thus, in this dissertation, been interrogated by the empirical study of a conceptual relationship between silence and excess. While the silence/excess progression has been presented as empirically sound-that survivors and society remained silent until the 1980s, after which Holocaust memory became industrialized, fetishized and made into kitsch-I suggest that these relationships are as much conceptual as they are real. Furthermore, assessments of physical excess and physical silence are inherently problematic as they assume that there is an upper and a lower limit. What is too much survivor talk? What is too little? Who decides what the best balance is between silence and excess?

Even though critical assessments of Holocaust representation and survivor expression cannot satisfactorily answer these questions, they still act as exclusionary 


\section{Conclusion}

mechanisms that serve to disguise differences in the lived experience of survivors during and after the Holocaust. The expert opinion and culture critique that reasserts boundaries according to the concepts of silence and excess thus contribute, as Dean phrases it, to the "erasure" of victims' lives and experiences from the historical record. ${ }^{1029}$

\section{4 The Gendered Survivor: Objects of Care and the Transcendental Genius}

Vulnerability is a central aspect of Holocaust witnessing; the more vulnerable the victim, the more credible the witness account will seem. ${ }^{1030}$ As proposed by Cole and Dean, vulnerability is connected to perceived levels of innocence, 'proper' emotional responses to past event(s), and complete powerlessness in the face of perpetration. ${ }^{1031}$ Because of this understanding of vulnerability, women as passive objects of care fit neatly into the ideal of the "True Victim". Even though the Jewish-Danish escapees were met with a measure of suspicion by some newspapers and were problematized as economic burdens on society, their depiction as civilians of war-as women and children-helped communicate their actual strife and helplessness under Nazi occupation. The female victim as fundamentally vulnerable thus became a symbol of Holocaust victimization and survival as early as 1943 in a Swedish context. This notion of true victimization and its connection to female victims also continued to inform the descent and emergence of the Holocaust survivor in the following decades.

Vittnesbördet exemplifies this connection by positioning female camp survivors as passive objects who were being cared for by the Swedish state. While the male Scandinavian rescuees were also cared for, the representation of their recoverythe regaining of spirits, humor and their swift return to health and an everyday life-humanized them and made them subjects rather than objects of care. This difference is crucial, as female victims of the Holocaust have continued to be reduced to their wounds, Anne Frank and Nelly Sachs being seen as fundamentally defined by them. To be sure, non-Scandinavian female victims were also portrayed as recovering and making lives for themselves even if these portrayals came later during the autumn of 1945 . With pressure from the international community,

1029 Dean, Aversion and Erasure, 144.

1030 Cole, The Cult of True Victimbood, 5.

1031 Cole, The Cult of True Victimbood, 5-6. 
Sweden's role in returning its non-Scandinavian rescuees to humanity also became a priority. Hence, female survivors came to embody many forms of victimization and recovery making their bodies, rather than their voices, ideal witnesses to the horrors of the Holocaust.

With regards to witnessing, there were two ideals in particular that significantly affected the survivor's descent and emergence in Swedish public discourse during the 1950s and 1960s; both were intimately connected to a gendered understanding of the Holocaust witness. One ideal emphasized the importance of emotive restraint and objectivity (often imposed on camp survivor witnesses). Within the other ideal, emotional expression—albeit of a noble kind-was stressed. As camp survivors and prolific writers, Edvardson and Larsson fell under the pressure of both ideals with some critics appreciating their prose as gripping and inspirational, while others criticized them for not 'telling it exactly like it was'. Göndör and Leiser were often discussed in relation to the 'documentarian' ideal; an ideal that was strengthened by the historicization of Anne Frank at the end of the 1950s. It thus seems that the female survivor-witness, as Waxman has asserted, was made to bear a greater responsibility with regards to connecting with readers and audiences in an emotional way. ${ }^{1032}$ If the female witness was not exceptional at this, however, her expressions would also be subjected to the rigorous standards of the documentarian ideal of witnessing. In no other cases were these gendered ideals more apparent than in those of Erwin Leiser and Nelly Sachs.

Leiser's documentaries were referenced in relation to different forms of Holocaust representation in the 1960s-his assemblage of moving images filmed during the war both contributing to and reflecting the documentarian ideal. Although Leiser had Holocaust experience, having escaped Germany at 15, these experiences were never related to his work of mediating Holocaust memory. Like Sachs, however, Leiser was represented as a conduit of Holocaust experience; his renditions of the Nazi epoch described as "strict" and objective while hers were described as moving and existentially cataclysmic. They had both felt the persecution of the Nazis acutely in the years leading up to the War but managed to escape arrest, ghettoization and deportation. In addition, they both shared the dedication and commitment to the upholding of Holocaust memory, although they chose to express these commitments in different ways; her through her poetry and 


\section{Conclusion}

him through films about the Holocaust. ${ }^{1033}$ The most significant difference between their construction, however, was that Sachs's commitment to Holocaust memory was continuously connected to her Holocaust experiences-her genius hinging on her memories of victimization — while Leiser's experiences only served to incriminate his endeavors to document the Holocaust. Hence, although they had similar experiences from the war and similar perspectives on the importance of witnessing, one was not constructed as a survivor while the other became the 'exemplary' survivor.

In contrast to Anne Frank, however, the construction of Sachs as the 'exemplary' survivor was intimately connected to traumatic emotion. It was the ongoing trauma that Sachs experienced that constituted her genius. Yet, like Anne Frank, Sachs's poetry was also said to transcend the feelings that usually come after trauma-of emptiness, of meaninglessness, depressive thoughts about life's transience. As demonstrated by the poem, "Chorus of the Saved", Sachs created a "we" in the trauma of the survivor; a "we" that became increasingly difficult to question after Sachs won the Nobel Prize in 1966.

\section{5 What is Next?}

In chapter one, I emphasized the importance of trying the 'thesis of silence'. Indeed, this is an endeavor that needs to continue with regards to Swedish Holocaust memory. During my research process I encountered innumerable sources and materials that show different aspects of Holocaust memory in Sweden before the 1980s and 1990s; some of which have been explored in this dissertation. In addition, the period between 1970 and 1979 (including 1979) has not been sufficiently studied either. Even though my analysis ends in 1966, there are other events occurring at the end of the 1960s and early 1970s that yet again actualize the role of the survivor, including antisemitism and discrimination against Jews in Poland and Eastern Europe, the Six-day War, the Sobibor and Treblinka trials and the continuous remembrance of the "White Buses" mission. ${ }^{1034}$ Through these

1033 In 1986, Leiser made a film about Elie Wiesel called Elie Wiesel_-Im Zeichen des Feuers (the Swedish title is "I eldens tecken—ett porträtt av Elie Wiesel"). For autobiographical accounts of Leiser's life see Samtal $i$ Berlin and Gott han kein kleingeld: Erinnerungen.

1034 See, for example, Zenia Larsson, “Att kanske ännu ett krig återstår, och ännu ett...,” February 6, 1971, Expressen, 4. Madeleine Katz “Nej, vi driver inte ut judar ur Sverige. Men...," datum, 


\section{Chapter 7}

events and subsequently through the broadcast of Holocaust, survivors were represented by different mediums and engaged in public fora. Many of these Swedish survivors have been visible in public discourse throughout the decades, examples including Hédi Fried, Lidia Fränkel, Emerich Roth and Ferenc Göndör. Others have been remembered through scholarly works that have attempted to understand survivors' output (visual art, poetry, novels, etc.) although never focused on their relation to concepts of survival, victimization and witnessing.

In my research, there were a handful of individuals who, in their roles as survivor-witnesses or mediators of Holocaust memory, travelled between mediums; Cordelia Edvardson and Erwin Leiser being two of the foremost examples. When I looked further for these individuals in the secondary literature, I also found that they were either absent or constituted mere footnotes in the narrative. In my searches, however, they were everywhere. Leiser as the lauded film-maker and journalist who translated Nelly Sachs's work and made films about Elie Wiesel and Edvardson as social and political commentator, journalist and author-always debating issues pertaining to Israel, the middle east and the Holocaust. These individuals thus appear to be crucial to Holocaust memory in Sweden and their lives and work need further scrutiny in order to restore them to the national historical record. Furthermore, there are survivor activists-some of whom were more visible in the early decades of Holocaust memory-that have been completely absent in the historical record. The Polish-Jewish camp survivor and Swedish researcher, Halina Neujahr, serves as one of the most glaring examples of this. 1035

Expressen, 4. (The latter is a review of Larsson's Morfars kopparslantar, which was described as a "personal reaction after the Six-day War"). "Treblinkas chef greps i Brasilien," March 3, 1967, DN, 13. In 1971, Aftonbladet published a series of articles published under the heading, "Flyktingarna som Bernadotte räddade" ("The refugees rescued by Bernadotte"). In the series, Halina Neujahr is featured together with three other male camp survivors. See, for example, "De kunde lika väl skjuta mig direkt"” May 16, 1971, Aftonbladet, "Hon började sin forskarbana i ghettot," April 25, 1971, Aftonbladet.

1035 For a journalistic account of Neujahr's involvement in the creation of the Holocaust memorial in Stockholm see Victoria Martínez, "The Stockholm Holocaust Memorial—a Restoration of Human Dignity and a Warning against Inhumanity," The Local, (August 3, 2017),

https:/ / www.thelocal.se/20170803/the-stockholm-holocaust-memorial-a-restoration-of-humandignity-and-a-warning-against-inhumanity, (accessed on December 15, 2019). Currently, Martínez is working on her doctoral dissertation under the working title Afterlives: Histories of Women Concentration Camp Survivors in Sweden which, as the title suggests, will focus on the postHolocaust lives of female survivors, including Halina Neujahr, in Sweden. 
However, other than show that the early decades of Holocaust memory are important to perspectives on the survivor, I have also attempted to demonstrate how concepts of silence and excess have always permeated discussions on Holocaust representation. Although Dean has studied a similar phenomenon with regards to the Holocaust witness from the early 1960s onwards, further research using material from other regional, national and local contexts are needed in order to show the actual effects of such discourses. Hence, how can the "erasures" that affect survivor histories be understood? And how should expert discourse ranging from museums and archives to researchers and journalists be understood as actors in this process? As of 2019, the Swedish government has also set in motion an investigation into a new Swedish Holocaust museum. What will the role of survivors and the survivor object be in this project? And how will expert discourse discipline their physical participation and the position of their accounts and stories in the new museum? These are questions that will hopefully characterize any future endeavors to understand the survivor in Sweden. 


\title{
References
}

\section{References}

\author{
Physical Archives
}

Riksarkivet (RA)

Kommittén Forum för Levande Historia med Projekt Levande Historia, vol. 12, 13, 14, 17, 19.

Kommittén för Levande Historia, vol. 14, 25.

Barn och ungdomsdelegationen, vol. 22

Svenska Riksteatern, del 1, B: 2, B3: vol. 1, F6C: vol. 5.

Nobelarkivet (NA)

Utlåtande av svenska akademiens Nobelkommitté, 1963, 1964, 1965, 1966.

Sakkunnigutlåtanden rörande Agnon (1966) och Sachs (1963, 1964,1965).

Förslagsskrivelser/Nomination Letters Nelly Sachs,1966

\section{Digital Archives}

Kungliga Bibliotekets Digitala Nyhetsarkiv

Dagens Nyheter (DN)

Svenska Dagbladet (SvD)

Expressen

Aftonbladet

Göteborgs Handels- och Sjöfartstidning

Stockholmstidningen

Göteborgsposten

Provistidningen Dalsland

Svensk Mediedatabas (SMDB)

"koncentrationslägerfångar anländer till Malmö: om stämningen i Köpehamn kort före tyskarnas kapitulation," radio program, May 2, 1945.

"Dagens eko," radio program, May 4, 1945.

Manne Berggren, 'En last med levnadskval ombord," June 28, 1945

"Skol-TV," April 14, 1961.

"Aktuellt," April 10, 1961.

"Aktuellt," April 28, 1961.

"Från Mauthausen till Liljeholmen," September 28, 1980.

"Intervju med Nelly Sachs hemma hos Holmqvists". Television interview, 1966. 


\section{References}

"Intervju med Nelly Sachs," audio-recording, 1966.

"Ferenc Göndör: A6171,” Film, 1987.

\section{Filmarkivet.se}

Vittnesbördet, directed by Nils Jerring, (Sweden, Svensk Filmindustri AB, 1945)

\section{Films}

Hoppets hamn, directed by Magnus Gertten (Auto Images AB, 2011).

Operation Eichmann, directed by R.G. Springsteen (United States: Allied Artists Pictures, 1961).

Kapo, directed by Gillo Pontevcorvo (Italy, France, Yugoslavia: Cineriz, 1960).

Eichmann und das Dritte Reich, directed by Erwin Leiser (Switzerland, West Germany:

Praesens Film, 1961).

\section{Websites}

"Forum för Levande Historia," SOU 2001: 5. https://www.regeringen.se/rattsligadokument/statens-offentliga-utredningar/2001/02/sou-20015/ , (accessed on November 18, 2019).

Protokoll 1996/97: 119, 22. https://data.riksdagen.se/fil/62A0CA5E-31EE-4431-BE69 BA7A41688D2A, (accessed on July 2, 2015).

\section{Bibliography}

Aare, Cecilia. “A Narratological Approach to Literary Journalism: how an Interplay Between Voice and Point of View may Create Empathy with the Other." Literary Journalism Studies 8, no. 1 (2016): 106-139.

Allwork, Larissa. Holocaust Remembrance between the National and the Transnational: The Stockholm International Forum and the first decade of the International Task. Force. London: Bloomsbury, 2015.

Anaïs, Seantel. "Genealogy and Critical Discourse Analysis in Conversation." Critical Discourse Studies 10, no. 2 (2013) 123-135.

Andersen, Niels Åkerstrøm. Discursive Analytical Strategies: Understanding Foucault, Koselleck, Laclau, Lubmann. London: The Policy Press, 2003.

Andersson Lars M. En jude är en jude är en jude: Representationer av "juden" i svensk skämtpress omkring 1900-1930. Doctoral diss., Lund: Nordic Academic Press, 2000).

Andersson, Lars M. "Att moralisera över det moraliska historiebruket." Historisk tidskrift 123, no. 2 (2003): 319-323.

Andersson, Lars M. "Historikerna och morale." In Sverige och Nazityskland: Skuldfrågor och moraldebatt, edited Lars M Andersson, 9-25. Stockholm: Dialogos, 2007. 
Andersson Lars M. and Karin Kvist Geverts eds En problematiske relation? Flyktingpolitik och judiska flyktingar i Sverige 1920-1950. Uppsala: Opuscula Historica Upsaliensia 36, 2008.

Arendt, Hannah. Eichmann in Jerusalem: A report on the Banality of Evil. New York: Viking Press, 1963.

Arendt, Hannah. Den Banala Ondskan: Eichmann i Jerusalem. Stockholm: Aldus/Bonnier, 1964.

Assmann, Aleida. "History, Memory and the Genre of Testimony." Poetics Today 27, no. 2 (2006): 261-273.

Assmann, Aleida. "The Holocaust—a Global Memory? Extensions and Limits of a New Memory Community." In Memory in a Global Age: Discourses, Practices and Trajectories, edited by Aleida Assmass and Sebastian Conrad, 97-117. Basingstike: Palgrave Macmillan, 2010.

Bacchi, Carol Lee. Women Politics and Policy: The construction of policy problems. London: Sage, 1999.

Bacchi, Carol Lee. Analysing Policy: What's the Problem Represented to be? Frenchs Forest N.S.W., Pearson, 2009.

Bachner, Henrik. Aterkomsten: Antisemitism i Sverige efter 1945. Stockholm: Natur och Kultur, 1999.

Bachner, Henrik. Judefragan: debatt om antisemitism i 1930-talets Sverige. Stockholm: Atlantis, 2009.

Bahr, Erhard. Nelly Sachs. München: C.H. Beck, 1980.

Bak, John S. and Bill Reynolds eds. Literary Journalism Across the Globe. Amherst: University of Massachusetts Press, 2011.

Bak, Sofie Lene. Nothing to Speak of: War-time Experiences of the Danish Jews. Copenhagen: The Danish Jewish Museum, 2011.

Bak, Sofie Lene. Jødeaktionen oktober 1943: Forestillinger i offentlighed og forskning. Copenhagen: Museum Tusculanum, 2001.

Bak, Sofie Lene. "Repatriation and Restitution of Holocaust victims in Post-war Denmark." Jewish Studies in the Nordic Countries Today vol. 27 (2016): 134-152.

Baldwin, Annabelle. "Sexual Violence and the Holocaust: Reflections on Memory and Witness Testimony." Holocaust Studies 16, no. 3 (2010): 112-134.

Ball, Karyn. Disciplining the Holocaust. Albany NY: SUNY Press, 2009.

Barnaouw, David. The Phenomenon of Anne Frank, trans. Jeanette K. Ringold. Indianapolis: Indiana University Press, 2018.

Battersby, Christine. Gender and Genius: Towards a Feminist Aesthetics. London: Women's Press, 1989.

Battersby, Christine. The Phenomenal Woman: Feminist Metaphysics and the Patterns of Identity. New York: Routledge, 2013), 9-10.

Bell, Allan. The Language of News Media. Oxford: Blackwell, 1991.

Bell, Allan. "News Discourse." In Approaches to Media Discourse, edited by Allan Bell and Peter Garrett, 1-20. Oxford: Blackwell, 1998.

Benz, Wolfgang. "Emigration as Rescue and Trauma: The Historical Context of 


\section{References}

the Kindertransport." Shofar 23, no. 1 (2004): 2-7

Bettelheim, Bruno. Surviving and Other Essays. New York: Knopf, 1979.

Bloxham, Donald. Genocide on Trial: War Crimes Trial and the formation of Holocaust Memory. Oxford: Oxford University Press, 2001.

Bodnarek, Monika and Helen Caple. News Discourse. London: Bloomsbury Publishing, 2012.

Boëthius, Maria-Pia. Heder och samvete: Sverige och andra världskriget. Stockholm: Norstedt, 1991.

Borg, Margareta. Skol-TV - traditioner, visioner och former: En studie av skol-TV:s förutsättningar, framväxt och utveckling under 1960-talet. Doctoral diss., Lund: Lund University, 2006.

Bothe, Alina and Markus Nesselrodt. "Survivor: Towards a Conceptual History." Leo Baeck Institute Year Book vol. 61 (2016): 57-82.

Bower, Katherine M. Ethics and Remembrance in the Poetry of Nelly Sachs and Rose Ausländer. Columbia SC: Camden House, 2000.

Brenner, Rachel Feldhay. Writing as Resistance: Four women confronting the Holocaust: Edith Stein, Simone Weil, Anne Frank and Etty Hillesum. University Park, PA: Pennsylvania State University Press, 1997.

Byström, Mikael. En broder, gäst och parasit: Uppfattningar och föreställningar om utlänningar, flyktingar och flyktingpolitik $i$ svensk offentlig debatt 1942-1947. Stockholm: Almqvist and Wiksell, 2006.

Byström, Mikeal and Pär Frohnert. Reaching a State of Hope-Refugees, Immigrants and the Swedish Welfare State, 1930-2000. Stockholm: Nordic Academic Press, 2013.

Carlsson, Carl-Henrik. Medborgarskap och diskriminering: Östjudar och andra invandrare $i$ Sverige, 1860-1920. Doctoral diss., Uppsala: Studia Historica Upsaliensia, 2004).

Cesarani, David. Eichmann: His Life and Crimes. London: Heinemann, 2004.

Cesarani, David. "Introduction.” Journal of Israeli History 23, no. 1 (2004): 1-17.

Cesarani, David. Becoming Eichmann: Rethinking the life, Crimes, and Trial of a "desk murderer". Cambridge, MA: Da Capo Press, 2007.

Cesarani, David. "Challenging the 'Myth of Silence': Postwar Responses to the destruction of European Jewry." in After the Holocaust: Challenging the Myth of Silence, edited by David Cesarani \& Eric J Sundquist, 15-38. Abingdon: Routledge, 2012.

Chouliaraki, Lilie. "Self-Mediation: New Media and Citizenship." Critical Discourse Studies 7, no. 4 (2010): 227-232.

Cohen, Beth B. Case Closed: Holocaust Survivors in Post-W ar America. New Brunswick, NJ: Rutgers University Press.

Cohen, Boaz. "The Children's Voice: Postwar Collection of Testimonies from Child Survivors of the Holocaust." Holocaust and Genocide Studies 21, no. 1 (Spring, 2007): 73-95.

Cohen, Boaz. "Survivor Care-givers and Child Survivors: Rebuilding Lives." Holocaust and Genocide Studies vol. 32, no. 1 (2018): 49-65.

Cohen, Robert. "The Political Aesthetics of Holocaust Literature: Peter Weiss's 


\section{References}

The Investigation and its Critics." History \& Memory 10, no. 2 (Fall 1998): 4367.

Cole, Alyson M. The Cult of True Victimhood: From the War on Welfare to the War on Terror. Standford, CA: 2007.

Cole, Tim. Selling the Holocaust: From Auschwitz, to Schindler; How History is bought, Packaged and Sold. New York: Routledge, 2000.

Conway, Paul. "Digital Transformations and the archival nature of surrogates." Archival Science, vol. 15, (2015): 51-69.

Connolly, William E. "Beyond Good and Evil: The Ethical Responsibility of Michel Foucault." Political Theory 21, no. 3 (Aug, 1993): 365-389.

Consonni, Manuella. “The Impact of the 'Eichmann Event' in Italy, 1961.” Journal of Israeli History 23, (2003): 91-99.

Cowie, Elizabeth. "Seeing and hearing for ourselves: the spectacle of reality in the Holocaust documentary." In Holocaust and the Moving Image, edited by Toby Haggith and Joanna Newman, 182-188. London: Wallflower, 2005.

Cronqvist, Marie and Christoph Hilgert. "Entangled media histories." Media History 23, no. 1 (2017): 130-141.

Dahl, Izabela A. “"...this is material arousing interest in common history'. Zygmunt Lakocinski and Polish survivors' protocols." Jewish History Quarterly vol. 3, (2007): 319-338.

Dahlén, Peter. "En säregen radioreporter: Ett yrkesporträtt av Manne Berggren." In Presshistorisk årsbok, edited by Birgitta Ney, Lars-Åke Engblom, Kristina Lundgren, Gunilla Lundström, Birgit Petersson, and Per Rydén, 7-28. Bromma: Svensk Presshistorisk Förening, 2015.

Dahlin, Johanna. Kriget är inte över förrän den sista soldaten är begraven. Doctoral diss., Linköping: Linköping University Press, 2012.

Dean, Carolyn J. The Moral Witness: Trials and Genocide after Genocide. Ithaca; London: Cornell University Press, 2019.

Dean, Carolyn. Aversion and Erasure: The Fate of the Victim after the Holocaust, Ithaca and London: Cornell University Press, 2010.

Della Pergola, Sergio. "Jewish Shoah Survivors: Neediness Assessment and Resource Allocation." In Holocaust Survivors: Resettlement, Memories, Identities, edited by Dalia Ofer, Françoise S. Ouzan, and Judy Tydor Baumel-Schwartz, 292-314. New York and Oxford: Berghahn Books, 2011.

Dinesen, Ruth. Nelly Sachs: En biografi. Ringkøbing: After Hand, 1993.

Diner, Hasia R. We Remember with Reverence and Love: American Jews and the Myth of Silence after the Holocaust, 1945-1962. New York: New York University Press, 2009.

Djerf-Pierre, Monika. "Journalistikens kön. Fältets struktur och logik under 1900talet." Kvinnovetenskaplig tidsskrift 2, no. 3 (2003): 29-52.

Djerf-Pierre, Monika and Lennart Weibull. Spegla, granska, tolka: Aktualitetsjournalistik $i$ svensk radio och tv under 1900-talet. Stockholm: Prisma, 2001.

Ebbrecht-Hartmann, Tobias. "Dokumentarfilm als Gerichtverfahren: Erwin 


\section{References}

Leisers Eichmann und das Dritte Reich (1961).” Filmblatt 51 (2013): 47-57.

Ebbrecht-Hartmann, Tobias. "Trophy, Evidence, Document: Appropriating an Archive Film from Liepaja, 1941." Historical Journal of Film, Radio and Television 6, no. 4 (2016): 509-528.

Edfeldt, Johannes. "Inledning." In Flykt och förvandling: ett dikturval, /Nelly Sachs, edited by. Erwin Leiser, (Stockholm: FIB:s lyrikklubb), 1961.

Edin, Anna. Den föreställda publiken: programpolitik, publikbilder och tilltalsformer i svensk. public service-television. Eslöv: B Östlings bokförlag, 2000.

Edin, Anna. "I takt med tiden: Om Tv-tablån som mediehistorisk text," in, Svensk television: En mediehistoria, vol. 6, edited by Anna Edin and Per Vesterlund, 85107. Lund: Mediehistoriskt arkiv, 2008.

Edin, Anna. "Tillbaka till framtiden: Om publiken som public service-problem." In Medieproblem: Mediestudiets formering, edited by Mats Hyvönen, Pelle Snickars, and Per Vesterlund, 105-122. (Lund: Mediehistoria, Lund University, 2015.

Edin, Anna and Per Vesterlund. "Svensk television och mediehistoria-en inledning." In Svensk television: en mediehistoria, vol. 6, edited by Anna Edin \& Per Vesterlund, 9-31. Stockholm: Statens Ljud och Bildarkiv, 2008.

Ekman, Stig. "Sverige under andra världskriget_erfarenheter från arbetet i ett project." Historisk Tidsskift 99 (1979): 152-165.

Engblom, Lars-Åke. “Tidningar dör men pressen lever vidare.” Den svenska pressens bistoria (Efter 1945), edited by Lars-Erik Engblom, Sverker Jonsson, and KarlErik Gustafsson, 20-133. Stockholm: Ekerlids, 2002.

Erll, Astrid. "Cultural Memory Studies: An Introduction." In Cultural Memory Studies, edited by Ansgar Nünning and Astrid Erll, 1-13. Berlin: De Gruyter, 2008.

Elgemyr, Göran. "Maktkampen kring dagens eko—uppkomst och utveckling." In Dagens Eko. Nyheter $i$ radio under 50 år, edited by Kerstin Brunnberg and Göran Elgemyr, 9-34. Stockholm: Sveriges radios förlag, 1987.

Elgemyr, Göran. "Inventiveness and a Desire to Experiment: The Development of Production Technology in Swedish Radio 1925-1955." In Swedish Broadcasting: Communicative Ethos, Genres and Institutional Change, edited by Monica Djerf Pierre and Mats Ekström, 55-82. Gothenburg: Nordicom, 2013.

Erll, Astrid. "Cultural Memory Studies: An Introduction.” In Cultural Memory Studies eds Ansgar Nünning and Astrid Erll, 1-13. Berlin; De Gruyter, 2008.

Falkenstein, Henning. Nelly Sachs. Berlin: Colloquium, 1984.

Felman, Shoshana. The Juridical Unconscious: Trials and Traumas in the Twentieth Century. Cambridge, MA: Harvard University Press, 2002.

Finkelstein, Norman. The Holocaust Industry: Reflections on the Exploitation of Jewish Suffering. New York: Verso Books, 2000.

Fioretos, Aris. Flyket och förvandling: Nelly Sachs, författare Berlin/Stockholm. Stockholm: Ersatz, 2010.

Frank, Anne. The Diary of a Young Girl. London: Vallentine Mitchell, 1952.

Frank, Anne. Anne Franks dagbok. trans. Ella Wilcke. Stockholm: Hökerberg, 1953.

Fredriksson, Jessica. "Europas bödel' fast efter 15 år’": En kvalitativ presstudie av 
den svenska pressens rapportering om Eichmannrättegången 1961. Master's thesis, Uppsala: Uppsala University.

Fried, Hédi. Fragments of a life: the road to Auschwitz, trans. Michael Meyer. Bath: Chivers, 1990.

Fried, Hédi. The Road to Auschwitr: fragments of a life, trans. Michael Meyer. Lincoln, NE: University of Alaska Press, 1996.

Fried, Hédi. Questions I am asked about the Holocaust, trans. Alice E. Olsson. London: Scribe, 2019.

Friedländer, Saul. Memory, History, and the Extermination of the Jews of Europe. Bloomington, IN: Indiana University Press, 1993.

Frosh, Paul and Amit Pinchevski. "Introduction: Why Media Witnessing? Why now?" In Media Witnessing: Testimony in the Age of Mass Communication, edited by Paul Frosh and Amit Pinchevski, 1-19. London: Palgrave Macmillan, 2009.

Forser, Tomas. Kritik av kritiken: 1900-talets svenska litteraturkritik. Gråbo: Anthropos, 2002.

Foucault, Michel. Aesthetics, Method and Epistemology. New York: The New Press, 1999.

Foucault, Michel. "The Ethics of the Concern of the Self as a Practice of Freedom." In Essential Works of Foucault, 1954-1984, vol. 1. Ethics: subjectivity and Truth, edited Paul Rabinow, 281-301. London: Penguin Books, 2000.

Foucault, Michel. Essential Works of Foucault, 1954-1984: vol. 2 Aesthetics, Method and Epistemology, edited by James Faubion. London: Penguin, 2000.

Foucault, Michel. The Archaeology of Knowledge. Abingdon: Routledge, 2006.

Garde, Pia-Christina. De Dödsdömda Vittnar-60 Ar Senare. Stockholm: Megilla förlaget, 2004.

Geva, Sharon. "To Collect the Tears of the Jewish People': the story of Miriam Novitch." Holocaust Studies 21, no.1 (2015): 73-92.

Geverts K. Kvist, Ett Främmande Element i Nationen: Svensk Flyktingpolitik och de Judiska Flyktingarna. Uppsala: Acta Universitatis Upsaliensis, 2008.

Giles, Fiona and William Roberts. "Mapping Nonfiction Narrative: A New Theoretical Approach to Analyzing Literary Journalism." Literary Journalism Studies 6, no. 2 (Fall 2014): 100-117.

Gopfert, Rebekka and Andrea Himmel. "Kindertransport: History and Memory." Shofar 23, no. 1 (2004): 21-27.

Gottfarb, Inga. Den livsfarliga glömskan. Stockholm: Langenskiöld, 1986.

Greenspan, Henry. On listening to Holocaust Survivors: Beyond Testimony, 2nd ed. Ann Arbor, MI: Paragon press, 2010.

Gross, Peter and Gerd G. Kopper. Understanding Foreign Correspondence: A EuroAmerican handbook of Concepts, Methodologies and Theories. New York: Peter Lang, 2011.

Grossman, Atina. "The 'Goldhagen effect': Memory, Repetition, and Responsibility in New Germany." In History, Memory, Nazism—Facing the German Past, edited by Geoff Eley, 89-129. Ann Arbor: The University of Michigan Press, 2000. 


\section{References}

Grossmann, Atina, Mark Edele \& Sheila Fitzpatrick. Shelter from the Holocaust: Rethinking Jewish survival in the Soviet Union. Detroit: Wayne State University Press, 2017.

Hacking, Ian. The Social Construction of What?. Cambridge, MA \& London: Harvard University Press, 1999.

Hacking, Ian. Historical Ontology. Cambridge MA: Harvard University Press, 2002.

Hacking, Ian. "Between Michel Foucault and Erving Goffman: Between discourse in the abstract and face-to-face interaction." Economy and Society 33, no. 3 (2004): 277-302.

Hadenius, Stig. Dagens nyheters historia: Tidningen och makten 1864-2000. Stockholm: Bokförlaget DN, 2002.

Hamrin, Agne. Bokslut i Jerusalem. Stockholm: Bonnier, 1961.

Hammerstein, Kai. "Inventing History: Toward a Gay Holocaust Literature." The German Quarterly 70, no. 1 (1997): 18-26.

Hansson, Lars. Vid gränsen, Mottagningen av flyktingar frän Norge, 1940-1945. Doctoral diss., Gothenburg: Gothenburg University Press, 2019.

Hansson, Svante. Flykt och överlevnad: flyktingverksambet i mosaiska församlingen i Stockholm, 1933-1950. Stockholm: Hillelförlaget, 2004.

Haraway, Donna. "Situated knowledges: The Science Question in Feminism and the Privilege of Partial Perspective." Feminist Studies 14, no. 3 (Autumn 1988): 575-599.

Hartman, G.H. The Longest Shadow: In the Aftermath of the Holocaust. Bloomington and Indianapolis: Indiana University Press, 1996.

Hass, Aron. The Aftermath: Living with the Holocaust. Cambridge: Cambridge University Press, 1995.

Heuman, Johannes. The Quest for Recognition: The Holocaust and French Historical Culture, 1945-1965. Doctoral Diss., Stockholm: Stockholm University.

Heumann, Johannes and Pontus Rudberg. Early Holocaust Memory in Sweden. London: Palgrave Macmillan, Forthcoming.

Herf, Jeffrey. Divided Memory: The Nazi Past in the two Germanys. Cambridge, MA: Harvard University Press, 1997.

Hirdman, Yvonne. Att lägga livet till rätta: Studier i svensk folkhemspolitik. Stockholm: Carlsson, 1989.

Hirsch, Marianne. The Generation of Post-Memory: Writing and Visual Culture after the Holocaust. New York and Chichester, Columbia University Press, 2012.

Hirsch, Marianne and Leo Spitzer. "The Witness in the Archive: Holocaust Studies/Memory Studies." Memory Studies 2, no. 2 (2009): 151-170.

Hjavard, Stig. "The Mediatization of Society. A theory of the Media as Agents of Social and Cultural Change." Nordicom Review 2 (2008): 105-134.

Holmila, Antero. Reporting the Holocaust in the British, Swedish and Finnish Press, 1945 1950. Basingstoke: Palgrave Macmillan, 2011.

Holmila, Antero and Karin Kvist Geverts. "On forgetting and rediscovering the Holocaust in Scandinavia." Scandinavian Journal of History vol. 36, no. 5 (2011): 
520-535.

Holmqvist, Bengt. Das Buch der Nelly Sachs. Frankfurt am Main: Suhrkamp, 1968.

Horowitz, Sara R. "Gender, Genocide, and Jewish Memory." Prooftexts 20, no. 1\&2 (Winter/Spring 2000): 158-190.

Hoyer, Jennifer Miller. "The Space of Words": exile and diaspora in the works of Nelly Sachs. Rochester, NY: Camden House, 2014.

Innsdorf, Annette. Indelible Shadows: Film and the Holocaust. Cambridge: Cambridge University Press, 2003.

Jacobs, Janet. "Women, Genocide, and Memory: The Ethics of Feminist Ethnography in Holocaust Research.” Gender \& Society 18, no. 2 (April 2004): 223-238.

Jacobs, Janet. "Remembering Genocide: Gender Representation and the Objectification of Jewish Women at Majdanek." In Religion, Violence, Memory, and Place, edited by Oren Baruch Stier and J. Shawn Landres, 163-173. Indianapolis and Bloomington: Indiana University Press, 2006.

Jacobs, Janet. "Gender and Collective Memory: Women and Representation at Auschwitz." Memory Studies 1, no. 2 (2008): 211-225.

Jockusch, Laura. "Historiography in Transit: Survivor Historians and the Writing of Holocaust History in the late 1940s." Leo Baeck Institute Year Book vol. 58, (2013): 75-94.

Jockusch, Laura. Collect and Record! Jewish Holocaust Documentation in Early Post-war Europe. Oxford: Oxford University Press, 2015.

Johannison, Karin. Den sårade divan: om psykets estetik (och om Agnes von K, Sirid H och Nelly S). Stockholm: Bonnier, 2015.

Johnson, Heather L. "Click to Donate: Visual Images, Constructing Victims and Imagining the Female Refugee.” Third World Quarterly 32, no. 6 (2011): 10151037.

Jonsson, Sverker. "TV förändrar världen (1958-1975)." In Den Svenska pressens historia: Bland andra massmedier (efter 1945), edited by Lars-Åke Engblom, Sverker Jonsson, and Karl-Erik Gustafsson, 143-247. Stockholm: Ekerlids, 2002.

Jönsson, Mats. "Non-Fiction Film Culture in Sweden circa 1920-1960: Pragmatic Governance and Consensual Solidarity in a Welfare State." In A Companion to Nordic Cinema, edited by Mette Hjort \& Ursula Lindqvist, 125-47. Malden, MA: John Wiley and Sons, 2016.

Kahn-Harris, Aaron. "Creating a Safe Harbor: Depictions of Swedish Refugee Assistance Actions in Wartime Propaganda Film." Journal of Scandinavian Cinema 2, no. 3 (2012): 217-130.

Kansteiner, Wulf. "Finding Meaning in Memory: A Methodological Critique of Contemporary Memory Studies.” History and Theory 41 (2002): 179-197.

Kansteiner, Wulf. "Success, Truth and Modernism in Holocaust Historiography: Reading Saul Friedländer Thirty-Five Years after the Publication of 'Metahistory." History and Theory 48, no. 2 (2009): 25-30.

Karlsson, Klas-Göran. "Förintelsen som historiekulturellt fenomen-en översikt." Historisk Tidskrift 125, no. 4 (2005): 721-733. 


\section{References}

Karlsson, Klas-Göran. “Tell Ye Your Children...' The Twisted Road to Swedish Holocaust Recognition.” Scandinavian-Canandian Studies vol. 23 (2016): 78-94.

Karlsson, Klas-Göran \& Kristian Gerner. "Förintelsen-i historien eller över historien." Historisk Tidskrift 123, no. 2 (2003): 317-318.

Karlsson, Klas-Göran and Ulf Zander eds. The Holocaust on Post-war Battlefields: Genocide as Historical Culture. Malmö: Sekel Bokförlag, 2006.

Katz, Esther and Joan Miriam Ringelheim eds. Women Surviving the Holocaust: Proceedings of the Conference. New York: Institute for Research on History, 1983.

Katz Thor, Rebecka. Beyond the Witness: Holocaust Representation and the Testimony of Images. PhD diss., Stockholm: Art and Theory Publishing: 2018.

Kerner, Aron. Film and the Holocaust: New Perspectives on Dramas, Documentaries, and Experimental Films. London: Continuum, 2011.

Ketelaar, Eric. "Tacit Narratives: The Meaning of Archives." Archival Science 1, no. 2 (2001): 131-141.

Kielbach, Judith. "The Eichmann Trial on East German Television: On (not) Reporting about a Transnational Media Event." Journal of European Television, History and Culture 3, no. 5 (2014): 17-22.

Klein, Kerwin Lee. "On the emergence of memory in historical discourse." Representations 69 (2000): 127-150.

Kleinberg, Ethan. Haunting History: For a Deconstructive approach to the Past. Stanford, Stanford University Press, 2017.

Koblik, Steven. The Stones Cry Out: Sweden's Response to the Persecution of Jews 19331945. New York: Holocaust Library cop., 1988.

Kolinsky, Eva. After the Holocaust: Jewish Survivors in Germany after 1945. London: Pimlico, 2004.

Koonz, Claudia. Mothers in the Fatherland: Women, the Family and Nazi Politics. London: Jonathan Cape, 1987.

Koopman, Colin. Genealogy as Critique: Foucault and the Problems of Modernity. Bloomington: Indiana University Press, 2013.

Kushner, Tony. The Holocaust and the Liberal Imagination: A Social and Cultural History. Oxford: Paul Springer Publishing, 1994.

Kverndokk, Kyrre. Pilegrim, turist og elev. Norrköping: Linköping studies in Arts and Science, 2007.

Kvist Geverts, Karin. Ett Främmande Element i Nationen: Svensk Flyktingpolitik och de Judiska Flyktingarna. Uppsala: Acta Universitatis Upsaliensis, 2008.

LaCapra, Dominick. History \& Criticism. Ithaca NY: Cornell University Press, 1985.

LaCapra, Dominick. Representing the Holocaust: History, Theory, Trauma. Ithaca and New York: Cornell University Press, 1994.

LaCapra, Dominick. History and Memory after Auschwitz. Ithaca NY: Cornell University Press, 1998.

LaCapra, Dominick. History in Transit: Experience, Identity, Critical Theory. Ithaca NY: Cornell University Press, 2004.

LaCapra, Dominick. History at its Limits. Ithaca NY: Cornell University Press, 2009. 
Lagercrantz, Olof. Den pågående skapelsen: en studie $i$ Nelly Sachs diktning. Stockholm: Wahlström \& Widstrand, 1966.

Lagercrantz, Olof. Nelly Sacbs. Stuttgart: Richard Boorberg Vlg, 1969.

Lagrou, Pieter. The Legacy of Nazi Occupation: Patriotic Memory and National Recovery in Western Europe, 1945-1965. Cambridge: Cambridge University Press, 2000.

Lange, Anders et al. Utsatthet för etniskt och politisket relaterat vald hot $m m$, spridning av rasistisk och antirasistisk, propaganda samt attityder till demokrati $m m$ bland skolelever. Stockholm: Centrum för invandringsforskning, Stockholms universitet, 1997.

Langer, Lawrence L. Admitting the Holocaust: Collected Essays. Oxford: Oxford University Press, 1995.

Langer, Lawrence L. "The Americanization of the Holocaust on Stage and Screen." In Admitting the Holocaust: Collected Essays, edited by Lawrence L. Langer, 157178. New York and Oxford: Oxford University Press, 1995.

Langer, Lawrence L. "The Uses—and Misuses_ of a Young Girl's Diary: 'If Anne Frank could return from among the murdered, she would be appalled." In Anne Frank: Reflections on her Life and Legacy, edited by Hyman A. Enzer and Sandra Solotaroff-Enzer, 203-205. Urbana-Champaign: University of Illinois Press, 2000.

Laub, Dori. "Bearing witness, or the vicissitudes of listening." In Testimony: Crisis of Witnessing in Literature, psychoanalysis and history edited by Dori Laub and Shoshana Felman, 57-74. Routledge: New York: Taylor and Francis, 1992.

Leiser, Erwin. Samtal i Berlin. Stockholm: Pan/Norstedt, 1969.

Leiser, Erwin. Gott hat kein kleingeld: Erinnerungen. Köln: Kiepenheuer \& Witsch, 1993.

Leth, Göran. "The Construction of Indifference: The Swedish Press and Kristallnacht." Yad Vashem Studies 36, no. 2 (2008): 155-187.

Levine, Paul. "Whither Holocaust Studies in Sweden? Some Thoughts on Levande Historia and Other Matters Swedish." Holocaust Studies: A Journal of Culture and History vol. 11, no. 1 (2005): 75-89.

Levine, Paul A. From Indifference to Activism. Uppsala: Acta Universitatis Upsaliensis, 1996.

Levine, Paul A. and Stephane Bruchfeld. Om detta må ni berätta. Stockholm: Regeringskansliet, 1997.

Lev-Wiesel, Rachel \& Marianne Amir. "Posttraumatic Stress Disorder Symptoms, Psychological Distress, Personal Resources, and Quality of Life in Four Groups of Holocaust Child Survivors." Family Process 39, no. 4 (2000): 445-459.

Lev-Wiesel, Rachel \& Marianne Amir. "Post-traumatic growth among Holocaust Child Survivors." Journal of Loss and Trauma vol. 8, no. 4 (2003): 229-237.

Lev-Wiesel, Rachel \& Marianne Amir. "Holocaust Child Survivors and Child Sexual Abuse." Journal of Child Sexual Abuse vol. 14 (2005): 69-83.

Levy, Daniel and Natan Sznaider. The Holocaust and Memory in the Global Age. Philadelphia: Temple UP, cop., 2006.

Liljequist, Ann-Margret. Sandro Malmquist och hans verksambet som scenograf. Doctoral 


\section{References}

diss., Stockholm: Stockholm University, 1985.

Lipstadt, Deborah E. The Eichmann Trial. New York: Nextbook/Schocken, 2011.

Loshitskyed, Yosheva, ed. Spielberg's Holocaust: Critical Perspectives on Schindler's List.

Bloomington: Indiana University Press, 1997.

Lomfors, Ingrid. Blind Fläck: Minne och glömska kring Svenska röda korsets hjälpinsats $i$ Narityskland 1945. Stockholm: Atlantis, 2006.

Lomfors, Ingrid. Förlorad barndom, återvunnet liv. Phd diss., Gothenburg: Gothenburg University Press, 1996.

Lomfors, Ingrid. "Inledning." In Judiska minnen: Berättelser från Förintelsen, edited by Britta Johansson. Stockholm: Nordiska Museet, 2000.

Lorenz, Dagmar C.G. "Jewish women authors and the exile experience: Claire Goll, Veza Canetti, Else Lasker-Schuler, Nelly Sachs, Cordelia Edvardson.” German Life and Letters 51, no. 2 (April 1998): 225-239.

Ludvigsson, David. "Levande Historia Inte Bara Levande Historia." Mod Nye Historier: Rapporter till det 24. Nordiske Historikermöde 49 (2001): 144-177.

Lundstedt, Göran. Till bords med de bästa: om kritikern Knut Jaensson. Lund: Nova Press, 1997.

Lööw, Helene. Nazismen i Sverige, 1980-1999_den rasistiska undergroundrörelsen: musiken, myterna, riterna. Stockholm: Ordfront förlag, 2000.

Manoff, Marlene. "Archive and Database as Metaphor: Theorizing the Historical Record." Libraries and the Academy 10, no. 4 (2010): 385-398.

Marcuse, Harold. Legacies of Dachau: uses and abuses of a concentration camp, 1933-2001. Cambridge: Cambridge University Press, 2001.

Marrus, Michael \& Robert O. Paxton. Vichy France and the Jews. Stanford: Stanford University Press, 1995.

Marrus, Michael. The Unwanted: European Refugees from the First World War through the Cold War. Philadelphia: Temple University Press, 2002.

Marrus, Michael. Some Measure of Justice: The Holocaust era Restitution Campaign of the 1990s. Madison: Wisconsin University Press, 2009.

Martin, Elaine. Nelly Sachs. Berlin: Walter de Gruyter, 2011.

Martínez, Victoria. "The Stockholm Holocaust Memorial-a Restoration of Human Dignity and a Warning against Inhumanity." The Local, (August 3, 2017), https://www.thelocal.se/20170803/the-stockholm-holocaust-memorial-a-restoration-of-human-dignity-and-a-warning-against-inhumanity, accessed on December 15, 2019.

Merton, Robert K. and Elinor Barber. The Travels and Adventures of Serendipity: $A$ Study in the Historical Semantics and the Sociology of Science. Princeton, NJ: Princeton University Press, 2004.

Mogensen, Michael. “October 1943_-The Rescue of the Danish Jews.” In Denmark and the Holocaust, edited by Mette Bastholm Jensen and Steven L. B. Jensen, 3360. Copenhagen: Institute for International Studies, Department for Holocaust and Genocide Studies, 2003.

Moore, Bob. Survivors. Oxford and New York: Oxford University Press, 2004. 
Nahson, Edna. "Anne Frank from Page to Stage.” In Anne Frank Unbound: Media, Imagination, Memory, edited by Jeffrey Shandler and Barbara Kischenblatt-Gimblett, 59-92. Bloomington: Indiana University Press, 2012.

Nilsson, Sven. Det offentliga samtalet: Storstadspressen som medium for kulturinformation och kulturdebatt. Phd diss., Lund: Lund University, 1975.

Nilsson, Sven and Rolf Yrlid eds. Svensk litteratur i kritik och debatt 1957-1970: en antologi. Stockholm: Prisma, 1972.

Niven, Bill. Facing the Nazi Past: United Germany and the Legacy of the Third Reich. London: Routledge, 2002.

Niven, Bill ed. Germans as Victims: Remembering the Past in Contemporary Germany (Houndmills, Basingstoke, Hampshire: Palgrave Macmillan, 2006.

Nordberg, Karin. Folkhemmets Röst: Radion som folkbildare 1925-1950.Stockholm: Brutus Östlings Bokförlag Symposion, 1998.

Novick, Peter. The Holocaust in American Life. Boston: Houghton Mifflin, 1999.

Nycander, Sven. Makten över åsikterna: DN under Olof Lagercrantz och Sven-Erik Larsson. Stockholm: Atlantis, 2014.

Ofer, Dalia and Lenore J. Weitzman, eds. Women in the Holocaust. New Haven \& London: Yale University Press, 1988.

Ofer, Dalia. "The Strength of Remembrance: Commemorating the Holocaust during the First Decade of Israel." Jewish Social Studies 6, no. 2 (2000): 24-55.

Ofer, Dalia, Francoise S. Ouzan \& Judy Tydor Baumel-Schwartz. Holocaust Survivors: Resettlement, Memories, Identities. New York: Berghahn Books, 2012.

Ohlsson, Anders. "Men ändå måste jag berätta," Studier i skandinavisk förintelselitteratur. Falun: Nya Doxa, 2002.

Olsson, Anders. "Nelly Sachs och Lenke Rothman, några fragment.” In Bokstäverna jag färdas $i$ : En antologi om Nelly Sachs, edited by Anders Olsson, 185-191. Stockholm: Themis, 2001.

Olsson, Lars. På tröskeln till folkhemmet: Baltiska flyktingar och polska koncentrationslägerfängar som reservarbetskeraft i skainskt jordbruk kring slutet av andra världskriget. Lund: Morgonrodnad, 1995.

Otterberg, Stina. Klädd i sitt språk. Kritikern Olof Lagercrantz. PhD diss., Lund: Ellerströms förlag, 2010.

Oredsson, Sverker. "Tes_-antites_-syntes? Synen på den svenska politiken under andra världskriget." In Sverige och Narityskland: skuldfragor och moraldebatt, edited by Lars M. Andersson, 66-83. Stockholm: Dialogos, 2007.

Packalén, Sture. "Peter Weiss_-Brevskrivaren," Samlaren: Tidskrift för svensk litteraturvetenskaplig forskning 111 (1990): 5-31.

Packalén, Sture. “'Som om det under varje år låg en skugga.' Peter Weiss-författare mellan två språk", Samlaren: tidskrift för svensk litteraturvetenskaplig forskning 113, (1992): 27-33.

Packalén, Sture. "From the 'Third Reich' to the 'Third Space': Paul Celan, Erich Fried, and Peter Weiss." In Exile and Otherness: New Approaches to the Experience of the Nazi Refugees, edited by Alexander Stephan, 121-134. Berlin: Peter Lang, 


\section{References}

2005.

Packalén, Sture. Tyska minnesgemenskaper: Nazism, krig, förföljelse och folkmord $i$ tyskspråkig litteratur efter 1945. Stockholm: Carlssons Bokförlag, 2010.

Pedersen, Daniel. Tärarnas Poetik: Nelly Sachs författarskap fram till och med In den Wohnungen des Todes. Doctoral diss., Stockholm: University of Stockholm, 2016.

Pendas, Devin O. "'I didn't know what Auschwitz was': The Frankfurt Auschwitz Trial and the German Press, 1963-1965." Yale Journal of Law and the Humanities 12, no. 2 (Summer 2000): 397-446.

Pendas, Devin O. The Frankfurt Auschwits Trial, 1963-1965: Genocide, History, and the Limits of the Law. Cambridge: Cambridge University Press, 2006.

Pendas, Devin O. "'Eichmann in Jerusalem', Arendt in Frankfurt: The Eichmann Trial, the Auschwitz Trial, and the Banality of Justice." New German Critique 100 (Winter, 2007): 77-109.

Person, Katarzyna. "Sexual Violence during the Holocaust-The Case of Forced Prostitution in the Warsaw Ghetto." Shofar: An Interdisciplinary Journal of Jewish Studies 33, no. 2 (2015): 103-121.

Persson, Sune. "Vi åker till Sverige”: De vita bussarna 1945. Stockholm: Fischer \& co., 2002.

Phillips, Raymond ed. War Crimes Trials. Vol. 2: Trial of Josef Kramer and 44 others. London: William Hodge, 1949.

Pinchevski, Amit, Tamar Liebes, and Ora Herman. "Eichmann on the Air: Radio and the Making of an Historic Trial." Historical Journal of Film, Radio and Television 27, no. 1 (2007): 1-25.

Porat, Dina. Israeli Society, the Holocaust and its Survivors. London: Vallentine Mitchell, 2008.

Prado, C.G. Starting with Foucault: An Introduction to Genealogy. New York: Routledge, 2018.

Prose, Francine. Anne Frank: The Book, the Life, the Afterlife. New York: Harper, 2009.

Rasch, William. "Introduction: looking again at the rubble." In German Postwar Films. Studies in European Culture and History, edited by Wilfried Wilms and William Rasch, 1-5. Basingstoke: Palgrave Macmillan, 2008.

Reading, Anna. "Scarlet lips in Belsen: culture, gender and ethnicity in the policies of the Holocaust." Media, Culture \& Society 21, no. 4 (1999): 481-502.

Roos, Lene. "Barmhärtiga svenskar och tacksamma flyktingar: Ett beredskapssjukhus sommaren 1945 i svensk press." Nordisk Judaistik 26, no. 1-2 (2008):133156.

Rosengren, Anna. "Offentlighetsprincipen i teori och praktik." Arkiv, sambälle och forskning no. 1 (2017): 26-57.

Rothberg, Michael. Multi-directional Memory: Remembering the Holocaust in the age of decolonization. Stanford, CA: Stanford University Press, 2009.

Rudberg, Pontus. The Swedish Jews and the Victims of Nari Terror, 1933-1945. PhD diss., Uppsala: Studia Historica Upsaliensia, 2015. 
Runcis, Maija. Sterilieringar i folkhemmet. Stockholm: Ordfront, 1998.

Sahlström, Julia. "Recognition, Justice and Memory: Swedish Jewish Reactions to the Holocaust and the Major Trials." In Early Holocaust Memory in Sweden, edited by Johannes Heuman and Pontus Rudberg. London: Palgrave Macmillan, Forthcoming.

Saidel, Rochelle. The Jewish Women of Ravensbruck Concentration Camp. Madison: University of Wisconsin Press, 1999.

Saidel, Rochelle. "The Jewish Victims of Ravensbrück Concentration Camp." In Lessons and Legacies Volume VII: The Holocaust in International Perspective, edited by Dagmar Herzog, 201-16. Evanston, IL: Northwestern University Press, 2006.

Samuelsson, Lina. Kritikens ordning: Svenska bokrecensioner 1906, 1956, 2006. Doctoral diss., Karlstad: Bild, text \& form, 2013.

Sandlund, Elisabeth. "Beredskap och Repression." In Den svenska pressens historia, edited by Karl Erik Gustafson and Per Rydén, 266-382. Stockholm: Ekerlids förlag, 2001.

Saxton, Libby. Haunted Images: Film, Ethics, Testimony and the Holocaust. London: Wallflower Press, 2008.

Schult, Tanja. "Gestaltningen och etableringen av Förintelseminnet i Sverige." Nordisk Judaistik 27, no. 2 (2017): 3-21.

Schult, Tanja. "Gestaltningen och etableringen av Förintelseminnet i Sverige: Förintelsemonument i Sverige, 1990-2009.” Nordisk Judaistik 28, no. 2 (2017): $39-62$.

Schult, Tanja. A Hero's Many Faces: Raoul Wallenberg in Contemporary Monuments. Doctoral diss., Stockholm: Stockholm University, 2009.

Schult, Tanja and Diana Popescu eds. Revisiting Holocaust Representation in the Postwitness Era. London: Palgrave Macmillan, 2015.

Schweber, Simone. "Holocaust Fatigue." Social Education 7, no. 1 (2006): 48-55.

Schweber, Simone. "Holocaust Fatigue in Teaching Today." In Social Studies Today: Research and Practice, edited by Walter C. Parker, 151-162. New York: Routledge, 2010.

Schwartz-Bart, André. The last of the Just. Secker \& Warburg, 1961.

Segev, Tom. The Seventh Million: the Israelis and the Holocaust, trans. Haim Watzman. New York: Henry Holt, 2000.

Selling, Jan. "Between history and politics: the Swedish Living History project as discursive formation." Scandinavian Journal of History 36, no. 6 (2011): 555-569.

Shandler, Jeffrey. "The Man in the Glass-box: Watching the Eichmann Trial on American Television." In Visual Culture and the Holocaust, edited by Barbie Zelizer, 91-110. London: Athlone, 2001.

Shandler, Jeffrey. "From Diary to Book: Text, Object, Structure." In Anne Frank Unbound: Media, Imagination, Memory, edited by Jeffrey Shandler and Barbara Kischenblatt-Gimblett, 25-57. Indiana University Press, 2012.

Shandler, Jeffrey and Barbara Kirschenblatt-Gimblett. "Introduction: Anne Frank, the Phenomenon." In Anne Frank Unbound: Media, Imagination, Memory, edited 


\section{References}

by Jeffrey Shandler and Barbara Kischenblatt-Gimblett, 1-22. Bloomington: Indiana University Press, 2012.

Shapira, Anita. "The Holocaust: Private Memories, Public Memory." Jewish Social Studies 4, no. 2 (1998): 46-58.

Shapira, Anita. "The Eichmann Trial: Changing Perspectives." The Journal of Israeli History 23, no.1 (Spring 2004): 18-39.

Sharples, Caroline. "Reconstructing the Past: Refugee Writings on the Kindertransport." Holocaust Studies vol. 12, no. 3 (2006): 40-62.

Shenker, Noah. Re-framing Holocaust Testimony. Bloomington: Indiana University Press, 2015.

Sinnreich, Helene. "“And it was something we didn't talk about': Rape of Jewish Women during the Holocaust." Holocaust Studies 14, no. 2 (2008): 1-22.

Sköld, Gullan. Med känsla för klass: Thea Oljelund och Marianne Höök i femtiotalets folkhem och finrum. Stockholm: Leopard förlag, 2006.

Slany, William Z. and Stuart Eizenstadt. U.S. and Allied wartime and postwar relations and negotiations with Argentina, Portugal, Spain, Sweden, and Turkey on looted gold and German external assets and U.S. concerns about the fate of the wartime Ustasha Treasury. Washington DC: United States Department of State, June 1998.

Snickars, Pelle. "Remarks on a Failed Film Archival Project." Journal of S candinavian Cinema 5, no. 1 (2017): 63-67.

Snickars, Pelle and Johan Jarlbrink. "Cultural Heritage as Digital Noise in Nineteenth Century Newspapers in the Digital Archive." Journal of Documentation 73, no. 6 (2017): 1228-1243.

Snyder, Timothy. "Holocaust: The Ignored Reality." New York Review of Books 56, no. 12 (2009).

Steedman, Carolyn. Dust. Manchester: Manchester University Press, 2001.

Steedman, Carolyn. "Something she called a Fever: Michelet, Derrida and Dust." American Historical Review 106, no. 4 (2001): 1159-1180.

Sterner Carlberg, Miriam. Gemenskap och Överlevnad: om den judiska gruppen $i$ Borås och dess Historia. Doctoral diss., Gothenburg: Gothenburg University Press, 1994.

Stone, Dan. Responses to Narism in Britain, 1933-1939. Basingstoke: Palgrave Macmillan, 2003.

Stone, Dan. The Liberation of the Camps: The end of the Holocaust and its Aftermath. New Haven: Yale University Press, 2015.

Suleiman, Susan Rubin. "Problems of Memory and Factuality in Recent Holocaust Memoirs: Wilkomirski/Wiesel.” Poetics Today vol. 21, no. 3 (2000): 543-459.

Svanberg, Ingvar and Mattias Tydén. Sverige och Förintelsen: Debatt och dokumentation om Europas judar, 1933-1945. Stockholm: Dialogos, 2005.

Svedjedal, Johan. "Kritiska tankar: Om litteraturkritiken och det litterära systemet." Tidskrift för litteraturvetenskap no. 1 (1998): 49-61.

Taikon, Katarina. Zigenare är vi. Stockolm: Tidens Förlag, 1967.

Tec, Nechama. Resilience and Courage: Women, Men and the Holocaust. New Haven \& London: Yale University Press, 2003. 
Tegen, Gunhild and Einar Tegen. De dödsdömda vittna: Enquetesvar och intervjuer. Stockholm: Wahlström och Widstrand, 1945.

Thaler, Henri Lustiger and Wilfried Wiedemann. "Hauntings of Anne Frank: Sightings in Germany." In Anne Frank Unbound: Media, imagination, memory, edited by Barbara Kirschenblatt-Gimblett and Jeffrey Shandler, 137-159. Bloomington: Indiana University Press, 2012.

Thor Tureby, Malin. Hechaluz-en rörelse i tid och rum. Tysk-judiska ungdomars exil $i$ Sverige 1933-1943. PhD diss., Växjö: Växjö University Press, 2005.

Thor Tureby, Malin. "Svenska änglar och hyenor möter tacksamma flyktingar. Mottagningen av befriade koncentrationslägerfångar i skånsk press under året 1945." Historisk Tidsskrift 135, no. 2 (2015): 266-300.

Thor Tureby, Malin. "Swedish Jews and the Jewish survivors: The first public Narratives about the Survivors in Swedish-Jewish Press." In Reaching a State of Hope-Refugees, Immigrants and the Swedish Welfare State, 1930-2000, edited by Mats Byström and Pär Frohnert, 145-164. Stockholm: Nordic Academic Press, 2013.

Thor Tureby, Malin. "To Hear with the Collection: The Contextualisation and Recontextualisation of Archived Interviews." Oral History 41, no. 2 (Autumn 2013): 63-74.

Thurén, Torsten. Medier i Blåsväder: Den svenska radion och televisionen som sambällsbevarare och sambällskritiker. Stockholm: Norstedt, 1997.

Tinning, Katrine. “To Survive Ravensbrück: Considerations on Museum Pedagogy and the Passing on of Holocaust Remembrance." Museum and Society 14, no. 2 (2016): 338-353.

Trenter, Cecilia. "I mötet med minnet-historiekulturer i Skandinavien." Historisk tidsskrift 122 no. 2, (2002): 289-307.

Tydén, Mattias. Svensk antisemitism 1880-1930. Uppsala: Reprocentralen, 1986.

Tydén, Mattias och Gunnar Broberg. Oönskade i folkhemmet: Rashygien och sterilisering i Sverige. Stockholm: Gidlund, 1991.

Tydén, Mattias och Ingvar Svanberg. Sverige och Förintelsen: Debatt och dokument om Europas judar 1933-1945. Stockholm: Arena, 1997.

Tydén, Mattias. Från politik till praktik: de svenska steriliseringslagarna 1954-1975: Rapport till 1997 ars steriliseringsutredning. Stockholm: Statens Offentliga Utredningar, 2000.

Van Dijk, Teun. "Introduction: Discourse Analysis in Mass Communications Research." In Discourse and Communication: New Approaches to the Analysis of Mass Media, edited by Teun Van Dijk, 1-10. Berlin: De Gruyter, 1985.

Van Dijk, José. The Culture of Connectivity: A Critical History of Social Media. New York: Oxford University Press, 2013.

Van Dijk, Teun A. News as Discourse. New York and London: Routledge: 2009.

Van Dijk, Teun A. Racism and the Press. London and New York: Routledge, 1991.

Vesterlund, Per. "Filmkrönika_filmkritik i ljud och bild." In Svensk Television: En Mediehistoria, edited by Anna Edin \& Per Vesterlund, 108-134. Sotckholm: 


\section{References}

Statens ljud- och bildarkiv, 2008.

Wagrell, Kristin. "Jews, Gender, and the Scandinavian Subject: Understanding the Context and Content of the Film Vittnesbördet [The Testimony]." In Early Holocaust Memory in Sweden, edited by Johannes Heuman and Pontus Rudberg. London: Palgrave Macmillan, Forthcoming.

Waxman, Zoe. "Unheard Testimony, Untold Stories: The Representation of Women's Holocaust Experiences.” Women's History Review 12, no. 4 (2003): 661667.

Waxman, Zoë. Writing the Holocaust: Identity, Testimony, Representation. Oxford: Oxford University Press, 2007.

Waxman, Zoë. Anne Frank. Stroud: The History Press, 2015.

Waxman, Zoë. Women in the Holocaust: A Feminist History. Oxford, Oxford University Press, 2017.

Weitz, Yechiam. "Political Dimensions of Holocaust Memory in Israel during the 1950s." Israel Affairs 1, (1995): 129-145.

White, Hayden. Metahistory: The Historical Imagination in Nineteenth Century Europe. Baltimore: Johns Hopkins University Press, 1973.

White, Hayden. The Content of the Form: Narrative Discourse and Historical Representation. Baltimore: Johns Hopkins University Press, 1987.

White, Hayden. "Figural Realism in Witness Literature." Parallax vol. 10, no. 1 (2004): 113-124.

Weibull, Lennart. "New Media between Technology and Content. The Introduction of Radio and Television in Sweden." In A History of Swedish Broadcasting: Communicative Ethos, Genres and Institutional Change, edited by Monika Djerf-Pierre and Mats Ekström, 31-54. Gothenburg: Nordicom, 2013.

Wieviorka, Annette. Déportation et génocide: Entre la mémoire et l'oubli. Paris: Plon, 1992.

Wieviorka, Annette. The Era of the Witness, trans. Jared Stark. Ithaca: Cornell University Press, 2006.

Wigerfeldt, Berit. "Klippan—bilden av en ort som rasisthåla.” In Att möta främlingar, edited by Göran Rystad and Svante Lundberg, 193-217. Lund: Arkiv Förlag, 1999.

Wijk, Johnny. “'Censur och propagandaministeriet' - en översikt av Informationsstyrelsens verksamhet 1940-1945 utifrån dess efterlämnade arkiv.” Historisk Tidsskrift 1 (1990): 21-49.

Wittmann, Rebecca. "Indicting Auschwitz? The Paradox of the Frankfurt Auschwitz Trial." German History 21, no. 4 (2003): 506-532.

Wittmann, Rebecca. "Telling the Story: Survivor Testimony and the Narration of the Frankfurt Auschwitz Trial." Bulletin of the GHI Washington 32 (Spring, 2003): 94-101.

Wittmann, Rebecca. Beyond Justice: The Auschwitz, Trial. Cambridge, Mass., Harvard University Press, 2005.

Wodak, Ruth. "The Discourse-Historical Approach.” In Methods of Critical Discourse Analysis, edited by Ruth Wodak and Michael Meyer. 63-94. London: Sage, 2001. 


\section{References}

Yablonka, Hanna. Survivors of the Holocaust: Israel after the War. Basingstoke: Palgrave Macmillan, 1998.Young, J. E. "Between History and Memory: The Uncanny Voices of Historian and Survivor." History and Memory, vol. 9, no 2 (1997): 4758.

Young, James E. Writing and Re-Writing the Holocaust: Narrative and the Consequences of Interpretation. Indianapolis: Indiana University Press, 1988.

Young, James E. "Between History and Memory: The Uncanny Voices of Historian and Survivor." History and Memory 9, no. 1/2, (Fall 1997): 47-58.

Yablonka, Hanna. Survivors of the Holocaust: Israel after the War. Basingstoke: Palgrave Macmillan, 1998.

Yablonka, Hanna."'The Development of Holocaust Consciousness in Israel: The Nuremburg, Kapos, Kastner, and Eichmann Trials." Israel Studies 8, no. 3 (Fall 2003): 1-24.

Yablonka, Hanna. The State of Israel vs. Adolf Eichmann. New York: Schocken books, 2004.

Zander, Ulf. "Holocaust at the limits." In Echoes of the Holocaust: Historical Cultures in Contemporary Europe, edited by Klas-Göran Karlsson and Ulf Zander, 255-292. Lund: Nordic Academic Press, 2003.

Zander, Ulf. "Efterskrift." In Befrielsen av Bergen-Belsen, edited by Ben Shephard, 219233. Lund: Historiska Media, 2005.

Zander, Ulf. "I våldets virvelvind-representationer av Adolf Eichmann i förintelsens historiekulturer." In Våld: Representation och Verklighet, edited by Eva Österberg and Marie Lindstedt Cronberg, 303-322. Lund: Nordic Academic Press, 2006.

Zelizer, Barbie. "Gender and Atrocity: Women in Holocaust Photographs.” In Visual Culture and the Holocaust, edited by Barbie Zelizer, 247-271. London: The Athlone Press, 2001.

Åberg, Lars and Magnus Gertten. Hoppets hamn. När överlevarna kom till Sverige. Malmö: Roos och Tegnér, 2012.

Åmark, Klas. "Sweden and the Refugees, 1933-45." In Refugees, Immigrants and the Swedish Welfare State, 1930-2000, edited by Mikael Byström and Per Frohnert, 54-66. Stockholm: Nordic Academic Press, 2013.

Österberg, Andreas. Katalogisering av ljudupptagningar: En komparativ studie av Statens ljud- och bildarkiv och Sveriges Radios grammofonarkiv. Master's thesis. University of Borås, 2004.

Östling, Johan. Nazismens sensmoral: Svenska erfarenheter $i$ andra världskrigets efterdyning. Stockholm; Atlantis, 2008.

Östling, Johan. "The Rise and Fall of Small-State Realism.” In Nordic Narratives of the Second World War: National Historiographies Revisited, edited by Henrik Stenius, Mirja Österberg, and Johan Östling, 127-147. Lund: Nordic Academic Press, 2011. 
References 


\section{References}

\section{Tema Q-presentation}

Tema kultur och samhälle (Tema Q) bedriver problemorienterad kulturvetenskaplig forskning i skärningspunkten mellan humaniora och samhällsvetenskap. Med betoning på ett kritiskt och analytiskt grundperspektiv, inkluderar forskningen såväl samtida som historiska ämnen och studier som betraktar kultur som tecken, representation eller som ett verksamhetsområde påverkat av ekonomi, juridik och politik. Tema Q utgör en del av Institutionen för kultur och samhälle (IKOS) vid Linköpingsuniversitet.

Culture Studies (Tema Q) conducts problem-oriented cultural science research at the intersection of the humanities and social sciences. Grounded in a critical and analytical understanding of culture, research includes both contemporary and historical topics and studies that focus both on culture as representation or as an area of activity influenced by economics, law and politics. Tema Q is part of the larger Department of Culture and Society (IKOS) at Linköping university. 


\section{Avhandlingar vid Tema Kultur och samhälle:}

Lindaräng, Ingemar: Ett jubileum i tiden. Birgittajubileet 2003 som bistoriebruk. Licentiatavhandling, 2005.

Johansson, Carina: Mellan ruinromantik och partyfabrik? En etnografisk studie av Visby $i$ bild, berättelse, fantasi och minne. Licentiatavhandling, 2006.

Hillström, Magdalena: Ansvaret för kulturarvet. Studier i formeringen av det kulturhistoriska museiväsendet i Sverige med särskild inriktning på Nordiska museets etablering 1870-1920. Doktorsavhandling, 2006.

Gunnarsson, Andreas: Genetik i fiktion. Licentiatavhandling, 2006.

Seifarth, Sofia: Råd i radion: Modernisering, allmänhet och expertis 1939-1968. Doktorsavhandling, 2007.

Lindaräng, Ingemar: Helgonbruk i moderniseringstider. Bruket av Birgitta- och Olavstraditionerna i samband med minnesfiranden i Sverige och Norge 1891-2005. Doktorsavhandling, 2007.

Harding, Tobias: Nationalising Culture: The Reorganisation of National Culture in Swedish Cultural Policy 1970-2002. Doktorsavhandling, 2007.

Egeland, Helene: Det ekte, det gode og det coole. Södra Teatern og den dialogiske formasjonen av mangfoldsdiskursen. Doktorsavhandling, 2007.

Kverndokk, Kyrre: Pilegrim, turist og elev. Norske skoleturer til dods- og konsentrasjonsleirer. Doktorsavhandling, 2007.

Kåks, Helena: Mellan erfarenhet och förväntan: Betydelser av att bli vuxen $i$ ungdomars livsberättelser. Doktorsavhandling, 2007.

Brusman, Mats: Den verkliga staden?: Norrköpings innerstad mellan urbana idéer och lokala identiteter. Doktorsavhandling, 2008.

Eskilsson, Anna: På plats $i$ bistorien. Studier av hembygdsföreningar på 2000-talet. Doktorsavhandling, 2008.

Holt, Kristoffer: Publicisten Ivar Harrie. Ideologi, offentlighetsdebatt och idékritik i Expressen 1944-1960. Doktorsavhandling, 2008. 


\section{References}

Andersson, Ragnar: Flernivåstyrning av komplexa mål genom nätverk. Implementering av integrationspolicy $i$ ett regionalt partnerskap för tillväxt 1998-2004. Licentiatavhandling, 2008.

Nyblom, Andreas: Ryktbarhetens ansikte: Verner von Heidenstam, medierna och personkulten $i$ sekelskiftets Sverige. Doktorsavhandling, 2008.

Rindzeviciute, Egle: Constructing Soviet Cultural Policy: Cybernetics and Governance in Lithuania after World W ar II. Doktorsavhandling, 2008.

Nilsson, Micael: Genusregim i förändring. Jämställdhet och makt $i$ kommunal politik mellan åren 1970 och 2006. Doktorsavhandling, 2008.

Andersson, Joakim: Skilda världar. Samtida föreställningar om kulturarvsplatser", den 21 november. Doktorsavhandling, 2008.

Jarlbrink, Johan: Det våras för journalisten: Symboler och handlingsmönster för den svenska pressens medarbetare fran 1870-tal till 1930-tal. Doktorsavhandling, 2009.

Ivarsson Lilieblad, Björn: Moulin Rouge på svenska - Varietéunderhålning i Stockholm 1870-1920. Doktorsavhandling, 2009.

Johansson, Carina: Visby visuellt: Föreställningar om en plats med utgangspunkt $i$ bilder och kulturarv. Doktorsavhandling, 2009.

Werner, Ann: Smittsamt - En kulturstudie av musikbruk bland tonårstjejer. Doktorsavhandling, 2009.

Wänström, Johan: Samråd om Ostlänken. Raka spåret mot en bättre demokrati? Medborgarinflytande i svensk sambällsplanering. Doktorsavhandling, 2009.

Lee, Jenny: The Market Hall Revisited. Cultures of Consumption in Urban Food Retail during the Long twentieth century. Doktorsavhandling, 2009.

Fredriksson, Martin: Skapandets rätt. Ett kulturvetenskapligt perspektiv på den svenska upphovsrättens historia. Doktorsavhandling, 2010.

Gruber, Göran: Medeltider. Samtida mobiliseringsprocesser kring det förflutnas värden. Doktorsavhandling, 2010.

Andersson, Ragnar: Mainstreaming av integration, om översättning av policy och nätverksstyrning med förhinder $i$ den regionala utvecklingspolitiken, 1998-2007. Doktorsavhandling, 2011. 


\section{References}

Grip, Björn: Sambällsförändring och det ömtåliga hjärtat: En analys av sambälle, obälsa och bjärtdödlighet i Linköping och Norrköping från 1950-tal till 2000-tal. Licentiatuppsats, 2012.

Källstrand, Gustav: Medaljens framsida. Nobelpriset i pressen 1897-1911. Doktorsavhandling, 2012.

Dahlin, Johanna: Kriget är inte över förrän den sista soldaten är begraven. Minnesarbete och gemenskap kring andra världskriget i S:t Petersburg med omnejd. Doktorsavhandling, 2012.

Gilboa Runnvik, Ann-Charlotte: Rum, rytm och resande. Genusperspektiv på järnvägsstationer. Doktorsavhandling 2014.

Johansson. Marit: Livet i en verdensarvby. En casestudie av diskusjoner og omstridte verdier $i$ Angra do Heroismo, Asorene : Doktorsavhandling 2015.

Grip, Björn: Den ojämlika dödligheten. Hjärtdödlighet och sambällsutveckling $i$ två städer: Doktorsavhandling 2016.

Landgraf, Svante: Faingenskap och flykt. Om fribetstemat $i$ svensk barndomsskildring, reseskildring och science fiction decennierna kring 1970 : Doktorsavhandling 2016.

Lindström, Sofia: (Un)bearable freedom. Exploring the becoming of the artist in education, work and family life: Doktorsavhandling 2016.

Wagrell, Kristin, The Common Sense of forgetting; Interrogating the Policy-Process of the Living History Forum's Testimonial Archive, 1997-2016. Licentiatexamen 2017.

Karlsson, Mattis: Discovering Denisova. Licentiatexamen 2017.

Peterson, Erik: Vadstena krigsmanshus En studie av den svenska kronans inrättning för sårade och gamla soldater cirka 1640-1780. Doktorsexamen 2017.

Marcus, Gustaf: Paria: brottslingen och normaliseringen av människan i Strindbergs, Hanssons och Geijerstams författarskap. Doktorsexamen 2018. 


\section{FACULTY OF ARTS AND SCIENCES}

Linköping Studies in Arts and Science No. 783, 2020

Department of Culture and Society

Linköping University

SE-581 83 Linköping, Sweden

www.liu.se 